\title{
UNIVERSIDAD POLITÉCNICA DE
} MADRID

\section{Escuela Técnica Superior de Edificación}

\section{CARACTERIZACIÓN FISICOQUÍMICA Y APLICACIONES DE YESO CON ADICIÓN DE RESIDUO PLÁSTICO DE CABLES MEDIANTE CRITERIOS DE ECONOMÍA CIRCULAR}

\author{
TESIS DOCTORAL
}

Autora:

Alejandra Vidales Barriguete

Directoras:

Mercedes del Río Merino Doctora Arquitecta

Evangelina Atanes Sánchez

Doctora en Ciencias Químicas 





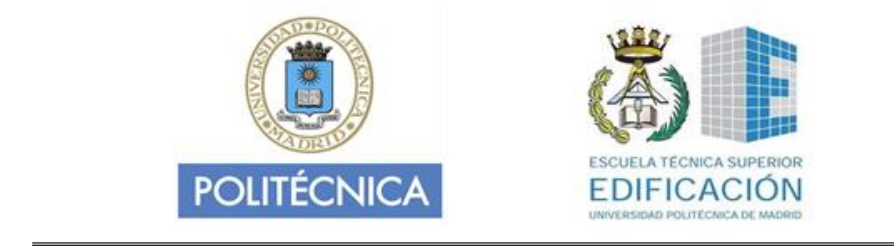

UNIVERSIDAD POLITÉCNICA DE MADRID

Escuela Técnica Superior de Edificación

Programa de Doctorado en Innovación Tecnológica en Edificación CARACTERIZACIÓN FISICOQUÍMICA Y APLICACIONES DE YESO CON ADICIÓN DE RESIDUO PLÁSTICO DE CABLES MEDIANTE CRITERIOS DE ECONOMÍA CIRCULAR
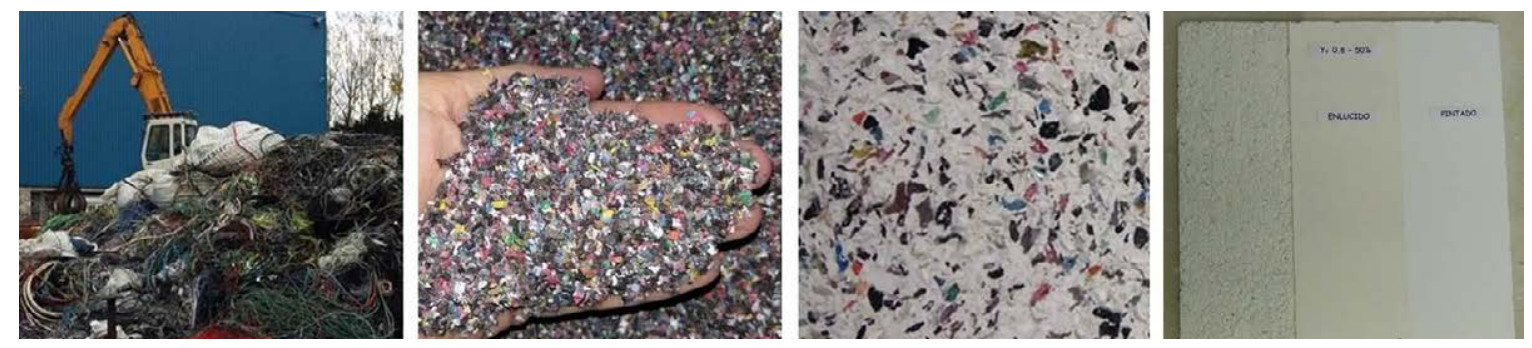

Tesis Doctoral

Alejandra Vidales Barriguete - Máster Oficial en Profesorado especialidad Tecnología Directora: Mercedes del Río Merino - Doctora Arquitecta Codirectora: Evangelina Atanes Sánchez - Doctora en Ciencias Químicas Madrid, 2019 



\section{TESIS DOCTORAL}

TÍTULO: “Caracterización fisicoquímica y aplicaciones de yeso con adición de residuo plástico de cables mediante criterios de economía circular"

Tribunal nombrado por el Sr. Rector Magfco. de la Universidad Politécnica de Madrid, el día de de 2019.

\section{Presidente}

$\mathrm{D} / \mathrm{D}^{\mathrm{a}}$

\section{Vocales}

$\mathrm{D} / \mathrm{D}^{\mathrm{a}}$

$\mathrm{D} / \mathrm{D}^{\mathrm{a}}$

$\mathrm{D} / \mathrm{D}^{\mathrm{a}}$

\section{Secretario}

$\mathrm{D} / \mathrm{D}^{\mathrm{a}}$

Realizado el acto de defensa y lectura de Tesis el día de de 2019 en la Escuela Técnica Superior de Edificación, acuerda otorgarla la calificación de:

EL PRESIDENTE

EL SECRETARIO

LOS VOCALES 



\section{A mis padres, mi marido y mis hijos.}

"No tenía miedo a las dificultades: lo que la asustaba era la obligación de tener que escoger un camino. Escoger un camino significaba abandonar otros." Paulo Coelho 



\section{Agradecimientos}

Son muchas las personas que han aportado, de forma especial, al desarrollo de mi Tesis Doctoral. A todas ellas van dirigidas estas palabras porque, sin su apoyo, esto habría sido mucho más difícil y duro:

A Mercedes del Río, mi directora de Tesis, por sus conocimientos, su entusiasmo con la investigación y su ánimo constante. Gracias por todos tus consejos, he aprendido muchísimo contigo y de ti, tengo la suerte de tenerte cerca y poder seguir aprendiendo.

A Evangelina Atanes, mi codirectora de Tesis, por su exquisito gusto por hacer las cosas perfectas, por sus sugerencias, por darme su mano en momentos de caída. Gracias por todo, me alegro de haberte conocido, me llevo además una amiga de una gran calidad humana.

A Marta Kossior-Kazberuk, vicerrectora de la Universidad Tecnológica de Bialystok (Polonia), por facilitarme la estancia allí y hacérmela más agradable.

A la Escuela Técnica Superior de Edificación, por posibilitar en la medida de lo posible, el viaje a Bialystok y cederme un rinconcito de su laboratorio de materiales.

Al Departamento de Tecnología de la Edificación, por colaborar siempre que han podido.

A la Escuela Técnica Superior de Ingeniería y Diseño Industrial, por permitir la realización de los ensayos químicos en sus laboratorios.

A la empresa Lyrsa Álava, por proporcionarme tan amablemente todos los residuos plásticos de cable de esta investigación.

A mis compañeros de la asignatura de Instalaciones, en especial a Santiago Martínez por la fabricación de los moldes y su compañía en las interminables tardes de ensayos.

A Santiago Villa, técnico del laboratorio de materiales, por su ayuda en la elaboración de los ensayos. Gracias por esas charlas de las que tanto se aprende.

A Rubén Serrano, del cuerpo de bomberos de la Comunidad de Madrid, por su colaboración desinteresada en la realización del ensayo real a fuego.

A José María Chillón, jefe del laboratorio de Instalaciones del Instituto de Ciencias de la Construcción Eduardo Torroja, por su tiempo y generosa aportación del ensayo térmico.

A Paola y César, compañeros de la Universidad, por tener siempre un momento para resolver cualquier duda. Gracias por vuestra paciencia y amabilidad. 
A Carol, Patri y Sheila, mis compañeras de doctorado, porque un camino largo, acompañada se lleva mejor. Ánimo para lo que queda por venir.

A Antonio Pendán, mi maestro, por sus palabras llenas de sabiduría que han sabido guiarme en la búsqueda de mi vocación. Me conformaría con llegar a ser la mitad de lo que tú eres. Gracias por todas tus acertadas observaciones, eres mi ángel, el destino lo quiso así.

A mi familia, por su ilusión ante cualquiera de mis locuras. En especial a mi hermano Roberto que me animó a echarle un órdago a la vida; a mi cuñada Noelia por su ayuda con los textos de inglés; y a mis abuelos, Tomás y Luisa, por su preocupación constante por que consiga mi sueño.

A mis padres, Marcelino y Luisa, por estar siempre ahí y cuidar a mis dos estrellas. Gracias por no fallar nunca, lo que soy os lo debo a vosotros.

A mi marido, Juan, por creer en mí, por su confianza incondicional. Gracias por escucharme, aguantarme y darme fuerzas para seguir adelante. Eres la mejor elección que pude hacer.

A mis pequeños, Juan y Pablo, porque esta tesis les ha robado demasiado tiempo sin su mamá. Sois mi vida y os quiero infinito. 


\section{ÍNDICE}

RESUMEN

ABSTRACT

1. INTRODUCCIÓN Y MARCO DE REFERENCIA _................................................................... 1

1.1 MEDIOAMBIENTE Y DESARROLLO SOSTENIBLE

1.2 CONSTRUCCIÓN SOSTENIBLE ............................................................................. 8

1.2.1 Materiales de construcción ................................................................... 9

1.2.2 Incidencia ambiental de los materiales de construcción .......................... 9

1.2.3 Los residuos de construcción y demolición (RCD) .................................... 16

1.2.4 Gestión de los RCD ................................................................................ 18

1.3 EL PLÁSTICO: CARACTERÍSTICAS Y PROBLEMÁTICA …........................................

1.3.1 Clasificación de los plásticos ................................................................ 25

1.3.1.1 Termoplásticos ...................................................................... $\quad 25$

1.3.1.2 Termoestables ........................................................................ $\quad 26$

1.3.2 El plástico en construcción ................................................................... 27

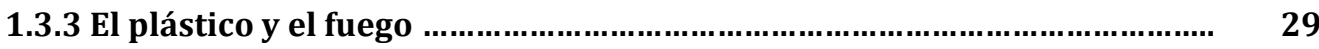

1.3.4 El plástico como aislamiento de cables eléctricos .................................... 30

1.3.5 Reciclaje del plástico de cables eléctricos ............................................. 32

1.3.4.1 Proceso del reciclado ....................................................................... 33

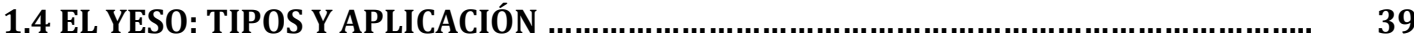

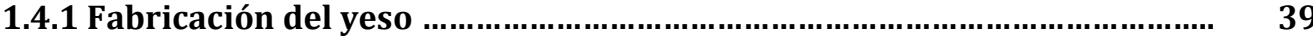

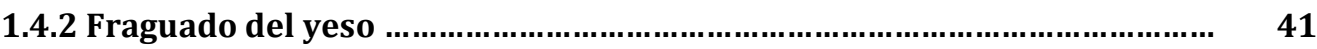

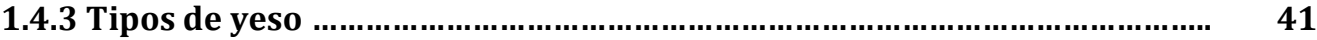

1.4.4 Propiedades de los yesos ................................................................. 42

1.4.5 Aplicaciones del yeso ........................................................................... 43

1.5 CONSIDERACIONES PARCIALES DEL CAPÍTULO _............................................... 45

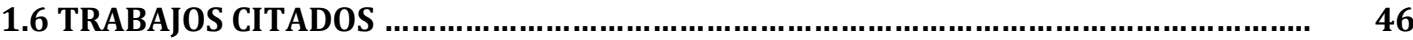

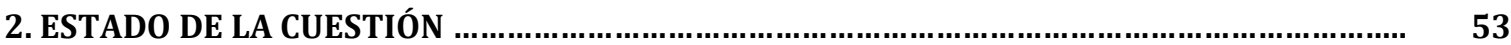

2.1 ESTUDIOS SOBRE COMPUESTOS DE YESO CON ADICIÓN DE RESIDUOS ................ 57

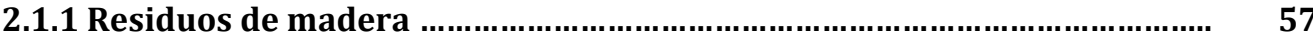

2.1.2 Residuos agrícolas ................................................................................ 58

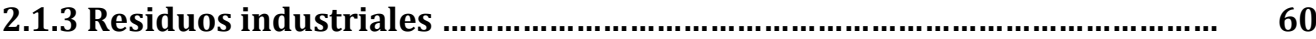

2.1.4 Residuos de construcción y demolición (RCD) ...................................... 62

2.2 ESTUDIOS SOBRE COMPUESTOS DE YESO CON ADICIÓN DE POLÍMEROS .............. 65

2.2.1 Adición de polímeros ......................................................................... 65

2.2.2 Adición de residuos poliméricos.......................................................... 67

2.3 PATENTES DE YESO CON POLÍMEROS ............................................................... 71

2.4 CONSIDERACIONES PARCIALES DEL CAPÍTULO _............................................. 77

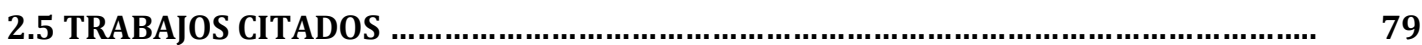


5.1 CARACTERIZACIÓN DE LA MATERIA PRIMA UTILIZADA (OB. 1) ........................... 99

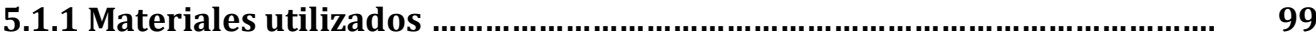

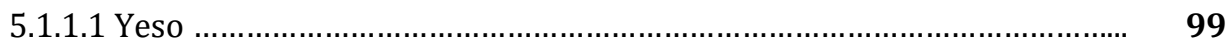

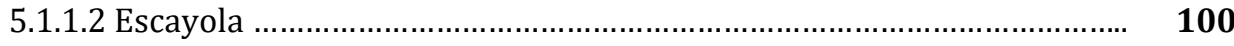

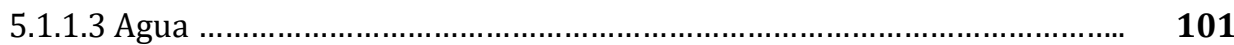

5.1.1.4 Residuo plástico de cables ......................................................... $\mathbf{1 0 3}$

5.1.2 Fase I del plan experimental. Caracterización de la materia prima ......... 103

5.1.2.1 Ensayos físicos de la materia prima .............................................. 103

5.1.2.1.1 Determinación de la densidad de empaquetamiento o de Bulk

5.1.2.1.2 Determinación de la densidad real o picnometría de Helio ...

104

5.1.2.1.3 Determinación de la humedad de la materia prima .............. 106

5.1.2.1.4 Granulometría del residuo plástico de cables ...................... 106

5.1.2.2 Ensayos mineralógicos y químicos de la materia prima ..................... $\quad \mathbf{1 0 7}$

5.1.2.2.1 Análisis termogravimétrico ............................................ 107

5.1.2.2.2 Difracción de Rayos X ....................................................... 108

5.1.2.2.3 Análisis elemental - Fluorescencia de Rayos X .................... 109

5.2 COMPUESTOS CON RESIDUOS PLÁSTICOS DE CABLES (OB. 2) ............................ 110

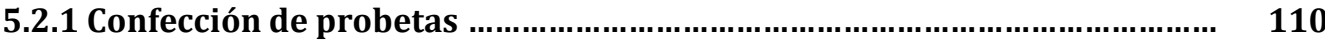

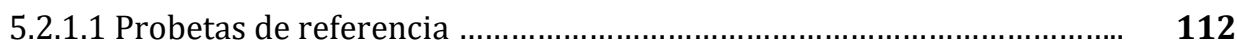

5.2.1.2 Probetas de yeso con residuo plástico de cables.............................. 112

5.2.2 Fase II del plan experimental. Compuestos con residuos plásticos de cables

5.2.2.1 Consistencia de las pastas y relación agua/yeso ............................... $\mathbf{1 1 4}$

5.2.2.2 Determinación de los tiempos de fraguado ...................................... $\mathbf{1 1 5}$

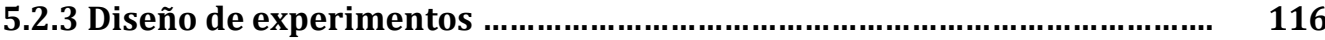

\subsection{CARACTERIZACIÓN DE LOS COMPUESTOS DE YESO Y RESIDUO PLÁSTICO DE} CABLES (OB. 3)

5.3.1 Fase III del plan experimental. Caracterización de los compuestos de yeso con PR

5.3.1.1 Ensayos mecánicos de los compuestos de yeso con residuo plástico de cables

5.3.1.1.1 Dureza superficial Shore C

5.3.1.1.2 Resistencia a flexión

5.3.1.1.3 Resistencia a compresión

5.3.1.2 Ensayos físicos de los compuestos de yeso con residuo plástico de cables

5.3.1.2.1 Densidad en estado endurecido ........................................... 121

5.3.1.2.2 Módulo de Young .................................................................. 122 


\subsection{APLICACIONES PARA COMPUESTOS SELECCIONADOS DE YESO Y RESIDUO PLÁSTICO DE CABLES (OB. 4)}

5.4.1 Viabilidad de las aplicaciones

5.4.1.1 Análisis económico de la aplicación seleccionada

5.4.2 Fase IV del plan experimental. Propiedades de los compuestos seleccionados de yeso con residuo plástico de cables

5.4.2.1 Ensayos químicos de los compuestos seleccionados

5.4.2.1.1 Porosimetría de mercurio

5.4.2.1.2 Microscopía electrónica de barrido SEM

5.4.2.2 Ensayos mecánicos de los compuestos seleccionados

5.4.2.2.1 Resistencia al choque-impacto

5.4.2.2.2 Resistencia a la flexión de paneles

5.4.2.2.3 Adherencia superficial

5.4.2.3 Ensayos físicos de los compuestos seleccionados

5.4.2.3.1 Comportamiento frente al agua

5.4.2.3.1.1 Absorción de agua por capilaridad

5.4.2.3.1.2 Permeabilidad al vapor de agua

5.4.2.3.1.3 Cámara húmeda

5.4.2.3.1.4 Ciclos humedad-sequedad

5.4.2.3.1.5 Absorción total de agua

5.4.2.3.2 Comportamiento frente al fuego

5.4.2.3.2.1 Ensayo real a fuego directo

5.4.2.3.2.2 Análisis y detección de los gases desprendidos en combustión

5.4.2.3.3 Propiedades térmicas

5.4.2.3.3.1 Coeficiente de conductividad térmica según técnica modificada de fuente plana transitoria

5.4.2.3.3.2 Coeficiente de conductividad térmica mediante el método de flujo de calor

5.4.2.3.3.3 Análisis energético de los compuestos propuestos mediante simulación

5.4.2.3.4 Acabados superficiales

5.4.2.3.4.1 Confort superficial

5.4.2.3.4.2 Análisis visual de la superficie

5.5 ESTUDIO DEL IMPACTO AMBIENTAL (OB. 5)

5.5.2 Minimización del residuo plástico de cables. Criterio de economía circular 
6.1.1.2 Densidad real o picnometría de Helio

6.1.1.3 Contenido de humedad de la materia prima .................................... 153

6.1.1.4 Granulometría del PR ................................................................... 153

6.1.2 Ensayos mineralógicos y químicos de la materia prima .......................... 154

6.1.2.1 Análisis termogravimétrico ............................................................ 155

6.1.2.2 Difracción de Rayos X ............................................................ 159

6.1.2.3 Análisis elemental ................................................................... 159

6.2 FASE II DEL PLAN EXPERIMENTAL - OBJETIVO 2 ........................................ 161

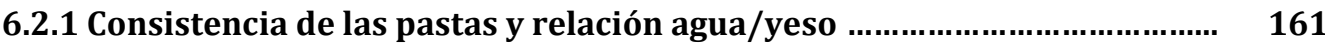

6.2.2 Tiempos de fraguado ...................................................................... 162

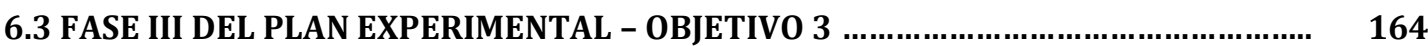

6.3.1 Ensayos mecánicos de los compuestos con residuo plástico de cables ... 164

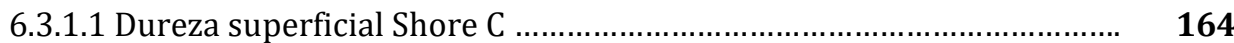

6.3.1.1.1. Análisis estadístico de la variable Dureza Shore $C$................. 166

6.3.1.2 Resistencias a flexión y compresión ................................................. 167

6.3.1.2.1 Análisis estadístico de la variable R. Flexión ............................ 169

6.3.1.2.2 Análisis estadístico de la variable R. Compresión ...................... 170

6.3.2 Ensayos físicos de los compuestos con residuo plástico de cables ........... 171

6.3.2.1 Densidad y módulo de Young dinámico y estático ............................ 171

6.3.2.1.1 Análisis estadístico de la variable Densidad ........................... 174

6.4 FASE IV DEL PLAN EXPERIMENTAL - OBJETIVO 4 ........................................... 175

6.4.1 Propuesta de posibles aplicaciones ................................................ 175

6.4.1.1 Análisis económico ...................................................................... 176

6.4.2 Propiedades de los compuestos seleccionados de escayola con residuo plástico de cables

6.4.2.1 Ensayos químicos de los compuestos seleccionados .....

6.4.2.1.1 Porosimetría de mercurio

6.4.2.1.2 Microscopía electrónica de barrido SEM ................................... 180

6.4.2.2 Ensayos mecánicos de los compuestos seleccionados ........................ $\quad \mathbf{1 8 1}$

6.4.2.2.1 Resistencia al choque-impacto ....................................................... 181

6.4.2.2.2 Resistencia mecánica a la flexión de paneles ........................... 182

6.4.2.2.3 Adherencia superficial ....................................................... 186

6.4.2.3 Ensayos físicos de los compuestos seleccionados ........................ $\quad \mathbf{1 8 7}$

6.4.2.3.1 Comportamiento frente al agua .............................................. 187

6.4.2.3.1.1 Absorción de agua por capilaridad ..................................... 188

6.4.2.3.1.2 Permeabilidad al vapor de agua .......................................... 190

6.4.2.3.1.3 Cámara húmeda ................................................................. 191

6.4.2.3.1.4 Ciclos humedad-sequedad ...................................................... 192

6.4.2.3.1.5 Absorción total de agua ....................................................... 194

6.4.2.3.1.6 Conclusiones parciales de las propiedades de los
compuestos sometidos a la acción del agua ......................................... 195

6.4.2.3.2 Comportamiento frente al fuego................................................ 197

6.4.2.3.2.1 Ensayo real a fuego directo ............................................ 197 
6.4.2.3.2.2 Análisis y detección de los gases desprendidos en combustión

6.4.2.3.2.2.1 Gases desprendidos en la combustión de polímeros

6.4.2.3.2.2.2 Cálculo del $\mathrm{CO}_{2}$ y CO emitidos en la combustión del residuo plástico de cables

6.4.2.3.2.2.3 Estimación de $\mathrm{CO}_{2}$ y $\mathrm{CO}$ emitidos en un supuesto tipo

6.4.2.3.3 Propiedades térmicas

6.4.2.3.3.1 Coeficiente de conductividad térmica según técnica modificada de fuente plana transitoria

6.4.2.3.3.2 Coeficiente de conductividad térmica mediante el método del flujo de calor

6.4.2.3.3.3 Análisis energético de las aplicaciones propuestas

6.4.2.3.3.3.1 Envolvente vertical: cerramiento de fachada ...........

6.4.2.3.3.3.2 Envolvente horizontal: cerramiento de cubierta plana

6.4.2.3.4 Propiedades superficiales de los paneles y placas elaborados con los compuestos seleccionados

6.4.2.3.4.1 Confort térmico

6.4.2.3.4.2 Análisis visual de la superficie

6.5 IMPACTO AMBIENTAL - OBJETIVO 5

6.5.1 Análisis del uso de recursos naturales

7. CONCLUSIONES

INDICIOS DE CALIDAD

BIBLIOGRAFÍA

SIGLAS Y ACRÓNIMOS

LISTADO DE TABLAS, GRÁFICAS, FIGURAS Y FOTOS

ANEXOS

A.1 RESUMEN COMPLETO DE RESULTADOS DE ENSAYOS ......................................... CD

A.2 INFORME DEL ANÁLISIS ELEMENTAL ....................................................... CD

A.3 INFORME DEL ENSAYO DE POROSIMETRÍA DE MERCURIO _................................. CD

A.4 INFORME DEL ENSAYO TÉRMICO MEDIANTE FLUJO DE CALOR ........................... CD

A.5 INDICIOS DE CALIDAD. ARTÍCULOS CIENTÍFICOS PUBLICADOS 


RESUMEN $-A B S T$ RACT




\section{Resumen}

La toma de conciencia ambiental está generando un nuevo concepto de organización social pues se está modificando desde la forma de vivir y consumir, hasta el modo de desplazarse de un sitio a otro. Es en esta nueva forma de pensar de la sociedad donde tiene cabida la construcción sostenible que, de algún modo, tiene como finalidad el minimizar todos los posibles impactos ambientales causados por la industria de la construcción. Una forma de conseguirlo es a través del estudio y desarrollo de materiales y técnicas que permitan una disminución del uso de recursos naturales, la reducción de generación de residuos y/o su reutilización y la minoración de emisiones de $\mathrm{CO}_{2}$.

La reutilización, el reciclaje o la valoración de los residuos, por tanto, desempeñan un papel primordial que pasa por un cambio de actitud en el modelo de economía lineal predominante y real hacia un modelo de economía circular. La economía circular levanta los cimientos de un nuevo paradigma de diseño inteligente basado en el cierre del ciclo de vida de los productos, como ocurre en la naturaleza. Para las empresas de materiales de construcción, la incorporación de residuos en los llamados "materiales tradicionales" es una alternativa que debe aprovecharse, en línea con el objetivo establecido en la actual Directiva Marco de Residuos 2008/98/CE. 
En este sentido, se realiza esta Tesis Doctoral con el objetivo de contribuir al desarrollo sostenible mediante el diseño de un nuevo material más eficiente. Se trata de un compuesto de matriz de yeso/escayola al que se añaden cargas de residuos plásticos procedentes del reciclaje de cables que, de otra manera, serían enviados a vertedero o incinerados. El propósito es obtener un material con propiedades mejoradas con el que reducir la cantidad de materia prima utilizada (piedra de aljez y agua) y reutilizar el residuo plástico tal cual se obtiene de la empresa de reciclaje, logrando, con ello, uno de los propósitos de la mencionada Directiva.

Para el diseño del compuesto y previo análisis de otras investigaciones, se ha utilizado una metodología basada en la caracterización de la materia prima y la comprobación de viabilidad y caracterización de las mezclas yeso-residuo plástico planteadas tanto en estado fresco como en estado endurecido. Asimismo, y una vez seleccionado el compuesto óptimo, se ha realizado una propuesta de la aplicación más adecuada y el estudio de su impacto ambiental. Para la constatación de la hipótesis, se ha diseñado y desarrollado un plan experimental basado en cuatro fases en las que se han realizado ensayos para determinar propiedades químicas, físicas, mecánicas, térmicas y de comportamiento ante la acción de agua y de fuego, así como una simulación energética del compuesto incluido en dos sistemas constructivos.

Los resultados finales muestran compuestos con densidad y propiedades higrotérmicas similares al compuesto de referencia de yeso que no incorpora residuo, resistencias mecánicas ajustadas a normativa, mucho más elásticos, con mejor adherencia superficial, mayor dureza superficial y una excelente mejora en el comportamiento ante la acción del agua. Además el coeficiente de conductividad térmica obtenido es menor que el de la referencia y presenta un aceptable comportamiento frente a la acción del fuego debido al recubrimiento de yeso.

Por otra parte, del análisis de la viabilidad de su fabricación también se deduce que se consigue reducir entre un $25-30 \%$ la utilización de los recursos naturales empleados (aljez y agua), así como la reutilización del 100\% del residuo plástico siguiendo con ello el criterio de economía circular. 


RESUMEN - ABSTRACT


Environmental awareness is generating a new concept of social organization as it is changing the way people live, their consumption habits, and how they travel from one place to another. This new form of social thinking that encompasses sustainable building seeks to minimize all possible environmental impacts caused by the construction industry. One way to achieve this is through the study and development of materials and techniques with a view to decreasing the use of natural resources, minimising $\mathrm{CO}_{2}$ emissions, and reducing or reusing waste.

The reuse, recycling or evaluation of waste therefore plays a primary role that implies a change of attitude in the prevailing linear economy model towards a circular economy. The circular economy paves the way for a new paradigm of intelligent design based on closing the circle at the end of a product's life, as occurs in nature. For construction material companies, the incorporation of waste into socalled "traditional materials" is an alternative that must be used, in line with the objective established in the current Waste Framework Directive 2008/98/EC.

Therefore, the objective of this Doctoral Thesis is to contribute to sustainable development by designing a new more efficient material. It is a gypsum/plaster matrix compound to which plastic waste is added from the recycling of cables that 
would otherwise be sent to landfills or incinerated. The purpose of this is to obtain a material with improved properties, to reduce the amount of raw material used (gypsum and water) and reuse the plastic waste, as it is obtained from the recycling Company, to fulfil one of the purposes of the aforementioned Directive.

After an analysis of prior studies, a methodology was developed based on the characterisation of the raw material as well as the verification of the viability and the characterisation of the gypsum-plastic waste mixtures presented in both their fresh and hardened states. Once the best compound was selected, a proposal was also made for the most appropriate application and the study of its environmental impact. To confirm this theory, an experimental plan based on four phases was designed and developed in which tests were carried out to determine chemical, physical, mechanical, thermal characteristics and the material's resistance to water and fire. A simulation of energy consumption of the compound included in two construction systems was also carried out.

The results show that the compounds have a similar density and hygrothermal properties as the reference gypsum compound that does not incorporate waste. Additionally they have a mechanical resistance that complies with regulations, a much greater elasticity and better surface adhesion, greater surface hardness and higher water resistance. The thermal conductivity coefficient obtained is also lower than that of the reference value and presents sufficient fire resistance due to its gypsum coating.

A viability analysis of the manufacturing process also shows that it is possible to reduce the amount of natural resources used by $25-30 \%$ (gypsum and water) and to reuse $100 \%$ of the plastic waste based on the principle of circular economy. 


\section{INTRODUCCIÓN Y MARCo DE REFERENCIA}

1.1 MEDIOAMBIENTE Y DESARROLLO SOSTENIBLE

1.2 CONSTRUCCIÓN SOSTENIBLE

1.3 EL PLÁSTICO: CARACTERÍSTICAS Y PROBLEMÁTICA

1.4 EL YESO: TIPOS Y APLICACIÓN

1.5 CONSIDERACIONES PARCIALES DEL CAPÍTULO

1.6 TRABAJOS CITADOS 


\section{INTRODUCCIÓN Y MARCO DE REFERENCIA}

Son muchas las singularidades que definen a nuestra sociedad actual, pero sin ninguna duda, una de ellas podría definirse como "tener conciencia medioambiental" y, aunque cada vez es mayor la preocupación por conservar todo lo que nos rodea, todavía queda un gran camino que recorrer para alcanzar una verdadera cultura ecológica.

En la línea de la innovación tecnológica en edificación, este hecho ha intensificado la realización de investigaciones enfocadas al desarrollo de nuevos materiales con los que, además de reducir la utilización de los recursos naturales, que no son infinitos, en pro del reciclaje de los residuos, que no llegan a ser asimilados por los ciclos naturales, se mejoran las condiciones térmicas de los edificios, disminuyendo la demanda energética y, con ello, las emisiones de $\mathrm{CO}_{2}$. Es decir, se está apostando por conservar los ecosistemas naturales a través de una construcción sostenible, "un paradigma orientado hacia el medioambiente, que resuelve las necesidades de habitabilidad y confort, conservando el entorno natural" (López de Asiain, 2001). 


\subsection{MEDIOAMBIENTE Y DESARROLLO SOSTENIBLE}

Desde su origen y hasta finales del siglo XVIII, inicio de la Revolución Industrial, la humanidad ha estado utilizando los recursos naturales que ha tenido a su alcance en la naturaleza sin apenas causar impacto ambiental sobre ella. Se extraía materia prima y se devolvía residuo en unas cantidades que la propia naturaleza era capaz de absorber mediante ciclos naturales.

En cambio, con el inicio de la Era Industrial, surge toda la problemática ecológica, pues "el mundo cambia radicalmente en los aspectos sociales, económicos y ambientales" (Romaniega Piñeiro, 2016). Con el desarrollo de la ciencia y la tecnología, se comienza a dominar la naturaleza para ponerla al servicio de la sociedad. Sociedad en la que ya se empiezan a manifestar otras grandes preocupaciones, como el agotamiento de los recursos naturales o la contaminación y la acumulación de residuos, como consecuencia de las nuevas actividades industriales que están surgiendo, de la globalización del comercio y del estallido demográfico y económico del momento. A pesar de ello, se empiezan a vislumbrar algunas medidas encaminadas a controlar, por un lado la contaminación del aire, la cifra de partes por millón (ppm) es en ese momento de 278 partes de dióxido de carbono por millón de partículas de aire (National Oceanic and Atmospheric Administration, 2017b) y, por otro lado, la recogida de residuos que, por la cantidad generada, ya no son asimilados por los ciclos naturales, y empiezan a ocasionar problemas de salud, plagas y epidemias en la población y, por ende, en los trabajadores.

En el siglo XX y, más concretamente, a partir del último cuarto, el problema empieza a tomar dimensiones alarmantes, pues, además de triplicarse la población en apenas unas décadas, 6.035 billones de personas en 1999 (The World Bank Group, 1999), "se origina una economía basada en el consumo, una cultura del usar y tirar" (UNED, 2016). Esto, junto con los grandes cambios generados por los avances tecnológicos, ocasiona un grave impacto ambiental. "La utilización de materiales en el mundo se multiplica por diez desde el año 1900 hasta la actualidad y podría duplicarse nuevamente antes de 2030" (Sanjuán-Barbudo, 2016). Las partes de dióxido de carbono por millón de partículas de aire en el 2000, rondan la cifra de 368 (National Oceanic and Atmospheric Administration, 2017a), un aumento de un 32\% en poco más de un siglo. En cuanto a la generación de residuos, en el año 2000 se produjo una media de 916,8 millones de toneladas en Europa (excluyendo residuos minerales importantes), lo que representa $1806 \mathrm{Kg} / \mathrm{habitante} \mathrm{y}$, de los que a España corresponde 58,2 millones de toneladas (1435 Kg/habitante) (ONU, 2000b). 
Estos datos alertan a la comunidad internacional (representada por la Organización de Naciones Unidas - ONU) que, en 1972, convoca la Conferencia de las Naciones Unidas sobre el Medio Humano (ONU, 1972). En esta Conferencia celebrada en Estocolmo (Suecia), se proclaman criterios y principios comunes en materia ambiental, especialmente relacionados con la degradación ambiental y la "contaminación transfronteriza" y, además, se requiere la colaboración entre naciones y una adopción de medidas internacionales por el interés general. Se crea con ello el “Programa de las Naciones Unidas para el Medio Ambiente” (PUMA).

Estas medidas conciencian a los países

Figura 1.1. Programa 21. Fuente: (ONU, 1992)

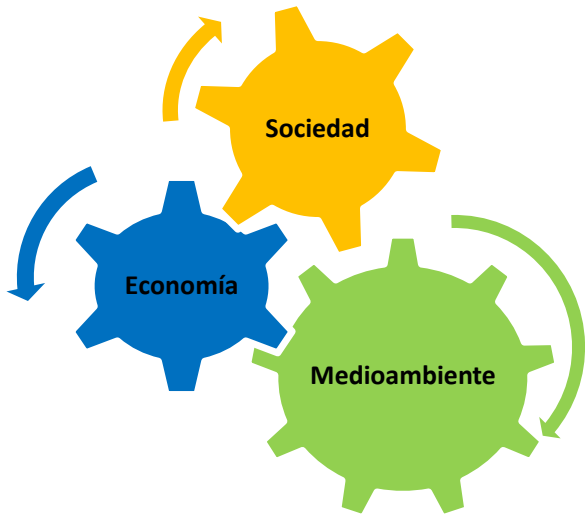
sobre los temas medioambientales más acuciantes como la deforestación excesiva; la desertificación y degradación de la tierra; la contaminación; los vertidos peligrosos; el cambio climático; el uso y administración de océanos y recursos de agua dulce; la disminución de la diversidad biológica y la reducción de la capa de ozono, dando lugar a acuerdos importantes, en cuanto a legislación ambiental, llevados a cabo por el PUMA,

en las Convenciones de Basilea, Estocolmo y Rotterdam y, en el Protocolo de Montreal (ONU, 1980).

Con la sucesión de estos acontecimientos la ONU crea, en 1983, la Comisión Mundial de Medio Ambiente y Desarrollo (CMMAD) que, en 1987, aporta un informe, conocido como Informe Brundtland - "Nuestro futuro en común" - en consideración de la presidenta Gro Harlem Brundtland, en el que se intentan hallar procedimientos efectivos para revertir el problema ambiental y de desarrollo en el mundo, demostrándose en él que, medioambiente, economía y sociedad están íntimamente relacionados (Figura 1.1). Es en este informe donde se define por primera vez el término "desarrollo sostenible" como "desarrollo que satisface las necesidades del presente sin comprometer las necesidades de las futuras generaciones" (ONU, 2002).

Esta idea supone un cambio radical en la percepción de la sustentabilidad o sostenibilidad, entendiéndose como tal, el equilibrio entre la sociedad y el entorno que la rodea y, sobre ello, se empieza a trabajar a través de una serie de programas, acuerdos, actividades, asociaciones, etc, que nacen para intentar aportar soluciones a los problemas ambientales existentes. Así, se adopta en 1987 el Protocolo de 
Montreal, formulado unos años antes, que "supone el primer acuerdo internacional de limitación de producción y consumo de productos químicos que agotan el ozono" (ONU, 1987). En 1988 se crea el Intergovernmental Panel on Climate Change (IPCC) con un grupo de expertos sobre el cambio climático, cuyos informes tendrán mucha influencia en la Convención Marco de las Naciones Unidas sobre el Cambio Climático y en el Protocolo de Kyoto. En 1989 entra en vigor lo acordado en la Convención de Basilea de 1987, donde se regula el movimiento y eliminación de desechos peligrosos. En 1991 se establece el Fondo para el Medio Ambiente Mundial (GEF) que supone la financiación de proyectos ambientales en todo el mundo y, gracias a esto, el desarrollo e implantación de alguno de ellos. Ese mismo año se convoca la $2^{a}$ Conferencia Mundial de la Industria sobre Gestión Ambiental donde se emite la primera Carta Empresarial sobre Desarrollo Sostenible con el fin de aumentar la conciencia ambiental, aclarar y encuadrar el concepto de desarrollo sostenible y, resaltar áreas en las que las empresas pueden avanzar más contribuyendo al desarrollo sostenible (ONU, 1991).

En la década de los 90, se celebra la "Cumbre para la Tierra", uno de los acontecimientos más relevantes en materia ambiental, que tiene lugar en Río de Janeiro en 1992 (ONU, 1992). Constituye una nueva Conferencia de las Naciones Unidas sobre el Medio Ambiente y Desarrollo y, tiene como resultado la adopción del denominado Programa 21, un plan de acción para el desarrollo sostenible, que se caracteriza por la campaña de concienciación pública sobre la necesidad de integrar consideraciones sociales y medioambientales en las políticas de desarrollo económico. Para asegurar el seguimiento eficaz de las labores de esta Conferencia, se crea un nuevo órgano denominado "Comisión sobre el Desarrollo Sostenible" (CSD). En 1998, se promueven responsabilidades compartidas en relación con la importación de productos químicos y pesticidas peligrosos cuando entra en vigor la Convención de Rotterdam (ONU, 1998). Finalizando el siglo XX, en 1999, tiene lugar el Pacto Mundial de las Naciones Unidas que trabaja en políticas sostenibles y socialmente responsables (ONU, 1999).

Ya iniciado el siglo XXI "nos encontramos ante uno de los mayores desafíos de la humanidad: el conseguir un modelo global verdaderamente sustentable" (Barrón Ruiz, 2002). Nuestra conciencia ambiental está despertando y, constantemente, se apuesta "por nuevas ideas, por fórmulas distintas que, junto a la imaginación, la equidad y la resiliencia, construyan caminos hacia otro mundo posible" (Novo Villaverde, 2006). Los datos comparativos respecto al fin del siglo XX siguen siendo críticos: por un lado el aumento de un 23\% de la población en apenas 16 años, superando los 7.426 billones de habitantes en 2016 (The World Bank Group, 2016) y, por otro lado las partes de 
dióxido de carbono por millón de partículas de aire en el 2016 que superan la cifra de 402 (National Oceanic and Atmospheric Administration, 2017a) y suponen un aumento aproximado de un 10\% en 16 años. En cuanto a la generación de residuos en Europa, ha disminuido en un 1,3\% con cifras de 904,9 millones de toneladas durante el año 2016 (excluyendo residuos minerales importantes), que representan 1772 $\mathrm{Kg} /$ habitante; en cambio, en España, se ha incrementado un 18,2\% que suponen 68,8 millones de toneladas (1480 Kg/habitante) (Eurostat, 2019).

Con una fecha tan marcada como es el cambio de siglo y de milenio, los líderes mundiales se reúnen, en septiembre de 2000, en la denominada "Cumbre del Milenio" donde se comprometen para una colaboración global (ONU, 2000a). Se tratan problemas mundiales que quedan recogidos en 8 puntos dentro de los cuales, el séptimo, una vez más, trata de garantizar la sostenibilidad del medio ambiente. En 2002, después de comprobar la decepción del escaso logro de desarrollo sostenible desde la Cumbre de la Tierra de 1992, la Asamblea General declara que lo que la sociedad demanda es una nueva Cumbre de acciones y resultados y, se convoca para ello la "Cumbre de Johannesburgo", en la que se indican 5 cuestiones fundamentales para iniciar un verdadero cambio sostenible: agua y saneamiento, energía, salud, agricultura y diversidad biológica y ordenación de los ecosistemas, con las que "mejorar la calidad de vida de las personas pero garantizando la conservación de los recursos naturales" (ONU, 2002).

Además, se pone mucho énfasis por evitar el cambio climático y, en 2005 entra en vigor el "Protocolo de Kioto" (Ministerio para la transición ecológica, 2002), un acuerdo internacional, inicialmente adoptado en 1997, sobre el cambio climático que tiene por objetivo el reducir las emisiones de seis gases de efecto invernadero y que, llega a su culmen en diciembre de 2015, en París, tras lograrse un pacto global, el “Acuerdo de París”, que en tan solo 11 meses entra en vigor (Planelles, 2016).

En la actualidad, la toma de conciencia ecológica es lo que está haciendo que la sociedad modifique aspectos en su forma de vivir, de consumir, de producir, incluso de moverse de un sitio a otro, es decir, se está generando un nuevo concepto de organización social. Es en este nuevo pensamiento de la sociedad donde tiene cabida la construcción sostenible que, de algún modo, engloba esa mentalidad ecológica pues pretende minimizar, en el conjunto de sus actividades, todos los impactos ambientales posibles: residuos, contaminación, disminución de recursos naturales, reducción de emisiones de $\mathrm{CO}_{2}$, etc. Es decir, "la construcción sostenible se considera la manera que tiene el sector de la construcción de contribuir al desarrollo sostenible" (Soriano Baeza, 2010). 


\subsection{CONSTRUCCIÓN SOSTENIBLE}

La forma de construir se ha ido adaptando lentamente a las necesidades de cada época, respondiendo a una realidad social y económica a la que, en nuestros días, lo "ecológico" se ha añadido como un requisito más (Baño Nieva \& Vigil-Escalera del Pozo, 2005).

Cuando se habla de construcción sostenible, por tanto, debe entenderse "el desarrollo de la construcción tradicional pero con una responsabilidad considerable con el medioambiente por todas las partes y participantes" (Alavedra, Domínguez, Gonzalo, \& Serra, 1997). Para ello es imprescindible tener en cuenta la totalidad de las fases que integran el proceso edificatorio, desde la selección de los materiales a emplear, a los residuos que se van a generar o la energía que se va a consumir, con el fin de considerar la minimización de los recursos en todas ellas (Figura 1.2).

"El sector de la construcción es responsable de la utilización del 30-50\% de los recursos naturales, del 30-40\% de la energía consumida (incluyendo la energía en uso) $y$ del 50\% del total de los residuos generados" (Arenas Cabello, 2008). En base a esto, para considerar que una construcción es sostenible, se debería apreciar el cumplimiento de algunos principios básicos:

- que se adapte y sea respetuosa con su entorno,

- que ahorre recursos,

- que ahorre energía,

- que cuente con los usuarios (Baño Nieva \& Vigil-Escalera del Pozo, 2005).

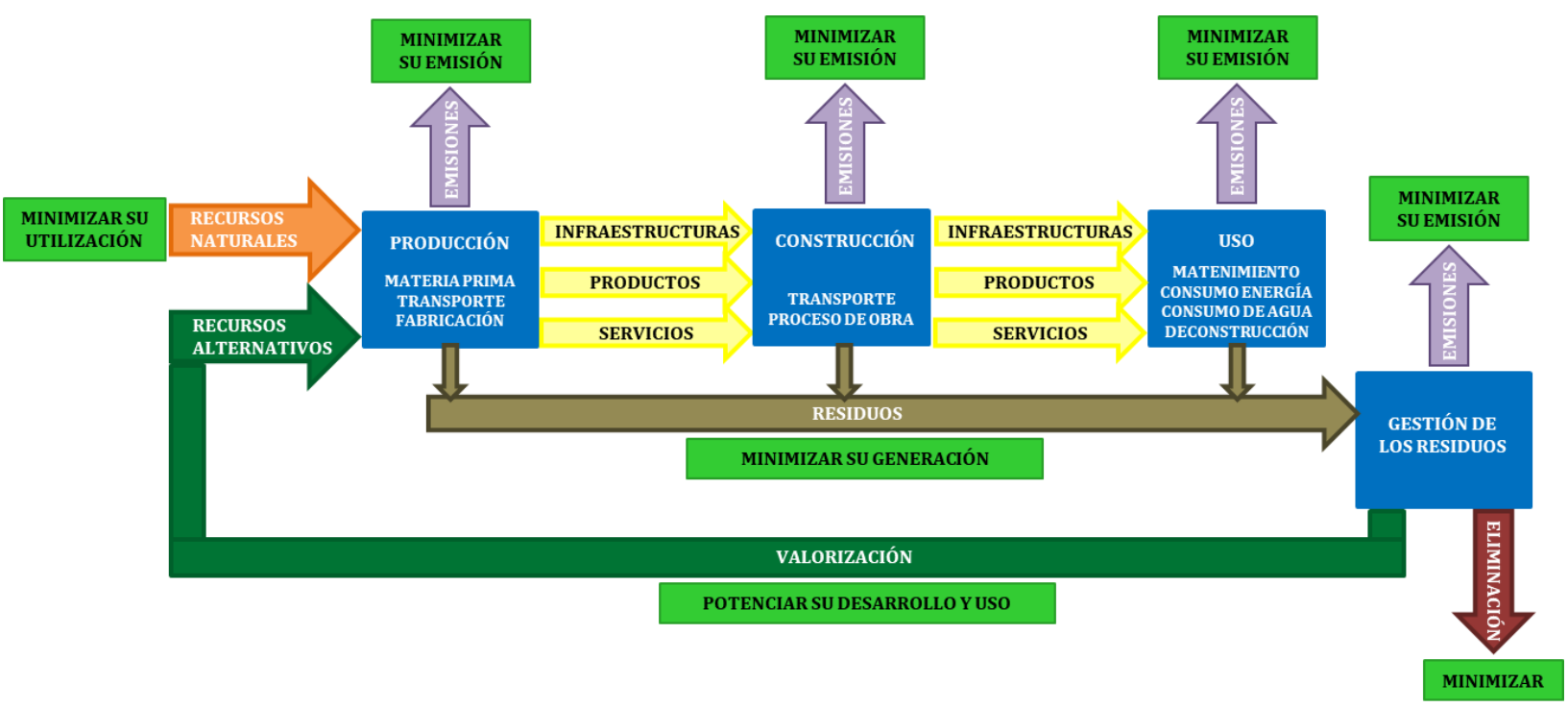


Esta manera de enfocar el proceso constructivo mediante una construcción sostenible, reside en percibir que es posible construir con criterios más racionales (Soriano Baeza, 2010), es posible minimizar el uso de recursos naturales y de energía $\mathrm{y}$, además, es posible reducir la generación de residuos y las emisiones de $\mathrm{CO}_{2}$. Por tanto, uno de los retos que se proponen con este campo es el desarrollo de materiales y sistemas innovadores y sostenibles.

\subsubsection{Materiales de Construcción}

El paso del tiempo ha dado lugar a un cambio radical en la obtención de los materiales de construcción, pasando de adquirirlos en la propia zona y con los mínimos procesos de extracción y transformación, a adquirirlos en cualquier punto del mundo mediante laboriosos y sofisticados procesos de extracción y transformación.

Seguimos utilizando materiales tradicionales como la piedra, el yeso y la madera que alternamos con otros de más reciente invención como el hormigón, los metales, las fibras o los plásticos pero, en las últimas décadas, es creciente el empleo de sistemas innovadores alternativos a estos materiales convencionales de construcción a través de la introducción de componentes de bajo impacto ambiental.

Tal y como apunta el profesor Francisco J. Arenas Cabello (Arenas Cabello, 2008), cabe señalar que, "en España aún se encuentran en fase embrionaria los criterios o parámetros de sostenibilidad ambiental aplicados a la Construcción en general, y a la Edificación en particular, relativos al empleo de materiales con menor impacto ambiental para su uso en la edificación con alta eficiencia energética, durabilidad, recuperabilidad y recursos renovables" pero, también es cierto, que cada vez están más presentes en el establecimiento de normativas, decretos y/o leyes que atañen a esta actividad tal y como puede observarse tras la entrada en vigor del Código Técnico de la Edificación (CTE), los sucesivos Planes Estatales de Gestión de Residuos, o los Reales Decretos 235/2013 y 56/2016 de mejora de la eficiencia energética y la promoción del ahorro energético para la contribución a la reducción de emisiones de $\mathrm{CO}_{2}$, entre otros.

\subsubsection{Incidencia ambiental de los materiales de construcción}

Como ya se ha comentado, los materiales de construcción inciden en el medio ambiente durante todo su ciclo de vida: desde la extracción de la materia prima hasta su desecho como residuo tras la deconstrucción, pasando por el proceso de 
transformación, la puesta en obra y el mantenimiento. Por tanto, el análisis de los impactos ambientales provocado por ellos, "debe hacerse desde una visión global de todo ese ciclo de vida", a través del control de los procesos que producen los efectos negativos del medioambiente (Barrios, 2012):

1) Agotamiento de recursos naturales

2) Consumo de energía

3) Contaminación

4) Emisión de sustancias perjudiciales para la salud de las personas

5) Producción de residuos

En un alto porcentaje de la industria asociada a la manufactura de los materiales de construcción, se utiliza materia prima procedente de recursos naturales no renovables, entendiendo como no renovables aquellos recursos que, por las cantidades empleadas, la propia naturaleza no es capaz de regenerarlos o de los que se dispone en cuantía limitada. Ejemplo de ello son el uso de agua, suelo o madera, o de minerales, como granitos, calizas, arenas, arcillas, etc, o combustibles fósiles, como carbón o petróleo entre otros, todos ellos utilizados desde la antigüedad hasta nuestros días.

En los últimos años, en España se ha registrado un descenso del consumo de recursos naturales en la fabricación de materiales de construcción. Se ha pasado de emplear 20,1 toneladas de recursos y materiales por persona y año $(16,5$ toneladas media UE), en el año 2007, a emplear 14 toneladas de recursos y materiales por persona y año en 2010 (Cerrillo, 2012). Añadido a este camino de reducción del uso de recursos naturales, es interesante también, la apuesta por la "sustitución de una economía lineal basada en producir, consumir y tirar, por una economía circular en la que se reincorporen al proceso productivo una y otra vez los materiales que contienen residuos para la producción de nuevos productos de construcción" (Secretaría de Estado y Medio Ambiente, 2016). En este sentido, la UE desde la Comisión Europea, ofrece fondos para llevar a cabo planes de acción que cierren los ciclos de vida de los materiales y productos priorizando el reciclaje y la reutilización, dando importancia a la idea de que "todo tiene un valor" y "aquí nada se tira", incrementándose con ello, estudios e investigaciones sobre nuevos materiales para la construcción (Núñez, 2017).

En cuanto al consumo de energía, cabe destacar que la cuantificación del uso de energía de un material de construcción debe tenerse en cuenta en todas y cada una de las fases de su existencia, esto es, desde la energía consumida durante la obtención de la materia prima necesaria para la fabricación, pasando por el proceso de producción, 
transporte, almacenaje, puesta en obra, uso, mantenimiento, deconstrucción y gestión del residuo.

Materiales tradicionales como la tierra, arena, grava y piedra, junto con la madera son los materiales de construcción que presentan un menor impacto energético durante todo su ciclo de vida, mientras que, en el lado opuesto, encontramos los metales y plásticos que, sobre todo en su proceso de fabricación, consumen gran cantidad de energía (Baño Nieva \& Vigil-Escalera del Pozo, 2005).

Existen numerosos estudios que tratan de calcular de alguna manera valores indicadores del consumo de energía de algunos de los materiales más utilizados en construcción. Entre ellos los profesores Geoff Hammond y Craig Jones de la Universidad de Bath (Inglaterra), en su informe "Inventory of Carbon \& Energy (ICE) Version 2.0", de enero de 2011, considerando un análisis Cradle-to-gate, es decir, considerando un análisis solo desde la fase de extracción de la materia prima hasta el lugar de producción, sin considerar el resto de fases, estiman lo indicado en la Tabla 1.1 (Hammond \& Jones, 2011):

Tabla 1.1: Resumen del Informe "Inventory of Carbon \& Energy (ICE) versión 2.0". Fuente: (Hammond \& Jones, 2011)

\begin{tabular}{lc}
\hline Material & Energía incorporada (MJ/Kg) \\
\hline Arena & 0,0081 \\
\hline Agregados & 0,083 \\
\hline Hormigón & 0,75 \\
\hline Piedra & 1,26 \\
\hline Yeso & 1,8 \\
\hline Ladrillos cerámicos & 3 \\
\hline Cemento & 4,51 \\
\hline Azulejos & 6,5 \\
\hline Cartón yeso & 6,75 \\
\hline Madera & 10 \\
\hline Productos cerámicos & 10 \\
\hline Vidrio primario & 15 \\
\hline Papel & 24,8 \\
\hline Hierro & 25 \\
\hline Acero & 35,4 \\
\hline Plásticos & 35,6 \\
\hline Caucho & 40 \\
\hline Tubería e hilos de cobre & 42 \\
\hline Aislamientos & 45 \\
\hline Pinturas & 70 \\
\hline
\end{tabular}


En la actualidad, tanto en Europa como en España, las normativas de aplicación para reducir el consumo de energía están volcadas en el logro de edificios "Passivhaus" o "Edificios Pasivos", donde esto se consigue básicamente, a través de la incorporación de buenos aislamientos, un sistema mecánico de ventilación y la inexistencia de puentes térmicos, pero todavía no existen medidas para la limitación de la energía del resto de etapas del ciclo de vida de los materiales, que supondrían una disminución de lo que se está observando en los últimos años (Gráfica 1.1):
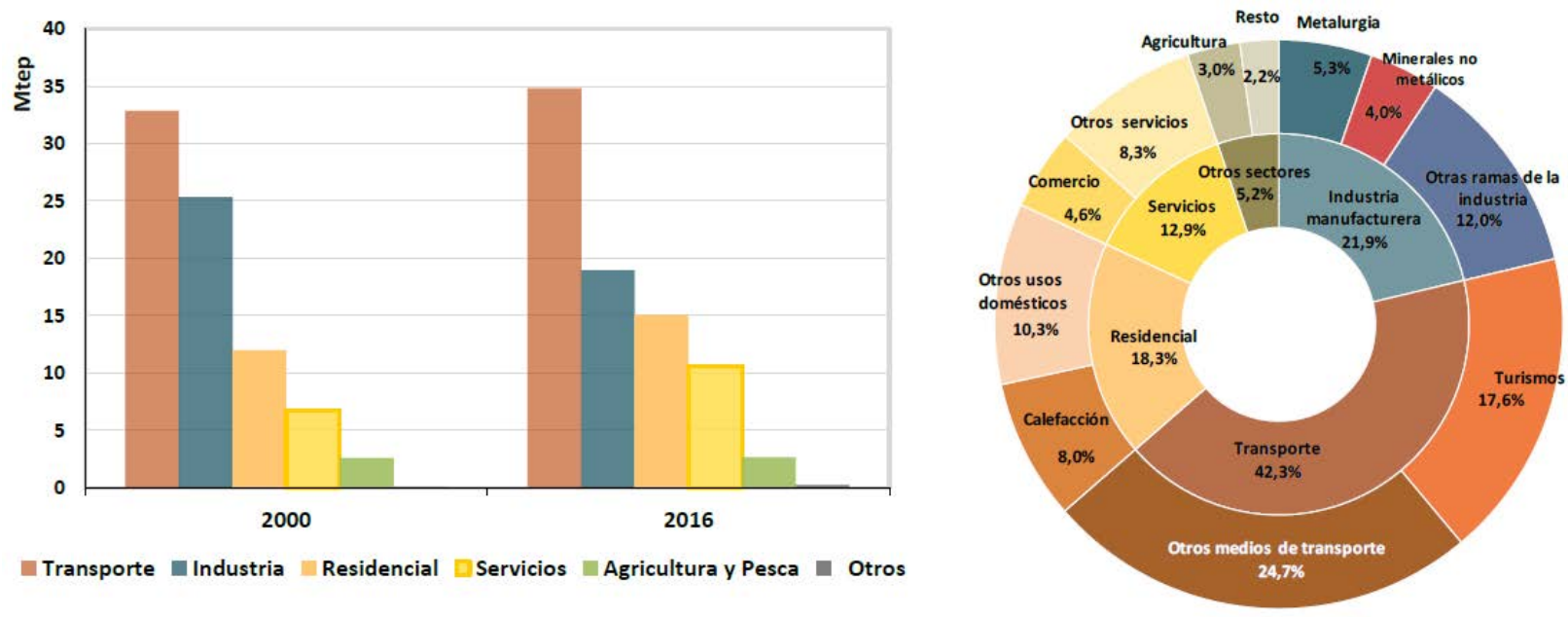

Gráfica 1.1. Consumo de Energía Final en España por Sectores 2000-2016. Fuente: (IDAE, 2018)

En cuanto al problema de la contaminación, cabe señalar que dentro de la contaminación que ocasionan los materiales de construcción durante todo el ciclo de su vida se deben considerar, además de las emisiones ocasionadas a la atmósfera, como la destrucción de la capa de ozono, los gases invernadero, las lluvias ácidas o los oxidantes fotoquímicos; las emisiones emitidas al agua, como la eutrofización, las grasas y aceites, los detergentes, o las materias orgánicas e inorgánicas y; las emitidas a la Tierra, como la acidificación, los pesticidas, los metales pesados o las filtraciones del alcantarillado.

Aunque, si bien es cierto que, en función del tipo de material de construcción del que se habla, su contaminación es más o menos acentuada en una etapa u en otra de su ciclo de vida, la mayoría de los materiales utilizados en las edificaciones siempre tienen un efecto negativo (Tabla 1.2). Por ejemplo, materiales tan utilizados como el yeso y el cemento tienen un impacto ambiental negativo en todo su proceso de manufactura, desde la emisión de partículas volátiles y deterioro del suelo durante la extracción en la cantera, el transporte y la cocción de las materias primas, hasta los 
lixiviados generados en los hornos tras la obtención del producto que pueden afectar gravemente al agua si no se controlan.

Tabla 1.2. Impacto ambiental de algunos materiales de construcción. Fuente: (Baño Nieva \& Vigil-Escalera del Pozo, 2005)

\begin{tabular}{|c|c|c|c|c|c|}
\hline Material & $\begin{array}{l}\text { Efecto } \\
\text { invernadero }\end{array}$ & Acidificación & $\begin{array}{l}\text { Contaminación } \\
\text { atmosférica }\end{array}$ & Ozono & $\begin{array}{l}\text { Metales } \\
\text { pesados }\end{array}$ \\
\hline Cerámica & - & ○ & - & ㅇ & 웅 \\
\hline Piedra & ○ & ○ & 룽 & 당 & 웅 \\
\hline Acero & 단 & ○ & 군 & - & ㄱ. \\
\hline Aluminio & 군 & ? & 운 & - & 궁 \\
\hline PVC & 운 & O & - & ? & () \\
\hline Poliestireno & 운 & O & ㄱ. & 단 & ? \\
\hline Poliuretano & 웅 & ? & ? & 운 & 운 \\
\hline Pino & P & ○ & - & C & P \\
\hline
\end{tabular}

impacto pequeño; impacto medio; impacto elevado.

Para el control de buena parte de los sistemas que provocan contaminación se están generando, cada vez más, normativas tanto de ámbito europeo como estatal del orden de:

- Contaminación atmosférica: desde la Directiva 2008/50/CE del Parlamento Europeo y del Consejo, relativa a la calidad del aire ambiente y a una atmósfera más limpia en Europa, hasta la Ley 34/2007, de calidad del aire y protección de la atmósfera, pasando por normativas autonómicas como la Orden 665/2014, del Consejero de Medio Ambiente y Ordenación del Territorio, por la que se aprueba la estrategia de calidad del aire y cambio climático de la Comunidad de Madrid 2013-2020 Plan Azul +.

- Contaminación del agua: desde las Directivas 2000/60/CE y 2008/105/CE del Parlamento Europeo y del Consejo, por las que se establece un marco comunitario de actuación en el ámbito de la política de aguas, hasta el RD 606/2003, de aguas, pasando por normativas autonómicas como la Ley 10/1993, sobre vertidos líquidos industriales al sistema integral de saneamiento de la Comunidad de Madrid.

- Contaminación del suelo: desde la Comunicación de la Comisión Europea COM (2006) 231 final, de estrategia temática para la protección del suelo, hasta la Ley 22/2011, de residuos y suelos contaminados, pasando por normativas autonómicas como la Orden 761/2007, de niveles genéricos de elementos en suelos contaminados de la Comunidad de Madrid. 
En cuanto a la emisión de sustancias perjudiciales, en las últimas décadas se ha demostrado que algunos materiales de construcción pueden liberar sustancias tóxicas para las personas que pasan mucho tiempo en sus aledaños. Sin ir más lejos el caso del plomo, que se utilizaba en tuberías de agua potable y puede llegar a ocasionar lesiones en el cerebro, hígado, riñones y huesos; el del amianto, que se utilizó durante algunos años como componente en la fabricación del fibrocemento y puede provocar enfermedades graves respiratorias; el de barnices protectores de la madera que pueden causar daños digestivos; o el de las fibras minerales utilizadas en los aislamientos, que pueden originar irritaciones de ojos y piel. Existen reglamentaciones que regulan tanto la fabricación como la manipulación o retirada de estos materiales tóxicos, así como la prohibición de uso de aquellos con mayor efecto sobre la salud.

Al igual que ocurre con la energía, la producción de residuos de los materiales de construcción y demolición, denominados RCD, se da en todas y cada una de las fases de su ciclo de vida. Su producción desproporcionada ocasiona daños, no solo en su entorno más próximo, con acumulaciones desmesuradas, sino también, hay que añadir las consecuencias que se derivan de estas acumulaciones: contaminación del suelo donde están depositados, contaminación del agua de escorrentía o de ríos cercanos, contaminación atmosférica por los elementos volátiles y olores, degradación de los alrededores y consumo de energía de transporte y mantenimiento de vertederos. Es por ello que la problemática de residuos tiene una incidencia muy importante en otras problemáticas ambientales.

Según el PEMAR 2016-2022, el objetivo de las orientaciones comunitarias en relación con el desarrollo sostenible, es convertir a Europa, en una sociedad eficiente en el uso de los recursos, que produzca menos residuos y que utilice como recursos, siempre que sea posible, los que no pueden ser evitados (Secretaría de Estado y Medio Ambiente, 2016). En este sentido, la reutilización, el reciclaje o la valoración de residuos, juegan un papel primordial y, esto pasa, por un cambio de actitud sobre el modelo de economía predominante.

Fueron dos estadounidenses, el arquitecto Mc Donough y el químico Braungart, quienes en los años noventa, introdujeron el concepto cradle to cradle (de la cuna a la cuna), con el que se consideran los materiales involucrados en los procesos industriales y comerciales como nutrientes, de manera que son fácilmente regenerados o devueltos a la tierra (Hermida Balboa \& Domínguez Somonte, 2014). Este arquetipo plantea las bases de un nuevo paradigma de diseño inteligente basado en el cierre del ciclo de vida de los productos, tal y como ocurre en la naturaleza: la economía circular (Braungart, McDonough, \& Bollinger, 2007) (Figura 1.3). 


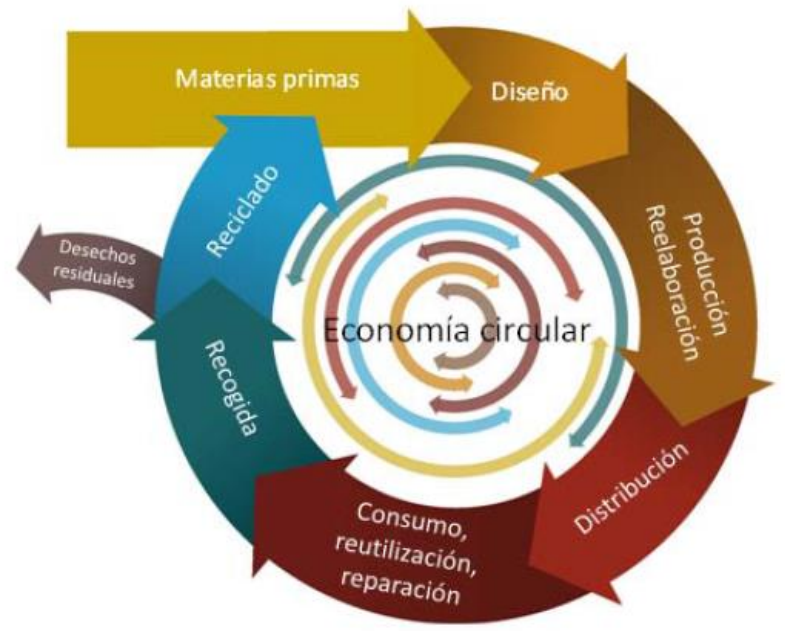

Figura 1.3. Esquema de economía circular - Fuente: (Ministerio de Agricultura Alimentación y Medio Ambiente, 2016)

En la actualidad "el modelo de sistema lineal de la economía (extracción, fabricación, utilización y eliminación) ha alcanzado sus límites o está a punto de llegar, por tanto, es necesario encontrar alternativas" (Moraño Rodríguez, 2016). Esta necesidad de cambio, está dando lugar a una economía circular como respuesta a los problemas no solo ambientales, sino también sociales y económicos, que se han ido acumulando durante los últimos años (Fresneda, 2014).

Principales defensores de la economía circular, como Ellen McArthur, apuntan que ésta va mucho allá del reciclaje, es decir, la economía circular es hablar de diseño e innovación, de reaprovechamiento de recursos, de apertura de nuevos mercados, de creación de valor e, incluso, en buena medida, de creación de empleo (Fresneda, 2016).

En el sector de la construcción esto no es una excepción. El presidente de la Asociación Española de Reciclaje de Residuos de Construcción y Demolición (RCD Asociación), José Ignacio Tertre, señala que "los RCD, por su gran volumen de producción, impacto en el medio y, facilidad de reciclaje, representan uno de los cinco sectores prioritarios del Plan de Acción de la Unión Europea para la economía circular" (Tertre Torán, 2016).

El enfoque de la economía circular en la construcción supone una oportunidad para el diseño y la innovación de nuevos materiales. Teniendo en cuenta que se debe mantener el valor añadido de los productos el mayor tiempo posible, se deben plantear materiales durables con los que, además, se evite la generación y vertido de residuos (Argiz, 2016). 


\subsubsection{Los residuos de construcción y demolición (RCD)}

En el ámbito europeo, los residuos se controlan a través de la Directiva Marco de Residuos 2008/98/CE del Parlamento Europeo y del Consejo (Parlamento Europeo, 2008) y su modificación según Directiva (UE) 2018/851 (Parlamento Europeo, 2018); junto con la Decisión de la Comisión 2000/532/CE (Comisión de las Comunidades Europeas, 2000) y su modificación por Decisión de la Comisión 2014/955/UE (Comisión Europea, 2014), que establece una lista de residuos de conformidad con la Directiva 75/442/CEE y sus modificaciones (Parlamento Europeo, 1975). Quedan traspuestas a la legislación española a través del Real Decreto 105/2008 por el que se regula la producción y gestión de los residuos de construcción y demolición (Ministerio de la Presidencia, 2008); la Orden APM/1007/2017 sobre normas generales de valorización de materiales naturales excavados para su utilización en operaciones de relleno y obras distintas a aquellas en las que se generaron (Ministerio de Agricultura y Pesca Alimentación y Medio, 2017); la Ley 22/2011, de 28 de julio, de residuos y suelos contaminados (Jefatura del Estado, 2011) y sucesivos Planes Estatales Marco de Gestión de residuos (PEMAR), como el último, que regula el intervalo de años 2016-2022 (Ministerio de Agricultura Alimentación y Medio Ambiente, 2016), así como otras normativas de consideración autonómica.

Es en la Directiva Marco de Residuos 2008/98/CE, donde se define "residuo como cualquier sustancia u objeto del cual su poseedor se desprenda o tenga la intención o la obligación de desprenderse" (Parlamento Europeo, 2008). Pero la definición más específica de RCD se encuentra en el Real Decreto 105/2008 en el que, a lo anterior, se añade “...y que se genere en una obra de construcción o demolición" (Ministerio de la Presidencia, 2008).

De la composición de los RCD "se considera que el 75\% de los residuos generados en obra son de tipo inerte (minerales en su mayoría) y comúnmente se les denomina "escombros" y, el 25\% restante es una combinación heterogénea de otros residuos, algunos tóxicos y peligrosos" (Santos Marián, Monercillo Delgado, \& García Martínez, 2011) (Gráfica 1.2). Esto es algo en lo que la mayoría de las estadísticas coinciden y que se puede definir como:

- Residuos no peligrosos (Gráfica 1.3): residuos inertes, es decir, aquellos que no experimentan transformaciones físicas, químicas o biológicas significativas. No son solubles, ni combustibles, ni biodegradables, ni afectan a otras materias con las que entran en contacto contaminándolas, ni perjudican a la salud humana (del Río Merino, 2008). 
- Residuos peligrosos, según Anexo III de la Directiva Marco de Residuos (Gráfica 1.3): residuos que presentan una o varias de las siguientes características peligrosas, explosivos, comburentes, inflamables, irritantes, tóxicos en determinados órganos o tóxicos por aspiración, tóxicos de valoración aguda, carcinógenos, corrosivos, infecciosos, tóxicos para la reproducción, mutágenos, liberan gases tóxicos, sensibilizantes, y/o ecotóxicos (Parlamento Europeo, 2008).

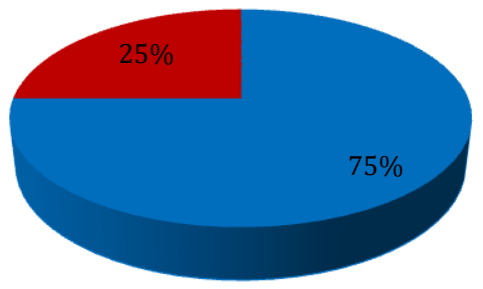

- RCD No Peligrosos $\quad$ RCD Peligrosos

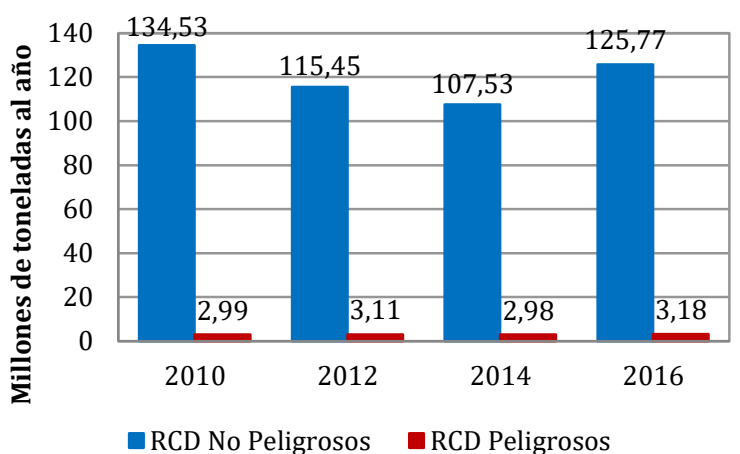

Gráfica 1.2. Izquierda: Composición de los RCD. Fuente: (Santos Marián et al., 2011)

Gráfica 1.3. Derecha: RCD no peligrosos y peligrosos generados en España entre 2010 y 2016 - Fuente: (Eurostat, 2019)

De los residuos generados en Europa durante el año 2016, se estima que, aproximadamente el 36\% proceden del sector de la construcción (Gráfica 1.4) y suponen 4737,19 millones de toneladas. En España, este dato se reduce hasta el 28\%, esto es, 36,11 millones de toneladas (Eurostat, 2019) (Gráfica 1.4).

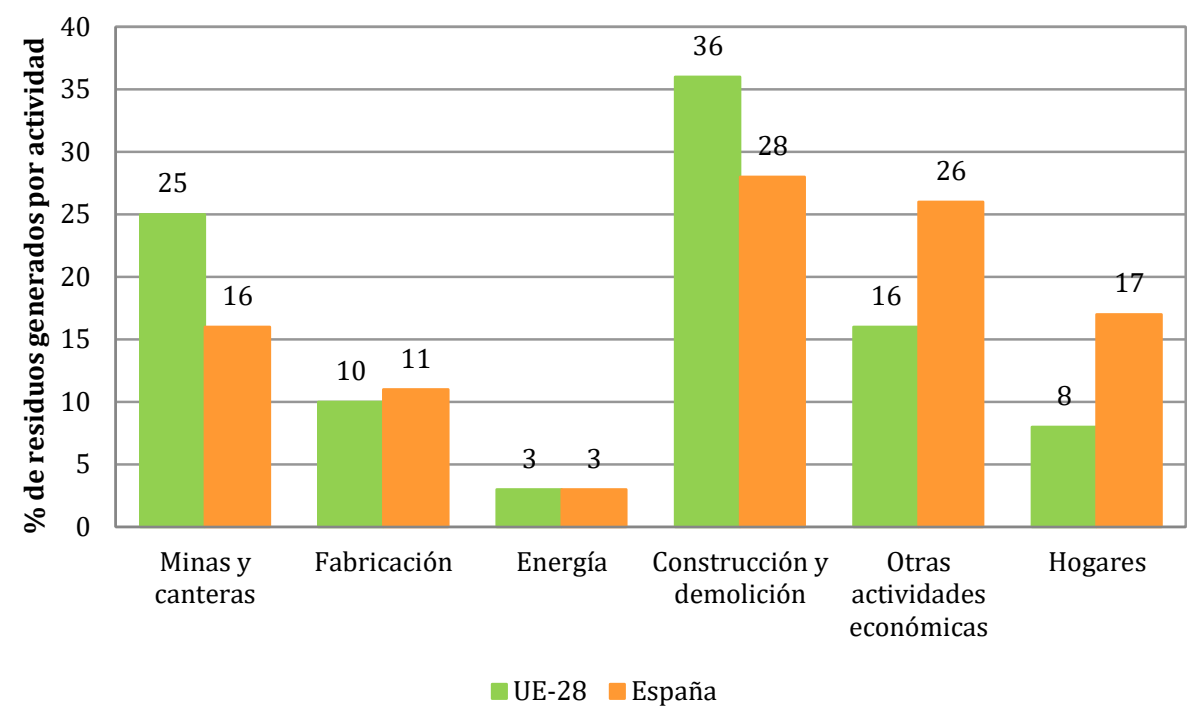

Gráfica 1.4. Residuos generados por actividades económicas y hogares en la UE-28 y España-Año 2016. Fuente: (Eurostat, 2019) 
La evolución decreciente de la generación de los RCD en España durante los años 2009-2011 supone el fin de una etapa en alza (2001-2006) que mostraba una cifra insostenible de crecimiento del 8,7\% anual (Ministerio de Medio Ambiente y Medio Rural y Marino, 2009). Este hecho ha sido debido, probablemente, a la fuerte crisis inmobiliaria sufrida en los últimos años, tal y como se desprende de los datos recogidos por el INE en cuanto a disminución de personas ocupadas en el sector de la construcción, licitación de obras por las administraciones públicas y visados de dirección de obra de proyectos de edificación. En la actualidad, la generación de RCD en España está volviendo a aumentar pero, a diferencia de la época anterior, con una disminución significativa de los RCD No controlados: en 2009 suponían un 124\% de los RCD controlados y en 2015 suponen un 35,7\% de los mismos (Gráfica 1.5).

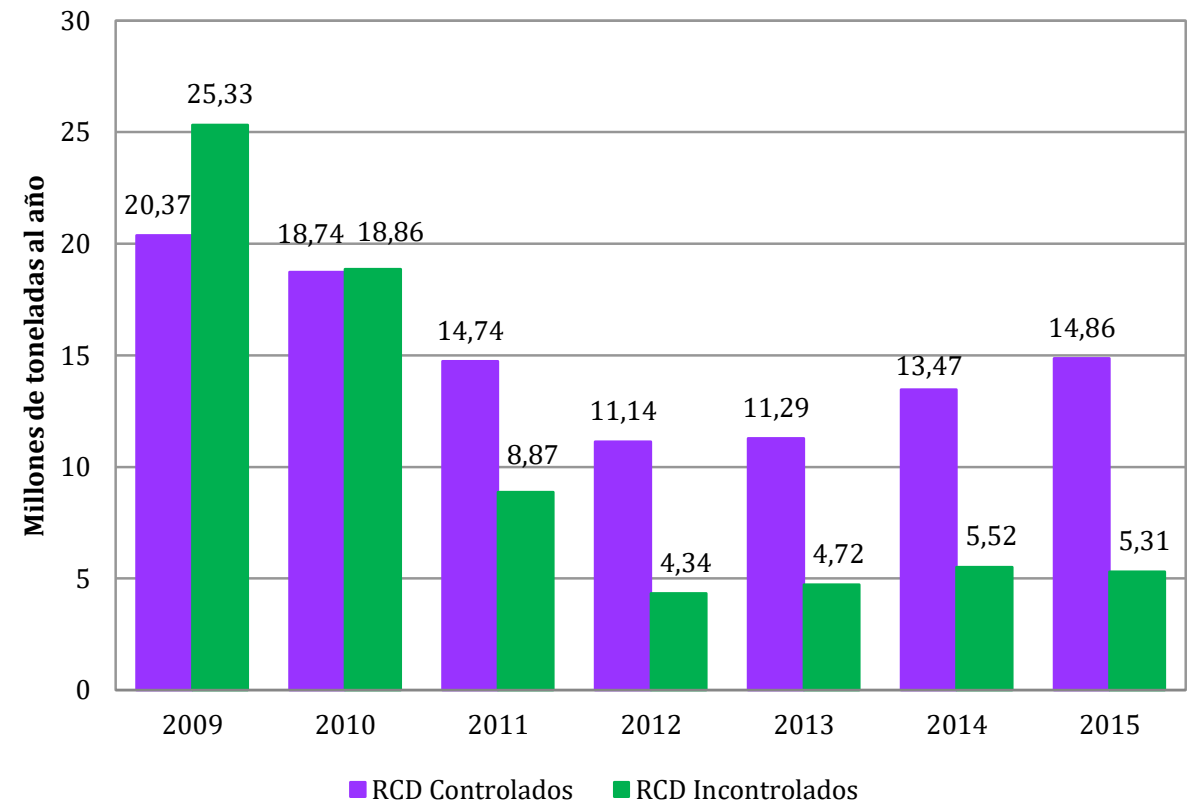

Gráfica 1.5. Evolución de los RCD generados en España en los últimos años - Fuente: (FERCD y RCD Asociación, 2019)

\subsubsection{Gestión de los RCD}

En el objeto de la Directiva Marco de Residuos 2008/98/CE, su artículo 1 dice, "se establecen medidas destinadas a proteger el medio ambiente y la salud humana mediante la prevención o la reducción de los impactos adversos de la generación y gestión de los residuos, la reducción de los impactos globales del uso de los recursos y la mejora de la eficacia de dicho uso"(Parlamento Europeo, 2008). Con ello, cambia el planteamiento de la gestión de residuos en Europa que estaba implantado hasta entonces y se da prioridad a la prevención, reutilización y reciclado frente a la eliminación y valorización (Figura 1.4). A partir de esta Directiva, además, se empieza a considerar el ciclo de vida de los productos y materiales (no solo la etapa de 
residuos) como algo fundamental para reducir el impacto medioambiental (del Río Merino, García Navarro, \& Villoria Sáez, 2011).

JERARQUÍA EUROPEA EN LA GESTIÓN DE RESIDUOS

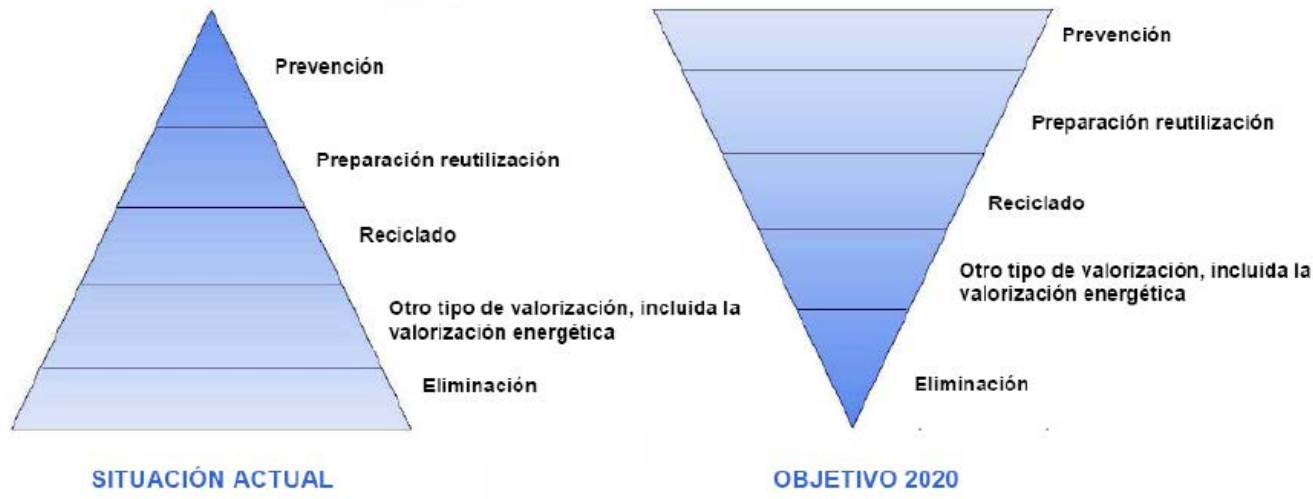

Figura 1.4. Jerarquía en la gestión de residuos - Fuente: (Parlamento Europeo, 2008)

También es la que marca que los Estados miembros son los que deben tener en cuenta los principios generales de precaución y sostenibilidad en el ámbito de la protección medioambiental y, por ello, garantizar que el desarrollo de la política de residuos sea un proceso plenamente transparente y adoptar las medidas necesarias para proporcionar el mejor resultado ambiental global.

En España, el régimen jurídico de la producción y gestión de los RCD se establece a través del RD 105/2008 y de la Orden APM/1007/2017 cuyo fin es el de fomentar, según el orden indicado en la Directiva Marco de Residuos, la prevención, reutilización, reciclado y otras formas de valorización de los RCD, asegurando que los destinados a operaciones de eliminación reciban un tratamiento adecuado y, contribuir con ello, a un desarrollo sostenible de la actividad de construcción.

Según este RD 105/2008 se define Gestión "como la recogida, el almacenamiento, el transporte, la valorización y la eliminación de los residuos, incluida la vigilancia de estas actividades, así como la vigilancia de los lugares de depósito o vertido después de su cierre" (Ministerio de la Presidencia, 2008). Aparece, por tanto, la figura del Gestor de RCD como "la persona o entidad, pública o privada, que realice cualquiera de las operaciones que componen la gestión de los residuos, sea o no el productor de los mismos" (Ministerio de la Presidencia, 2008).

Asimismo surgen las otras dos figuras importantes en la gestión de RCD (Ministerio de la Presidencia, 2008):

- El Productor de RCD (artículo 2): 
"1ํ La persona física o jurídica titular de la licencia urbanística en una obra de construcción o demolición; en aquellas obras que no precisen de licencia urbanística, tendrá la consideración de productor del residuo la persona física o jurídica titular del bien inmueble objeto de una obra de construcción o demolición.

$2^{\circ}$ La persona física o jurídica que efectúe operaciones de tratamiento, de mezcla o de otro tipo, que ocasionen un cambio de naturaleza o de composición de los residuos.

$3^{\circ}$ El importador o adquirente en cualquier Estado miembro de la Unión Europea de residuos de construcción y demolición".

- El Poseedor de RCD (artículo 2): "la persona física o jurídica que tenga en su poder los residuos de construcción y demolición y que no ostente la condición de gestor de residuos. En todo caso, tendrá la consideración de poseedor la persona física o jurídica que ejecute la obra de construcción o demolición, tales como el constructor, los subcontratistas o los trabajadores autónomos. En todo caso, no tendrán la consideración de poseedor de residuos de construcción y demolición los trabajadores por cuenta ajena".

Las obligaciones para cada uno de estos agentes quedan establecidas en este RD 105/2008, junto con las actividades y/o tratamiento de los RCD y su planificación, con la intención de conseguir una adecuada gestión de los mismos, tal y como se exige en la Directiva Marco de Residuos.

Con la Ley 22/2011 (Jefatura del Estado, 2011), de residuos y suelos contaminados, se fijan varios propósitos, entre ellos que, para el 2020 la cantidad de residuos no peligrosos de construcción y demolición destinada a la reutilización, el reciclado y otra forma de valorización, alcance como mínimo el $70 \%$ en peso de los residuos generados. Además, con esta Ley, se establece un registro único de producción y gestión de los RCD para mejora de la información disponible: tipo, cantidad, fuente, sistemas de recogida, instalaciones de eliminación y valorización, etc.

Datos obtenidos por Eurostat (Eurostat, 2019) nos informan de que, si bien es cierto que los resultados de España, en cuanto a tratamiento de residuos, está cercano a la media europea, también se encuentra alejada de países como Italia y Bélgica que reciclan aproximadamente el 75\% (Gráfica 1.6). 


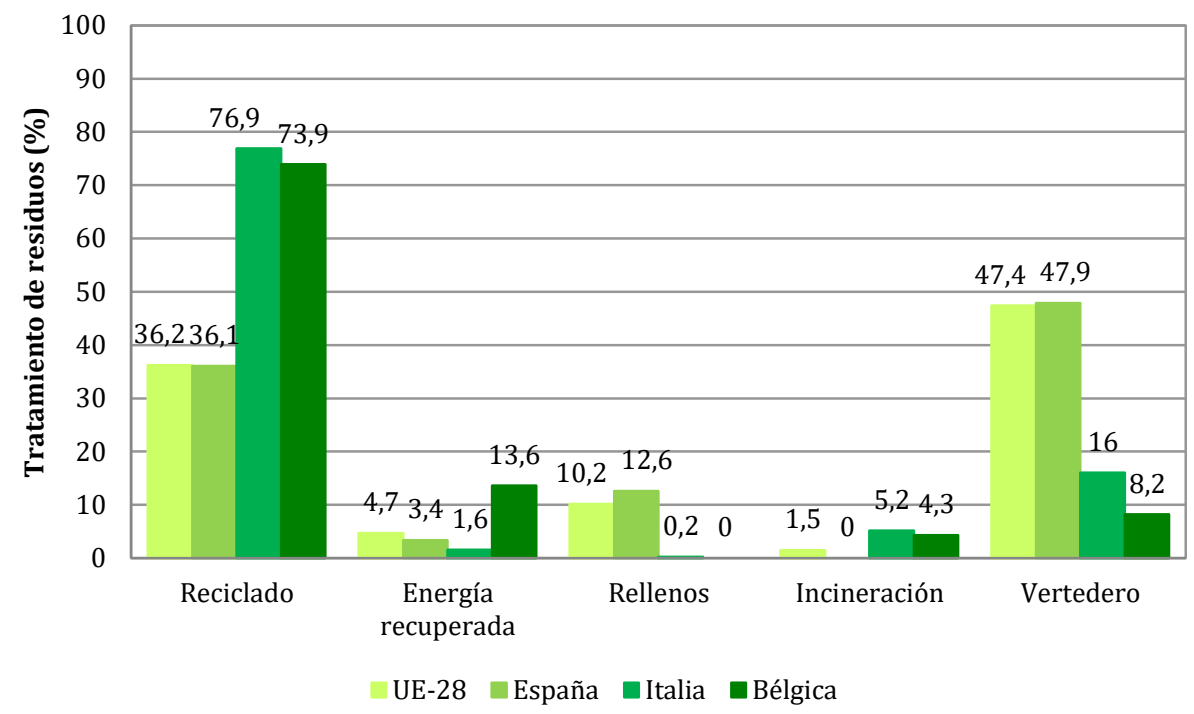

Gráfica 1.6. Tratamiento de los residuos totales en Europa, España, Italia y Bélgica (año 2017) - Fuente: (Eurostat, 2019)

Con el Plan Estatal Marco de Gestión de Residuos (PEMAR) 2016-2022 es con el que se diferencian las posibilidades de destino de los RCD (Ministerio de Agricultura Alimentación y Medio Ambiente, 2016):

- Plantas de transferencia: son instalaciones para el depósito temporal de los RCD que posteriormente van a ser tratados en instalaciones localizadas a grandes distancias. Su cometido principal es agrupar residuos y abaratar costes de transporte, si bien en ocasiones se efectúa en ellas algún proceso menor de triaje y clasificación de las fracciones de los residuos, buscando mejorar o adecuar las características de los RCD enviados a las instalaciones de tratamiento.

- Plantas de tratamiento: son instalaciones de tratamiento de RCD en las que se seleccionan, clasifican y valorizan las diferentes fracciones que contienen estos residuos, a fin de obtener productos aptos para su utilización directa, o residuos cuyo destino será otro tratamiento posterior de valorización o reciclado, y si éste no fuera posible, se eliminaría en vertedero. Pueden ser fijas o móviles:

- Plantas fijas: son instalaciones ubicadas en un emplazamiento determinado, con autorización administrativa para realizar operaciones de tratamiento de RCD, cuya maquinaria, fundamentalmente los equipos de trituración, es fija; estas plantas no operan fuera del emplazamiento donde estén ubicadas.

- Plantas móviles: están constituidas por maquinaria y equipos que se desplazan a las obras con una determinada autorización, para tratar en 
origen $\mathrm{o}$ en centros de tratamiento para realizar temporalmente determinados tratamientos.

- Vertederos: son instalaciones para el depósito definitivo de los RCD. Dichas instalaciones deben cumplir los requisitos que les sean de aplicación incluidos en el Real Decreto 1481/2001 y sus modificaciones posteriores, por el que se regula la eliminación de residuos mediante depósito en vertedero.

En él se indica que, con carácter general, España dispone de instalaciones de tratamiento suficientes para gestionar los residuos generados (Tabla 1.3) e incluso en algunos casos existe un cierto sobredimensionamiento en relación con los residuos que actualmente se generan (Ministerio de Medio Ambiente, 2002b). Este hecho podría atenuarse mediante la consolidación de actividades de reciclado.

Tabla 1.3. Instalaciones de transferencia, tratamiento y vertederos de RCD en España - Fuente: (Ministerio de Agricultura Alimentación y Medio Ambiente, 2016)

\begin{tabular}{|c|c|c|c|c|}
\hline COMUNIDAD AUTÓNOMA & $\begin{array}{c}\text { Plantas de } \\
\text { transferencia } \\
\left(\mathrm{n}^{\circ}\right)\end{array}$ & $\begin{array}{c}\text { Plantas de } \\
\text { tratamiento } \\
\text { fija (no) }\end{array}$ & $\begin{array}{c}\text { Plantas de } \\
\text { tratamiento } \\
\text { móvil (no) }\end{array}$ & $\begin{array}{l}\text { Vertederos } \\
\quad\left(\mathrm{n}^{\circ}\right)\end{array}$ \\
\hline Andalucía & 92 & 119 & 21 & 71 \\
\hline Aragón & 18 & 6 & 1 & 5 \\
\hline Asturias & 3 & 4 & 5 & 1 \\
\hline Baleares & 6 & 2 & $\mathrm{~s} / \mathrm{d}$ & 1 \\
\hline Canarias & 0 & 23 & $\mathrm{~s} / \mathrm{d}$ & 7 \\
\hline Cantabria & 12 & 4 & 12 & 2 \\
\hline Castilla la Mancha & $\mathrm{s} / \mathrm{d}$ & 28 & 27 & 12 \\
\hline Castilla y León & 0 & 45 & 0 & 3 \\
\hline Cataluña & 12 & 50 & 0 & 57 \\
\hline Ceuta & $\mathrm{s} / \mathrm{d}$ & $\mathrm{s} / \mathrm{d}$ & $\mathrm{s} / \mathrm{d}$ & $\mathrm{s} / \mathrm{d}$ \\
\hline Comunidad Valenciana & $\mathrm{s} / \mathrm{d}$ & $\mathrm{s} / \mathrm{d}$ & $\mathrm{s} / \mathrm{d}$ & $\mathrm{s} / \mathrm{d}$ \\
\hline Extremadura & 16 & 21 & 1 & 0 \\
\hline Galicia & 3 & 43 & 21 & 5 \\
\hline La Rioja & $\mathrm{s} / \mathrm{d}$ & 16 & 0 & 2 \\
\hline Madrid & 10 & 14 & 0 & 4 \\
\hline Melilla & $\mathrm{s} / \mathrm{d}$ & s/d & $\mathrm{s} / \mathrm{d}$ & $\mathrm{s} / \mathrm{d}$ \\
\hline Murcia & 2 & 4 & 32 & 19 \\
\hline Navarra & $\mathrm{s} / \mathrm{d}$ & 7 & 3 & 7 \\
\hline País Vasco & $\mathrm{s} / \mathrm{d}$ & $\mathrm{s} / \mathrm{d}$ & 11 & $\mathrm{~s} / \mathrm{d}$ \\
\hline TOTAL & 174 & 386 & 134 & 196 \\
\hline
\end{tabular}

Como bien indica el presidente de la Federación Española de Asociaciones del Medio Ambiente (FEAMA) D. Fernando Reyero Suárez, en las obras todavía cuesta entender que funcionan igual de bien materiales reciclados que materiales 
tradicionales y, sin embargo, "un coche nuevo contiene un mínimo de un 60\% en peso de material reciclado y nadie se lo plantea" (Elías Castells et al., 2009).

Es fundamental, por tanto, que para la minimización de los residuos de materiales de construcción y demolición, tome aún más importancia el estudio de su valorización y reciclaje, es decir, que se enfatice en el desarrollo de la puesta en el mercado de productos que incorporen residuos y/o, en el desarrollo de la reincorporación de productos reciclados al mercado.

Uno de los RCD más abundante y, a la vez complicado, es el plástico que, si bien es cierto que ofrece muchas ventajas, la variedad, la durabilidad, la lenta degradación en el medio, etc, estas mismas son algunos de los problemas que plantea (González Pericot, 2010; Schwarz, 2009). 


\subsection{EL PLÁSTICO: CARACTERÍSTICAS Y PROBLEMÁTICA}

"Es probable que, la segunda mitad del siglo XX y el siglo XXI sean conocidos como la época de los productos sintéticos, del mismo modo que el hierro y el acero caracterizaron al siglo XIX" (Miravete, 1995).

A grandes rasgos se puede decir que los plásticos son sustancias químicas denominadas polímeros, de estructura macromolecular, que pueden ser moldeados bajo presión o calor y cuyo componente principal es el Carbono. Según las acepciones que figuran en la RAE queda definido polímero como "compuesto químico, natural o sintético formado por polimerización que consiste esencialmente en unidades estructurales repetidas" (RAE, 2017). Es decir, los polímeros son grandes agrupaciones de monómeros unidos mediante un proceso químico llamado polimerización. En construcción, hablar de polímeros naturales como la celulosa, la goma laca o la resina de algunos vegetales, no es habitual. Sí lo es hablar de polímeros sintéticos como el PVC (policloruro de vinilo) de tuberías de evacuación, el polietileno del recubrimiento de los cables eléctricos o el poliestireno de los aislamientos térmicos, entre otros.

En la Exposición Universal de Londres de 1862, Alexander Parkes presenta lo que se considera el primer plástico fabricado por el hombre e inspiración de los plásticos actuales: la parkesina. Este nuevo material mezcla el nitrato de celulosa con alcanfor formando una sustancia transparente, que puede ser coloreada, dura pero flexible, que puede ser calentada y moldeada y mantiene su forma al enfriarse (Roberto, 2013).

Aproximadamente 10 años más tarde, John Wesley Hyatt desarrolla el producto de Parkes añadiendo a la parkesina alcohol y obteniendo el celuloide, material que presenta problemas de reblandecimiento frente al calor, agrietamiento y alta inflamabilidad.

No es hasta 1907 que Hendrik Baekeland crea el primer polímero totalmente artificial, la baquelita. El propósito de Baekeland era obtener un material aislante eléctrico debido a la escasez de la goma-laca de origen natural (Shellac) que se estaba utilizando hasta entonces y, para ello realiza la síntesis de moléculas de fenol y formaldehído, en proporción 2 a 3, obteniendo un producto moldeable a medida que se endurece, que no conduce la electricidad, resistente al agua y a los solventes y que es fácilmente mecanizable.

En los años 20, el premio nobel Hermann Staudinger establece las bases de la moderna ciencia de los polímeros, cuando demuestra que los polímeros naturales y 
sintéticos son moléculas de cadena larga con grupos terminales característicos (Seymour, 1995).

A partir de ese momento y comprobando las múltiples posibilidades de utilización de los plásticos en cualquier sector, comienza una rápida evolución de los mismos que da lugar a la infinidad de variantes existentes en la actualidad. Los plásticos proporcionan la relación necesaria de propiedades que no pueden lograrse con otros materiales como color, bajo peso, tacto agradable y resistencia a la degradación ambiental y biológica, entre otros.

Aunque la mayoría de los plásticos de hoy en día se elaboran a partir de derivados del petróleo, lo que supone entre un 3-5\% de cada barril de petróleo del mundo, están en marcha muchas investigaciones basadas en el uso de otras materias primas, como el plátano, la celulosa, las legumbres o la fécula de patata, que dan origen, por ejemplo, a plásticos biodegradables.

\subsubsection{Clasificación de los plásticos}

Debido a la gran diversidad de compuestos plásticos se pueden realizar multitud de clasificaciones de los mismos, desde la que tiene en cuenta la disposición de sus macromoléculas, hasta la que tiene en cuenta la aplicación en el mercado y, por tanto, su importancia comercial. En el caso del sector de la edificación, es más interesante clasificar los plásticos en función de su comportamiento ante el calor puesto que es una de las propiedades fundamentales que se le requiere a los materiales de construcción.

En función de esto, entonces, los plásticos se clasifican en dos grandes grupos, "los termoplásticos que disponen de moléculas bidimensionales que pueden ablandarse con el calor y volver a su estado inicial al enfriarse y, los termoestables que son polímeros de red tridimensional que no pueden moldearse por calentamiento" (Seymour, 1995) (Figura 1.5).

\subsubsection{Termoplásticos}

Su nombre procede de las palabras thermos (calor, cálido) y plastos (dúctil, maleable) debido a que pueden ser deformados bajo la influencia del calor y la compresión y mantienen su nueva forma al enfriarse y dejar de actuar la fuerza. Se caracterizan porque su moldeo es reversible, es decir, el ciclo de reblandecimiento y endurecimiento puede repetirse muchas veces, salvo varias excepciones 
(PlasticsEurope, 2019). A su vez, los termoplásticos se clasifican en dos grandes grupos:

- Termoplásticos amorfos: aquellos cuyas cadenas moleculares están fuertemente ramificadas (como un trozo de algodón), cadenas laterales largas y que carecen de orden estructural. Son transparentes en su estado natural. Ejemplo de ellos es el PVC rígido (PVC-U).

- Termoplásticos parcialmente cristalinos: aquellos cuyas cadenas moleculares presentan poca ramificación, cadenas laterales cortas de las cuales, un determinado número, se encuentran ordenadas y en forma compacta (unas al lado de otras) a las que se denomina regiones cristalinas y, otro número sigue en estado amorfo. Nunca se produce una cristalización perfecta o completa del compuesto, al igual que nunca llegan a ser transparentes sino que presentan un estado lechoso o turbio. Ejemplo de ellos es el polietileno de baja densidad (PELD).

En el sector de la construcción los termoplásticos son usados en multitud de elementos, como tuberías, aislamiento de cables eléctricos, aislantes térmicos, puertas y ventanas, etc. debido a características como la resistencia a los efectos de la corrosión de los productos químicos y una fácil y rápida instalación.

\subsubsection{Termoestables}

Su nombre procede de las palabras thermos (calor, cálido) y estabilis (firme, seguro), también pueden ser deformados bajo la influencia del calor y la compresión durante su fase fluida y mantener su nueva forma al enfriarse y dejar de actuar la fuerza pero, se caracterizan, porque su moldeo es irreversible, es decir, el producto final no se reblandece nuevamente por la acción de la temperatura y la presión sino que se degrada (PlasticsEurope, 2019). Las cadenas moleculares forman una red tridimensional espacial con fuertes enlaces equivalentes.

Ejemplo de ellos en la construcción son el poliuretano de aislamientos térmicos, la silicona, la resina epoxi, etc. Todos presentan una estructura rígida y dura y, si se les flexiona en exceso, parten; no aparece fácilmente llama en ellos y no son soldables (PlasticsEurope, 2019).

Presentan algunas ventajas respecto a los termoplásticos como mejor resistencia al impacto, a los solventes, a la permeabilidad de gases y a las temperaturas extremas. Pero también muestran varias desventajas como la dificultad de procesamiento, la necesidad del curado, la fragilidad del material y, la falta de refuerzo al someterlo a una tensión (PlasticsEurope, 2019). 


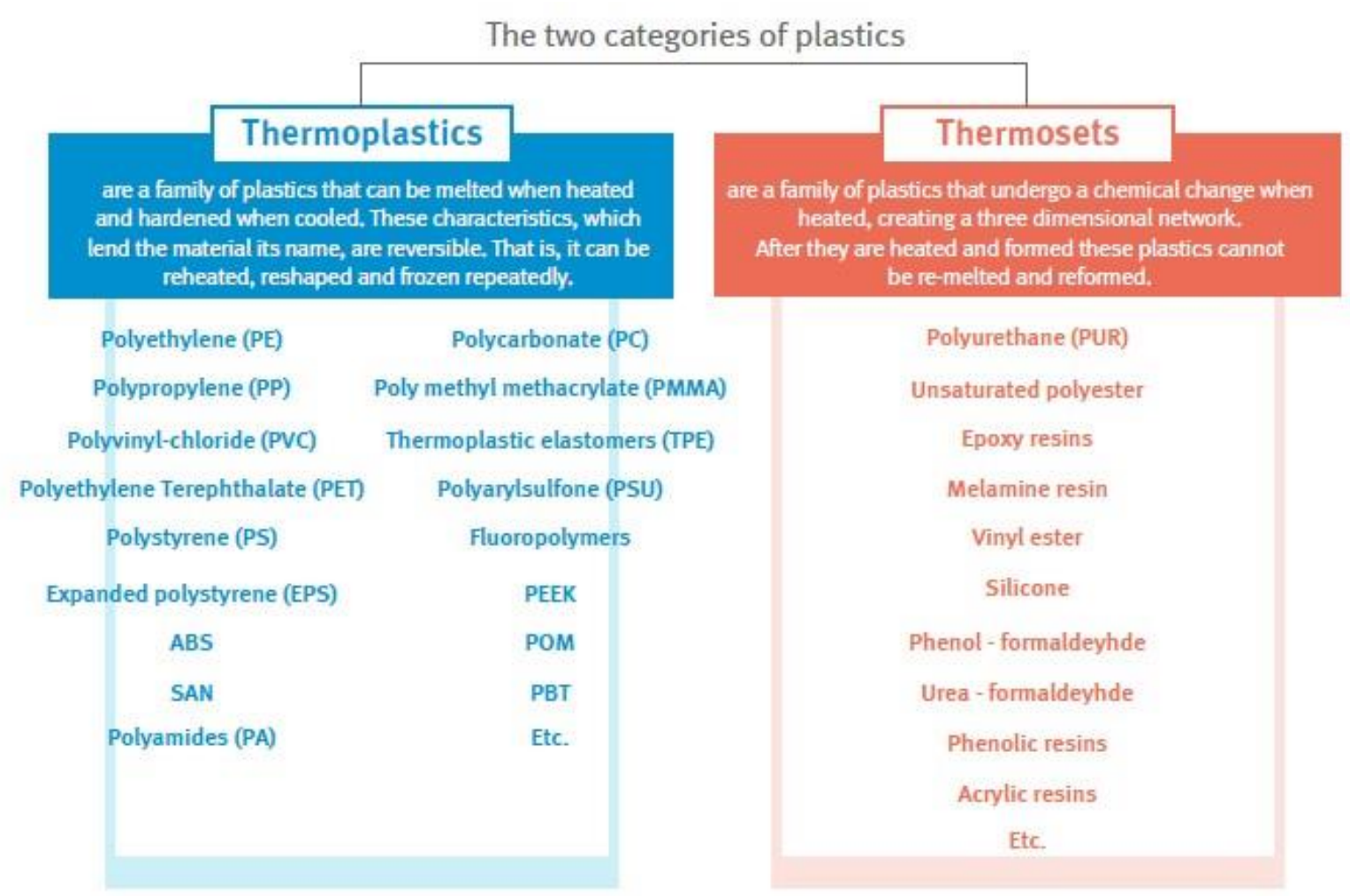

Figura 1.5. Clasificación de los plásticos - Fuente: (PlasticsEurope, 2018)

\subsubsection{El plástico en construcción}

Los plásticos están presentes en todos los ámbitos de nuestra vida y su utilización se ha estabilizado en los últimos años (Figura 1.6). Asia es el mayor productor de plásticos (50,1\%) seguido de Europa (18,5\%). Esta última, concentra casi el 70\% de su demanda de plástico en sus 6 países más grandes: Alemania, Italia, Francia, España, Inglaterra y Polonia. Según los indicadores de la asociación de fabricantes de plásticos europeos, los sectores del envase y de la construcción suponen casi el 60\% del consumo de plástico en Europa (Gráfica 1.7) (PlasticsEurope, 2018).

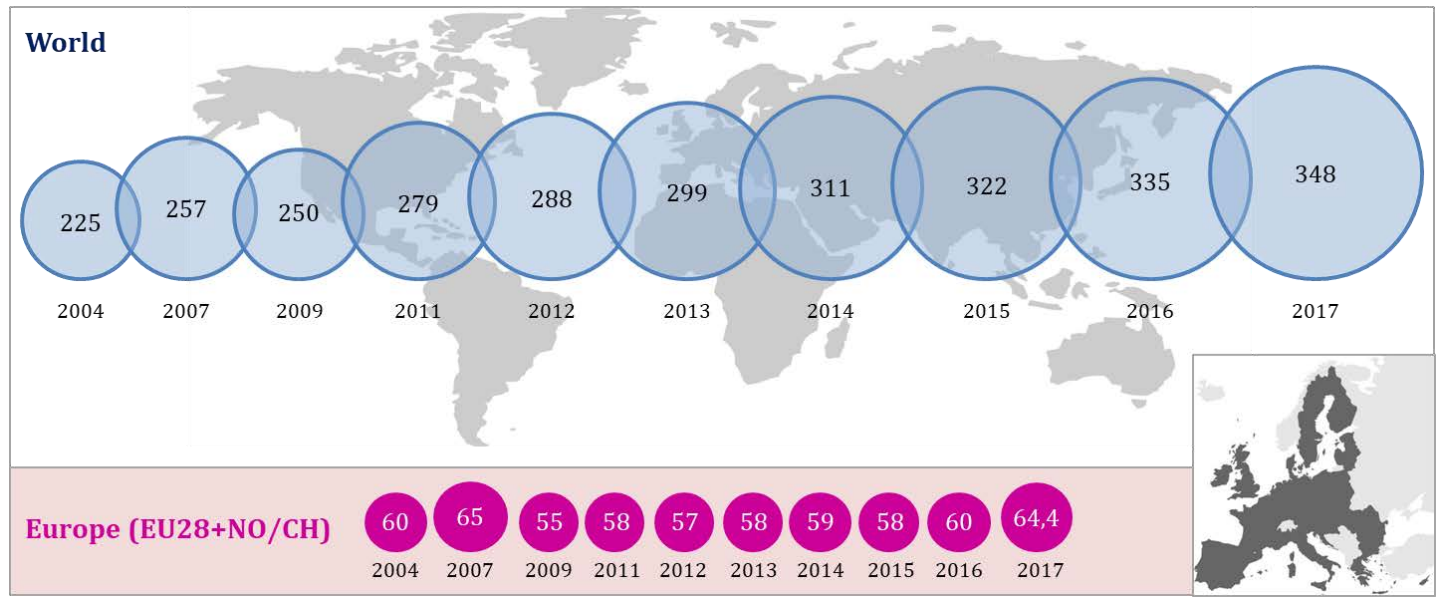

Figura 1.6. Producción de plástico en millones de toneladas al año - Fuente: (PlasticsEurope, 2019) 


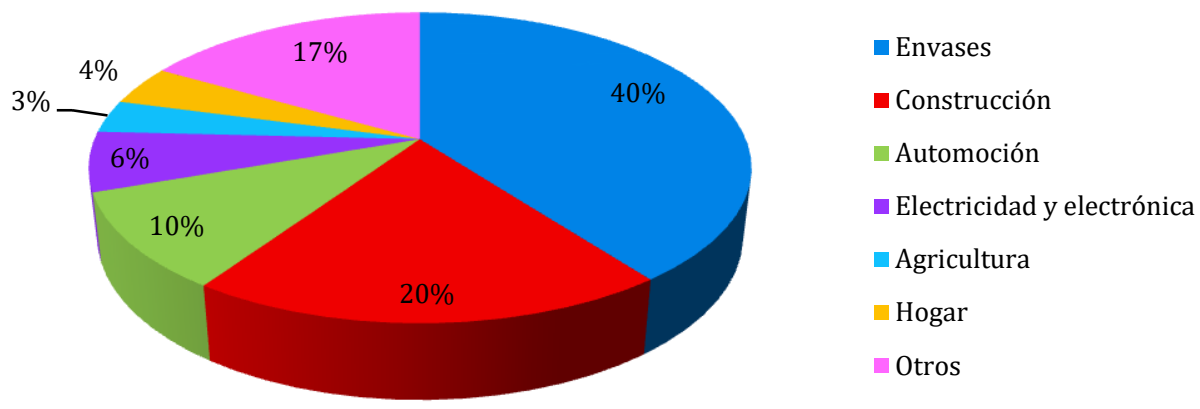

Gráfica 1.7. Consumo de plástico en Europa (año 2017) - Fuente: (PlasticsEurope, 2019)

Se utilizan en muy diversas aplicaciones en el sector de la construcción; además de en el recubrimiento de cables, caso que nos ocupa en esta investigación, se emplean en marcos de ventanas, tuberías, aislamiento y revestimiento de paredes, suelos y techos. Se dispone, por tanto, de una gran variedad de plásticos para llegar a cubrir las necesidades de todos los sectores (Gráfica 1.8). Características como la ligereza, la versatilidad y/o el precio hacen de él un material imprescindible en este sector; tomando también importancia otras propiedades como, la resistencia a corrosión, la capacidad de aislamiento térmico, eléctrico y acústico, la impermeabilidad, su escaso mantenimiento, etc.

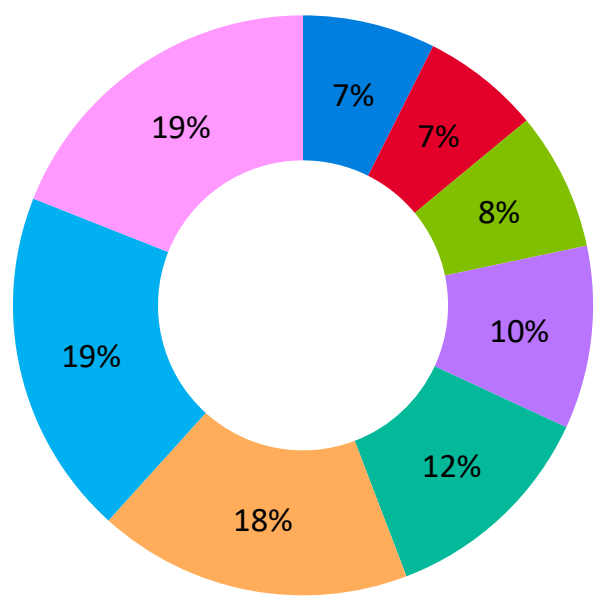

PET

PS, PS-E

$\square$ PUR

- PVC

- PE-HD, PE-MD

- PE-LD, PE-LLD

$\square \mathrm{PP}$

OTROS 


\subsubsection{El plástico y el fuego}

Los fabricantes de plásticos destinados a construcción diseñan sus productos para que cumplan la normativa europea y nacional existente, desarrollando productos con características mejoradas y/o específicas de comportamiento ante el fuego (PlasticsEurope, 2017).

Por ejemplo, se utilizan aditivos retardantes de la llama en la formulación, que aumentan la duración de la etapa de fuego latente anterior al punto de inflamación, lo que permite aumentar el tiempo de escape y reduce el riesgo de incendio y de propagación del fuego. También puede mejorarse la formulación de un plástico para reducir su inflamabilidad. Otra de las estrategias a seguir para obtener un mejor comportamiento frente al fuego pasa por establecer barreras físico-químicas entre el polímero y la fuente de ignición (Buezas Sierra, 2010), como pueden ser capas de refuerzo, o paneles de yeso o mortero.

Los productos utilizados en el sector de la construcción, incluidos los plásticos, deben someterse a ensayos respecto a su reacción ante del fuego, conforme al sistema de Euroclases. El RD 842/2013, de 31 de octubre, establece la clasificación de los productos de construcción y elementos constructivos en función de sus propiedades de reacción y resistencia frente al fuego, de acuerdo al Reglamento de Productos de la Construcción (CPR-Construction Products Regulations), Reglamento 305/2011 de 9 de marzo de 2011 del Parlamento Europeo. El CPR se aplica también a cables de energía, comunicaciones, datos y control, y el Reglamento Delegado 2016/364 de 1 de Julio de 2015, define las prestaciones de reacción al fuego para dichos cables.

El sistema de Euroclases clasifica a los productos según su combustibilidad en 7 categorías (desde no combustibles a combustibles de distinta contribución al fuego), según la opacidad de los humos y según la caída de gotas o partículas inflamadas. Estos ensayos son realizados por Centros acreditados oficialmente para ello, y se realizan según procedimientos normalizados que permiten conocer la respuesta de un material al fuego, medida en términos de su contribución al desarrollo del mismo con su propia combustión y unas condiciones específicas.

El estudio de los procesos de combustión de plásticos abarca un abanico tan amplio que da lugar a tesis completas como es el caso de la realizada por Ignacio Aracil Sáez (Aracil Sáez, 2008). De todos los contaminantes detallados en ella, destacan, para este estudio, los siguientes:

- Monóxido de carbono (CO): es el producto que aparece en mayor cantidad en la combustión de un polímero. Es un gas que, con exposiciones altas, puede 
producir envenenamiento e incluso la muerte por sustituir al oxígeno de la hemoglobina en sangre. Un $0,1 \%$ de monóxido de carbono en el aire puede producir la muerte en tres horas de una persona que permaneciera realizando un ejercicio moderado (Peinado Moreno, 2003). Se forma por la combustión incompleta de material orgánico en presencia deficitaria de oxígeno. Es incoloro, inodoro, inflamable y, como ya se ha comentado, tóxico (Téllez, Rodríguez, \& Fajardo, 2006).

- Dióxido de carbono $\left(\mathrm{CO}_{2}\right)$ : aparece en la combustión de polímeros cuando la combustión es completa, es decir, cuando se realiza en ambientes aireados. Se considera un gas inerte pero puede llegar a ser peligroso ya que, al ser más pesado que el aire, desplaza al oxígeno; produce aumento del ritmo de la respiración y, por tanto, se inhala más cantidad de gases tóxicos; es narcótico, pues provoca jaquecas, somnolencia, confusiones e incluso puede ocasionar el coma profundo (Peinado Moreno, 2003).

- Metales pesados volátiles: productos muy tóxicos para el ser humano y el medio ambiente. Los problemas más importantes surgen con el mercurio, antimonio, arsénico, selenio, cadmio, plomo y sus compuestos. En general tienen una baja volatilidad que puede verse aumentada en presencia de cloro y azufre, dando lugar a sulfuros y cloruros (Williams, 1994).

- Gases ácidos: se generan con la presencia de cloro, flúor, nitrógeno y azufre en la composición del polímero. Tiene efectos negativos en la salud, por producir irritación y, en el medio ambiente, por producir lluvia ácida (Moltó, Font, Gálvez, \& Conesa, 2009).

- Dioxinas (PCDDs) y furanos (PCDFs): compuestos aromáticos clorados, formados a muy bajas temperaturas. Algunos de ellos de elevada toxicidad incluso en bajas exposiciones, como es el caso de los que presentan cloro en las posiciones 2, 3, 7 y 8 simultáneamente (Font, Aracil, Fullana, Martín-Gullón, \& Conesa, 2003).

\subsubsection{El plástico como aislamiento de cables eléctricos}

Los cables eléctricos son uno de los materiales de construcción imprescindibles en los edificios puesto que hacen llegar la electricidad a los mismos. En España, la definición que se le da a cable queda recogida en el RD 842/2002 por el que se aprueba el Reglamento electrotécnico de baja tensión y que dice "conjunto constituido por uno o varios conductores aislados, su eventual revestimiento individual, la eventual protección del conjunto y el/los eventuales revestimientos de protección que se 
dispongan. Puede tener, además, uno o varios conductores no aislados" (Ministerio de Ciencia y Tecnología, 2002).

$\mathrm{Si}$ bien los conductores son materiales metálicos como el cobre y el aluminio, el aislamiento (no conductor de la electricidad), es un material plástico que envuelve al conductor de forma continua y uniforme en toda su longitud con el espesor adecuado para aguantar la tensión de trabajo del mismo (Figura 1.7).

Son muchos los factores que intervienen

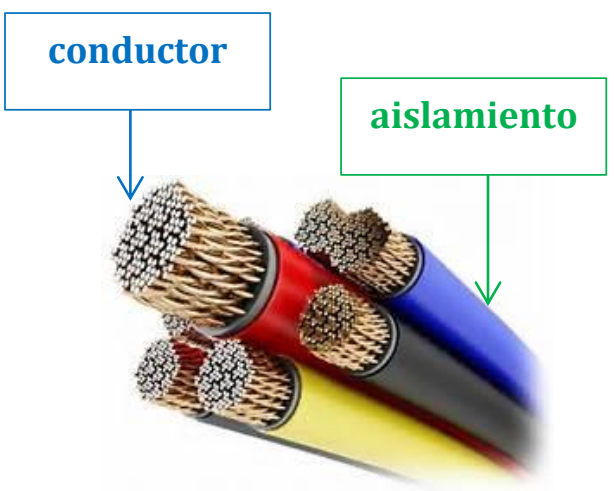

Figura 1.7. Cables. Fuente: topcable.es para la exigencia de un plástico u otro en un cable, como el tipo de atmósfera en el que se va a colocar; la tensión de trabajo que debe aguantar; el tiempo de resistencia a fuego o de propagación de llama; la baja emisión de humos, etc. Es por ello que, estas propiedades, hacen que exista un gran abanico de posibilidades en el mercado de cables.

Volviendo a la normativa española, el REBT determina en su Instrucción Técnica Complementaria 2 (ITC-BT-02), las normas de referencia que los aislamientos de cables deben cumplir: UNE 21027, UNE 21031, UNE 21123, UNE 21150 y UNE-EN 61196. En ellas quedan recogidas las especificaciones de los siguientes tipos:

- Goma: polímero termoestable con un comportamiento elástico. A temperatura ambiente suele ser blando y deformable. En este campo, se obtiene generalmente de la polimerización de un látex sintético como el cloropreno, dando lugar al policloropreno (neopreno) que presenta muy buena estabilidad química.

- Silicona: polímero termoestable con un comportamiento inerte y estable a altas temperaturas. Se obtiene generalmente de la polimerización de átomos de oxígeno y silicio alternados (polisiloxano).

- Etileno-propileno (EPR): polímero termoestable, que se caracteriza por su resistencia al calor, a la oxidación, al ozono, a la intemperie y a solventes. Se obtiene de la polimerización del etileno con el propileno y, se utiliza en cables de alto voltaje.

- Poliuretano: polímero termoplástico con un comportamiento elástico. Se caracteriza por su alta resistencia a la abrasión y desgaste y, por la conservación de sus propiedades mecánicas a baja temperatura. Se obtiene de la polimerización de bases hidroxílicas combinadas con diisocianatos. 
- Acetato de etil-vinil (EVA): polímero termoplástico con un comportamiento elástico. Se caracteriza por resistencia a estrés-cracking, a bajas temperaturas, al agua y a radiación UV. Se obtiene de la polimerización del etileno y el acetato de vinilo.

- Polietileno reticulado (XLPE-PEX): polímero termoestable con enlaces entrecruzados. Se caracteriza por resistencia al impacto, tracción y rayado y, resistencia a bajas temperaturas y disolución. Se obtiene de la polimerización del polietileno de alta densidad.

- Policloruro de vinilo (PVC): polímero termoplástico más versátil. Se caracteriza por su resistencia eléctrica, a la propagación de llama y al ambiente, presentando buena estabilidad dimensional. Se obtiene de la polimerización del cloruro de vinilo.

- Politetrafluoretileno (PTFE): polímero termoplástico, más conocido como teflón. Se caracteriza por ser prácticamente inerte, bajo coeficiente de rozamiento y gran impermeabilidad y no se altera con la luz. Se obtiene de la polimerización del etileno en el que los átomos de hidrógeno se han sustituido por átomos de flúor.

Según la Asociación española de fabricantes de cables y conductores eléctricos y de fibra óptica, este sector facturó en 2015, la cifra global de 1470,7 millones de euros, y en 2018 1549,6 millones de euros (FACEL, 2018). Aunque es cierto que la tendencia en tecnología parece ir encaminada a la ausencia de cables, los datos anteriores indican que, en cambio, su fabricación, es un sector estable. No se puede decir lo mismo de su reciclaje, no hay datos fiables y, muchas de las empresas dedicadas a ello en los últimos años, han cerrado debido a la dificultad del sistema de reciclaje y las pocas opciones de salida del material plástico.

\subsubsection{Reciclaje del plástico de cables eléctricos}

La práctica habitual, sobre todo, cuando se ha tratado de demoliciones, ha sido "el recuperar aquellos materiales fácilmente extraíbles que pudieran tener cierto valor en el mercado de la reutilización o el reciclado, es decir, materiales como los metales, las maderas y algunos materiales cerámicos como las tejas" (Aguilar, 1997).

Cualquier plástico de construcción, al final de su vida, es considerado como un RCD. En este sentido el RD 105/2008 (Ministerio de la Presidencia, 2008), en su artículo 5.5, obliga al poseedor del residuo a:

- su separación del resto de residuos cuando la cantidad prevista supere la cantidad de 0,5 toneladas, 
- su entrega a un gestor autorizado que lo destine, en este orden a, operaciones de reutilización, reciclado u otras formas de valorización.

Dentro de la lista europea de residuos, recogida en la Orden MAM/304/2002 (Ministerio de Medio Ambiente, 2002a), los plásticos quedan incluidos dentro de los siguientes epígrafes:

- 1702 03, "Residuos plásticos de la construcción y la demolición",

- 170411 "Cables distintos de los especificados en el código 170410 (cables que contienen hidrocarburos, alquitrán de hulla y otras sustancias peligrosas)".

El problema de los residuos de cables eléctricos reside en que el cable eléctrico, como ya se ha mencionado, posee un núcleo metálico (conductor) recubierto por un plástico (aislamiento). Al tratarse de dos elementos totalmente diferentes, metal y plástico, el proceso de reciclaje es complicado.

\subsubsection{Proceso de reciclado}

- Recogida: los cables viejos, rotos o sobrantes de las obras son recogidos y llevados a empresas de reciclaje (Foto 1.1).

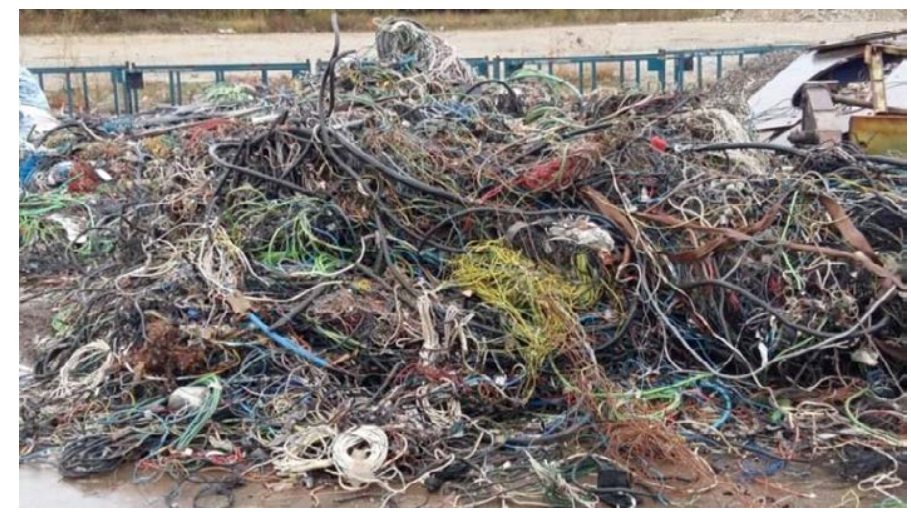

Foto 1.1. Recogida de cables - Fuente: Lyrsa Álava

- Selección: una vez en las instalaciones, se procede a la separación y clasificación manual de cables de cobre y cables de aluminio, independientemente del tipo de aislamiento que tengan (Foto 1.2). Desde este momento los cables deben ser pasados por distintas líneas de trabajo para no volver a ser mezclados. 


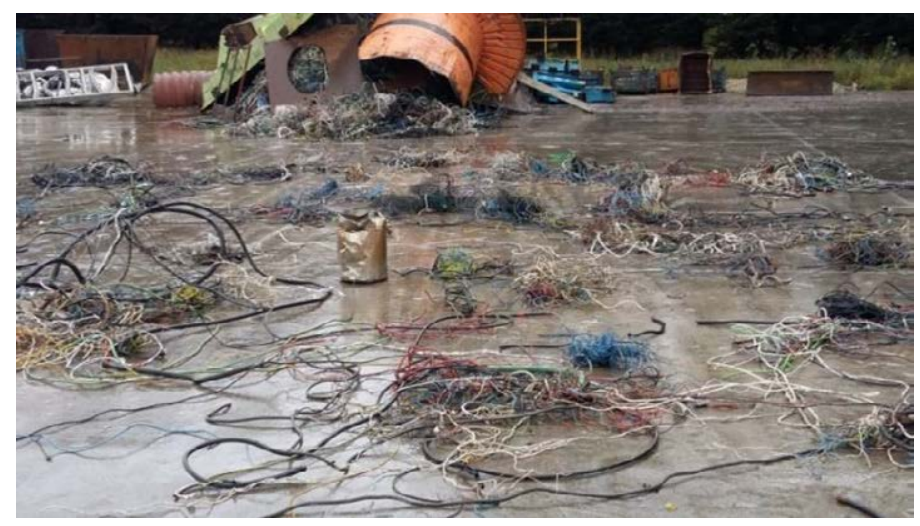

Foto 1.2. Clasificación manual por tipo de conductor - Fuente: Lyrsa Álava

- Trituración: mediante maquinaria específica, el cable es llevado a una trituradora con la que se consigue reducir su tamaño de tres a cinco centímetros (Fotos 1.3-1.4-1.5).
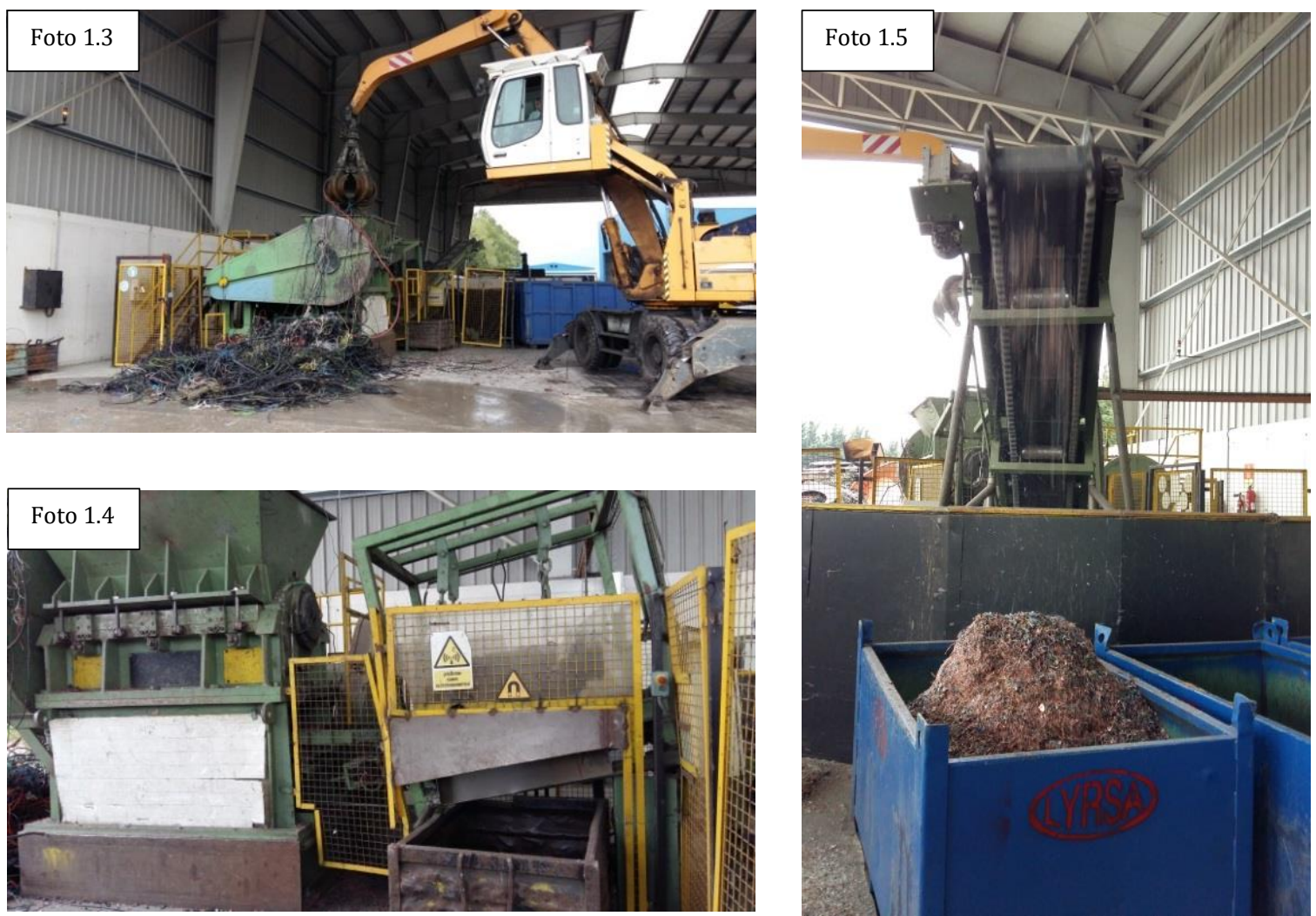

Fotos 1.3-1.4-1.5. Primera trituración - Fuente: Lyrsa Álava

- Fragmentación: el material triturado pasa a una maquinaria de fragmentación con la que llega a un tamaño máximo de 3 mm (Fotos 1.6-1.7-1.8-1.9). 

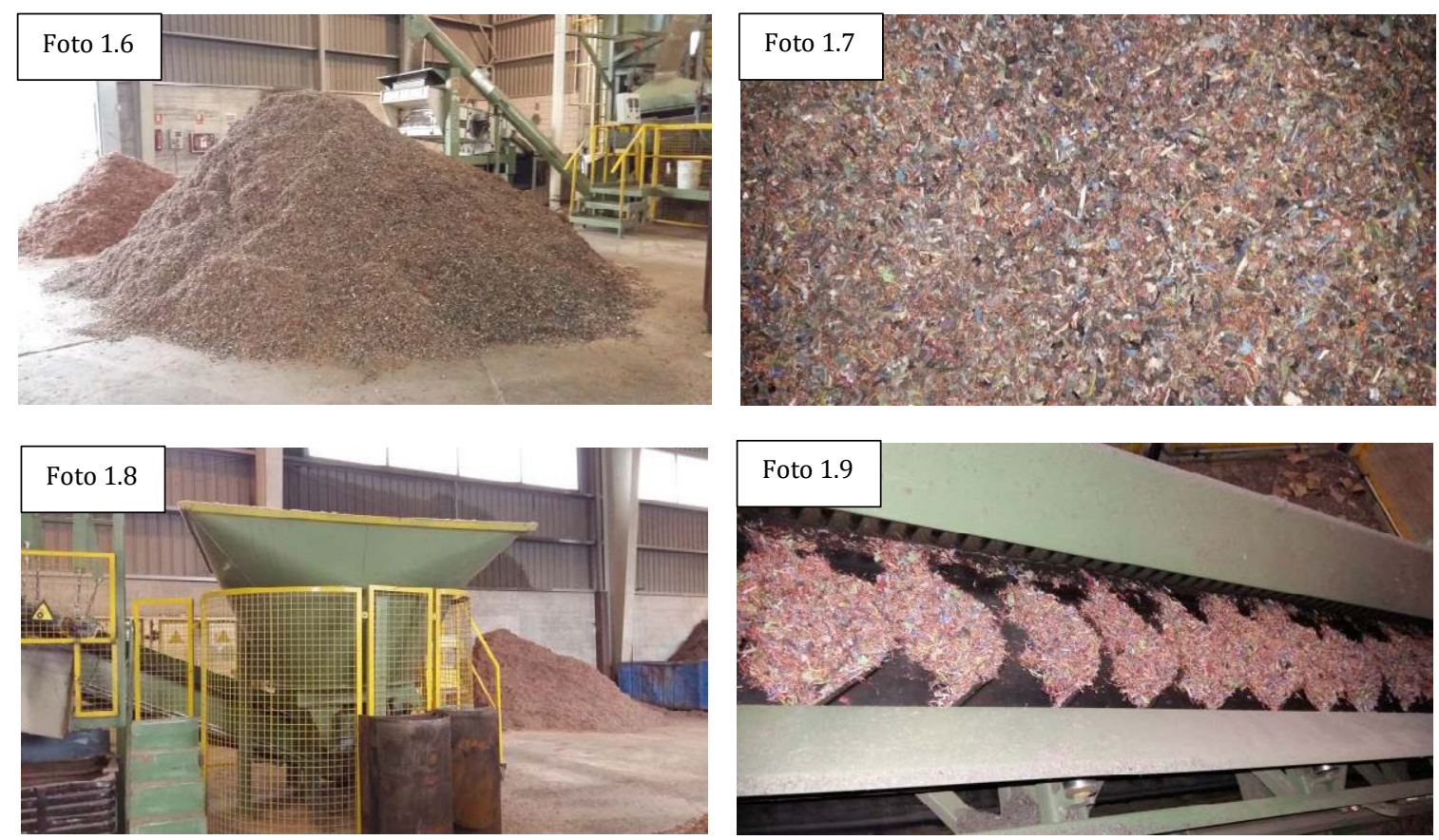

Fotos 1.6-1.7-1.8-1.9. Segunda trituración - Fuente: Lyrsa Álava

- Tamizado: una vez descartado parte del material, pasa por un tamiz de diámetro $3 \mathrm{~mm}$ (Fotos 1.10-1.11-1.12).
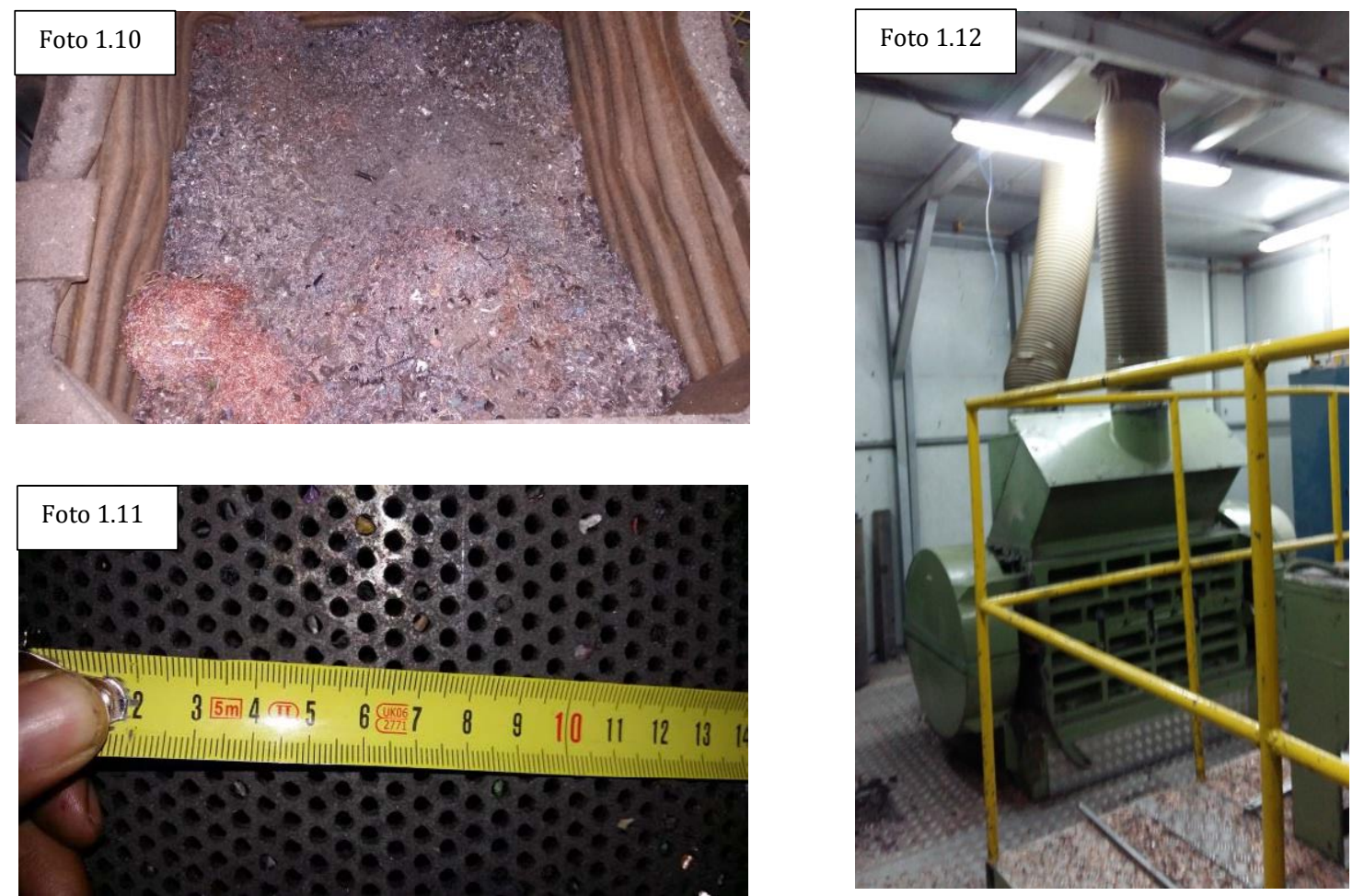

Fotos 1.10-1.11-1.12. Tamizado - Fuente: Lyrsa Álava 
- Separación: las partículas menores de $3 \mathrm{~mm}$ atraviesan una banda ligeramente inclinada a la que se insufla aire comprimido, de manera que, las partículas metálicas que son más pesadas caen en un recipiente y quedan listas para fundir y volver a utilizar. El plástico, que es menos pesado, se desplaza hacia el lado inclinado para caer en otra cinta que lo transporta a unos depósitos. A continuación, se cargan los contenedores que lo transportarán a su destino definitivo (Fotos 1.13-1.14-1.15-1.16).

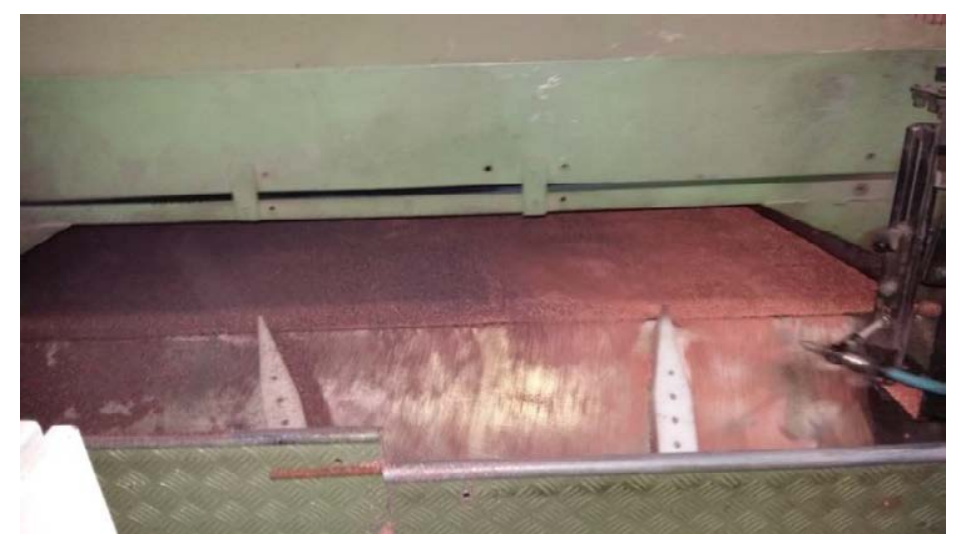

Foto 1.13. Soplado por aire comprimido - Fuente: Lyrsa Álava

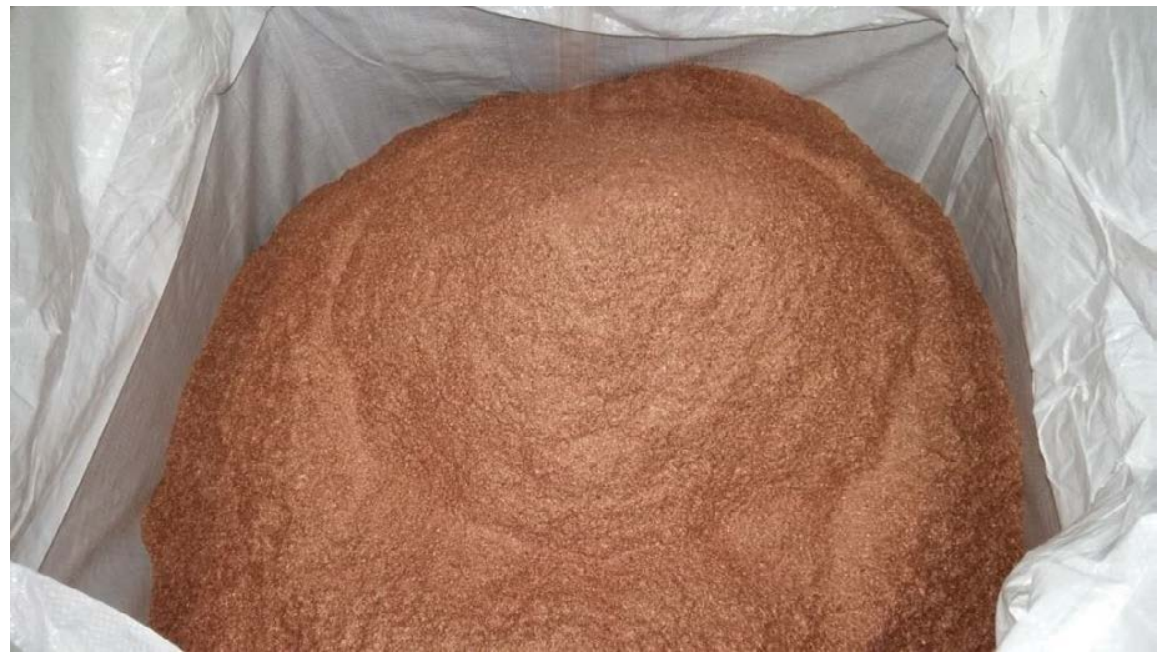

Foto 1.14. Cobre preparado para ser fundido de nuevo - Fuente: Lyrsa Álava 


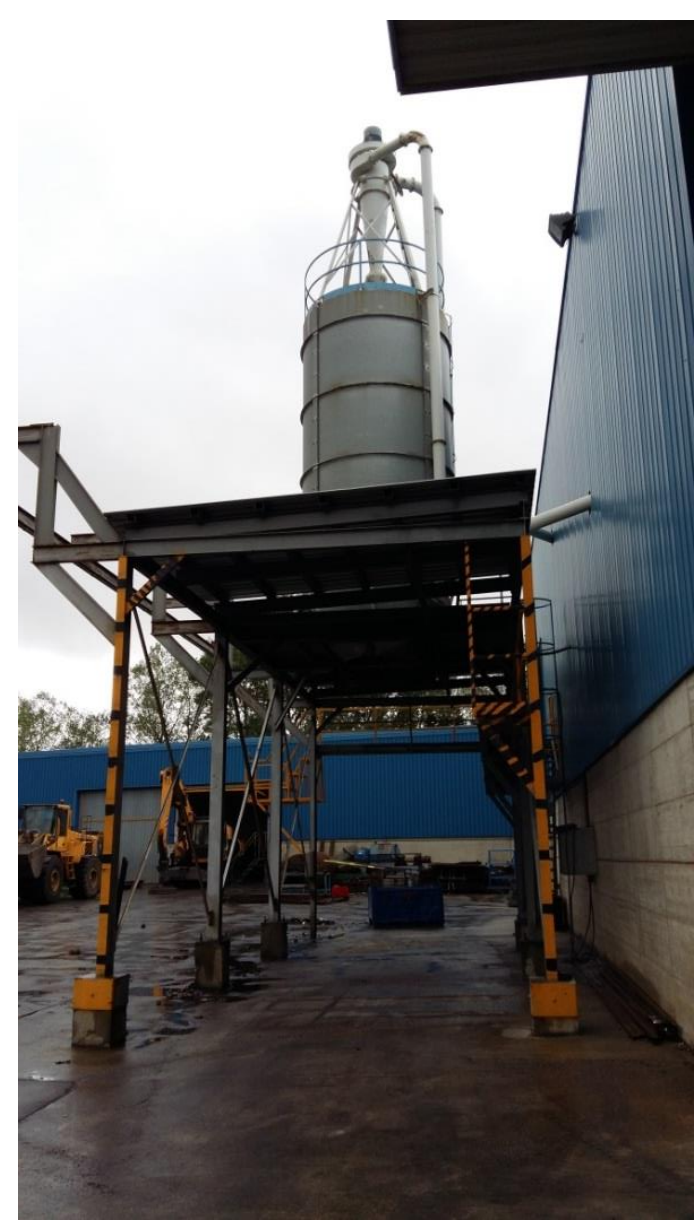

Foto 1.15. Depósito del plástico recuperado (granza) - Fuente: Lyrsa Álava

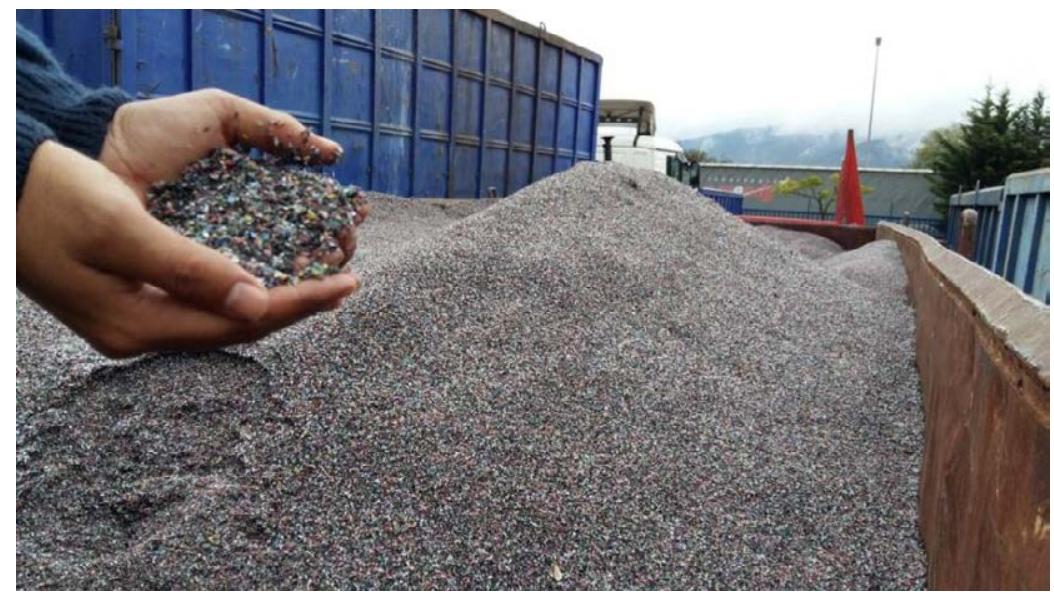

Foto 1.16. Contenedor de la granza de plástico obtenida - Fuente: Lyrsa Álava

- Destino final: la granza de plástico es cargada en camiones con dos posibles destinos: la incineración o el reciclaje del plástico. 
A diferencia de los plásticos recogidos de los residuos domésticos (de los que se recicla el 75,8\%), según las empresas de reciclaje de cables, el reciclaje de estos plásticos no llega a apenas un 10\% (Gráfica 1.9) (Ecoembes, 2019). Según datos proporcionados por Lyrsa Álava, aproximadamente a cada una de estas empresas de reciclaje de cables llegan del orden de 100 toneladas de cables al mes, equivalentes a unas 50 toneladas de metal y 50 toneladas de plástico. Durante el período de esta investigación no ha sido posible el cómputo de las empresas recicladoras de cables en España puesto que no se ha encontrado un listado oficial que lo indique.

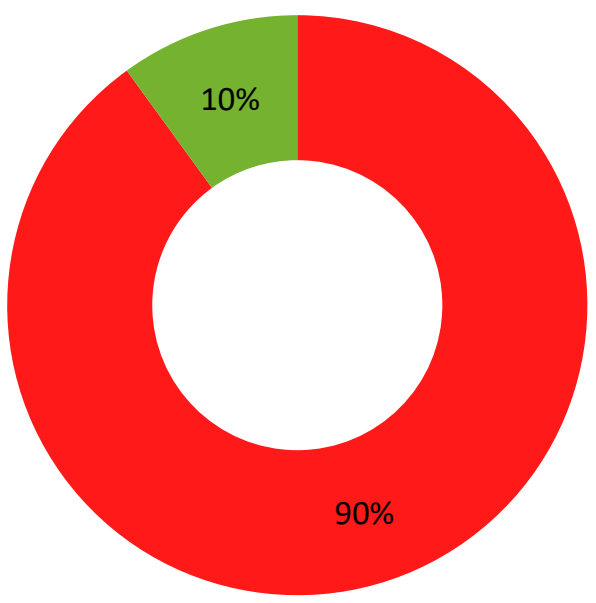

- Incineración

Reciclaje

Gráfica 1.9. Destino de la granza de plástico obtenida en el reciclaje de cables - Fuente: Lyrsa Álava

Si bien es cierto que la incineración, en algunos casos, supone generación de energía, también es cierto que este hecho supone daños al medio ambiente por la contaminación que se produce en sus instalaciones en cuanto a: emisiones de contaminantes a la atmósfera, residuos sólidos o cenizas y aguas residuales contaminadas (Aracil Sáez, 2008).

Las emisiones atmosféricas son la mayor fuente de contaminación, en ellas pueden aparecer partículas sólidas, gases ácidos, metales pesados o productos de combustión incompleta; los residuos sólidos o cenizas procedentes de los hornos de combustión, constituyen un problema menor por su deposición y tratamiento final controlado pero puede aparecer sílice, óxidos de metales, metales pesados, alúmina, etc, y; las aguas residuales contaminadas derivadas de los tanques de enfriamiento de las instalaciones que también pueden arrastrar los mismos tipos de contaminantes.

En este ámbito se necesita, por tanto, encontrar algún uso nuevo para el residuo con el que llegar, al menos, a la situación favorable de los plásticos de los hogares (reciclaje 75,8\%). 


\subsection{EL YESO: TIPOS Y APLICACIÓN}

"El yeso es uno de los materiales más usados y con más fuerte arraigo en nuestras tradiciones constructivas" (Almagro Gorbea, 1986). Utilizado en construcción como conglomerante artificial, ha estado presente en todas las épocas de la historia (Universidade da Coruña, 2008).

Procedente de la deshidratación parcial de la piedra de aljez, ya desde el Neolítico empieza a elaborarse sustituyendo al mortero de barro. Todas las civilizaciones pasadas dan buena cuenta de su utilización, desde el ensamble de los bloques de las grandes pirámides en el antiguo Egipto, a las descripciones como enlucido y ornamentación del escritor griego Teofrasto o del arquitecto romano Vitruvio. En España, fue la cultura musulmana la que difundió el empleo de yeso dejando buenas muestras estéticas de su empleo en zonas como Granada, Sevilla, Toledo o Aragón.

$\mathrm{Su}$ empleo toma gran importancia en el siglo XV tras comprobar su comportamiento ignífugo a partir del gran incendio de Londres; pero no es hasta el siglo XVIII, tras las aportaciones de Lavoisier, Vant'Hoff y Le Chatelier, que se describen los procesos de deshidratación del yeso, sentando las bases científicas del conocimiento posterior (Amador Blanco, Díaz-Guerra Pérez, \& Fernández del Olmo, 2016).

\subsubsection{Fabricación del yeso}

En la actualidad, la fabricación del yeso comprende un proceso normalizado del que se obtiene el producto pulverulento, listo para la obra o para la elaboración de elementos prefabricados, como paneles y placas. Las fases de este proceso son (Amador Blanco et al., 2016):

- Extracción de materia prima: la roca de aljez es abundante en la naturaleza y se obtiene de la explotación de canteras a cielo abierto. Se trata de un dihidrato, $\mathrm{CaSO}_{4} \cdot 2 \mathrm{H}_{2} \mathrm{O}$ (sulfato de calcio con dos moléculas de agua), muy poco soluble en agua, que aumenta su solubilidad a medida que aumenta la temperatura. Sus características se muestran en la Tabla 1.4: 
Tabla 1.4. Características de la piedra de yeso o aljez - Fuente: Manual del yeso (Villanueva Domínguez \& García Santos, 2001)

\begin{tabular}{lr} 
Solubilidad & $2,1 \mathrm{~g} / \mathrm{l} \mathrm{a} 20^{\circ} \mathrm{C}$ \\
Dureza al rayado (escala de Mohs) & 2 \\
Densidad & $2,3-2,4 \mathrm{Kg} / \mathrm{dm}^{3}$ \\
Resistencia mecánica & Baja \\
\hline
\end{tabular}

- Preparación de la materia prima: después de la extracción se procede a la trituración para reducir los fragmentos de piedra en partículas de 2 a $3 \mathrm{~cm}$. Debido a su baja conductividad térmica, estos fragmentos deben ser lo más homogéneos posibles para la correcta cocción posterior de los mismos.

- Cocción: a medida que se aumenta la temperatura se van desprendiendo, en forma de vapor, las moléculas de agua débilmente combinadas, de manera que se pueden obtener distintos productos durante el proceso (Tabla 1.5):

Tabla 1.5. Productos de yeso según la temperatura de cocción - Fuente: Manual del yeso (Villanueva Domínguez \& García Santos, 2001)

\begin{tabular}{cl}
\hline Temperatura ambiente & Aljez - dihidrato CaSO $\mathrm{CH}_{4} \cdot 2 \mathrm{H}_{2} \mathrm{O}$ \\
\hline $107^{\circ} \mathrm{C}$ & Formación del hemihidrato $\mathrm{CaSO}_{4} \cdot 1 / 2 \mathrm{H}_{2} \mathrm{O}$ \\
\hline $150-180^{\circ} \mathrm{C}$ & Desecación del hemihidrato: yeso para estuco \\
\hline $180-300^{\circ} \mathrm{C}$ & $\begin{array}{l}\text { Anhidrita soluble: yeso de fraguado lentísimo y de gran } \\
\text { resistencia }\end{array}$ \\
\hline $300-400^{\circ} \mathrm{C}$ & $\begin{array}{l}\text { Anhidrita difícilmente soluble: yeso de fraguado aparentemente } \\
\text { rápido pero de muy baja resistencia }\end{array}$ \\
\hline $500-700^{\circ} \mathrm{C}$ & $\begin{array}{l}\text { Anhidrita insoluble: yeso de fraguado lentísimo o nulo (yeso } \\
\text { muerto) }\end{array}$ \\
\hline $800-1000^{\circ} \mathrm{C}$ & Yeso hidráulico normal o de pavimento \\
\hline $1000-1400^{\circ} \mathrm{C}$ & Yeso hidráulico con mayor proporción de cal libre y fraguado \\
más rápido
\end{tabular}

- Molienda: a la salida del horno, el producto se muele en molinos de martillos o de bolas, si se quiere una gran finura, y se almacena en silos. En función de la utilidad posterior del yeso, se le realizará (yeso fino) o no (yeso grueso) una molienda de ajuste de su finura.

- Control de calidad del producto terminado: las comprobaciones o ensayos necesarios para el control de las características del yeso fabricado, se realizan por el fabricante o empresa de control de calidad ajena.

- Almacenaje en silos, envasado y expedición: el almacenaje se realiza en silos metálicos, elevados del suelo y cerrados herméticamente para evitar la 
hidratación del yeso por la humedad ambiente. La expedición suele realizarse en sacos de papel o a granel en camión cisterna, a la salida del silo.

\subsubsection{Fraguado del yeso}

El yeso, fabricado en polvo, se amasa con agua y "se endurece a través de un proceso físico-químico que se conoce como fraguado", que hace referencia al tiempo que transcurre entre la mezcla y el endurecimiento de la masa (rehidrato o yeso rehidratado) (Romaniega Piñeiro, 2016). La cantidad de agua a incorporar en el yeso para un correcto amasado, depende del yeso en cuestión, siendo habitual en los yesos la relación agua/yeso entre 0,50 y 0,70 (Villanueva Domínguez \& García Santos, 2001).

Debido a la gran rapidez de fraguado del yeso, en la actualidad es normal el uso de aditivos retardadores del fraguado. Estos aditivos son compuestos químicos que actúan catalíticamente sobre la velocidad de fraguado y permiten, prácticamente, regularlo según las necesidades. Esto, junto a la variedad de productos obtenidos en base a la temperatura de cocción, hace que exista una gran variedad en el mercado del yeso.

\subsubsection{Tipos de yesos}

La normalización de los yesos queda recogida en la norma europea UNE-EN 13279-1:2009 "Yesos de construcción y conglomerantes a base de yeso para la construcción. Parte 1: Definiciones y especificaciones" (CTN 102-Yeso y productos a base de yeso, 2009). Algunas de las denominaciones se muestran en la Tabla 1.6:

Tabla 1.6. Yesos y conglomerantes de yeso para la construcción - Fuente: UNE-EN 13279-1:2009

Designación

\begin{tabular}{lc}
\multicolumn{1}{c}{ Designación } & Identificación \\
\hline CONGLOMERANTE A BASE DE YESO (incluye las escayolas) & A \\
\hline Para su uso directo o para su transformación (producto en polvo, secos) & $\mathrm{A} 1$ \\
\hline Para su empleo directo en obra & $\mathrm{A} 2$ \\
\hline $\begin{array}{l}\text { Para su transformación (paneles de yeso, placas de yeso laminado, placas de } \\
\text { escayola para techos, placas de yeso reforzadas con fibras) }\end{array}$ & $\mathrm{A} 3$ \\
\hline YESO PARA LA CONSTRUCCIÓN & $\mathrm{B}$ \\
\hline Yeso de construcción & $\mathrm{B} 1$ \\
\hline Mortero de yeso & $\mathrm{B} 2$ \\
\hline
\end{tabular}




\begin{tabular}{ll}
\hline Mortero de yeso y cal & B3 \\
\hline Yeso de construcción aligerado & B4 \\
\hline Mortero aligerado de yeso & B5 \\
\hline Mortero aligerado de yeso y cal & $\mathrm{B} 6$ \\
\hline Yeso de construcción de alta dureza & $\mathrm{B} 7$ \\
\hline YESOS PARA APLICACIONES ESPECIALES & $\mathrm{C}$ \\
\hline Yeso para trabajos con yeso fibroso & $\mathrm{C} 1$ \\
\hline Yeso para morteros de agarre & $\mathrm{C} 2$ \\
\hline Yeso acústico & $\mathrm{C} 3$ \\
\hline Yeso con propiedades de aislamiento térmico & $\mathrm{C} 4$ \\
\hline Yeso para protección contra el fuego & $\mathrm{C} 5$ \\
\hline Yeso para su aplicación en capa fina, producto de acabado & $\mathrm{C} 6$ \\
\hline Producto de acabado & $\mathrm{C} 7$ \\
\hline
\end{tabular}

\subsubsection{Propiedades de los yesos}

El yeso es un material de muy baja densidad, entre 0,8 y $1,2 \mathrm{~kg} / \mathrm{dm}^{3}$ (yesos de moldeo y yesos comunes respectivamente), poco soluble en agua que favorece la corrosión de elementos férricos y que, si no está aditivado, fragua en pocos minutos.

En cuanto a las propiedades térmicas: el yeso se considera un buen aislante térmico. Su coeficiente de conductividad para densidades de $0,8 \mathrm{~kg} / \mathrm{dm}^{3}$ toma valores de $\lambda=0,35 \mathrm{~W} / \mathrm{mK}$, para densidades de $1,2 \mathrm{~kg} / \mathrm{dm}^{3}$ toma valores de $\lambda=0,50 \mathrm{~W} / \mathrm{mK}$. Estos coeficientes suponen que por $1 \mathrm{~cm}$ de yeso, serían necesarios $2 \mathrm{~cm}$ de mortero de cemento para conseguir el mismo aislamiento térmico.

En cuanto a las propiedades acústicas: el yeso se considera un buen aislante acústico puesto que opone resistencia al paso del sonido que se propaga por el aire, cuanto mayor es su espesor, mayor es su resistencia al paso del sonido; absorbe parte de ese sonido, disminuyendo la resonancia; dificulta la transmisión de ruidos de impacto y; dificulta la transmisión de ruidos por vibración. Estos tres últimos aspectos mejoran cuanto más poroso es el yeso, es decir, cuanto menor es su densidad.

En cuanto a las propiedades ignífugas, (protección contra el fuego): el yeso es un material incombustible y protector de otros materiales que no se contabiliza a la hora de contabilizar la carga de fuego de los edificios. 
En cuanto a la regulación higrotérmica: el yeso, por su condición de permeabilidad e intercambio continuo de humedad con el ambiente, se considera un material muy eficaz en el acondicionamiento higrotérmico de los edificios.

En cuanto a las resistencias mecánicas: aunque varían de unos yesos a otros (Tabla 1.7), en general son bajas comparadas con otros materiales de construcción. La resistencia a flexión, tracción y compresión disminuye a medida que se eleva la cantidad de agua en la masa.

Tabla 1.7. Especificaciones para los yesos de construcción (B) - Fuente: UNE-EN 13279-1:2009

\begin{tabular}{|c|c|c|c|c|c|c|c|}
\hline \multirow[b]{2}{*}{$\begin{array}{l}\text { Yeso para la } \\
\text { construcción }\end{array}$} & \multirow{2}{*}{$\begin{array}{l}\text { Contenido en } \\
\text { conglomerante } \\
\text { de yeso }(\%)\end{array}$} & \multicolumn{2}{|c|}{$\begin{array}{l}\text { Tiempo de principio de } \\
\text { fraguado (min) }\end{array}$} & \multirow{2}{*}{$\begin{array}{c}\text { Resistencia a } \\
\text { flexión } \\
\left(\mathrm{N} / \mathbf{m m}^{2}\right)\end{array}$} & \multirow{2}{*}{$\begin{array}{c}\text { Resistencia a } \\
\text { compresión } \\
\left(\mathrm{N} / \mathrm{mm}^{2}\right)\end{array}$} & \multirow{2}{*}{$\begin{array}{c}\text { Dureza } \\
\text { superficial } \\
\left(\mathrm{N} / \mathbf{m m}^{2}\right)\end{array}$} & \multirow{2}{*}{$\begin{array}{c}\text { Adherencia } \\
\left(\mathrm{N} / \mathbf{m m}^{2}\right)\end{array}$} \\
\hline & & $\begin{array}{c}\text { Yeso de } \\
\text { aplicación } \\
\text { manual } \\
\end{array}$ & $\begin{array}{c}\text { Yeso de } \\
\text { proyección } \\
\text { mecánica }\end{array}$ & & & & \\
\hline $\mathrm{B} 1$ & $>50$ & \multirow{6}{*}{$>20^{b}$} & \multirow{6}{*}{$>50$} & \multirow{6}{*}{$\geq 1,0$} & \multirow{6}{*}{$\geq 2,0$} & \multirow{6}{*}{--} & \multirow{7}{*}{$\begin{array}{c}\text { La rotura se } \\
\text { manifiesta en } \\
\text { el soporte o } \\
\text { en la masa de } \\
\text { yeso; cuando } \\
\text { la rotura } \\
\text { aparece en la } \\
\text { interfase } \\
\text { yeso-soporte } \\
\text { el valor debe } \\
\text { ser } \geq 0,1\end{array}$} \\
\hline $\mathrm{B} 2$ & $<50$ & & & & & & \\
\hline B3 & $\mathrm{a}$ & & & & & & \\
\hline B4 & $>50$ & & & & & & \\
\hline B5 & $<50$ & & & & & & \\
\hline B6 & $\mathrm{a}$ & & & & & & \\
\hline B7 & $>50$ & & & $\geq 2,0$ & $\geq 6,0$ & $\geq 2,5$ & \\
\hline
\end{tabular}

a Según las definiciones de yeso de construcción, mortero de yeso, mortero de yeso y cal, y yeso de construcción aligerado.

$\mathrm{b}$ En algunas aplicaciones manuales se permite un valor menor que $20 \mathrm{~min}$. En ese caso, el productor debe declarar el tiempo de principio de fraguado.

El conjunto de todas estas propiedades, térmicas, acústicas, ignífugas, higrotérmicas y estéticas, hacen del yeso un material muy demandado además de en el sector de la construcción, en otros sectores como la medicina, la farmacéutica, la industria de los alimentos, etc.

\subsubsection{Aplicaciones del yeso}

La aplicación más característica del yeso en construcción es como revestimiento de paredes y techos (guarnecidos, enlucidos, estucados, etc) o como material de agarre (para unir otros materiales, realizar recibidos, etc). En ambos casos, el yeso se aplica en forma de pasta $y$, una vez endurecido, permite trabajar sobre él, por ejemplo para realizar rozas. 
Algunos de los yesos especificados en la Tabla 1.6, se utilizan para la elaboración de elementos prefabricados como paneles, placas para falso techo, placas de yeso laminado o molduras de decoración:

- Paneles de yeso: elementos prefabricados constituidos por sulfato de calcio y agua. Pueden conseguirse propiedades como el color o la hidrofugación mediante la incorporación de aditivos, fibras, áridos, etc, que cumplan con la normativa. Se fabrican con distintas densidades y dimensiones y se utilizan para la construcción de elementos de tabiquería.

- Placas de escayola para falsos techos: elementos prefabricados constituidos por escayola y agua. Pueden reforzarse con fibras y telas para aumentar la rigidez de las mismas, e incorporar aditivos y/o agregados. Existen dos tipos:

- Para techos continuos no desmontables, con dimensiones estándar de 1000x600 mm ó 600x600 mm.

- Para techos desmontables con perfilería metálica que queda fijada al forjado. Las dimensiones estándar coinciden con las modulaciones de obra, esto es, 1200x600 mm ó 600x600 mm.

- Placas de yeso laminado: elementos prefabricados constituidos por yeso y agua y elaborados por laminación continua. Consiste en un alma de yeso fraguado al que se incorpora una lámina de cartón, de propiedades físicas adecuadas, por cada una de sus caras. Pueden incorporar, previo a la puesta en obra, tratamientos sobre la cara y/o dorso, para mejorar alguna de sus propiedades (aislamiento, hidrofugación, resistencia la desgaste, etc). Se utilizan para la construcción de elementos de tabiquería, trasdosados, falsos techos contínuos, base para solados y otras aplicaciones especiales. También se utilizan para la fabricación de paneles compuestos y paneles sándwich.

- Molduras de decoración: elementos prefabricados constituidos por escayola y agua vertida sobre unos moldes que forman la moldura. Se pueden reforzar con fibras o esparto. Se utilizan como elementos decorativos. 


\subsection{CONSIDERACIONES PARCIALES DEL CAPÍTULO}

La sociedad actual está reaccionando a los problemas medioambientales introduciendo el respeto al medioambiente como un hito más en su filosofía de vida. En el sector de la construcción, este hecho se lleva a cabo a través de la construcción sostenible, con la que se pretende aportar al desarrollo sostenible mediante la disminución del uso de recursos, la minimización de residuos o la reducción de emisiones de $\mathrm{CO}_{2}$.

Los materiales de construcción inciden en el medio ambiente durante todo el ciclo de vida aunque, si bien es cierto, no todos ellos de la misma manera. Uno de los impactos ambientales más graves que producen los materiales, junto con la generación de residuos, es el empleo de recursos naturales de procedencia no renovable.

En el caso de los plásticos, aunque son materiales de gran versatilidad, presentan la dificultad del reciclaje, acentuada por varios motivos: no se descomponen fácilmente y existe una amplia variedad que debe ser separada para poder proceder a su reciclaje. Ante esta realidad, se han aportado soluciones para el reciclaje de muchos de estos residuos plásticos mediante el marcado de un distintivo. No es el caso de los cables eléctricos, de los que se recicla el conductor metálico de su interior y se rechaza el material aislante que generalmente es incinerado.

El yeso es un material muy utilizado en construcción con unas buenas propiedades térmicas, acústicas e ignífugas, que podrían ser mejoradas con la adición de estos residuos plásticos de cables en su matriz.

Con la incorporación del residuo plástico de los cables en una matriz de yeso, no se pretende simplemente la eliminación del residuo, sino que, como recomienda la Directiva Marco de Residuos, se apuesta, mejor, por una reutilización del mismo. La intención es obtener un nuevo producto que vuelva a introducirlo en el mercado, de manera que, lo que hoy es un residuo, mañana se convierta en un recurso, cumpliendo, con ello, los criterios de economía circular. 


\subsection{TRABAJOS CITADOS}

Aguilar, A. (1997). Reciclado de materiales de construcción. Residuos, 2. https://doi.org/1578-097X

Alavedra, P., Domínguez, J., Gonzalo, E., \& Serra, J. (1997). La construcción sostenible: el estado de la cuestión. Informes de La Construcción, 49(451), 41-47. https://doi.org/10.3989/ic.1997.v49.i451

Almagro Gorbea, A. (1986). El yeso, material mudéjar. Actas Del III Simposio Internacional de Mudejarismo. http://hdl.handle.net/10261/21641

Amador Blanco, J. J., Díaz-Guerra Pérez, J., \& Fernández del Olmo, E. (2016). Materiales de construcción. Ligantes, yeso y cal. Madrid (España)

Aracil Sáez, I. (2008). Formación de contaminantes y estudio cinético en la pirólisis y combustión de plásticos (PE, PVC y PCP) (Tesis Doctoral, Universidad de Alicante (España)). https://doi.org/978-84-691-6015-2

Arenas Cabello, F. J. (2008). Los materiales de construcción y el medio ambiente. Ecosostenible, 41, 30-37. https://doi.org/1699-3942

Argiz, C. (2016). La economía circular en el contexto de las futuras normas de especificaciones de cementos. Cemento Hormigón, 976(8). http://cementohormigon.com/Articulos/Articulos?id=1061

Baño Nieva, A., \& Vigil-Escalera del Pozo, A. (2005). Guía de construcción sostenible. https://doi.org/M-51636-2005

Barrios, Á. (2012). Impactos ambientales en construcción sostenible. In Construcción sostenible. https://www.eoi.es/wiki/index.php/Construcción_sostenible

Barrón Ruiz, Á. (2002). Ética, ecología y educación ambiental en el siglo XXI. (Universidad de Salamanca Ed.), La educación y el medio ambiente natural y humano: libro homenaje al profesor Nicolás S. Sosa. 21-38

Braungart, M., McDonough, W., \& Bollinger, A. (2007). Cradle to cradle design: creating healthy emissions - a strategy for ecoeffective product and system design. Journal of Cleaner Production, 15(13), 1337-1348. https://doi.org/https://doi.org/10.1016/j.jclepro.2006.08.003

Buezas Sierra, N. (2010). Guía: plásticos y fuego (p. 66). Valencia (España): AIMPLAS Instituto Tecnológico del Plástico

Cerrillo, A. (2012, February 19). España modera el uso de recursos naturales. La Vanguardia. https://www.lavanguardia.com/medio-ambiente/20120219/54256331741/espana-modera-uso-recursos-naturales.html

Comisión de las Comunidades Europeas. (2000). Comisión 2000/532/CE, que establece una lista de residuos. L226/3-L226/24. Diario oficial de las Comunidades 


\section{Europeas}

Comisión Europea. (2014). Comisión 2014/955/UE, que establece una lista de residuos. L370/44-L370/86. Diario oficial de la Unión Europea

CTN 102-Yeso y productos a base de yeso. (2009). UNE-EN 13279-1:2009 Yesos de construcción y conglomerantes a base de yeso para la construcción. Parte 1: Definiciones y especificaciones. AENOR

del Río Merino, M. (2008). Los residuos de construcción-demolición. https://www.edificacion.upm.es/personales/mercedesdelrio/documentos

del Río Merino, M., García Navarro, J., \& Villoria Sáez, P. (2011). Legal aspects which implement good practice measures in the management of construction and demolition waste. Open Construction \& Building Technology Journal, 5, 124-130. https://doi.org/10.2174/1874836801105010124

Ecoembes. (2019). El reciclaje en datos. https://www.ecoembes.com/es/ciudadanos

Elías Castells, X., Altadill Colominas, R., Andrés Payán, A. M., Bruno, A., Bruno, J., Canales Rojas, Á. M., ... Soliva Torrentó, M. (2009). Reciclaje de residuos industriales $\left(2^{\mathrm{a}}\right)$. Ediciones Díaz de Santos

Eurostat. (2019). Toneladas de residuos en Europa y España. https://ec.europa.eu/eurostat/data/statistics-a-z/abc

FACEL. (2018). Estadísticas generales. https://www.facel.es/estadisticas

FERCD y RCD Asociación. (2019). Evolución de los RCD generados en España en los últimos años. http://www.rcdasociacion.es/

Font, R., Aracil, I., Fullana, A., Martín-Gullón, I., \& Conesa, J. A. (2003). Semivolatile compounds in pyrolysis of polyethylene. Journal of Analytical and Applied Pyrolysis, 68, 599-611. https://doi.org/10.1016/S0165-2370(03)00038-X

Fresneda, C. (2014, March 8). La economía circular. El Mundo. https://www.elmundo.es/economia/2014/03/08/5319cae3e2704e3b248b457 a.html

Fresneda, C. (2016, November 26). Las ciudades serán el motor de la economía circular. El Mundo.

https://www.elmundo.es/economia/2016/11/26/582eec07e2704eb87c8b466 a.html

González Pericot, N. (2010). Gestión de residuos de embalajes en una obra de edificación (Trabajo Fin de Máster, Universidad Politécnica de Madrid (España)). http://oa.upm.es/10764/2/TESIS_MASTER_NATALIA_GONZALEZ_PERICOT.pdf

Hammond, G., \& Jones, C. (2011). Embodied energy and carbon. http://www.circularecology.com/embodied-energy-and-carbon-footprintdatabase.html\#.XSYwE2Z7nMU

Hermida Balboa, C., \& Domínguez Somonte, M. (2014). Economía circular como marco 
para el ecodiseño: el modelo ECO-3. Informador Técnico, 78(1), 82-90. https://doi.org/10.23850/22565035.71

IDAE. (2018). Consumo de energía final en España por sectores 2000-2016. https://www.idae.es/sites/default/files/estudios_informes_y_estadisticas/infor me_indicadores_ee_2016_accesib.pdf

Jefatura del Estado. (2011). Ley 22/2011, de 28 de julio, de residuos y suelos contaminados. 85650-85705. BOE núm. 181

López de Asiain, J. (2001). Arquitectura, ciudad, medioambiente (Universidad de Sevilla, Ed.). Sevilla (España)

Ministerio de Agricultura Alimentación y Medio Ambiente. (2016). Plan Estatal Marco de Gestión de Residuos (PEMAR) 2016-2022

Ministerio de Agricultura y Pesca Alimentación y Medio. (2017). Orden APM/1007/2017, de 10 de octubre, sobre normas generales de valorización de materiales naturales excavados para su utilización en operaciones de relleno y obras distintas a aquéllas en las que se generaron

Ministerio de Ciencia y Tecnología. (2002). Real Decreto 842/2002, de 2 de agosto, por el que se aprueba el Reglamento electrotécnico para baja tensión

Ministerio de la Presidencia. (2008). Real Decreto 105/2008, de 1 de febrero, por el que se regula la producción y gestión de los residuos de construcción y demolición

Ministerio de Medio Ambiente. (2002a). Orden MAM/304/2002, de 8 de febrero, por la que se publican las operaciones de valorización y eliminación de residuos y la lista europea de residuos

Ministerio de Medio Ambiente. (2002b). Real Decreto 1481/2001, de 27 de diciembre, por el que se regula la eliminación de residuos mediante depósito en vertedero

Ministerio de Medio Ambiente y Medio Rural y Marino. (2009). Plan Nacional Integrado de Residuos para el período 2008-2015

Ministerio para la transición ecológica. (2002). Protocolo de Kioto. https://www.miteco.gob.es/es/cambio-climatico

Miravete, A. (1995). Los nuevos materiales en la construcción (2a; Reverté, Ed.). Zaragoza (España)

Moltó, J., Font, R., Gálvez, A., \& Conesa, J. A. (2009). Pyrolysis and combustion of electronic wastes. Journal of Analytical and Applied Pyrolysis, 84(1), 68-78. https://doi.org/10.1016/j.jaap.2008.10.023

Moraño Rodríguez, A. J. (2016). Hormigón estructural térmico. Economía circular. Cemento Hormigón, 976(8).

http://cemento-hormigon.com/Articulos/Articulos?id=1061

National Oceanic and Atmospheric Administration. (2017a). Partes de dióxido de carbono por millón de partículas de aire. https://www.noaa.gov 
National Oceanic and Atmospheric Administration. (2017b). PPM en los inicios de la Revolución Industrial. https://www.noaa.gov/news/carbon-dioxide-levels-inatmosphere-hit-record-high-in-may

Novo Villaverde, M. (2006). El desarrollo sostenible: su dimensión ambiental y educativa (Pearson, Ed.). Madrid (España).

Núñez, M. (2017, September 25). Economía circular, echa a rodar la mayor revolución global en 250 años. $A B C$. https://www.abc.es/economia/abci-economia-circularecha-rodar-mayor-revolucion-global-250-anos-201602151450_noticia.html

ONU. (1972). Conferencia de las Naciones Unidas sobre el Medio Humano. https://www.un.org/es/index.html

ONU. (1980). Convenciones de Basilea, Estocolmo y Rotterdam y Protocolo de Montreal. https://www.un.org/es/index.html

ONU. (1987). Protocolo de Montreal. https://www.undp.org

ONU. (1991). Temas mundiales-Medio ambiente. https://www.un.org/es/index.html

ONU. (1992). Cumbre para la Tierra. https://www.un.org/es/index.html

ONU. (1998). Convención de Rotterdam. https://www.un.org/es/index.html

ONU. (1999). Pacto mundial de las Naciones Unidas.

https://www.un.org/es/index.html

ONU. (2000a). Cumbre del Milenio. https://www.un.org/es/index.html

ONU. (2000b). Toneladas de residuos por habitante.

https://www.un.org/es/index.html

ONU. (2002). Cumbre de Johannesburgo. https://www.un.org/es/index.html

Parlamento Europeo. (1975). Directiva 75/442/CEE

Parlamento Europeo. (2008). Directiva Marco de Residuos 2008/98/CE

Parlamento Europeo. (2018). Directiva (UE) 2018/851

Peinado Moreno, A. (2003). Manual S.E.P.E.I de Bomberos (Dipualba, Ed.). Albacete (España)

Planelles, M. (2016, November 4). El acuerdo de París contra el cambio climático entra en vigor en un tiempo récord. El País.

https://elpais.com/internacional/2016/11/03/actualidad/1478183747_14165 2.html

PlasticsEurope. (2017). Los plásticos y la seguridad contra incendios en el sector de la construcción. https://www.plasticseurope.org/es/resources/publications/319los-plasticos-y-la-seguridad-contra-incendios-en-el-sector-de-la-construccion

PlasticsEurope. (2018). An analysis of European plastics production, demand and 
waste data. https://www.plasticseurope.org/es/resources/publications/1240plasticos-situacion-en-2018

PlasticsEurope. (2019). Tipos de plásticos. https://www.plasticseurope.org

RAE. (2017). Diccionario de la Lengua Española. http://www.rae.es

Roberto, Á. (2013). La parkesina y sus hermanos. https://historiasdeempaques.wordpress.com

Romaniega Piñeiro, S. (2016). Refuerzo de la escayola mediante fibras de lana mineral procedentes del reciclaje de RCD (Tesis Doctoral, Universidad Politécnica de Madrid (España)). https://doi.org/10.20868/UPM.thesis.43030

Sanjuán-Barbudo, M. Á. (2016). Cemento y hormigón en la economía circular. Cemento Hormigón, 976(10). http://cemento-hormigon.com/Articulos

Santos Marián, D. de, Monercillo Delgado, B., \& García Martínez, A. (2011). Gestión de residuos en las obras de construcción y demolición (2a; S. L. . Tornapunta Ediciones, Ed.). Madrid (España)

Schwarz, M. J. (2009, March 9). El plástico y sus problemas. El Comercio. https://www.elcomercio.es/gijon/20090309/sociedad

Secretaría de Estado y Medio Ambiente. (2016). Plan Estatal Marco de Gestión de Residuos 2016-2022. 192. https://www.miteco.gob.es/es/calidad-y-evaluacionambiental/planes-y-estrategias/pemaraprobado6noviembrecondae_tcm30170428.pdf

Seymour, R. B. (1995). Introducción a la química de los polímeros (2a; Editorial Reverté S.A, Ed.). Mississippi (EEUU).

Soriano Baeza, M. (2010). Innovación y medio ambiente en materiales de construcción. http://www.coiim.es/rrii/Descargas/jornadasyconferencias/innovacion_medio ambiente

Soriano Baeza, M. (2011). Valorización energética de residuos. http://www.coiim.es/rrii/Descargas/jornadasyconferencias/mediambiente201 1/msoriano.pdf

Téllez, J., Rodríguez, A., \& Fajardo, Á. (2006). Contaminación por monóxido de carbono: un problema de salud ambiental. Revista de Salud Pública, 8(1), 108117. https://doi.org/10.1590/S0124-00642006000100010

Tertre Torán, J. I. (2016). Realizaciones con áridos reciclados. Cemento Hormigón, 976(8). http://cemento-hormigon.com/Articulos/Articulos?id=1061

The World Bank Group. (1999). World development indicators.

https://data.worldbank.org/indicator

The World Bank Group. (2016). Población mundial.

https://data.worldbank.org/indicator

UNED. (2016). Gestión y tratamiento de los residuos urbanos. 
https://www2.uned.es/biblioteca/rsu

Universidade da Coruña. (2008). Ligantes: Yesos.

ftp://ceres.udc.es/ITS_Caminos/1_Ciclo/Materiales_Construccion

Villanueva Domínguez, L. de, \& García Santos, A. (2001). Manual del yeso (Asociación Técnica y Empresarial del Yeso. ATEDY, Ed.). Madrid (España).

Williams, P. T. (1994). Pollutants from incineration: an overview. In R. M. Harrison R. E. Hester (Ed.), Waste incineration and the environment (pp. 27-52). https://doi.org/10.1039/9781847552327 


\section{Estado de la cuestión}

2.1 ESTUDIOS SOBRE COMPUESTOS DE YESO CON ADICIÓN DE RESIDUOS

2.2 ESTUDIOS SOBRE COMPUESTOS DE YESO CON ADICIÓN DE POLÍMEROS

2.3 PATENTES DE YESO CON POLÍMEROS

2.4 CONSIDERACIONES PARCIALES DEL CAPÍTULO

2.5 TRABAJOS CITADOS 
CAPITULO 2: ESTADO DE LA CUESTION 


\section{Estado de la CUESTIÓN}

En este capítulo se resumen los documentos encontrados en la búsqueda bibliográfica y documental sobre investigaciones que incorporan distintos residuos, y en concreto los plásticos, en matrices de yesos en los cuales, además, se estudia la posibilidad de realizar elementos constructivos con los compuestos resultantes.

Algunas de estas investigaciones, no solamente han consistido en analizar la forma de reducir el coste de producción (pasando de la leña al carbón, por ejemplo), sino también, han tratado de modificar alguna de las propiedades del yeso mezclándolo con otros materiales durante el proceso de obra, obteniendo cambios en el tiempo de fraguado, el endurecimiento, la impermeabilidad, etc.

Con la llegada de la industrialización en el s. XVIII, se consiguen productos de yeso con características más definidas al introducir aditivos durante su proceso productivo (Villanueva Domínguez, 2004). Otro hecho significativo relacionado con los estudios del yeso sucede en Estados Unidos en 1888 donde, tras las investigaciones de Augustine Sackett y Fred L. Kane, se fabrica la primera placa de yeso laminado como elemento sencillo y protector de las estructuras de la época (Sackett, 2017). La fabricación de otros productos de yeso (aligerados, de proyección, aislantes, etc) se 
empieza a estudiar más en profundidad después de la II Guerra Mundial (Leiva Aguilera, 2017).

Más recientemente, las investigaciones se centran en buscar compuestos de yeso con los que mejorar los siguientes aspectos: densidad, resistencias mecánicas, comportamiento térmico y acústico, tiempos de fraguado y endurecimiento, capacidad de absorción de agua, comportamiento ante el fuego y propiedades higrotérmicas (San Antonio González, del Río Merino, Viñas Arrebola, \& Villoria Sáez, 2016).

En este sentido, los estudios analizados para esta tesis doctoral se han clasificado en los siguientes apartados:

- Estudios sobre compuestos de yeso con adición de residuos.

- Estudios sobre compuestos de yeso con adición de polímeros.

- Patentes de yesos con polímeros. 


\subsection{ESTUDIOS SOBRE COMPUESTOS DE YESO CON ADICIÓN DE RESIDUOS}

En la actualidad existe una tendencia a utilizar materiales procedentes del reciclaje, como alternativa a la utilización de recursos naturales y para evitar la acumulación de residuos. En este apartado se analizan estos estudios y se agrupan según el residuo empleado:

- Residuos de madera.

- Residuos agrícolas.

- Residuos industriales.

- Residuos de construcción y demolición (RCD).

\subsubsection{Residuos de madera}

Con respecto a los estudios sobre el yeso con adiciones de residuos procedentes de la madera cabe destacar a C. R. Haselein, que realiza paneles de yeso a los que adiciona papel reciclado, procedente de periódico y offset, y residuos de madera de pino. Los resultados obtenidos, respecto a paneles sin adición, muestran un aumento de las resistencias mecánicas y de la dureza, mientras que la absorción de agua y el hinchamiento no sufren variaciones considerables. Los mejores resultados fueron los obtenidos con residuos de periódico (Haselein et al., 2002).

También se han encontrado investigaciones sobre la incorporación de residuos del alcornoque (corcho) en el yeso:

- Del Río Merino incorpora, además de corcho, bornizos y restos de podas de encina, obteniendo compuestos de menor densidad, mejor capacidad de deformación y mayor coeficiente de aislamiento acústico. Las resistencias mecánicas disminuyen respecto a yeso sin adición pero siempre con valores superiores a los mínimos indicados en normativa (del Río Merino, 2005).

- A. Cherki, realiza sus estudios sobre paneles de residuos de corcho y yeso y, comprueba la mejora que se produce en estos compuestos, en cuanto al aislamiento térmico (Cherki, Remy, Khabbazi, Jannot, \& Baillis, 2014).

- G. Vasconcelos analiza un conglomerado a base de yeso y residuos de corcho con fibras procedentes del reciclado de neumáticos usados. En sus resultados se observa la disminución de resistencia a compresión a medida que se incrementa el porcentaje de residuo de corcho, así como el aumento en la energía de fractura en modo I del material compuesto cuanto mayor es el porcentaje de fibras añadidas (Vasconcelos, Lourenco, Camoes, Martins, \& Cunha, 2015). 
Otros investigadores como M. J. Morales Conde agregan residuos de serrín y virutas de madera en matrices de yeso. Como resultados positivos consigue una reducción en la densidad de los compuestos, así como una ligera disminución del coeficiente de conductividad térmica. Por otra parte, obtiene menores durezas Shore C y menores resistencias mecánicas (flexión y compresión) a medida que incorpora mayor porcentaje de estos residuos. En todos los casos fueron los compuestos con virutas de madera los que presentaron peores resultados (Morales-Conde, RodríguezLiñán, \& Pedreno Rojas, 2016).

Por último, en este apartado merece destacar S. Liuzzi que analiza la incorporación de arcilla y restos de la poda de olivos en compuestos de yeso, obteniendo como resultado una mejora en el comportamiento higrotérmico (Liuzzi, Rubino, \& Stefanizzi, 2017).

\subsection{2 $\quad \underline{\text { Residuos agrícolas }}$}

En cuanto a los estudios encontrados sobre yesos que incorporan residuos agrícolas, son varias las investigaciones que se centran en mezclas de residuos de caña de azúcar (bagazo) y yeso, entre ellas:

- M. Nazerian, estudia la posibilidad de incorporar residuos de caña de azúcar (bagazo), además de paja de trigo, en paneles aglomerados de yeso. Los resultados obtenidos fueron: mejora de la absorción de agua con disminución de valores cuanto mayor porcentaje de residuos incorpora; disminución de los módulos de rotura y elasticidad y la resistencia de unión interna; aumento del valor de hinchamiento, aunque en este caso, siempre cumpliendo con lo exigido en normativa para inmersión de 24 horas. Asimismo, define una adición máxima de 12,5\% de residuo para que los resultados obtenidos en las resistencias mecánicas se ajusten a los mínimos indicados en normativa (Nazerian \& Kamyab, 2013).

- F. Hernández Olivares, introduce fibras de bagazo y ceniza de bagazo en matrices de yeso para la fabricación de paneles y tableros. Los compuestos obtenidos admiten porcentajes elevados de adición de fibras, cuyos ensayos mecánicos y físicos cumplen con las especificaciones requeridas en normativa para elementos no estructurales. La adición de cenizas de bagazo supone la mejora de prestaciones de paneles y tableros y, la de fibras, supone buena resistencia al fuego. En todos los casos, el valor de hinchamiento es inferior al establecido en normativa (Hernández Olivares, Zuñiga Suárez, Medina Alvarado, \& Burneo Valdivieso, 2015).

También se han encontrado estudios con cáscaras de arroz, como los de: 
- M. N. Musa, se centra en la obtención del valor de conductividad térmica de estas mezclas que va disminuyendo a medida que incrementa el porcentaje de residuo (Musa \& Abdul Aziz, 2016).

- Por su parte, M. J. Leiva Aguilera, en su tesis doctoral, desarrolla el estudio de matrices de escayola y cáscaras de arroz en formato de residuo entero, triturado y ceniza. La densidad de los compuestos obtenidos es similar a la de los compuestos sin residuos. Aumenta la dureza y la tenacidad y disminuye la absorción de agua por capilaridad, comportándose como aditivos hidrófugos. Por el contrario, disminuyen las resistencias mecánicas (excepto en el caso de la incorporación de la ceniza de arroz donde mejora la resistencia a compresión). En todos los compuestos disminuye el tiempo de fraguado, excepto en el caso de la ceniza en el que aumenta (Leiva Aguilera, 2017).

Otros estudios como el de C. Oliveira, adiciona endocarpio leñoso de residuos de nuez y aserrín en mezclas de yeso. Los valores obtenidos indican una disminución de resistencias mecánicas y un aumento de densidad en compuestos con porcentaje superior al 7,5\% de residuo de nuez. En cuanto a los compuestos con adición de aserrín, obtuvieron valores superiores de resistencias mecánicas (superiores a las mínimas de normativa) y, disminuyeron su densidad (Oliveira, Oliveira, Oliveira, \& Damasceno, 2016).

También A. Bicer, en sus investigaciones, añade resinas de la planta de tragacanto con el fin de crear poros artificiales en bloques de yeso y residuos de espuma de poliestireno expandido. A medida que se incrementa el porcentaje de resina y residuo en los compuestos, disminuye el coeficiente de conductividad térmica pero, también disminuyen las resistencias mecánicas y, aumenta la absorción de agua (Bicer \& Kar, 2017).

N. Belayachi, analiza el efecto del tratamiento natural o artificial sobre la degradación térmica y la inflamabilidad, en compuestos de yeso y fibras de paja de trigo y cebada. Para ello, impregna las fibras con aceite de linaza y agua hervida. Este tratamiento, consigue retardar la llama y prevenir la degradación del compuesto. Además, la llama se detiene después de retirar el quemador. El comportamiento de los compuestos con cebada es peor respecto a los de trigo (Belayachi, Hoxha, \& Ismail, 2016).

H. Binici, introduce cáscaras de cebolla, cáscaras de cacahuete, cenizas volantes, piedra pómez, perlita y barita en un conglomerante de yeso tratando de buscar un material con propiedades aislantes. Sus resultados son los siguientes: los pesos de las muestras con ceniza volante y barita son mayores, mientras que su capacidad de absorción de agua es menor; los pesos de las muestras de piedra pómez y perlita son más bajos, mientras que su capacidad de absorción de agua es mayor; la velocidad de penetración ultrasónica del sonido y los coeficientes de conductividad térmica de las muestras de piedra pómez y perlita son menores que las otras; todas las muestras 
cumplen con los valores mínimos de resistencia a la flexión y compresión de la normativa empleada. También todos los valores de conductividad térmica se reducen respecto a las mezclas sin adición (Binici \& Aksogan, 2017).

I. Amara, analiza la incorporación de fibras de palmera en matrices de yeso con el fin de mejorar sus propiedades de aislamiento térmico para la envolvente de edificios. En estos compuestos disminuye la conductividad y efusividad térmica respecto a compuestos sin adición (Amara, Mazioud, Boulaoued, \& Mhimid, 2017). También, A. Braiek, analiza estas propiedades termofísicas y añade la ligereza. Sus resultados son similares, en cuanto a que se mejoran las propiedades térmicas pero, además, obtiene valores de densidad menores a las mezclas de referencia (Braiek, Karkri, Adili, Ibos, \& Ben Nasrallah, 2017).

Por último se ha encontrado un estido de F. Iucolano en el que agrega residuos de fibras de cáñamo como refuerzo de compuestos de yeso. Una vez que son tratadas las fibras biógicamente para minimizar su naturaleza hidrófila, los resultados obtenidos muestran un aumento de la resistencia a flexión y al choque de impacto (Iucolano, Liguori, Aprea, \& Caputo, 2018).

\subsection{3 $\quad$ Residuos industriales}

Varias investigaciones se interesan por la incorporación de diferentes tipos de escorias en matrices de yeso. Entre ellas:

- H. Tayibi, que utiliza polvo de aluminio generado en la molienda y clasificación de las escorias resultantes en el proceso de fusión de chatarras, estabilizado con yeso. En todas las mezclas estudiadas, los valores de dureza Brinell y los de resistencia a compresión son más altos que los del yeso sin adición. En cuanto a la resistencia a flexotracción, son las probetas fabricadas a partir de un $50 \%$ de yeso las que presentan, también, valores mayores a las probetas sin adición (Tayibi, Pérez, López, \& López Delgado, 2005).

- M. S. Morsy, que adiciona lodos de escoria de altos hornos en matrices de yeso. Las propiedades térmicas mejoran respecto a compuestos sin adición y las propiedades acústicas indican que puede ser utilizado como tratamiento acústico en el rango del habla frecuencia. También se analiza la resistencia al fuego obteniéndose un resultado de 45 minutos (Morsy, Shebl, \& Saif, 2008).

- V. Calderón, que realiza varios estudios con yeso y adición de escorias de horno de cuchara procedentes de la fundición de barras de acero para su uso en mampostería. Algunos de los resultados que obtiene, muestran buenas propiedades físicas de los compuestos obtenidos y resistencias mecánicas que cumplen con los mínimos exigidos en normativa (Calderón, Rodríguez, Horgnies, \& Gadea, 2013). En otro estudio utiliza, además, un superfluidificador 
para reducir la absorción de agua y una emulsión adhesiva para mejorar la adherencia de la superficie, obteniendo un aumento de densidad y permeabilidad al vapor y porosidad; una disminución de adherencia, durabilidad y resistencias mecánicas y; una buena interacción entre los constituyentes, según imágenes de microscopía de barrido (Rodríguez, Gutiérrez-González, Horgnies, \& Calderón, 2013).

También se han encontrado estudios con residuos procedentes de la industria papelera, como los de:

- A. M. Quinchía, que analiza conglomerados de yeso con adición de lodos procedentes de la industria papelera para la fabricación de paneles. Utiliza grandes porcentajes de lodos (80-85-90\%) deshidratados con un $45 \%$ de humedad. Los paneles con $80 \%$ de lodos cumplen la norma en cuanto a resistencia a flexión, dureza de base, bordes y extremos y resistencia a la extracción del clavo; Además, su densidad es menor que la de los paneles comerciales (Quinchía Figueroa, Valencia García, \& Giraldo Orozco, 2007).

- Z. Cong, también analiza un material de aislamiento alternativo realizado con papeles de periódico de desecho, tallos de caña, vermiculita, perlita, bórax de zinc y yeso. Para ello, los papeles de periódico permanecen en agua 1 día, se añade vermiculita y bórax de zinc para aumentar la resistencia a fuego $\mathrm{y}$, los tallos de caña se colocan en forma de rejilla simple y doble. Todas las muestras presentan valores de resistencias mecánicas superiores a los mínimos indicados en normativa y, coeficientes de conductividad térmica y permeabilidad de sonido bajos (Zhu, Zhang, Peng, Cao, \& Liu, 2018).

Por otra parte, D. M. Tasán Cruz, realiza estudios en los que trata el refuerzo de yesos mediante la adición de fibras recuperadas de eslingas textiles de un solo uso. Consigue compuestos de menor densidad y mayor resistencia a flexotracción. Por el contrario, en estos compuestos se reduce la dureza Shore C y la resistencia a compresión (Tasán Cruz, 2011).

La doctora Gutiérrez González, agrega dos tipos de residuos de poliuretano al conglomerante de yeso: un subproducto de la industria del automóvil (gris) y un subproducto de la fabricación de poliuretano para el aislamiento térmico en la industria de la construcción (blanco). Los resultados obtenidos son, aumento de la porosidad y disminución de la densidad, resistencias mecánicas, adherencia y conductividad térmica. El comportamiento de las mezclas con poliuretano blanco fue mejor que el de las mezclas con poliuretano gris (Gutiérrez González, Gadea, Rodríguez, Junco, \& Calderón, 2012).

De las investigaciones examinadas los siguientes autores adicionan cenizas para la fabricación de paneles compuestos de yeso: 
- M. D. Alba, analiza cenizas procedentes de la combustión de orujillo (residuo que se genera durante la extracción de aceite a la aceituna) y carbón de centrales térmicas. Sus resultados, mejores en los paneles de cenizas de orujillo, arrojan valores de conductividad térmica ligeramente superiores a paneles sin adición y superiores a los mínimos exigidos (Alba Rodríguez, Marrero, Leiva Fernández, Montes, \& Vilches, 2012).

- M. Marrero, estudia la minimización del impacto ambiental en la ejecución de fachadas. Para ello, utiliza en sus paneles, cenizas procedentes de la combustión de orujillo $(60 \%)$, vermiculita $(9,5 \%)$ y fibras de polipropileno y vidrio (1,5\%). La incorporación de las fibras supone, para los paneles, el cumplimiento de las resistencias mínimas a compresión (polipropileno) y flexión (vidrio). Además, consigue reducir, significativamente, la energía incorporada y, por tanto, las emisiones de $\mathrm{CO}_{2}$ (Marrero, Martínez Escobar, Mercader Moyano, \& Leiva Fernández, 2013).

También se han encontrado varios estudios sobre la incorporación de desechos de cuero:

- H.Lakrafli, realiza estudios sobre el efecto de la adición de desechos de cuero, virutas de cromo y polvo de pulir, sobre las propiedades mecánicas y térmicas del yeso. Sus resultados muestran una disminución significativa de la densidad, las resistencias mecánicas y la conductividad térmica (Lakrafli, Tahiri, Albizane, \& El Otmani, 2012).

- También Barriga Miño en su investigación, utiliza residuos sólidos procedentes del rebajado del cuero de una empresa de curtidería. Los compuestos obtenidos retienen el calor pudiéndose definir, térmicamente, como un comportamiento aislante (Barriga Miño, 2017).

El último de los estudios encontrados de este apartado es el de Flores Medina que incorpora residuos de grafito en compuestos de yeso reforzados con fibras de polipropileno. En sus resultados se observa el aumento de resistencias mecánicas (resistencia a la compresión, resistencia a la flexión, módulo de Young, dureza), densidad y conductividad térmica y, por otro lado, la disminución de la porosidad y de la capacidad de absorción de agua (Flores Medina \& Barbero Barrera, 2017).

\subsubsection{Residuos de construcción y demolición (RCD)}

En el caso de adiciones de RCD, son muchos los estudios encontrados como el de González Madariaga que analiza la posibilidad de incorporar residuos de poliestireno expandido en la fabricación de paneles o placas de yeso. Sus resultados apuntan ventajas y desventajas. Como ventajas destaca la ligereza, la buena reacción al fuego, la mejora de las propiedades de conductividad térmica y la menor capacidad de 
absorción al agua. Como desventaja, la pérdida de resistencias mecánicas (González Madariaga, 2008).

Entre estos estudios con RCD, cabe destacar el realizado en el marco del proyecto W2R "De residuos a recursos: valorización integral de los residuos generados en la rehabilitación energética de edificios", del grupo TEMA encabezado por M. del Río Merino, que aborda la problemática de los residuos de RCD tratando de devolverlos al mercado de la construcción, mediante su incorporación en materiales "tradicionales". De sus estudios con yeso, destacan las investigaciones en las que se incorporan las siguientes adiciones:

- Residuos cerámicos, con los que se mejora en dureza superficial, absorción por capilaridad y adherencia. Por el contrario, empeoran las resistencias mecánicas (Santos Jiménez, del Río Merino, \& González Cortina, 2013).

- Residuos obtenidos de desechos de placas de yeso laminado. Obtienen resultados similares en dureza superficial respecto a compuestos sin residuos, mayor resistencia a compresión en casi todas las mezclas y, menor resistencia a flexión (Rodríguez Orejón, del Río Merino, \& Fernández Martínez, 2014).

- Residuos de poliestireno extruido (XPS). Los resultados son, disminución de la densidad y resistencias mecánicas y; mejora de la absorción por capilaridad y resistencia térmica (San-Antonio-González, Del Río-Merino, Viñas-Arrebola, \& Villoria-Sáez, 2015).

- Fibras de lana mineral recogidas en vertedero (lana de roca y lana de fibra de vidrio). Sus resultados arrojan características tales como aumento de densidad, dureza superficial Shore $C$, resistencia a flexión y, disminución de resistencia a compresión pero dentro de los límites establecidos en normativa (Romaniega Piñeiro, del Río Merino, \& Pérez García, 2015).

- Residuos de poliestireno expandido (EPS) que, aunque material más liviano, necesita de aditivos y fibras como refuerzo. Se obtienen resultados positivos de disminución de densidad, propiedades mecánicas mejoradas y excelente comportamiento térmico. Como resultado negativo, la disminución de la dureza superficial Shore C (San Antonio González et al., 2016).

- Residuos de vidrio procedentes del desmontaje de carpinterías. En los compuestos realizados, se obtiene un aumento de la densidad de los compuestos respecto a la referencia sin adición, un aumento de la dureza superficial Shore $\mathrm{C}$ y de las resistencias mecánicas de flexión y compresión y, una disminución del coeficiente de conductividad térmica (Villoria Sáez, Santa Cruz Astorqui, \& del Río Merino, 2016). 
- Residuos cerámicos y de poliestireno extruido en la matriz de yeso. En los resultados obtenidos aumenta la dureza superficial y disminuye la capacidad de absorción de agua por capilaridad, a la par que disminuyen las resistencias a flexión y compresión, aunque siempre con valores superiores a los mínimos indicados en normativa (del Río Merino, Santa Cruz Astorqui, \& Villoria Sáez, 2018).

Por su parte, el grupo de investigación en Ingeniería de la Edificación (GIIE), perteneciente a la Universidad de Burgos, también aporta al campo de estudios de compuestos de yeso y adición de residuos de RCD. Entre ellos:

- Residuos obtenidos de desechos de placas de yeso laminado (elaboradas con espuma de poliuretano y reforzadas con fibras de polipropileno), con el fin de volver a fabricar nuevas placas de yeso laminado. Tras los ensayos realizados a las placas fabricadas, se obtienen densidades similares a la de placa sin residuos. Además, aumenta sensiblemente la resistencia a flexión y la dureza superficial en ellas, a la vez que disminuye su capacidad de absorción de agua (Alameda, Calderón, Gadea, \& Gutiérrez-González, 2015).

Siguiendo la línea de los residuos de yeso, se han encontrado otros autores que también los analizan:

- Pinheiro, los somete a varios ciclos de reciclaje para su incorporación en matrices de yeso. Las propiedades físicas y químicas de estos compuestos resultantes, no difieren de los compuestos de yeso comercial, incluso cuando se trata de residuos procedentes de varios ciclos de reciclaje (Pinheiro \& Camarini, 2015).

- También de Moraes o Erbs, estudian estas propiedades de reciclaje de yeso, comprobando la similitud de las características de las resistencias mecánicas respecto al yeso comercial y la pérdida de trabajabilidad de las mezclas tras sucesivos ciclos de reciclaje (de Moraes Rossetto, Santos Correia, Henrique Geraldo, \& Camarini, 2016; Erbs et al., 2018). 


\subsection{ESTUDIOS SOBRE COMPUESTOS DE YESO CON ADICIÓN DE POLÍMEROS}

Dada la diversidad de polímeros existentes y la heterogeneidad de sus propiedades, los investigadores tratan de ver el aporte de alguna de ellas en los compuestos de yeso. Por su parte, la problemática del reciclaje de plásticos hace que sea un tema recurrente para la innovación de materiales que trata de cerrar su ciclo de vida incorporándolo nuevamente en algún otro material. En este apartado se analizan los estudios que recogen compuestos de yeso con las siguientes cargas:

- Adición de polímeros.

- Adición de residuos poliméricos.

\subsubsection{Adición de polímeros}

En las investigaciones encontradas con adición de polímeros destacan las siguientes:

A. García Santos, en su tesis doctoral de 1988 y posteriores investigaciones, incorpora fibras acrílicas, de poliéster y de polipropileno (termoplásticas) como refuerzo de yesos en lo que denomina material "híbrido". En ella concluye que existe buena compatibilidad entre yeso y fibras y además que, con la adición de las fibras, es posible modificar las características mecánicas del yeso, aumentar su ductilidad e incluso, en el caso de las fibras de polipropileno, aumentar sus resistencias mecánicas (García Santos, 1988, 2004).

Son varios investigadores más los que plantean agregar fibras de polipropileno (PP) en compuestos de yeso, entre ellos:

- Y.H Deng, que realiza una investigación sobre la influencia de la longitud de las fibras de polipropileno incorporadas en paneles de yeso reforzados. Observa que la longitud y la cantidad de fibras de polipropileno tienen efecto reductor en la unión interna y en el módulo de rotura de los paneles pero, por el contrario, aumentan las resistencias mecánicas y disminuye el hinchamiento de los mismos (Deng \& Furuno, 2001).

- En su tesis doctoral y sucesivas investigaciones, A. Oliver Ramírez estudia materiales de cambio de fase mediante compuestos de yeso con agregados de melamina formaldehído y fibras de polipropileno. Obtiene placas compuestas que, con el mismo espesor de una placa de yeso laminado, 
almacenan 5 veces más de energía térmica (Oliver-Ramírez, 2009; Oliver Ramírez, García Santos, \& Neila González, 2011).

- En otro estudio como el de J. Aghazadeh, se desarrolla un modelo analítico en el que se refuerzan compuestos de yeso con fibras cortas de polipropileno y poliparafenileno tereftalamida (PPTA), consiguiendo una mejora significativa en la resistencia a flexión, muy importante para materiales de construcción en edificios de áreas de gran movimiento sísmico (Mohandesi, Sangghaleh, Nazari, \& Pourjavad, 2011).

- O. Gencel, también analiza la incorporación de fibras de polipropileno y vermiculita en compuestos de yeso, obteniendo mejoras en las propiedades físicas y mecánicas de los compuestos debido a las fibras y, mejoras en las propiedades térmicas debido a la vermiculita (Gencel et al., 2014).

- En la investigación de L. E. Tapia Batallas se analiza la fabricación de paneles de yeso con adición de piedra pómez y polipropileno en láminas y en fragmentos. Los resultados de los paneles con piedra pómez solamente, muestran una menor densidad y una menor resistencia a compresión que aumenta cuando se incorporan las láminas de polipropileno (Tapia Batallas, 2015).

- S. Gutiérrez González continuando sus estudios de yesos con residuos de espuma de poliuretano (apartado 1.1.3), refuerza los compuestos mencionados, con fibras de polipropileno. Obtiene una disminución de la densidad y una mejora de la resistencia térmica. Por el contrario, disminuyen las resistencias mecánicas, la dureza superficial y la capacidad de absorción de agua. La reacción al fuego confirmó la posibilidad de su empleo para la fabricación de placas de yeso laminado (Alameda et al., 2016).

- N. Flores Medina añade, además de fibras de polipropileno, adiciones de relleno de grafito isostático (IGF). En este estudio, se comprueba que, el aumento progresivo de la adición, aumenta las resistencias mecánicas, la densidad y la conductividad térmica y, por otro lado, reduce la porosidad y la capacidad de absorción de agua (Flores Medina \& Barbero Barrera, 2017).

En cuanto a estudios con otros polímeros O. I. Miranda Nieto analiza, en su tesis doctoral, la incorporación de esferas de polimetilmetacrilato (PMMA) en yesos compuestos, como mejora de la calidad de la vivienda económica. Las mezclas obtenidas presentan un valor de conductividad térmica bastante inferior al de las 
mezclas sin adición. Las propiedades mecánicas disminuyen pero dentro de los valores indicados en normativa (Miranda Nieto, 2012).

Otras investigaciones como la de A. M. Borreguero lo que incorpora son fibras de poliestireno en compuestos de yeso. Sus resultados muestran, respecto a compuestos de yeso sin fibra, una disminución de las resistencias mecánicas aunque dentro de los límites establecidos en normativa $\mathrm{y}$, una mejora de las propiedades térmicas (Borreguero, Serrano, Garrido, Rodríguez, \& Carmona, 2014).

Por último, también se han encontrado varios autores que analizan las cargas de polivinilo alcohol (PVA) en matrices de yeso:

- A. A. Khalil, utiliza distintas adiciones de residuos de cáscara de arroz sin quemar, escorias de alto horno, carbonato de calcio e incluso polímeros del tipo polivinilo alcohol (PVA). Todas las mezclas aumentan la porosidad y disminuyen la densidad. La resistencia a compresión aumenta con pequeñas dosis de adición pero disminuye al aumentar las cantidades (Khalil, Tawfik, Hegazy, \& El-Shahat, 2014).

- En otro estudio realizado por C. Zhu, se analiza la influencia de fibras de polivinilo alcohol (PVA) y polipropileno (PP) sobre las propiedades de compuestos de yeso. En los resultados obtenidos se observa que las fibras de PVA reducen considerablemente la trabajabilidad de las mezclas, aceleran el proceso de hidratación, aumentan la resistencia a flexión y la tenacidad, respecto a los compuestos con fibras de PP (Zhu et al., 2018).

\subsubsection{Adición de residuos poliméricos}

En cuanto a estudios que analizan la incorporación de residuos poliméricos cabe destacar los realizados por los siguientes autores con residuos de caucho:

- P. L. Mayor Lobo, estudia la posibilidad de fabricar losas de escayola con adición de polvo de caucho procedente de neumáticos fuera de uso. La densidad y la dureza Shore $\mathrm{C}$ que obtiene es menor en todas ellas respecto a losas sin adición. Disminuye la conductividad térmica y se mantiene la conductividad acústica pero, se mejora notablemente la capacidad de aislamiento frente a impacto. El módulo de elasticidad, la resistencia a flexión y la resistencia a compresión, disminuyen a medida que se incorpora mayor porcentaje de polvo (Mayor Lobo, Bustamante Montoro, Rangel, \& Hernández Olivares, 2008). 
- A. Jiménez Rivero, analiza la adición de residuos de caucho sintético procedente de coquillas aislantes de tuberías como parte de un material compuesto escayola-caucho. Los resultados analizados muestran disminución de propiedades mecánicas (flexión y compresión), buena compatibilidad entre el residuo y el conglomerante, menor densidad y ligereza (Jiménez Rivero, Guzmán Báez, García Navarro, \& González Cortina, 2011).

- La investigación de T. Abu-Lebdeh, se centra en analizar la conductividad térmica de este tipo de compuestos, yeso y residuos de caucho. En todas las mezclas, los resultados obtenidos de conductividad térmica mejoran respecto a las mezclas sin residuos independientemente del tamaño del grano (Abu-Lebdeh, Fini, \& Fadiel, 2014).

- También S. Herrero del Cura, en su tesis doctoral y posteriores investigaciones, estudia la influencia de la dosificación y granulometría de residuos de caucho en placas de yeso-caucho. Determina que a mayor cantidad y tamaño de caucho, menor es la trabajabilidad y homogeneidad del compuesto. En todas sus mezclas disminuye la densidad hasta poder considerarlas yesos aligerados. Comprueba la reducción de la dureza Shore C y de las resistencias a flexión y compresión, con una mejora de la tenacidad. Las propiedades térmicas y acústicas mejoran y la capacidad absorción de agua aumenta (Herrero del Cura, 2016; López-Zaldívar, Lozano-Díez, Herrero del Cura, Mayor-Lobo, \& Hernández-Olivares, 2017; Lozano-Díez, López-Zaldívar, Herrero del Cura, Mayor-Lobo, \& HernándezOlivares, 2019).

- Otros investigadores como T. A. Urzulin, que incorpora diferentes granulometrías de residuos de caucho en compuestos de yeso, también observan la disminución de las resistencias mecánicas en estos compuestos respecto a compuestos sin residuos, así como la reducción del diámetro de la consistencia de las pastas (Urzulin, Akasaki, \& Pinto, 2016).

También se han encontrado estudios que adicionan residuos poliméricos procedentes del "reciclaje domiciliario", destacando entre ellos el de J. A. Domínguez Lepe, que trata de reciclar envases de tetrabrik (polietileno PE), incorporándolos a una matriz de yeso, como alternativa al panel de yeso. Los resultados obtenidos muestran las siguientes características: la perforación del panel con tetrabrik no produce polvo, el hinchamiento y absorción son menores, la porosidad es constante, aumenta considerablemente la flexibilidad y presenta buenas resistencias a impacto y 
flexión, así como a la acción de elementos químicos como el detergente (Domínguez Lepe \& Guemez Pacheco, 2011).

Otros autores analizan el efecto de la incorporación de residuos de botellas de plástico (polietileno PET) en compuestos de yeso. Entre ellos:

- S. Alcón Calla, utiliza estos residuos de botellas de plástico en compuestos de yeso, como alternativa a morteros de cemento en juntas de tabiquería interior. Obtiene resistencias a compresión similares a la de los compuestos sin residuos, una adherencia muy por encima de lo indicado como mínimo en normativa y unos valores de inicio y fin de fraguado que también cumplen con las especificaciones de dicha normativa (Alcón Calla, Salcedo Quispe, Gallardo Tapia, \& Echazú Cortez, 2011).

- También F. J. H. T. V. Ramos, en su estudio añade residuos de botellas de plástico en matrices de yeso. En sus resultados se observa el efecto de retardante de llama que realiza el yeso respecto al polietileno incorporado en su matriz, así como el efecto impermeabilizante que realiza el polietileno respecto al yeso. La resistencia a compresión fue otra de las características ensayadas y, en este caso, disminuyó sensiblemente respecto a compuestos sin residuo (Ramos \& Mendes, 2014).

- Otra investigación como la de D. Mamani Delgado para su tesis doctoral, analiza las propiedades mecánicas del yeso frente a compuestos de yeso y materiales reciclados. Los materiales que utiliza como adición son sacos de cemento (celulosa), tapones de botellas de vino (corcho), cámara de neumáticos (caucho) y botellas de agua mineral (polietileno tereftalato PET). Tras una comparativa obtiene resultados positivos en cuanto a que todos los compuestos aumentan su resistencia a flexión, su resistencia a compresión y su dureza Brinell (Mamani Delgado, 2016).

- S. Erdem, desarrolla un análisis sobre compuestos de yeso reforzados con residuos de botellas de plástico en el que obtiene como resultados que es interesante aditivar polivinilo alcohol (PVA) para mejorar la adherencia entre las fibras y la matriz. De esta manera consigue mayores resistencias mecánicas, dureza superficial y módulo de elasticidad (Erdem \& Arioglu, 2017).

En otros estudios, la investigación se centra en el reciclaje de envases o embalajes de poliestireno (EPS): 
- A. Ahmed, estudia el uso de yeso reciclado "bassanita" con bandejas de plástico alimentario de desecho, como mejora del suelo. Utiliza este yeso como agente estabilizador para mejorar la resistencia a compresión y, las bandejas plásticas de desecho para mejorar la resistencia a tracción. La incorporación del residuo en formato tiras, aumenta las resistencias mecánicas y el valor del módulo secante lo que ayuda a reducir el aumento de poros y, por ende, la formación de lentes de hielo (Ahmed, Ugai, \& Kamei, 2011).

- Por otro lado, S. Sahin adiciona piedra pómez y residuos procedentes del embalaje de televisores y frigoríficos para la fabricación de bloques de yeso. Estos compuestos presentan menor densidad que los bloques de yeso sin adición, ven reducidas sus resistencias mecánicas pero dentro de los límites de normativa para usos no estructurales, aumentan su capacidad de aislamiento térmico y, presentan valores de absorción de agua menores que los bloques de hormigón (Sahin \& Karaman, 2012).

Por otro lado, se han considerado también los estudios de S. Gutiérrez González que incorporan polvo de poliamidas. Muestran en sus resultados que, a mayor porcentaje de poliamida, menores valores de densidad y resistencias mecánicas y, mayores valores de permeabilidad y resistencia térmica (Gutiérrez-González, Gadea, Rodríguez, Blanco-Varela, \& Calderón, 2012). Además, en otra de sus investigaciones, trata la influencia de estos residuos sobre las propiedades reológicas de las pastas de yeso obteniendo como resultado una disminución de la resistencia a esfuerzo cortante y de la viscosidad a medida que se incorpora residuo (Gutiérrez-González, Alonso, Gadea, Rodríguez, \& Calderón, 2013). 


\subsection{PATENTES DE YESO CON POLÍMEROS}

En referencia a las patentes encontradas que incorporan algún tipo de polímero en elementos de yeso, destacan las siguientes:

- "Producing hollow construction blocks - by mixing and homogenising materials such as cellulose fibres, barley flour, wheat and rice husks, esparto grass, plastics and resins".

Número de patente: ES2083312-A1 ; ES2083312-B1

Cesionario de patente: SANCHO GARCIA J (GARC-Individual)

Inventores: SANCHO GARCIA J.

Año: 1996

Se patenta el proceso por el que se obtienen bloques por moldeado o extrusión, que consiste en mezclar y homogeneizar diversos materiales, como papel o fibras de celulosa, harina de cebada, trigo y cáscaras de arroz, esparto, plásticos y resinas, con cemento, cal o yeso. Mejora la consistencia, la impermeabilidad y facilita el enlucido posterior.

- "Lightweight thermal insulating and sound-proofing energy-saving brick".

Número de patente: CN1120526-A

Cesionario de patente: ZHOU X

Inventores: Zhou X; Shen Q; He S.

Año: 1997

Se patentan ladrillos de aislamiento térmico y acústico formado por residuos de plásticos y cemento o yeso. Tienen mejoras en el peso y a prueba de fuego.

- "Environment protection type porcelain mirror gypsum material - includes waste plastics or plastic-rubber, gypsum, magnesium chloride, ferrous oxide and pigment in a specified weight ratio".

Número de patente: CN1202470-A

Cesionario de patente: SHEN J(SHEN-Individual)

Inventores: Shen J; Zhou X.

Año: 1999

La patente se refiere a un método para la fabricación de un compuesto de yeso con residuo plástico, cloruro de magnesio como agente de fermentación, óxido ferroso como agente solidificante y pigmento.

- "Yeso aligerado con corcho y su aplicación en paneles para construcción". 
Número de patente: P9902034 (solicitud)

Cesionario de patente: UNIVERSIDAD POLITÉCNICA DE MADRID

Inventor: Mercedes del Río M; Jaime Santacruz A; Francisco Hernández O.

Año: 1999

Se patenta un material a base de yeso aligerado con residuos de corcho natural o corcho artificial (poliestireno), reforzado con fibras de vidrio, superfluidificantes y retardadores del fraguado.

- "Laminated plate material has two plate materials having metallic plate, wood plate, plastic plate, expanded plastic plate, gypsum board and rubber plate".

Número de patente: JP2001301079-A

Cesionario de patente: NORDSON CORP(NORS-C)

Inventores: Yoshimura M; Yonemoto Y.

Año: 2002

La patente se refiere a un método para la fabricación de una placa laminada mediante placas de metal, madera, plástico yeso y goma. Cuando el laminado usado se elimina, cada material de placa puede ser recuperado.

- $\quad$ "Manufacturing method of extrusion-foamed compact used as plastic building material, involves mixing low density polyethylene, gypsum powder, wood meal and pellet containing thermoplastic elastomer and resin, and foaming agent".

Número de patente: JP2008006630-A; JP4173172-B2

Cesionario de patente: SEKISUI HOUSE KK(SEKL-C)

Inventores: Tsukiji M.

Año: 2008

La patente se refiere a un método para la fabricación de un material compacto de espuma por extrusión utilizando polietileno de baja densidad, yeso, polvo de madera, pellet con elastómero termoplástico, resina termoplástica y un agente espumante. Presentan una excelente retardancia a la llama.

- "Thermoplastic-composite composition useful for making marine piling, and railroad tie for making a railroad track comprises thermoplastic resin, and calcium sulfate composition with specific amount of calcium sulfate".

Número de patente: US2008179417-A1

Cesionario de patente: COMPOSITECH A LOUISIANA LLC LLC

Inventores: Bayer J. C; Gandolfo T. C. 
Año: 2008

Se patentan unos termoplásticos reciclados (poliolefinas) junto con un subproducto de fosfoyeso (sulfato de calcio) procedente del proceso húmedo de fertilización con fosfato. Se realizan diversos artículos como pilotes marinos y rieles de ferrocarril.

- "Preparation of calcium sulfate crystal whisker e.g. for use as insulation material, by mixing desulfurization gypsum and clear water, adding inhibitor, insulating modulated desulfurization gypsum suspension, filtering, washing and modifying".

Número de patente: CN101311337-A; CN101311337-B

Cesionario de patente: UNIV. NORTHEASTERN

Inventores: Shi P; Liu C; Jiang M.

Año: 2009

La patente se refiere a un método que reduce la producción de yeso mediante desulfuración de gases de combustión y flujo de proceso reducido, obteniendo un producto de alta compatibilidad con compuestos orgánicos de alto peso molecular, como resinas, cauchos y plásticos.

- "Composite plate for building formed by hot pressing a mixture of waste plastic including waste polypropylene plastic, waste polyethylene plastic, waste polystyrene plastic and waste PVC plastic, and industrial gypsum".

Número de patente: CN101429000-A; CN101429000-B

Cesionario de patente: UNIV. GUIZHOU

Inventores: Chen Q; Liu T; Yang G; Zeng G.

Año: 2009

Se patentan placas compuestas de plástico residual en polvo de menos de $30 \mathrm{~mm}$, mezcladas con yeso industrial que, calentadas a $180-240^{\circ} \mathrm{C}$ forman el producto final mediante moldeo, fusión o fundición a presión.

- "Method of disposing post-consumer plastic waste (PCPW), such as empty or used packaging formed from plastics, involves mixing PCPW in form of particles having specific size distribution, with substrate".

Número de patente: W02009087399-A2; W02009087399-A3; GB2468614A

Cesionario de patente: PLASTIC RAW MATERIALS LTD

Inventor: David J.

Año: 2009 
La patente se refiere a un método de eliminación de PCPW (envases vacíos o usados de plástico). Las partículas plásticas de desecho están en una forma en la que pueden agregarse a diversos sustratos para usos posteriores variados como cubrición de vertederos, campos de juego o mejorador del suelo en agricultura.

- "Procedimiento de obtención de yeso aligerado con residuos de poliuretano espumado".

Número de patente: P201001011 (solicitud); ES 2381726 B1

Cesionario de patente: UNIVERSIDAD DE BURGOS

Inventor: Calderón Carpintero V; Gadea Sainz J; Rodríguez Saiz A; Garabito López J; Gutiérrez González S; Campos de la Fuente P. L.

Año: 2013

Se patenta un compuesto de yeso aligerado con residuos industriales de espumas rígidas de poliuretano para su uso en construcción.

- "Procedimiento de obtención de yeso aligerado con residuo de poliamida en polvo".

Número de patente: P201100886 (solicitud); 2396096

Cesionario de patente: UNIVERSIDAD DE BURGOS

Inventor: Gutiérrez González S; Serna Avendaño S; Calderón Carpintero V;

Gadea Sainz J; Junco Petrement C. S; Rodríguez Saiz A; Alameda CuencaRomero L.

Año: 2013

Se patenta un compuesto de yeso aligerado fabricado a partir de sulfato cálcico dihidratado con diferentes sustituciones de yeso por poliamida en polvo reciclada.

- $\quad$ "Placa de yeso natural con fibras reforzadas de galces desiguales continuos en sus cuatro bordes".

Número de patente: E04B9/04; E04C2/04

Cesionario de patente: EL ALTERÓN, S.L.

Inventor: Miguel Requena A; Joaquín Requena A.

Año: 2014

La patente se refiere a un método de fabricación de placas de yeso con fibras de vidrio reforzadas de galces desiguales continuos en sus cuatro bordes con la finalidad de crear sistemas constructivos verticales y horizontales sin remate de juntas. 
- "Procedimiento de obtención de placas de yeso laminado aligeradas con residuo de espuma de poliuretano".

Número de patente: P201300464 (solicitud); ES 2522792 B1

Cesionario de patente: UNIVERSIDAD DE BURGOS

Inventor: Gadea Sainz J; Garabito López J; Calderón Carpintero V; Junco

Petrement C. S; Rodríguez Saiz A; Alameda Cuenca-Romero M. C; Gutiérrez González S.

Año: 2015

Se describe un procedimiento de obtención de placa de yeso laminada aligerada con residuo de espuma de poliuretano concebida para su utilización en la construcción, especialmente para su empleo en la realización de tabiquería interior.

- "Procedimiento de obtención de placas de yeso laminado aligeradas con residuo de poliamida en polvo".

Número de patente: P201300846 (solicitud); ES 2531461 B2

Cesionario de patente: UNIVERSIDAD DE BURGOS

Inventor: Alameda Cuenca-Romero L; Gutiérrez González S; Calderón Carpintero V; Rodríguez Saiz A; Junco Petrement C. S; Gadea Sainz J; Garabito López J.

Año: 2015

Se describe un procedimiento de obtención de placa de yeso laminada aligerada con residuos de poliamida en polvo, con la posible incorporación de aditivos y fibras, especialmente para su empleo en la realización de tabiquería interior y exterior.

- "Gypsum core aluminium -plastic".

Número de patente: CN205276747 (U)

Cesionario de patente: JIANGSU HAIDEMAN NEW MAT CO LTD

Inventor: Huang X.

Año: 2016

Se patenta un modelo de panel yeso-aluminio-plástico consistente en una conexión de tableros de yeso estriado y la cooperación de una placa de aluminio y un tablero de plástico. Se consigue aumentar la capacidad de carga y de resistencia a compresión.

- "Sandwich composite wall body prepared by utilizing industrial wastes and preparation method".

Número de patente: CN107555928 (A) 
Cesionario de patente: ZHONGSHAN CONSTRUCTION DEVELOPMENT RES INSTITUTE

Inventor: Sun Z; Zhu Ch; Sun L; Tan J; Li G.

Año: 2017

La patente se refiere a un método de preparación de un panel sándwich utilizando como núcleo, plástico espumado triturado de diámetro menor a 3 $\mathrm{mm}$, yeso desulfurizado, polialcohol vinílico y dodecilsulfato sódico.

- "Sound-absorbing board for buildings and preparation method thereof". Número de patente: CN107383842 (A)

Cesionario de patente: HEFEI OUSHIJIA ELECTROMECHANICAL EQUIPMENT CO LTD

Inventor: Kong L.

Año: 2017

La patente se refiere a un método de fabricación de una placa de absorción acústica para edificios. Se prepara mediante resina fenólica termoplástica, yeso, poliamidas, espuma de poliestireno, humo nano, polvo de ganga de carbón, fibra de colágeno, perlas de vidrio, cenizas volantes y otros compuestos químicos. Tiene buenas propiedades higrotérmicas, acústicas y frente a la humedad. Además, se comporta como retardante de llama, es flexible, liviana y no tóxica.

- "Prefabricado de yeso aligerado con residuos de espuma de poliuretano, su procedimiento de fabricación y utilización del mismo".

Número de patente: P201930054 (solicitud) Cesionario de patente: UNIVERSIDAD DE BURGOS

Inventor: Cuenca Romero L. A; Gutiérrez González S; Junco Petrement C S; Calderón Carpintero V; Rodríguez Saiz Ángel; Gadea Sainz Jesús; Gómez Rojo R.

Año: 2019

Se patenta un prefabricado de yeso aligerado con espuma de poliuretano procedente de residuos industriales, en forma de placa para techo suspendido, incluyendo el prefabricado de yeso una mezcla de yeso, agua y residuos de espuma de poliuretano de origen industrial, así como fibras de refuerzo y aditivos; procedimiento de fabricación del mismo, así como su utilización en forma de placa para la construcción. 


\subsection{CONSIDERACIONES PARCIALES DEL CAPÍTULO}

En este capítulo se han resumido algunos de los estudios encontrados sobre yeso con adición de residuos y adición de polímeros.

En general se puede decir que los compuestos de yeso que incorporan residuos de madera, presentan un buen comportamiento higrotérmico, una menor densidad, menores coeficientes de conductividad térmica y acústica $\mathrm{y}$, además, mejoran su capacidad de deformación. Por otro lado, aunque disminuyen sus resistencias mecánicas, estos valores cumplen normativa.

En el caso de la adición de residuos agrícolas, la densidad y la capacidad de absorción de agua por capilaridad, varían en más o en menos, en función del residuo adicionado. También disminuyen las resistencias mecánicas, excepto en el caso de las fibras de cáñamo y el aserrín y, en todas ellas se mejora el coeficiente de conductividad térmica.

Para las mezclas con residuos industriales, se consigue mejorar en densidad y conductividad térmica pero, empeora en la adherencia y en las resistencias mecánicas. La excepción la presenta la adición de grafito con resultados totalmente distintos al resto.

En cuanto a los residuos de construcción y demolición (RCD), varían mucho los resultados en función del residuo agregado:

- Residuos de aislamientos, EPS o XPS: se consiguen mejoras en densidad, conductividad térmica y absorción de agua. Empeoran las resistencias mecánicas.

- Residuos cerámicos: aumenta su dureza y adherencia; disminuyen sus resistencias mecánicas y su capacidad de absorción de agua.

- Residuos de yeso: se comportan con características similares al yeso sin residuo.

En cambio, las propiedades de los yesos con adición de plásticos (ya sean o no residuos) son bastante similares, en cuanto a que, en general, disminuye la capacidad de absorción por agua, el hinchamiento, el coeficiente de conductividad térmica, la porosidad, el módulo de Young así como las resistencias mecánicas. Es decir, se consiguen compuestos que, aunque de menor capacidad a compresión y flexión, son más impermeables, mejor aislantes térmicos y más flexibles.

En el análisis de la bibliografía, se observa que, en muchos de los estudios, se incorporan varios residuos, no solo uno, para mejorar en distintos aspectos del 
compuesto resultante, como la densidad, la conductividad térmica y acústica, capacidad de absorción de agua, capacidad de deformación, etc. Además, en algunas ocasiones, también se ha observado que es necesaria la aportación de aditivos que facilitan la trabajabilidad y cohesión de las mezclas.

En cuanto a las aplicaciones, no es una única aplicación, sino que son varias las resultantes de estas investigaciones: revestimientos interiores, paneles, tableros, bloques, juntas de mampostería, placas e, incluso mejoras del suelo.

El objetivo de las investigaciones analizadas no solo pasa por aportar en sostenibilidad a través de la reducción de residuos devolviéndolos al ciclo de vida y, minimización del uso de materia prima, sino también a través de la disminución de aporte de energía térmica que se traduce en menores emisiones de $\mathrm{CO}_{2}$.

Pues bien, a pesar de todos los trabajos encontrados donde los investigadores adicionan y analizan el comportamiento de todos estos residuos en matrices de yeso, no se han encontrado estudios en los que se incorporen cargas de residuos plásticos de cables. En este contexto, se entiende de gran importancia estudiar la viabilidad de utilizar residuos plásticos de cables en matrices de yeso para conseguir un nuevo ecoyeso como alternativa a los yesos tradicionales, analizar la afectación en sus propiedades físicas, químicas, mecánicas y térmicas y comprobar su impacto ambiental. 


\subsection{TRABAJOS CITADOS}

Abu-Lebdeh, T., Fini, E., \& Fadiel, A. (2014). Thermal conductivity of rubberized gypsum board. American Journal of Engineering and Applied Sciences, 7(1), 1222. https://doi.org/10.3844/ajeassp.2014.12.22

Ahmed, A., Ugai, K., \& Kamei, T. (2011). Investigation of recycled gypsum in conjunction with waste plastic trays for ground improvement. Construction and Building Materials, 25, 208-217. https://doi.org/10.1016/j.conbuildmat.2010.06.036

Alameda, L., Calderón, V., Gadea, J., \& Gutiérrez-González, S. (2015). Reciclado de placas de yeso laminado aligeradas con residuos de poliuretano. Anales de Edificación, 1(1), 33-39. https://doi.org/10.20868/ade.2015.3037

Alameda, L., Calderón, V., Junco, C., Rodríguez, Á., Gadea, J., \& Gutiérrez-González, S. (2016). Characterization of gypsum plasterboard with polyurethane foam waste reinforced with polypropylene fibers. Materiales de Construcción, 66(324), e100. https://doi.org/10.3989/mc.2016.06015

Alba Rodríguez, M. D., Marrero, M., Leiva Fernández, C., Montes, M. V., \& Vilches, L. (2012). Facade solutions using panels made of power plant byproducts. Informes de La Construcción, 64(526), 179-190. https://doi.org/10.3989/ic.10.042

Alcón Calla, S., Salcedo Quispe, F., Gallardo Tapia, V., \& Echazú Cortez, J. (2011). Mortero de yeso reforzado con fibra reciclada de botellas PET para su aplicación como junta en mampostería de ladrillo. Revista Investigación y Desarrollo, 6(6). https://doi.org/2078-7731

Amara, I., Mazioud, A., Boulaoued, I., \& Mhimid, A. (2017). Experimental study on thermal properties of bio-composite (gypsum plaster reinforced with palm tree fibers) for building insulation. International Journal of Heat and Technology, 35(3), 576-584. https://doi.org/10.18280/ijht.350314

Barriga Miño, C. R. (2017). Estudio de la conductividad térmica de residuos sólidos dentro de una matriz de yeso, provenientes del proceso de rebajado del cuero en la empresa Curtiduría Tungurahua S.A. (Proyecto Fin de Grado, Universidad Técnica de Ambato (Ecuador)).

http://repositorio.uta.edu.ec/jspui/handle/123456789/25258

Belayachi, N., Hoxha, D., \& Ismail, B. (2016). Impact of fiber treatment on the fire reaction and thermal degradation of building insulation straw composite. International Conference on Materials \& Energy, 544-549. https://doi.org/10.1016/j.egypro.2017.11.251

Bicer, A., \& Kar, F. (2017). Thermal and mechanical properties of gypsum plaster mixed with expanded polystyrene and tragacanth. Thermal Science and Engineering Progress, 1, 59-65. https://doi.org/10.1016/j.tsep.2017.02.008

Binici, H., \& Aksogan, O. (2017). Insulation material production form onion skin and 
peanut shell fibers, fly ash, pumice, perlite, barite, cement and gypsum. Materials Today Communications, 10, 14-24.

https://doi.org/10.1016/j.mtcomm.2016.09.004

Borreguero, A. M., Serrano, Á., Garrido, I., Rodríguez, J. F., \& Carmona, M. (2014). Polymeric-SiO 2 -PCMs for improving the thermal properties of gypsum applied in energy efficient buildings. Energy Conversion and Management, 87, 138-144. https://doi.org/10.1016/j.enconman.2014.07.027

Braiek, A., Karkri, M., Adili, A., Ibos, L., \& Ben Nasrallah, S. (2017). Estimation of the thermophysical properties of date palm fibers/gypsum composite for use as insulating materials in building. Energy and Buildings, 140, 268-279. https://doi.org/10.1016/j.enbuild.2017.02.001

Calderón, V., Rodríguez, Á., Horgnies, M., \& Gadea, J. (2013). Morteros de yeso fabricados con escorias de horno de cuchara. Workshop on Environmental Impact of Buildings Construction. Madrid (España)

Cherki, A., Remy, B., Khabbazi, A., Jannot, Y., \& Baillis, D. (2014). Experimental thermal properties characterization of insulating cork-gypsum composite. Construction and Building Materials, 54, 202-209.

https://doi.org/10.1016/j.conbuildmat.2013.12.076

de Moraes Rossetto, J. R., Santos Correia, L., Henrique Geraldo, R., \& Camarini, G. (2016). Gypsum plaster waste recycling: analysis of calcination time. Key Engineering Materials, 668, 312-321.

https://doi.org/10.4028/www.scientific.net/KEM.668.312

del Río Merino, M. (2005). Nuevas aplicaciones del corcho en el campo de la edificación. III Encuentro Eurocork. http://oa.upm.es/1896/

del Río Merino, M., Santa Cruz Astorqui, J., \& Villoria Sáez, P. (2018). Eco plaster mortars with addition of waste for high hardness coatings. Construction and Building Materials, 158, 649-656.

https://doi.org/10.1016/j.conbuildmat.2017.10.037

Deng, Y.-H., \& Furuno, T. (2001). Properties of gypsum particleboard reinforced with polypropylene fibers. Journal of Wood Science, 47(6), 445-450. https://doi.org/10.1007/BF00767896

Domínguez Lepe, J., \& Guemez Pacheco, D. (2011). Fabricación y evaluación de paneles aplicables a la industria de la construcción a partir del reciclaje de envases multicapa. Ingeniería, 14(3), 191-195. https://doi.org/1665-529-X

Erbs, A., Nagalli, A., de Carvalho, K. Q., Mymrin, V., Passig, F. H., \& Mazer, W. (2018). Properties of recycled gypsum from gypsum plasterboards and commercial gypsum throughout recycling cycles. Journal of Cleaner Production, 183, 13141322. https://doi.org/10.1016/j.jclepro.2018.02.189

Erdem, S., \& Arioglu, N. (2017). An analysis of the properties of recycled pet fibergypsum composites. A/Z ITU Journal of the Faculty of Architecture, 14(1), 91-101. https://doi.org/10.5505/itujfa.2017.70288 
Flores Medina, N., \& Barbero Barrera, M. del M. (2017). Mechanical and physical enhancement of gypsum composites through a synergic work of polypropylene fiber and recycled isostatic graphite filler. Construction and Building Materials, 131, 165-177. https://doi.org/10.1016/j.conbuildmat.2016.11.073

García Santos, A. (1988). Comportamiento mecánico de yeso reforzado con polímeros sintéticos (Tesis Doctoral, Universidad Politécnica de Madrid (España)). https://doi.org/oai:oa.upm.es:10747

García Santos, A. (2004). Caracterización de compuestos de escayola reforzados, en relación con el tipo de refuerzo y la relación A/Y. Informes de La Construcción, 56(493), 19-31. https://doi.org/10.3989/ic.2004.v56.i493.436

Gencel, O., del Coz Diaz, J. J., Sutcu, M., Koksal, F., Rabanal, F. P. A., Martinez-Barrera, G., \& Brostow, W. (2014). Properties of gypsum composites containing vermiculite and polypropylene fibers: Numerical and experimental results. Energy and Buildings, 70, 135-144. https://doi.org/10.1016/j.enbuild.2013.11.047

González Madariaga, F. J. (2008). Mezclas de residuos de poliestireno expandido (EPS) conglomerados con yeso o escayola para su uso en la construcción. Informes de La Construcción, 60(509), 35-43.

https://doi.org/10.3989/ic.2008.v60.i509.589

Gutiérrez-González, S., Alonso, M. M., Gadea, J., Rodríguez, Á., \& Calderón, V. (2013). Rheological behaviour of gypsum plaster pastes with polyamide powder wastes. Construction and Building Materials, 38, 407-412. https://doi.org/10.1016/j.conbuildmat.2012.08.034

Gutiérrez-González, S., Gadea, J., Rodríguez, Á., Blanco-Varela, M. T., \& Calderón, V. (2012). Compatibility between gypsum and polyamide powder waste to produce lightweight plaster with enhanced thermal properties. Construction and Building Materials, 34, 179-185. https://doi.org/10.1016/j.conbuildmat.2012.02.061

Gutiérrez González, S., Gadea, J., Rodríguez, Á., Junco, C., \& Calderón, V. (2012). Lightweight plaster materials with enhanced thermal properties made with polyurethane foam wastes. Construction and Building Materials, 28(1), 653-658. https://doi.org/10.1016/j.conbuildmat.2011.10.055

Haselein, C. R., Calegari, L., Alberti, L. F., Minello, A. L., da Silva, P. A., \& Pintos Figueredo, R. G. (2002). Manufacturing gypsum-bonded-particleboard with recycled paper and pine wood particle. Ciência Florestal, 12(1), 81-88. https://doi.org/10.5902/198050981703

Hernández Olivares, F., Zuñiga Suárez, A., Medina Alvarado, R., \& Burneo Valdivieso, X. (2015). Reuse of organic waste type in the development of ecoefficient and sustainable composites. Universidad de Sevilla (Ed.), II International congress on sustainable construction and ecoefficient solutions (pp. 297-309). https://doi.org/978-84-61739646

Herrero del Cura, S. (2016). Influencia de la dosificación y granulometría del caucho de neumático fuera de uso (NFU) y de las dimensiones físicas en las propiedades térmicas, acústicas y mecánicas de placas de mortero de yeso y caucho (Tesis 
Doctoral, Universidad Politécnica de Madrid (España)). https://doi.org/10.20868/UPM.thesis.43070

Iucolano, F., Liguori, B., Aprea, P., \& Caputo, D. (2018). Evaluation of bio-degummed hemp fibers as reinforcement in gypsum plaster. Composites Part B: Engineering, 138, 149-156. https://doi.org/10.1016/j.compositesb.2017.11.037

Jiménez Rivero, A., Guzmán Báez, A. de, García Navarro, J., \& González Cortina, M. (2011). Nuevos materiales de base yeso con incorporación de residuos de caucho: caracterización físico-mecánica. Actas de IX Jornadas Iberoamericanas de Materiales de Construcción, (1), 1-13. http://oa.upm.es/12206/

Khalil, A. A., Tawfik, A., Hegazy, A. A., \& El-Shahat, M. F. (2014). Effect of some waste additives on the physical and mechanical properties of gypsum plaster composites. Construction and Building Materials, 68, 580-586. https://doi.org/10.1016/j.conbuildmat.2014.06.081

Lakrafli, H., Tahiri, S., Albizane, A., \& El Otmani, M. E. (2012). Effect of wet blue chrome shaving and buffing dust of leather industry on the thermal conductivity of cement and plaster based materials. Construction and Building Materials, 30, 590-596. https://doi.org/10.1016/j.conbuildmat.2011.12.041

Leiva Aguilera, M. J. (2017). Escayola aditivada con residuos de cáscara de arroz (Tesis Doctoral, Universidad Politécnica de Madrid (España)).

https://doi.org/10.20868/UPM.thesis.54716

Liuzzi, S., Rubino, C., \& Stefanizzi, P. (2017). Use of clay and olive pruning waste for building materials with high hygrothermal performances. 72nd Conference of the Italian Thermal Machines Engineering Association, 234-241. https://doi.org/10.1016/j.egypro.2017.08.145

López-Zaldívar, Ó., Lozano-Díez, R., Herrero del Cura, S., Mayor-Lobo, P., \& Hernández-Olivares, F. (2017). Effects of water absorption on the microstructure of plaster with end-of-life tire rubber mortars. Construction and Building Materials, 150, 558-567. https://doi.org/10.1016/j.conbuildmat.2017.06.014

Lozano-Díez, R., López-Zaldívar, Ó., Herrero del Cura, S., Mayor-Lobo, P., \& Hernández-Olivares, F. (2019). Influencia de la incorporación de fibras de caucho procedente de neumáticos fuera de uso (NFU) en morteros de yeso. Estudio de las propiedades mecánicas, térmicas y acústicas. Dyna Ingeniería e Industria, 94, 460-464. https://doi.org/10.6036/9020

Mamani Delgado, D. (2016). Evaluación comparativa de las propiedades mecánicas entre el yeso y el yeso adicionado con materiales reciclados según la norma UNEEN 13279-2 para uso en la fabricación de placas de yeso (Proyecto Fin de Grado, Universidad Andina del Cusco (Perú)).

https://doi.org/repositorio.uandina.edu.pe/handle/UAC/699

Marrero, M., Martínez Escobar, L., Mercader Moyano, P., \& Leiva Fernández, C. (2013). Minimización del impacto ambiental en la ejecución de fachadas mediante el empleo de materiales reciclados. Informes de La Construcción, 65(529), 89-97. https://doi.org/10.3989/ic.11.034 
Mayor Lobo, P., Bustamante Montoro, R., Rangel, C., \& Hernández Olivares, F. (2008). Propiedades térmicas, acústicas y mecánicas de placas de mortero de yesocaucho. Instituto de Ciencias de la Construcción Eduardo Torroja (Ed.), Actas de II Jornadas de Investigación en Construcción. https://doi.org/oai:oa.upm.es:4611

Miranda Nieto, O. I. (2012). Mejora de la calidad de vivienda económica mediante el uso de polímeros y compuestos inorgánicos tradicionales para mejorar su aislamiento térmico (Proyecto Fin de Grado, Universidad Autónoma de Querétaro (México)). https://doi.org/handle/123456789/1847

Mohandesi, J. A., Sangghaleh, A., Nazari, A., \& Pourjavad, N. (2011). Analytical modeling of strength in randomly oriented PP and PPTA short fiber reinforced gypsum composites. Computational Materials Science, 50(5), 1619-1624. https://doi.org/10.1016/j.commatsci.2010.12.020

Morales-Conde, M. J., Rodríguez-Liñán, C., \& Pedreno Rojas, M. A. (2016). Physical and mechanical properties of wood-gypsum composites from demolition material in rehabilitation works. Construction and Building Materials, 114, 6-14. https://doi.org/10.1016/j.conbuildmat.2016.03.137

Morsy, M. S., Shebl, S. S., \& Saif, M. A. E. G. (2008). Development of perlite-gypsumslag-lime sludge-composite system for building application. Building Research Journal, 56(1), 49-58.

Musa, M. N., \& Abdul Aziz, M. F. (2016). Thermal conductivity for mixture of rice husk fiber and gypsum. Applied Mechanics and Materials, 819, 69-73. https://doi.org/10.4028/www.scientific.net/AMM.819.69

Nazerian, M., \& Kamyab, M. (2013). Gypsum-bonded particleboard manufactured from agricultural based material. Forest Science and Practice, 15(4), 325-331. https://doi.org/10.1007/s11632-013-0420-6

Oliveira, C. E. A., Oliveira, M., Oliveira, J. L., \& Damasceno, F. A. (2016). Gypsum-based composites with addition of woody endocarp of Barueiro nut residue and sawdust. ASABE Annual International Meeting. https://doi.org/10.13031/aim.20162461357

Oliver-Ramírez, A. (2009). Integración de materiales de cambio de fase en placas de yeso reforzadas con fibras de polipropileno. Aplicación a sistemas de refrigeración y calefacción pasivos para almacenamiento de calor latente en edificios (Tesis Doctoral, Universidad Politécnica de Madrid (España)).

https://doi.org/oa.upm.es/2910

Oliver Ramírez, A., García Santos, A., \& Neila González, F. J. (2011). Caracterización física y mecánica de placas de yeso con materiales de cambio de fase incorporados para almacenamiento de energía térmica mediante calor latente. Materiales de Construcción, 61(303), 465-484. https://doi.org/0465-2746

Pinheiro, S. M. M., \& Camarini, G. (2015). Characteristics of gypsum recycling in different cycles. International Journal of Engineering and Technology, 7(3), 215218. https://doi.org/10.7763/IJET.2015.V7.794 
Quinchía Figueroa, A. M., Valencia García, M. F., \& Giraldo Orozco, J. M. (2007). Uso de lodos provenientes de la industria papelera en la elaboración de paneles prefabricados para la construcción. Revista EIA, 8, 9-19. https://doi.org/24630950

Ramos, F., \& Mendes, L. (2014). Recycled high-density polyethylene/gypsum composites: evaluation of the microscopic, thermal, flammability, and mechanical properties. Green Chemistry Letters and Reviews, 7(2), 199-208. https://doi.org/10.1080/17518253.2014.924591

Rodríguez, A., Gutiérrez-González, S., Horgnies, M., \& Calderón, V. (2013). Design and properties of plaster mortars manufactured with ladle furnace slag. Materials \& Design, 52, 1980-2015. https://doi.org/10.1016/j.matdes.2013.06.041

Rodríguez Orejón, A., del Río Merino, M., \& Fernández Martínez, F. (2014). Characterization mixtures of thick gypsum with addition of treated waste from laminated plasterboards. Materiales de Construcción, 64(314). https://doi.org/10.3989/mc.2014.03413

Romaniega Piñeiro, S., del Río Merino, M., \& Pérez García, C. (2015). New plaster composite with mineral wool fibres from CDW recycling. Advances in Materials Science and Engineering, 9. https://doi.org/10.1155/2015/854192

Sackett, C. (2017). Augustine Sackett. Retrieved from https://sackettfamily.info

Sahin, S., \& Karaman, S. (2012). The Properties of Expanded Polystyrene - Pumice Gypsum Blocks as a Building Material. Journal of Tekirdag Agricultural Faculty, 9(1), 51-56. https://doi.org/1302-7050

San-Antonio-González, A., Del Río-Merino, M., Viñas-Arrebola, C., \& Villoria-Sáez, P. (2015). Lightweight material made with gypsum and extruded polystyrene waste with enhanced thermal behaviour. Construction and Building Materials, 93, 57-63. https://doi.org/10.1016/j.conbuildmat.2015.05.040

San Antonio González, A., del Río Merino, M., Viñas Arrebola, C., \& Villoria Sáez, P. (2016). Lightweight material made with gypsum and EPS waste with enhanced mechanical strength. Journal of Materials in Civil Engineering, 28(2). https://doi.org/10.1061/(ASCE)MT.1943-5533.0001382

Santos Jiménez, R., del Río Merino, M., \& González Cortina, M. (2013). Análisis de la viabilidad del yeso con adiciones de residuo cerámico para la aplicación en edificación. Jornadas Internacionales de Investigación en Construcción. Vivienda: Pasado, Presente y Futuro. Resúmenes y Actas. https://doi.org/9788472924215

Tapia Batallas, L. E. (2015). Diseño de una planta para la fabricación de paneles de yeso con la adición de piedra pómez y polipropileno como materiales alternativos (Proyecto Fin de Grado, Escuela Politécnica Nacional de Quito (Ecuador)). https://doi.org/http://bibdigital.epn.edu.ec/handle/15000/11108

Tasán Cruz, D. M. (2011). Caracterización de morteros de yeso reforzados con fibras recuperadas de eslingas textiles de un solo uso (Trabajo Fin de Máster, Universidad Politécnica de Madrid (España)). http://oa.upm.es/10836 
Tayibi, H., Pérez, C., López, F. A., \& López Delgado, A. (2005). Evolución de las propiedades mecánicas de un residuo de la metalurgia secundaria del aluminio estabilizado con yeso. Revista de Metalurgia, 41(4).

https://doi.org/10.3989/revmetalm.2005.v41.i4.215

Urzulin, T. A., Akasaki, J. L., \& Pinto, N. A. (2016). Estudo de compósitos de gesso incorporados com duas diferentes granulometrias de borracha de pneus. Revista Científica ANAP Brasil, 9(16). https://doi.org/10.17271/1984324091620161439

Vasconcelos, G., Lourenco, P. B., Camoes, A., Martins, A., \& Cunha, S. (2015). Evaluation of the performance of recycled textile fibres in the mechanical behaviour of a gypsum and cork composite material. Cement and Concrete Composites, 58, 2939. https://doi.org/10.1016/j.cemconcomp.2015.01.001

Villanueva Domínguez, L. de. (2004). Evolución histórica de la construcción con yeso. Informes de La Construcción, 56(493), 5-12. https://doi.org/0020-0883

Villoria Sáez, P., Santa Cruz Astorqui, J., \& del Río Merino, M. (2016). Conglomerados sostenibles realizados con residuos de construcción generados en obras de rehabilitación energética. Universidad de los Andes (Ed.), Proceedings of the VII Elagec. Bogotá (Colombia)

Zhu, C., Zhang, J., Peng, J., Cao, W., \& Liu, J. (2018). Physical and mechanical properties of gypsum-based composites reinforced with PVA and PP fibers. Construction and Building Materials, 163, 695-705.

https://doi.org/10.1016/j.conbuildmat.2017.12.168 
CAPITULO 2: ESTADO DE LA CUESTION 


\section{JuSTIFICACIÓN DEL TRABAJO}




\section{Justificación del Trabajo}

Atendiendo a los antecedentes expuestos y a las noticias que nos llegan constantemente no solo del consumo masivo de recursos naturales, sino también de la alarmante generación de residuos plásticos en la actualidad, resulta fundamental la investigación en este campo de cara a la consecución de un desarrollo sostenible. Con esta tesis se pretende contribuir desde la construcción sostenible a través de los siguientes aspectos:

Preservación del medio ambiente: mediante un uso más racional de los recursos naturales garantizando su existencia para las futuras generaciones. En este sentido, en esta investigación se prima la reducción del uso de agua y de la piedra aljez. Con ello, indirectamente, se contribuye también a la conservación del entorno natural, lo que supone mantener el valor paisajístico de la zona, su flora y su fauna.

Reutilización de residuos: priorizando la solución de reutilización de residuos frente a su eliminación tal y como se indica en la actual Directiva Marco de Residuos. Con esta investigación se desecha la idea de incineración y se valoriza el residuo plástico de cables, aplicando los criterios de economía 
circular y convirtiéndolo nuevamente en un recurso, minimizando su acumulación en vertederos o empresas de reciclaje.

Búsqueda de nuevas aplicaciones: la dificultad de reciclaje que presenta el plástico de cables en desuso debido en gran medida a su gran heterogeneidad, hace que sean escasos los estudios sobre ello. La reutilización del mismo, sin considerar ningún otro proceso intermedio que no sea el transporte, desde la empresa de reciclaje de cables a la empresa de fabricación de los productos de yeso, supone un valor añadido en la investigación de innovación de materiales.

Ahorro de consumo de energía en los edificios y reducción de sus emisiones: con la mejora de las condiciones térmicas de los edificios al utilizar materiales que se comportan mejor como aislantes térmicos. Con esta investigación se propone la utilización de un material en la envolvente del edificio, con menor coeficiente de conductividad térmica. Sin olvidar que la menor necesidad de energía en el edificio significa, además, una reducción del uso de los recursos naturales utilizados en la propia generación de la energía y en el transporte de la misma hasta el punto de consumo. 


\section{4. Овjetivos}


CAP 


\section{4. ОBjetivos}

El objetivo principal de esta tesis doctoral es el estudio de nuevos compuestos de yeso y residuos plásticos de cable de menor impacto ambiental. En la investigación se desarrolla tanto el análisis detallado de las propiedades físicas, químicas, mecánicas y térmicas de dichos compuestos, como su propuesta de aplicaciones, teniendo en cuenta criterios de economía circular.

Para alcanzar este objetivo se proponen los siguientes objetivos específicos:

OBJETIVO 1: Caracterización de la materia prima utilizada: yeso, escayola y residuo plástico procedente del reciclaje de cables (denominado PR en esta investigación).

OBJETIVO 2: Análisis de la viabilidad de compuestos de yeso con PR.

- Estudio de investigaciones previas de compuestos de yesos con agregados poliméricos para determinar las variables a analizar.

- Determinación de la cantidad de residuo más adecuada para incorporar en la matriz de yeso.

○ Evaluación del cumplimiento de los compuestos, en estado fresco, de las prescripciones de la normativa en vigor. 
OBJETIVO 3: Caracterización de los compuestos de yeso con PR.

- Determinación de las propiedades mecánicas y físicas de los compuestos de yeso con residuo plástico de cables, en estado endurecido, y su cumplimiento con los mínimos exigidos en normativa vigente.

OBJETIVO 4: Propuestas de aplicaciones para los compuestos de yeso con PR.

- Selección de los compuestos más apropiados para la aplicación en enlucidos, prefabricados de techos, tabiques y trasdosados.

- Análisis del comportamiento frente al agua, frente al fuego y propiedades térmicas de los compuestos seleccionados.

OBJETIVO 5: Estudio del impacto ambiental.

- Análisis del uso de recursos naturales, piedra de aljez y agua.

- Análisis de la minimización del PR. Criterio de economía circular. 
5.1 CARACTERIZACIÓN DE LA MATERIA PRIMA UTILIZADA (OB. 1)

5.2 COMPUESTOS CON RESIDUOS PLÁSTICOS DE CABLES (OB. 2)

5.3 CARACTERIZACIÓN DE LOS COMPUESTOS DE YESO Y PR (OB.3)

5.4 APLICACIONES PARA COMPUESTOS SELECCIONADOS DE YESO Y PR (OB. 4)

5.5 ESTUDIO DEL IMPACTO AMBIENTAL (OB. 5)

5.6 TRABAJOS CITADOS 


\section{Metodología}

En base a los objetivos específicos planteados se describe la metodología llevada a cabo, que corresponde con el desarrollo de la investigación:

OBJETIV0 1: Caracterización de la materia prima utilizada. Para conseguir este objetivo se determinan la composición y propiedades de los materiales utilizados (yeso, escayola y residuo plástico de cables) mediante:

- Fase I del plan experimental, descrita en el apartado 5.1 .2 "Caracterización de la materia prima”.

OBJETIVO 2: Análisis de la viabilidad de compuestos de yeso con PR. Para ello se determina la cantidad máxima de residuo a incorporar en las mezclas, se evalúa la adaptación de los compuestos, en estado fresco, a las prescripciones de la normativa vigente $y$, finalmente, se plantea un diseño de experimentos. Se realizan, por tanto, los siguientes pasos:

- Búsqueda bibliográfica (ver Cap. 2).

- Fase II del plan experimental, descrita en el apartado 5.2 .2 "Compuestos con residuos plásticos de cables".

- Diseño de experimentos (Apartado 5.2.3). 
OBIETIVO 3: Caracterización de los compuestos de yeso con PR. Para alcanzar este objetivo se analizan las propiedades mecánicas y físicas de los compuestos, en estado endurecido, y su cumplimiento con los mínimos exigidos en normativa vigente, mediante:

- Fase III del plan experimental, descrita en el apartado 5.3 .1 "Caracterización de los compuestos de yeso con PR".

OBJETIV0 4: Propuesta de aplicaciones para los compuestos obtenidos mediante:

- Selección de los compuestos más adecuados para las distintas aplicaciones, detallado en el apartado 5.4.1.

- Fase IV del plan experimental, descrita en el apartado 5.4 .2 "Propiedades de los compuestos seleccionados de yeso con PR".

OBJETIVO 5: Estudio del impacto ambiental, a través de:

- Análisis de la disminución del uso de recursos naturales descrito en el apartado 5.5.1 "Uso de los recursos naturales".

- Análisis de la minimización de los residuos plásticos de cables a través del criterio de economía circular, detallado en el apartado 5.5.2 "Minimización del PR". 


\subsection{CARACTERIZACIÓN DE LA MATERIA PRIMA (Objetivo 1)}

En la Fase I del Plan Experimental se realiza la caracterización física de la materia prima a través de los siguientes ensayos:

- Determinación de la densidad de empaquetamiento o de Bulk. UNE 102042 "Yesos y escayolas de construcción. Otros métodos de ensayo".

- Determinación de la densidad real mediante picnometría de helio.

- Determinación del contenido de humedad de la materia prima. UNE-EN 12880 "Caracterización de lodos. Determinación de la humedad y del contenido en materia seca".

- Granulometría del residuo plástico de cables. UNE-EN 933-1 "Ensayos para determinar las propiedades geométricas de los áridos. Método del tamizado".

Y la caracterización mineralógica y química mediante:

- Análisis termogravimétrico.

- Difracción de rayos X.

- Análisis elemental.

\subsubsection{Materiales utilizados}

Los materiales utilizados para la elaboración de los ensayos: yeso, escayola y residuo plástico de cables, se describen en este apartado.

\subsubsection{Yeso}

Se ha utilizado el yeso Iberplast de Placo, tanto para los ensayos realizados en la Universidad Politécnica de Madrid, como para los realizados en la Bialystok University of Technology (Polonia).

El yeso Iberplast, es un producto de la marca Placo de granulometría gruesa y fraguado rápido (Figura 5.1). Por su origen, se le designa como tipo B1 según la denominación europea. Tiene la marca $\mathrm{N}$ de AENOR y el certificado CE según UNE EN 13279 "Yesos de construcción y conglomerantes a base de yeso para la construcción" (UNE-EN 13279-1:2009, 2009). Procede de la factoría de San Martín de la Vega, Madrid (España). 
Se utiliza para trabajos de albañilería en general, cierre de pequeños huecos y recibido de elementos auxiliares como reglas, marcos, cajas, etc. Sus características técnicas son las detalladas en la Tabla 5.1.

Tabla 5.1. Características técnicas Yeso Iberplast - Placo

Características técnicas

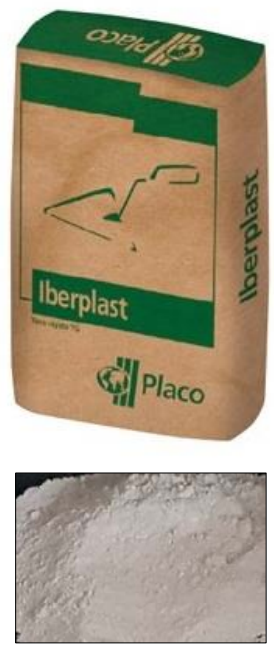

Figura 5.1. Yeso Iberplast - Placo

\begin{tabular}{lc} 
& Vega \\
\hline Índice de pureza & $>75 \%$ \\
Resistencia mecánica a flexión & $>2,0 \mathrm{~N} / \mathrm{mm}^{2}$ \\
Resistencia mecánica a & $>2,0 \mathrm{~N} / \mathrm{mm}^{2}$ \\
compresión & $>6$ \\
PH & $0-2 \mathrm{~mm}$ \\
Granulometría & $1,0-1,2$ litros $/ \mathrm{Kg}$ \\
Relación A/Y & $0,30 \mathrm{~W} / \mathrm{mK}$ \\
Coeficiente de conductividad & 6 \\
térmica & $\geq 45$ \\
Difusión al vapor de agua & Tradicional: ladrillo cerámico, \\
Dureza superficial Shore C & hormigón y bloque picón \\
Tipo de soporte recomendado & $>0,1 \mathrm{~N} / \mathrm{mm}^{2}$ \\
Adherencia & $12-14$ minutos \\
Tiempo de empleo & $5-40^{\circ} \mathrm{C}$ \\
Temperatura de aplicación & Euroclase A1 \\
recomendada &
\end{tabular}

\subsubsection{Escayola}

La escayola E-35 Iberyola, es un producto de la marca Placo de granulometría muy fina. De las dos versiones que se fabrican, se ha optado por la de fraguado rápido (Figura 5.2). Por su origen, se le designa como tipo A según la denominación europea. Tiene la marca N de AENOR y el certificado CE según UNE EN 13279 "Yesos de construcción y conglomerantes a base de yeso para la construcción" (UNE-EN 132791:2009, 2009). Procede de la factoría de San Martín de la Vega, Madrid (España).

Se utiliza en cadenas de producción de paneles, placas o molduras. Sus características técnicas son las detalladas en la Tabla 5.2. 
Tabla 5.2. Características técnicas Escayola Iberyola - Placo

\section{Características técnicas}
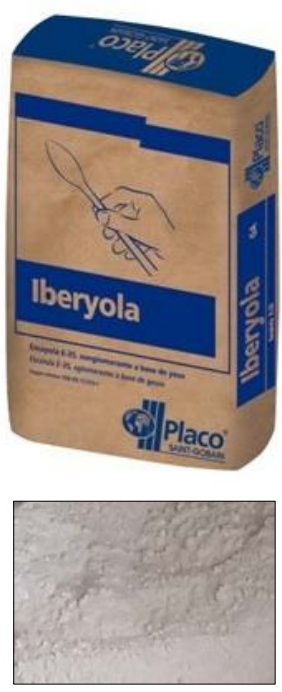

Figura 5.2. Escayola Iberyola - Placo
Índice de pureza

Resistencia mecánica a flexión

Resistencia mecánica a

compresión

$\mathrm{PH}$

Granulometría

Relación A/Y

Coeficiente de conductividad térmica

Difusión al vapor de agua

Dureza superficial Shore C

Tipo de soporte recomendado

Adherencia

Tiempo de empleo

Temperatura de aplicación recomendada

Reacción al fuego

\section{Placo}

Factoría de San Martín de la

Vega

$>90 \%$

$$
>3,0 \mathrm{~N} / \mathrm{mm} 2
$$

No indicada

$$
\begin{aligned}
>6 \\
0-0,2 \mathrm{~mm}
\end{aligned}
$$

$0,7-0,8$ litros/Kg

$0,30 \mathrm{~W} / \mathrm{mK}$

6

No indicada

No indicado

No indicada

15-22 minutos

$5-40^{\circ} \mathrm{C}$

Euroclase A1

\subsubsection{Agua}

El agua utilizada procede del Canal de Isabel II de Madrid y cumple con las características técnicas establecidas en la normativa UNE EN 13279-2 (UNE-EN 13279-2:2014, 2014). Su composición se muestra en la Tabla 5.3. 
Tabla 5.3. Composición química del agua utilizada en los ensayos

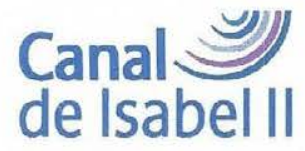

\begin{abstract}
Características Medias del Agua de Consumo en el Sistema de Distribución (Intervalo del 95\% de las muestras)
\end{abstract} AÑO: 2016

\begin{tabular}{|c|c|c|c|c|c|}
\hline $\begin{array}{l}\text { PARAMETROS } \\
\text { ORGANOLÉPTICOS }\end{array}$ & VALOR & V.P* & $\begin{array}{l}\text { PARAMETROS } \\
\text { FísICO-QUímICOS (Cont.) }\end{array}$ & VALOR & $\underline{\text { V.P* }}$ \\
\hline & & & Fluoruro (mg/L) & $<0,150$ & 1,5 \\
\hline Olor/Sabor $\left(\right.$ ID a $25^{\circ} \mathrm{C}$ ) & $0-1$ & 3 & Cianuro $(\mu \mathrm{g} / \mathrm{L})$ & $<1,5$ & 50 \\
\hline Color (mg Pt-Co/L) & $0-5$ & 15 & Aluminio $(\mu \mathrm{g} / \mathrm{L})$ & $10-150$ & 200 \\
\hline \multirow[t]{2}{*}{ Turbidez (U.N.F.) } & $<1$ & 5 & Hierro $(\mu g / L)$ & $<70$ & 200 \\
\hline & & & Manganeso $(\mu \mathrm{g} / \mathrm{L})$ & $<20$ & 50 \\
\hline PARÁMETROS & & & Boro $(\mathrm{mg} / \mathrm{L})$ & $<0,050$ & 1,0 \\
\hline \multirow[t]{2}{*}{ MICROBIOLÓGICOS } & & & Cobre $(\mathrm{mg} / \mathrm{L})$ & $<0,050$ & 2,0 \\
\hline & & & Antimonio $(\mu \mathrm{g} / \mathrm{L})$ & $<2,5$ & 5,0 \\
\hline Aerobios $22^{\circ} \mathrm{C}(\mathrm{UFC} / \mathrm{ml})$ & $<50$ & - & Arsénico $(\mu \mathrm{g} / \mathrm{L})$ & $<2,5$ & 10,0 \\
\hline Bacterias coliformes (UFC/100 ml) & 0 & 0 & Cadmio $(\mu \mathrm{g} / \mathrm{L})$ & $<2,5$ & 5,0 \\
\hline Escherichia coli (UFC/100 ml) & 0 & 0 & Cromo $(\mu \mathrm{g} / \mathrm{L})$ & $<2,5$ & 50 \\
\hline \multirow{3}{*}{$\begin{array}{l}\text { Enterococos (UFC/100 ml) } \\
\text { Clostridium perfringens (UFC/100 } \\
\mathrm{ml} \text { ) }\end{array}$} & 0 & 0 & Níquel ( $\mu \mathrm{g} / \mathrm{L})$ & $<2,5$ & 20 \\
\hline & 0 & 0 & Plomo $(\mu g / L)$ & $<2,5$ & 10 \\
\hline & & & Selenio $(\mu g / L)$ & $<2,5$ & 10 \\
\hline \multirow{3}{*}{$\begin{array}{l}\text { PARÁMETROS } \\
\text { FISICO-QUIMICOS }\end{array}$} & & & Mercurio $(\mu g / L)$ & $<0,1$ & 1,0 \\
\hline & & & Benzo $(\square \alpha)$ pireno $(\mu \mathrm{g} / \mathrm{L})$ & $<0,002$ & 0,010 \\
\hline & & & H.A.P. $\quad(\mu g / L)$ & $<0,010$ & 0,10 \\
\hline $\mathrm{pH}$ (unidades) & $6,6-8,5$ & $6,5-9,5$ & Aldrín $(\mu \mathrm{g} / \mathrm{L})$ & $<0,01$ & 0,03 \\
\hline Conductividad $\left(\mu \mathrm{S} / \mathrm{cm} 20^{\circ} \mathrm{C}\right)$ & $75-250$ & 2.500 & Dieldrin $(\mu \mathrm{g} / \mathrm{L})$ & $<0,01$ & 0,03 \\
\hline Amonio (mg/L) & $0,20-0,50$ & 0,50 & Heptacloro $(\mu \mathrm{g} / \mathrm{L})$ & $<0,01$ & 0,03 \\
\hline Nitratos (mg/L) & $0,5-5$ & 50 & Heptacloro epóxido ( $\mu \mathrm{g} / \mathrm{L})$ & $<0,01$ & 0,03 \\
\hline Nitritos (mg/L) & $<0,100$ & 0,500 & Total Plaguicidas $(\mu \mathrm{g} / \mathrm{L})$ & $<0,05$ & 0,5 \\
\hline Cloro libre residual (mg/L) & $<0,15$ & 1,0 & Trihalometanos $(\mu \mathrm{g} / \mathrm{L})$ & $5-80$ & 150 \\
\hline Cloro combinado residual ( $\mathrm{mg} / \mathrm{L}$ ) & $0,3-2,0$ & 2,0 & Bromato $(\mu \mathrm{g} / \mathrm{L})$ & $<5,0$ & 25 \\
\hline C.O.T. (mg/L) & $1,0-2,5$ & - & Benceno $(\mu \mathrm{g} / \mathrm{L})$ & $<0,3$ & 1,0 \\
\hline Cloruros (mg/L) & $10-40$ & 250 & 1,2,Dicloroetano $(\mu \mathrm{g} / \mathrm{L})$ & $<0,3$ & 3,0 \\
\hline Sulfatos $(\mathrm{mg} / \mathrm{L})$ & $5,0-30$ & 250 & $\begin{array}{l}\text { Tricloroeteno+Tetracloroeteno } \\
(\mu \mathrm{g} / \mathrm{L})\end{array}$ & $<0,5$ & 10 \\
\hline Calcio (mg/L) & $5,0-25$ & - & Microcistina $(\mu \mathrm{g} / \mathrm{L})$ & $<0,2$ & 1 \\
\hline Magnesio $(\mathrm{mg} / \mathrm{L})$ & $1,0-5,0$ & - & & & \\
\hline Sodio (mg/L) & $1,0-20$ & 200 & RADIACTIVIDAD & & \\
\hline Potasio (mg/L) & $0,5-2,0$ & - & & & \\
\hline \multirow[t]{4}{*}{ Dureza total $\left(\mathrm{mg} / \mathrm{L} \mathrm{CO}{ }_{3} \mathrm{Ca}\right)$} & $10-80$ & - & Actividad $\alpha$ total $(\mathrm{Bq} / \mathrm{L})$ & $<0,05$ & 0,1 \\
\hline & & & Actividad $\beta$ resto $(\mathrm{Bq} / \mathrm{L})$ & $<0,06$ & 1 \\
\hline & & & Tritio $(B q / L)$ & $<20$ & 100 \\
\hline & & & Dosis indicativa total (mSv/año) & $<0,1$ & 0,1 \\
\hline
\end{tabular}

- Valor Paramétrico (establecido en el R.D. 140/2003 de 7 de Febrero).

Temperatura media del agua en los diferentes meses del año

\begin{tabular}{|c|c|c|c|c|c|c|c|c|c|c|c|c|}
\hline $\mathbf{E}$ & $\mathbf{F}$ & $\mathbf{M}$ & $\mathbf{A b}$ & $\mathbf{M y}$ & Jn & JI & Ag & S & O & N & D & \\
\hline 9,8 & 9,5 & 9,3 & 10,9 & 12,7 & 15,0 & 16,9 & 17,8 & 17,7 & 15,5 & 12,5 & 10,8 & ${ }^{\circ} \mathrm{C}$ \\
\hline
\end{tabular}




\subsubsection{Residuo plástico de cables}

El residuo plástico de cables empleado, ha sido proporcionado por una de las empresas de reciclaje del Grupo LYRSA, concretamente LYRSA Álava, dedicada al reciclaje de chatarras férricas y metales no férricos, tras el proceso de reciclaje al que se someten los cables para la recuperación del metal del hilo conductor (Foto 5.1). Queda convertido en granza de tamaño máximo 3mm (previo paso por un tamiz) y se almacena en grandes contenedores al aire libre a la espera de ser transportado por gestor autorizado.

Esta granza, PR, está constituida por una gran variedad de plásticos termoestables y termoplásticos cuya selección y clasificación supondría una tarea costosa y prácticamente imposible de realizar. Debido a este inconveniente, finalmente solo un $10 \%$ es reciclada (en el mejor de los casos), siendo el 90\% restante incinerado (dato proporcionado por Lyrsa Álava).

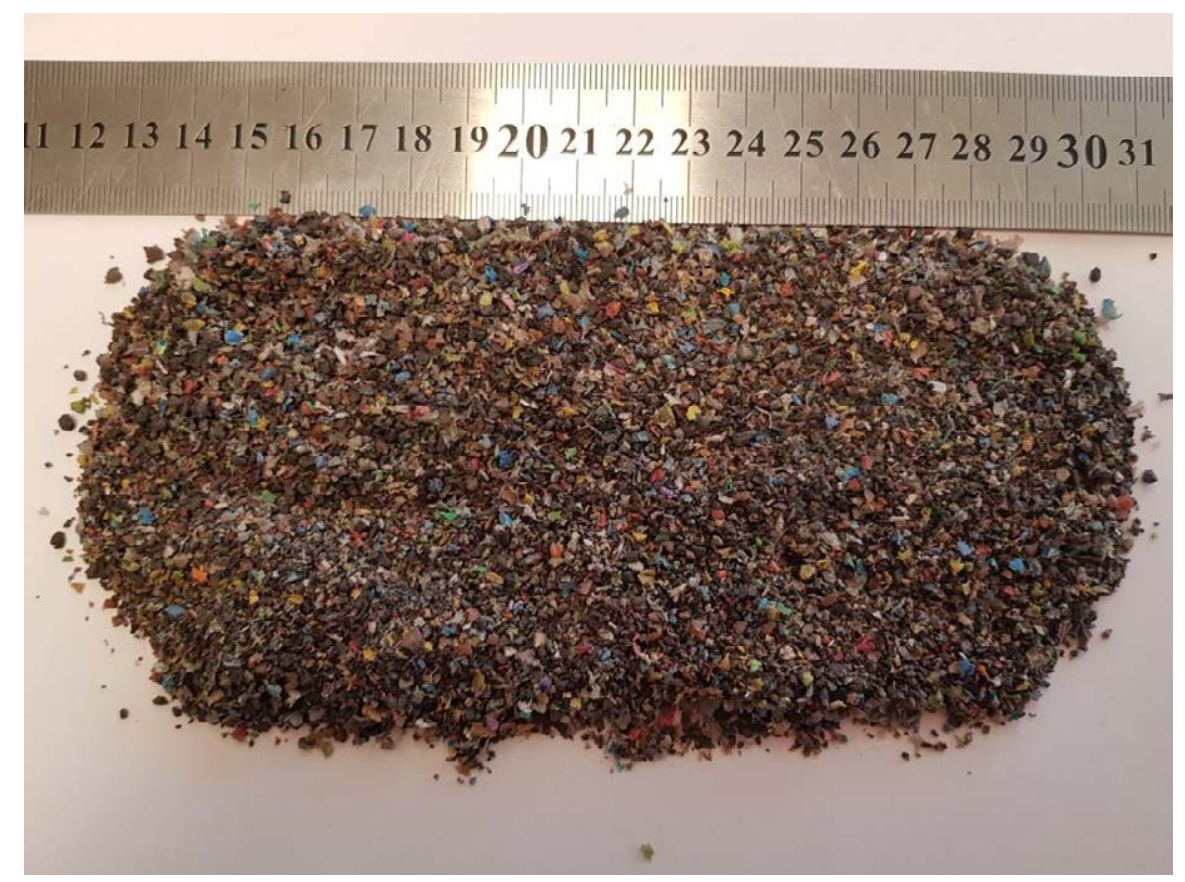

Foto 5.1. Residuo plástico de cables - Granza procedente de LYRSA Álava

\subsubsection{Fase I del plan experimental: Caracterización de la materia prima}

\subsubsection{Ensayos físicos de la materia prima}

Los ensayos para la caracterización física de la materia prima se describen en este apartado. 


\subsection{Determinación de la densidad de empaquetamiento o de Bulk}

Se ha obtenido la densidad de empaquetamiento o de Bulk del yeso, escayola y PR mediante el ensayo del Método de la masa hidrostática según norma UNE 102042 (UNE 102042, 2014), realizado en el Laboratorio de Análisis Químico de la Escuela Técnica Superior de Ingeniería y Diseño Industrial de la Universidad Politécnica de Madrid.

La densidad de empaquetamiento, también denominada densidad bulk, incluye los poros y los espacios interparticulares. Se determina pesando el contenido de una probeta graduada (Foto 5.2). En este estudio se empleó una probeta graduada de 50 $\mathrm{cm}^{3}$ para la determinación de la densidad bulk.
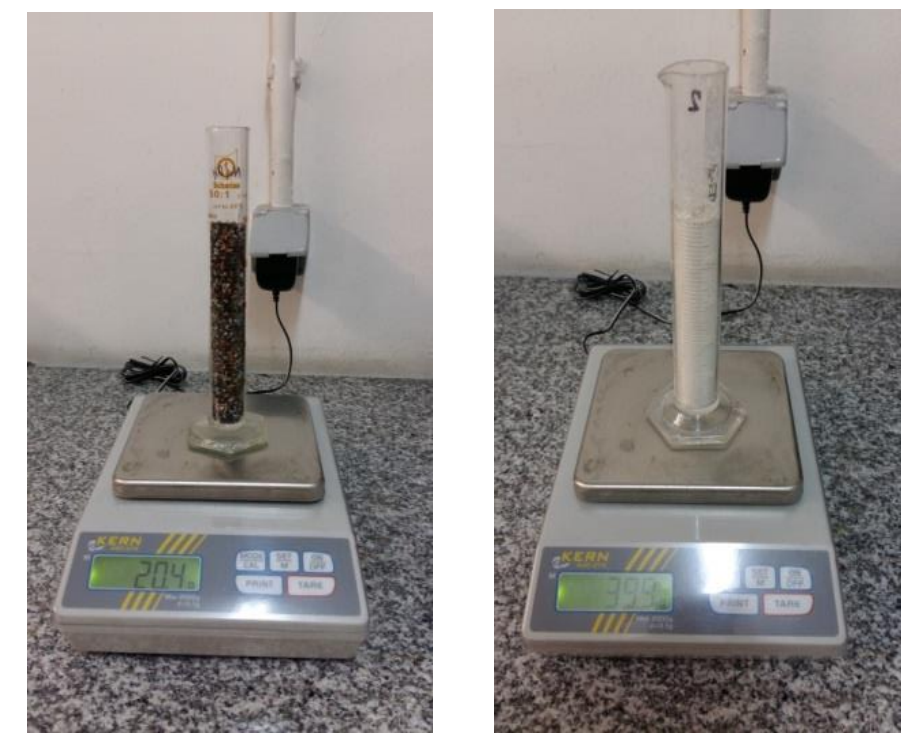

Foto 5.2. Determinación de densidad bulk de PR (izquierda) y yeso (derecha)

\subsection{Determinación de la densidad real o picnometría de Helio}

Se ha determinado la densidad real de las materias primas yeso, escayola y PR mediante picnometría de helio, que, dado el pequeño tamaño de su molécula, es capaz de penetrar en los poros más pequeños. Este ensayo se ha realizado en el Laboratorio de Análisis Químico de la Escuela Técnica Superior de Ingeniería y Diseño Industrial de la Universidad Politécnica de Madrid.

La densidad real, también denominada densidad de helio o densidad de esqueleto, se define como la densidad del material excluyendo poros y espacios interparticulares, y se determina por desplazamiento de un fluido que penetra en los poros, generalmente helio. En este estudio, se emplea un estereopicnómetro modelo Stereopycnometer de la marca comercial QuantaChrome (Foto 5.3), que mide el 
cambio en la presión cuando el helio (Air Liquide, 99,999\% pureza) fluye desde la celda que contiene la muestra (celda de volumen conocido) hasta una celda de referencia de volumen también conocido, a temperatura ambiente. Para ello, se llenan 2/3 de la cápsula de la cámara con la muestra y se realiza la pesada inicial de la muestra (M). Esta cápsula se introduce en el picnómetro en la celda de muestra $\left(\mathrm{V}_{\mathrm{c}}=\right.$ $155,88 \mathrm{~cm}^{3}$ ), se desgasifica durante diez minutos con Helio para eliminar el aire ocluido en los poros y se presuriza también con Helio, indicándose en el display digital la presión $\left(\mathrm{P}_{2}\right)$. A continuación se gira la válvula selectora y el gas helio fluye de la celda de muestra a la celda de referencia $\left(V_{a}=76,67 \mathrm{~cm}^{3}\right)$, con lo cual el volumen que ocupa el Helio aumenta indicándose un nuevo valor de presión menor que el anterior $\left(\mathrm{P}_{3}\right)$.

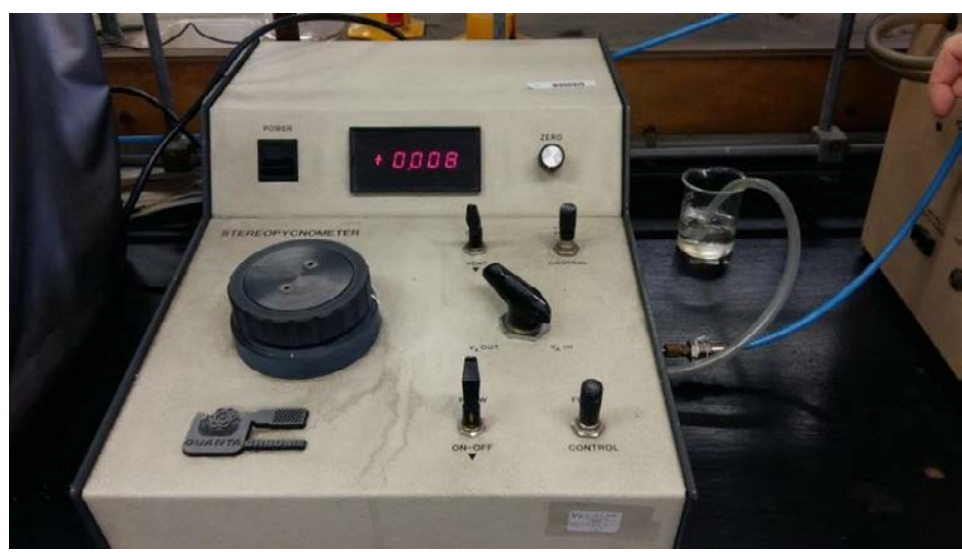

Foto 5.3. Equipo de determinación de la densidad real mediante picnómetro de Helio

La densidad real o picnometría de Helio viene dada por la expresión:

$$
\rho_{\mathrm{s}}=\mathrm{M} / \mathrm{V}_{\mathrm{s}}
$$

donde,

$\rho_{\mathrm{s}}$ es la densidad real del sólido en $\mathrm{g} / \mathrm{cm}^{3}$.

$\mathrm{M}$ es la masa de la muestra en $\mathrm{g}$.

$\mathrm{V}_{\mathrm{s}}$ es el volumen que ocupa la muestra en $\mathrm{cm}^{3}$ según la siguiente ecuación:

$$
V_{s}=V_{c}+\left[V_{a} / 1-\left(P_{2} / P_{3}\right)\right]
$$

donde,

$\mathrm{V}_{\mathrm{s}}$ es el volumen de la muestra en $\mathrm{cm}^{3}$.

$V_{c}$ es el volumen de la celda de muestra en $\mathrm{cm}^{3}$.

$V_{a}$ es el volumen de la celda de referencia en $\mathrm{cm}^{3}$.

$\mathrm{P}_{2}$ es la lectura de la presión después de presurizar la celda de muestra.

$\mathrm{P}_{3}$ es la lectura de presión después de incluir el volumen de la celda de referencia $\mathrm{Va}$. 


\subsection{Determinación del contenido de humedad de la materia prima}

Se ha obtenido el contenido de humedad de la materia prima según la norma UNEEN 12880 (UNE-EN 12880, 2001). El ensayo se ha realizado en el Laboratorio de Materiales de la Escuela Técnica Superior de Edificación de la Universidad Politécnica de Madrid.

El procedimiento utilizado ha consistido en pesar $100 \mathrm{~g}$ de muestra en una balanza analítica e introducirla en estufa de secado a una temperatura de $\left(40 \pm 2^{\circ} \mathrm{C}\right)$ hasta peso constante (Foto 5.4).

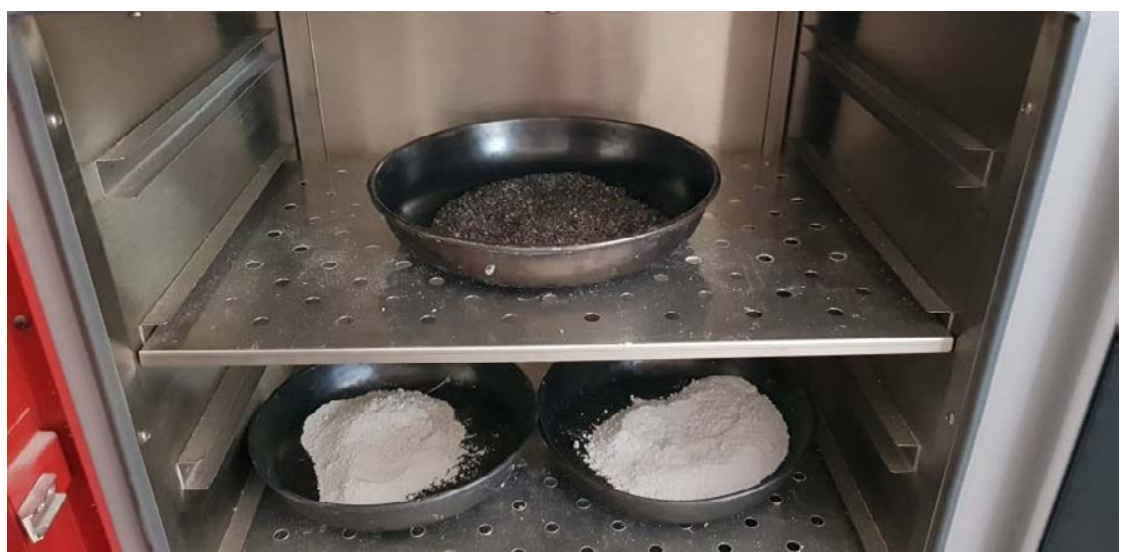

Foto 5.4. Determinación del contenido de humedad de la materia prima

El contenido de humedad de cada muestra viene dado por la expresión:

$\%$ humedad $=\frac{(\text { masa muestra húmeda }- \text { masa muestra seca })}{(\text { masa muestra húmeda })} \times 100$

\subsection{Granulometría del residuo plástico de cables}

Para la determinación de la granulometría del PR se ha seguido el método del tamizado por vía seca de la UNE-EN 933-1 (UNE-EN 933-1, 2012). En el apartado 3.1 de dicha norma se especifica la definición de "árido" en la que queda englobado por tratarse de materiales granulares utilizados en construcción que pueden ser naturales o artificiales. El ensayo se ha realizado en el Laboratorio de Materiales de la Escuela Técnica Superior de Edificación de la Universidad Politécnica de Madrid.

El método consiste en introducir una cantidad del material de PR en la columna de tamizado compuesta por los siguientes tamices: $4 \mathrm{~mm}-2 \mathrm{~mm}-1 \mathrm{~mm}-0,5 \mathrm{~mm}-$ 0,25 mm - 0,125 mm - 0,063 mm (según Norma EN 933-2) (UNE-EN 933-2, 1996), 
colocados en orden decreciente de tamaños de abertura con fondo y tapa (Foto 5.5). Se inicia el agitado mecánico de la columna durante unos minutos y se procede a retirar los tamices uno a uno agitándolos manualmente, comenzando con el de mayor abertura. A continuación se pesa el material retenido en cada tamiz y se registra la masa.
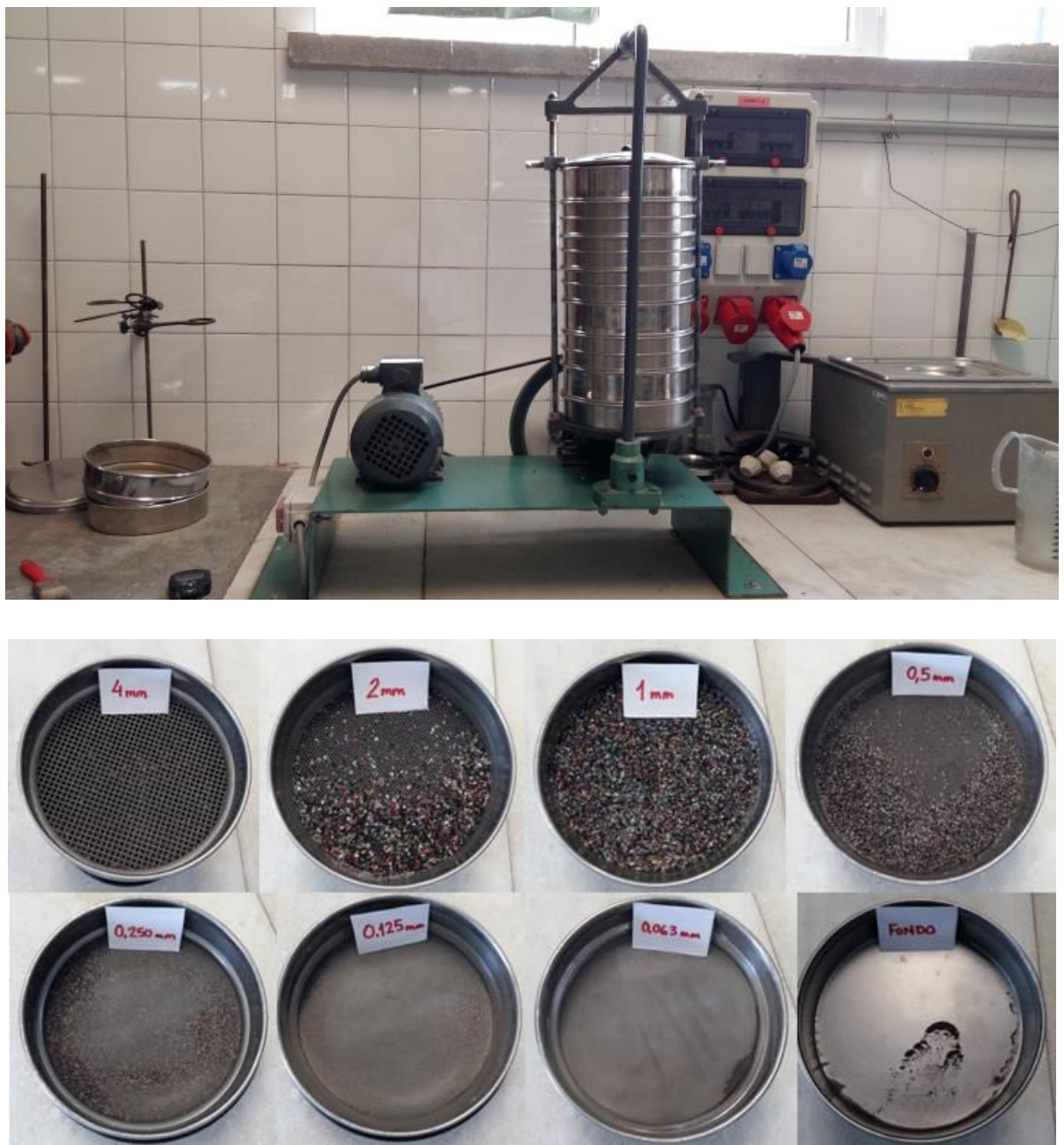

Foto 5.5. Superior: columna de tamizado. Inferior: PR retenido en cada tamiz

\subsubsection{Ensayos mineralógicos y químicos de la materia prima}

Los ensayos para la caracterización mineralógica y química de la materia prima se describen en este apartado.

\subsection{Análisis termogravimétrico}

En el Laboratorio de Análisis Químico de la Escuela Técnica Superior de Ingeniería y Diseño Industrial de la Universidad Politécnica de Madrid se ha realizado análisis 
térmico gravimétrico dinámico del yeso, escayola y PR. El análisis consiste en someter la muestra a un tratamiento térmico en un horno, con velocidad de calentamiento y atmósfera dinámica controladas, en el que se monitoriza la masa en función de la temperatura, así como los eventos térmicos asociados (Sastre de Andrés \& Ferreira Aparicio, 2002).

Para la realización de este ensayo se utiliza una termobalanza TA Instruments SDT Q600 (Foto 5.6). En ella se calienta la muestra, dispuesta sobre una cápsula de platino (llena solo 2/3), comparando su masa, medida al inicio del ensayo, con la masa de la cápsula de referencia (vacía). Se disponen discos de alúmina entre la cápsula de platino y el brazo de la termobalanza para evitar que se suelde la cápsula al brazo. A continuación, y en una atmósfera seleccionada de $100 \mathrm{ml} / \mathrm{min}$ de aire suministrado por un compresor y previamente filtrado, se inicia una rampa de temperatura controlada iniciándose a temperatura ambiente, elevándose $10^{\circ} \mathrm{C}$ por minuto, $\mathrm{y}$ finalizando en $1000^{\circ} \mathrm{C}$. Se registra la evolución de la masa de la muestra (tanto en \% respecto a la masa inicial como en unidades de masa) y el calor desprendido o absorbido frente a la temperatura y el tiempo.
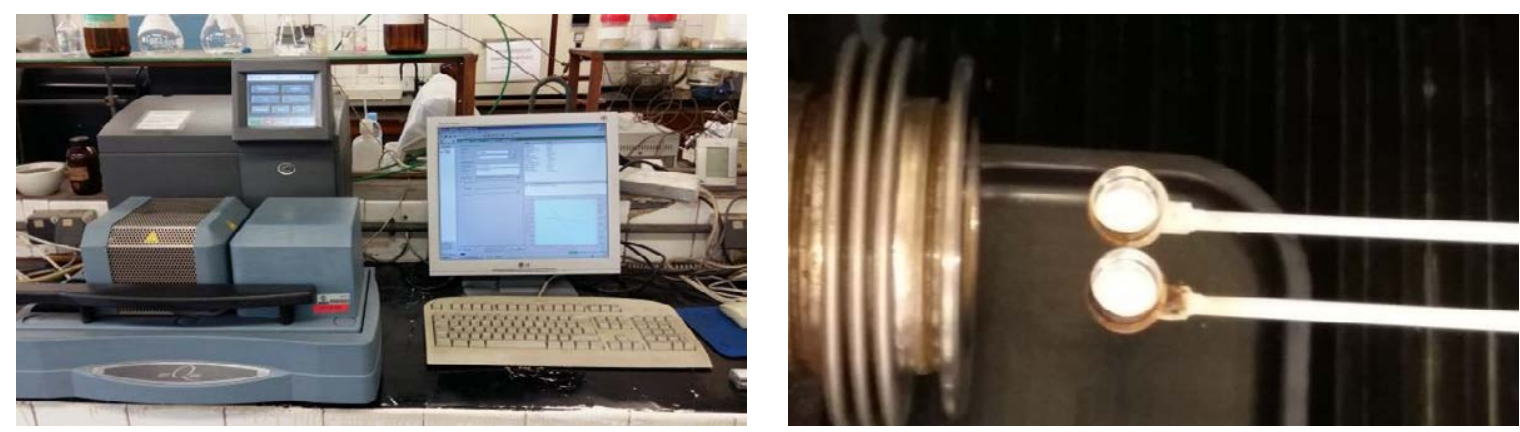

Foto 5.6. Izquierda: equipo de análisis térmico gravimétrico. Derecha: brazos de la termobalanza (interno de referencia, externo de muestra) con cápsulas de platino

\subsection{Difracción de Rayos X}

El ensayo de difracción de Rayos X se ha realizado a los materiales yeso y escayola en el Laboratorio de Análisis Químico de la Escuela Técnica Superior de Ingeniería y Diseño Industrial de la Universidad Politécnica de Madrid, con el fin de conocer la composición y estructura cristalina de las muestras (Mascarós, 2002). No se ha podido realizar el análisis del PR, ya que el gran tamaño de partícula y la no adherencia entre las mismas, hace imposible disponer la muestra en el portamuestras de forma correcta para llevar a cabo el análisis.

Se utiliza un difractrómetro Siemens Diffraktometer D5000 con radiación Cu Ka $(1,2)$ y monocromador de grafito (Foto 5.7); se obtuvo el difractograma en un rango entre $5^{\circ} \leq 2 \theta \leq 100^{\circ}$ cada $0.04^{\circ}, 1$ segundo por paso. 

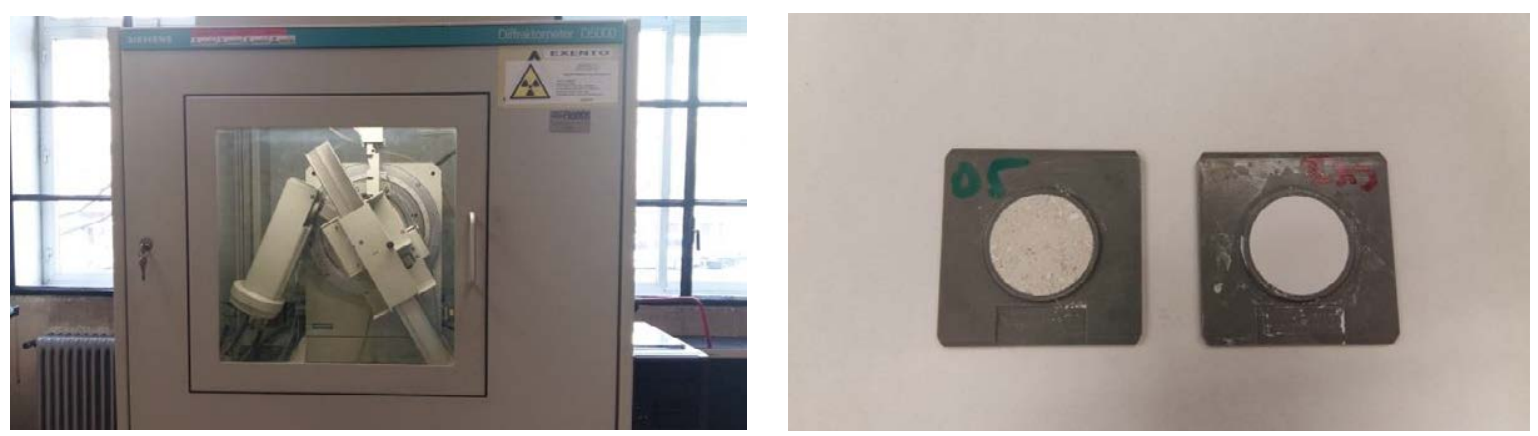

Foto 5.7. Izquierda: equipo de Difracción de Rayos X. Derecha: cápsulas de yeso y escayola preparadas para ensayo

\subsection{Análisis elemental - Fluorescencia de Rayos X}

El análisis químico para determinar la composición química del yeso, escayola y PR se ha realizado mediante fluorescencia de rayos X (FRX) en el Centro de Apoyo Tecnológico de la Universidad Rey Juan Carlos.

Se ha utilizado un espectrofotómetro por dispersión de longitudes de onda, con generador de Rayos X de $1 \mathrm{~kW}$ y ánodo de rodio de la casa Philips modelo-Magic (Foto 5.8), dotado de 3 colimadores primarios intercambiables y cambiador de cristales bidireccional con hasta 8 posiciones, que cubren un amplio rango de longitudes de onda. Las muestras se introducen en portamuestras cubiertas con plástico Mylar (polímero sin trazas de metales) que, previamente pesadas, se analizan en atmósfera de Helio en el equipo de trabajo mencionado.
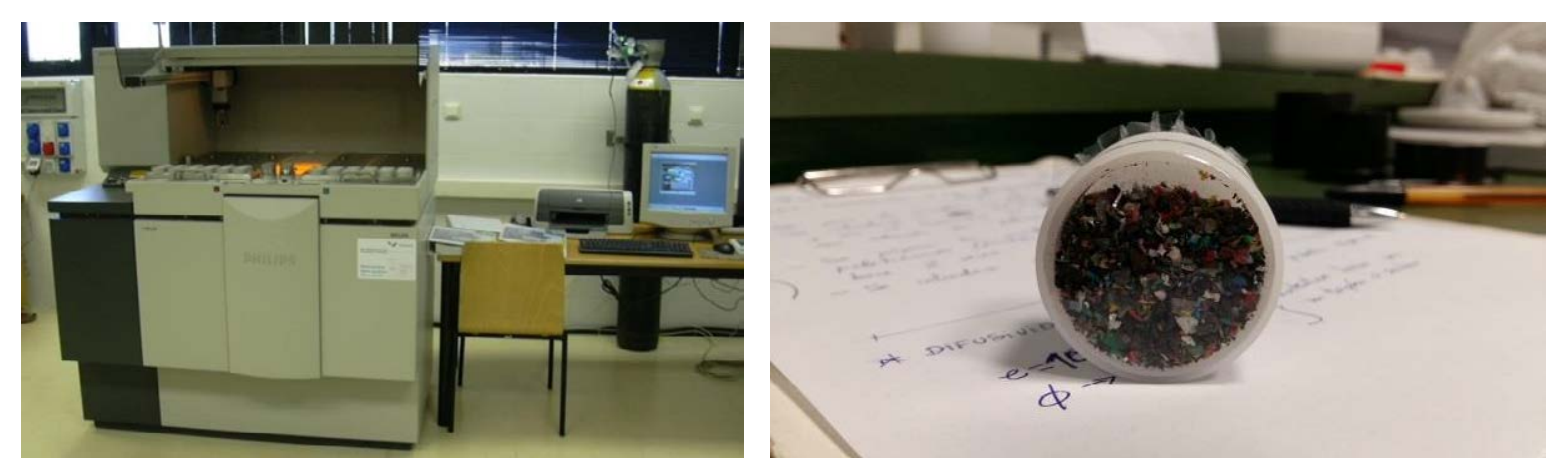

Foto 5.8. Izquierda: equipo espectrofotómetro. Derecha: portamuestras con PR preparada para ensayo 


\subsection{COMPUESTOS CON RESIDUOS PLÁSTICOS DE CABLES (Objetivo 2)}

Una vez analizadas las investigaciones encontradas en la búsqueda bibliográfica sobre la incorporación de residuos plásticos en compuestos de yeso (ver capítulo 2), se evalúa la incorporación de agregados de PR en matrices de yeso y escayola a través de los ensayos elaborados en estado fresco realizados en la Fase II del plan experimental:

- Consistencia de las pastas y determinación de la relación agua/yeso. UNE-EN 13279-2 "Yesos de construcción y conglomerantes a base de yeso para la construcción. Métodos de ensayo".

- Determinación de los tiempos de fraguado. UNE-EN 13279-2 "Yesos de construcción y conglomerantes a base de yeso para la construcción. Métodos de ensayo".

A continuación, se plantea un diseño de experimentos para la planificación de los ensayos de los compuestos en estado endurecido.

\subsubsection{Confección de probetas}

Las probetas utilizadas durante las fases se han realizado con distintos moldes en función del ensayo a desarrollar.

Para la elaboración de las probetas se han seguido las indicaciones de la UNE-EN 13279 (UNE-EN 13279-2:2014, 2014). Primero el yeso se va incorporando al agua de forma paulatina y se amasa durante dos minutos, el primer minuto de manera manual y el segundo minuto en la amasadora eléctrica. La mezcla se vierte en el molde rellenando bien huecos y esquinas, se eleva $10 \mathrm{~mm}$ y se deja caer durante cinco veces sobre la mesa de trabajo para intentar evitar la producción de burbujas de aire. Cuando ha fraguado, se elimina la pasta sobrante y se alisa la probeta sin ejercer presión sobre la misma, mediante un movimiento de sierra (Foto 5.9). Por último, una vez alcanzado un grado adecuado de resistencia, se desmoldan las probetas, se pesan y se identifican. 


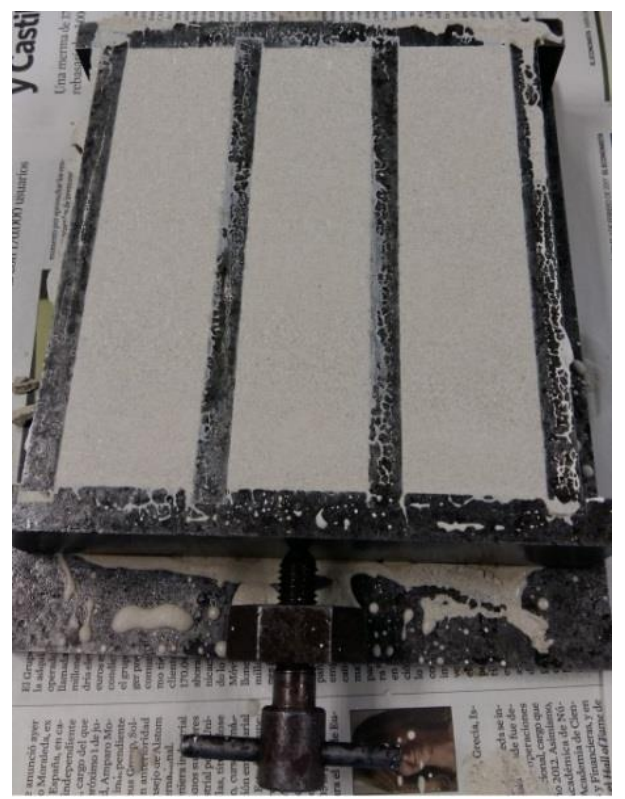

Foto 5.9. Confección de probetas (molde $4 \times 4 \times 16 \mathrm{~cm}^{3}$ )

Durante sietes días, las probetas se mantienen en el laboratorio en condiciones atmosféricas de $23 \pm 2^{\circ} \mathrm{C}$ y $50 \pm 5 \%$ de humedad relativa y, se vuelven a pesar. Después pasan $24 \mathrm{~h}$ en estufa con una temperatura de $40 \pm 2^{\circ} \mathrm{C}$ para ser desecadas hasta masa constante $y$, finalmente, se dejan enfriar en desecador, hasta la temperatura ambiente del laboratorio (Foto 5.10).
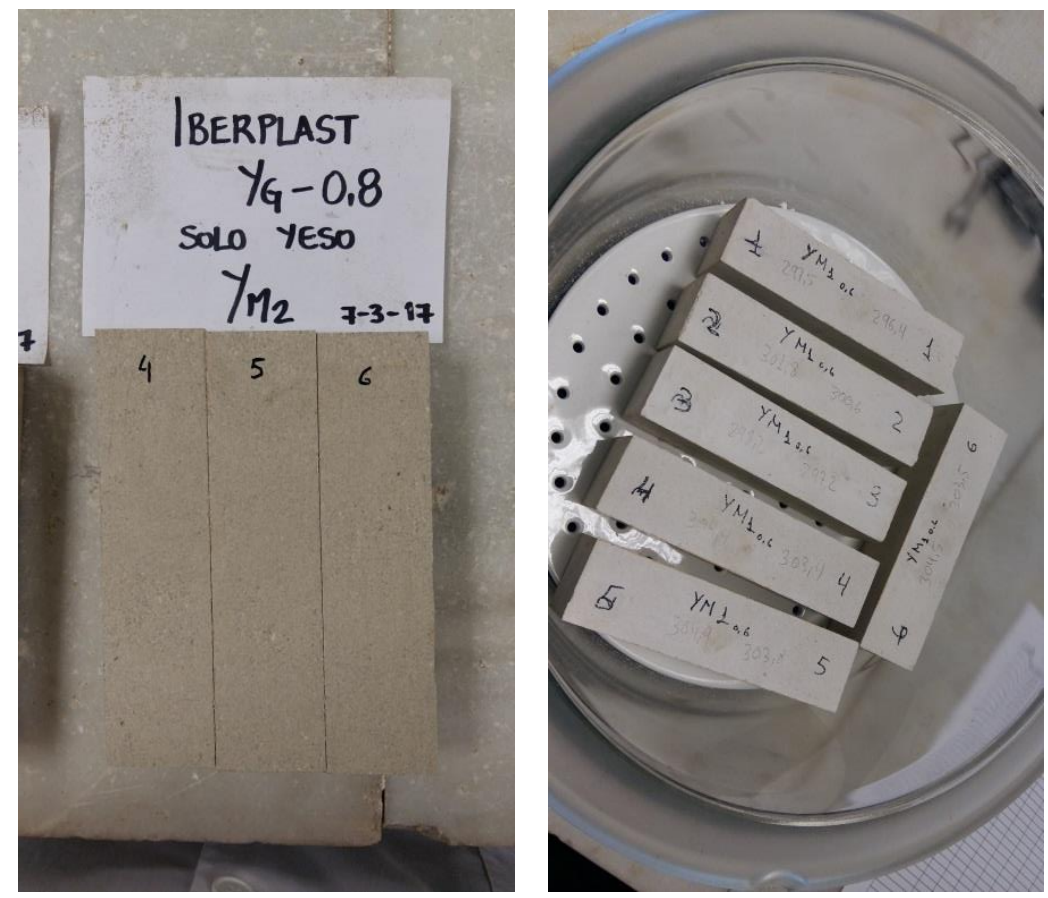

Foto 5.10. Izquierda: probetas en condiciones de laboratorio. Derecha: probetas en desecador 
Para la elaboración de los ensayos, se han cumplido las especificaciones indicadas en la normativa vigente en cuanto a las siguientes condiciones:

- Humedad relativa del aire: $50 \pm 5 \%$.

- Temperaturas de ambiente del laboratorio, del yeso y del agua: $23 \pm 2{ }^{\circ} \mathrm{C}$.

- Muestra de ensayo: guardada en recipiente estanco.

- Recipientes y moldes utilizados para el amasado y confección de probetas: estancos y de materiales impermeables y resistentes al sulfato cálcico.

- Material utilizado durante los ensayos: limpio previamente.

\subsubsection{Probetas de referencia}

Se confeccionan probetas sin adición, denominadas probetas de referencia, según lo especificado en el apartado anterior. Se realizan las series con la misma relación agua/yeso que las series de probetas con cargas de PR estudiadas en esta investigación y se las somete a los mismos ensayos para su comparación (Foto 5.11). $\mathrm{Su}$ denominación (Y yeso, E escayola, PR residuo plástico), dimensiones y relación agua/yeso $(0,8-0,9-1,0)$, se indican en la tabla realizada en cada Fase.

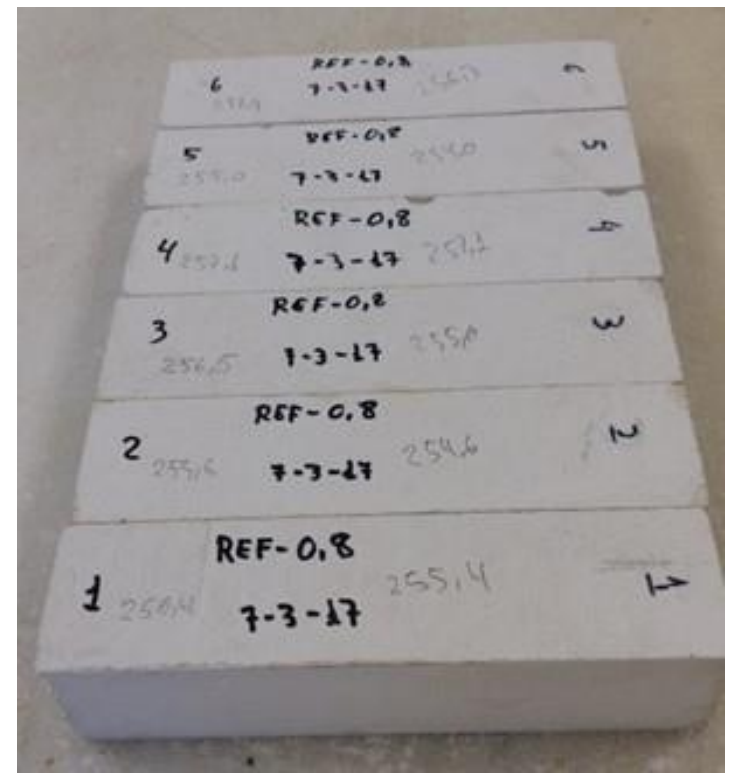

Foto 5.11. Probetas de referencia

\subsubsection{Probetas de yeso con PR}

El mayor porcentaje de PR a agregar en las pastas se selecciona buscando una buena trabajabilidad de las mismas. Entendiendo, según indica del Río Merino (del Río Merino, 1999) que, "la trabajabilidad del yeso depende de la moldeabilidad, la consistencia variable, el fraguado rápido regulable, la expansión de fraguado, la 
adherencia, las resistencias iniciales y la modificabilidad o facilidad de trabajo sobre elementos ya fraguados". La moldeabilidad, la expansión de fraguado y la modificabilidad de las pastas se observan visualmente durante la fabricación de las probetas. Para la determinación de la consistencia se utiliza el método de la mesa de sacudidas (apartado 5.2.3.1); para la determinación del principio de fraguado se utiliza el método del cono de Vicat (apartado 5.2.3.2); y la determinación de las resistencias se detalla en el apartado 5.3.2.1, 5.3.2.2 y 5.3.2.3 (dureza y resistencias a flexión y compresión).

En base a estas premisas y tras los ensayos previos, se decide elaborar series con la máxima adición de PR posible. Esto supone, en porcentaje de PR de 50\%, 60\% y $70 \%$ en base al peso del yeso sin sustituir éste y sin incorporar más agua (Foto 5.12). La relación agua/yeso seleccionada es de 0,8-1,0 para yeso Iberplast de Placo y 0,80,9 para escayola Iberyola de Placo.
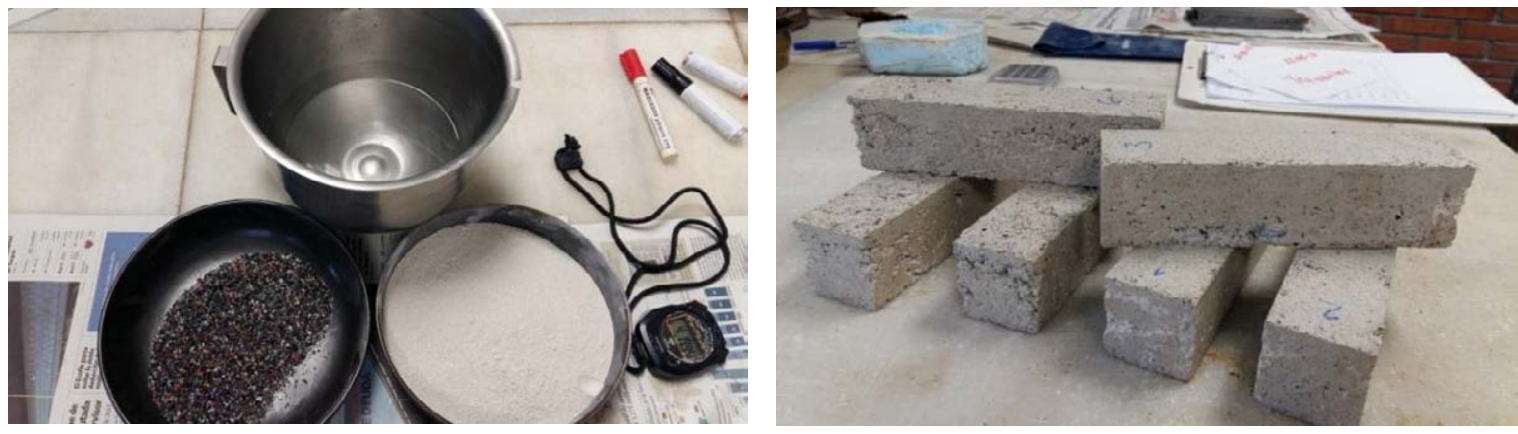

Foto 5.12. Izquierda: materia prima del compuesto (agua, yeso, PR). Derecha: probetas del compuesto

Para la fabricación de las probetas se ha procedido según lo indicado en el apartado 5.2.2 pero teniendo en cuenta que los materiales, yeso/escayola y PR, se han mezclado en seco durante unos segundos, antes de incorporarse al agua paulatinamente (Foto 5.13). Su denominación (Y yeso, E escayola, PR residuo plástico), dimensiones, relación agua/yeso $(0,8-0,9-1,0)$ y su porcentaje de adición (50\%-60\%-70\%), se indican en la tabla realizada en cada Fase.
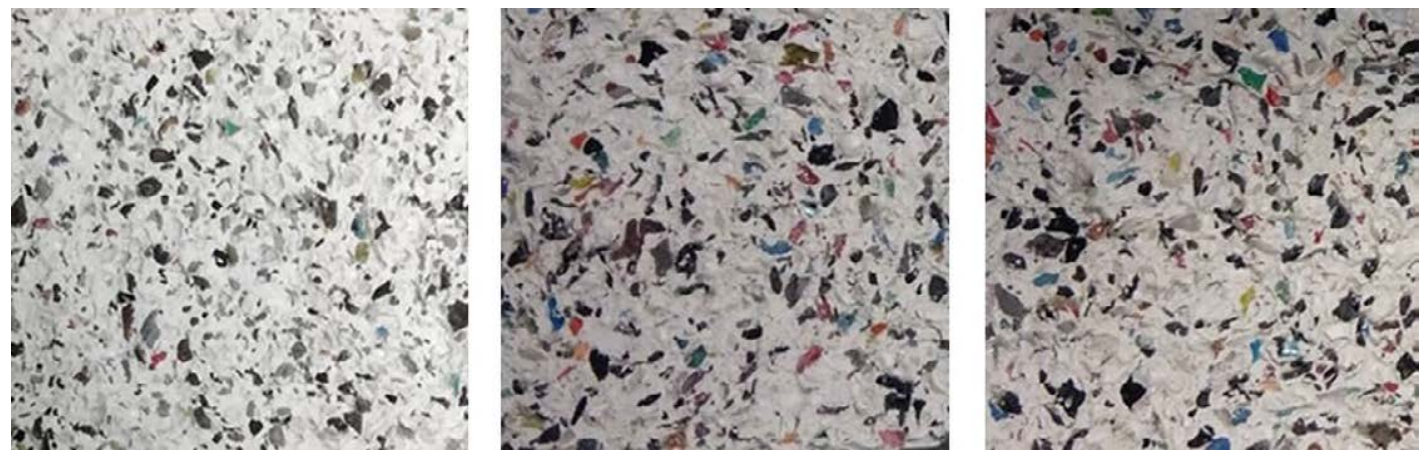

Foto 5.13. Compuestos (sección de probetas endurecidas). De izquierda a derecha: 50\%PR - 60\%PR - 70\%PR 


\subsubsection{Fase II del plan experimental: Compuestos con residuos plásticos de cables}

En este apartado se describen los ensayos realizados para comprobar la cantidad máxima de cargas de PR a agregar en las matrices de yeso y escayola.

\subsubsection{Consistencia de las pastas y relación agua/yeso}

La consistencia de las diferentes mezclas se ha determinado según el Método de la mesa de sacudidas que se indica en la norma UNE EN 13279-2 (UNE-EN 13279$2: 2014,2014)$, recomendado para yesos premezclados. Este ensayo se ha realizado en el Laboratorio de Materiales de la Escuela Técnica Superior de Edificación de la Universidad Politécnica de Madrid.

Se pesan entre $1,2 \mathrm{dm}^{3}$ y 1,5 $\mathrm{dm}^{3}$ de yeso con una precisión de $1 \mathrm{~g}\left(\mathrm{~m}_{4}\right)$, el agua $\left(\mathrm{m}_{3}\right)$ y la adición de PR en la proporción elegida y se mezclan. Se remueven manualmente durante un minuto y durante otro minuto en la amasadora a baja velocidad en rotación y con movimiento planetario.

El molde cónico se coloca en el centro de la placa de vidrio de la mesa de sacudidas y se vierte en él la pasta eliminando el exceso mediante una espátula. A los 10-15 segundos se levanta el cono verticalmente y se aplican 15 golpes mediante la mesa de sacudidas, a una velocidad constante de 1 revolución por segundo.

Se mide el diámetro de la galleta resultante en dos direcciones perpendiculares y con una precisión de $1 \mathrm{~mm}$. La media de ambas medidas debe estar comprendida entre $160 \pm 5 \mathrm{~mm}$ y $165 \pm 5 \mathrm{~mm}$ (ver Foto 5.14 ).

La relación de agua/yeso queda definida por la expresión:

$$
\mathrm{R}=\mathrm{m}_{3} / \mathrm{m}_{4}
$$

donde,

$\mathrm{m}_{3}$ es la masa del agua de amasado en gramos

$\mathrm{m}_{4}$ es la masa del yeso en gramos
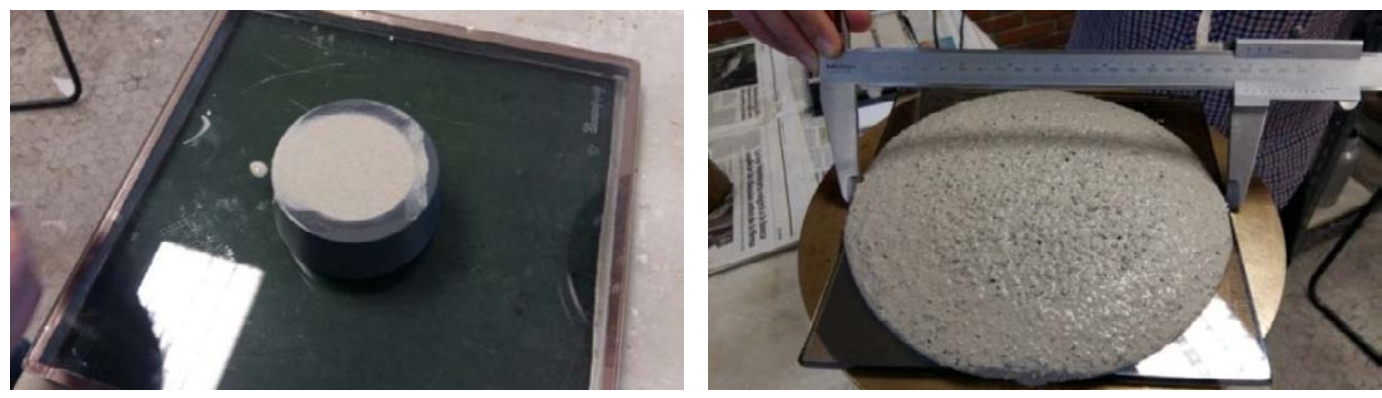

Foto 5.14. Determinación de la consistencia de la pasta 


\subsubsection{Determinación de los tiempos de fraguado}

Para la determinación del tiempo de fraguado inicial de las mezclas se ha utilizado el ensayo del Cono de Vicat, indicado en la norma UNE EN 13279-2 (UNE-EN 13279$2: 2014,2014)$, recomendado para yesos premezclados. Este ensayo se ha realizado en el Laboratorio de Materiales de la Escuela Técnica Superior de Edificación de la Universidad Politécnica de Madrid.

Se realiza la mezcla, agua, agregado de PR y yeso, y se amasa manualmente durante un minuto $\left(\mathrm{t}_{0}\right)$ y en amasadora otro minuto a baja velocidad en rotación y con movimiento planetario. Se rellena el cono, previamente colocado en la placa de vidrio, y se enrasa con una espátula con un movimiento de sierra.

Se pone en contacto el cono con la superficie de la pasta soltando el dispositivo de Vicat. La barra guía se abre utilizando el mecanismo de disparo (ver Foto 5.15). El fraguado comienza en el momento en el que el cono penetra una profundidad de $22 \pm 2 \mathrm{~mm}$ sobre la placa de vidrio $\left(\mathrm{t}_{1}\right)$.

El tiempo de fraguado viene dado por la expresión:

$$
\mathrm{T}_{\mathrm{i}}=\mathrm{t}_{1}-\mathrm{t}_{0}
$$

donde,

$\mathrm{t}_{1}$ es el tiempo, en minutos, hasta llegar a la profundidad de $22 \pm 2 \mathrm{~mm}$

$t_{0}$ es el tiempo, en minutos, desde que el yeso se pone en contacto con el agua

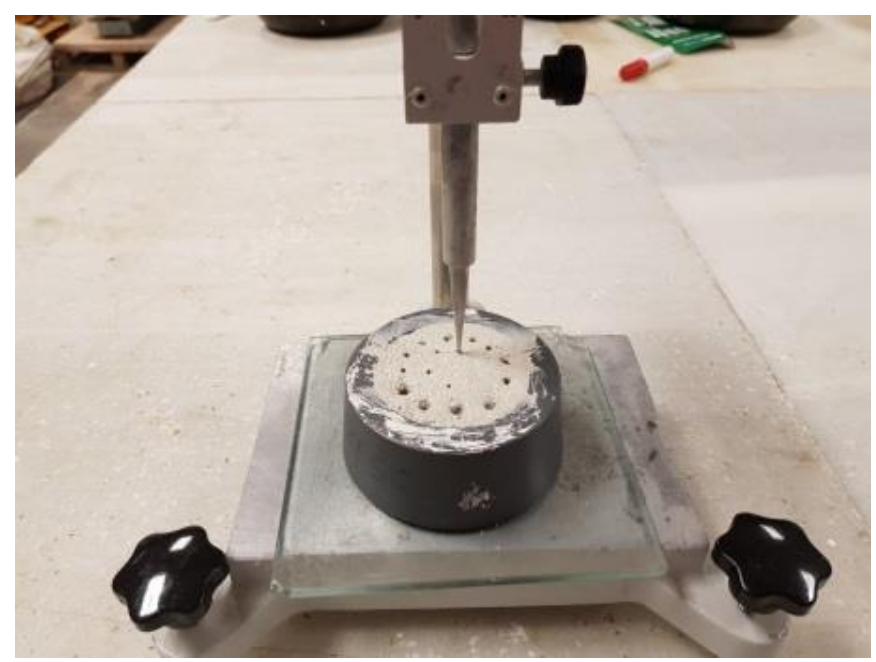

Foto 5.15. Dispositivo de Vicat para la determinación del tiempo de fraguado 


\subsubsection{Diseño de experimentos}

Con la propuesta de compuestos, se elabora la matriz general de muestras experimentales con 3 factores: contenido de PR (0\%-50\%-60\%-70\% en base a la masa del conglomerante teniendo en cuenta lo indicado en el apartado 5.2.1.2), conglomerante utilizado (yeso y escayola) y contenido de agua (0,8-0,9-1,0 relación agua/conglomerante) (Tabla 5.4):

Tabla 5.4. Matriz general - Diseño de experimentos

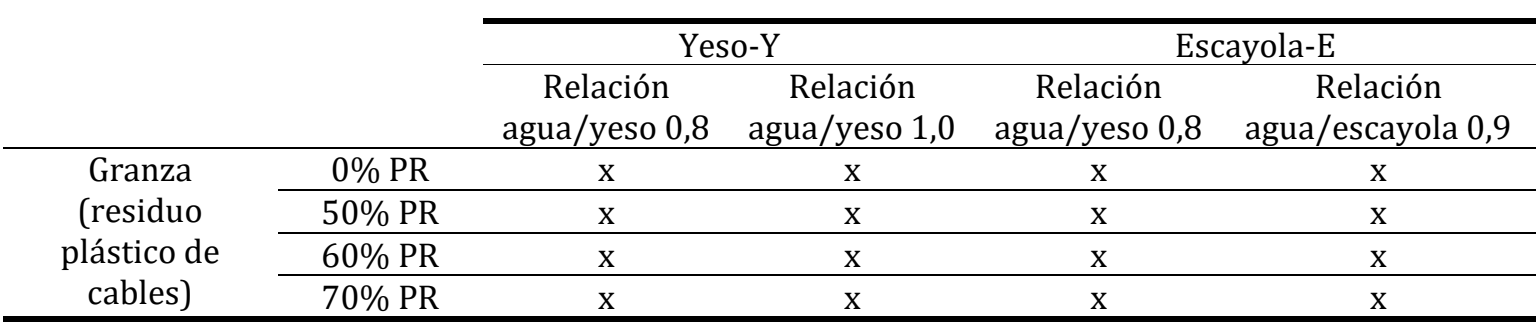

\begin{tabular}{l|c|c|c|c|}
\hline Factores: & \multicolumn{1}{c|}{$\begin{array}{c}\text { Tipo de } \\
\text { conglomerante }\end{array}$} & \multicolumn{1}{|c|}{$\begin{array}{c}\text { Interacción \% PR - tipo } \\
\text { de conglomerante }\end{array}$} \\
Variables: & $\begin{array}{c}\text { Dureza Shore } \\
\mathrm{C}\end{array}$ & $\begin{array}{c}\text { Resistencia a } \\
\text { flexión }\end{array}$ & $\begin{array}{c}\text { Resistencia a } \\
\text { compresión }\end{array}$ & Densidad aparente \\
\cline { 2 - 5 } & &
\end{tabular}

A partir de las variables de la matriz planteada: dureza Shore C, resistencia a flexión, resistencia a compresión, densidad aparente, se elaboran los ensayos de forma aleatoria con el fin de analizar la interacción entre dichas variables. Se realiza un análisis de la varianza utilizando el software Statgraphics Centurion, de manera que, para una muestra concreta, se comparan los resultados obtenidos, definiendo si existen diferencias significativas entre los mismos o no. Además, con los resultados de cada variable, se comprueba si existe relación entre los distintos factores.

La metodología del análisis de la varianza exige que se cumplan las siguientes condiciones de Cochran (para tres o más muestras):

- Las observaciones deben ser independientes, para lo que es necesario que se hayan realizado de forma aleatoria.

- La variable aleatoria en cada nivel de factor debe ser una normal.

- Se debe dar homocedasticidad, es decir, homogeneidad de las varianzas de cada nivel de factor. 


\subsection{CARACTERIZACIÓN DE LOS COMPUESTOS DE YESO Y PR (Objetivo 3)}

Se analizan las propiedades mecánicas y físicas de los compuestos en estado endurecido y su cumplimiento con los mínimos exigidos en normativa vigente (Fase III del plan experimental), elaborando los siguientes ensayos mecánicos:

- Dureza superficial Shore C. UNE 102042 "Yesos y escayolas de construcción. Otros métodos de ensayo".

- Resistencia a flexión. UNE-EN 13279-2 "Yesos de construcción y conglomerantes a base de yeso para la construcción. Métodos de ensayo".

- Resistencia a compresión. UNE-EN 13279-2 "Yesos de construcción y conglomerantes a base de yeso para la construcción. Métodos de ensayo".

Y los siguientes ensayos físicos:

- Densidad en estado endurecido. UNE 102042:2014 "Yesos y escayolas de construcción. Otros métodos de ensayo".

- Módulo de Young.

\subsubsection{Fase III del plan experimental: Caracterización de los compuestos de yeso con PR}

Las series realizadas para ello se describen en la Tabla 5.5, definiéndose en primer lugar el conglomerante (Y-E), después las dimensiones de las probetas de ensayo, la matriz de yeso utilizada (IP: Iberplast de Placo; IY: Iberyola de Placo), la relación agua/yeso $(0,8-0,9-1,0)$, la cantidad de PR agregada (0\%PR-50\%PR-60\%PR-70\%PR) y por último, el ensayo realizado:

Tabla 5.5. Denominación probetas del compuesto. FASE III

\begin{tabular}{|c|c|c|c|c|c|c|c|}
\hline & Referencia & Denomin. & Dimensiones & $\begin{array}{c}\text { Matriz } \\
\text { utilizada }\end{array}$ & $\begin{array}{c}\text { Relación } \\
\text { agua/yeso }\end{array}$ & $\% P R$ & Ensayo realizado \\
\hline \multirow{13}{*}{ 量 } & & $\mathrm{Y}_{0,8}$ & $4 \times 4 \times 16 \mathrm{~cm}^{3}$ & IP & 0,8 & $0 \%$ & \multirow{13}{*}{$\begin{array}{l}\text { - Dureza ShoreC } \\
\text { - R. Flexión } \\
\text { - R. Compresión }\end{array}$} \\
\hline & Sorio I & $\mathrm{Y}_{0,8-50 \mathrm{PR}}$ & $4 \times 4 \times 16 \mathrm{~cm}^{3}$ & IP & 0,8 & $50 \%$ & \\
\hline & serie I & $\mathrm{Y}_{0,8-60 \mathrm{PR}}$ & $4 \times 4 \times 16 \mathrm{~cm}^{3}$ & IP & 0,8 & $60 \%$ & \\
\hline & & $\mathrm{Y}_{0,8-70 \mathrm{PR}}$ & $4 \times 4 \times 16 \mathrm{~cm}^{3}$ & IP & 0,8 & $70 \%$ & \\
\hline & \multirow{4}{*}{ Serie II } & $Y_{1,0}$ & $4 \times 4 \times 16 \mathrm{~cm}^{3}$ & IP & 1,0 & $0 \%$ & \\
\hline & & $Y_{1,0-50 \mathrm{PR}}$ & $4 \times 4 \times 16 \mathrm{~cm}^{3}$ & IP & 1,0 & $50 \%$ & \\
\hline & & $Y_{1,0-60 P R}$ & $4 \times 4 \times 16 \mathrm{~cm}^{3}$ & IP & 1,0 & $60 \%$ & \\
\hline & & $\mathrm{Y}_{1,0-70 \mathrm{PR}}$ & $4 \times 4 \times 16 \mathrm{~cm}^{3}$ & IP & 1,0 & $70 \%$ & \\
\hline & \multirow{4}{*}{ Serie III } & $\mathrm{E}_{0,8}$ & $4 \times 4 \times 16 \mathrm{~cm}^{3}$ & IY & 0,8 & $0 \%$ & \\
\hline & & $\mathrm{E}_{0,8-50 \mathrm{PR}}$ & $4 \times 4 \times 16 \mathrm{~cm}^{3}$ & IY & 0,8 & $50 \%$ & \\
\hline & & $\mathrm{E}_{0,8-60 \mathrm{PR}}$ & $4 \times 4 \times 16 \mathrm{~cm}^{3}$ & IY & 0,8 & $60 \%$ & \\
\hline & & $\mathrm{E}_{0,8-70 \mathrm{PR}}$ & $4 \times 4 \times 16 \mathrm{~cm}^{3}$ & IY & 0,8 & $70 \%$ & \\
\hline & Serie IV & $E_{0,9}$ & $4 \times 4 \times 16 \mathrm{~cm}^{3}$ & IY & 0,9 & $0 \%$ & \\
\hline
\end{tabular}




\begin{tabular}{|c|c|c|c|c|c|c|}
\hline & $\begin{array}{l}\mathrm{E}_{0,9-50 \mathrm{PR}} \\
\mathrm{E}_{0,9-60 \mathrm{PR}} \\
\mathrm{E}_{0,9-70 \mathrm{PR}}\end{array}$ & $\begin{array}{l}4 \times 4 \times 16 \mathrm{~cm}^{3} \\
4 \times 4 \times 16 \mathrm{~cm}^{3} \\
4 \times 4 \times 16 \mathrm{~cm}^{3}\end{array}$ & $\begin{array}{l}\text { IY } \\
\text { IY } \\
\text { IY }\end{array}$ & $\begin{array}{l}0,9 \\
0,9 \\
0,9\end{array}$ & $\begin{array}{l}50 \% \\
60 \% \\
70 \%\end{array}$ & \\
\hline \multirow{4}{*}{ Serie V } & $\mathrm{Y}_{0,8}$ & $4 \times 4 \times 16 \mathrm{~cm}^{3}$ & IP & 0,8 & $0 \%$ & \multirow{16}{*}{$\begin{array}{l}\text { - Densidad } \\
\text { - Módulo de } \\
\text { Young }\end{array}$} \\
\hline & $\mathrm{Y}_{0,8-50 \mathrm{PR}}$ & $4 \times 4 \times 16 \mathrm{~cm}^{3}$ & IP & 0,8 & $50 \%$ & \\
\hline & $Y_{0,8-60 \mathrm{PR}}$ & $4 \times 4 \times 16 \mathrm{~cm}^{3}$ & IP & 0,8 & $60 \%$ & \\
\hline & $\mathrm{Y}_{0,8-70 \mathrm{PR}}$ & $4 \times 4 \times 16 \mathrm{~cm}^{3}$ & IP & 0,8 & $70 \%$ & \\
\hline \multirow{4}{*}{ Serie VI } & $Y_{1,0}$ & $4 \times 4 \times 16 \mathrm{~cm}^{3}$ & IP & 1,0 & $0 \%$ & \\
\hline & $\mathrm{Y}_{1,0-50 \mathrm{PR}}$ & $4 \times 4 \times 16 \mathrm{~cm}^{3}$ & IP & 1,0 & $50 \%$ & \\
\hline & $Y_{1,0-60 P R}$ & $4 \times 4 \times 16 \mathrm{~cm}^{3}$ & IP & 1,0 & $60 \%$ & \\
\hline & $\mathrm{Y}_{1,0-70 \mathrm{PR}}$ & $4 \times 4 \times 16 \mathrm{~cm}^{3}$ & IP & 1,0 & $70 \%$ & \\
\hline \multirow{4}{*}{ Serie VII } & $\mathrm{E}_{0,8}$ & $4 \times 4 \times 16 \mathrm{~cm}^{3}$ & IY & 0,8 & $0 \%$ & \\
\hline & $\mathrm{E}_{0,8-50 \mathrm{PR}}$ & $4 \times 4 \times 16 \mathrm{~cm}^{3}$ & IY & 0,8 & $50 \%$ & \\
\hline & $\mathrm{E}_{0,8-60 \mathrm{PR}}$ & $4 \times 4 \times 16 \mathrm{~cm}^{3}$ & IY & 0,8 & $60 \%$ & \\
\hline & $\mathrm{E}_{0,8-70 \mathrm{PR}}$ & $4 \times 4 \times 16 \mathrm{~cm}^{3}$ & IY & 0,8 & $70 \%$ & \\
\hline \multirow{4}{*}{ Serie VIII } & $\mathrm{E}_{0,9}$ & $4 \times 4 \times 16 \mathrm{~cm}^{3}$ & IY & 0,9 & $0 \%$ & \\
\hline & $\mathrm{E}_{0,9-50 \mathrm{PR}}$ & $4 \times 4 \times 16 \mathrm{~cm}^{3}$ & IY & 0,9 & $50 \%$ & \\
\hline & $\mathrm{E}_{0,9-60 \mathrm{PR}}$ & $4 \times 4 \times 16 \mathrm{~cm}^{3}$ & IY & 0,9 & $60 \%$ & \\
\hline & $\mathrm{E}_{0,9-70 \mathrm{PR}}$ & $4 \times 4 \times 16 \mathrm{~cm}^{3}$ & IY & 0,9 & $70 \%$ & \\
\hline
\end{tabular}

\subsubsection{Ensayos mecánicos de los compuestos de yeso con PR}

Los ensayos mecánicos realizados en los compuestos yeso con PR se describen en este apartado.

\subsection{Dureza superficial Shore C}

Se determina la dureza superficial de todas las mezclas que posteriormente se van a ensayar a flexión y compresión, mediante el ensayo de dureza Shore C especificado en la norma UNE 102042:2014 (UNE 102042, 2014). Este ensayo se ha realizado en el Laboratorio de Materiales de la Escuela Técnica Superior de Edificación de la Universidad Politécnica de Madrid.

El ensayo se ejecuta sobre las dos caras longitudinales laterales de la probeta prismática de $4 \mathrm{~cm} \times 4 \mathrm{~cm} \times 16 \mathrm{~cm}$.

Mediante un durómetro, que mide la Dureza Shore $\mathrm{C}$, se aplica una fuerza perpendicular a la probeta en ensayo, considerando un mínimo de tres puntos situados a $1 / 4$ de la longitud de la probeta en el plano que pasa por el eje lateral y teniendo en cuenta que los puntos extremos deben estar situados a una distancia de $20 \mathrm{~mm}$ de cada uno de los extremos de la probeta (Foto 5.16). A continuación se realiza la media aritmética de los resultados obtenidos, rechazando los valores no comprendidos entre un 0,9 y un 1,1 de dicha media. 


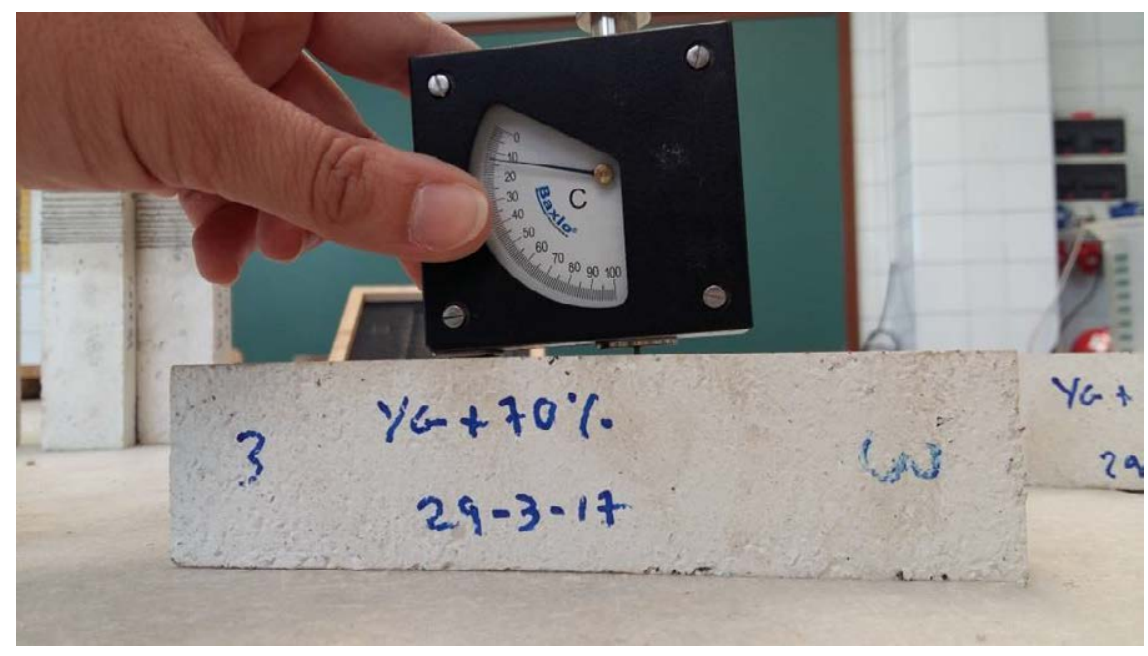

Foto 5.16. Determinación de la Dureza Shore C mediante durómetro

\subsection{Resistencia a flexión}

Para determinar el valor de rotura máximo de flexión de cada serie de probetas de todas las mezclas, se utiliza el ensayo de flexión especificado en la norma UNE EN 13279-2 (UNE-EN 13279-2:2014, 2014). Este ensayo se ha realizado en el Laboratorio de Materiales de la Escuela Técnica Superior de Edificación de la Universidad Politécnica de Madrid.

Se introduce cada probeta prismática de $4 \mathrm{~cm} \times 4 \mathrm{~cm} \times 16 \mathrm{~cm}$ en el equipo de trabajo Autotest 200-10SW de Ibertest, de manera que queda una de sus caras laterales apoyada sobre los rodillos inferiores (cuyos centros están separados $100 \mathrm{~mm}$ ) (Foto 5.17). A continuación se aplica la carga mediante un rodillo superior centrado sobre la probeta, hasta que se produce la rotura y se anota la carga máxima en Newton.

La resistencia a flexión viene dada por la expresión:

$$
\mathrm{R}_{\mathrm{f}}=0,00234 \times \mathrm{P}
$$

donde,

$\mathrm{R}_{\mathrm{f}}$ es la resistencia a flexión en $\mathrm{N} / \mathrm{mm}^{2}$.

$\mathrm{P}$ es la carga media de rotura en $\mathrm{N}$ de, al menos, tres valores obtenidos. 


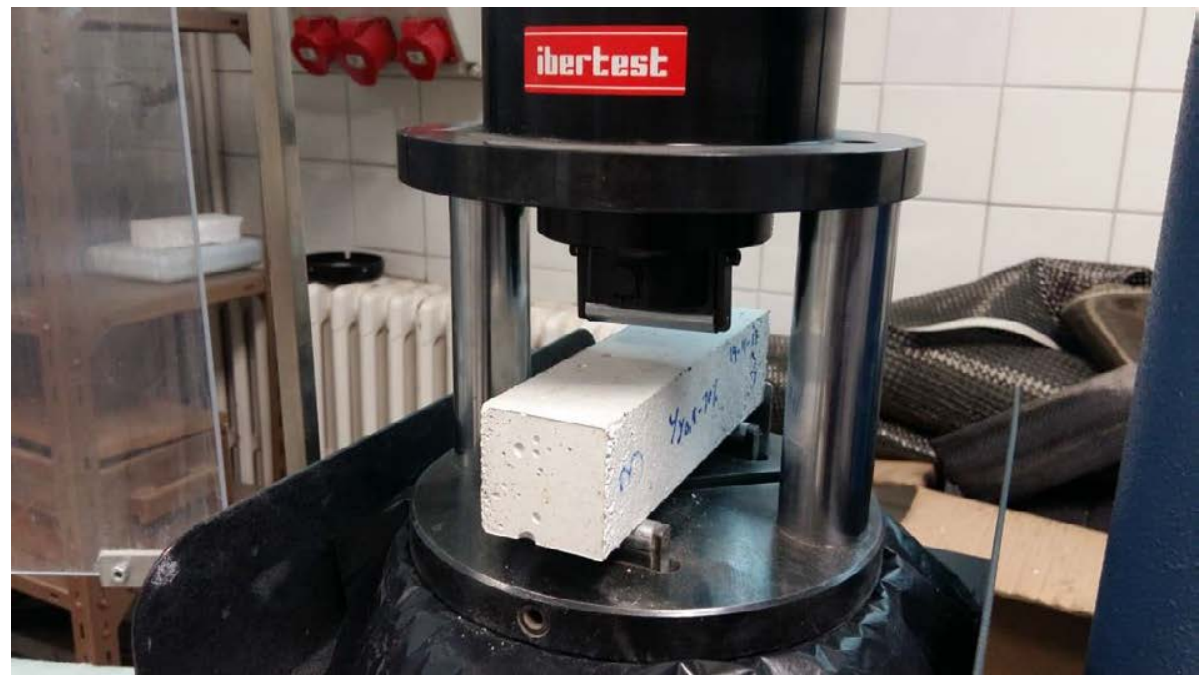

Foto 5.17. Determinación de la resistencia a flexión mediante equipo Autotest de Ibertest

\subsection{Resistencia a compresión}

El valor de rotura máximo a compresión de cada serie de probetas de todas las mezclas, se determina mediante el ensayo de compresión especificado en la norma UNE EN 13279-2 (UNE-EN 13279-2:2014, 2014). Este ensayo se ha realizado en el Laboratorio de Materiales de la Escuela Técnica Superior de Edificación de la Universidad Politécnica de Madrid.

Para ello se introduce el equipo de trabajo Autotest 200-10SW de Ibertest cada mitad resultante de la probeta prismática de $16 \mathrm{~cm} \times 4 \mathrm{~cm} \times 4 \mathrm{~cm}$ procedente del ensayo a flexión. Sus caras laterales se colocan hacia arriba y hacia abajo entre los dos platos de acero de la prensa de compresión, de manera que están en contacto una sección de $40 \mathrm{~mm}$ x $40 \mathrm{~mm}$ (Foto 5.18). A continuación se aplica la carga hasta la rotura de la probeta y se anota la carga máxima en Newton.

La resistencia a compresión viene dada por la expresión:

$$
\mathrm{R}_{\mathrm{c}}=\mathrm{F}_{\mathrm{c}} / 1600
$$

donde,

$\mathrm{R}_{\mathrm{c}}$ es la resistencia a compresión en $\mathrm{N} / \mathrm{mm}^{2}$

$\mathrm{F}_{\mathrm{c}}$ es la carga media de rotura en $\mathrm{N}$ de, al menos, seis valores obtenidos

1600 es el área de la probeta en $\mathrm{mm}^{2}$ 


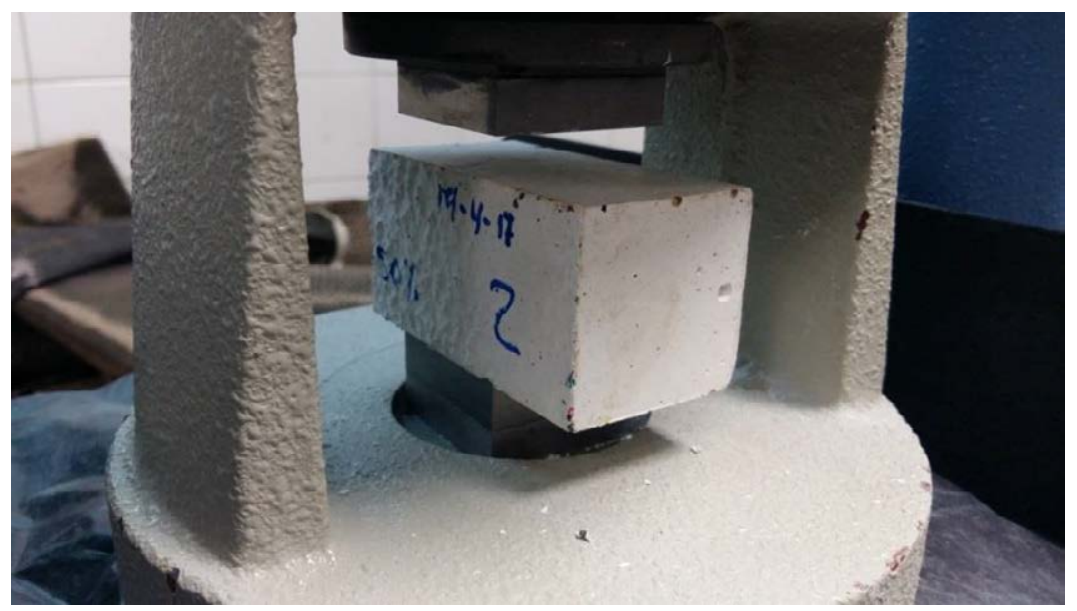

Foto 5.18. Determinación de la resistencia a compresión mediante equipo Autotest de Ibertest

\subsubsection{Ensayos físicos de los compuestos de yeso con PR}

Los ensayos físicos realizados en los compuestos yeso con PR se describen en este apartado.

\subsection{Densidad en estado endurecido}

Se determina la densidad en estado endurecido y seco de las mezclas mediante el ensayo de relación masa y volumen según UNE 102042:2014 (UNE 102042, 2014), realizado en el Laboratorio de Materiales de la Escuela Técnica Superior de Edificación de la Universidad Politécnica de Madrid.

La densidad $\left(\mathrm{kg} / \mathrm{m}^{3}\right)$ es la media de la masa $(\mathrm{kg})$ dividida entre las dimensiones de cada probeta $\left(\mathrm{m}^{3}\right)$ (Foto 5.19$)$.

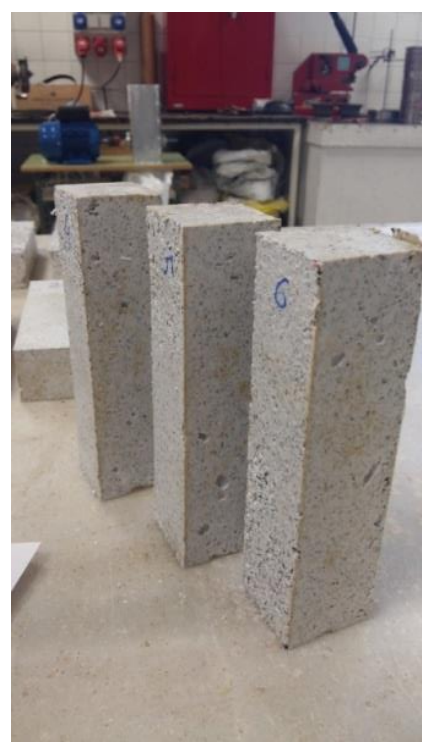

Foto 5.19. Probetas prismáticas 


\subsection{Módulo de Young}

Se realiza la determinación del módulo de Young de todos los compuestos, mediante método dinámico y estático según la norma UNE EN 13279-2 (UNE-EN 13279-2:2014, 2014). Los ensayos se han realizado en el Laboratorio de Materiales de la Escuela Técnica Superior de Edificación de la Universidad Politécnica de Madrid.

Para el módulo de Young dinámico por ultrasonidos se determina la velocidad de propagación de ultrasonidos a través de la probeta, mediante el equipo Ultrasonic tester E46 de Ibertest. Para ello, se aplica un gel en cada una de las caras donde se coloca un emisor y un receptor, favoreciendo la transmisión de las ondas sonoras y, longitudinalmente, se realizan lecturas de tiempo de paso entre dichas caras (Foto $5.20)$.

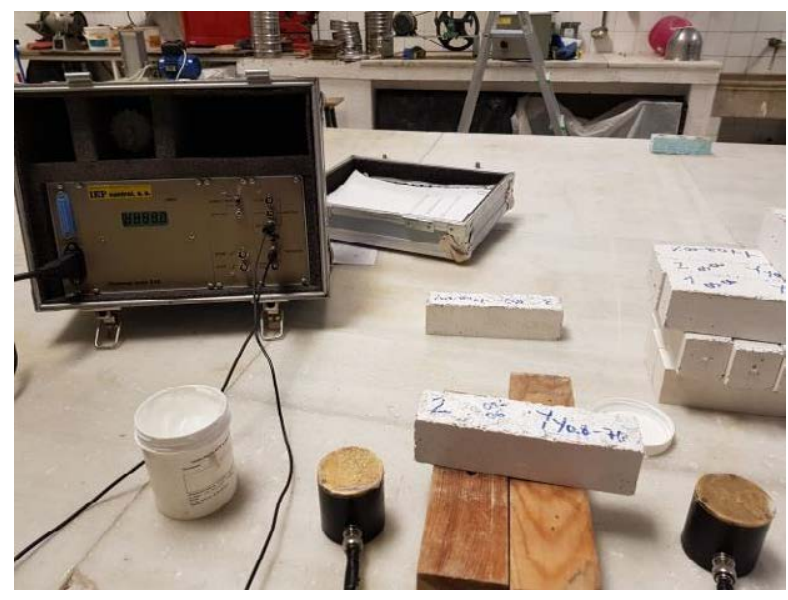

Foto 5.20. Equipo Ultrasonic tester para la determinación del Módulo de Young dinámico

El módulo de elasticidad dinámico viene dado por la expresión:

$$
E_{D}=V^{2} \times Q
$$

donde,

$E_{D}$ es el módulo dinámido de elasticidad en $\mathrm{MN} / \mathrm{m}^{2}$

$\mathrm{V}$ es la velocidad en $\mathrm{Km} / \mathrm{sg}$

$\mathrm{Q}$ es la densidad en $\mathrm{Kg} / \mathrm{m}^{3}$

Para el módulo de Young estático se determina el módulo de elasticidad mediante el equipo Autotest 200-10SW de Ibertest. Se posiciona la probeta verticalmente y se la colocan unos extensores (Foto 5.21). A continuación, el equipo comprime la probeta y deja registrado el valor numérico de Young en MPa. 


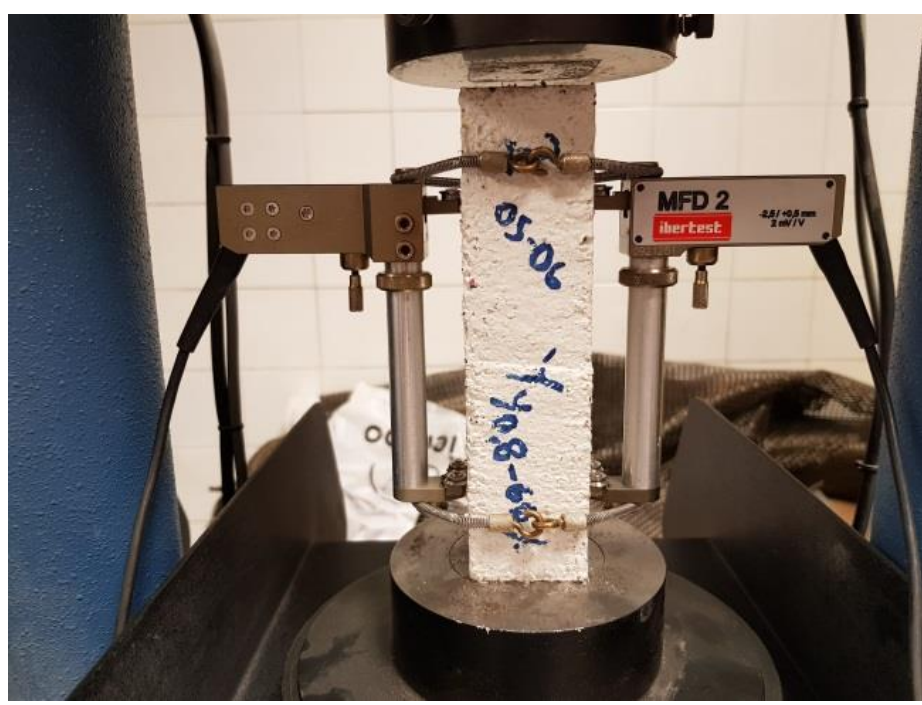

Foto 5.21. Equipo Autotest de Ibertest para la determinación del Módulo de Young estático 


\subsection{APLICACIONES PARA COMPUESTOS SELECCIONADOS DE YESO Y PR (Objetivo}

4)

Se realiza la propuesta de aplicaciones para los compuestos en base a los estudios previos realizados por otros investigadores (San Antonio González, 2017; Sorrentino, 2017).

Una vez realizada la propuesta de aplicaciones, se comprueba el comportamiento de los compuestos seleccionados frente a distintas acciones, mediante los ensayos planteados en la Fase IV del plan experimental:

Ensayos químicos:

- Porosimetría de mercurio.

- Microscopía electrónica de barrido SEM.

Ensayos mecánicos:

- Resistencia al choque-impacto. UNE-EN 520 "Placas de yeso laminado. Definiciones, especificaciones y métodos de ensayo".

- Resistencia a la flexión de paneles. UNE-EN 12859 "Paneles de yeso. Definiciones, especificaciones y métodos de ensayo".

- Adherencia superficial. UNE-EN 13279-2 "Yesos de construcción y conglomerantes a base de yeso para la construcción. Métodos de ensayo".

Ensayos físicos:

- Comportamiento frente al agua:

- Absorción de agua por capilaridad. Norma RILEM RC 25-PEM.

- Permeabilidad al vapor de agua. UNE-EN ISO 12572 "Prestaciones higrotérmicas de los productos y materiales para edificación. Determinación de las propiedades de transmisión de vapor de agua. Método de la taza".

- Cámara húmeda. Ensayo no normalizado (del Río Merino, 1999).

- Ciclos humedad-sequedad. Ensayo no normalizado (del Río Merino, 1999).

- Absorción total de agua. UNE-EN 520 "Placas de yeso laminado. Definiciones, especificaciones y métodos de ensayo".

- Comportamiento frente al fuego:

- Ensayo real a fuego. ISO 834 "Fire resistance tests. Elements of building construction"

- Análisis y detección de los gases desprendidos en combustión. 
- Propiedades térmicas:

- Coeficiente de conductividad térmica mediante técnica modificada de fuente plana transitoria. ASTM D7984 "Standard Test Method for Measurement of Thermal Effusivity of Fabrics Using a Modified Transient Plane Source (MTPS) Instrument".

- Coeficiente de conductividad por el método del medidor de flujo de calor. UNE-EN 12667 "Materiales de construcción. Determinación de la resistencia térmica por el método de la placa caliente guardada y el método del medidor de flujo de calor. Productos de alta y media resistencia térmica".

- Análisis energético mediante simulación.

- Acabados superficiales:

- Confort superficial. Ensayo no normalizado (Villanueva Domínguez \& García Santos, 2001).

- Análisis visual de la superficie. Ensayo no normalizado.

\subsubsection{Viabilidad de las aplicaciones}

Se seleccionan los compuestos más óptimos para cada una de las siguientes aplicaciones de yeso:

- Revestimientos de yeso sobre soportes rígidos y aplicación manual.

- Paneles de yeso para trasdosados y/o particiones interiores colocados de forma directa, semidirecta o con entramado autoportante.

- Placas de yeso para falsos techos sobre estructura portante.

Se utiliza la encuesta diseñada por San Antonio González A. en su investigación, en la que se ponderan las variables básicas de los compuestos de yeso: densidad, dureza superficial, resistencia mecánica a flexión y a compresión (San Antonio González, 2017). Esta encuesta se difunde entre expertos del sector que valoran la importancia de cada una de las variables para cada aplicación y, mediante un análisis de la varianza, se estudia estadísticamente.

Las conclusiones que se obtienen tras este estudio son:

- Para revestimientos de yeso sobre soportes rígidos y aplicación manual, los principales parámetros son la densidad y la dureza.

- Para paneles de yeso trasdosados y/o particiones interiores colocados de forma directa, semidirecta o con entramado autoportante, los principales parámetros son la densidad y la resistencia a compresión.

- Para placas de yeso de falsos techos sobre estructura portante, los principales parámetros son la densidad y la resistencia a flexión. 
Se tiene en cuenta también la investigación de Sorrentino M. en la que sugiere que, en revestimientos, se debe considerar la absorción de agua por capilaridad y, en paneles y placas la densidad (Sorrentino, 2017).

Además de esto, es importante conocer la velocidad de fraguado de la mezcla, de manera que se seleccionen compuestos de baja velocidad de fraguado en revestimientos de aplicación manual que necesitan un mayor periodo de trabajabilidad y, por el contrario, se seleccionen compuestos de alta velocidad de fraguado en paneles y placas prefabricados que necesitan de un rápido endurecimiento en su fabricación.

\subsubsection{Análisis económico de la aplicación seleccionada}

Se realiza un análisis económico en base a la investigación realizada por Sorrentino M. para comprobar la viabilidad económica de los compuestos con PR respecto a los productos de mercado (Sorrentino, 2017). Para ello se utiliza la siguiente fórmula:

$$
C_{t o t}=C_{m}+C_{t}+C_{p}
$$

donde,

$\mathrm{C}_{\mathrm{m}}$ es el coste de la materia prima utilizada.

$\mathrm{C}_{\mathrm{t}}$ es el coste del transporte desde la producción de materia prima hasta la producción de la aplicación.

$\mathrm{C}_{\mathrm{p}}$ es el coste del proceso de producción.

Para ello se consideran los siguientes datos:

- El precio de mercado del saco de $17 \mathrm{~kg}$ de escayola Iberyola es de 1,45€ $(0,09$ $€ / \mathrm{kg})$.

- El precio del agua según tarifas del Canal de Isabel II para el año 2018 es de $0,001486 € /$ litro.

- El precio del PR se considera 0,00 € al tratarse de un residuo del que se deshace la empresa de reciclaje y a la que está generando unos costes de unos $45,95 € / \mathrm{m}^{3}(22,47 €$ de transporte y $23,48 €$ de canon de vertedero). Precios obtenidos de "Generador de precios. Cype España".

- El precio estimado del transporte de la granza en camión de 10 toneladas, desde la empresa de reciclaje y, considerando la carga y cambio de contenedor de $7 \mathrm{~m}^{3}$, es de $157,32 € / \mathrm{ud}$. Por tanto el precio por $\mathrm{m}^{3}$ es de 22,47€. El CO y $\mathrm{CO}_{2}$ generado en el transporte desde la empresa de reciclaje a la empresa de producción de paneles, se considera similar al generado en el transporte desde la empresa de reciclaje a la empresa de gestión de residuos donde sería incinerado el PR. 
- Se toman $411 \mathrm{~kg}$ de PR para un volumen de $1 \mathrm{~m}^{3}$, teniendo en cuenta la densidad aparente de la granza $\left(0,411 \mathrm{~g} / \mathrm{cm}^{3}\right.$ - apartado 6.1.1.1).

- Se valora el coste de producción en un $+10 \%$ respecto al coste de producción del compuesto sin granza.

\subsubsection{Fase IV del plan experimental: Propiedades de los compuestos seleccionados de yeso con PR}

Al igual que para la Fase III, las series realizadas en la Fase IV del plan experimental se describen en la Tabla 5.6, definiéndose tipo de conglomerante (E: escayola), dimensiones de probetas, matriz de yeso utilizada (IY: Iberyola de Placo), relación agua/yeso $(0,8)$, cantidad de PR agregada (0\%PR-50\%PR-60\%PR-70\%PR) y ensayo realizado:

Tabla 5.6. Denominación probetas del compuesto. FASE IV

\begin{tabular}{|c|c|c|c|c|c|c|c|}
\hline & Referen. & Denom. & Dimensiones & $\begin{array}{c}\text { Matriz } \\
\text { utilizada }\end{array}$ & $\begin{array}{c}\text { Relación } \\
\text { agua/yeso }\end{array}$ & $\% P R$ & $\begin{array}{c}\text { Ensayo } \\
\text { realizado }\end{array}$ \\
\hline \multirow{33}{*}{$\sum_{\substack{5 \\
5}}^{2}$} & \multirow{4}{*}{ Serie IX } & $\mathrm{E}_{0,8}$ & $\emptyset 1 \mathrm{~cm} \mathrm{h:} 1 \mathrm{~cm}$ & IY & 0,8 & $0 \%$ & \multirow{4}{*}{$\begin{array}{l}\text { - Porosimetría } \\
\text { de mercurio } \\
\text { - Microscopía } \\
\text { de barrido }\end{array}$} \\
\hline & & $\mathrm{E}_{0,8-50 \mathrm{PR}}$ & $\emptyset 1 \mathrm{~cm} \mathrm{~h}: 1 \mathrm{~cm}$ & IY & 0,8 & $50 \%$ & \\
\hline & & $\mathrm{E}_{0,8-60 \mathrm{PR}}$ & $\varnothing 1 \mathrm{~cm} \mathrm{~h}: 1 \mathrm{~cm}$ & IY & 0,8 & $60 \%$ & \\
\hline & & $\mathrm{E}_{0,8-70 \mathrm{PR}}$ & $\emptyset 1 \mathrm{~cm} \mathrm{~h}: 1 \mathrm{~cm}$ & IY & 0,8 & $70 \%$ & \\
\hline & \multirow{4}{*}{ Serie X } & $\mathrm{E}_{0,8}$ & $40 \times 20 \times 1 \mathrm{~cm}^{3}$ & IY & 0,8 & $0 \%$ & \multirow{4}{*}{$\begin{array}{l}\text { - Adherencia } \\
\text { superficial }\end{array}$} \\
\hline & & $\mathrm{E}_{0,8-50 \mathrm{PR}}$ & $40 \times 20 \times 1 \mathrm{~cm}^{3}$ & IY & 0,8 & $50 \%$ & \\
\hline & & $\mathrm{E}_{0,8-60 \mathrm{PR}}$ & $40 \times 20 \times 1 \mathrm{~cm}^{3}$ & IY & 0,8 & $60 \%$ & \\
\hline & & $\mathrm{E}_{0,8-70 \mathrm{PR}}$ & $40 \times 20 \times 1 \mathrm{~cm}^{3}$ & IY & 0,8 & $70 \%$ & \\
\hline & \multirow{4}{*}{ Serie XI } & $\mathrm{E}_{0,8}$ & $15 \times 15 \times 2 \mathrm{~cm}^{3}$ & IY & 0,8 & $0 \%$ & \multirow{4}{*}{ - R. a Impacto } \\
\hline & & $\mathrm{E}_{0,8-50 \mathrm{PR}}$ & $15 \times 15 \times 2 \mathrm{~cm}^{3}$ & IY & 0,8 & $50 \%$ & \\
\hline & & $\mathrm{E}_{0,8-60 \mathrm{PR}}$ & $15 \times 15 \times 2 \mathrm{~cm}^{3}$ & IY & 0,8 & $60 \%$ & \\
\hline & & $\mathrm{E}_{0,8-70 \mathrm{PR}}$ & $15 \times 15 \times 2 \mathrm{~cm}^{3}$ & IY & 0,8 & $70 \%$ & \\
\hline & \multirow{4}{*}{ Serie XII } & $\mathrm{E}_{0,8}$ & $40 \times 30 \times 1 \mathrm{~cm}^{3}$ & IY & 0,8 & $0 \%$ & \multirow{4}{*}{$\begin{array}{l}\text { - R. a Flexión de } \\
\text { paneles }\end{array}$} \\
\hline & & $\mathrm{E}_{0,8-50 \mathrm{PR}}$ & $40 \times 30 \times 1 \mathrm{~cm}^{3}$ & IY & 0,8 & $50 \%$ & \\
\hline & & $\mathrm{E}_{0,8-60 \mathrm{PR}}$ & $40 \times 30 \times 1 \mathrm{~cm}^{3}$ & IY & 0,8 & $60 \%$ & \\
\hline & & $\mathrm{E}_{0,8-70 \mathrm{PR}}$ & $40 \times 30 \times 1 \mathrm{~cm}^{3}$ & IY & 0,8 & $70 \%$ & \\
\hline & \multirow{4}{*}{$\begin{array}{l}\text { Serie } \\
\text { XIII }\end{array}$} & $\mathrm{E}_{0,8}$ & $4 \times 4 \times 16 \mathrm{~cm}^{3}$ & IY & 0,8 & $0 \%$ & \multirow{4}{*}{$\begin{array}{l}\text { - Absorción de } \\
\text { agua por } \\
\text { capilaridad }\end{array}$} \\
\hline & & $\mathrm{E}_{0,8-50 \mathrm{PR}}$ & $4 \times 4 \times 16 \mathrm{~cm}^{3}$ & IY & 0,8 & $50 \%$ & \\
\hline & & $\mathrm{E}_{0,8-60 \mathrm{PR}}$ & $4 \times 4 \times 16 \mathrm{~cm}^{3}$ & IY & 0,8 & $60 \%$ & \\
\hline & & $\mathrm{E}_{0,8-70 \mathrm{PR}}$ & $4 \times 4 \times 16 \mathrm{~cm}^{3}$ & IY & 0,8 & $70 \%$ & \\
\hline & \multirow{4}{*}{$\begin{array}{l}\text { Serie } \\
\text { XIV }\end{array}$} & $\mathrm{E}_{0,8}$ & $\emptyset 16,5 \mathrm{~cm} \mathrm{h:} 1,5 \mathrm{~cm}$ & IY & 0,8 & $0 \%$ & \multirow{4}{*}{$\begin{array}{l}\text { - Permeabilida } \\
\text { d al vapor de } \\
\text { agua }\end{array}$} \\
\hline & & $\mathrm{E}_{0,8-50 \mathrm{PR}}$ & $\emptyset 16,5 \mathrm{~cm}$ h: $1,5 \mathrm{~cm}$ & IY & 0,8 & $50 \%$ & \\
\hline & & $\mathrm{E}_{0,8-60 \mathrm{PR}}$ & $\emptyset 16,5 \mathrm{~cm} \mathrm{~h}: 1,5 \mathrm{~cm}$ & IY & 0,8 & $60 \%$ & \\
\hline & & $\mathrm{E}_{0,8-70 \mathrm{PR}}$ & $\emptyset 16,5 \mathrm{~cm} \mathrm{h:} 1,5 \mathrm{~cm}$ & IY & 0,8 & $70 \%$ & \\
\hline & \multirow{4}{*}{ Serie XV } & $\mathrm{E}_{0,8}$ & $4 \times 4 \times 16 \mathrm{~cm}^{3}$ & IY & 0,8 & $0 \%$ & \multirow{4}{*}{$\begin{array}{l}\text { - Cámara } \\
\text { húmeda }\end{array}$} \\
\hline & & $\mathrm{E}_{0,8-50 \mathrm{PR}}$ & $4 \times 4 \times 16 \mathrm{~cm}^{3}$ & IY & 0,8 & $50 \%$ & \\
\hline & & $\mathrm{E}_{0,8-60 \mathrm{PR}}$ & $4 \times 4 \times 16 \mathrm{~cm}^{3}$ & IY & 0,8 & $60 \%$ & \\
\hline & & $\mathrm{E}_{0,8-70 \mathrm{PR}}$ & $4 \times 4 \times 16 \mathrm{~cm}^{3}$ & IY & 0,8 & $70 \%$ & \\
\hline & \multirow{4}{*}{$\begin{array}{l}\text { Serie } \\
\text { XVI }\end{array}$} & $\mathrm{E}_{0,8}$ & $4 \times 4 \times 16 \mathrm{~cm}^{3}$ & IY & 0,8 & $0 \%$ & \multirow{4}{*}{$\begin{array}{l}\text { - Ciclo de agua- } \\
\text { estufa }\end{array}$} \\
\hline & & $\mathrm{E}_{0,8-50 \mathrm{PR}}$ & $4 \times 4 \times 16 \mathrm{~cm}^{3}$ & IY & 0,8 & $50 \%$ & \\
\hline & & $\mathrm{E}_{0,8-60 \mathrm{PR}}$ & $4 \times 4 \times 16 \mathrm{~cm}^{3}$ & IY & 0,8 & $60 \%$ & \\
\hline & & $\mathrm{E}_{0,8-70 \mathrm{PR}}$ & $4 \times 4 \times 16 \mathrm{~cm}^{3}$ & IY & 0,8 & $70 \%$ & \\
\hline & Serie & $\mathrm{E}_{0,8}$ & $30 \times 30 \times 1,5 \mathrm{~cm}^{3}$ & IY & 0,8 & $0 \%$ & - Absorción \\
\hline
\end{tabular}




\begin{tabular}{|c|c|c|c|c|c|c|}
\hline XVII & $\begin{array}{l}\mathrm{E}_{0,8-50 \mathrm{PR}} \\
\mathrm{E}_{0,8-60 \mathrm{PR}} \\
\mathrm{E}_{0,8-70 \mathrm{PR}}\end{array}$ & $\begin{array}{l}30 \times 30 \times 1,5 \mathrm{~cm}^{3} \\
30 \times 30 \times 1,5 \mathrm{~cm}^{3} \\
30 \times 30 \times 1,5 \mathrm{~cm}^{3}\end{array}$ & $\begin{array}{l}\text { IY } \\
\text { IY } \\
\text { IY }\end{array}$ & $\begin{array}{l}0,8 \\
0,8 \\
0,8\end{array}$ & $\begin{array}{l}50 \% \\
60 \% \\
70 \%\end{array}$ & total de agua \\
\hline $\begin{array}{l}\text { Serie } \\
\text { XVIII }\end{array}$ & $\begin{array}{c}E_{0,8} \\
E_{0,8-50 P R} \\
E_{0,8-60 P R} \\
E_{0,8-70 P R}\end{array}$ & $\begin{array}{l}32 \times 15 \times 1,5 \mathrm{~cm}^{3} \\
32 \times 15 \times 1,5 \mathrm{~cm}^{3} \\
32 \times 15 \times 1,5 \mathrm{~cm}^{3} \\
32 \times 15 \times 1,5 \mathrm{~cm}^{3}\end{array}$ & $\begin{array}{l}\text { IY } \\
\text { IY } \\
\text { IY } \\
\text { IY }\end{array}$ & $\begin{array}{l}0,8 \\
0,8 \\
0,8 \\
0,8\end{array}$ & $\begin{array}{c}0 \% \\
50 \% \\
60 \% \\
70 \% \\
\end{array}$ & - Fuego real \\
\hline $\begin{array}{l}\text { Serie } \\
\text { XIX }\end{array}$ & $\begin{array}{c}\mathrm{E}_{0,8} \\
\mathrm{E}_{0,8-50 \mathrm{PR}} \\
\mathrm{E}_{0,8-60 \mathrm{PR}} \\
\mathrm{E}_{0,8-70 \mathrm{PR}}\end{array}$ & $\begin{array}{l}4 \times 4 \times 16 \mathrm{~cm}^{3} \\
4 \times 4 \times 16 \mathrm{~cm}^{3} \\
4 \times 4 \times 16 \mathrm{~cm}^{3} \\
4 \times 4 \times 16 \mathrm{~cm}^{3}\end{array}$ & $\begin{array}{l}\text { IY } \\
\text { IY } \\
\text { IY } \\
\text { IY }\end{array}$ & $\begin{array}{l}0,8 \\
0,8 \\
0,8 \\
0,8\end{array}$ & $\begin{array}{c}0 \% \\
50 \% \\
60 \% \\
70 \% \\
\end{array}$ & $\begin{array}{l}\text { - Conductivida } \\
\text { d térmica C- } \\
\text { Therm TCi }\end{array}$ \\
\hline Serie XX & $\begin{array}{c}\mathrm{E}_{0,8} \\
\mathrm{E}_{0,8-50 \mathrm{PR}} \\
\mathrm{E}_{0,8-60 \mathrm{PR}} \\
\mathrm{E}_{0,8-70 \mathrm{PR}}\end{array}$ & $\begin{array}{l}30 \times 30 \times 3 \mathrm{~cm}^{3} \\
30 \times 30 \times 3 \mathrm{~cm}^{3} \\
30 \times 30 \times 3 \mathrm{~cm}^{3} \\
30 \times 30 \times 3 \mathrm{~cm}^{3}\end{array}$ & $\begin{array}{l}\text { IY } \\
\text { IY } \\
\text { IY } \\
\text { IY }\end{array}$ & $\begin{array}{l}0,8 \\
0,8 \\
0,8 \\
0,8\end{array}$ & $\begin{array}{c}0 \% \\
50 \% \\
60 \% \\
70 \% \\
\end{array}$ & $\begin{array}{l}\text { - Conductivida } \\
\text { d térmica } \\
\text { IETcc (UNE- } \\
\text { EN 12667) }\end{array}$ \\
\hline $\begin{array}{l}\text { Serie } \\
\text { XXI }\end{array}$ & $\begin{array}{c}\mathrm{E}_{0,8} \\
\mathrm{E}_{0,8-50 \mathrm{PR}} \\
\mathrm{E}_{0,8-60 \mathrm{PR}} \\
\mathrm{E}_{0,8-70 \mathrm{PR}}\end{array}$ & $\begin{array}{l}30 \times 30 \times 3 \mathrm{~cm}^{3} \\
30 \times 30 \times 3 \mathrm{~cm}^{3} \\
30 \times 30 \times 3 \mathrm{~cm}^{3} \\
30 \times 30 \times 3 \mathrm{~cm}^{3}\end{array}$ & $\begin{array}{l}\text { IY } \\
\text { IY } \\
\text { IY } \\
\text { IY }\end{array}$ & $\begin{array}{l}0,8 \\
0,8 \\
0,8 \\
0,8\end{array}$ & $\begin{array}{c}0 \% \\
50 \% \\
60 \% \\
70 \%\end{array}$ & $\begin{array}{l}\text { - Acabado } \\
\text { superficial }\end{array}$ \\
\hline
\end{tabular}

\subsubsection{Ensayos químicos de los compuestos seleccionados}

Los ensayos químicos realizados a los compuestos seleccionados se describen en este apartado.

\subsection{Porosimetría de mercurio}

Para la determinación del volumen de poros y la distribución de tamaños de poro en las mezclas, se ha realizado el ensayo de porosimetría de mercurio en el Laboratorio de Sólidos Porosos perteneciente a los Servicios Centrales de Apoyo a la Investigación de la Universidad de Málaga.

El equipo de trabajo utilizado ha sido el modelo Autopore IV 9500 de la casa comercial Micromeritics Instrument Corporation. Se elaboran probetas cilíndricas de $10 \mathrm{~mm}$ de diámetro y $10 \mathrm{~mm}$ de altura (Foto 5.22) y se introducen en el equipo que, a través de la intrusión de mercurio en la estructura porosa de la muestra mediante presión controlada, aporta información sobre volumen, tamaño, área superficial y diámetro medio de poros, además de la densidad aparente y de esqueleto. En el tratamiento de los datos presión aplicada-volumen de mercurio introducido se emplea la ecuación de Washburn. El ensayo se realiza a temperatura ambiente, llevando la muestra a un vacío de $50 \mu \mathrm{mHg}$ que se mantiene durante cinco minutos. A continuación se somete la muestra a presiones crecientes que fuerzan la entrada del mercurio en los poros hasta una presión máxima de 206 MPa. 


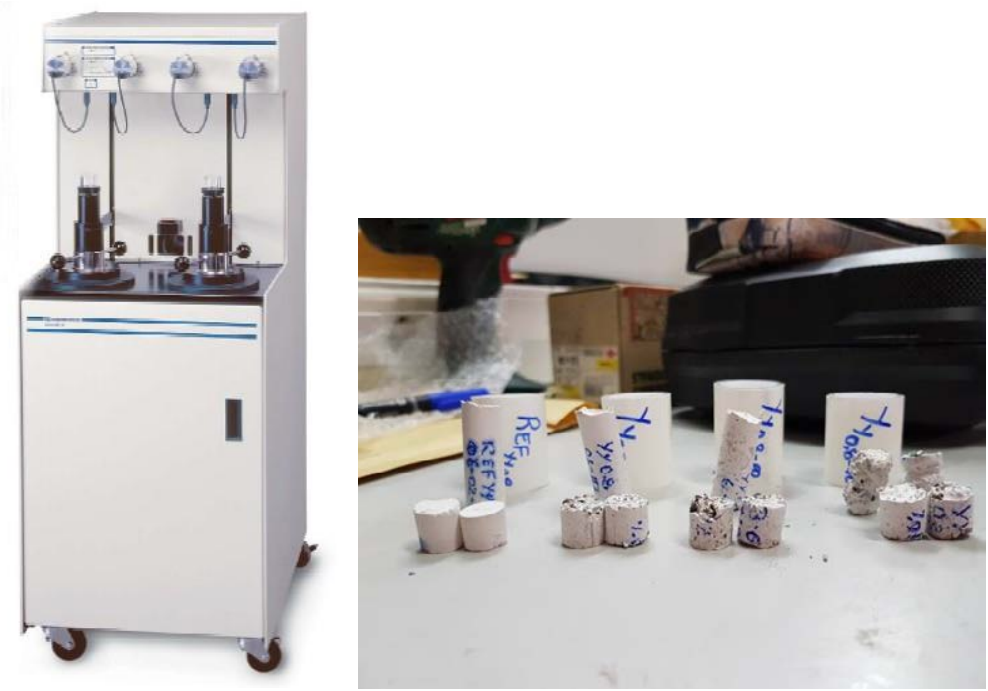

Foto 5.22. Izquierda: Equipo Autopore para la determinación del volumen de poros de los compuestos. Derecha: muestras preparadas para analizar

\subsection{Microscopía electrónica de barrido SEM}

Se ha realizado ensayo de microscopía electrónica de barrido (SEM), en el Laboratorio de Materiales de Construcción de la Faculty of Civil and Environmental Engineering de Bialystok University of Technology (Polonia).

Para ello el microscopio electrónico de barrido ambiental utilizado ha sido el SEMQuanta FEG-250 (Foto 5.23), que permite la observación de muestras biológicas de tamaño hasta $50 \mathrm{~mm}$, poco conductoras, sin tratamiento previo y, posibilita la desaceleración de electrones sobre dichas muestras, dando a conocer la morfología y textura cristalina de la muestra así como la interfaz con la granza.
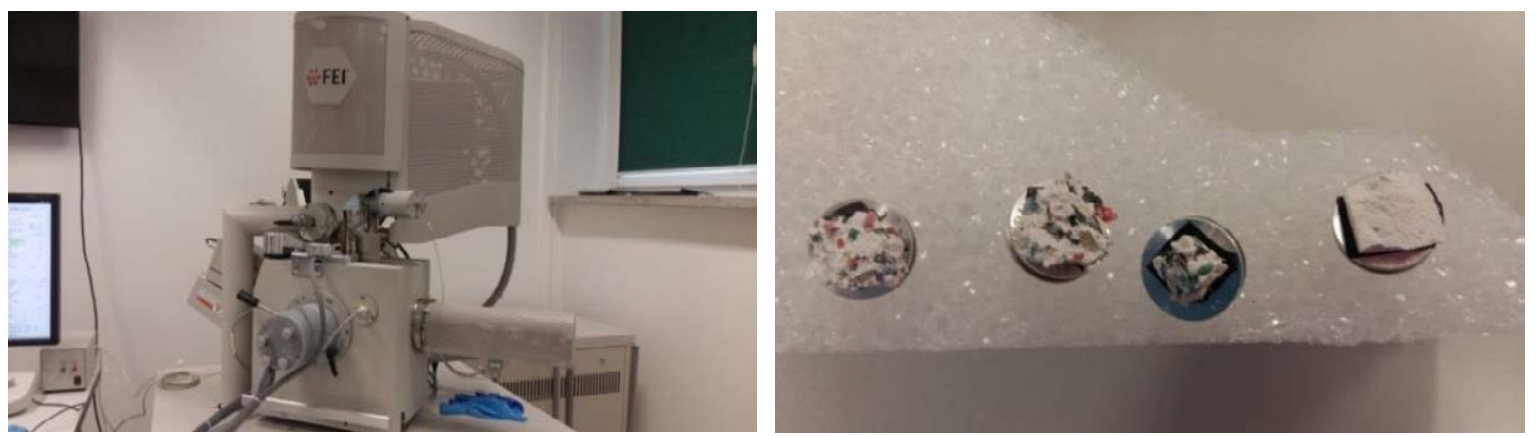

Foto 5.23. Izquierda: equipo SEM-Quanta para la realización de ensayo de microscopía electrónica de barrido (SEM). Derecha: muestras preparadas para su análisis

Las muestras ensayadas proceden de pequeños fragmentos de las probetas ensayadas a flexión y compresión, de aproximadamente $1 \times 1 \mathrm{~cm}^{2}$, colocadas sobre portamuestras de acero inoxidable. Una vez colocadas en el microscopio, "el haz pasa a través de las lentes condensadoras y de objetivo, y es barrido a lo largo de la muestra 
por las bobinas de barrido, mientras que un detector cuenta el número de electrones secundarios de baja energía emitidos por cada punto de la superficie" (Díaz Carretero, Landa Cánovas, \& Otero-Díaz, 2002), de manera que se forma una imagen SEM.

\subsubsection{Ensayos mecánicos de los compuestos seleccionados}

Los ensayos mecánicos realizados a los compuestos seleccionados se describen en este apartado.

\subsection{Resistencia al choque-impacto}

Se determina la resistencia al choque-impacto mediante el ensayo de dureza superficial de placa indicado en la norma UNE EN 520 (UNE-EN 520:2005+A1, 2010). Este ensayo se ha realizado en el Laboratorio de Materiales de la Escuela Técnica Superior de Edificación de la Universidad Politécnica de Madrid.

Sobre una mesa rígida se coloca la probeta con la cara hacia arriba. Se sitúa la bola de acero, de $50 \mathrm{~mm}$ de diámetro y $510 \pm 10$ g de masa, a una altura de $500 \pm 5 \mathrm{~mm}$ desde la parte baja de la misma hasta la cara superior de la placa y se deja caer (Foto 5.24). Se mide el diámetro de la huella dejada por el impacto con precisión de $1 \mathrm{~mm}$.
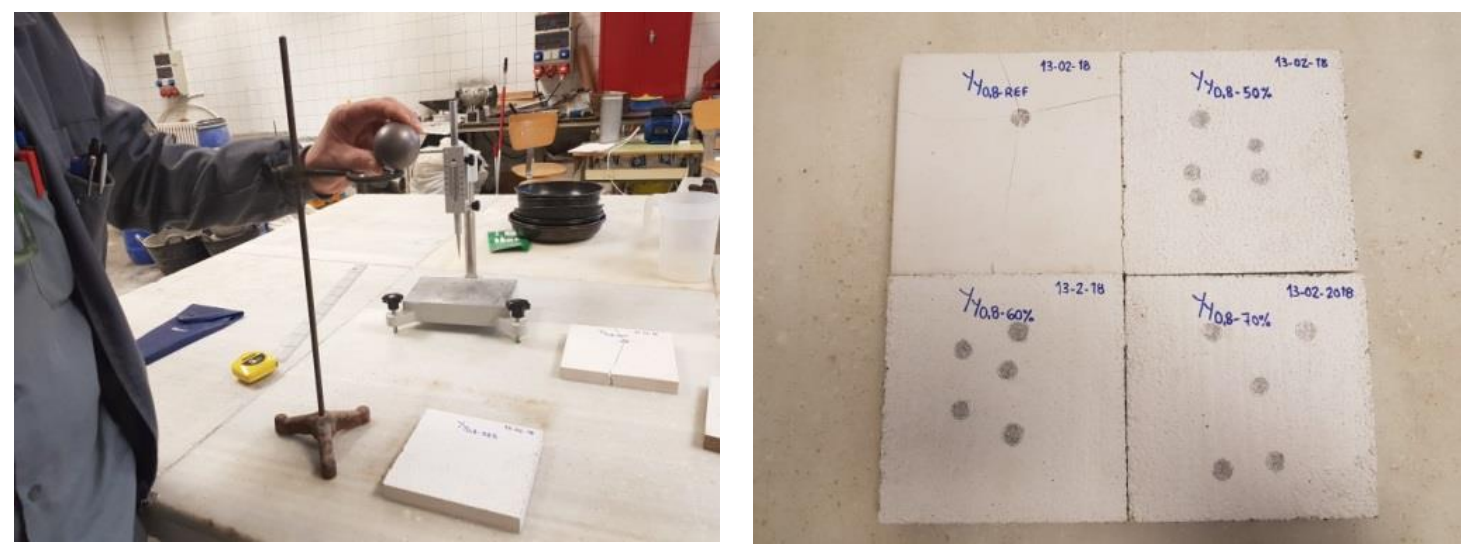

Foto 5.24. Izquierda: bola de acero. Derecha: huella de la bola por impacto

La resistencia al choque de impacto se mide por la profundidad de huella determinada por la bola de acero después del impacto, según la expresión:

$$
h=\left[D-\sqrt{\left.\left(D^{2}-d^{2}\right)\right] / 2}\right.
$$


donde,

$\mathrm{h}$ es la profundidad de la huella después de impacto en $\mathrm{mm}$

D es el diámetro de la bola de acero en $\mathrm{mm}$

d es el diámetro de la huella después de impacto en mm

\subsection{Resistencia a la flexión de paneles}

La resistencia mecánica de rotura a flexión de paneles sometidos a una carga en tres puntos, se realiza según la norma UNE-EN 12859 (UNE-EN 12859, 2012) en el Laboratorio de Materiales de la Escuela Técnica Superior de Edificación de la Universidad Politécnica de Madrid.

Los paneles se sitúan en posición horizontal sobre la máquina de ensayo modelo MPX-22 de PÁCAM provista de dos soportes cilíndricos paralelos dispuestos sobre una base nivelada (Foto 5.25). A continuación y mediante un rodillo de carga, se aplica la carga en el centro del panel de forma continua y a una velocidad aproximada de $20 \mathrm{~N} / \mathrm{s}$ hasta su rotura.
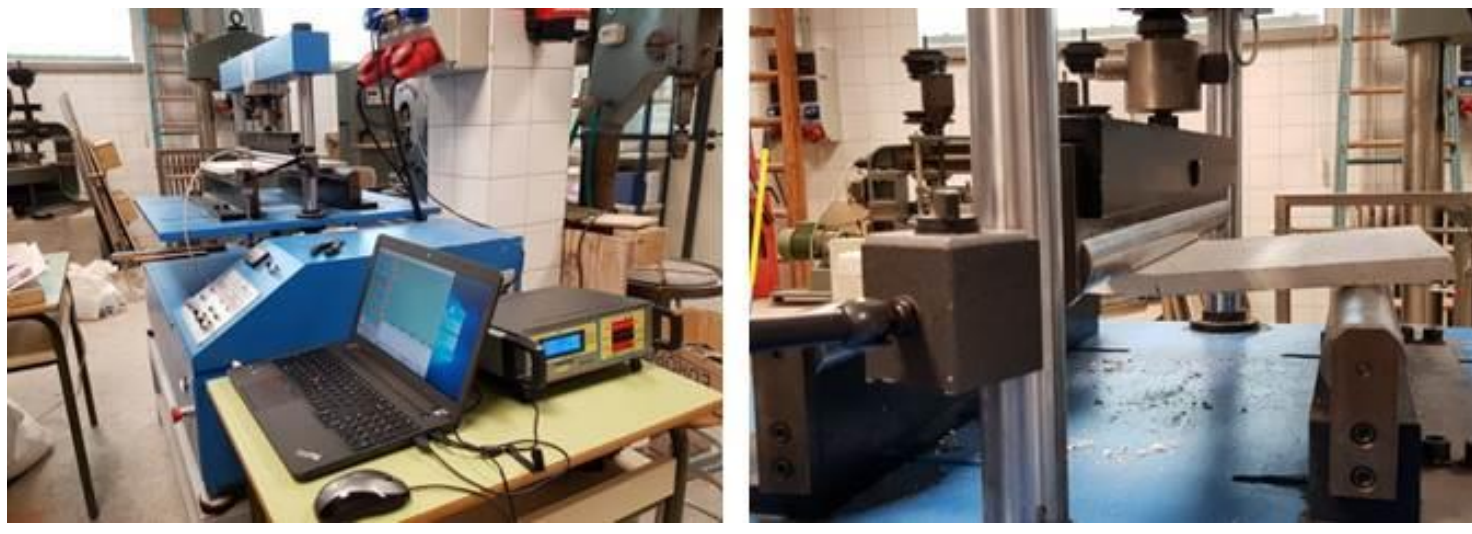

Foto 5.25. Izquierda: equipo MPX-22. Derecha: carga aplicada en el centro del panel

La resistencia a flexión de los paneles en estudio no debe ser menor de 0,18 kN en base a las proporciones aplicadas a la Tabla 4 a) Carga de rotura de los paneles de yeso tipo $A$ de la norma UNE-EN 12859 (UNE-EN 12859, 2012). En concreto se asigna un $53 \%$ por diferencia de distancia entre soportes $(0,9 \mathrm{kN})$ y posteriormente un $20 \%$ por diferencia de espesor de panel $(0,18 \mathrm{kN})$. 


\subsection{Adherencia superficial}

Mediante el ensayo de determinación de la adherencia indicado en la norma UNE EN 13279-2 (UNE-EN 13279-2:2014, 2014), se obtiene el valor de adherencia de un yeso a un soporte específico. Este ensayo se ha realizado en el Laboratorio de Materiales de la Escuela Técnica Superior de Edificación de la Universidad Politécnica de Madrid.

Se prepara la superficie de los soportes seleccionados (ladrillos huecos sencillos de $40 \mathrm{~cm} \times 20 \mathrm{~cm}$ ). Se amasa la mezcla de yeso y se aplica sobre el soporte siguiendo las recomendaciones del fabricante. Cuando la mezcla de las probetas ha fraguado éstas se mantienen 7 días en atmósfera de laboratorio.

A continuación, mediante la corona metálica de $50 \mathrm{~mm}$ de diámetro y $10 \mathrm{~mm}$ de espesor se realizan 5 cortes de $5 \mathrm{~mm}$ de profundidad en cada probeta. Sobre los cortes y con adhesivo epoxi, se pega el disco de metal centrado, asegurándose que no se ocupa el hueco existente entre la zona circular y el resto de la probeta. Finalmente, se aplica la carga de forma perpendicular a la superficie del ensayo mediante el téster de adhesión modelo Dynatest de la marca comercial Ibertest, a una velocidad de carga constante por segundo comprendida entre $0,003 \mathrm{~N} / \mathrm{mm}^{2}$ y $0,1 \mathrm{~N} / \mathrm{mm}^{2}$ (Foto 5.26 ).
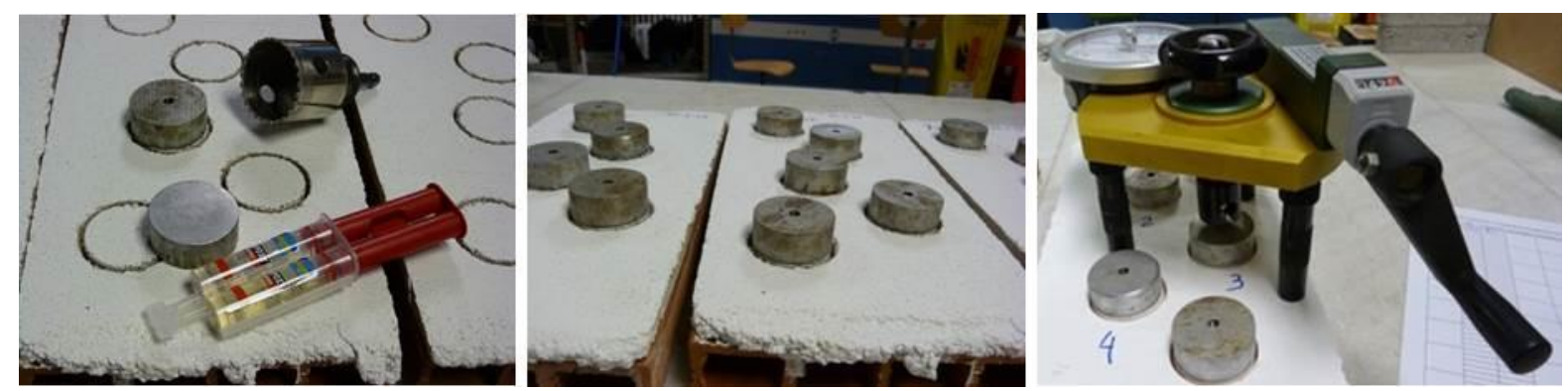

Foto 5.26. Izquierda: superficie del soporte con cortes $\mathrm{de} 5 \mathrm{~mm}$ de profundidad. Centro: discos de metal pegados con adhesivo epoxi al conglomerante aplicado sobre el soporte. Derecha: equipo Dynatest aplicando carga.

La resistencia de adherencia viene dada por la expresión:

$$
\mathrm{R}_{\mathrm{u}}=\mathrm{F}_{\mathrm{u}} / \mathrm{A}
$$

donde,

$\mathrm{R}_{\mathrm{u}}$ es la fuerza de adherencia en $\mathrm{N} / \mathrm{mm}^{2}$

$\mathrm{F}_{\mathrm{u}}$ es la carga media de rotura en $\mathrm{N}$ de los tres valores obtenidos

A es el área de ensayo de la probeta cilíndrica en $\mathrm{mm}^{2}$

Según la norma UNE EN 13279-1 (UNE-EN 13279-1:2009, 2009), cuando la rotura aparece en la interfase capa de yeso-soporte, rotura por adhesión, el valor debe ser 
mayor o igual de $0,1 \mathrm{~N} / \mathrm{mm}^{2}$. Cuando la rotura aparece en la masa del yeso, rotura por cohesión, el valor de la resistencia de adherencia es superior a los valores indicados por el equipo de ensayo.

\subsubsection{Ensayos físicos de los compuestos seleccionados}

Los ensayos físicos realizados a los compuestos seleccionados se describen en este apartado.

\subsection{Comportamiento frente al agua}

Para el análisis del comportamiento de los compuestos frente al agua se han realizado los ensayos que se describen a continuación.

\subsection{Absorción de agua por capilaridad}

Para conocer la velocidad de absorción por capilaridad de las diferentes mezclas, se realiza el ensayo de absorción de agua, basado en la norma RILEM RC 25-PEM (RILEM RC 25-PEM, 1980). Este ensayo se ha realizado en el Laboratorio de Materiales de la Escuela Técnica Superior de Edificación de la Universidad Politécnica de Madrid.

Para ello, una vez desecadas las probetas de $40 \times 40 \times 160 \mathrm{~mm}^{3}$ en estufa 24 horas a $40^{\circ} \mathrm{C} \pm 5^{\circ} \mathrm{C}$ hasta masa constante, se introducen en un recipiente con agua, colocadas en posición vertical, sobre unos soportes y con un nivel de agua que las rebase en 10 $\mathrm{mm} \pm 1 \mathrm{~mm}$. Durante 10 minutos se va midiendo el nivel de agua alcanzado en cada cara cada uno de los minutos (Foto 5.27). El resultado se expresa en milímetros por minuto.

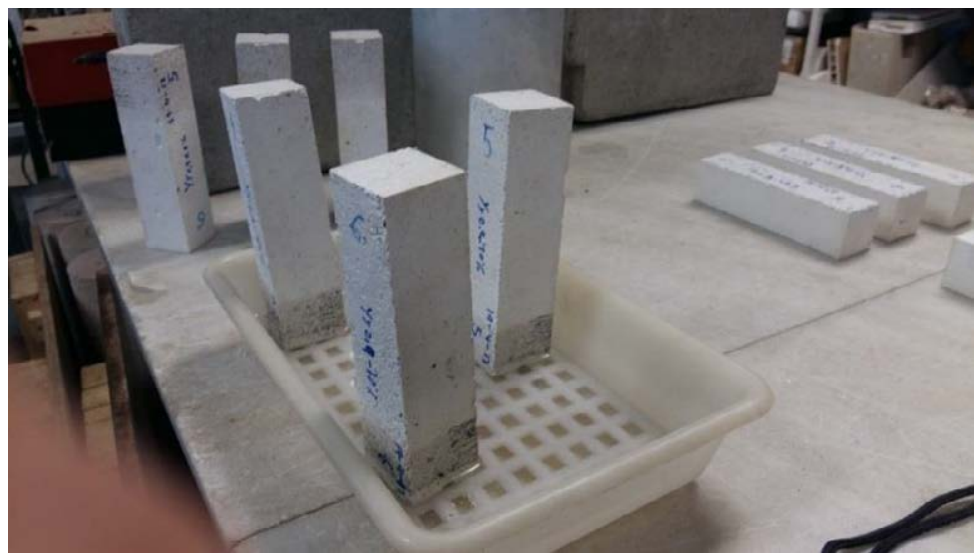

Foto 5.27. Determinación de la absorción de agua por capilaridad 


\subsection{Permeabilidad al vapor de agua}

Mediante el ensayo del método del vaso indicado en la norma UNE EN ISO 12572 (UNE-EN ISO 12572:2018, 2018), se obtienen las propiedades de transmisión de vapor de agua de los compuestos, de manera que se calcula la cantidad de vapor de agua que pasa a través de la superficie de un material con un espesor definido. Este ensayo se ha realizado en el Laboratorio de Materiales de la Escuela Técnica Superior de Edificación de la Universidad Politécnica de Madrid.

Sobre moldes circulares se realizan probetas de espesor $1,5 \pm 0,5 \mathrm{~cm}$ que se almacenan a $23 \pm 5^{\circ} \mathrm{C}$ y $50 \pm 5 \%$ de humedad relativa durante 7 días (Foto 5.28). Una vez transcurrido este tiempo se procede a introducir una solución saturada acuosa, nitrato potásico disuelto en agua, en la taza de ensayo para asegurar la humedad relativa del interior al $94 \%$ a una temperatura de $23 \pm 5^{\circ} \mathrm{C}$. A continuación se sella la probeta circular sobre la cara abierta de la taza de ensayo y se procede a la anotación del peso semanalmente.
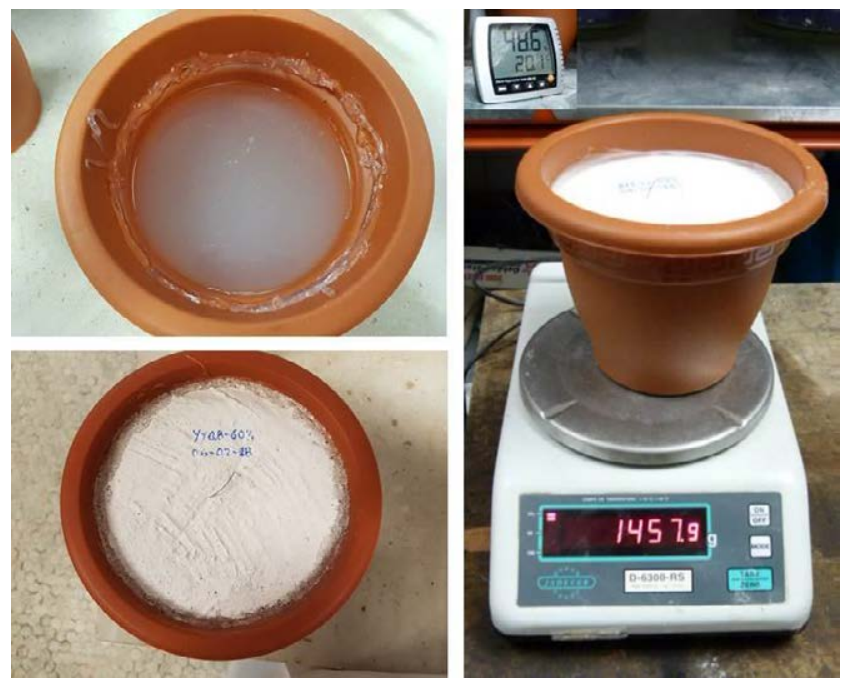

Foto 5.28. Izquierda superior: recipiente con solución saturada acuosa (nitrato potásico disuelto en agua). Izquierda inferior: moldes circulares sellados. Derecha: anotación semanal del peso de las probetas

La permeabilidad al vapor de agua viene dada por la expresión:

$$
\mathrm{P}=\mathrm{PR} \times \mathrm{e}
$$

donde,

$\mathrm{P}$ es la permeabilidad al vapor de agua $[\mathrm{g} /(\mathrm{m} \times \mathrm{h} \times \mathrm{mm} \mathrm{Hg})]$

$\mathrm{PR}$ es la permeancia al vapor de agua $\left[\mathrm{g} /\left(\mathrm{m}^{2} \mathrm{x} \mathrm{h} \mathrm{x} \mathrm{mm} \mathrm{Hg}\right)\right]$

e es el espesor de la probeta en $\mathrm{m}$ 
La permeancia al vapor de agua viene dada por la expresión:

$$
\mathrm{PR}=\mathrm{TVA} / \Delta \mathrm{p}
$$

donde,

TVA es el grado de transmisión de vapor de agua $\left[\mathrm{g} /\left(\mathrm{m}^{2} \mathrm{x} h\right)\right]$

$\Delta \mathrm{p}$ se obtiene de la expresión $\Delta \mathrm{p}=\mathrm{S}\left(\mathrm{R}_{1}-\mathrm{R}_{2}\right)$

$\mathrm{S}$ es la presión de saturación del vapor de agua a la temperatura del ensayo en $\mathrm{mm}$ Hg. Temperatura media $21^{\circ} \mathrm{C}$, presión de saturación 18,663mm Hg.

$\mathrm{R}_{1}$ es el \% de humedad relativa, del lado con mayor presión de vapor (expresado como fracción). Con nitrato de potasio la humedad relativa alcanzada es de $94 \%$.

$\mathrm{R}_{2}$ es el \% de humedad relativa, del lado con menor presión de vapor (expresado como fracción). La humedad relativa ambiental es de 50\%.

El grado de transmisión de vapor de agua viene dado por la expresión:

$$
\mathrm{TVA}=\Delta \mathrm{m} /(\mathrm{t} \times \mathrm{A})
$$

donde,

$\Delta \mathrm{m}$ es el cambio de masa, $\mathrm{g}$, en el tiempo, $\mathrm{t}$

t es el tiempo transcurrido entre lecturas en $h$

A es el área de ensayo de la muestra en $\mathrm{m}^{2}\left(0,02138246 \mathrm{~m}^{2}\right)$

Y, finalmente, la resistencia al vapor de agua viene dada por la expresión:

$$
\mathrm{R}=1 / \mathrm{PR}
$$

donde,

$\mathrm{R}$ es la resistencia al vapor de agua $\left[\left(\mathrm{m}^{2} \times \mathrm{h} \times \mathrm{mm} \mathrm{Hg} / \mathrm{g}\right)\right]$

\subsection{Cámara húmeda}

Se realiza ensayo no normalizado utilizado por del Río Merino en su tesis doctoral para analizar el comportamiento de los compuestos ante la humedad constante (del Río Merino, 1999). Este ensayo se ha realizado en el Laboratorio de Materiales de la Escuela Técnica Superior de Edificación de la Universidad Politécnica de Madrid.

Durante cinco días, las probetas prismáticas se introducen en cámara húmeda a temperatura $21^{\circ} \mathrm{C}$ y HR $72 \%$ (Foto 5.29 ). A los 5 días se toma nota de los incrementos de peso producidos en las mismas. Se dejan 7 días en atmósfera de laboratorio, se comprueba su dureza Shore $C$ y se ensayan a flexión y compresión con el equipo Ibertest definido en el apartado 5.3.1.2. 


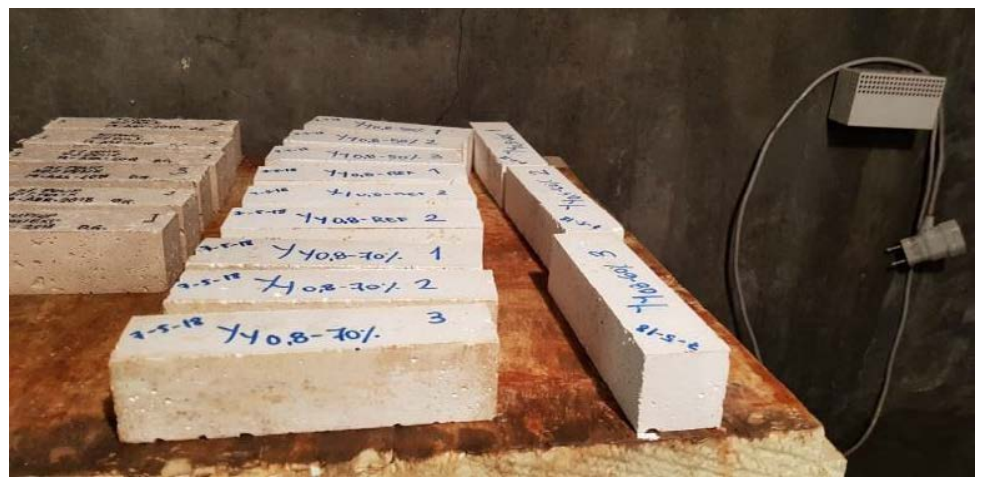

Foto 5.29. Probetas en cámara húmeda

\subsection{Ciclos humedad-sequedad}

Para determinar la capacidad de los compuestos para secarse, se realiza el procedimiento no normalizado seguido por del Río Merino en su tesis doctoral (del Río Merino, 1999). Este ensayo se ha realizado en el Laboratorio de Materiales de la Escuela Técnica Superior de Edificación de la Universidad Politécnica de Madrid.

Se utilizan probetas prismáticas que se introducen, totalmente sumergidas, durante dos días en un recipiente con agua (Foto 5.30). Pasado este tiempo, se sacan, se pesan y se introducen en estufa a $40 \pm 5^{\circ} \mathrm{C}$ otros dos días. Se realiza dos veces el método $\mathrm{y}$, finalmente, se comprueba su dureza Shore $\mathrm{C}$ y se ensayan a flexión y compresión con el equipo Ibertest definido en el apartado 5.3.1.2.
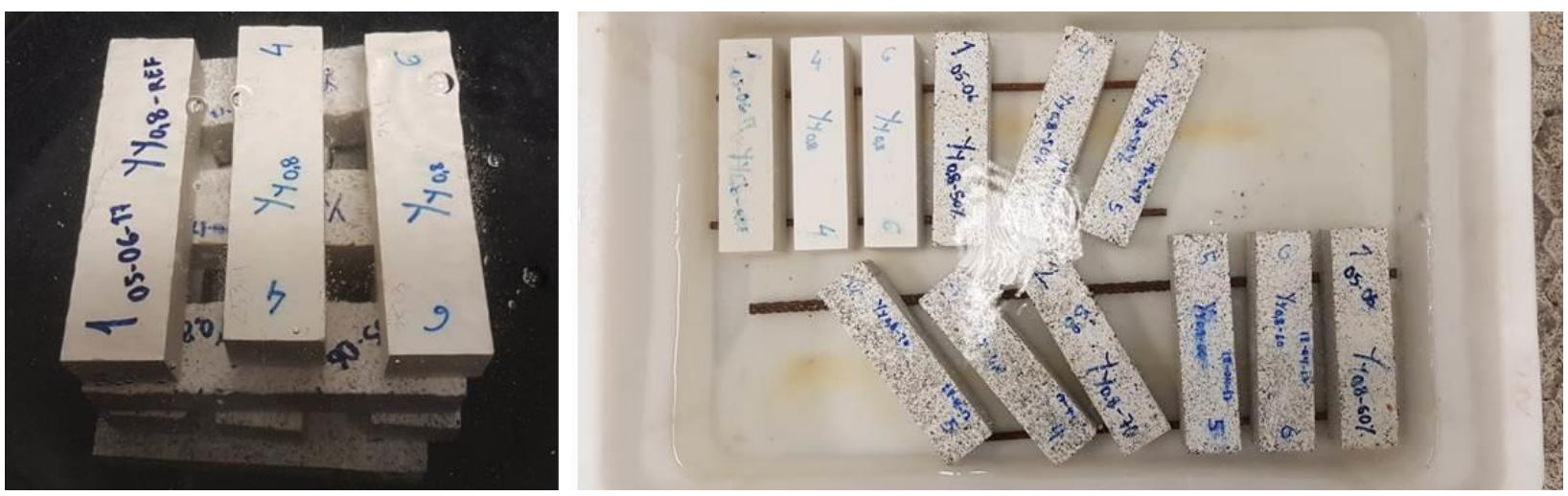

Foto 5.30. Izquierda probetas sumergidas 1er ciclo agua-estufa. Derecha: probetas sumergidas 2o ciclo agua-estufa

\subsection{Absorción total de agua}

Se determina la absorción total de agua de los compuestos, mediante el ensayo definido en la norma UNE-EN 520(UNE-EN 520:2005+A1, 2010). Este ensayo se ha realizado en el Laboratorio de Materiales de la Escuela Técnica Superior de Edificación de la Universidad Politécnica de Madrid. 
Se utilizan probetas de dimensiones $300 \pm 1,5 \mathrm{~mm}$ x $300 \pm 1,5 \mathrm{~mm}$ y $15 \mathrm{~mm}$ de espesor. Una vez pesada la probeta, se sumerge en agua en posición horizontal (cubierta con $25 \mathrm{~mm}$ a $35 \mathrm{~mm}$ ) y sin apoyar en el fondo del recipiente, durante $2 \mathrm{~h} \pm 2 \mathrm{~min}$ (Foto 5.31). Finalmente, se retira la probeta eliminando el exceso de agua con papel secante y se vuelve a pesar.

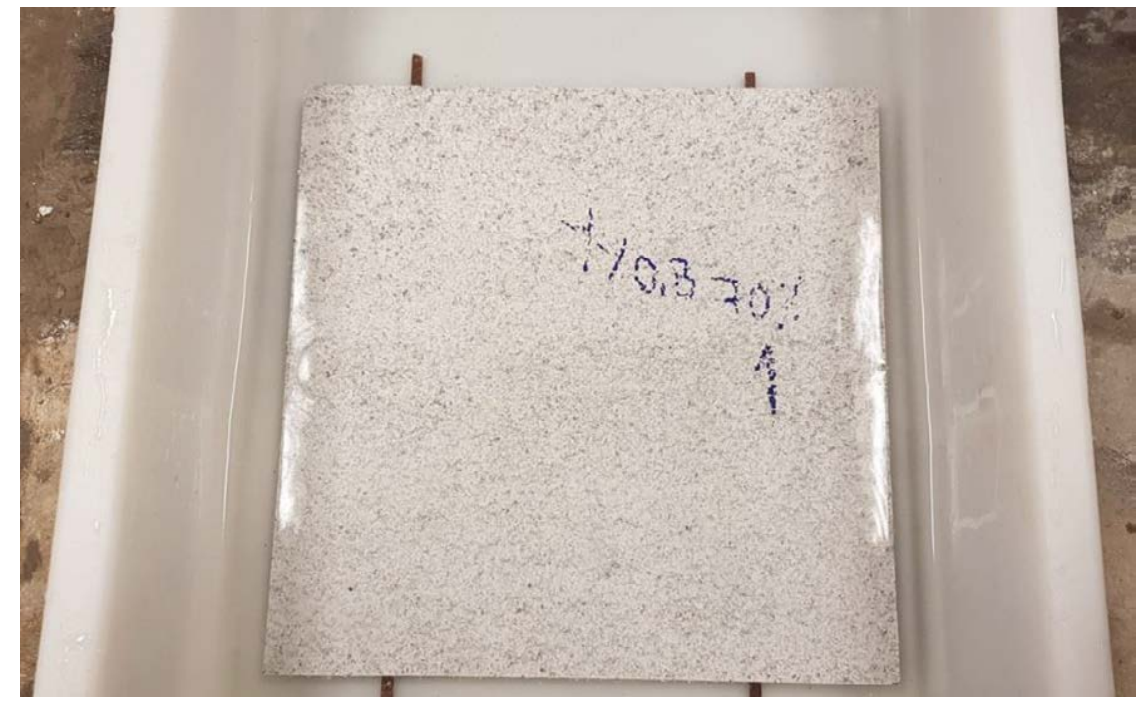

Foto 5.31. Panel sumergido completamente en agua

\subsection{Comportamiento frente al fuego}

Para el análisis del comportamiento de los compuestos frente al fuego se ha realizado un ensayo no normalizado así como una estimación de los gases desprendidos en la combustión de los compuestos que se describen a continuación.

\subsection{Ensayo real a fuego directo}

Para comprobar el efecto real del fuego en los compuestos se procede a la realización de un ensayo real no normalizado a fuego directo en el Parque de Bomberos de la Comunidad de Madrid situado en Collado Villalba, utilizando la carga de fuego indicada en la norma ISO 834 (ISO 834, 2014).

El ensayo de resistencia al fuego de los materiales de construcción, se basa en una curva de tiempo-temperatura definida en la ISO 834 que no representa ningún tipo de fuego natural (Figura 5.3), en cambio, un fuego real depende de la masa y energía de la estancia donde se produce, del tipo y cantidad de combustible y de las condiciones de ventilación existentes. El fuego real se desarrolla en cuatro fases: ignición, fuego latente, calentamiento y enfriamiento (Serrano, Cobo, Prieto, \& González, 2016). Se 
decide por tanto, observar el verdadero comportamiento de los compuestos y acometer este tipo de ensayo.

Para ello, siguiendo las indicaciones de la investigación de Serrano R. (Serrano Somolinos, 2018), se elaboran probetas a modo de paneles de $320 \pm 1,5 \mathrm{~mm} \times 150 \pm 1,5$ $\mathrm{mm}$ y espesor $15 \mathrm{~mm}$ y se dejan 7 días en condiciones de laboratorio. Se trasladan al lugar del ensayo y se sitúan sobre una parrilla de $1,00 \mathrm{~m}$ x 0,80 $\mathrm{m}$ en la que se colocan $20 \mathrm{~kg}$ de madera de pino troceada como carga de fuego, cantidad estimada para un ensayo de 30 minutos. Se pulveriza sobre la madera aproximadamente un litro de gasolina y se procede a encender el conjunto. Mediante un lector láser de temperatura modelo Testo 845 se hacen lecturas en 3 puntos de cada probeta cada 5 minutos, hasta completar los 30 minutos estimados (Fotos 5.32 y 5.33). La colocación de las probetas, en la parrilla, se realiza de modo que cada compuesto tenga una muestra en la zona más exterior al fuego, en la zona más interior y en la zona intermedia.

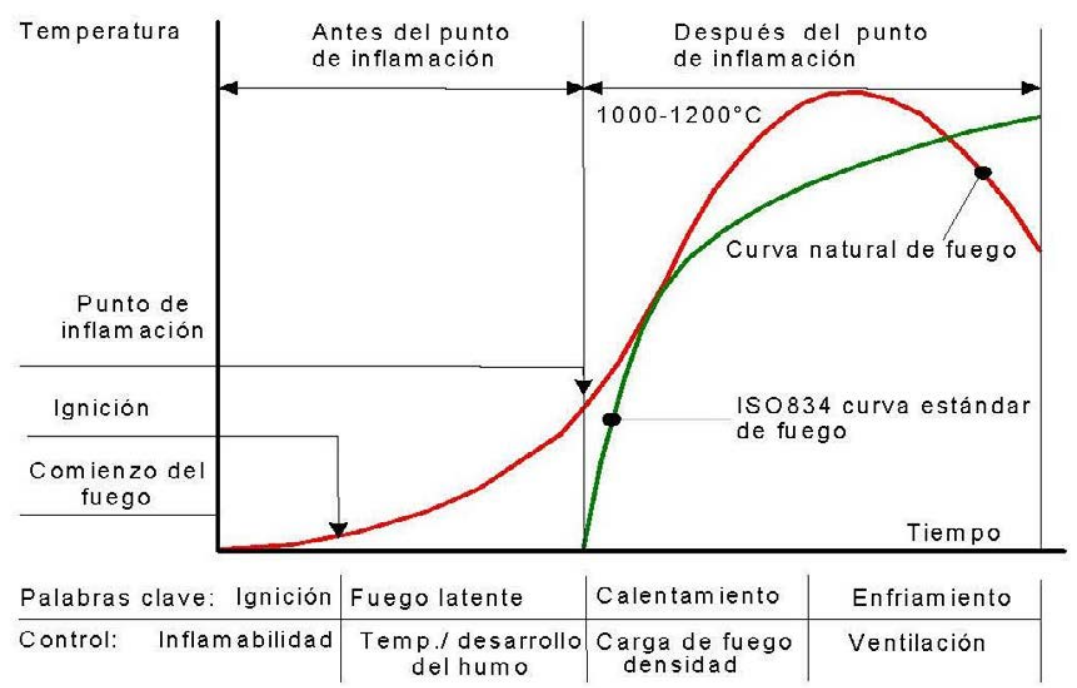

Figura 5.3. Fases de un fuego natural y fases de un fuego estandarizado (Serrano et al., 2016)
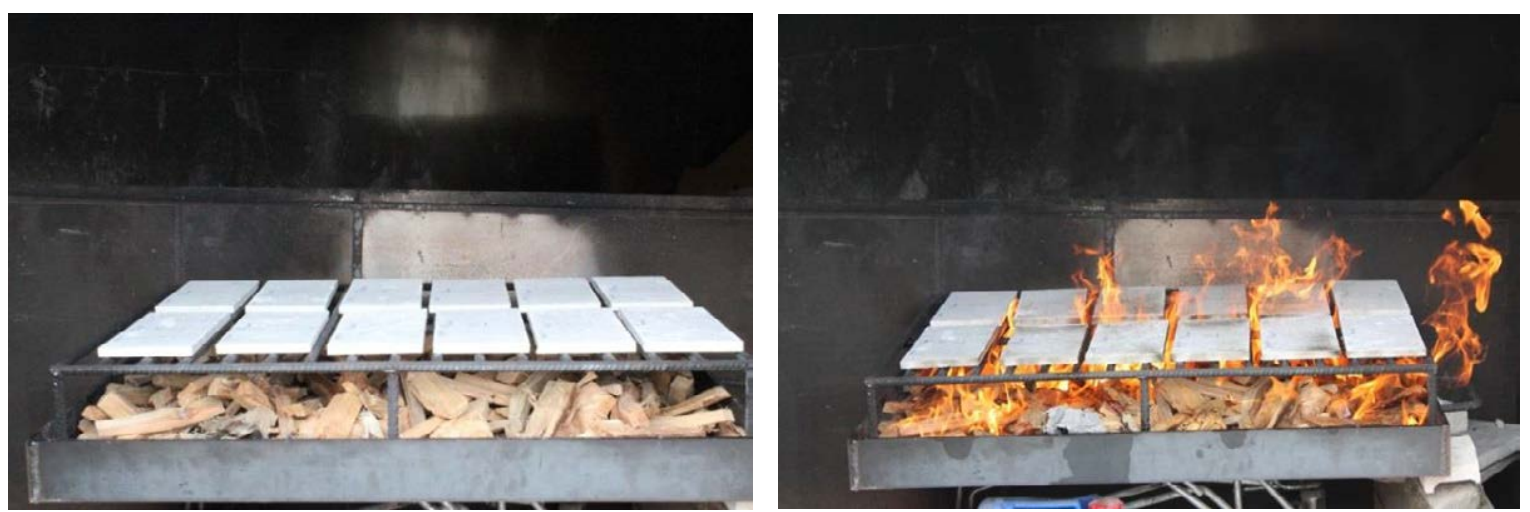

Foto 5.32. Fases del fuego - Parque de Bomberos Collado Villalba (Madrid). Izquierda: ignición; Derecha: fuego latente 

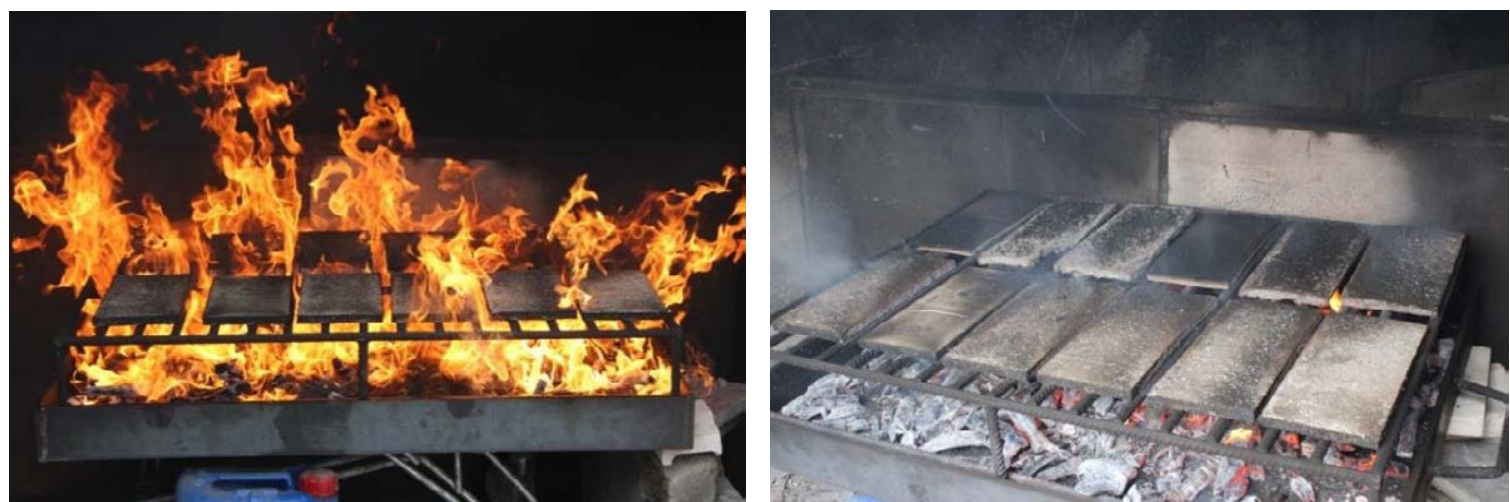

Foto 5.33. Fases del fuego - Parque de Bomberos Collado Villalba (Madrid). Izquierda: calentamiento; Derecha: enfriamiento

\subsection{Análisis y detección de los gases desprendidos en combustión}

Los principales productos de la combustión completa de la materia orgánica del PR son el dióxido de carbono $\left(\mathrm{CO}_{2}\right)$ y el agua $\left(\mathrm{H}_{2} \mathrm{O}\right)$ derivados, respectivamente, del carbono e hidrógeno presentes en el polímero. La combustión incompleta de la materia orgánica daría lugar a monóxido de carbono (CO).

Para el análisis y detección de los gases desprendidos por las mezclas durante la combustión (Foto 5.34), se ha examinado la bibliografía existente en este campo y se ha realizado un cálculo estimado de la cantidad de $\mathrm{CO}_{2}$ y $\mathrm{CO}$ que se generaría en base a la descomposición química que sufriría la granza PR según los resultados del ensayo de termogravimetría descrito en el apartado 5.1.2.2.1. y, del análisis elemental descrito en el apartado 5.1.2.2.3. Teniendo en cuenta este cálculo se ha realizado una estimación de la cantidad de $\mathrm{CO}$ y $\mathrm{CO}_{2}$ que emitirían los compuestos en una estancia tipo que sufriera un fuego real.

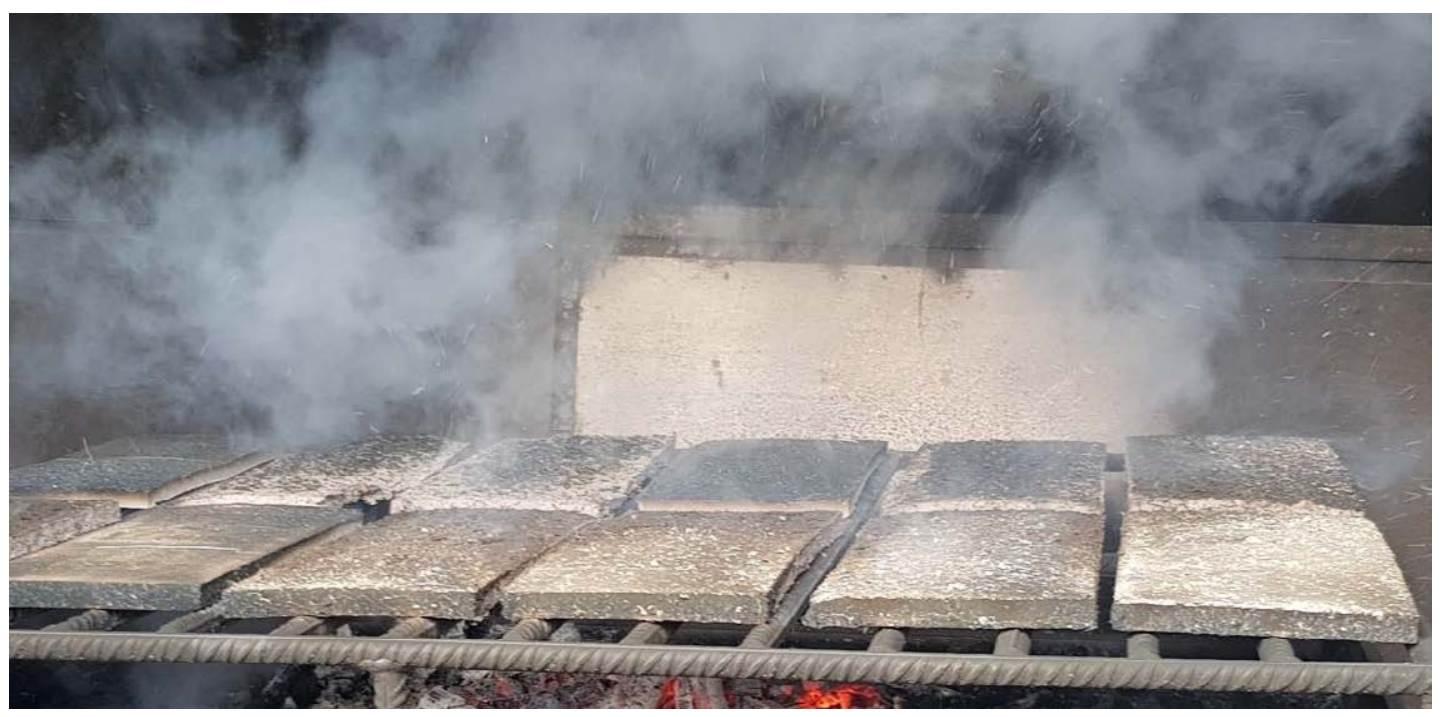

Foto 5.34. Humo originado en la combustión real de paneles del compuesto - Parque de Bomberos Collado Villalba (Madrid) 


\subsection{Propiedades térmicas}

Para el análisis de las propiedades térmicas de los compuestos se han realizado los ensayos que se describen a continuación.

\subsection{Coeficiente de conductividad térmica según técnica modificada de fuente plana transitoria}

Se determina el coeficiente de conductividad térmica mediante la técnica modificada de fuente plana transitoria definida en la norma ASTM D7984 (ASTM D7984, 2016). Este ensayo se ha realizado en el Laboratorio de Materiales de la Escuela Técnica Superior de Edificación de la Universidad Politécnica de Madrid.

Se utiliza el analizador de conductividad térmica modelo TCi de la casa comercial C-THERM en las probetas de 320 $\pm 1,5 \mathrm{~mm} \times 150 \pm 1,5 \mathrm{~mm}$ y espesor $15 \mathrm{~mm}$ elaboradas para el ensayo de fuego. Se selecciona el método de calibración de polímeros y, previa incorporación de un agente de contacto (Wakefield), se coloca la probeta sobre el sensor de reflectancia de calor de un solo lado que aplica calor constante y momentáneo a la muestra (Foto 5.35). Se obtiene en pocos segundos la conductividad y efusividad térmica.
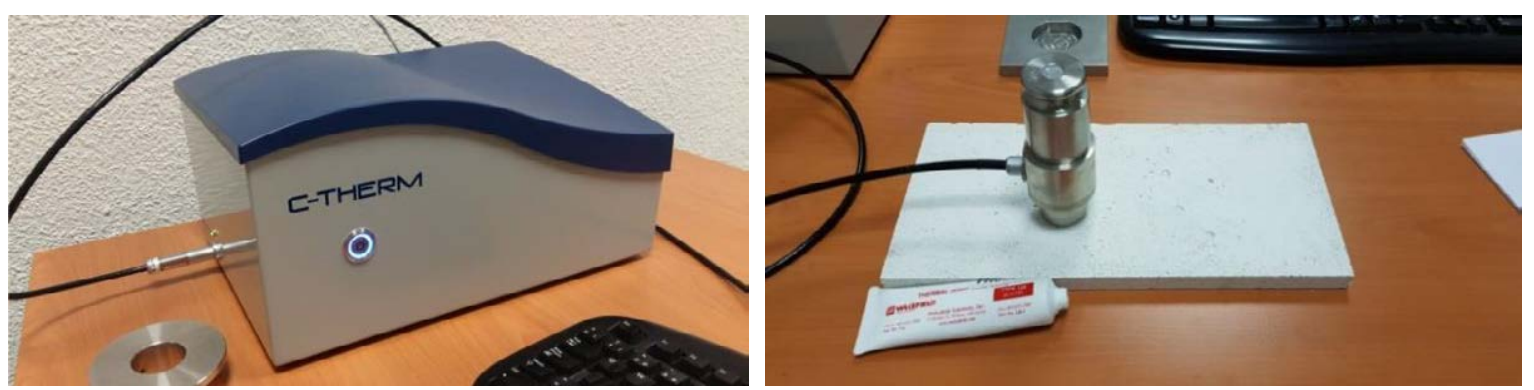

Foto 5.35. Izquierda: analizador de conductividad térmica TCi. Derecha: probeta durante el análisis térmico

\subsection{Coeficiente de conductividad térmica mediante el método de flujo de calor}

Se determina el coeficiente de conductividad térmica mediante el método de flujo de calor definido en la norma UNE-EN 12667 (UNE-EN 12667:2002, 2002). Se trata de un ensayo realizado en el Laboratorio de Instalaciones del Instituto de Ciencias de la Construcción Eduardo Torroja de Madrid.

Se utiliza el equipo Fox 304 de la casa comercial Lasercomp, en el que se introducen las probetas elaboradas con dimensiones específicas de $300 \mathrm{~mm}$ x 300 mm y $30 \mathrm{~mm}$ de espesor y planeidad de las caras, pesadas previamente (Foto 5.36). 
El equipo establece en el interior de las muestras una relación constante y una uniformidad en la densidad del flujo de calor, mediante una unidad calefactora, medidores de flujo de calor y una unidad enfriadora. La densidad de la relación del flujo de calor se mide a través de la diferencia de temperatura generada por esta densidad de la relación del flujo de calor a través de la muestra y el propio flujo de calor del medidor. El equipo proporciona los siguientes datos: densidad, espesor, conductividad térmica, flujo de calor y resistencia térmica.
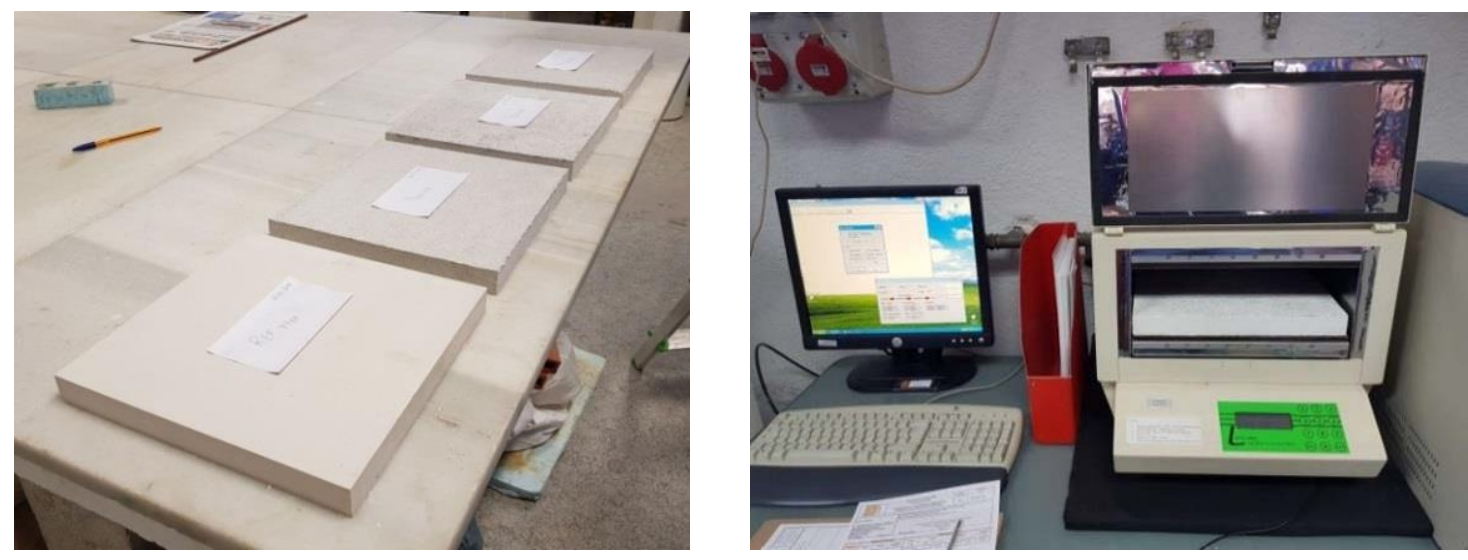

Foto 5.36. Izquierda: paneles para el ensayo. Derecha: equipo Fox de Lasercomp para la determinación del flujo de calor

\subsection{Análisis energético de los compuestos propuestos mediante simulación}

Se analizan, mediante simulación, dos soluciones constructivas de la envolvente térmica del edificio para el compuesto considerado más óptimo ( $\left.\mathrm{E}_{0,8-60 \mathrm{PR}}\right)$. La selección del compuesto se hace en base a su comportamiento térmico según el ensayo realizado en el Instituto de Ciencias de la Construcción "Eduardo Torroja" denominado "Determinación de la resistencia térmica por el método de la placa caliente y el método del medidor de flujo de calor. Productos de alta y media resistencia térmica" y especificado en el apartado 5.4.2.3.3.2.

Se decide realizar una simulación del comportamiento térmico de una fachada tipo y de un forjado tipo con falso techo. Se utiliza la herramienta informática STAR_CCM+ para los cálculos de la simulación, de manera que se evalúa la transferencia de calor de los dos sistemas constructivos mencionados comparándolos con los prototipos en los que se incorporan los compuestos en estudio. 


\section{Condiciones iniciales}

En base a la metodología utilizada por Porras Amores, C. (Porras Amores, Viñas Arrebola, Rodríguez Sánchez, \& Villoria Sáez, 2014) en la que se trabaja sobre modelos obtenidos a partir de datos del Código Técnico de la Edificación y, a la metodología utilizada por Iousef (Iousef, Montazeri, Blocken, \& Van Wesemael, 2017) en la que se recomienda la utilización de modelos cúbicos, se diseñan los modelos con los que realizar la simulación.

En primer lugar se definen los sistemas constructivos a analizar, en segundo lugar se crean unos modelos de referencia y, en tercer lugar, se establecen unos nuevos modelos (escenarios) donde se sustituyen uno o varios de los materiales del modelo de referencia por alguna de las aplicaciones de los compuestos en estudio.

Los sistemas constructivos a simular son:

- Envolvente vertical: cerramiento de fachada.

- Envolvente horizontal: cerramiento de cubierta plana.

Cada uno de los modelos se configura con una superficie de 1 x $1 \mathrm{~m}^{2}$ y los espesores correspondientes a cada elemento que lo compone.

\section{Modelo envolvente vertical: cerramiento de fachada}

Para el cerramiento vertical creado como modelo de referencia 1, se opta por una fachada de fábrica de ladrillo, no ventilada y con aislamiento por el interior que está compuesta de: medio pie de ladrillo cara vista, enfoscado, cámara de aire, aislamiento térmico, trasdosado de ladrillo hueco doble y un revestimiento de yeso. El esquema se muestra en la Figura 5. y sus características, recogidas del prontuario de soluciones constructivas de CTE WEB (CTE, 2007), en la Tabla 5.7.

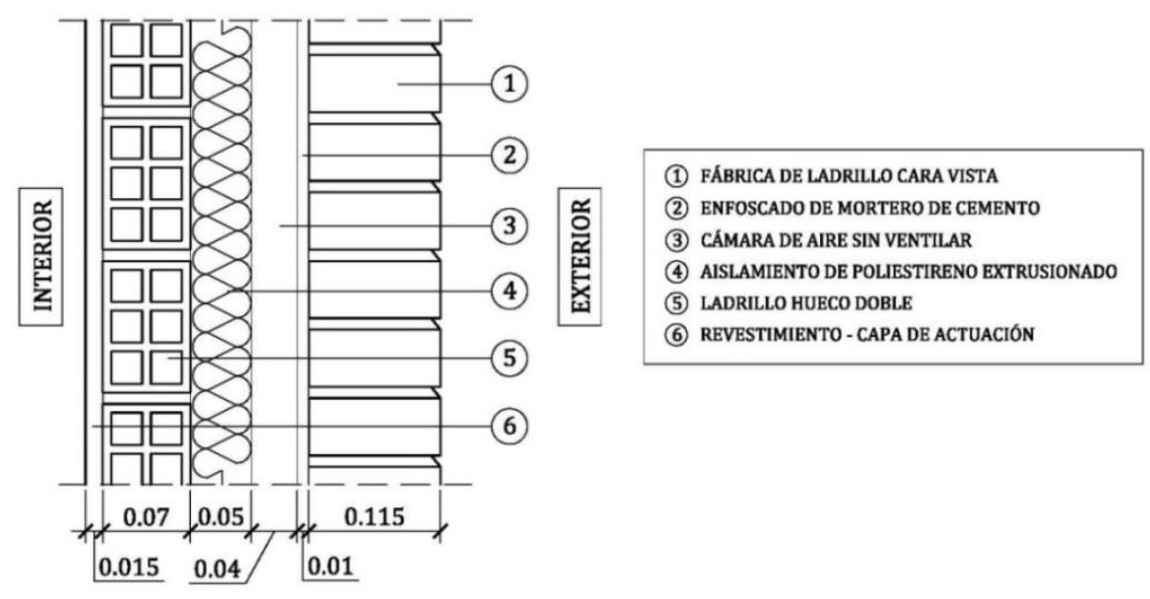

Figura 5.4. Modelo de referencia 1 - envolvente vertical 
Tabla 5.7. Datos iniciales para modelo de referencia 1

\begin{tabular}{|c|c|c|c|c|}
\hline Denominación & Espesor $(\mathrm{cm})$ & $\begin{array}{c}\text { Coeficiente de conductividad } \\
\text { térmica } \lambda(\mathrm{W} / \mathrm{mK})\end{array}$ & $\begin{array}{c}\text { Densidad } \\
\left(\mathrm{kg} / \mathrm{m}^{3}\right)\end{array}$ & $\begin{array}{c}\text { Calor específico } \\
\text { (J/kGK) }\end{array}$ \\
\hline $\begin{array}{l}\text { Fábrica de ladrillo } \\
\text { cara vista }\end{array}$ & 11,5 & 0,85 & 2300 & 1000 \\
\hline $\begin{array}{l}\text { Enfoscado de } \\
\text { mortero de cemento }\end{array}$ & 1,0 & 1,00 & 1600 & 1000 \\
\hline $\begin{array}{l}\text { Cámara de aire } \\
\text { vertical }\end{array}$ & 4,0 & $\mathrm{R}=0,177 \mathrm{~m}^{2} \mathrm{~K} / \mathrm{W}$ & --- & --- \\
\hline $\begin{array}{l}\text { Aislamiento térmico } \\
\text { XPS }\end{array}$ & 5,0 & 0,034 & 35 & 1000 \\
\hline Ladrillo hueco doble & 7,0 & 0,32 & 770 & 1000 \\
\hline $\begin{array}{l}\text { Revestimiento - } \\
\text { enlucido de yeso }\end{array}$ & 1,5 & 0,30 & 900 & 1000 \\
\hline
\end{tabular}

El elemento denominado "revestimiento" es el que se modifica en el Escenario 1 pasando de ser un enlucido de yeso tradicional a un panel con el compuesto seleccionado más óptimo.

\section{Modelo envolvente horizontal: cerramiento de cubierta plana}

Para el cerramiento horizontal creado como modelo de referencia 2, se opta por una cubierta plana no transitable autoprotegida, no ventilada, con aislamiento por encima del forjado y, que está compuesta de: lámina impermeable autoprotegida, geotextil, aislamiento térmico, barrera de vapor, formación de pendiente con hormigón ligero, forjado tipo, cámara de aire y placas de yeso. El esquema se muestra en la Figura 5.5 y sus características, recogidas del prontuario de soluciones constructivas de CTE WEB (CTE, 2007), en la Tabla 5.8.

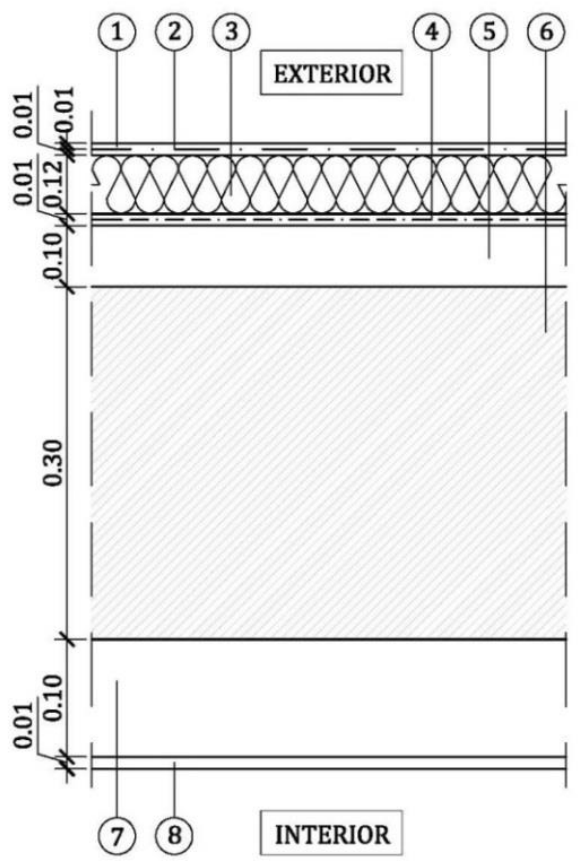

(1) LÁMINA IMPERMEABLE AUTOPROTEGIDA

(2) GEOTEXTIL

(3) AISLAMIENTO DE POLIESTIRENO EXTRUSIONADO

(4) BARRERA DE VAPOR

(5) FORMACIÓN DE PENDIENTE CON HORM. LIGERO

(6) FORJADO TIPO $25+5 \mathrm{~cm}$

(7) CÁMARA DE AIRE NO VENTILADA

(8) REVESTIMIENTO - CAPA DE ACTUACIÓN

Figura 5.5. Modelo de referencia 2 - envolvente horizontal 
Tabla 5.8. Datos iniciales para modelo de referencia 2

\begin{tabular}{|c|c|c|c|c|}
\hline Denominación & Espesor $(\mathrm{cm})$ & $\begin{array}{c}\text { Coeficiente de conductividad } \\
\text { térmica } \lambda(\mathrm{W} / \mathrm{mK})\end{array}$ & $\begin{array}{c}\text { Densidad } \\
\left(\mathrm{kg} / \mathrm{m}^{3}\right)\end{array}$ & $\begin{array}{c}\text { Calor específico } \\
(\mathrm{J} / \mathrm{kGK})\end{array}$ \\
\hline $\begin{array}{l}\text { Lámina } \\
\text { impermeable } \\
\text { autoprotegida }\end{array}$ & 0,5 & 0,23 & 1100 & 1000 \\
\hline Geotextil & 0,5 & 0,05 & 120 & 1300 \\
\hline $\begin{array}{l}\text { Aislamiento térmico } \\
\text { XPS }\end{array}$ & 5,0 & 0,034 & 35 & 1000 \\
\hline Barrera de vapor & 0,5 & 0,23 & 1100 & 1000 \\
\hline $\begin{array}{l}\text { Formación de } \\
\text { pendiente con } \\
\text { hormigón ligero }\end{array}$ & 5,0 & 0,41 & 900 & 1000 \\
\hline $\begin{array}{l}\text { Forjado tipo } \\
(25+5 \mathrm{~cm})\end{array}$ & 30,0 & $\mathrm{R}=0,32 \mathrm{~m}^{2} \mathrm{~K} / \mathrm{W}$ & 1110 & 1000 \\
\hline $\begin{array}{l}\text { Cámara de aire } \\
\text { horizontal }\end{array}$ & 10,0 & $\mathrm{R}=0,16 \mathrm{~m}^{2} \mathrm{~K} / \mathrm{W}$ & --- & --- \\
\hline $\begin{array}{l}\text { Revestimiento - } \\
\text { placa de yeso }\end{array}$ & 1,2 & 0,25 & 900 & 1000 \\
\hline
\end{tabular}

Al igual que en el modelo de referencia 1, el elemento denominado "revestimiento" es el que se modifica en el Escenario 2 pasando de ser un enlucido de yeso tradicional a una placa del compuesto seleccionado más óptimo.

\section{Análisis del comportamiento térmico}

Cada uno de los modelos y escenarios generados es analizado en cuanto a diferencia de temperatura entre sus caras interior y exterior y, diferencia de energía originada en el elemento constructivo en $\mathrm{W} / \mathrm{m}^{2}$.

\subsection{Acabados superficiales}

Para evaluar el acabado superficial de los compuestos seleccionados en las aplicaciones propuestas, se realizan los siguientes ensayos.

\subsection{Confort superficial}

Se comprueba el confort superficial de los compuestos en estudio según el "Manual del yeso" de Villanueva (Villanueva Domínguez \& García Santos, 2001). Para ello se calcula el coeficiente de penetración térmica que viene dado por la expresión:

$$
b=\sqrt{ }(\lambda \times c \times \rho)
$$

donde,

$\mathrm{b}$ es el coeficiente de penetración térmica en $\mathrm{J} / \mathrm{s}^{1 / 2} \mathrm{~m}^{2} \mathrm{~K}$.

$\lambda$ es la conductividad térmica en $\mathrm{W} / \mathrm{mK}$.

c es el calor específico en $\mathrm{J} / \mathrm{kgK}$. Según Código Técnico de la Edificación, para yeso de alta dureza es $1000 \mathrm{~J} / \mathrm{kgK}$. 
$\rho$ es la densidad en $\mathrm{kg} / \mathrm{m}^{3}$.

\subsection{Análisis visual de la superficie}

Se efectúa un análisis visual de los compuestos con distintos acabados superficiales mediante la aplicación de enlucido y pintura según método tradicional. Este ensayo se ha realizado en el Laboratorio de Materiales de la Escuela Técnica Superior de Edificación de la Universidad Politécnica de Madrid.

Sobre probetas de dimensiones $300 \mathrm{~mm}$ x $300 \mathrm{~mm}$ y $30 \mathrm{~mm}$ de espesor se ejecuta un enlucido de 1,5 mm de espesor al que, a su vez y una vez seco, se aplica una capa de pintura (Foto 5.37).
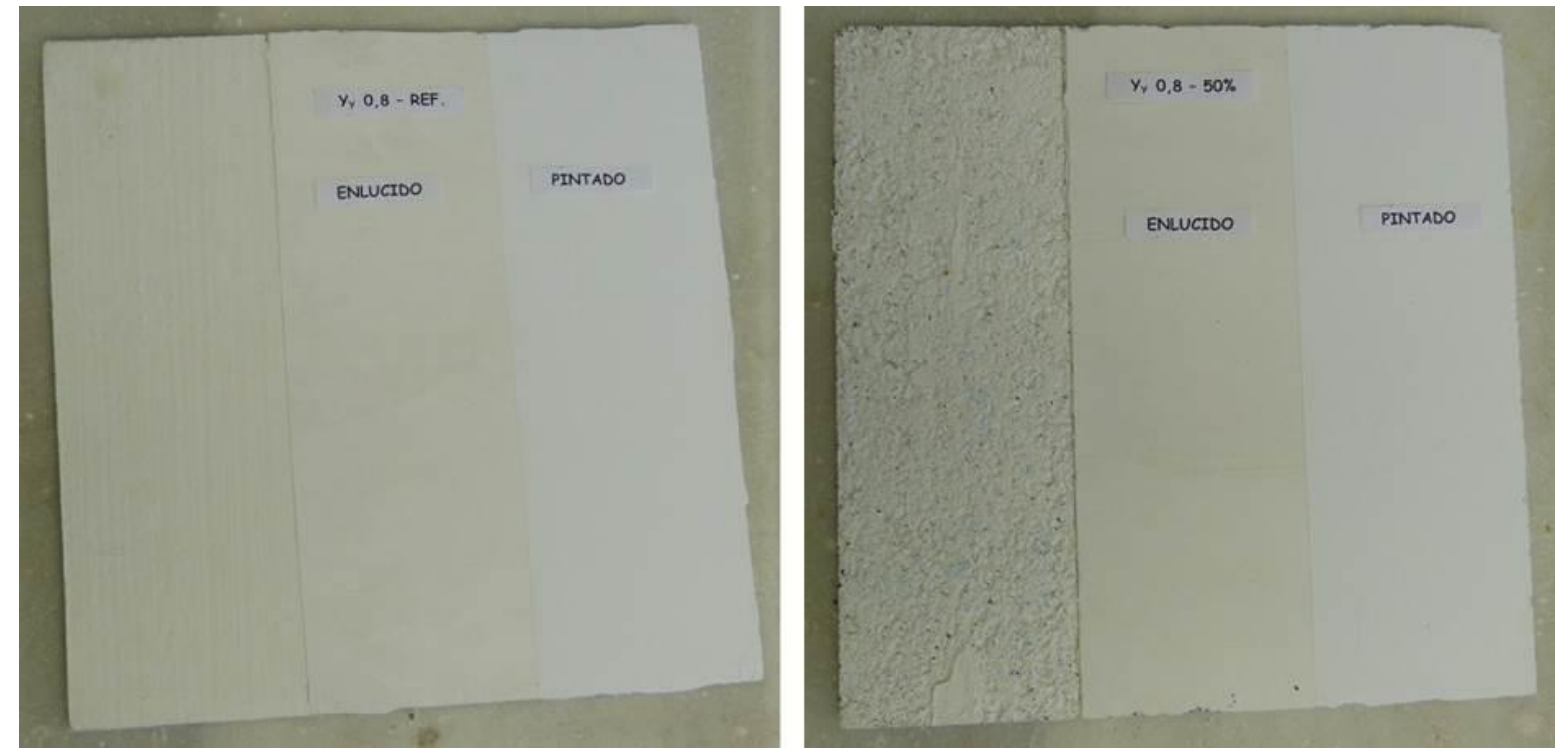

Foto 5.37. Acabados en panel de referencia (izquierda) y en panel de compuesto con PR (derecha) 


\subsection{ESTUDIO DEL IMPACTO AMBIENTAL (Objetivo 5)}

Para realizar el estudio del impacto ambiental se analiza:

- $\quad$ El uso de recursos naturales.

- La minimización del PR.

\subsubsection{Uso de los recursos naturales}

Para la comprobación de la cantidad de materia prima utilizada en los compuestos durante la investigación, se utiliza la metodología llevada a cabo por Santa Cruz Astorqui (Santa Cruz Astorqui, del Río Merino, Villoria Sáez, \& Porras Amores, 2019) en la que, a partir del peso húmedo de las probetas, del peso seco y de la densidad de la materia prima, se obtiene un porcentaje con el que poder comparar la cantidad de materia prima utilizada, respecto a las referencias.

\subsubsection{Minimización del PR. Criterio de economía circular}

Teniendo en cuenta lo comentado en el apartado 1.3.5 de la introducción de la tesis, y ante la imposibilidad de conocer el número de empresas de reciclaje de cables en España, para este análisis se considera que cada empresa de reciclaje genera unas $50 \mathrm{Tn} / \mathrm{mes}$ de residuo (dato proporcionado por Lyrsa Álava). A continuación, se realiza el cálculo de la cantidad de paneles tipo (2000 x $1200 \times 12,5 \mathrm{~mm}^{3}$ ) de cada compuesto que, al mes, se podría fabricar por cada una de estas empresas. Finalmente, se compara la cantidad de paneles que se podrían fabricar con el residuo existente en los centros de reciclaje, con la cantidad de paneles que produce una empresa media de prefabricados $(25.000$ uds/mes según datos de Pladur Gypsum, S.A.), para comprobar la disponibilidad de PR y su minimización. 


\subsection{TRABAJOS CITADOS}

ASTM D7984. (2016). Standard test method for measurements of thermal effusivity of fabrics using a modified transient plane source (MTPS) instrument.

CTE. (2007). Código Técnico de la Edificación. http://cte-web.iccl.es/sistemas.php

del Río Merino, M. (1999). Elaboración y aplicaciones constructivas de paneles prefabricados de escayola aligerada y reforzada con fibras de vidrio $E$ y otros aditivos (Tesis Doctoral, Universidad Politécnica de Madrid (España)). https://doi.org/http://oa.upm.es/612/

Díaz Carretero, I., Landa Cánovas, Á. R., \& Otero-Díaz, L. C. (2002). Microscopía electrónica de transmisión (TEM) y de barrido (SEM). Consejo Superior de Investigaciones Científicas (Ed.), Técnicas de análisis y caracterización de materiales (1a, pp. 455-459). Madrid (España)

Iousef, S., Montazeri, H., Blocken, B., \& Van Wesemael, P. J. V. (2017). On the use of non-conformal grids for economic LES of wind flow and convective heat transfer for a wall-mounted cube. Building and Environment, 119, 44-61. https://doi.org/10.1016/j.buildenv.2017.04.004

ISO 834. (2014). Fire resistance tests. Elements of building construction.

Mascarós, S. M. (2002). Difracción de rayos X. Consejo Superior de Investigaciones Científicas (Ed.), Técnicas de Análisis y Caracterización de Materiales (1ª). Madrid (España)

Porras Amores, C., Viñas Arrebola, C., Rodríguez Sánchez, A., \& Villoria Sáez, P. (2014). Assessing the potential use of strategies independent from the architectural design to achieve efficient ventilation: a Spanish case study. Building Services Engineering Research and Technology, 35(5), 529-542.

https://doi.org/10.1177/0143624414524065

RILEM RC 25-PEM. (1980). Recommended tests to measure the deterioration of stone and to assess the effectiveness of treatment methods. Materials and Structures, 13(75), 175-253

San Antonio González, A. (2017). Caracterización de compuestos eco-eficientes de yeso aligerado con residuo de poliestireno extruido (XPS) (Tesis Doctoral, Universidad Politécnica de Madrid (España)). https://doi.org/10.20868/UPM.thesis.48007

Santa Cruz Astorqui, J., del Río Merino, M., Villoria Sáez, P., \& Porras Amores, C. (2019). Análisis de la viabilidad de elementos prefabricados para particiones con yeso y EPS procedente del reciclaje. DYNA - Ingeniería e Industria, 94(4), 415420

Sastre de Andrés, E., \& Ferreira Aparicio, P. (2002). Análisis térmico. Consejo Superior de Investigaciones Científicas (Ed.), Técnicas de Análisis y Caracterización de Materiales (1 ${ }^{\mathrm{a}}$ ). Madrid (España)

Serrano, R., Cobo, A., Prieto, M. I., \& González, M. de las N. (2016). Analysis of fire 
resistance of concrete with polypropylene or steel fibers. Construction and Building Materials, 122, 302-309.

https://doi.org/10.1016/j.conbuildmat.2016.06.055

Serrano Somolinos, R. (2018). Estudio del comportamiento frente al fuego del hormigón en masa con adición de nanofibras de carbono (CNFS) y su comparación con hormigones sin adición y con otras adiciones (Tesis Doctoral, Universidad Politécnica de Madrid (España)). https://doi.org/10.20868/UPM.thesis.52181

Sorrentino, M. (2017). Viability of eco-gypsum composites with construction and demolition waste: physical, environmental and economic analysis for building applications. Trabajo Fin de Máster, Universidad Politécnica de Madrid (España).

UNE-EN 12667:2002. (2002). Materiales de construcción. Determinación de la resistencia térmica por el método de la placa caliente guardada y el método del medidor de flujo de calor. Productos de alta y media resistencia térmica

UNE-EN 12859. (2012). Paneles de yeso. Definiciones, especificaciones y métodos de ensayo

UNE-EN 12880. (2001). Caracterización de lodos. Determinación de la humedad y del contenido en materia seca

UNE-EN 13279-1:2009. (2009). Yesos de construcción y conglomerantes a base de yeso para la construcción. Parte 1: Definiciones y especificaciones

UNE-EN 13279-2:2014. (2014). Yesos de construcción y conglomerantes a base de yeso para la construcción. Parte 2: Métodos de ensayo

UNE-EN 520:2005+A1. (2010). Placas de yeso laminado. Definiciones, especificaciones y métodos de ensayo

UNE-EN 933-1. (2012). Ensayos para determinar las propiedades geométricas de los áridos. Parte 1: Determinación de la granulometría de las partículas. Método del tamizado

UNE-EN 933-2. (1996). Ensayo para determinar las propiedades geométricas de los áridos. Parte 2: Determinación de la granulometría de las partículas. Tamices de ensayo, tamaño nominal de las aberturas

UNE-EN ISO 12572:2018. (2018). Prestaciones higrotérmicas de los productos y materiales para edificación. Determinación de las propiedades de transmisión de vapor de agua. Método del vaso

UNE 102042. (2014). Yesos y escayolas de construcción. Otros métodos de ensayo

Villanueva Domínguez, L. de, \& García Santos, A. (2001). Manual del yeso (Asociación Técnica y Empresarial del Yeso. ATEDY, Ed.). Madrid (España) 


\section{Resultados y discusión}

6.1. FASE I DEL PLAN EXPERIMENTAL - OBJETIVO 1

6.2. FASE II DEL PLAN EXPERIMENTAL - OBJETIVO 2

6.3. FASE III DEL PLAN EXPERIMENTAL - OBJETIVO 3

6.4. FASE IV DEL PLAN EXPERIMENTAL - OBJETIVO 4

6.5. IMPACTO AMBIENTAL - OBJETIVO 5

6.6. CONSIDERACIONES PARCIALES DEL CAPÍTULO

6.7. TRABAJOS CITADOS 
CAPITUL0 6:RESULTADOSY DISCUSIÓN 


\section{RESUltadOS Y DISCUSIÓN}

En este capítulo se analizan los resultados logrados en cada una de las fases para dar respuesta a los objetivos específicos planteados:

- Fase I del plan experimental da respuesta al Objetivo 1.

- Fase II del plan experimental da respuesta al Objetivo 2.

- Fase III del plan experimental da respuesta al Objetivo 3.

- Fase IV del plan experimental da respuesta al Objetivo 4.

- Análisis del impacto ambiental da respuesta al Objetivo 5. 


\subsection{FASE I DEL PLAN EXPERIMENTAL - OBJETIVO 1}

A continuación se presentan los datos obtenidos en la Fase I del plan experimental tras la caracterización física, mineralógica y química de la materia prima, definida en el apartado 5.1.2. Permiten conocer las propiedades de la materia prima (yeso, escayola y PR) de la que se dispone.

\subsubsection{Ensayos físicos de la materia prima}

Los resultados obtenidos en los ensayos físicos de la materia prima se muestran en los siguientes apartados.

\subsubsection{Densidad de empaquetamiento o de Bulk}

La densidad de empaquetamiento obtenida en el ensayo para cada una de las materias primas (yeso, escayola y PR), se muestra en la Tabla 6.1:

Tabla 6.1. Resultados de densidad de empaquetamiento de materia prima (g/cm $\left.{ }^{3}\right)$ - UNE 102042

\begin{tabular}{|c|c|c|c|c|c|c|}
\hline Materia Prima & Muestra & $\begin{array}{c}\text { Peso } \\
\text { (g) }\end{array}$ & $\begin{array}{c}\text { Volumen } \\
\left(\mathrm{cm}^{3}\right) \\
\end{array}$ & $\begin{array}{c}\text { Densidad } \\
\text { Aparente } \\
\left(\mathrm{g} / \mathrm{cm}^{3}\right) \\
\end{array}$ & $\begin{array}{c}\text { Densidad } \\
\text { Aparente - } \\
\text { Media } \\
\left(\mathrm{g} / \mathrm{cm}^{3}\right) \\
\end{array}$ & $\begin{array}{c}\text { Desviación } \\
\text { Estándar } \\
\sigma \\
\end{array}$ \\
\hline & $\mathrm{Y}_{1}$ & 39,8 & 50 & 0,796 & & \\
\hline \multirow[t]{3}{*}{ Yeso } & $\mathrm{Y}_{2}$ & 39,4 & 50 & 0,788 & 0,794 & 0,005 \\
\hline & $\mathrm{Y}_{3}$ & 39,9 & 50 & 0,798 & & \\
\hline & $\mathrm{E}_{1}$ & 33,0 & 50 & 0,661 & & \\
\hline \multirow[t]{3}{*}{ Escayola } & $\mathrm{E}_{2}$ & 33,6 & 50 & 0,672 & 0,663 & 0,008 \\
\hline & $E_{3}$ & 32,8 & 50 & 0,656 & & \\
\hline & $\mathrm{PR}_{1}$ & 20,4 & 50 & 0,408 & & \\
\hline \multirow[t]{2}{*}{ Residuo Plástico } & $\mathrm{PR}_{2}$ & 20,2 & 50 & 0,404 & 0,411 & 0,009 \\
\hline & $\mathrm{PR}_{3}$ & 21,1 & 50 & 0,422 & & \\
\hline
\end{tabular}

La densidad de empaquetamiento del PR es un 48,24\% menor que la densidad del yeso y un $38,00 \%$ menor que la densidad de la escayola.

\subsubsection{Densidad real o picnometría de Helio}

Los resultados de la densidad real obtenidos en el ensayo de picnometría de Helio para cada una de las materias primas (yeso, escayola y PR), se reflejan en la Tabla 6.2: 
Tabla 6.2. Resultados de densidad real mediante picnometría de Helio $\left(\mathrm{g} / \mathrm{cm}^{3}\right)$

\begin{tabular}{|c|c|c|c|c|c|c|c|c|c|c|}
\hline $\begin{array}{l}\text { Materia } \\
\text { Prima }\end{array}$ & Muestra & (g) & $\begin{array}{c}\text { Volumen } \\
\text { celda } \\
\text { muestra }\end{array}$ & $\begin{array}{l}\text { Volumen } \\
\text { celda } \\
\text { referencia }\end{array}$ & $\begin{array}{c}\text { Lectura de } \\
\text { presión } \\
\text { después de } \\
\text { presurizar } \\
\text { la celda } \\
\text { muestra } \\
\left(P_{2}\right)\end{array}$ & $\begin{array}{c}\text { Lectura } \\
\text { de } \\
\text { presión } \\
\text { después } \\
\text { de incluir } \\
\mathrm{V}_{\mathrm{A}} \\
\left(\mathrm{P}_{3}\right)\end{array}$ & $\begin{array}{c}\begin{array}{c}\text { Volumen } \\
\text { de }\end{array} \\
\text { Muestra }\end{array}$ & $\begin{array}{l}\text { Densidad } \\
\text { real }\end{array}$ & $\begin{array}{c}\text { Densidad } \\
\text { real } \\
\text { Media }\end{array}$ & $\begin{array}{c}\text { Desviación } \\
\text { Estándar }\end{array}$ \\
\hline \multirow{3}{*}{ Yeso } & $Y_{1}$ & & & & 18,437 & 11,600 & 25,798 & 2,811 & \multirow{3}{*}{2,81} & \multirow{3}{*}{0,005} \\
\hline & $\mathrm{Y}_{2}$ & 72,53 & 155,88 & 76,67 & 18,128 & 11,403 & 25,877 & 2,803 & & \\
\hline & $\mathrm{Y}_{3}$ & & & & 18,260 & 11,486 & 25,878 & 2,803 & & \\
\hline \multirow{3}{*}{ Escayola } & $\mathrm{E}_{1}$ & & & & 18,121 & 11,532 & 21,693 & 2,710 & \multirow{3}{*}{2,72} & \multirow{3}{*}{0,005} \\
\hline & $\mathrm{E}_{2}$ & 58,78 & 155,88 & 76,67 & 18,164 & 11,561 & 21,641 & 2,716 & & \\
\hline & $E_{3}$ & & & & 18,246 & 11,614 & 21,615 & 2,720 & & \\
\hline \multirow{3}{*}{$\begin{array}{l}\text { Residuo } \\
\text { Plástico }\end{array}$} & $\mathrm{PR}_{1}$ & & & & 17,514 & 11,038 & 25,200 & 1,359 & \multirow{3}{*}{1,35} & \multirow{3}{*}{0,008} \\
\hline & $\mathrm{PR}_{2}$ & 34,25 & 155,88 & 76,67 & 17,425 & 10,974 & 25,454 & 1,346 & & \\
\hline & $\mathrm{PR}_{3}$ & & & & 17,407 & 10,963 & 25,443 & 1,346 & & \\
\hline
\end{tabular}

En este caso, la densidad real del PR respecto al yeso es un 51,96\% menor y un $50,37 \%$ menor respecto a la escayola.

\subsubsection{Contenido de humedad de la materia prima}

El contenido de humedad para cada una de las muestras (yeso, escayola y PR) se indica en la Tabla 6.3:

Tabla 6.3. Resultados de contenido de humedad (\%) - UNE EN 12880

\begin{tabular}{lcccc}
\hline Materia Prima & Muestra & $\begin{array}{c}\text { Muestra } \\
\text { húmeda } \\
\text { (g) }\end{array}$ & $\begin{array}{c}\text { Muestra } \\
\text { seca } \\
\text { (g) }\end{array}$ & $\begin{array}{c}\text { Humedad } \\
\text { (\%) }\end{array}$ \\
\hline Yeso & Y & 100,6 & 100,40 & 0,20 \\
Escayola & E & 100,4 & 99,90 & 0,50 \\
Residuo Plástico & PR & 100,0 & 99,90 & 0,10 \\
\hline
\end{tabular}

El yeso y la escayola se han ensayado procedentes del envase del fabricante; el PR se ha ensayado procedente del envase de recogida del contenedor de reciclaje. Como puede apreciarse todas las materias primas presentan un nivel muy bajo de humedad.

\subsubsection{Granulometría del PR}

En la Tabla 6.4 se especifican los pesos retenidos parciales y los porcentajes retenidos parciales y acumulados que pasan, conseguidos tras el tamizado del PR. 
Tabla 6.4. Análisis granulométrico del PR - UNE EN 933-1

\begin{tabular}{cccc}
\hline $\begin{array}{c}\text { Tamaño de apertura } \\
\text { del tamiz (mm) }\end{array}$ & $\begin{array}{c}\text { Masa de material } \\
\text { retenido parcial (g) }\end{array}$ & $\begin{array}{c}\text { Porcentaje de material } \\
\text { retenido parcial (\%) }\end{array}$ & $\begin{array}{c}\text { Porcentajes acumulados } \\
\text { que pasan (\%) }\end{array}$ \\
\hline 4 & 0,00 & 0,000 & 100,000 \\
2 & 21,28 & 14,187 & 85,813 \\
1 & 103,72 & 69,147 & 16,667 \\
0,5 & 21,00 & 14,000 & 2,667 \\
0,25 & 3,05 & 2,033 & 0,633 \\
0,125 & 0,44 & 0,293 & 0,340 \\
0,063 & 0,31 & 0,207 & 0,133 \\
Fondo & 0,20 & 0,133 & 0,000 \\
\hline
\end{tabular}

La curva granulométrica obtenida a través de los datos evidencia que el 100\% de la muestra pasa por el tamiz de $4 \mathrm{~mm}$, siendo la fracción de partículas con tamaños comprendidos entre 1-2 mm la más abundante (69,15\%) y que, el 97,33\% de las partículas presenta un tamaño superior a 0,5 mm (Gráfica 6.1).

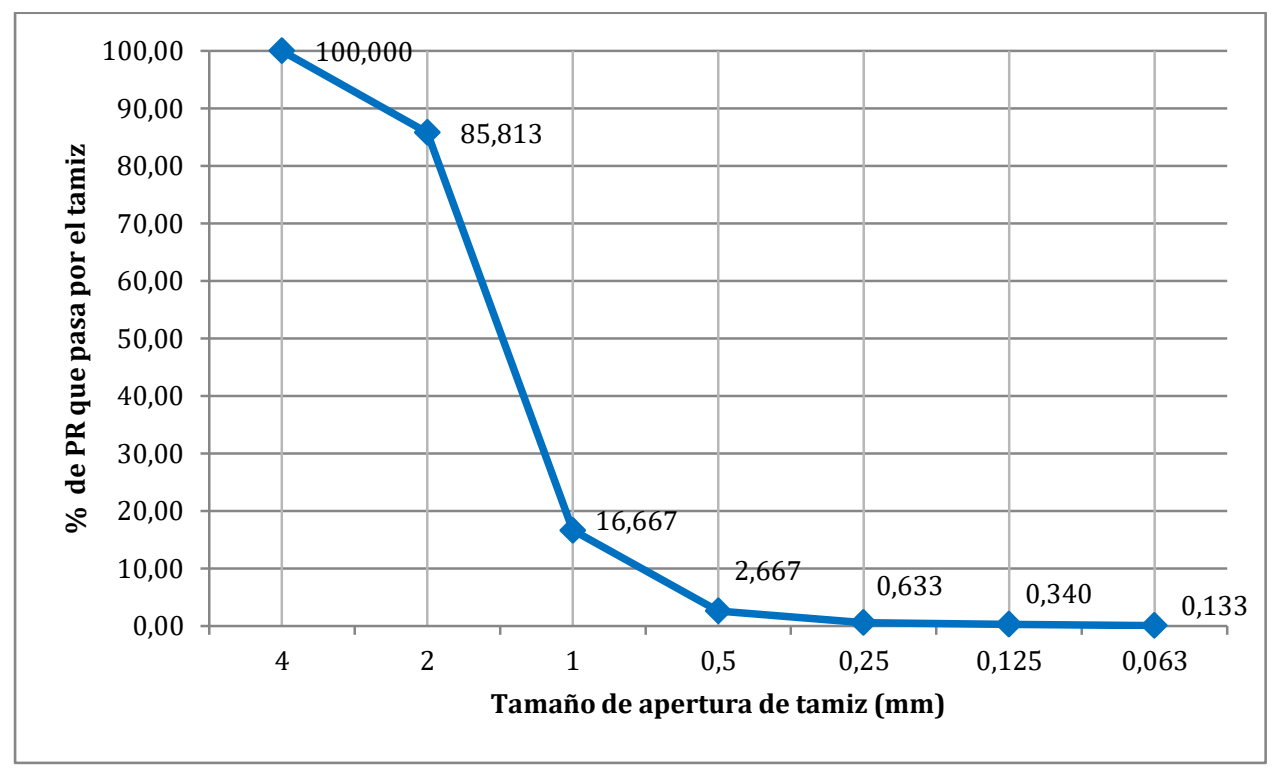

Gráfica 6.1. Curva granulométrica del PR

\subsubsection{Ensayos mineralógicos y químicos de la materia prima}

A continuación se exponen los resultados obtenidos en los ensayos mineralógicos y químicos de la materia prima. 


\subsubsection{Análisis termogravimétrico}

En la Tabla 6.5 quedan recogidos los datos numéricos asociados al ensayo termogravimétrico de las muestras de materia prima (yeso, escayola y PR).

Tabla 6.5. Pérdida de masa de las muestras en el análisis termogravimétrico (\%)

\begin{tabular}{|c|c|c|c|c|c|}
\hline Materia Prima & Muestra & $<100$ oC & $100^{\circ} \mathrm{C}-200^{\circ} \mathrm{C}$ & $550^{\circ} \mathrm{C}-800^{\circ} \mathrm{C}$ & $\begin{array}{c}\text { Total } \\
(\%)\end{array}$ \\
\hline Yeso & $Y$ & 0,34 & 4,3 & 4,3 & 9,5 \\
\hline \multirow[t]{3}{*}{ Escayola } & $\mathrm{E}$ & 1 & 5,8 & 0,8 & 7,7 \\
\hline & & & $<350 / 375^{\circ} \mathrm{C}$ & $\begin{array}{c}350 / 375- \\
700=\mathrm{C} \\
\end{array}$ & Total \\
\hline & $\mathrm{PR}_{1}$ & & $22,9 \%$ & $61,6 \%$ & $85,2 \%$ \\
\hline \multirow[t]{2}{*}{ Residuo Plástico } & $\mathrm{PR}_{2}$ & & $21 \%$ & $50,9 \%$ & $72,8 \%$ \\
\hline & $\mathrm{PR}_{3}$ & & $17,9 \%$ & $65,4 \%$ & $86,2 \%$ \\
\hline
\end{tabular}

Las Gráficas 6.2 y 6.3 muestran la pérdida de masa que sufrieron las muestras de yeso y escayola (respectivamente) en función de la temperatura, así como los efectos térmicos asociados. Estas muestras, presentan una pérdida de peso total inferior al $10 \%$; tras una primera pérdida de peso $(<1 \%)$ debida a la humedad débilmente asociada, una segunda pérdida de peso (endotérmica) en torno a un 4,3\% en el yeso y a un $5,8 \%$ en la escayola comprendida entre $100^{\circ} \mathrm{C}$ y $200^{\circ} \mathrm{C}$, puede asociarse a la deshidratación del yeso hemihidrato $\left(\mathrm{CaSO}_{4} \cdot 1 / 2 \mathrm{H}_{2} \mathrm{O}\right)$ para obtener sulfato cálcico anhidro o anhidrita III, que se produce a temperatura inferior a $200^{\circ} \mathrm{C}$ (Strydom \& Potgieter, 1999). La deshidratación del dihidrato puede dar lugar a hemihidrato $\alpha$ o hemihidrato $\beta$ dependiente de las condiciones de deshidratación. La forma $\alpha$ se produce bajo presión y la forma $\beta$ en condiciones normales de presión (Villanueva Domínguez \& García Santos, 2001). En esta investigación en concreto, el resultado del análisis térmico obtenido para yeso y escayola, muestra que se trata de hemihidrato $\beta$, ya que se observa que a una temperatura en torno a los $350^{\circ} \mathrm{C}$ tanto en el yeso como en la escayola, se produce el cambio exotérmico de fase de la anhidrita III (también denominada soluble) a la anhidrita II (insoluble); este cambio de fase, en el hemihidrato $\alpha$, se produce a una temperatura muy inferior, en torno a $200^{\circ} \mathrm{C}$ (Fleck, Jones, Kuntze, \& McAdie, 1960). Entre $550^{\circ} \mathrm{C}$ y $800^{\circ} \mathrm{C}$ se produce una pérdida de masa en torno a un $4,3 \%$ en el yeso y en torno a un $0,8 \%$ en la escayola. Dado que el sulfato de calcio no presenta cambios en su masa hasta una temperatura superior a $1000^{\circ} \mathrm{C}$, este último evento puede deberse a la presencia de algún aditivo retardador o acelerador del fraguado del conglomerante, de naturaleza orgánica puesto que se 
descompone en atmósfera de aire, cuya proporción como se observa es bastante superior en el yeso.

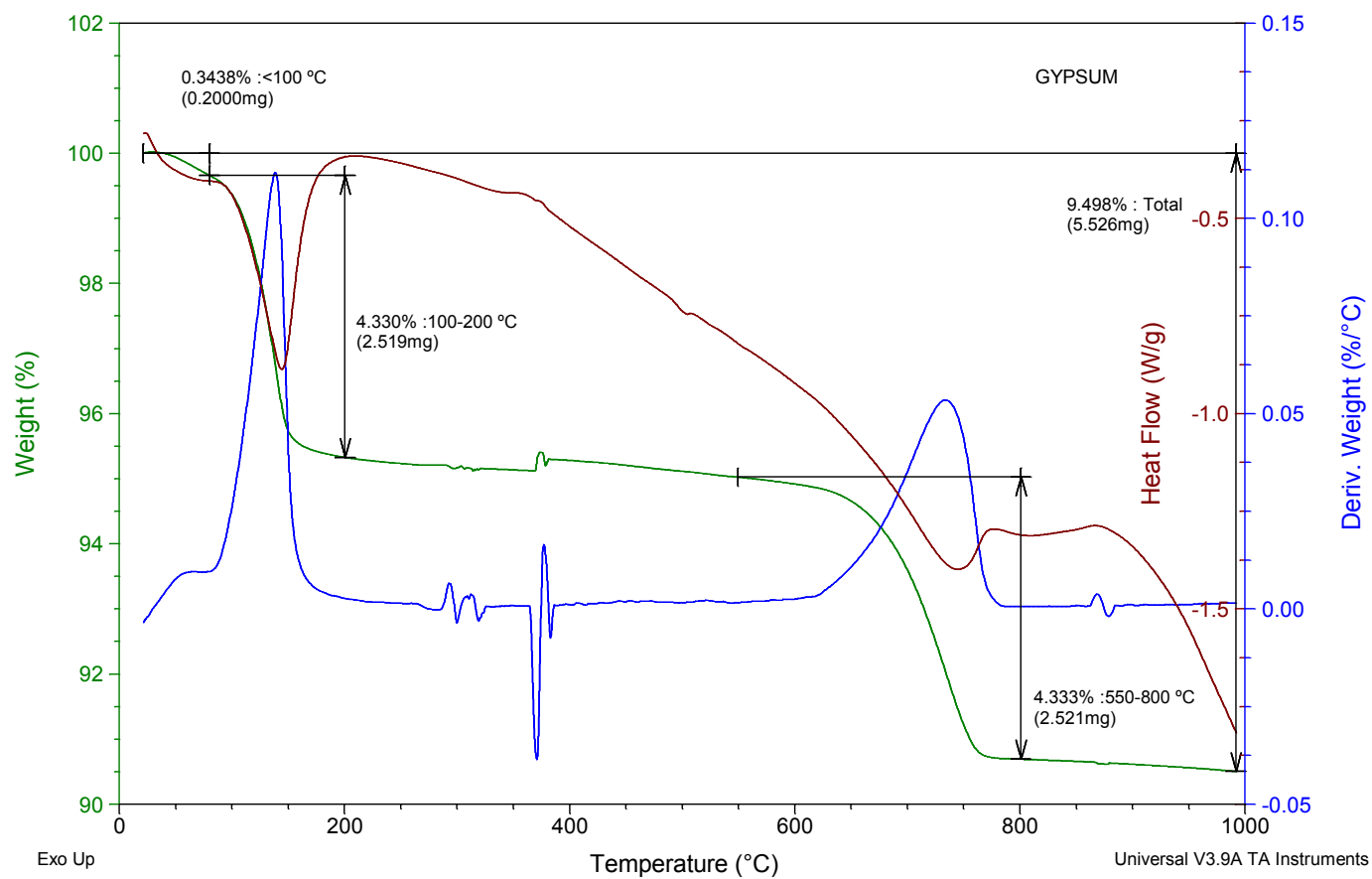

Gráfica 6.2. Resultado del análisis termogravimétrico del yeso

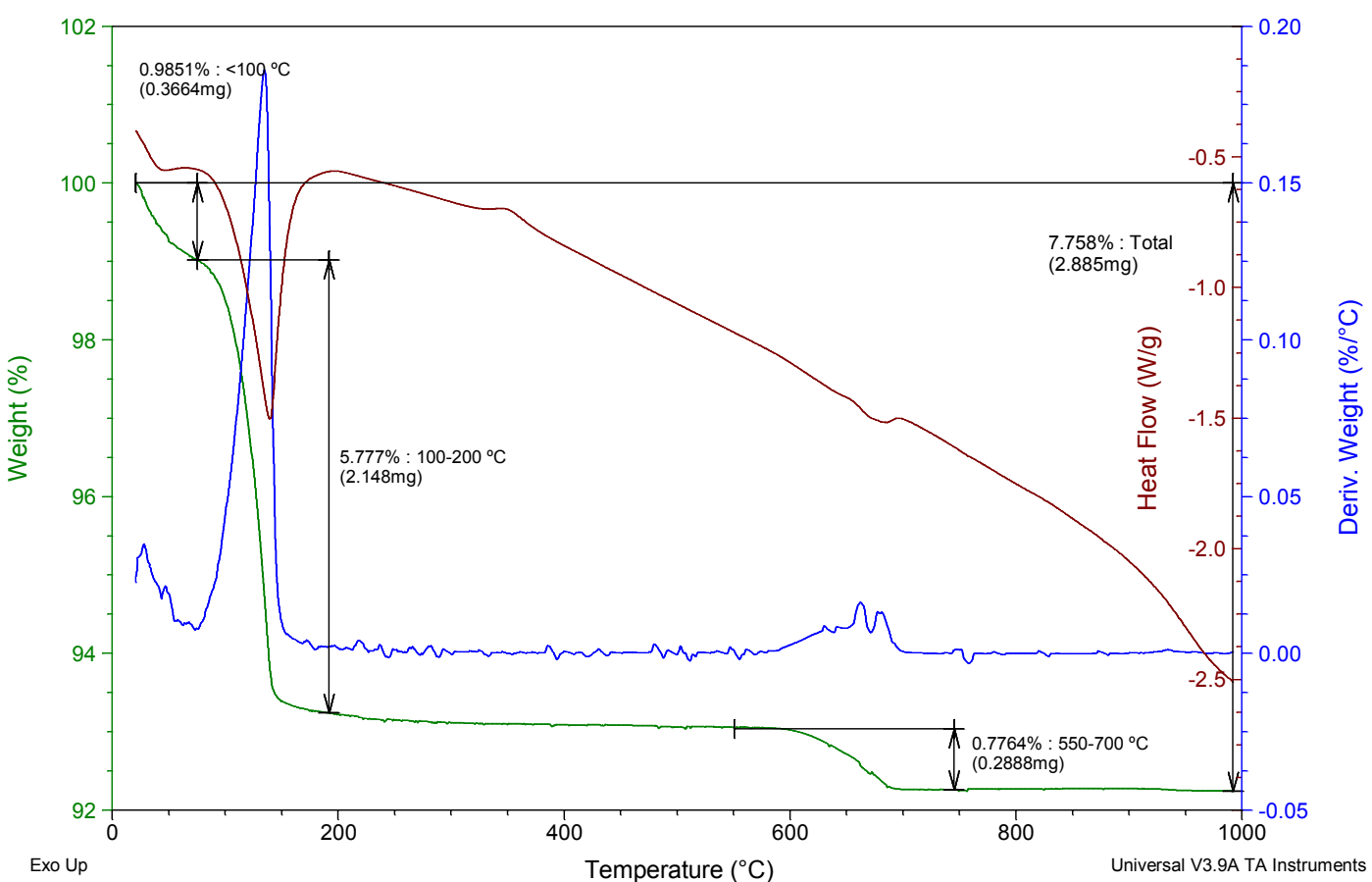

Gráfica 6.3. Resultado del análisis termogravimétrico de la escayola 
En el caso del PR y dada su heterogeneidad, se realizaron tres análisis con resultados cualitativamente similares. En las Gráficas 6.4-6.5-6.6 se muestra el resultado de cada uno de ellos. El PR es estable térmicamente hasta una temperatura aproximada de $200^{\circ} \mathrm{C}$, pero desde esa temperatura hasta los $700^{\circ} \mathrm{C}$ presenta una pérdida de masa continua, muy acusada, con un valor medio del $81,4 \%$, lo que indica que el restante $18,6 \%$ se debe a la presencia de un residuo inorgánico incombustible en el residuo. La derivada del peso con la temperatura muestra varios máximos en todo el intervalo de $200^{\circ} \mathrm{C}$ a $700^{\circ} \mathrm{C}$; cada uno de ellos correspondería a la descomposición térmica oxidativa de un componente de la muestra, lo que se corresponde claramente con la heterogeneidad de la misma (mezcla de polímeros), presentando todos ellos carácter exotérmico (Ehrenstein, Riedel, \& Trawiel, 2004). De forma aproximada, se distinguen dos zonas en la pérdida de masa con la temperatura entre 250 y $700^{\circ} \mathrm{C}$. La primera, de valor medio aproximado de $20,6 \%$, hasta aproximadamente $375^{\circ} \mathrm{C}$, que muestra a su vez varios procesos de descomposición, y una segunda, con una pérdida de masa de más del doble $(59,3 \%$ de valor medio) que muestra también varios máximos; en este tramo los tres ensayos muestran dos máximos comunes a temperaturas de $440-460{ }^{\circ} \mathrm{C}$ y $490-500{ }^{\circ} \mathrm{C}$.

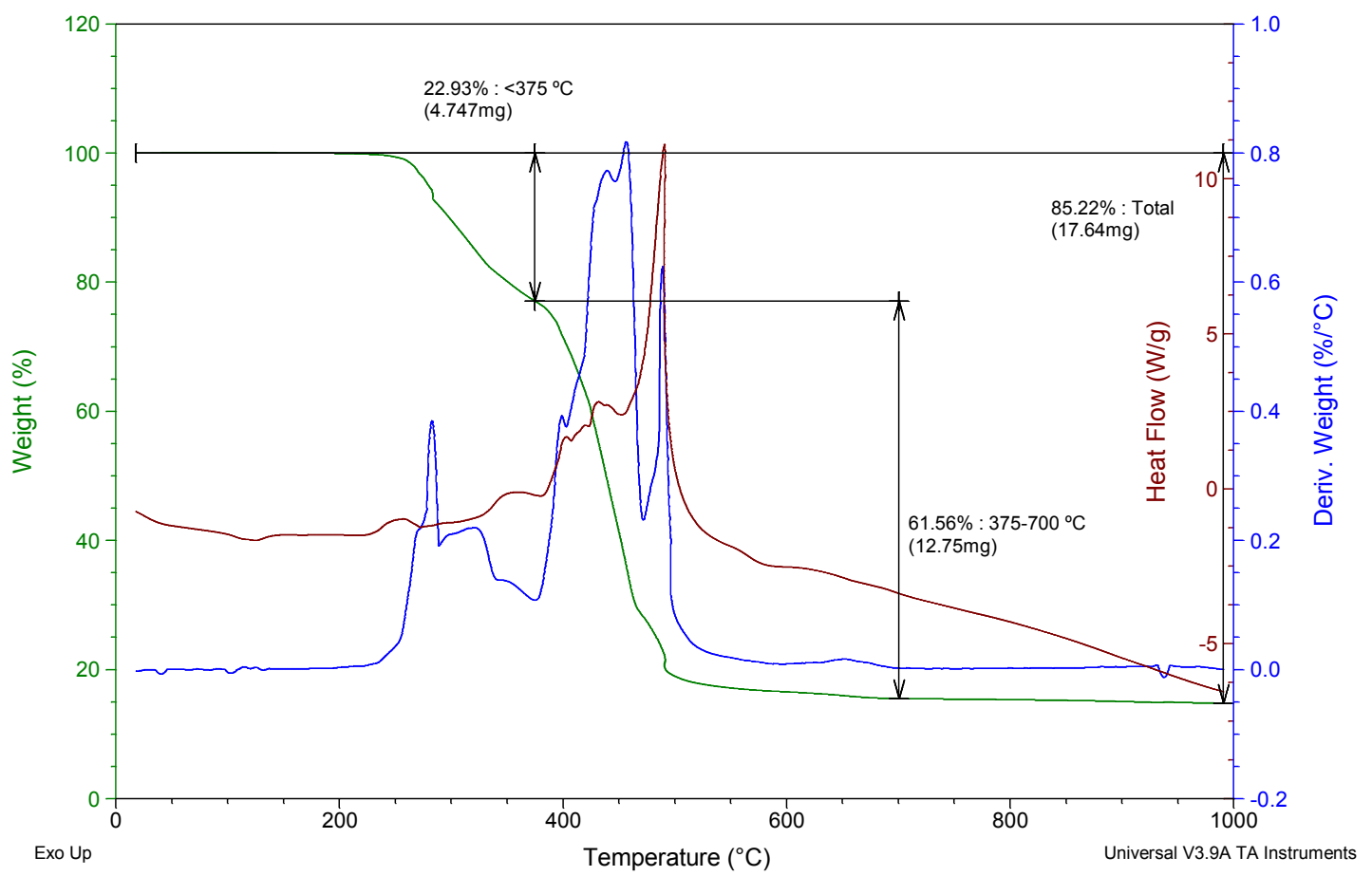

Gráfica 6.4. Resultado del análisis termogravimétrico del $P R_{1}$ 
Sample: granza_test2 Size: $32.1310 \mathrm{mg}$
Run Date: 22-Feb-17 12:43

Instrument: SDT Q600 V8.3 Build 101

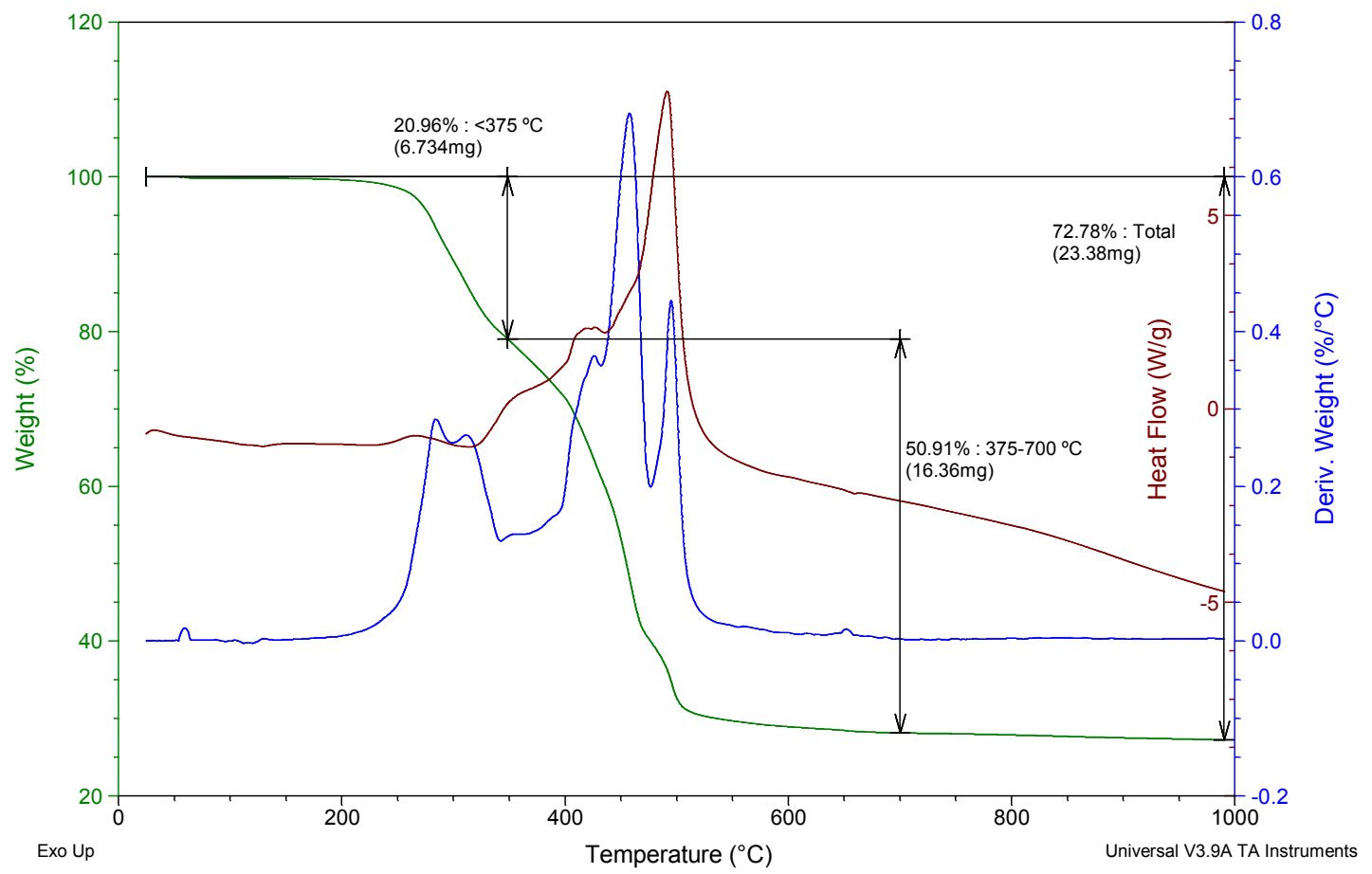

Gráfica 6.5. Resultado del análisis termogravimétrico del $P R_{2}$

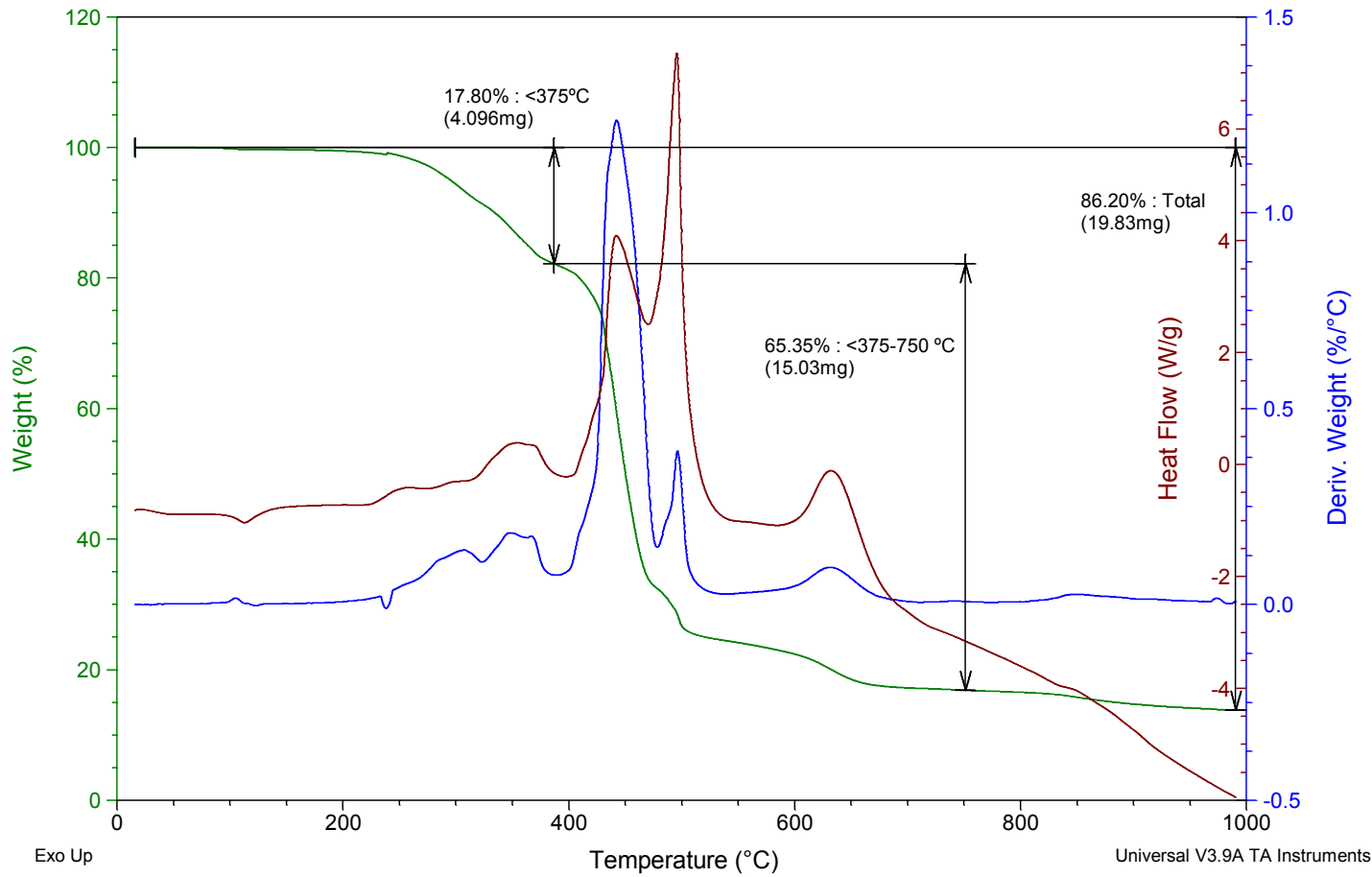

Gráfica 6.6. Resultado del análisis termogravimétrico del PR 


\subsubsection{Difracción de Rayos $X$}

En la Gráfica 6.7 se muestran los resultados obtenidos en el ensayo de difracción de Rayos X para yeso y escayola. En ambos casos, se identifica sulfato de calcio hemihidrato ( $\mathrm{CaSO}_{4} \cdot 0.5 \mathrm{H}_{2} \mathrm{O}$ ), y no se observa la presencia de dihidrato (Strydom \& Potgieter, 1999). Por su parte, el PR no pudo ser ensayado debido a que la granza de la que está compuesto no podía ser compactada para no salirse de la cápsula de ensayo.

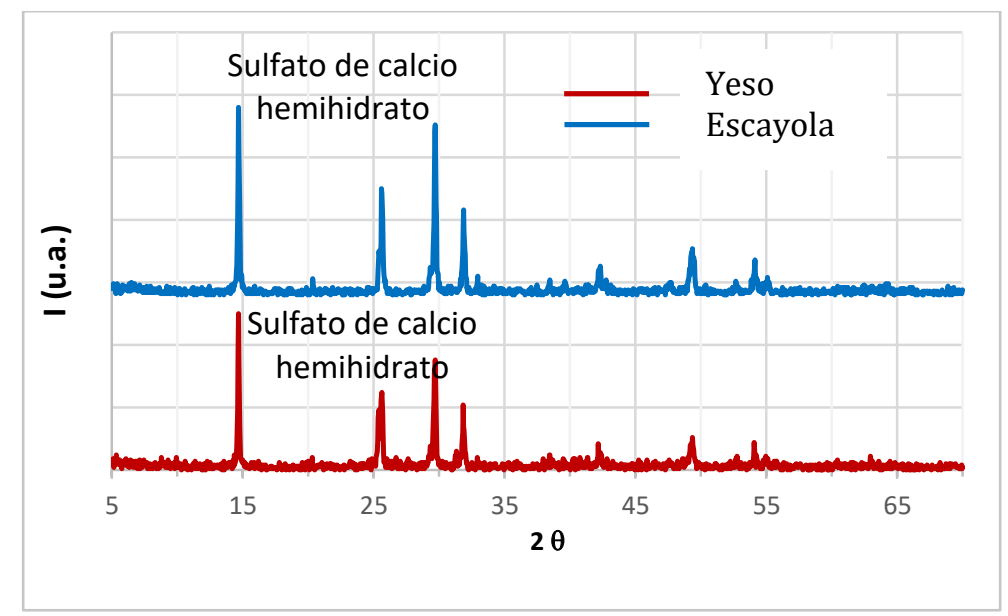

Gráfica 6.7. Difractograma de Rayos X en yeso y escayola

\subsubsection{Análisis elemental}

Los resultados del análisis elemental mediante fluorescencia de rayos $\mathrm{X}$ se muestran en la Tabla 6.6.

Tabla 6.6. Análisis elemental de las muestras - concentración (\%) superior a 0,5\%

\begin{tabular}{lcc|lc}
\hline Compuesto & Yeso & Escayola & \multicolumn{2}{c}{ Compuesto } \\
\hline Sulfato de calcio & $98,70 \%$ & $99,70 \%$ & $\begin{array}{l}\text { Materia orgánica (determinado } \\
\text { por diferencia de compuestos) }\end{array}$ & $77,20 \%$ \\
Aluminio & $0,144 \%$ & $0,022 \%$ & Bromo & $3,300 \%$ \\
Hierro & $0,361 \%$ & $0,035 \%$ & Calcio & $1,470 \%$ \\
Fósforo & & $0,010 \%$ & Cloro & $3,350 \%$ \\
Silicio & $0,359 \%$ & $0,068 \%$ & Cobre & $4,330 \%$ \\
Estroncio & $0,289 \%$ & $0,157 \%$ & Hierro & $0,520 \%$ \\
Potasio & $0,088 \%$ & & Magnesio & $0,176 \%$ \\
Rubidio & $0,004 \%$ & & Plomo & $1,350 \%$ \\
Titanio & & Azufre & $0,041 \%$ \\
Cloro & $0,027 \%$ & & Antimonio & $7,080 \%$ \\
& $0,009 \%$ & & Silicio & $0,467 \%$ \\
& & & Titanio & $0,314 \%$ \\
& & & Zinc & $0,443 \%$ \\
\hline
\end{tabular}


El yeso y la escayola están compuestos mayoritariamente por S y Ca, con un porcentaje de 98,7\% y 99,7\% respectivamente, como corresponde a su composición química de sulfato de calcio. En el caso del PR, la materia orgánica constituyente de los polímeros supone un 77,2\% de la composición. Destaca la presencia de cloro, que podría corresponder al PVC, uno de los polímeros presentes en mayor medida en los cables eléctricos (Suresh, Mohanty, \& Nayak, 2017); la presencia de cobre que podría deberse a residuos metálicos del cable eléctrico y; la presencia de bromo y antimonio que suelen utilizarse, en los plásticos, como retardante de llama (Morillas, Villavicencio, Valdemar, Pérez, \& Neyra, 2017). 


\subsection{FASE II DEL PLAN EXPERIMENTAL - OBJETIVO 2}

Para el análisis de la viabilidad de los compuestos de yeso con PR y la evaluación del cumplimiento con la normativa en vigor, se presentan los resultados obtenidos en la Fase II del plan experimental tras la realización de los ensayos definidos en el apartado 5.2.2. Esta fase corresponde a los ensayos en estado fresco de los compuestos.

\subsubsection{Consistencia de las pastas y relación $\mathrm{A} / \mathrm{Y}$}

En la Tabla 6.7 se indican los valores de los compuestos obtenidos en el ensayo de consistencia de las pastas.

Tabla 6.7. Resultados del ensayo de consistencia de las pastas (mm) - UNE EN 13279-2

\begin{tabular}{lcc}
\hline Denominación & A/E & Ø Escurrimiento medio (mm) \\
\hline $\mathrm{Y}_{0,8}$ & 0,8 & 150,50 \\
$\mathrm{Y}_{0,8-50 \mathrm{PR}}$ & 0,8 & 180,50 \\
$\mathrm{Y}_{0,8-60 \mathrm{PR}}$ & 0,8 & 134,50 \\
$\mathrm{Y}_{0,8-70 \mathrm{PR}}$ & 0,8 & 124,50 \\
\hline $\mathrm{Y}_{1,0}$ & 1,0 & 269,00 \\
$\mathrm{Y}_{1,0-50 \mathrm{PR}}$ & 1,0 & 235,00 \\
$\mathrm{Y}_{1,0-60 \mathrm{PR}}$ & 1,0 & 183,00 \\
$\mathrm{Y}_{1,0-70 \mathrm{PR}}$ & 1,0 & 181,50 \\
\hline $\mathrm{E}_{0,8}$ & 0,8 & 145,00 \\
$\mathrm{E}_{0,8-50 \mathrm{PR}}$ & 0,8 & 239,50 \\
$\mathrm{E}_{0,8-60 \mathrm{PR}}$ & 0,8 & 174,00 \\
$\mathrm{E}_{0,8-70 \mathrm{PR}}$ & 0,8 & 139,50 \\
\hline $\mathrm{E}_{0,9}$ & 0,9 & 268,00 \\
$\mathrm{E}_{0,9-50 \mathrm{PR}}$ & 0,9 & 201,50 \\
$\mathrm{E}_{0,9-60 \mathrm{PR}}$ & 0,9 & 201,00 \\
$\mathrm{E}_{0,9-70 \mathrm{PR}}$ & 0,9 & 170,50 \\
\hline
\end{tabular}

La consistencia de las mezclas tras la mesa de sacudidas, aunque no cumple el criterio de exigencia de consistencia establecido para yesos premezclados 160-165 ( \pm 5$)$ mm (UNE-EN 13279-2:2014, 2014) en ninguno de los compuestos, nos aporta los siguientes datos: aumenta la consistencia de la pasta cuanto mayor porcentaje de PR incorporamos en la misma; los compuestos de yeso presentan mayor consistencia respecto a los de escayola; entre igual conglomerante, las pastas con menor cantidad de agua en su composición presentan mayor consistencia. El compuesto con PR de 
valor de consistencia más próximo al indicado en la normativa referenciada en el apartado 5.2.3.1 fue el $\mathrm{E}_{0,9-70 \mathrm{PR}}(170,50)$ y el de valor más alejado el $\mathrm{E}_{0,8-50 \mathrm{PR}}(239,50)$.

El no cumplimiento del criterio de exigencia de consistencia, puede corregirse con la incorporación de una pequeña cantidad de fluidificante en el agua de amasado, en cuyo caso debería ser anotado, en la ficha de ensayo, el tipo y la cantidad añadida. Tratando de mantener el requisito de sostenibilidad adquirido en este estudio, se seleccionaría un fluidificante o retardador de fraguado natural como el utilizado por Santos Jiménez en su tesis doctoral, Plast Retard (Santos Jiménez, 2018).

\subsubsection{Tiempos de fraguado}

El tiempo de inicio del principio de fraguado para cada uno de los compuestos, se muestra en la Tabla 6.8.

Tabla 6.8. Principio de fraguado de los compuestos (minutos) - UNE EN 13279-2

\begin{tabular}{lccc}
\hline Denominación & A/E & Tiempo (minutos) & $\begin{array}{c}\Delta \text { de tiempo respecto a la } \\
\text { referencia }\end{array}$ \\
\hline $\mathrm{Y}_{0,8}$ & 0,8 & 13,50 & 0,00 \\
$\mathrm{Y}_{0,8-50 \mathrm{PR}}$ & 0,8 & 7,25 & $-46,30 \%$ \\
$\mathrm{Y}_{0,8-60 \mathrm{PR}}$ & 0,8 & 5,00 & $-62,97 \%$ \\
$\mathrm{Y}_{0,8-70 \mathrm{PR}}$ & 0,8 & 5,00 & $-62,97 \%$ \\
\hline $\mathrm{Y}_{1,0}$ & 1,0 & 19,50 & 0,00 \\
$\mathrm{Y}_{1,0-50 \mathrm{PR}}$ & 1,0 & 11,00 & $-43,59 \%$ \\
$\mathrm{Y}_{1,0-60 \mathrm{PR}}$ & 1,0 & 8,25 & $-57,69 \%$ \\
$\mathrm{Y}_{1,0-70 \mathrm{PR}}$ & 1,0 & 7,50 & $-61,54 \%$ \\
\hline $\mathrm{E}_{0,8}$ & 0,8 & 16,00 & 0,00 \\
$\mathrm{E}_{0,8-50 \mathrm{PR}}$ & 0,8 & 7,25 & $-54,69 \%$ \\
$\mathrm{E}_{0,8-60 \mathrm{PR}}$ & 0,8 & 7,25 & $-54,69 \%$ \\
$\mathrm{E}_{0,8-70 \mathrm{PR}}$ & 0,8 & 6,00 & $-62,50 \%$ \\
\hline $\mathrm{E}_{0,9}$ & 0,9 & 16,00 & 0,00 \\
$\mathrm{E}_{0,9-50 \mathrm{PR}}$ & 0,9 & 9,75 & $-39,06 \%$ \\
$\mathrm{E}_{0,9-60 \mathrm{PR}}$ & 0,9 & 9,75 & $-39,06 \%$ \\
$\mathrm{E}_{0,9-70 \mathrm{PR}}$ & 0,9 & 7,00 & $-56,25 \%$ \\
\hline & & &
\end{tabular}

En la Gráfica 6.8 se observa que, a medida que se incorpora PR en la mezcla, se acelera el inicio del fraguado, un $45 \%$ más en los compuestos con $50 \% \mathrm{PR}$, un $53 \%$ en los de $60 \% \mathrm{PR}$ y, un $62 \%$ en los de $70 \% \mathrm{PR}$, hecho que también ocurre en otras investigaciones con adición de polímeros (Herrero del Cura, 2016; Zhu, Zhang, Peng, Cao, \& Liu, 2018). Los compuestos de yeso inician el fraguado aproximadamente un $14 \%$ más rápido que los compuestos de escayola. Entre igual conglomerante, a medida que se incorpora agua en la matriz, se ralentiza el inicio de fraguado en 
aproximadamente un $17 \%$ en relación 0,8 respecto a 0,9 , en aproximadamente un $32 \%$ en relación 0,8 respecto a 1,0 .

Los compuestos que presentaron el principio de fraguado más rápido fueron el $\mathrm{Y}_{0,8-60 \mathrm{PR}}$ y el $\mathrm{Y}_{0,8-70 \mathrm{PR}}$ (5 minutos) y el más lento fue el $\mathrm{Y}_{1,0-50 \mathrm{PR}}$ (11 minutos).

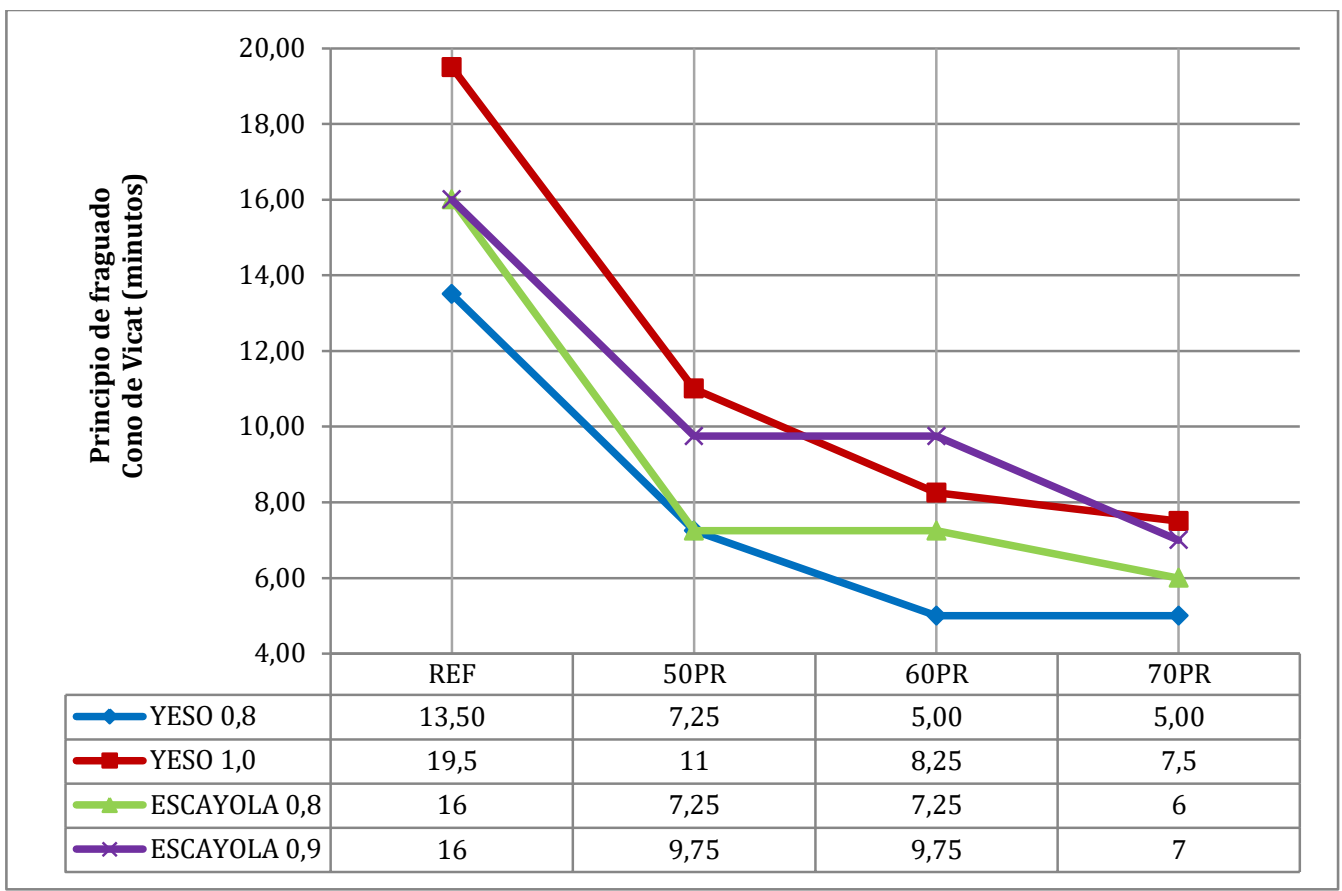

Gráfica 6.8. Principio de fraguado de los compuestos 


\subsection{FASE III DEL PLAN EXPERIMENTAL - OBJETIVO 3}

A continuación se presentan los resultados obtenidos en la Fase III del plan experimental tras la realización de los ensayos mecánicos y físicos definidos en el apartado 5.3.1, que suponen la caracterización de los compuestos y la comprobación del cumplimiento de la normativa vigente de los compuestos en estado endurecido. Para cada uno de los ensayos se puede observar, además, el grado de interacción entre variables a través del análisis estadístico desarrollado según el apartado 5.2.3.

\subsubsection{Ensayos mecánicos de los compuestos con PR}

Los resultados obtenidos en los ensayos mecánicos de los compuestos en estado endurecido se muestran a continuación.

\subsubsection{Dureza superficial Shore C}

En la Tabla 6.9 se indican los valores de dureza superficial Shore C de los compuestos de las Series I-II-III-IV, que quedan representados en la Gráfica 6.9.

Tabla 6.9. Dureza Shore C de los compuestos - UNE EN 102042:2014

\begin{tabular}{lcccc}
\hline Referencia & Denominación & A/E & Dureza Shore C & $\begin{array}{c}\Delta \text { de dureza superficial } \\
\text { respecto a la referencia }\end{array}$ \\
\hline \multirow{4}{*}{ Serie I } & $\mathrm{Y}_{0,8}$ & 0,8 & 66,83 & 0,00 \\
& $\mathrm{Y}_{0,8-50 \mathrm{PR}}$ & 0,8 & 73,90 & $+10.58 \%$ \\
& $\mathrm{Y}_{0,8-60 \mathrm{PR}}$ & 0,8 & 74,70 & $+11,78 \%$ \\
& $\mathrm{Y}_{0,8-70 \mathrm{PR}}$ & 0,8 & 75,17 & $+12,48 \%$ \\
\hline \multirow{4}{*}{ Serie II } & $\mathrm{Y}_{1,0}$ & 1,0 & 51,70 & 0,00 \\
& $\mathrm{Y}_{1,0-5 \mathrm{PR}}$ & 1,0 & 47,00 & $-9,09 \%$ \\
& $\mathrm{Y}_{1,0-6 \mathrm{PR}}$ & 1,0 & 63,17 & $+22,19 \%$ \\
& $\mathrm{Y}_{1,0-7 \mathrm{PR}}$ & 1,0 & 65,43 & $+26,56 \%$ \\
\hline \multirow{4}{*}{ Serie III } & $\mathrm{E}_{0,8}$ & 0,8 & 78,00 & 0,00 \\
& $\mathrm{E}_{0,8-50 \mathrm{PR}}$ & 0,8 & 81,17 & $+4,06 \%$ \\
& $\mathrm{E}_{0,8-60 \mathrm{PR}}$ & 0,8 & 80,60 & $+3,33 \%$ \\
& $\mathrm{E}_{0,8-70 \mathrm{PR}}$ & 0,8 & 81,60 & $+4,62 \%$ \\
\hline \multirow{3}{*}{ Serie IV } & $\mathrm{E}_{0,9}$ & 0,9 & 74,37 & 0,00 \\
& $\mathrm{E}_{0,9-50 \mathrm{PR}}$ & 0,9 & 67,00 & $-9,91 \%$ \\
& $\mathrm{E}_{0,9-60 \mathrm{PR}}$ & 0,9 & 77,17 & $+3,76 \%$ \\
\hline & $\mathrm{E}_{0,9-70 \mathrm{PR}}$ & 0,9 & 77,60 & $+4,34 \%$ \\
\hline
\end{tabular}

Al contrario de lo que ocurre en la mayoría de los "Estudios sobre compuestos de yeso con adición de polímeros" analizados en el capítulo 2, la dureza superficial aumenta a medida que aumenta la cantidad de PR en la matriz (a excepción de algún 
compuesto) comportándose, en este caso, de manera similar a los compuestos de yeso con cargas de residuos cerámicos (Santos Jiménez, 2018). Existen diferencias entre los compuestos de matriz de yeso y escayola, mientras que para los primeros, este aumento llega a ser de aproximadamente un 26,6\% respecto a la referencia, para los segundos, solo supone un 4,3\%. A pesar de esto, puede observarse que los compuestos de escayola presentan aproximadamente un $9 \%$ más de dureza que los compuestos de yeso.

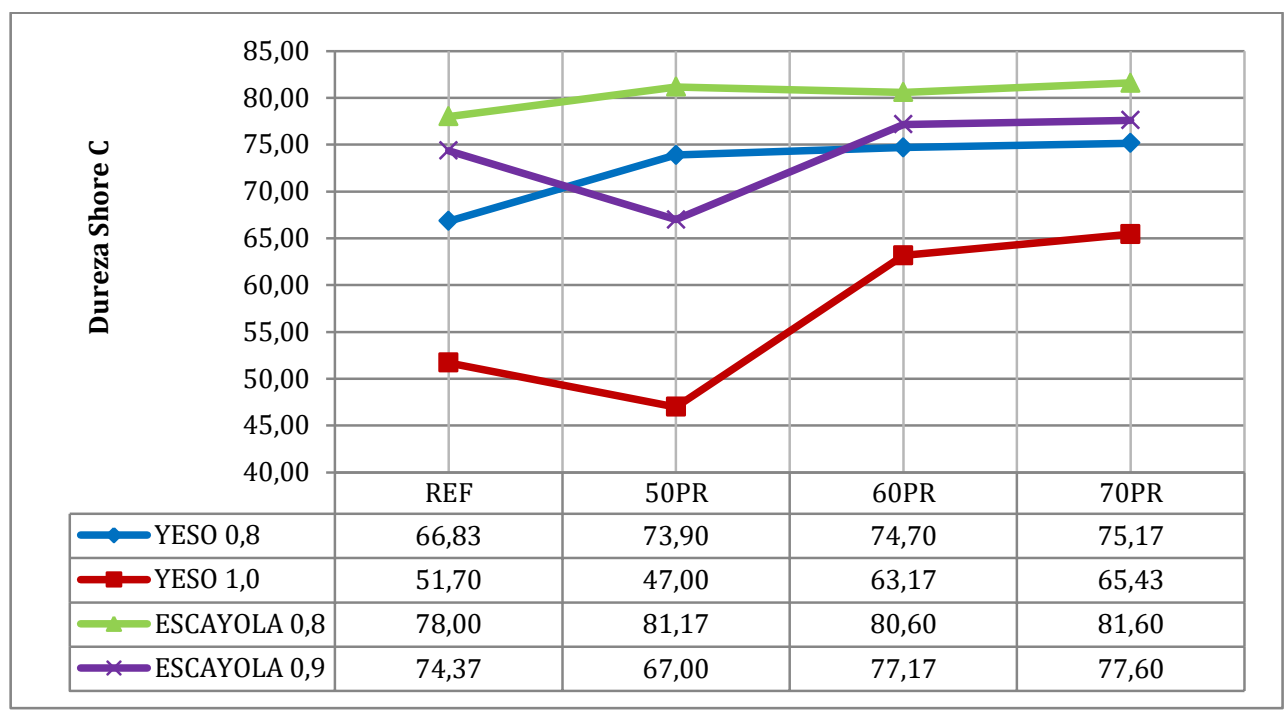

Gráfica 6.9. Dureza Shore C de los compuestos

En cuanto al agua, disminuye la dureza superficial a medida que se aumenta la cantidad de ésta en la composición, de manera que en los compuestos de relación 0,9 se observa una disminución del 4,5\% aproximadamente y, en los de relación 1,0 una disminución del 14\% aproximadamente, respecto a los compuestos con relación 0,8.

Los compuestos de escayola frente a los compuestos de yeso presentan, en general, un valor mayor de dureza superficial debido a la propia naturaleza del conglomerante. Entre compuestos del mismo conglomerante también se visualiza este hecho en los que presentan menor cantidad de agua en su composición respecto a los de mayor cantidad de agua, es decir, escayola 0,8 y yeso 0,8 mayor valor de dureza respecto a escayola 0,9 y yeso 1,0 .

El compuesto de mayor valor de dureza superficial fue el $E_{0,8-70 P R}(81,60)$ y el de menor valor fue el $\mathrm{Y}_{1,0-50 \mathrm{PR}}(47,00)$. 


\subsection{Análisis estadístico de la variable Dureza Shore C}

Para cada uno de los factores indicados en la matriz planteada en el apartado 5.2.3 se muestran, en la Tabla 6.10, los P-valores obtenidos en el análisis estadístico de las muestras para la variable dureza.

Se puede observar que tanto en los factores de \%PR y tipo de conglomerante, así como en su interacción, los P-valores correspondientes a la variable dureza son 0,0000, por lo que se consideran significativos. Es decir, la dureza superficial depende tanto del \%PR como del tipo de conglomerante y de su interacción.

Tabla 6.10. Tabla ANOVA para la variable Dureza

\begin{tabular}{lcccc}
\hline Fuente & $\begin{array}{c}\text { Suma de } \\
\text { cuadrados }\end{array}$ & G.I. & F & P-valor \\
\hline EFECTOS PRINCIPALES & & & & \\
A: \%PR & 588,182 & 3 & 145,07 & 0,0000 \\
B: tipo conglomerante & 3584,44 & 3 & 884,09 & 0,0000 \\
\hline INTERACCIONES & & & & \\
AB & 508,46 & 9 & 41,80 & 0,0000 \\
\hline RESIDUOS & 43,2467 & 32 & & \\
\hline TOTAL (CORREGIDO) & 4724,33 & 47 & & \\
\hline
\end{tabular}

La hipótesis del modelo de homocedasticidad y normalidad, para la variable dureza, se cumple tal y como se muestra en la Gráfica 6.10 de residuos. La independencia se considera cumplida por el procedimiento aleatorio realizado en el proceso de ensayos de probetas en el laboratorio.

Gráfico de Residuos para DurezaShoreC

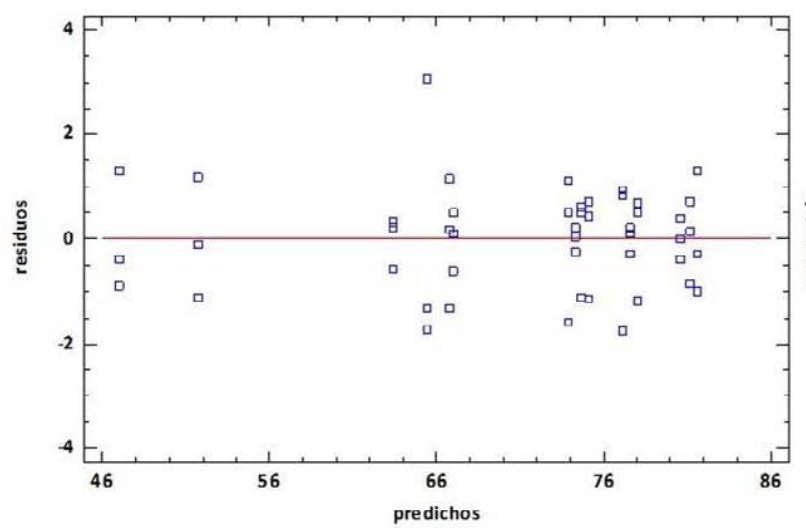

Gráfico de Probabilidad Normal con $95 \%$ limites

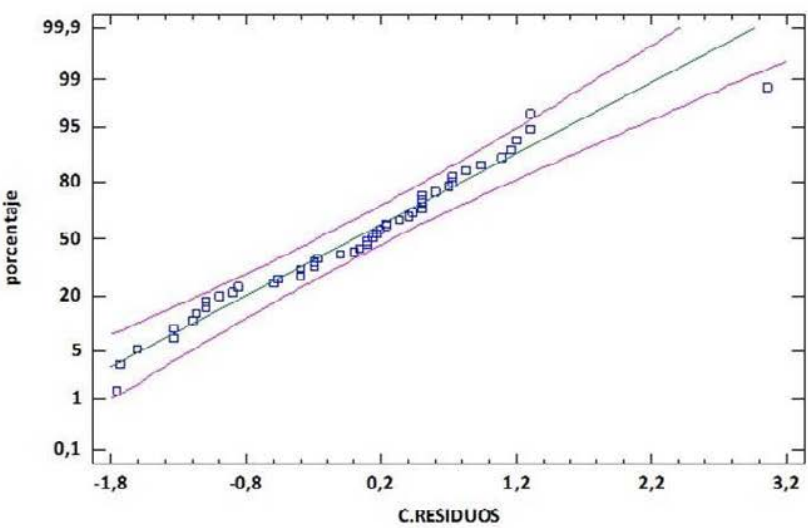

Gráfica 6.10. Diagnóstico del factor dureza 


\subsubsection{Resistencias a flexión y compresión}

Los resultados obtenidos en los ensayos de resistencia a flexión y compresión para los compuestos de las Series I-II-III-IV, se muestran en la Tabla 6.11.

Tabla 6.11. Resultados medios de ensayo a flexión y compresión de los compuestos (N/mm²) - UNE EN 13279-2

\begin{tabular}{|c|c|c|c|c|c|c|}
\hline Referencia & Denominación & $\mathbf{A} / \mathbf{E}$ & $\begin{array}{c}\text { R. Flexión } \\
\left(\mathrm{N} / \mathbf{m m}^{2}\right)\end{array}$ & $\begin{array}{c}\Delta \text { de R. flexión } \\
\text { respecto a la } \\
\text { referencia }\end{array}$ & $\begin{array}{l}\text { R. Compresión } \\
\left(\mathrm{N} / \mathrm{mm}^{2}\right)\end{array}$ & $\begin{array}{c}\Delta \text { de R. compresión } \\
\begin{array}{c}\text { respecto a la } \\
\text { referencia }\end{array} \\
\end{array}$ \\
\hline \multirow{4}{*}{ Serie I } & $\mathrm{Y}_{0,8}$ & 0,8 & 3,03 & 0,00 & 5,83 & 0,00 \\
\hline & $Y_{0,8-50 P R}$ & 0,8 & 2,56 & $-15,51 \%$ & 4,07 & $-30,19 \%$ \\
\hline & $Y_{0,8-60 P R}$ & 0,8 & 2,50 & $-17,49 \%$ & 4,18 & $-28,30 \%$ \\
\hline & $\mathrm{Y}_{0,8-70 \mathrm{PR}}$ & 0,8 & 2,11 & $-30,36 \%$ & 4,02 & $-31,05 \%$ \\
\hline \multirow{4}{*}{ Serie II } & $\mathrm{Y}_{1,0}$ & 1,0 & 2,24 & 0,00 & 3,72 & 0,00 \\
\hline & $Y_{1,0-50 P R}$ & 1,0 & 1,51 & $-32,59 \%$ & 2,24 & $-39,78 \%$ \\
\hline & $Y_{1,0-60 P R}$ & 1,0 & 1,55 & $-30,80 \%$ & 2,74 & $-26,34 \%$ \\
\hline & $\mathrm{Y}_{1,0-70 \mathrm{PR}}$ & 1,0 & 1,51 & $-32,59 \%$ & 2,75 & $-26,08 \%$ \\
\hline \multirow{4}{*}{ Serie III } & $\mathrm{E}_{0,8}$ & 0,8 & 4,78 & 0,00 & 10,62 & 0,00 \\
\hline & $\mathrm{E}_{0,8-50 \mathrm{PR}}$ & 0,8 & 2,55 & $-46,65 \%$ & 5,06 & $-52,35 \%$ \\
\hline & $\mathrm{E}_{0,8-60 \mathrm{PR}}$ & 0,8 & 2,63 & $-44,98 \%$ & 5,12 & $-51,79 \%$ \\
\hline & $\mathrm{E}_{0,8-70 \mathrm{PR}}$ & 0,8 & 2,40 & $-49,79 \%$ & 5,10 & $-51,98 \%$ \\
\hline \multirow{4}{*}{ Serie IV } & $E_{0,9}$ & 0,9 & 4,16 & 0,00 & 8,54 & 0,00 \\
\hline & $\mathrm{E}_{0,9-50 \mathrm{PR}}$ & 0,9 & 2,32 & $-44,23 \%$ & 3,81 & $-55,39 \%$ \\
\hline & $\mathrm{E}_{0,9-60 \mathrm{PR}}$ & 0,9 & 2,20 & $-47,12 \%$ & 4,30 & $-49,65 \%$ \\
\hline & $\mathrm{E}_{0,9-70 \mathrm{PR}}$ & 0,9 & 2,11 & $-49,28 \%$ & 4,30 & $-49,65 \%$ \\
\hline
\end{tabular}

En el ensayo de resistencia a flexión, tal y como ocurre en la mayoría de los estudios con polímeros analizados en el capítulo 2 , todos los valores obtenidos en las mezclas con PR disminuyen. Llegan a descender hasta aproximadamente un 50\% respecto a las referencias, pero siempre se mantienen por encima del mínimo indicado en normativa de $1 \mathrm{~N} / \mathrm{mm}^{2}$ (Gráfica 6.11) (UNE-EN 13279-2:2014, 2014). Los compuestos con escayolas y yesos presentan valores sensiblemente iguales de resistencia a flexión. La diferencia entre la resistencia a flexión de los compuestos se encuentra en la dosificación de agua, disminuyendo la resistencia a medida que se incorpora agua en la composición, llegando a un $12,5 \%$ menos en los compuestos con relación 0,9 y, a un 38,5\% menos en los compuestos con relación 1,0. El compuesto de mayor resistencia a flexión fue el $\mathrm{E}_{0,8-60 \mathrm{PR}}\left(2,63 \mathrm{~N} / \mathrm{mm}^{2}\right)$ y el de menor resistencia a flexión el $Y_{1,0-50 p R}$ y el $Y_{1,0-70 \text { PR }}\left(1,51 \mathrm{~N} / \mathrm{mm}^{2}\right)$. 
En cuanto a la forma de rotura, se observa que las probetas de referencia rompen completamente cuando son sometidas al esfuerzo de flexión mientras que, las probetas de los compuestos, quedan unidas como puede verse en la Foto 6.1.

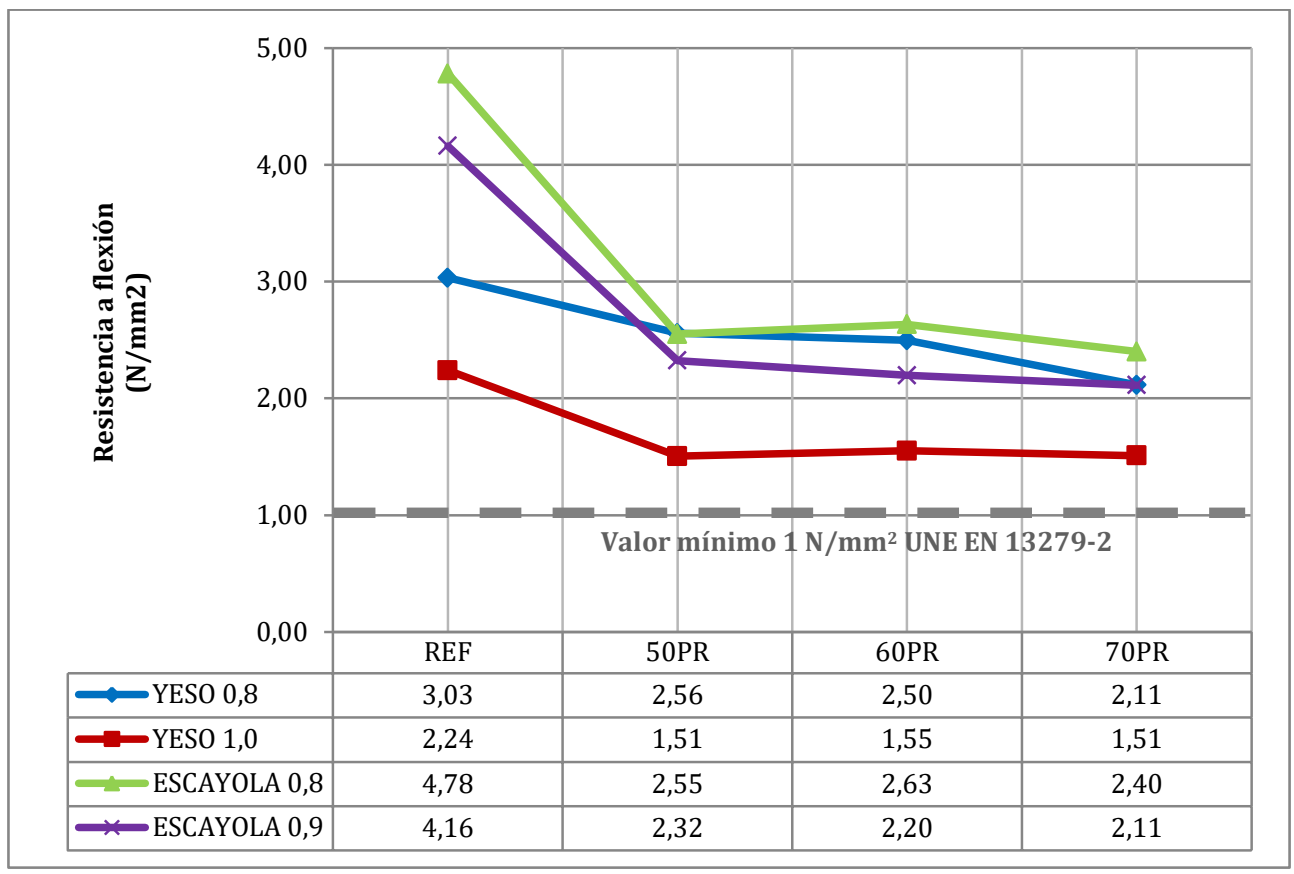

Gráfica 6.11. Resistencia a flexión de los compuestos
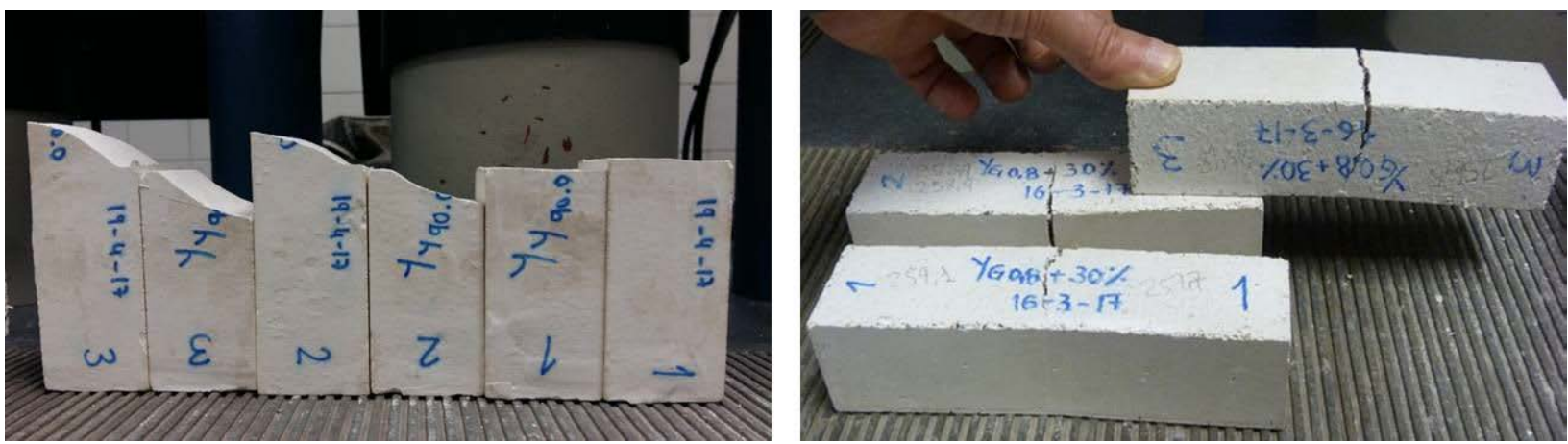

Foto 6.1. Ensayo de flexión realizado (izquierda: probetas de referencia; derecha: compuestos con PR)

Algo similar ocurre en el ensayo a compresión, con valores reducidos entre un tercio y la mitad en las mezclas con PR respecto a las referencias pero siempre por encima del valor mínimo indicado en normativa de $2 \mathrm{~N} / \mathrm{mm}^{2}$ (Gráfica 6.12) (UNE-EN 13279-2:2014, 2014). En esta ocasión, las escayolas presentan un 24,5\% más de resistencia a la compresión que los compuestos de yeso. También se puede observar que las pastas con mayor relación $\mathrm{A} / \mathrm{Y}$ presentan menores valores de resistencia a compresión, llegando a disminuir un 18,8\% en los compuestos con relación 0,9 y, un $37 \%$ en los compuestos con relación 1,0. El compuesto de mayor resistencia a 
compresión fue el $\mathrm{E}_{0,8-60 \mathrm{PR}}\left(5,12 \mathrm{~N} / \mathrm{mm}^{2}\right)$ y el de menor resistencia a compresión el $\mathrm{Y}_{1,0-50 \mathrm{PR}}\left(2,24 \mathrm{~N} / \mathrm{mm}^{2}\right)$.

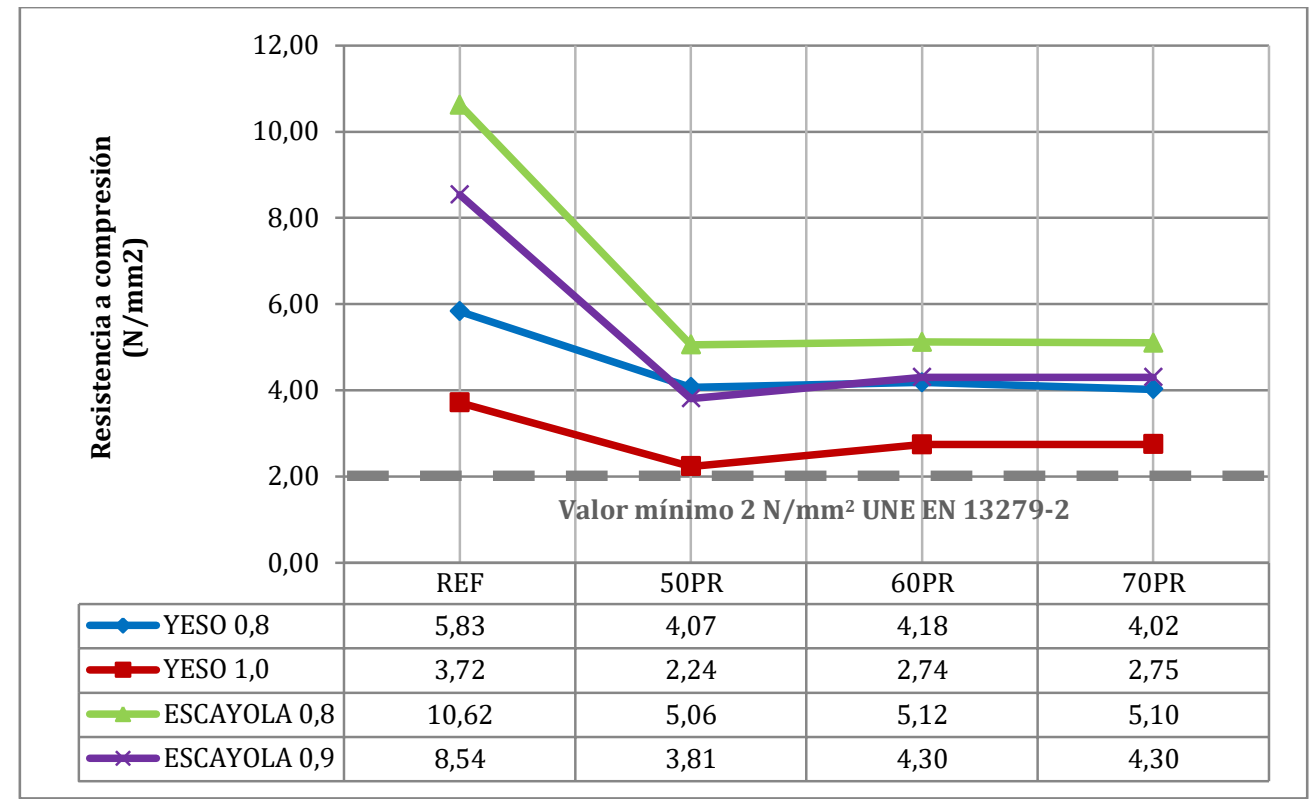

Gráfica 6.12. Resistencia a compresión de los compuestos

\subsection{Análisis estadístico de la variable R. Flexión}

Se muestran en la Tabla 6.12 los P-valores obtenidos en el análisis estadístico para cada uno de los factores indicados en la matriz planteada en el apartado 5.2.3, respecto a la variable R. Flexión.

Se puede observar que tanto en los factores de \%PR y tipo de conglomerante, así como en su interacción, los P-valores correspondientes a la variable R. Flexión son 0,0000 , por lo que se consideran significativos. Es decir, la resistencia a flexión depende tanto del \%PR como del tipo de conglomerante y de su interacción.

Tabla 6.12. Tabla ANOVA para la variable R. Flexión

\begin{tabular}{lcccc}
\hline Fuente & $\begin{array}{c}\text { Suma de } \\
\text { cuadrados }\end{array}$ & G.I. & F & P-valor \\
\hline EFECTOS PRINCIPALES & & & & 0,0000 \\
A: \%PR & 20,6509 & 3 & 524,97 & 0,0000 \\
B: tipo conglomerante & 13,1157 & 3 & 333,42 & 0,0000 \\
\hline INTERACCIONES & & & 29,85 & \\
AB & 3,52314 & 9 & & \\
\hline RESIDUOS & 0,4196 & 32 & & \\
\hline TOTAL (CORREGIDO) & 37,7094 & 47 & & \\
\hline
\end{tabular}


La hipótesis del modelo de homocedasticidad y normalidad, para la variable $\mathrm{R}$. Flexión, se cumple tal y como se muestra en la Gráfica 6.13 de residuos. La independencia se considera cumplida por el procedimiento aleatorio realizado en el proceso de ensayos de probetas en el laboratorio.
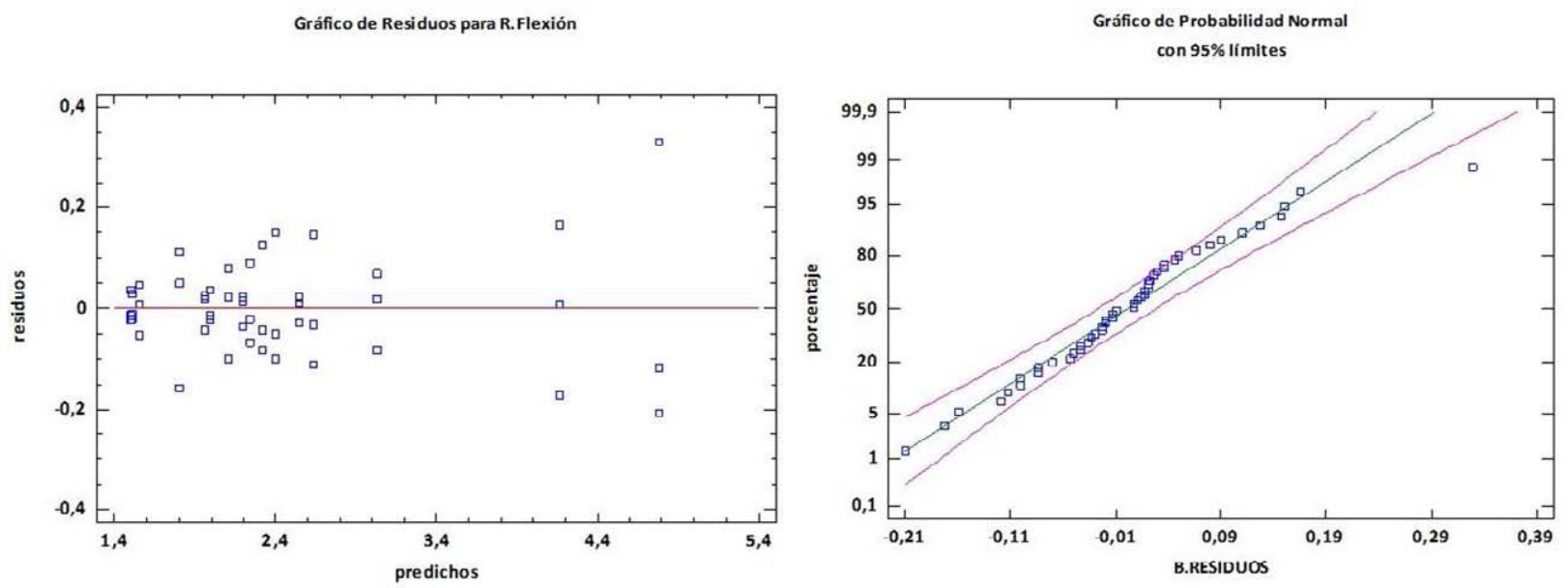

Gráfica 6.13. Diagnóstico del factor R. flexión

\subsection{Análisis estadístico de la variable R. Compresión}

A continuación, se muestran en la Tabla 6.13 los P-valores obtenidos en el análisis estadístico para cada uno de los factores indicados en la matriz planteada en el apartado 5.2.3, respecto a la variable R. Compresión.

Se puede observar que tanto en los factores de \%PR y tipo de conglomerante, así como en su interacción, los P-valores correspondientes a la variable R. Compresión son 0,0000 , por lo que se consideran significativos. Es decir, la resistencia a compresión depende tanto del \% PR como del tipo de conglomerante y de su interacción.

Tabla 6.13. Tabla ANOVA para la variable R. Compresión

\begin{tabular}{lcccc}
\hline Fuente & $\begin{array}{c}\text { Suma de } \\
\text { cuadrados }\end{array}$ & G.I. & F & P-valor \\
\hline EFECTOS PRINCIPALES & & & 1829,87 & 0,0000 \\
A: \%PR & 92,8889 & 3 & 1615,42 & 0,0000 \\
B: tipo conglomerante & 82,0029 & 3 & 198,16 & 0,0000 \\
\hline INTERACCIONES & 30,1778 & 9 & & \\
AB & 0,541467 & 32 & & \\
\hline RESIDUOS & 205,611 & 47 & & \\
\hline TOTAL (CORREGIDO) & & & & \\
\hline
\end{tabular}


La hipótesis del modelo de homocedasticidad y normalidad, para la variable $\mathrm{R}$. Compresión, no llega a cumplirse en normalidad, tal y como se muestra en la Gráfica 6.14 de residuos, pero eso no significa que se invaliden las conclusiones del ANOVA. La independencia se considera cumplida por el procedimiento aleatorio realizado en el proceso de ensayos de probetas en el laboratorio.
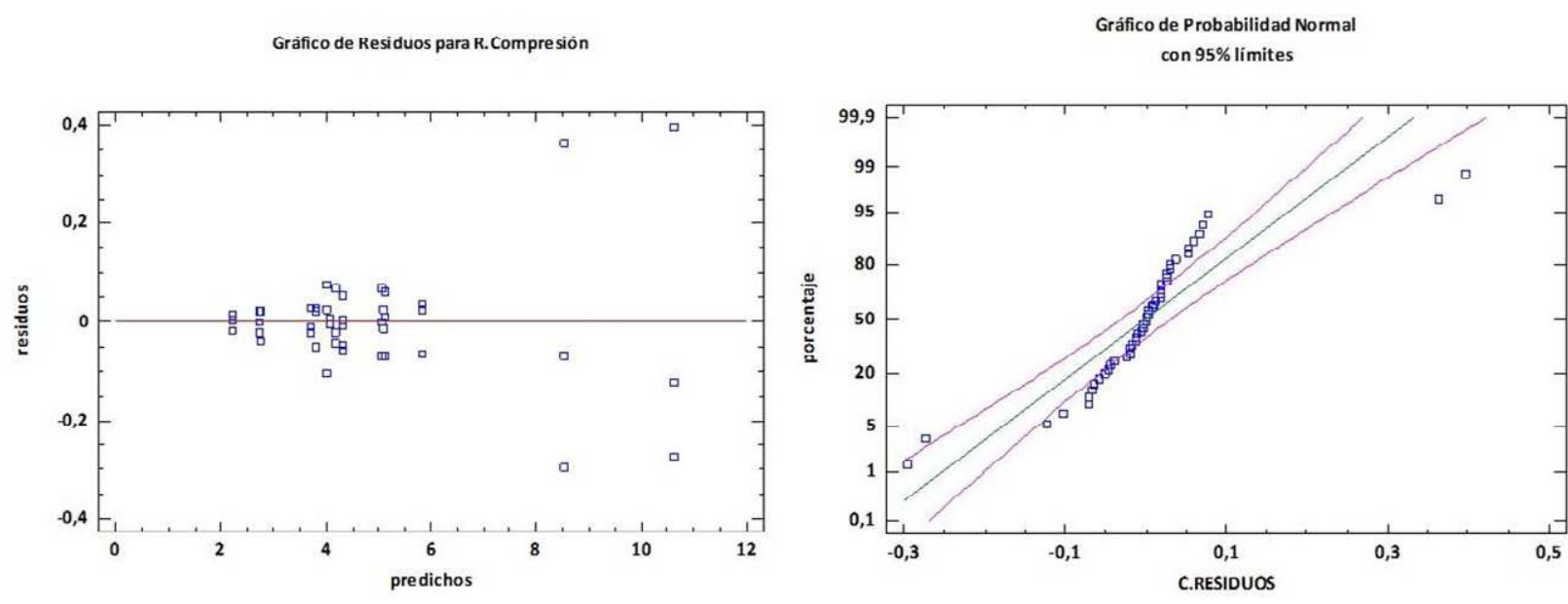

Gráfica 6.14. Diagnóstico del factor $R$. compresión

\subsubsection{Ensayos físicos de los compuestos con PR}

Del mismo modo, en los apartados siguientes se muestran los resultados obtenidos en los ensayos físicos de los compuestos en estado endurecido.

\subsubsection{Densidad y módulo de Young dinámico y estático}

En la Tabla 6.14 se indica la densidad en estado endurecido de cada compuesto así como el módulo de Young en las dos variantes estudiadas: estático y dinámico. Estos ensayos se realizaron en los compuestos de la Serie V-VI-VII-VIII.

Los resultados de la densidad de los compuestos (Gráfica 6.15) indican un aumento de todas las densidades de los compuestos respecto a sus referencias, aunque muy poco significativo (de acuerdo a los resultados de porosimetría, según se verá más adelante en el apartado 6.4.2.1.1). Los valores de densidad de las mezclas de yesos y escayolas con la misma dosificación de agua son similares, en cambio, disminuyen a medida que se incorpora agua en su composición, un 4\% aproximadamente con relación 0,9 y un 8,8\% aproximadamente con relación 1,0. El compuesto de menor densidad fue el $\mathrm{Y}_{1,0-60 \mathrm{PR}}\left(917,20 \mathrm{~kg} / \mathrm{m}^{3}\right)$ y el de mayor densidad el $Y_{0,8-60 P R}\left(1027,00 \mathrm{~kg} / \mathrm{m}^{3}\right)$.

En el Módulo de Young estático se observa una disminución significativa, alrededor del $50 \%$, de la rigidez de todos los compuestos respecto a las referencias (Gráfica 
6.16). Entre compuestos de diferente conglomerante, las mezclas de yeso son $33 \%$ más rígidas que las de escayola. Además se observa que, a medida que se incorpora agua en la mezcla, también disminuye la rigidez aproximadamente un 17,65\% con relación 0,9 y un $21,60 \%$ con relación 1,0 .

El compuesto de menor Módulo de Young estático, compuesto más elástico, fue el

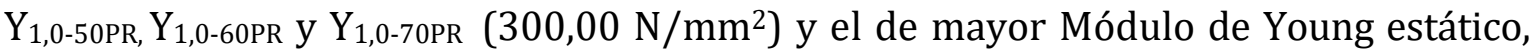
compuesto más rígido, el $\mathrm{E}_{0,8-50 \mathrm{PR}} \mathrm{y} \mathrm{E}_{0,8-60 \mathrm{PR}}\left(600,00 \mathrm{~N} / \mathrm{mm}^{2}\right)$.

Tabla 6.14. Densidad (UNE 102042:2014) y módulo de Young de los compuestos

\begin{tabular}{|c|c|c|c|c|c|c|c|}
\hline Referencia & Denomin. & $\begin{array}{c}\text { Densidad } \\
\left(\mathrm{kg} / \mathrm{m}^{3}\right)\end{array}$ & $\begin{array}{l}\Delta \text { de densidad } \\
\text { respecto a la } \\
\text { referencia }\end{array}$ & $\begin{array}{l}\text { M. Young } \\
\text { estático } \\
\left(\mathrm{N} / \mathrm{mm}^{2}\right)\end{array}$ & $\begin{array}{l}\Delta \text { de M. Young } \\
\text { estático respecto } \\
\text { a la referencia }\end{array}$ & $\begin{array}{l}\text { M. Young } \\
\text { dinámico } \\
\left(\mathrm{N} / \mathbf{m m}^{2}\right)\end{array}$ & $\begin{array}{c}\text { de M. Young } \\
\text { dinámico } \\
\text { respecto a la } \\
\text { referencia }\end{array}$ \\
\hline \multirow{4}{*}{ Serie V } & $\mathrm{Y}_{0,8}$ & 998,00 & 0,00 & 700,00 & 0,00 & 1649,03 & 0,00 \\
\hline & $\mathrm{Y}_{0,8-50 \mathrm{PR}}$ & 1018,80 & $+2,08 \%$ & 400,00 & $-42,86 \%$ & 861,68 & $-47,75 \%$ \\
\hline & $Y_{0,8-60 P R}$ & 1027,00 & $+2,91 \%$ & 400,00 & $-42,86 \%$ & 1083,12 & $-34,32 \%$ \\
\hline & $\mathrm{Y}_{0,8-70 \mathrm{PR}}$ & 1012,00 & $+1,40 \%$ & 333,33 & $-52,38 \%$ & 725,03 & $-56,03 \%$ \\
\hline \multirow{4}{*}{ Serie VI } & $\mathrm{Y}_{1,0}$ & 858,70 & 0,00 & 500,00 & 0,00 & 1549,69 & 0,00 \\
\hline & $\mathrm{Y}_{1,0-50 \mathrm{PR}}$ & 936,70 & $+9,08 \%$ & 300,00 & $-40,00 \%$ & 853,96 & $-44,89 \%$ \\
\hline & $Y_{1,0-60 P R}$ & 917,20 & $+6,81 \%$ & 300,00 & $-40,00 \%$ & 706,90 & $-54,38 \%$ \\
\hline & $\mathrm{Y}_{1,0-70 \mathrm{PR}}$ & 935,50 & $+8,94 \%$ & 300,00 & $-40,00 \%$ & 612,17 & $-60,50 \%$ \\
\hline \multirow{4}{*}{ Serie VII } & $\mathrm{E}_{0,8}$ & 988,90 & 0,00 & 1450,00 & 0,00 & 5136,65 & 0,00 \\
\hline & $\mathrm{E}_{0,8-50 \mathrm{PR}}$ & 1008,50 & $+1,98 \%$ & 600,00 & $-58,62 \%$ & 2976,26 & $-42,06 \%$ \\
\hline & $\mathrm{E}_{0,8-60 \mathrm{PR}}$ & 1022,10 & $+3,36 \%$ & 600,00 & $-58,62 \%$ & 2762,18 & $-46,23 \%$ \\
\hline & $\mathrm{E}_{0,8-70 \mathrm{PR}}$ & 1014,60 & $+2,60 \%$ & 500,00 & $-65,52 \%$ & 2664,15 & $-48,13 \%$ \\
\hline \multirow{4}{*}{ Serie VIII } & $E_{0,9}$ & 929,40 & 0,00 & 833,33 & 0,00 & 1071,02 & 0,00 \\
\hline & $\mathrm{E}_{0,9-50 \mathrm{PR}}$ & 986,00 & $+6,09 \%$ & 500,00 & $-40,00 \%$ & 781,41 & $-27,04 \%$ \\
\hline & $\mathrm{E}_{0,9-60 \mathrm{PR}}$ & 970,10 & $+4,38 \%$ & 500,00 & $-40,00 \%$ & 881,27 & $-17,72 \%$ \\
\hline & $\mathrm{E}_{0,9-70 \mathrm{PR}}$ & 967,00 & $+4,05 \%$ & 400,00 & $-52,00 \%$ & 675,07 & $-36,97 \%$ \\
\hline
\end{tabular}

\begin{tabular}{|c|c|c|c|c|c|}
\hline \multirow{9}{*}{ 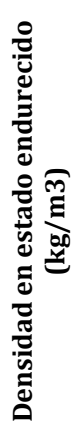 } & \multicolumn{5}{|l|}{1050,00} \\
\hline & \multicolumn{5}{|l|}{1030,00} \\
\hline & \multicolumn{5}{|l|}{990,00} \\
\hline & \multicolumn{5}{|l|}{950,00} \\
\hline & \multicolumn{5}{|l|}{930,00} \\
\hline & \multicolumn{5}{|l|}{910,00} \\
\hline & \multirow{3}{*}{$\begin{array}{l}870,00 \\
850,00\end{array}$} & \multicolumn{4}{|c|}{890,00} \\
\hline & & & & & \\
\hline & & \multirow{2}{*}{$\begin{array}{c}\text { REF } \\
998,00\end{array}$} & $50 \mathrm{PR}$ & $60 \mathrm{PR}$ & $70 \mathrm{PR}$ \\
\hline \multicolumn{2}{|c|}{$\longrightarrow$ YESO 0,8 } & & 858,7 & 988,9 & 929,4 \\
\hline \multicolumn{2}{|c|}{- YESO 1,0 } & 1018,80 & 936,7 & 1008,5 & 986 \\
\hline \multicolumn{2}{|c|}{$\simeq$ ESCAYOLA 0,8 } & 1027,00 & 917,2 & 1022,1 & 970,1 \\
\hline \multicolumn{2}{|c|}{$\because$ ESCAYOLA 0,9 } & 1012,00 & 935,5 & 1014,6 & 967 \\
\hline
\end{tabular}




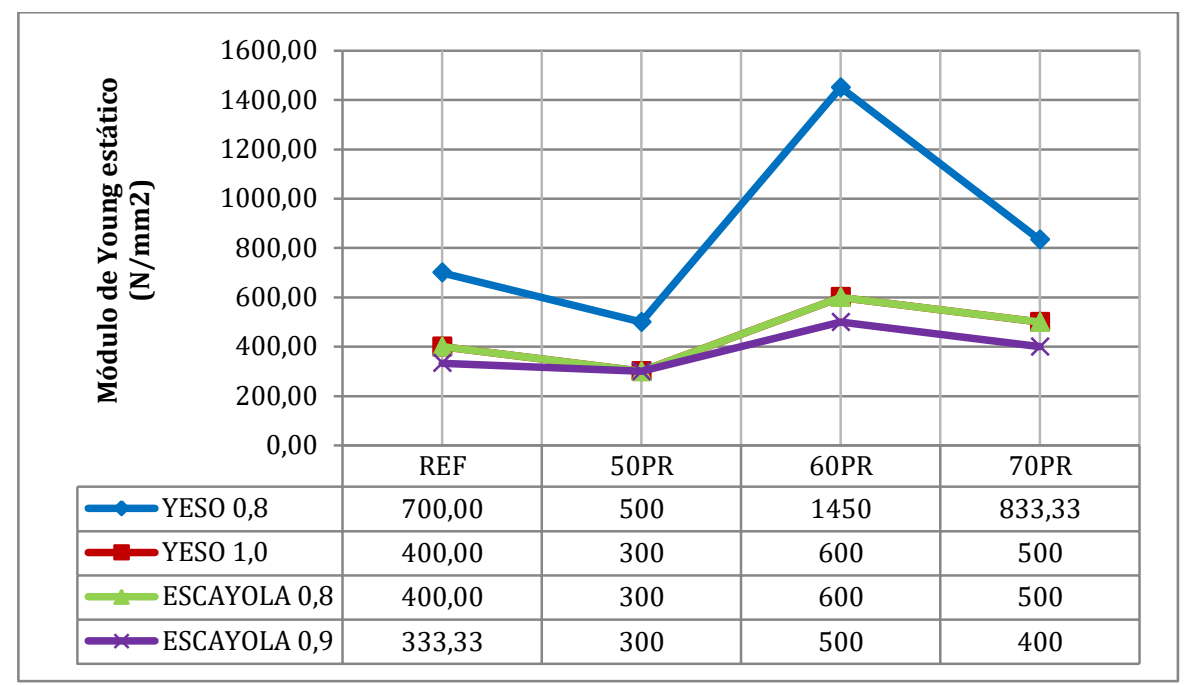

Gráfica 6.16. Módulo de Young estático

Los resultados para el Módulo de Young dinámico también indican una disminución significativa de la rigidez de las mezclas respecto a las referencias de aproximadamente el 50\% (Gráfica 6.17), excepto en los compuestos de relación agua/escayola 0,9 que solo alcanza el $27 \%$. Entre compuestos de diferente conglomerante, las mezclas de escayola son $57 \%$ menos rígidas que las de yeso. $\mathrm{Al}$ igual que el Módulo de Young dinámico se observa que, a medida que se incorpora agua en la mezcla, también disminuye la rigidez aproximadamente un 12,45\% con relación 0,9 y un 18,60\% con relación 1,0. El compuesto de menor Módulo de Young dinámico, compuesto más elástico, fue el $\mathrm{Y}_{1,0-70 \mathrm{PR}}\left(612,17 \mathrm{~N} / \mathrm{mm}^{2}\right)$ y el de mayor Módulo de Young dinámico, compuesto más rígido, el $\mathrm{E}_{0,8-50 \mathrm{PR}}\left(2977,02 \mathrm{~N} / \mathrm{mm}^{2}\right)$.

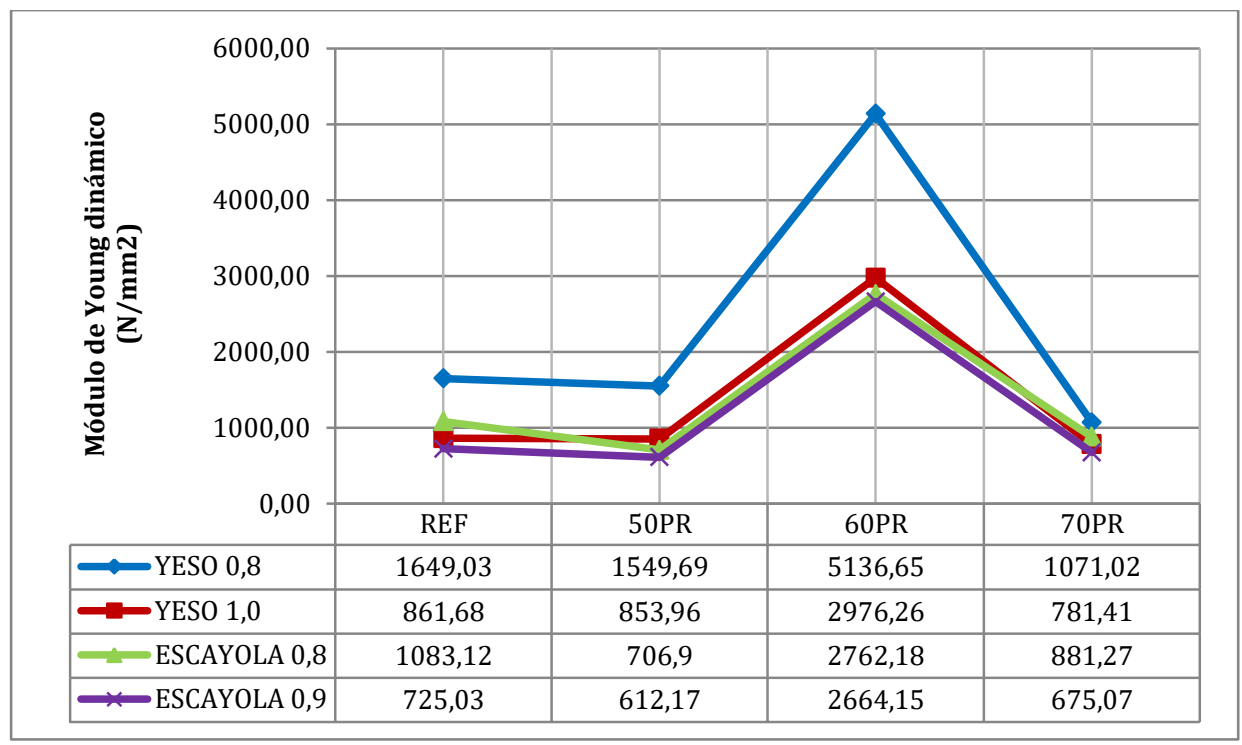

Gráfica 6.17. Módulo de Young dinámico 


\subsection{Análisis estadístico de la variable Densidad}

Para cada uno de los factores indicados en la matriz planteada en el apartado 5.2.3 se muestran, en la Tabla 6.15, los P-valores obtenidos en el análisis estadístico de las muestras, para la variable densidad.

Se puede observar que tanto en los factores de \%PR y tipo de conglomerante, así como en su interacción, los P-valores correspondientes a la variable densidad son 0,0000, por lo que se consideran significativos. Es decir, la densidad en estado endurecido depende tanto del \%PR como del tipo de conglomerante y de su interacción.

Tabla 6.15. Tabla ANOVA para la variable Densidad

\begin{tabular}{lcccc}
\hline Fuente & $\begin{array}{c}\text { Suma de } \\
\text { cuadrados }\end{array}$ & G.I. & F & P-valor \\
\hline EFECTOS PRINCIPALES & & & & 0,0000 \\
A: \%PR & 16961,8 & 3 & 222,02 & 0,0000 \\
B: tipo conglomerante & 83260,8 & 3 & 1089,84 & 0,0000 \\
\hline INTERACCIONES & & & 26,40 & \\
AB & 6051,62 & 9 & & \\
\hline RESIDUOS & 814,905 & 32 & & \\
\hline TOTAL (CORREGIDO) & 107089,0 & 47 & & \\
\hline
\end{tabular}

La hipótesis del modelo de homocedasticidad y normalidad, para la variable densidad, se cumple tal y como se muestra en la Gráfica 6.18 de residuos. La independencia se considera cumplida por el procedimiento aleatorio realizado en el proceso de ensayos de probetas en el laboratorio.
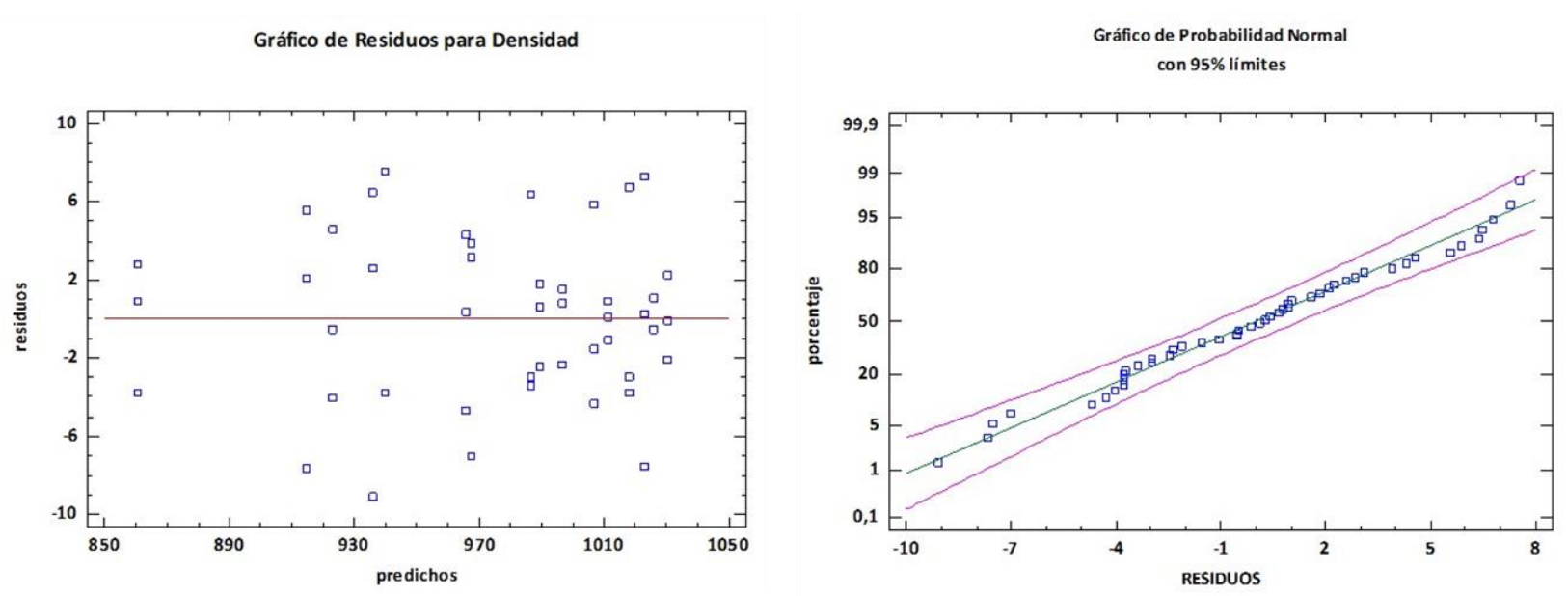

Gráfica 6.18. Diagnóstico del factor densidad 


\subsection{FASE IV DEL PLAN EXPERIMENTAL -OBJETIVO 4}

En este apartado se presentan los resultados obtenidos sobre las aplicaciones propuestas en el apartado 5.4.1. Asimismo y correspondiendo con la Fase IV del plan experimental (apartado 5.4.2), se muestran las propiedades de los compuestos seleccionados frente a la acción de distintos agentes externos.

\subsubsection{Propuesta de posibles aplicaciones}

En la Tabla 6.16 se indican las aplicaciones más acordes a los compuestos, revestimientos, paneles o placas, en relación a las propiedades analizadas por San Antonio González A. y Sorrentino M. en sus estudios de tesis doctoral y trabajo fin de máster respectivamente (densidad, dureza Shore C, resistencia a flexión y compresión y absorción de agua por capilaridad), a las que se ha incorporado, como un factor más, el tiempo de fraguado.

Tabla 6.16 Análisis de las aplicaciones

\begin{tabular}{|c|c|c|c|c|c|c|}
\hline Denomin. & $\begin{array}{c}\text { Densidad } \\
\left(\mathrm{kg} / \mathrm{m}^{3}\right)\end{array}$ & $\begin{array}{l}\text { Dureza } \\
\text { Shore C }\end{array}$ & $\begin{array}{l}\text { R. flexión } \\
\left(\mathrm{N} / \mathrm{mm}^{2}\right)\end{array}$ & $\begin{array}{l}\text { R. compresión } \\
\left(\mathrm{N} / \mathrm{mm}^{2}\right)\end{array}$ & $\begin{array}{c}\text { Absorción de agua } \\
\text { por capilaridad (\%) }\end{array}$ & $\begin{array}{c}\text { Tiempo de fraguado } \\
\text { (minutos) }\end{array}$ \\
\hline $\mathrm{Y}_{0,8-50 \mathrm{PR}}$ & 1018,80 & 73,90 & 1,990 & 4,073 & 7,38 & 7,25 \\
\hline $\mathrm{Y}_{0,8-60 \mathrm{PR}}$ & 1027,00 & 74,70 & 1,966 & 4,181 & 7,07 & 5,00 \\
\hline $\mathrm{Y}_{0,8-70 \mathrm{PR}}$ & 1012,00 & 75,17 & 1,801 & 4,023 & 7,54 & 5,00 \\
\hline $\mathrm{Y}_{1,0-50 \mathrm{PR}}$ & 936,70 & 47,00 & 1,505 & 2,235 & 13,54 & 11,00 \\
\hline $\mathrm{Y}_{1,0-60 \mathrm{PR}}$ & 917,20 & 63,37 & 1,551 & 2,740 & 10,92 & 8,25 \\
\hline $\mathrm{Y}_{1,0-70 \mathrm{PR}}$ & 935,50 & 65,43 & 1,510 & 2,748 & 9,88 & 7,50 \\
\hline $\mathrm{E}_{0,8-50 \mathrm{PR}}$ & 1008,50 & 81.17 & 2,550 & 5,058 & 6,82 & 7,25 \\
\hline$E_{0,8-60 P R}$ & 1022,10 & 80,60 & 2,634 & 5,118 & 5,59 & 7,25 \\
\hline $\mathrm{E}_{0,8-70 \mathrm{PR}}$ & 1014,60 & 81,60 & 2,401 & 5,100 & 5,90 & 6,00 \\
\hline$E_{0,9-50 P R}$ & 986,00 & 67,00 & 2,323 & 3,808 & 9,35 & 9,75 \\
\hline $\mathrm{E}_{0,9-60 \mathrm{PR}}$ & 970,10 & 77,17 & 2,196 & 4,302 & 7,13 & 9,75 \\
\hline$E_{0,9-70 P R}$ & 967,00 & 77,60 & 2,113 & 4,303 & 6,31 & 7,00 \\
\hline
\end{tabular}

En vista de los datos obtenidos, dureza alta, baja absorción de agua, fraguado rápido y valores de compresión y flexión dentro de la normativa, la aplicación más adecuada para los compuestos con PR sería la fabricación de paneles para trasdosados y/o particiones interiores colocados de forma directa, semidirecta o con entramado autoportante y, placas para falso techo sobre estructura portante. Los más idóneos resultan los elaborados con escayola, con una relación de agua/yeso de 0,8 y cargas del 60\% de PR. Para el caso de revestimientos continuos, sería conveniente añadir un retardador de fraguado para mantener la trabajabilidad de la pasta durante 
más tiempo. Como se ha comentado en el apartado 6.2.1. se podría utilizar un fluidificante natural, Plast Retard o similar, con el fin de seguir manteniendo el compromiso de sostenibilidad adquirido en esta investigación.

\subsubsection{Análisis económico}

Los valores utilizados para la realización del análisis económico se muestran en la Tabla 6.17. Para ello se tiene en cuenta el coste de la materia prima utilizada (escayola, agua y PR), el coste de transporte (del PR desde la empresa de reciclaje de cables hasta la fábrica del producto final) y el coste del proceso de producción, considerados en el apartado 5.4.1.1.

Tabla 6.17. Materia prima, transporte y producción para la fabricación de $1 \mathrm{~m}^{3}$ de compuesto

\begin{tabular}{lccccc}
\hline Denomin. & $\begin{array}{c}\text { Escayola para 1 } \\
\mathbf{m}^{\mathbf{3}} \mathbf{( k g )}\end{array}$ & $\begin{array}{c}\text { Agua para 1 } \\
\mathbf{m}^{\mathbf{3}} \mathbf{( \mathbf { k g } )}\end{array}$ & $\begin{array}{c}\text { PR para 1 } \\
\mathbf{~ m}^{\mathbf{3}} \mathbf{( \mathbf { k g } )}\end{array}$ & $\begin{array}{c}\text { Camiones para } \\
\mathbf{1 ~}^{\mathbf{3}} \mathbf{( \mathbf { u d } )}\end{array}$ & $\begin{array}{c}\text { Proceso de } \\
\text { producción (ud) }\end{array}$ \\
\hline $\mathrm{E}_{0,8}$ & 911,45 & 729,15 & 0,00 & 0,00 & $\mathrm{p}$ \\
$\mathrm{E}_{0,8-50 \mathrm{PR}}$ & 699,50 & 559,60 & 349,50 & 0,85 & $0,10 \mathrm{p}$ \\
$\mathrm{E}_{0,8-60 \mathrm{PR}}$ & 651,05 & 520,80 & 390,60 & 0,95 & $0,10 \mathrm{p}$ \\
$\mathrm{E}_{0,8-70 \mathrm{PR}}$ & 651,05 & 520,80 & 455,75 & 1,11 & $0,10 \mathrm{p}$ \\
\hline
\end{tabular}

Se toma como referencia la fabricación de $1 \mathrm{~m}^{3}$ de compuesto que se presenta en la Tabla 6.18.

Tabla 6.18. Costes totales para $1 \mathrm{~m}^{3}$ de compuesto

\begin{tabular}{|c|c|c|c|c|c|c|c|}
\hline Denomin. & $\begin{array}{l}\text { Coste de } \\
\text { escayola } \\
\left(€ / \mathrm{m}^{3}\right)\end{array}$ & $\begin{array}{c}\text { Coste de agua } \\
\left(€ / \mathrm{m}^{3}\right)\end{array}$ & $\begin{array}{c}\text { Coste de PR } \\
\left(€ / \mathbf{m}^{3}\right)\end{array}$ & $\begin{array}{c}\text { Transporte } \\
\left(€ / \mathbf{m}^{3}\right)\end{array}$ & $\begin{array}{c}\text { Proceso de } \\
\text { producción } \\
\left(€ / \mathbf{m}^{3}\right)\end{array}$ & $\begin{array}{c}\text { Coste total } \\
\left(€ / \mathbf{m}^{3}\right)\end{array}$ & $\begin{array}{c}\Delta \text { de coste total } \\
\text { respecto a la } \\
\text { referencia }\end{array}$ \\
\hline $\mathrm{E}_{0,8}$ & 82,03 & 1,08 & 0,00 & 0,00 & 1 & 84,11 & 0,00 \\
\hline $\mathrm{E}_{0,8-50 \mathrm{PR}}$ & 59,66 & 0,83 & 0,00 & 19,10 & 1,10 & 80,69 & $-4,07 \%$ \\
\hline $\mathrm{E}_{0,8-60 \mathrm{PR}}$ & 58,59 & 0,77 & 0,00 & 21,35 & 1,10 & 81,81 & $-2,73 \%$ \\
\hline $\mathrm{E}_{0,8-70 \mathrm{PR}}$ & 58,59 & 0,77 & 0,00 & 24,94 & 1,10 & 85,40 & $+1,53 \%$ \\
\hline
\end{tabular}

Se observa la viabilidad económica de los compuestos incluso con la incorporación del transporte de la granza desde la empresa de reciclaje hasta la empresa de fabricación del producto. Suponiendo, una reducción del coste total de un 4,07\% en el caso del $E_{0,8-50 \text { PR }}\left(80,69 € / \mathrm{m}^{3}\right)$, un $2,73 \%$ en el caso del $E_{0,8-60 \mathrm{PR}}\left(81,81 € / \mathrm{m}^{3}\right)$ y un ligero aumento del 1,53\% en el caso del $\mathrm{E}_{0,8-70 \mathrm{PR}}\left(85,40 € / \mathrm{m}^{3}\right)$.

Para la empresa de reciclaje puede significar, además, un ahorro de unos 45,45 $€ / \mathrm{m}^{3}$ de PR generado (precio de la incineración por gestor autorizado). 


\subsubsection{Propiedades de los compuestos seleccionados de escayola con PR}

Una vez comprobado que los compuestos que tienen un mejor comportamiento para las aplicaciones propuestas son los realizados con matriz de escayola y relación A/Y de 0,8 , se procede a la evaluación de la durabilidad mediante el análisis de su comportamiento cuando son sometidos a acciones externas como el agua, el fuego o el calor.

\subsubsection{Ensayos químicos de los compuestos seleccionados}

Se realizan los ensayos químicos para tratar de relacionar la morfología interna de las mezclas con las propiedades obtenidas tras los ensayos.

\subsection{Porosimetría de mercurio}

Los resultados experimentales obtenidos en los ensayos de porosimetría de mercurio de la Serie IX, se indican en la Tabla 6.19 y en las Gráficas 6.19 y 6.20.

Tabla 6.19. Propiedades texturales obtenidas a partir de la porosimetría de mercurio de los compuestos seleccionados

\begin{tabular}{|c|c|c|c|c|c|c|c|c|c|c|c|c|}
\hline Refer. & Denom. & $\begin{array}{c}\text { Volumen } \\
\text { total de } \\
\text { intrusión } \\
\left(\mathrm{cm}^{3} / \mathrm{g}\right)\end{array}$ & $\begin{array}{c}\text { Área } \\
\text { total de } \\
\text { poro } \\
\left(\mathbf{m}^{2} / \mathbf{g}\right)\end{array}$ & $\begin{array}{c}\text { Diámetro } \\
\text { medio de } \\
\text { poro - } \\
\text { volumen } \\
(\mathrm{nm}) \\
\end{array}$ & $\begin{array}{c}\text { Diámetro } \\
\text { medio de } \\
\text { poro - } \\
\text { área }(n m)\end{array}$ & $\begin{array}{c}\text { Densidad } \\
\text { Bulk a } \\
0,0036 \mathrm{MPa} \\
\left(\mathrm{g} / \mathrm{cm}^{3}\right) \\
\end{array}$ & $\begin{array}{c}\text { Densidad } \\
\text { aparente } \\
\left(\mathrm{g} / \mathrm{cm}^{3}\right)\end{array}$ & $\begin{array}{l}\text { Porosimetría } \\
\text { (\%) }\end{array}$ & $\begin{array}{c}\Delta \text { de } \\
\text { porosimetría } \\
\text { respecto a la } \\
\text { referencia }\end{array}$ & $\begin{array}{l}10 \% \\
V p<{ }^{(1)} \\
(\mathrm{nm})\end{array}$ & $\begin{array}{l}15 \% \\
V p<{ }^{(1)} \\
(n m)\end{array}$ & $\begin{array}{c}90 \% \\
V p<{ }^{(1)} \\
(n m)\end{array}$ \\
\hline \multirow{4}{*}{ Serie IX } & $\mathrm{E}_{0,8}$ & 0,5419 & 2,062 & 2172,7 & 757,6 & 1,0166 & 2,2639 & 55,0949 & 0,00 & 838 & 2143 & 72000 \\
\hline & $\mathrm{E}_{0,8-50 \mathrm{PR}}$ & 0,4067 & 4,134 & 1827,9 & 12,8 & 1,0542 & 1,8453 & 42,8734 & $-22,18 \%$ & 679 & 1819 & 3511 \\
\hline & $\mathrm{E}_{0,8-60 \mathrm{PR}}$ & 0,4276 & 4,755 & 1981,9 & 11,4 & 1,0235 & 1,8200 & 43,7624 & $-20,57 \%$ & 676 & 2000 & 3163 \\
\hline & $\mathrm{E}_{0,8-70 \mathrm{PR}}$ & 0,3447 & 4,890 & 2286,0 & 9,8 & 1,0776 & 1,7145 & 37,1454 & $-32,58 \%$ & 1169 & 2290 & 3916 \\
\hline
\end{tabular}




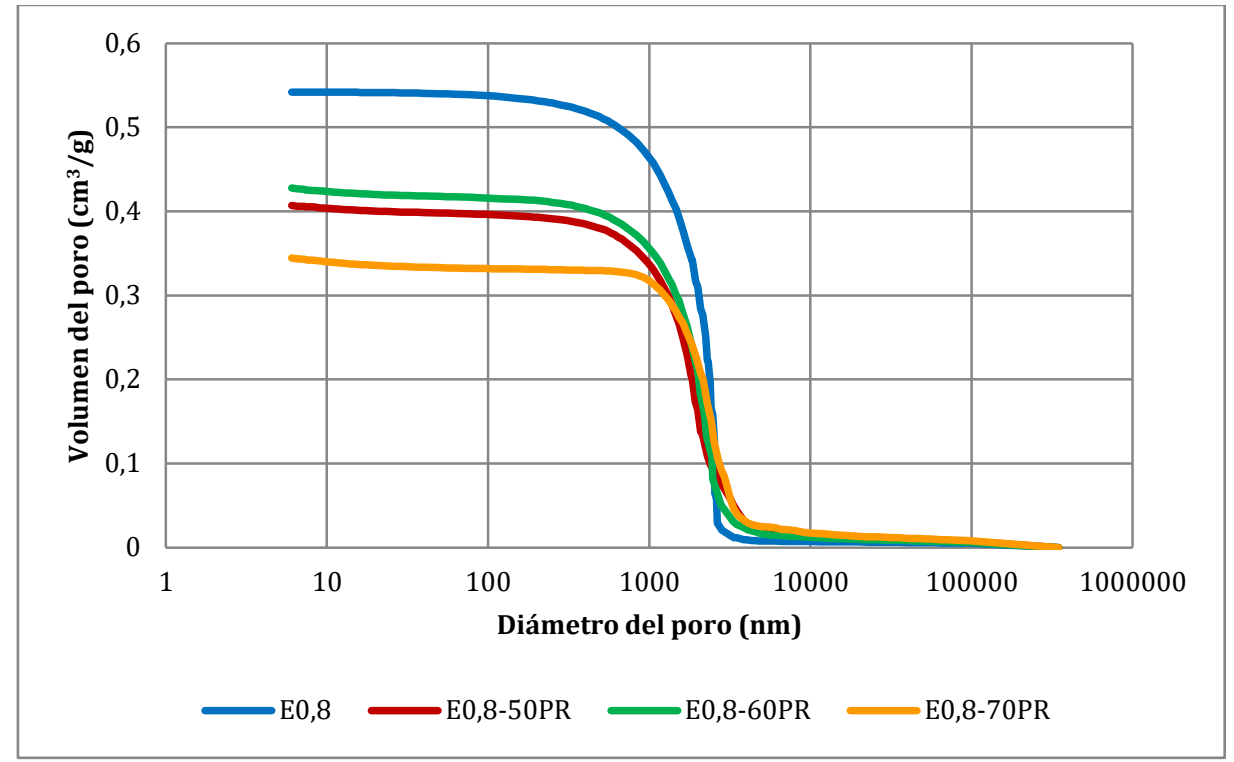

Gráfica 6.19. Distribución de tamaño de poro acumulada

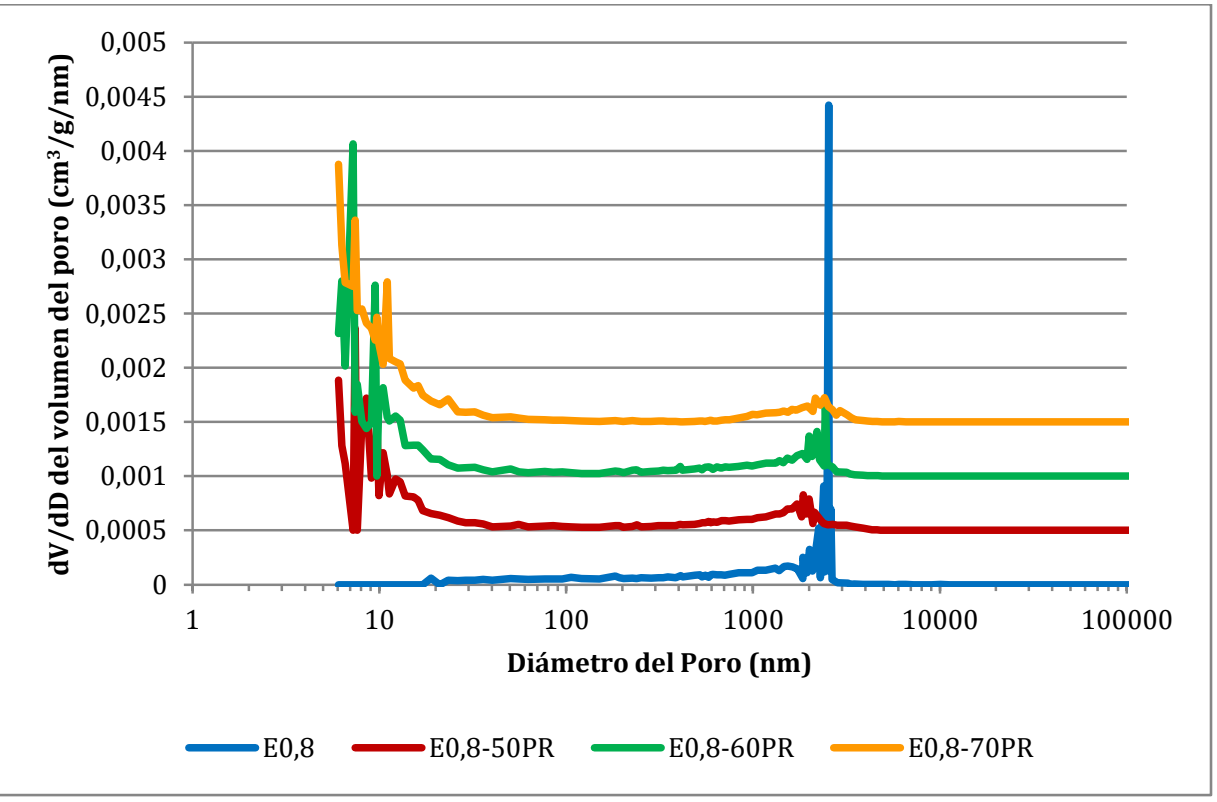

Gráfica 6.20. Distribución de tamaño de poro diferencial. Se han desplazado las curvas en el eje vertical para separarlas

Se observa que la muestra de referencia presenta el volumen de poro más alto. La adición de plástico disminuye el volumen de poro, y el compuesto del 70\% PR presenta el valor más pequeño de volumen de poro.

De acuerdo con estos resultados, el compuesto de referencia es el que presenta la menor densidad Bulk (densidad que incluye los poros), y los compuestos adicionados con plástico presentan valores mayores, siendo el valor más alto el del compuesto con $70 \%$ de PR. Se cumple, una relación inversa entre la porosidad del material y la densidad Bulk, es decir, cuanta mayor cantidad de poros, menor densidad Bulk presenta el compuesto. Este hecho es también visible en otras investigaciones (Ahmed, Ugai, \& Kamei, 2011; Flores Medina \& Barbero Barrera, 2017). 
Los valores de densidad real (densidad del material excluyendo los poros) son lógicamente mayores que los de densidad Bulk. El valor superior corresponde al compuesto de referencia, y los valores disminuyen a medida que aumenta el porcentaje de plástico en los compuestos, de forma que la muestra con $70 \%$ de PR es la de menor densidad real. Ello se correlaciona bien con el mayor valor de densidad real del yeso con respecto al PR presentados en el apartado 6.1.1.2 y otras investigaciones (Jiménez Rivero, Guzmán Báez, García Navarro, \& González Cortina, 2011; Khalil, Tawfik, Hegazy, \& El-Shahat, 2014; Tapia Batallas, 2015), de forma que la matriz de los compuestos adicionados con plástico es más ligera, tanto más cuanto mayor es la cantidad de PR que contiene.

Todos los compuestos, tanto la referencia como los que contienen PR, presentan una distribución de tamaño de poro muy similar, unimodal, correspondiente a macroporos (poros con tamaño superior a $50 \mathrm{~nm}$ ) según la clasificación de la IUPAC (Rouquerol, Rouquerol, Sing, Llewellyn, \& Maurin, 2014). La distribución de tamaños queda reflejada de forma numérica en la Tabla 6.19; en la distribución de tamaño de poro diferencial (Gráfica 6.20) puede observarse que todas las muestras presentan un máximo alrededor de 1500-2500 nm. En las muestras adicionadas con PR se observa que, para tamaños de poro inferiores a $20 \mathrm{~nm}$, se inicia un segundo máximo en el volumen de poro, pero como puede apreciarse en la distribución acumulada (Gráfica 6.21) este volumen de poro para las tres muestras adicionadas con PR supone un porcentaje muy pequeño del volumen de poro, con un 1,6\%-1,8\%-2,7\% para las muestras con 50-60-70\% PR respectivamente.

Por tanto, la adición de PR a la matriz de yeso tiene como principal efecto disminuir el volumen de poro, pero afecta escasamente a la distribución de tamaños de estos poros. Este resultado se explica teniendo en cuenta que el origen de estos poros se debe al entramado cristalino formado por los cristales de yeso dihidrato, en forma de agujas y placas, que se forman debido a la hidratación del hemihidrato durante el fraguado (Vidales Barriguete, del Río Merino, Atanes Sánchez, Piña Ramírez, \& Viñas Arrebola, 2018). Esta red porosa, con su tamaño de poro característico, simplemente está presente en menor proporción en las muestras con mayor cantidad de PR adicionado, lo que explica el menor volumen de poro.

En resumen, el índice de porosimetría en los compuestos es un 22,18\%-20,57\%$32,58 \%$ menor respecto a la referencia, a medida que se aumenta el porcentaje de PR (50\%PR-60\%PR-70\%PR). La mezcla de mayor porosimetría fue la $\mathrm{E}_{0,8-60 \mathrm{PR}}(43,76 \%)$ y la de menor porosimetría la $\mathrm{E}_{0,8-70 \mathrm{PR}}(37,15 \%)$. 


\subsection{Microscopía electrónica de barrido SEM}

La Foto 6.2 muestra dos imágenes de la cristalización del yeso sin adición. Se observan los cristales de yeso dihidrato formados en la hidratación del hemihidrato durante el fraguado, con forma de agujas y láminas, y longitudes inferiores entre 5 y 10 micras.
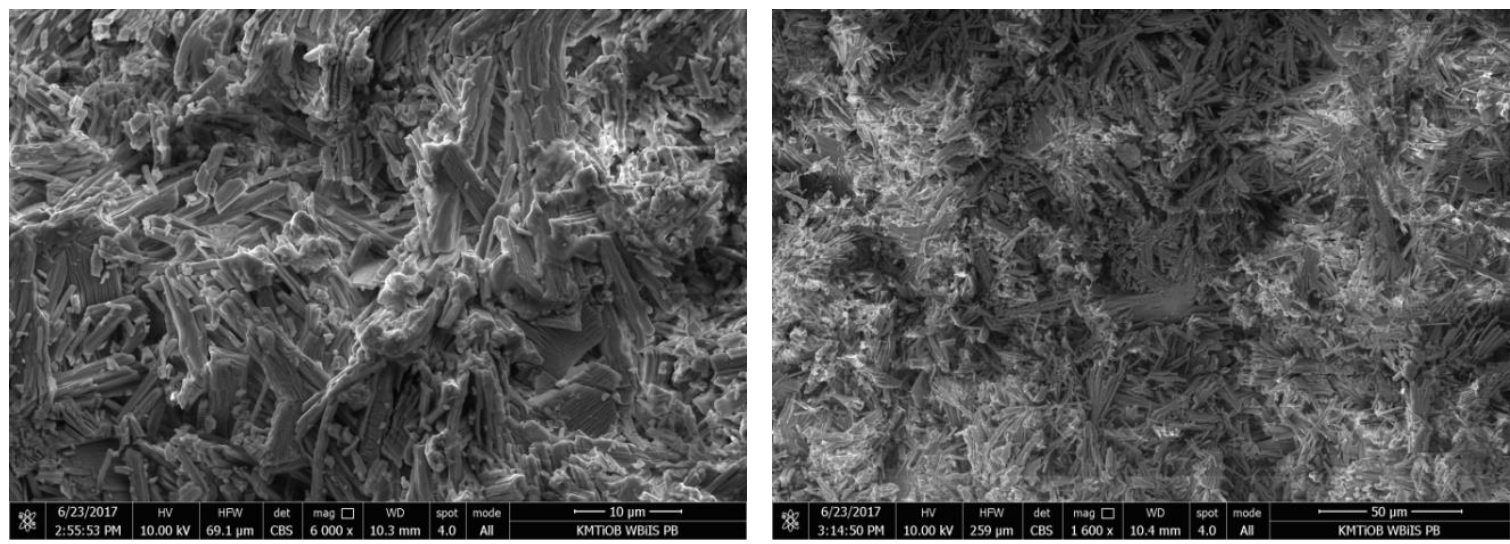

Foto 6.2. Microscopía de una muestra de $E_{0,8}$ a 600x (izquierda) y 1600x (derecha)

Las Fotos 6.3-6.4-6.5 muestran varias imágenes de la cristalización del yeso con un 60\%-50\%-70\% de adición de PR. En todos los casos, los cristales de yeso dihidrato forman un entramado poroso que envuelve a las partículas de granza, de tamaño muy superior. Se observan tanto superficies de unión yeso-granza continuas y con buena adhesión, como bordes con grietas y poca adhesión entre las dos fases. La presencia de una cierta cantidad de discontinuidades en la unión yeso-granza explicaría la disminución de las propiedades mecánicas respecto a la referencia tal y como también demuestran los "Estudios sobre compuestos de yeso con adición de polímeros" del capítulo 2 .
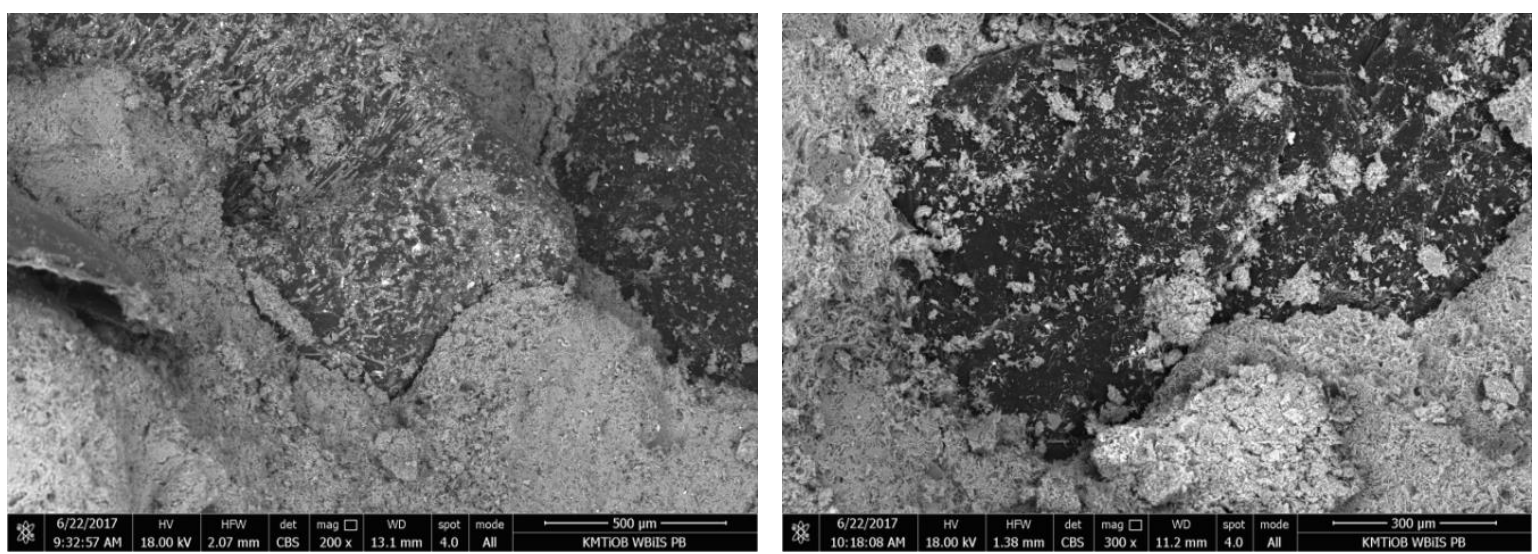

Foto 6.3. Microscopía de una muestra de E, $E_{0-60 P R}$ a 200x (izquierda) y 300x (derecha) 

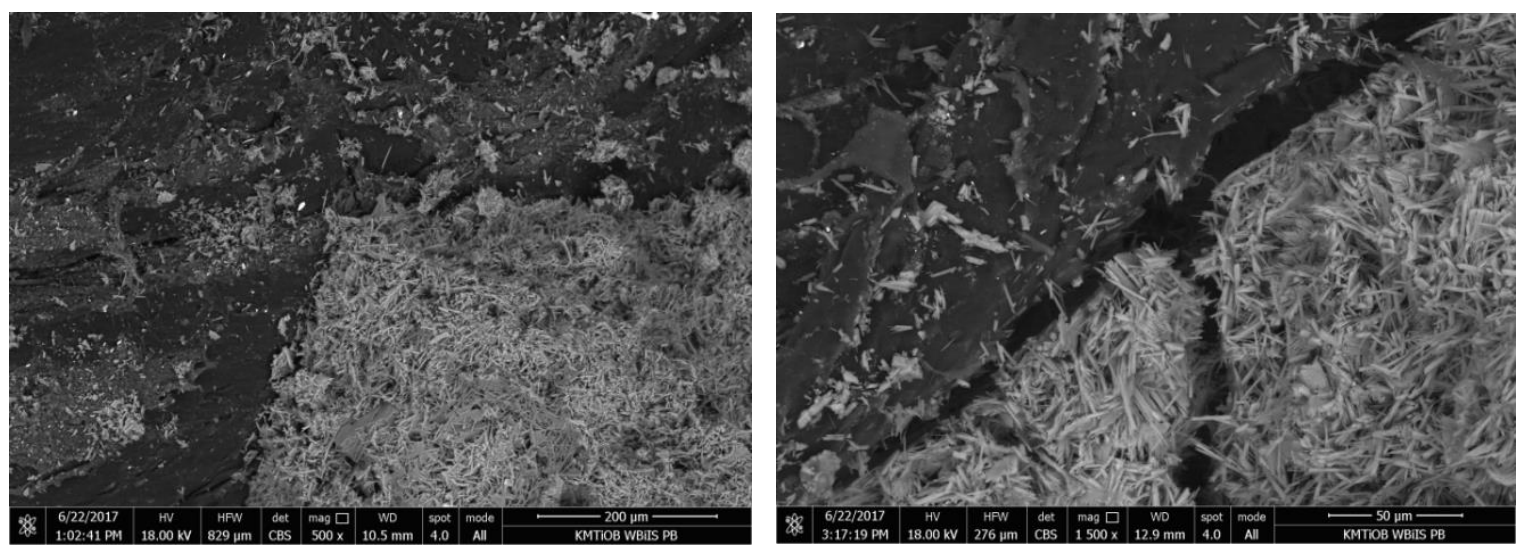

Foto 6.4. Microscopía de una muestra de $E_{0,8-50 P R}$ a 500x (izquierda) y 1500x (derecha)
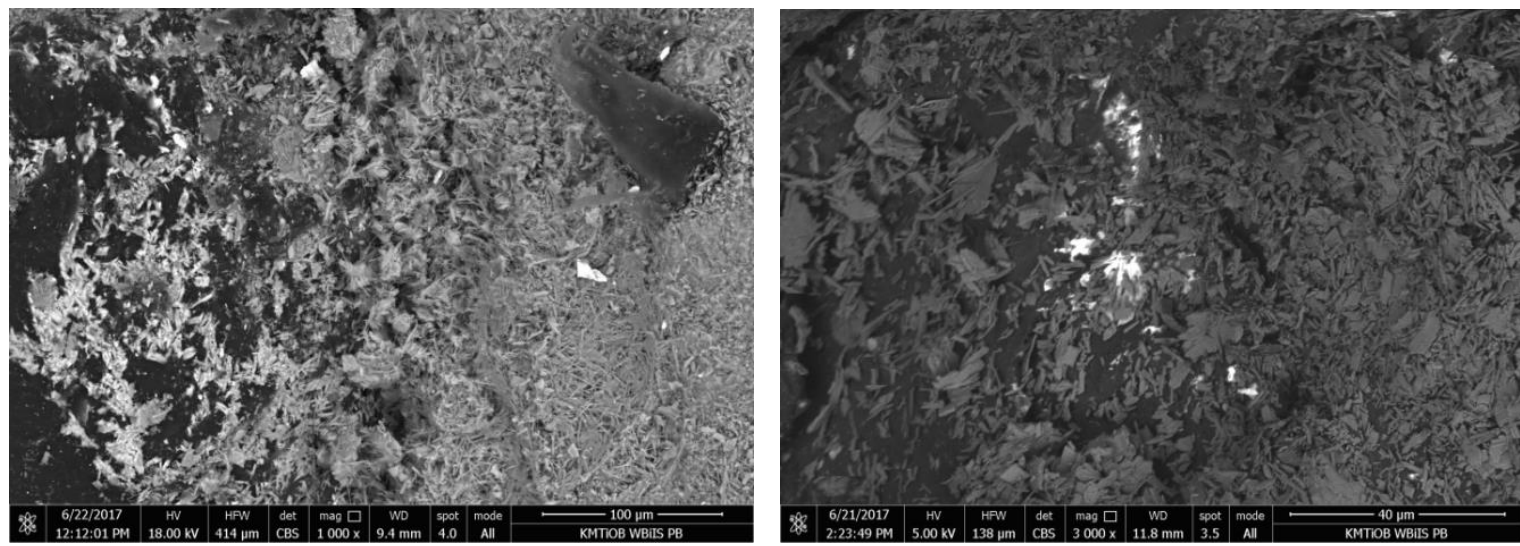

Foto 6.5. Microscopía de una muestra de E,8-70pR a 1000x (izquierda) y 3000x (derecha)

\subsubsection{Ensayos mecánicos de los compuestos seleccionados}

Para comprobar el efecto que fuerzas exteriores pueden tener en las propiedades mecánicas de los compuestos se les somete a los ensayos descritos en el apartado 5.4.2.2 cuyos resultados se exponen a continuación.

\subsection{Resistencia al choque-impacto}

Teniendo en cuenta que las aplicaciones propuestas, paneles y placas, están expuestas en cualquier momento al choque de objetos, es necesario comprobar la resistencia de los compuestos ante este efecto. En el análisis del ensayo de resistencia al choque-impacto, realizado en la Serie XI, se obtiene el diámetro y la profundidad de la huella de la bola de acero, indicados en la Tabla 6.20. 
Tabla 6.20. Resistencia al choque-impacto (mm) - UNE EN 520

\begin{tabular}{lllcccc}
\hline Refer. & Denom. & $\begin{array}{c}\text { Tipo de } \\
\text { soporte }\end{array}$ & $\begin{array}{c}\text { Dureza } \\
\text { Shore C }\end{array}$ & $\begin{array}{c}\text { Diámetro } \\
\text { de la huella } \\
\text { (mm) }\end{array}$ & $\begin{array}{c}\text { Profundidad de la } \\
\text { huella (mm) }\end{array}$ & $\begin{array}{c}\Delta \text { profundidad de } \\
\text { huella respecto a la } \\
\text { referencia }\end{array}$ \\
\hline \multirow{2}{*}{ Serie XI } & $\mathrm{E}_{0,8}$ & Cerámico & 78,00 & 14,70 & 1,17 & 0,00 \\
& $\mathrm{E}_{0,8-50 \mathrm{PR}}$ & Cerámico & 81,17 & 11,68 & 0,73 & $-37,61 \%$ \\
& $\mathrm{E}_{0,8-60 \mathrm{PR}}$ & Cerámico & 80,60 & 13,70 & 1,01 & $-13,68 \%$ \\
& $\mathrm{E}_{0,8-70 \mathrm{PR}}$ & Cerámico & 81,60 & 13,18 & 0,93 & $-20,51 \%$ \\
\hline
\end{tabular}

En el caso de la muestra de referencia, el primer impacto rompe la probeta (Foto 6.6 izquierda); por el contrario, en todos los impactos sobre las muestras con PR la bola de acero rebota (Foto 6.6 derecha), hecho que supone una fuerza de impacto mayor que la de cálculo y que corrobora el aumento de elasticidad conseguido en los compuestos en estudio y comprobado con el Módulo de Young en el apartado 6.3.2.1 y otras investigaciones (Domínguez Lepe \& Guemez Pacheco, 2011; Mayor Lobo, Bustamante Montoro, Rangel, \& Hernández Olivares, 2008). El compuesto de mayor resistencia al choque-impacto fue el $\mathrm{E}_{0,8-50 \mathrm{PR}}(0,73 \mathrm{~mm}$ de profundidad de huella) y el de menor resistencia al choque-impacto el $\mathrm{E}_{0,8-60 \mathrm{PR}}(1,01 \mathrm{~mm}$ de profundidad de huella).
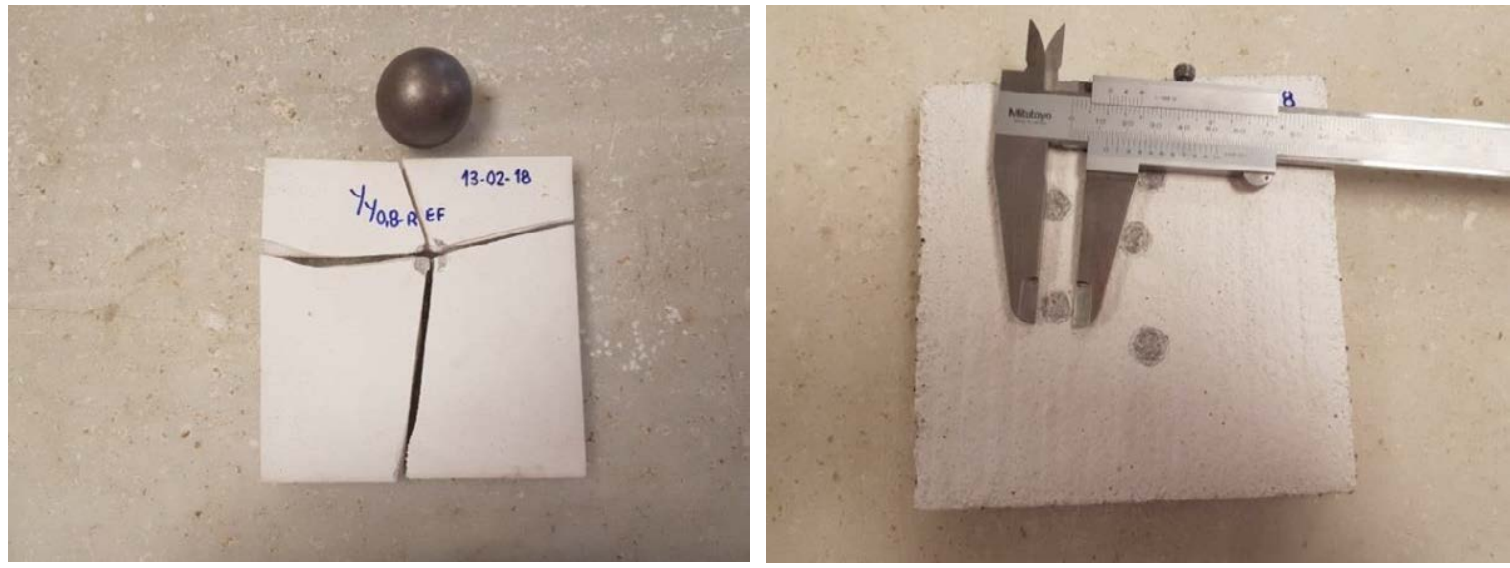

Foto 6.6. Impacto de bola de acero en paneles. Izquierda: panel de referencia $E_{0,8}$ (rotura). Derecha: panel con PR (sin rotura)

\subsection{Resistencia mecánica a la flexión de paneles}

Considerando que los paneles y placas pueden trabajar bajo el efecto mecánico de la flexión, se realizan las comprobaciones en los compuestos en estudio. En la Tabla 6.21 se muestra el resultado de la carga de rotura a flexión y de la deformación que se origina en los paneles realizados con las mezclas de la Serie XII. 
Tabla 6.21. Resistencia a flexión de paneles (kN) - UNE-EN 12859

\begin{tabular}{llcccc}
\hline Refer. & Denom. & $\begin{array}{c}\text { Carga de } \\
\text { rotura a } \\
\text { flexión (kN) }\end{array}$ & $\begin{array}{c}\Delta \text { carga de rotura a } \\
\text { flexión respecto a la } \\
\text { referencia }\end{array}$ & $\begin{array}{c}\text { Deformación bajo } \\
\text { carga (mm) }\end{array}$ & $\begin{array}{c}\Delta \text { deformación bajo } \\
\text { carga respecto a la } \\
\text { referencia }\end{array}$ \\
\hline \multirow{3}{*}{ Serie XII } & $\mathrm{E}_{0,8}$ & 0,284 & 0,00 & 2,06 & 0,00 \\
& $\mathrm{E}_{0,8-50 \mathrm{PR}}$ & 0,173 & $-39,08 \%$ & 14,37 & $+697,57 \%$ \\
& $\mathrm{E}_{0,8-60 \mathrm{PR}}$ & 0,160 & $-43,66 \%$ & 16,86 & $+818,45 \%$ \\
& $\mathrm{E}_{0,8-70 \mathrm{PR}}$ & 0,177 & $-37,68 \%$ & 16,25 & $+788,83 \%$ \\
\hline
\end{tabular}

La carga de rotura a flexión en las mezclas, disminuye un 39,08\%-43,66\%-37,68\% respectivamente con 50\%PR-60\%PR-70\%PR, en relación a la muestra de referencia, algo similar a lo que ocurre en los ensayos de flexión de probetas prismáticas. Por otro lado, la deformación que admiten los paneles de los compuestos con 50\%PR$60 \%$ PR-70\%PR, supera en 697,57\%-818,45\%-788,83\% la deformación que admite la mezcla de referencia, lo que viene a verificar, una vez más, los resultados obtenidos en los ensayos de módulo de Young en los que se aumenta considerablemente la elasticidad de los compuestos con PR (Foto 6.7). Sin embargo y por muy poco, ninguno de los paneles elaborados con PR llega a superar la carga mínima de 0,18kN exigida por la norma UNE-EN 12859 (Gráfica 6.21). Se evidencia de nuevo lo comentado por la mayoría de los autores analizados en el apartado 2.2 del capítulo 2 . Sería recomendable, por tanto, realizar el ensayo con paneles de mayor espesor o con paneles provistos de una capa de recubrimiento (papel o cartón) y volver a comprobar la resistencia.

El compuesto de mayor resistencia a flexión en paneles el $E_{0,8-70 P R}(0,177 \mathrm{kN})$ y el de menor resistencia a flexión en paneles el $\mathrm{E}_{0,8-60 \mathrm{PR}}(0,160 \mathrm{kN})$.
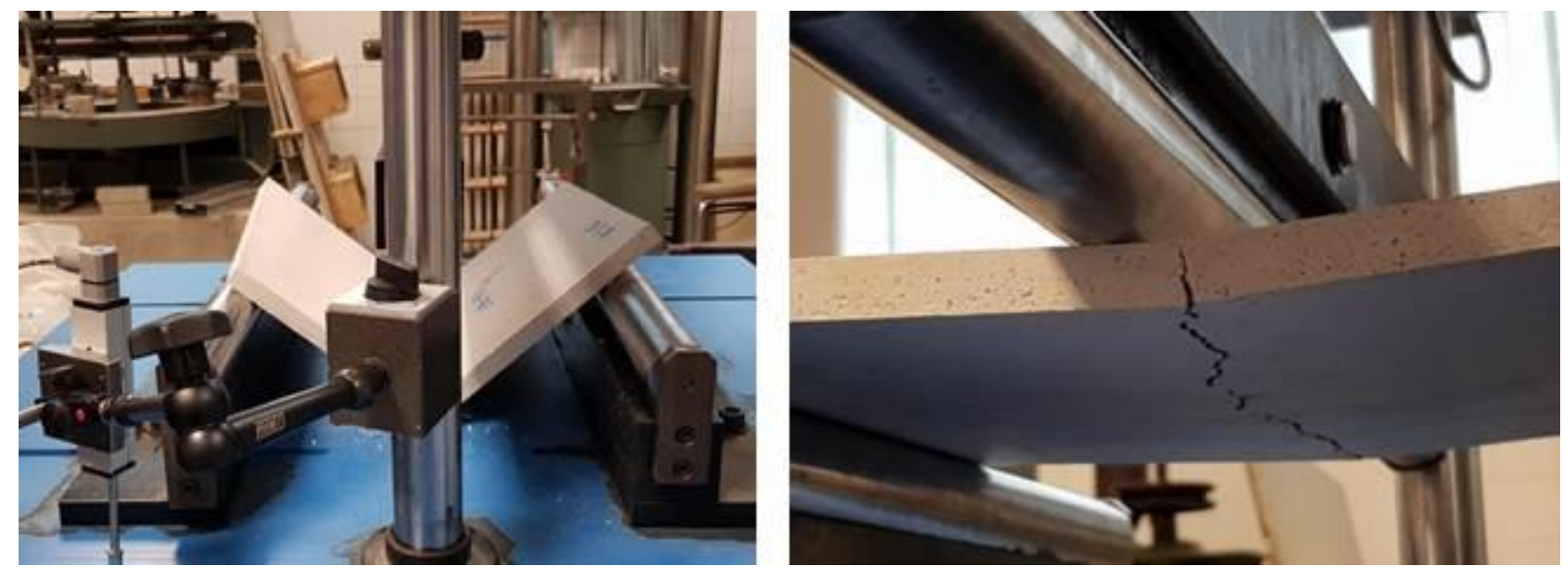

Foto 6.7. Deformación de panel. Izquierda: panel de referencia (rigidez). Derecha: panel con PR (elasticidad) 


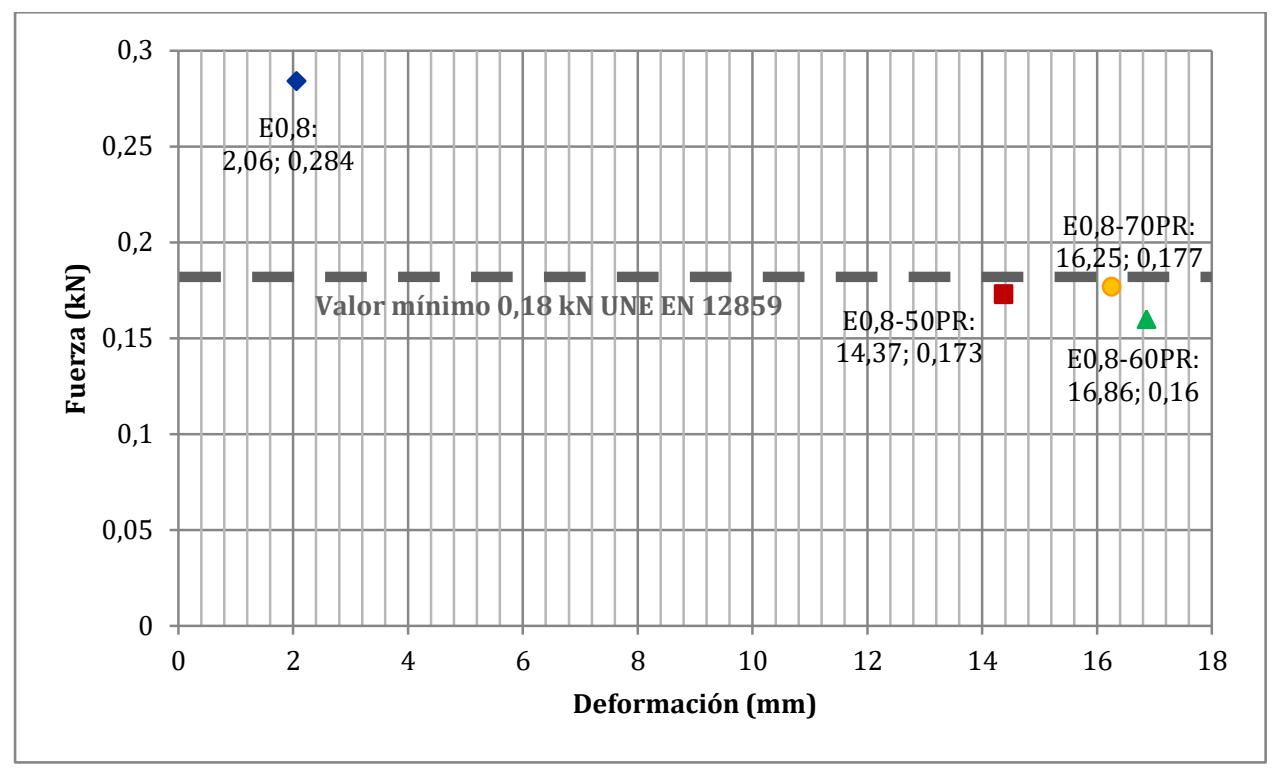

Gráfica 6.21. Valores medios de fuerza-deformación de los compuestos seleccionados

De las gráficas de fuerza-deformación de cada una de las mezclas, se deduce la mayor resistencia a flexión y rigidez de la referencia (Gráfica 6.22) así como la minoración de la resistencia a flexión de los compuestos con PR y su capacidad de deformación, elasticidad (Gráfica 6.23), como ocurría en el ensayo de las probetas prismáticas.

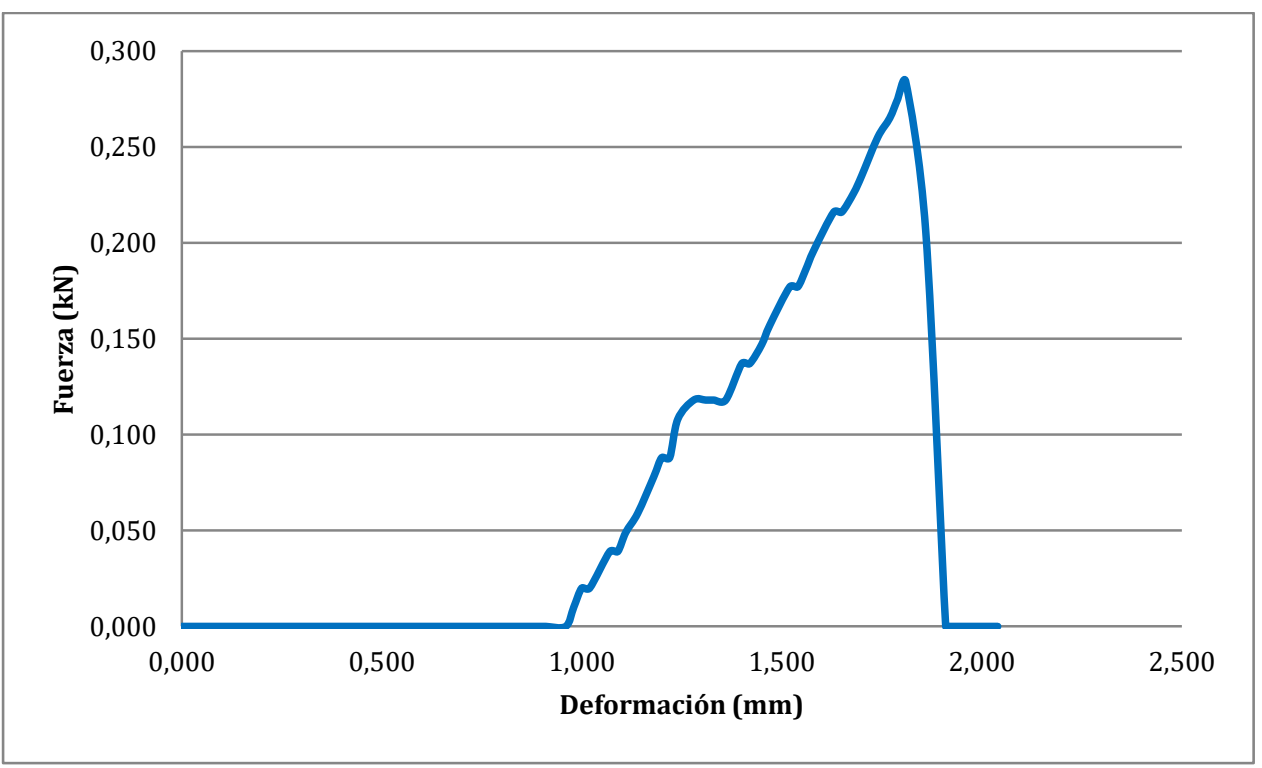

Gráfica 6.22. Gráfica fuerza-deformación del compuesto de referencia $E_{0,8}$ 

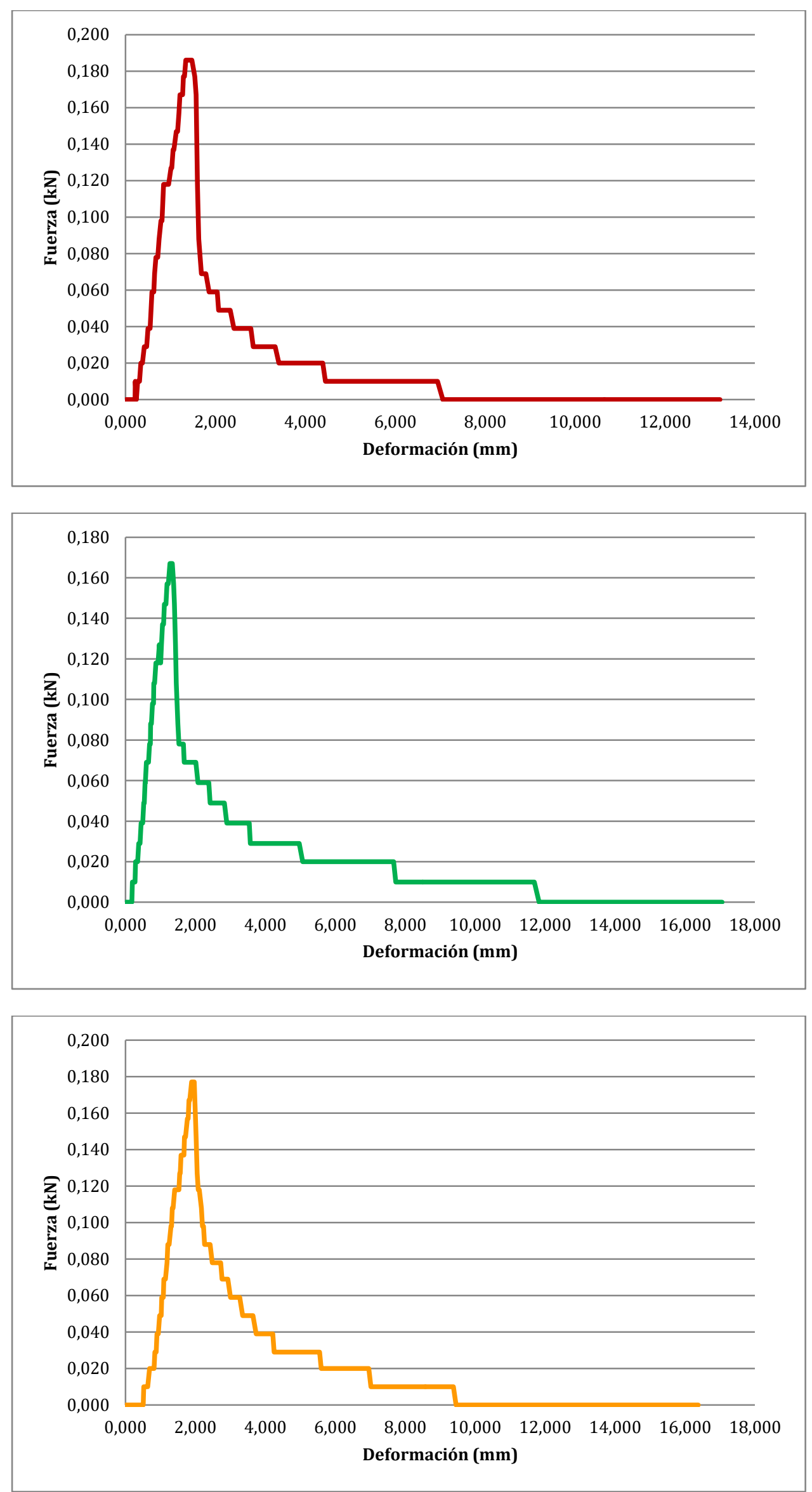

Gráfica 6.23. Gráficas fuerza-deformación de los compuestos con PR. Superior: $E_{0,8-50 P R ;}$ Centro: $E_{0,8-60 P R ;}$ Inferior: $E_{0,8-70 P R-}$ 


\subsection{Adherencia superficial}

Ante la posibilidad de utilizar los compuestos como revestimientos continuos, se considera interesante comprobar su adhesión, con el fin de verificar la capacidad de unión entre las superficies de distintos materiales. En la Tabla 6.22 se muestran los valores promedio de adherencia para los compuestos elaborados en la Serie X. La rotura tipo A indica un tipo de rotura por adhesión, es decir, en la interfase yesosoporte (Foto 6.8); la rotura tipo B indica un tipo de rotura por cohesión, es decir, en la masa del yeso (Foto 6.9).

Tabla 6.22. Adherencia superficial (N/mm²) - UNE EN 13279-2

\begin{tabular}{|c|c|c|c|c|c|c|}
\hline Refer. & Denom. & $\begin{array}{c}\text { Tipo de } \\
\text { adherencia }\end{array}$ & Fuerza (N) & Área $\left(\mathrm{mm}^{2}\right)$ & $\begin{array}{c}\text { Adherencia } \\
\text { superficial }\left(\mathrm{N} / \mathrm{mm}^{2}\right)\end{array}$ & $\begin{array}{c}\Delta \text { de adherencia } \\
\text { superficial respecto a } \\
\text { la referencia }\end{array}$ \\
\hline \multirow{4}{*}{ Serie $\mathrm{X}$} & $\mathrm{E}_{0,8}$ & A -adhesión & 570 & 1963,50 & 0,29 & 0,00 \\
\hline & $\mathrm{E}_{0,8-50 \mathrm{PR}}$ & A-adhesión & 320 & 1963,50 & 0,16 & $-44,83 \%$ \\
\hline & $\mathrm{E}_{0,8-60 \mathrm{PR}}$ & B - cohesión & 725 & 1963,50 & 0,37 & $+27,59 \%$ \\
\hline & $\mathrm{E}_{0,8-70 \mathrm{PR}}$ & A - adhesión & 470 & 1963,50 & 0,24 & $-17,24 \%$ \\
\hline
\end{tabular}
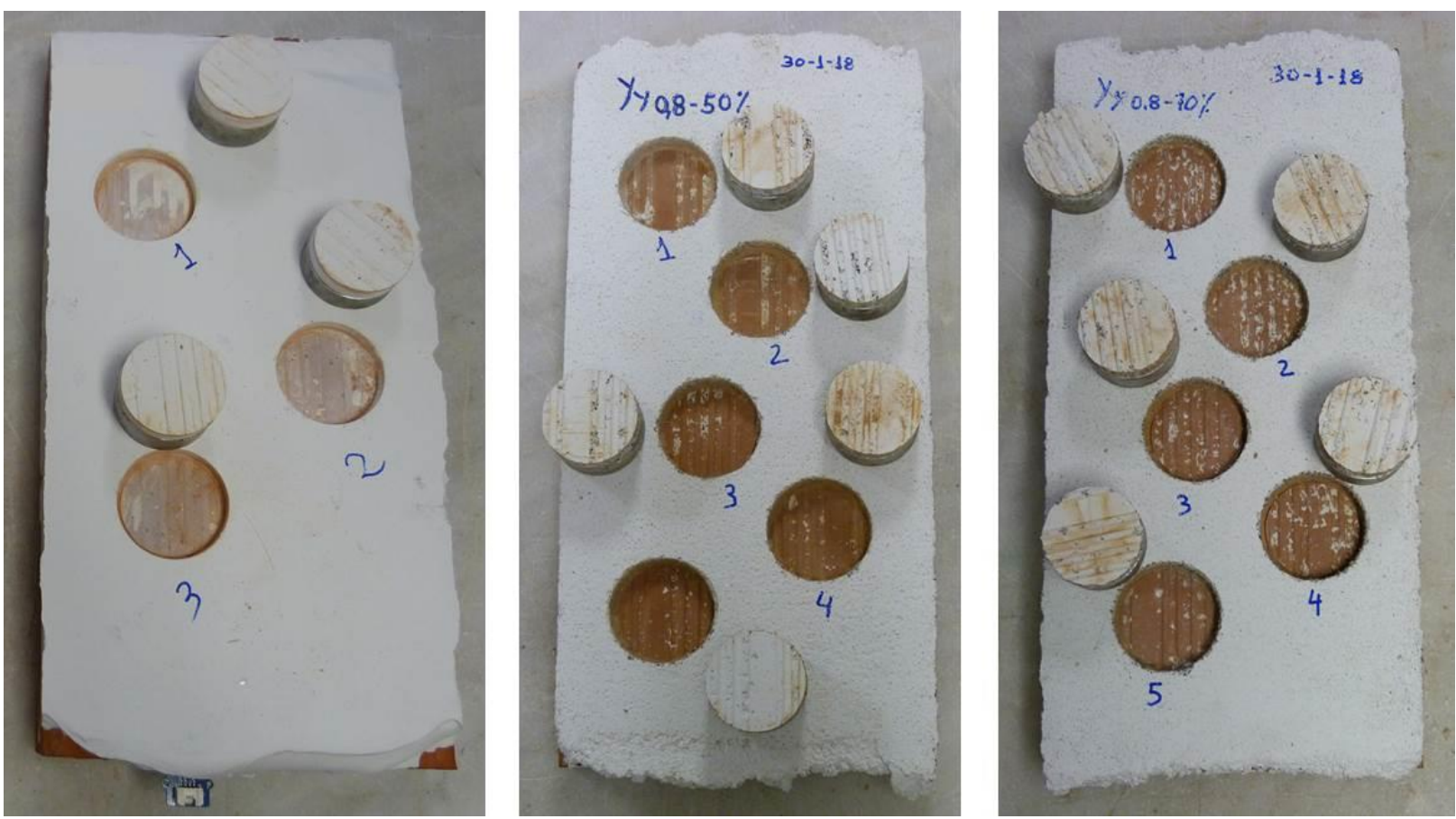

Foto 6.8. Adhesión de la mezcla de referencia (izquierda) y adhesión de los compuestos E, E-850PR (centro) y E,8-70pR (derecha) 


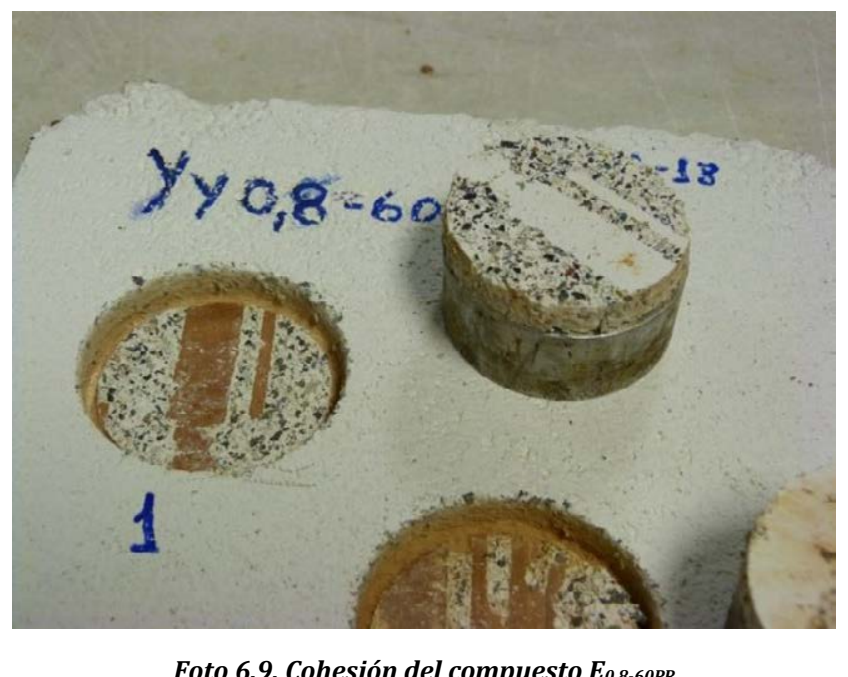

Foto 6.9. Cohesión del compuesto Eo,8-60PR

En los resultados obtenidos se observa que los compuestos con PR presentan menor resistencia a la adherencia que la referencia, concretamente un 44,83\% el $\mathrm{E}_{0,8-}$

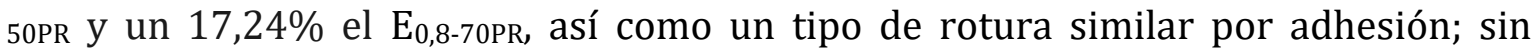
embargo, en el compuesto $\mathrm{E}_{0,8-60 \mathrm{PR}}$ se obtiene un $27,59 \%$ más de resistencia a la adherencia que la referencia y, un tipo de rotura por cohesión con un porcentaje aproximado de entre el $15-40 \%$ de yeso adherido al soporte, algo que también ocurre en la investigación de Alcón Calla (Alcón Calla, Salcedo Quispe, Gallardo Tapia, \& Echazú Cortez, 2011).

El compuesto de mayor resistencia a la adherencia superficial fue, por tanto, el $\mathrm{E}_{0,8-}$ ${ }_{60 \mathrm{PR}}\left(0,37 \mathrm{~N} / \mathrm{mm}^{2}\right)$ y el de menor resistencia a la adherencia superficial el $\mathrm{E}_{0,8-50 \mathrm{PR}}$ $\left(0,16 \mathrm{~N} / \mathrm{mm}^{2}\right)$.

\subsubsection{Ensayos físicos de los compuestos seleccionados}

Para evaluar los efectos físicos que, acciones externas, provocan en los compuestos, se analizan los resultados obtenidos en los ensayos del apartado 5.4.2.3.

\subsection{Comportamiento frente al agua}

Uno de los problemas que presenta el yeso es su capacidad de absorber agua. Si bien es cierto que la solubilidad del yeso es baja, $0,21 \mathrm{~g}$ por $100 \mathrm{~g}$ de solución a $20^{\circ} \mathrm{C}$, cuando el contenido de humedad llega a ser del 1\% la resistencia del material baja a la mitad y empieza su deterioro (Arroyo López, Villanueva Bringas, Gaytán Iniestra, \& García Vargas, 2014). Por ello se hace indispensable el estudio de su comportamiento 
frente a la acción del agua. A continuación se presentan los resultados obtenidos en los ensayos realizados a los compuestos seleccionados.

En la tabla 6.23 se muestran los datos de peso húmedo y desecado de las mezclas obtenidos en la Serie XIII, con los que se ha calculado la capacidad de retención de agua de las mismas durante su elaboración.

Tabla 6.23. Pesos húmedos y secos de los compuestos (g) - capacidad de retención de agua (\%)

\begin{tabular}{clcccc}
\hline Refer. & Denom. & $\begin{array}{c}\text { Peso } \\
\text { húmedo (g) }\end{array}$ & Peso desecado (g) & $\begin{array}{c}\text { Retención de agua } \\
\text { (\%) }\end{array}$ & $\begin{array}{c}\Delta \text { retención de agua } \\
\text { respecto a la } \\
\text { referencia }\end{array}$ \\
\hline \multirow{2}{*}{ Serie XIII } & $\mathrm{E}_{0,8}$ & 389,7 & 253,2 & 35,03 & 0,00 \\
& $\mathrm{E}_{0,8-50 \mathrm{PR}}$ & 354,2 & 258,2 & 27,10 & $-22,64 \%$ \\
& $\mathrm{E}_{0,8-60 \mathrm{PR}}$ & 352,6 & 261,7 & 25,78 & $-26,41 \%$ \\
& $\mathrm{E}_{0,8-70 \mathrm{PR}}$ & 346,2 & 259,8 & 24,96 & $-28,75 \%$ \\
\hline
\end{tabular}

La capacidad de retención de agua en las mezclas disminuye a medida que se incorpora PR en las mismas, un 27,10\%-25,78\%-24,96\% respectivamente con $50 \%$ PR-60\%PR-70\%PR en relación a la muestra de referencia. Este descenso en la capacidad de retención de agua puede explicarse debido a la adición de la granza que funciona como barrera dificultando, por tanto, la entrada de moléculas de agua en la mezcla y que también se corrobora con otras investigaciones con matriz de cemento y residuos poliméricos de PET (tereftalato de polietileno) (Mejía Betancourt, 2017). También se justifica la menor capacidad de absorción de agua, con el menor volumen de poro de las muestras adicionadas con PR obtenido en el apartado 6.4.2.1.1, así como la menor masa de yeso presente en las mismas (a mayor \% PR, menor \% yeso) obtenida en el apartado 6.4.1.1.

El compuesto de menor capacidad de retención de agua fue el $E_{0,8-70 P R}(24,96 \%)$ y el de mayor capacidad de retención de agua el $\mathrm{E}_{0,8-50 \mathrm{PR}}(27,10 \%)$ que, aun así, supone una mejora sobre la muestra de referencia que retuvo un $35,03 \%$.

\subsection{Absorción de agua por capilaridad}

La realidad de las edificaciones es que presentan defectos en su construcción y uno de ellos, muy habitual, es la falta de aislamiento frente a filtraciones de agua a través del terreno. El ensayo de absorción de agua por capilaridad nos muestra el ascenso de agua, cada minuto, en los compuestos de la Serie XIII (Tabla 6.24). Los pesos obtenidos antes y después del ensayo para cada una de las probetas se indican en la Gráfica 6.24. 
Tabla 6.24. Ascenso de agua por capilaridad en los compuestos (mm) - RILEM RC 25-PEM

\begin{tabular}{|c|c|c|c|c|c|c|c|c|c|c|c|c|c|}
\hline Refer. & Denom. & $\begin{array}{l}\text { Min. } 1 \\
\text { (mm) }\end{array}$ & $\begin{array}{l}\operatorname{Min} .2 \\
(\mathrm{~mm})\end{array}$ & $\begin{array}{l}\text { Min. } 3 \\
(\mathbf{m m})\end{array}$ & $\begin{array}{l}\text { Min. } 4 \\
(\mathbf{m m})\end{array}$ & $\begin{array}{l}\text { Min. } 5 \\
(\mathrm{~mm})\end{array}$ & $\begin{array}{l}\text { Min. } 6 \\
(\mathrm{~mm})\end{array}$ & $\begin{array}{l}\text { Min. } 7 \\
\text { (mm) }\end{array}$ & $\begin{array}{l}\text { Min. } 8 \\
(\mathbf{m m})\end{array}$ & $\begin{array}{l}\text { Min. } 9 \\
(\mathrm{~mm})\end{array}$ & $\begin{array}{c}\text { Min. } 10 \\
(\mathrm{~mm})\end{array}$ & $\begin{array}{l}\text { Total } \\
\text { (mm) }\end{array}$ & $\begin{array}{c}\Delta \text { ascenso de agua } \\
\text { por capilaridad } \\
\text { respecto a la } \\
\text { referencia }\end{array}$ \\
\hline \multirow{4}{*}{$\begin{array}{l}\text { Serie } \\
\text { XIII }\end{array}$} & $\mathrm{E}_{0,8}$ & 13,0 & 7,3 & 6,0 & 5,2 & 4,7 & 4,0 & 3,8 & 3,7 & 3,2 & 3,0 & 53,9 & 0,00 \\
\hline & $\mathrm{E}_{0,8-50 \mathrm{PR}}$ & 9,5 & 3,2 & 3,5 & 2,5 & 2,0 & 2,3 & 2,3 & 1,7 & 1,8 & 1,7 & 30,5 & $-43,41 \%$ \\
\hline & $\mathrm{E}_{0,8-60 \mathrm{PR}}$ & 7,8 & 3,2 & 2,3 & 1,7 & 2,0 & 1,2 & 1,3 & 1,5 & 1,2 & 1,0 & 23,2 & $-56,96 \%$ \\
\hline & $\mathrm{E}_{0,8-70 \mathrm{PR}}$ & 7,0 & 3,0 & 2,0 & 2,0 & 1,0 & 1,0 & 1,0 & 1,0 & 1,0 & 1,0 & 20,0 & $-62,89 \%$ \\
\hline
\end{tabular}

Se observa que, mientras que en la muestra de referencia el agua logra ascender hasta 53,9 mm, en las mezclas con 50\%PR-60\%PR-70\%PR esta cantidad no llega más allá de 30,5-23,2-20,0 mm respectivamente. Esto se traduce en una reducción del 43,41\%-56,96\%-62,89\% de la capacidad de absorción de agua por capilaridad, superándose el $40 \%$ de reducción conseguido en otros estudios realizados con matriz de yeso y residuos poliméricos de poliuretano (Alameda, Calderón, Gadea, \& Gutiérrez-González, 2015). El compuesto de menor capacidad de absorción de agua por capilaridad fue el $\mathrm{E}_{0,8-70 \mathrm{PR}}(20,0 \mathrm{~mm})$ y el de mayor capacidad de absorción de agua por capilaridad el $\mathrm{E}_{0,8-50 \mathrm{PR}}(30,5 \mathrm{~mm})$.

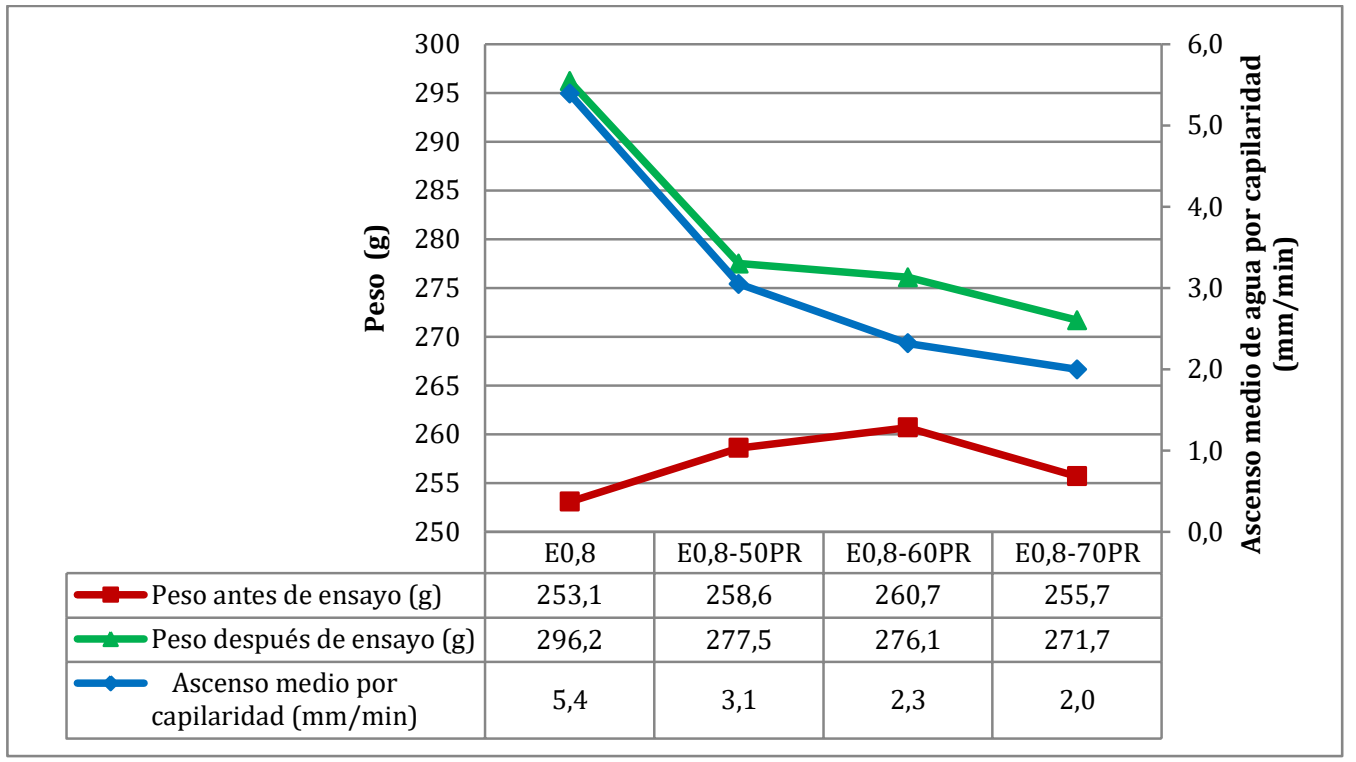

Gráfica 6.24. Pesos de los compuestos antes y después del ensayo de absorción de agua por capilaridad y ascenso medio del agua por capilaridad

El incremento de peso, pasados los 10 minutos del ensayo, supusieron para la referencia un 17,03\%. Para los compuestos con 50-60-70\% PR, en cambio, supusieron solo un incremento del 7,31\%-5,91\%-6,26\% respectivamente, lo que indica una disminución de agua por capilaridad de más del $50 \%$ en todos los casos. En esta ocasión, el compuesto que menos agua retuvo una vez realizado el ensayo fue el 
$\mathrm{E}_{0,8-60 \mathrm{PR}}(5,91 \%)$, con un valor muy cercano al del $\mathrm{E}_{0,8-70 \mathrm{PR}}(6,26 \%)$; el compuesto que más agua retuvo fue el $\mathrm{E}_{0,8-50 \mathrm{PR}}(7,31 \%)$.

\subsection{Permeabilidad al vapor de agua}

Una de las soluciones para evitar la condensación, se basa en la utilización de materiales en los paramentos que regulen la humedad relativa de las estancias según su grado de permeabilidad al vapor de agua (Villanueva Domínguez \& García Santos, 2001); por ello, se hace fundamental estudiar el comportamiento higrotérmico de los compuestos en estudio. El ensayo, realizado a la Serie XIV, se desarrolló a lo largo de 8 semanas y los resultados se muestran en la Gráfica 6.25. Asimismo, en la Tabla 6.25 se indican los valores unitarios obtenidos de permeabilidad (P), transmisión (TVA), permeancia (PR) y resistencia al vapor de agua (R), alcanzados al término de las 8 semanas.

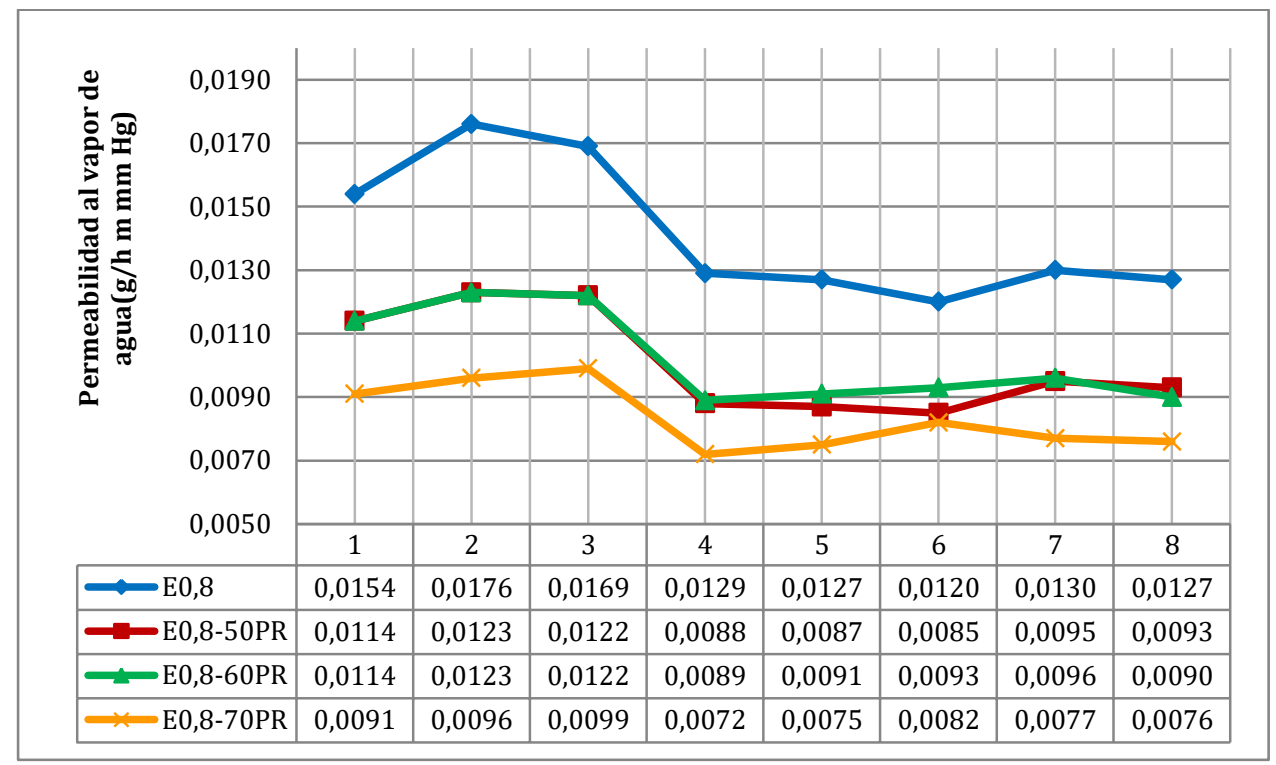

Gráfica 6.25. Permeabilidad al vapor de agua cada semana durante 8 semanas

El comportamiento de los distintos compuestos, incluida la referencia, es muy similar: en la segunda semana aumentó su permeabilidad respecto a la primera semana y, a partir de la tercera, los valores de permeabilidad sufrieron un ligero descenso a medida que se sucedieron las semanas. Finalmente, todos los compuestos y la referencia, presentaron valores de permeabilidad al vapor de agua muy parecidos, inferiores a la primera semana, esto es, la referencia un 17,53\% menos, el $50 \%$ PR y $60 \%$ PR un $18,42 \%$ menos y, el $70 \%$ PW un $16,48 \%$ menos. 
Tabla 6.25. Resultado final de transmisión, permeancia, permeabilidad y resistencia al vapor de agua - UNE-EN ISO 12572

\begin{tabular}{|c|c|c|c|c|c|c|c|}
\hline Refer. & Denom. & $\begin{array}{c}\text { TVA } \\
\left.\text { (g/h } \mathbf{~ m}^{2}\right)\end{array}$ & $\begin{array}{c}\text { PR } \\
\text { (g/h } \mathbf{m}^{2} \text { mmHg) }\end{array}$ & P (g/h m mmHg) & $\begin{array}{l}\Delta P \text { respecto a } \\
\text { la referencia }\end{array}$ & $\mathrm{R}\left(\mathrm{h} \mathrm{\mathbf {m } ^ { 2 }} \mathbf{m m H g} / \mathrm{g}\right)$ & $\begin{array}{l}\Delta \mathrm{R} \text { respecto a } \\
\text { la referencia }\end{array}$ \\
\hline \multirow{4}{*}{ Serie XIV } & $\mathrm{E}_{0,8}$ & 7,8850 & 0,9602 & 0,0163 & 0,00 & 1,0414 & 0,00 \\
\hline & $\mathrm{E}_{0,8-50 \mathrm{PR}}$ & 5,6789 & 0,6916 & 0,0118 & $-27,61 \%$ & 1,4459 & $+38,84 \%$ \\
\hline & $\mathrm{E}_{0,8-60 \mathrm{PR}}$ & 5,6580 & 0,6890 & 0,0117 & $-28,22 \%$ & 1,4514 & $+39,37 \%$ \\
\hline & $\mathrm{E}_{0,8-70 \mathrm{PR}}$ & 4,5654 & 0,5560 & 0,0095 & $-41,72 \%$ & 1,7986 & $+72,71 \%$ \\
\hline
\end{tabular}

Al término de las 8 semanas, los compuestos con 50\%PR-60\%PR-70\%PR redujeron la transmisión, permeancia y permeabilidad al vapor de agua respecto a la referencia en un $27,61 \%-28,22 \%-41,72 \%$ respectivamente. Por el contrario, en relación inversa, aumentaron su resistencia al vapor de agua en un 38,84\%-39,37\%$72,71 \%$ respecto al compuesto sin PR. El compuesto de menor permeabilidad y, por tanto, con mayor resistencia al vapor de agua fue el E0,8-70PR $(0,0095$ [g/(m·h $\cdot \mathrm{mmHg})]$ y $1,7986\left[\left(\mathrm{~h} \cdot \mathrm{m}^{2} \cdot \mathrm{mmHg} / \mathrm{g}\right)\right]$; el compuesto de mayor permeabilidad $\mathrm{y}$, por tanto, menor resistencia al vapor de agua fue el E0,8-50PR $(0,0118$ $[\mathrm{g} /(\mathrm{m} \cdot \mathrm{h} \cdot \mathrm{mmHg})]$ y $1,4459\left[\left(\mathrm{~h} \cdot \mathrm{m}^{2} \cdot \mathrm{mmHg} / \mathrm{g}\right)\right]$. Obviamente, cuanta menor cantidad de residuo plástico, menor barrera de vapor. Cabe destacar que, con los valores obtenidos de permeabilidad, los compuestos en estudio conservan la propiedad higrotérmica característica de los yesos respecto a otros materiales como el mortero de cemento que presenta valores de 1,32*10-12 Kg/msPa (Piña Ramírez, 2019).

\subsection{Cámara húmeda}

La capacidad de almacenar humedad en el interior de su masa, cuando ambientalmente se dan estas condiciones, y de cederla cuando se modifican dichas condiciones es una de las propiedades positivas que se asocian a los compuestos de yeso (Villanueva Domínguez \& García Santos, 2001). En la Tabla 6.26 se indican los valores de incremento de peso obtenidos durante la realización del ensayo de "cámara húmeda" especificado en el apartado 5.4.2.3.1.3 para la Serie XV. De esta Serie XV también se ensayó la dureza Shore C y las resistencias a flexión y compresión (Tablas 6.27 y 6.28 respectivamente) para compararlas con los resultados de la Serie III no sometida a ensayos con agua (apartado 6.3.1). 
Tabla 6.26. Retención de agua después de ensayo de cámara húmeda

\begin{tabular}{|c|c|c|c|c|c|}
\hline Refer. & Denom. & $\begin{array}{l}\text { Peso antes del } \\
\text { ensayo - seco } \\
(\mathrm{g})\end{array}$ & $\begin{array}{l}\text { Peso después del } \\
\text { ensayo - húmedo } \\
\text { (g) }\end{array}$ & $\begin{array}{l}\text { Retención de } \\
\text { agua (\%) }\end{array}$ & $\begin{array}{l}\Delta \text { retención de agua } \\
\text { respecto a la referencia }\end{array}$ \\
\hline \multirow{4}{*}{ Serie XV } & $\mathrm{E}_{0,8}$ & 254,20 & 260,80 & $+2,60 \%$ & 0,00 \\
\hline & $\mathrm{E}_{0,8-50 \mathrm{PR}}$ & 263,50 & 268,60 & $+1,94 \%$ & $-25,38 \%$ \\
\hline & $\mathrm{E}_{0,8-60 \mathrm{PR}}$ & 267,00 & 270,70 & $+1,39 \%$ & $-46,54 \%$ \\
\hline & $\mathrm{E}_{0,8-70 \mathrm{PR}}$ & 270,60 & 277,70 & $+2,62 \%$ & $+0,77 \%$ \\
\hline
\end{tabular}

Tabla 6.27. Resultados de dureza Shore C antes y después de ensayo de cámara húmeda

\begin{tabular}{clcccc}
\hline Refer. & Denomin. & $\begin{array}{c}\text { Dureza Shore C - antes } \\
\text { de cámara húmeda }\end{array}$ & $\begin{array}{c}\text { Dureza Shore C - después } \\
\text { de cámara húmeda }\end{array}$ & $\begin{array}{c}\text { Diferencia entre antes y } \\
\text { después de cámara húmeda }\end{array}$ & $\begin{array}{c}\Delta \text { dureza Shore C } \\
\text { respecto a la referencia }\end{array}$ \\
\hline \multirow{2}{*}{ Serie XV } & $\mathrm{E}_{0,8}$ & 78,00 & 78,00 & $+0,00 \%$ & 0,00 \\
& $\mathrm{E}_{0,8-50 \mathrm{PR}}$ & 81,17 & 74,10 & $-8,71 \%$ & $-5,00 \%$ \\
& $\mathrm{E}_{0,8-60 \mathrm{PR}}$ & 80,60 & 76,67 & $-4,88 \%$ & $-1,71 \%$ \\
& $\mathrm{E}_{0,8-70 \mathrm{PR}}$ & 81,60 & 75,60 & $-7,35 \%$ & $-3,08 \%$ \\
\hline
\end{tabular}

Tabla 6.28. Resultados de resistencias a flexión y compresión después de ensayo de cámara húmeda

\begin{tabular}{|c|c|c|c|c|c|}
\hline Refer. & Denomin. & $\begin{array}{l}\text { R. flexión } \\
\text { (N/mm²) }\end{array}$ & $\begin{array}{l}\Delta \text { R. flexión respecto a } \\
\text { la referencia }\end{array}$ & $\begin{array}{l}\text { R. compresión } \\
\left(\mathrm{N} / \mathbf{m m}^{2}\right)\end{array}$ & $\begin{array}{l}\Delta \mathrm{R} . \text { compresión } \\
\text { respecto a la referencia }\end{array}$ \\
\hline \multirow{4}{*}{ Serie XV } & $\mathrm{E}_{0,8}$ & 4,202 & 0,00 & 10,245 & 0,00 \\
\hline & $\mathrm{E}_{0,8-50 \mathrm{PR}}$ & 2,231 & $-46,91 \%$ & 3,803 & $-62,88 \%$ \\
\hline & $\mathrm{E}_{0,8-60 \mathrm{PR}}$ & 2,153 & $-48,76 \%$ & 3,847 & $-62,45 \%$ \\
\hline & $\mathrm{E}_{0,8-70 \mathrm{PR}}$ & 2,120 & $-49,55 \%$ & 3,610 & $-64,76 \%$ \\
\hline
\end{tabular}

La capacidad de retención de agua después del proceso de exposición a humedad continua, es un $25,38 \%$ y un $46,54 \%$ menor en los compuestos con $50 \%$ PR y $60 \%$ PR respecto al compuesto de referencia, algo similar a lo que ocurre en la investigación de la doctora del Río Merino (del Río Merino, 1999). Sin embargo, el comportamiento del compuesto con $70 \%$ PR es bastante similar a la referencia $(+0,77 \%)$. Respecto al propio compuesto, el de menor capacidad de retención de agua con humedad continua fue el $\mathrm{E}_{0,8-60 \mathrm{PR}}(+1,39 \%)$ y el de mayor capacidad de retención de agua con humedad continua el $\mathrm{E}_{0,8-70 \mathrm{Pr}}(+2,62 \%)$.

\subsection{Ciclos humedad-sequedad}

Es importante conocer también qué ocurre en los compuestos si se ven sometidos a ciclos de humedad y secado. Los datos obtenidos en el ensayo de 2 ciclos aguaestufa, en cuanto a peso, dureza superficial Shore $\mathrm{C}$ y resistencias a flexión y compresión para la Serie XVI, se muestran en las Tablas 6.29, 6.30 y 6.31 
respectivamente. Al igual que con el ensayo de Cámara Húmeda, sus resultados se compararon con los obtenidos en probetas sin ensayar con agua de la Serie III (apartado 6.3.1).

Tabla 6.29. Retención de agua después de 2 ciclos de agua-estufa

\begin{tabular}{llllcccccc}
\hline Refer. & Denom. & $\begin{array}{c}\text { Peso inicial - } \\
\text { seco } \mathbf{g})\end{array}$ & $\begin{array}{c}\text { Peso después } \\
\text { del ciclo 1 - } \\
\text { húmedo }(\mathbf{g})\end{array}$ & $\begin{array}{c}\text { Retención de } \\
\text { agua ciclo 1 } \\
\mathbf{( \% )}\end{array}$ & $\begin{array}{c}\text { Peso después } \\
\text { del ciclo 1 - } \\
\text { seco (g) }\end{array}$ & $\begin{array}{c}\Delta \text { peso } \\
\text { respecto al } \\
\text { peso inicial }\end{array}$ & $\begin{array}{c}\text { Peso después } \\
\text { del ciclo 2 - } \\
\text { húmedo }(\mathbf{g})\end{array}$ & $\begin{array}{c}\text { Retención de } \\
\text { agua ciclo 2 } \\
\text { (\%) }\end{array}$ & $\begin{array}{c}\Delta \text { retención de } \\
\text { agua respecto } \\
\text { a la referencia }\end{array}$ \\
\hline & $\mathrm{E}_{0,8}$ & 260,90 & 371,80 & $+42,51 \%$ & 257,00 & $-1,49 \%$ & 369,60 & $+43,81 \%$ & 0,00 \\
\multirow{2}{*}{ Serie XVI } & $\mathrm{E}_{0,8-50 \mathrm{PR}}$ & 259,10 & 349,30 & $+34,81 \%$ & 257,60 & $-0,58 \%$ & 349,30 & $+35,60 \%$ & $-18,74 \%$ \\
& $\mathrm{E}_{0,8-60 \mathrm{PR}}$ & 266,20 & 352,80 & $+32,53 \%$ & 264,30 & $-0,71 \%$ & 353,70 & $+33,83 \%$ & $-22,78 \%$ \\
& $\mathrm{E}_{0,8-70 \mathrm{PR}}$ & 260,20 & 343,60 & $+32,05 \%$ & 259,00 & $-0,46 \%$ & 344,10 & $+32,86 \%$ & $-24,99 \%$ \\
\hline
\end{tabular}

Tabla 6.30. Resultados de dureza Shore Cantes y después de 2 ciclos de agua-estufa

\begin{tabular}{clcccc}
\hline Refer. & Denomin. & $\begin{array}{c}\text { Dureza Shore C - antes de } \\
\text { 2 ciclos de agua-estufa }\end{array}$ & $\begin{array}{c}\text { Dureza Shore C - después } \\
\text { de 2 ciclos de agua-estufa }\end{array}$ & $\begin{array}{c}\text { Diferencia entre antes y } \\
\text { después de 2ciclos de } \\
\text { agua-estufa }\end{array}$ & $\begin{array}{c}\Delta \text { dureza Shore C } \\
\text { respecto a la referencia }\end{array}$ \\
\hline \multirow{2}{*}{ Serie XVI } & $\mathrm{E}_{0,8}$ & 78,00 & 73,73 & $-5,47 \%$ & 0,00 \\
& $\mathrm{E}_{0,8-50 \mathrm{PR}}$ & 81,17 & 73,37 & $-9,61 \%$ & $-0,49 \%$ \\
& $\mathrm{E}_{0,8-60 \mathrm{PR}}$ & 80,60 & 72,47 & $-10,09 \%$ & $-1,71 \%$ \\
& $\mathrm{E}_{0,8-70 \mathrm{PR}}$ & 81,60 & 72,70 & $-10,91 \%$ & $-1,40 \%$ \\
\hline
\end{tabular}

Tabla 6.31. Resultados de resistencias a flexión y compresión después de 2 ciclos de agua-estufa

\begin{tabular}{|c|c|c|c|c|c|}
\hline Refer. & Denomin. & $\begin{array}{c}\text { R. flexión después de } 2 \\
\text { ciclos agua-estufa (N/mm²) }\end{array}$ & $\begin{array}{l}\Delta R . \text { flexión respecto } \\
\text { a la referencia }\end{array}$ & $\begin{array}{l}\text { R. compresión después de } 2 \\
\text { ciclos agua-estufa }\left(\mathrm{N} / \mathrm{mm}^{2}\right)\end{array}$ & $\begin{array}{c}\Delta R \text {. compresión respecto a } \\
\text { la referencia }\end{array}$ \\
\hline \multirow{4}{*}{ Serie XVI } & $\mathrm{E}_{0,8}$ & 4,054 & 0,00 & 8,507 & 0,00 \\
\hline & $\mathrm{E}_{0,8-50 \mathrm{PR}}$ & 1,817 & $-55,18 \%$ & 3,583 & $-57,88 \%$ \\
\hline & $\mathrm{E}_{0,8-60 \mathrm{PR}}$ & 1,547 & $-61,84 \%$ & 3,533 & $-58,47 \%$ \\
\hline & $\mathrm{E}_{0,8-70 \mathrm{PR}}$ & 1,405 & $-65,34 \%$ & 3,335 & $-60,80 \%$ \\
\hline
\end{tabular}

Después de cada uno de los ciclos agua-estufa, la capacidad de retención de agua de los compuestos es similar (Tabla 6.30) del orden de un 35\% en las mezclas con PR y de un $43 \%$ en la mezcla de referencia. El deterioro sufrido por las probetas se muestra en la Foto 6.10 en la que se observa que, debido a la solubilidad del yeso, la capa superficial ha desaparecido y puede visualizarse la carga de residuos plásticos homogéneamente repartida (García Santos, 1988; Jiménez Rivero et al., 2011). Los compuestos con 50\%PR-60\%PR-70\%PR disminuyen la retención de agua un 18,74\%$22,78 \%-24,99 \%$ respecto al compuesto sin granza. El compuesto de menor capacidad de retención de agua después de 2 ciclos de agua-estufa fue el $E_{0,8-70 P R ~}(+32,86 \%)$ y el de mayor capacidad de retención de agua después de 2 ciclos de agua-estufa el $\mathrm{E}_{0,8 \text { - }}$ 50PR $(+35,60 \%)$. 

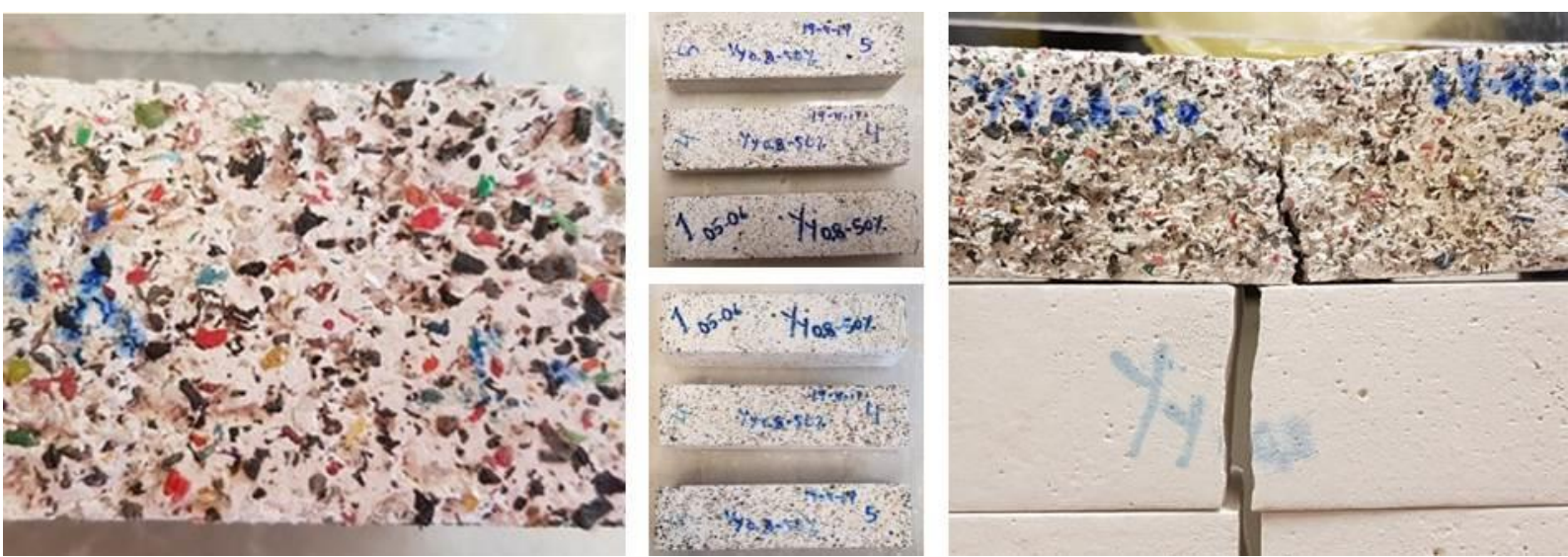

Foto 6.10. Izquierda y centro: deterioro de las probetas después de 2 ciclos de agua-estufa. Derecha: probetas ensayadas a flexión y preparadas para compresión

\subsection{Absorción total de agua}

Otra posibilidad dentro de las edificaciones es sufrir inundaciones, por ello es importante conocer los efectos que, dicha acción, produciría en los compuestos en estudio. En la Gráfica 6.26 se muestran los valores obtenidos de absorción total de agua de los paneles elaborados para la Serie XVII, según el ensayo especificado en el apartado 5.4.2.3.1.5.

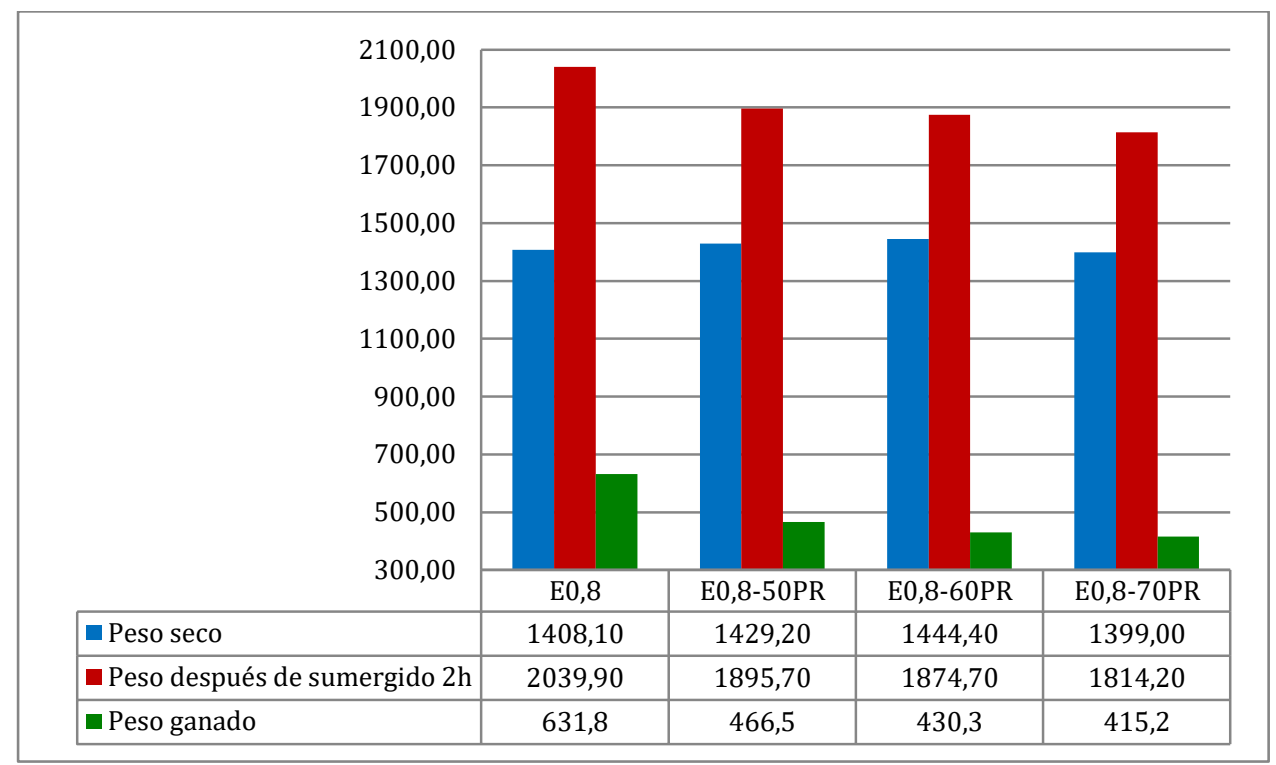

Gráfica 6.26. Pesos (g) antes y después del ensayo de absorción total de agua según UNE-EN 520

A medida que se incorpora PR en la mezcla, disminuye la capacidad de absorción de agua en un 32,64\%-29,79\%-29,68\% respectivamente en los compuestos con 50\%PR-60\%PR-70\%PR. Asimismo, se obtienen valores 27,26\%-33,61\%-33,85\% 
menores en estos compuestos que en la referencia. El compuesto de menor absorción total de agua fue el $\mathrm{E}_{0,8-70 \mathrm{PR}}(+29,68 \%)$ y el de mayor absorción total de agua el $\mathrm{E}_{0,8}$ 50PR $(+32,64 \%)$.

\subsection{Conclusiones parciales sobre las propiedades de los compuestos sometidos a la acción del agua}

Para comprobar el efecto del agua en las propiedades mecánicas, se realizó una comparativa entre los resultados en dureza Shore C, resistencia a flexión y resistencia a compresión de las probetas ensayadas a Cámara Húmeda (Serie XV) y Ciclos Aguaestufa (Serie XVI), con probetas que no habían sido sometidas a ensayos con agua (Serie III). Los resultados se muestran en las Gráficas 6.27, 6.28 y 6.29.

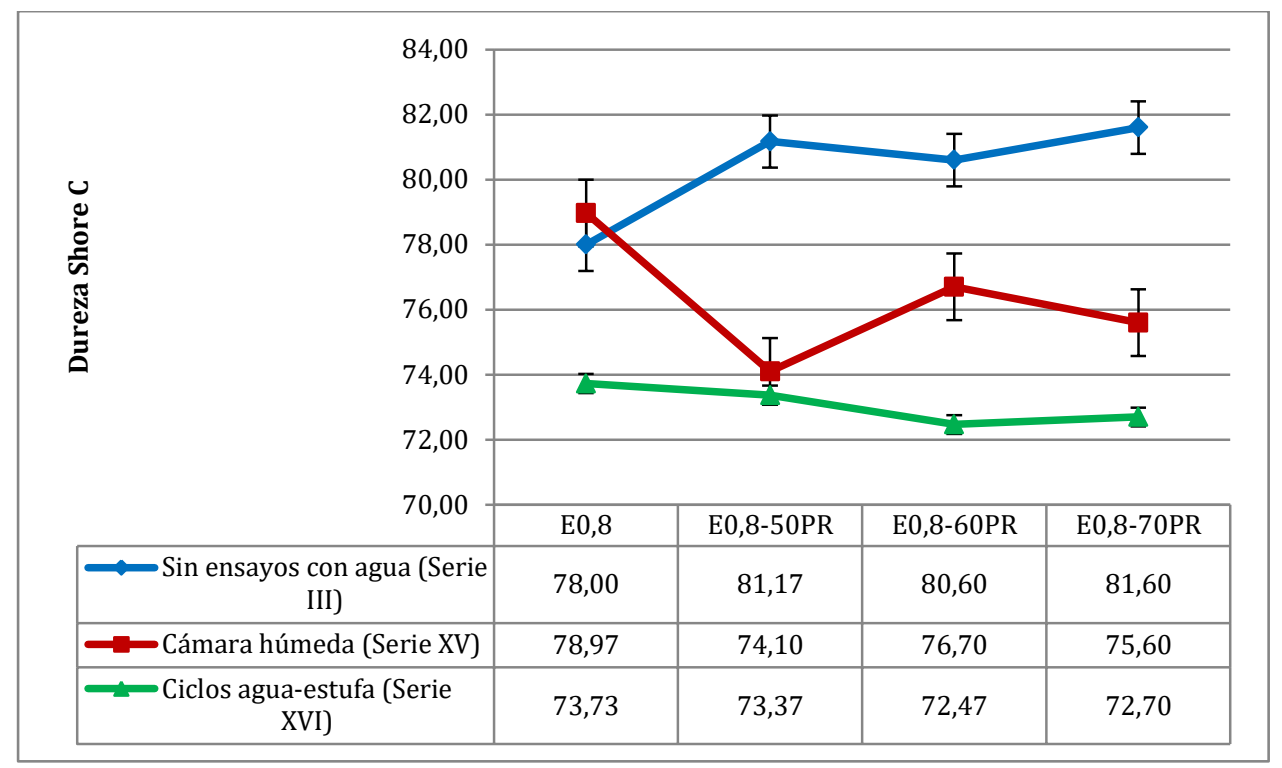

Gráfica 6.27. Dureza Shore C para compuestos no sometidos a ensayos con agua (Serie III) y sometidos a ensayos con agua en cámara húmeda (Serie XV) y ciclos agua-estufa (Serie XVI)

Respecto a las probetas que no han sido sometidas a ensayos con agua (Serie III), la dureza Shore $\mathrm{C}$ disminuye en todos los compuestos ensayados con agua entre un $5 \%$ y un $9 \%$ ante humedad continuada (Serie XV) y entre un 5\% y un $11 \%$ ante ciclos de saturación de agua y secado (Serie XVI), debido al deterioro que la capa superficial de las probetas ha sufrido tras los ensayos. Pese a ello, todos los valores se mantienen por encima de una Dureza Shore C de 70,00 (no se especifica valor mínimo en normativa para yesos de construcción). 


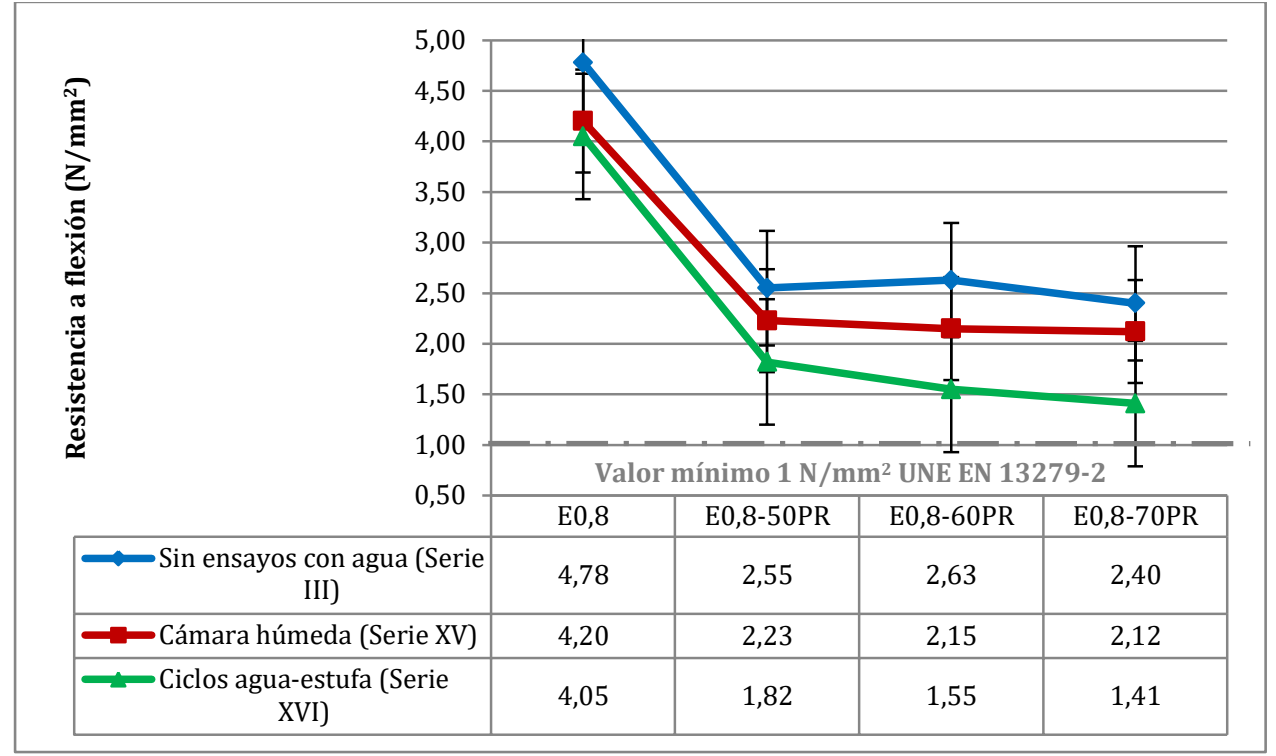

Gráfica 6.28. Resistencia a flexión para compuestos no sometidos a ensayos con agua (Serie III) y sometidos a ensayos con agua en cámara húmeda (Serie XV) y ciclos agua-estufa (Serie XVI)

Con humedad continuada (Serie XV) y comparándolo con la Serie III, la resistencia a flexión disminuye aproximadamente igual, un 12\%, en la probeta de referencia que en las probetas de los compuestos con PR. Sin embargo, con los ciclos de saturación de agua y secado (Serie XVI), la probeta de referencia se ve menos afectada, disminuye aproximadamente un $15 \%$ su resistencia a flexión, mientras que las probetas con PR reducen su resistencia hasta un 40\%. Cabe destacar que aun así, todos los valores se mantienen por encima de $1 \mathrm{~N} / \mathrm{mm}^{2}$ indicado como mínimo en la UNE EN 13279-2.

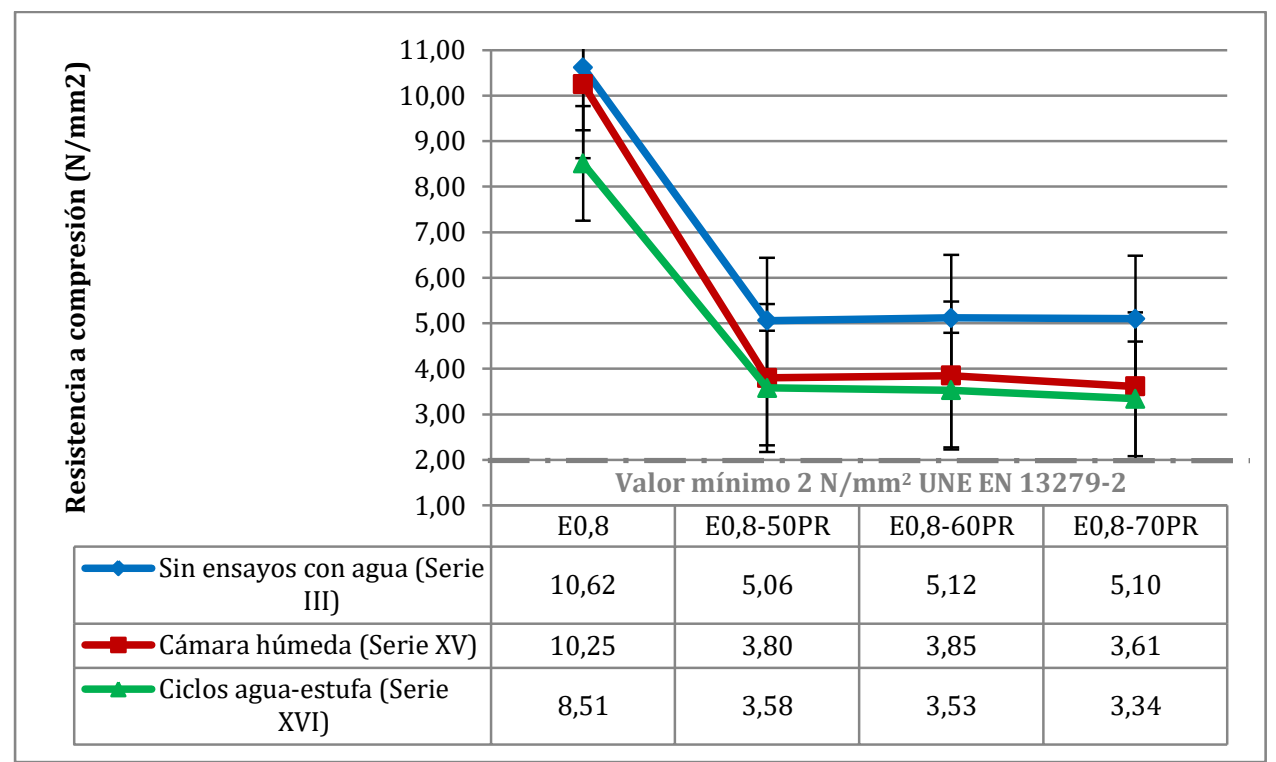

Gráfica 6.29. Resistencia a compresión para compuestos no sometidos a ensayos con agua (Serie III), y sometidos a ensayos con agua en cámara húmeda (Serie XV) y ciclos agua-estufa (Serie XVI) 
La resistencia a compresión con humedad continuada (Serie XV), en comparación a la Serie III, disminuye apenas un 3,48\% en la probeta de referencia y, en cambio entre un $24 \%$ y un $29 \%$ en las probetas del compuesto. Con los ciclos de saturación de agua y secado (Serie XVI) la probeta de referencia disminuye su resistencia a compresión aproximadamente un 20\% y, las probetas de compuestos, entre un $29 \%$ y un $34,5 \%$. En este caso también todos los valores están por encima del mínimo indicado en la UNE EN 13279-2 de $2 \mathrm{~N} / \mathrm{mm} 2$.

En definitiva, todos los resultados obtenidos en las propiedades mecánicas de los compuestos sometidos a la acción del agua, superan los mínimos de normativa, considerándose aptos incluso en las situaciones expuestas.

\subsection{Comportamiento frente al fuego}

El desarrollo, evolución y consecuencias de un incendio son fenómenos complejos que no solamente dependen de la cantidad y naturaleza del material que se está quemando. Otros factores también tienen una influencia decisiva en el desarrollo del fuego, tales como el diseño del edificio, la ubicación, posibles fuentes de ignición, la ventilación y los factores medioambientales. Además, y siendo muy importante la elección del material, el diseño de un producto y su forma de instalación, protección y uso desempeñan un papel importante en la seguridad contra incendios. En un incendio participan muchos materiales distintos, y los plásticos se comportan como otros materiales orgánicos.

En los apartados siguientes se analizan las consecuencias que causa el fuego en los compuestos en estudio.

\subsection{Ensayo real a fuego directo}

Es importante conocer el efecto que causa un fuego real en los compuestos seleccionados. La Figura 6.1 y la Foto 6.11 muestran la colocación de los paneles de la Serie XVIII durante el ensayo real a fuego directo. Esta colocación responde a la decisión de ensayar cada uno de los compuestos con las tres posibles posiciones dentro de la parrilla expuesta al fuego: exterior, medio, interior. 


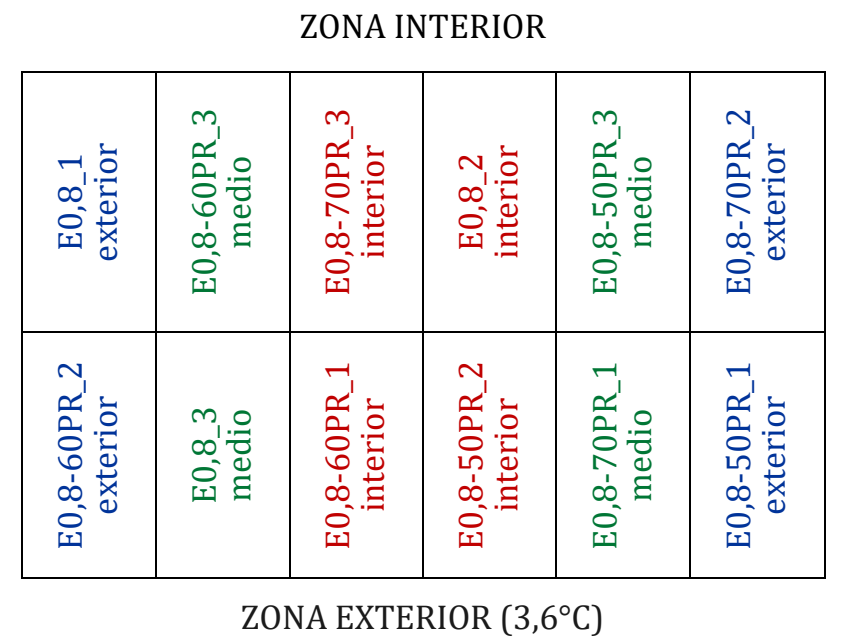

Figura 6.1. Esquema de la colocación de las probetas en la parrilla de ensayo

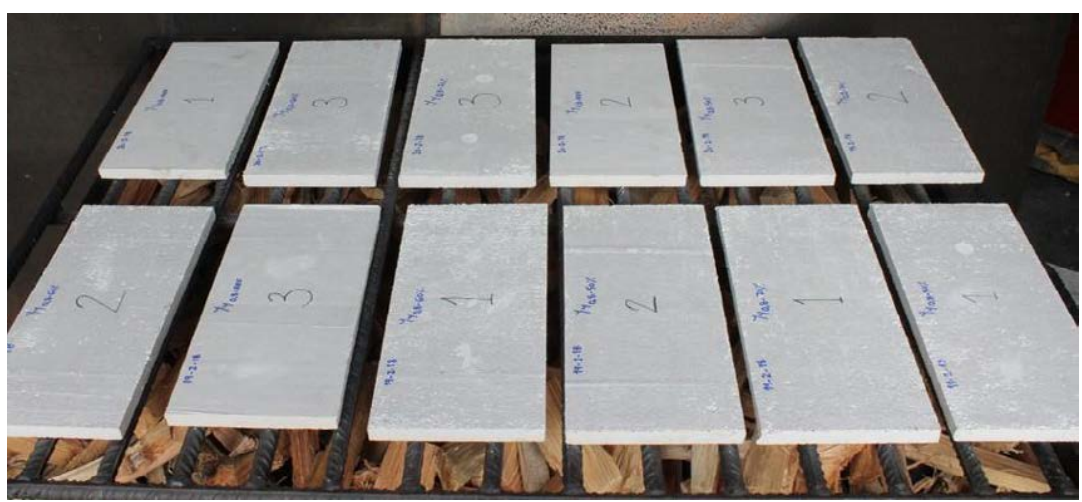

Foto 6.11. Parrilla de ensayo del parque de Bomberos de la Comunidad de Madrid

Los datos de temperatura obtenidos durante el ensayo cada 5 minutos se muestran en la Tabla 6.32.

Tabla 6.32. Temperatura media $\left({ }^{\circ} \mathrm{C}\right)$ de los paneles tomada cada 5 minutos

\begin{tabular}{|c|c|c|c|c|c|c|c|c|}
\hline \multirow[t]{2}{*}{ Refer. } & \multirow{2}{*}{ Denominación } & $\begin{array}{c}\text { Temperatura } \\
\left({ }^{\circ} \mathrm{C}\right)\end{array}$ & $\begin{array}{c}\text { Temperatura } \\
\left({ }^{\circ} \mathrm{C}\right)\end{array}$ & $\begin{array}{c}\text { Temperatura } \\
\left({ }^{\circ} \mathrm{C}\right)\end{array}$ & $\begin{array}{c}\text { Temperatura } \\
\left({ }^{\circ} \mathrm{C}\right)\end{array}$ & $\begin{array}{c}\text { Temperatura } \\
\left({ }^{\circ} \mathrm{C}\right)\end{array}$ & $\begin{array}{c}\text { Temperatura } \\
\left({ }^{\circ} \mathrm{C}\right)\end{array}$ & $\begin{array}{c}\text { Temperatura } \\
\left({ }^{\circ} \mathrm{C}\right)\end{array}$ \\
\hline & & $0 \mathrm{~min}$ & $5 \mathrm{~min}$ & $10 \mathrm{~min}$ & $15 \mathrm{~min}$ & $20 \mathrm{~min}$ & $25 \mathrm{~min}$ & $30 \mathrm{~min}$ \\
\hline \multirow{10}{*}{$\begin{array}{l}\text { Serie } \\
\text { XVIII }\end{array}$} & $\mathrm{E}_{0,8 \text {-EXTERIOR }}$ & 3,60 & 443,33 & 602,67 & 328,00 & 301,67 & 281,00 & 236,33 \\
\hline & $\mathrm{E}_{0,8 \text {-MEDIO }}$ & 3,60 & 354,00 & 229,00 & 269,33 & 248,67 & 264,00 & 217,00 \\
\hline & $\mathrm{E}_{0,8 \text {-INTERIOR }}$ & 3,60 & 567,00 & 603,33 & 344,67 & 333,00 & 308,00 & 260,33 \\
\hline & $\mathrm{E}_{0,8-50 P R-E X T E R I O R}$ & 3,60 & 369,00 & 231,67 & 174,33 & 176,33 & 166,33 & 178,67 \\
\hline & $\mathrm{E}_{0,8-50 \text { PR-MEDIO }}$ & 3,60 & 450,67 & 596,67 & 433,33 & 600,00 & 352,67 & 311,00 \\
\hline & $\mathrm{E}_{0,8-50 \text { PR-INTERIOR }}$ & 3,60 & 232,67 & 212,33 & 325,30 & 303,33 & 234,33 & 270,67 \\
\hline & $\mathrm{E}_{0,8-60 \mathrm{PR} \text {-EXTERIOR }}$ & 3,60 & 366,67 & 292,33 & 211,00 & 248,00 & 299,00 & 264,67 \\
\hline & $\mathrm{E}_{0,8-60 \mathrm{PR}-\mathrm{MEDIO}}$ & 3,60 & 531,67 & 603,33 & 479,33 & 533,33 & 359,67 & 318,00 \\
\hline & $\mathrm{E}_{0,8-60 \text { PR-INTERIOR }}$ & 3,60 & 298,33 & 179,33 & 269,67 & 229,33 & 276,67 & 266,33 \\
\hline & $\mathrm{E}_{0,8-70 \text { PR-EXTERIOR }}$ & 3,60 & 501,33 & 597,00 & 315,67 & 250,67 & 258,33 & 267,33 \\
\hline
\end{tabular}




\begin{tabular}{llllllll} 
E $_{0,8-70 \text { PR-MEDIO }}$ & 3,60 & 389,33 & 240,33 & 238,33 & 220,00 & 224,00 & 216,33 \\
E $_{0,8-70 \text { PR-INTERIOR }}$ & 3,60 & 628,33 & 665,33 & 600,00 & 596,67 & 378,00 & 334,33 \\
\hline
\end{tabular}

A los 5 minutos de exposición al fuego real directo, todos los compuestos superan los $200^{\circ} \mathrm{C}$. Las máximas temperaturas llegan entre los 5 y los 10 minutos de exposición, excepto en el caso de los compuestos con 50\%PR que llegan entre los 15 y los 20 minutos.

Por un lado se analiza el comportamiento entre los paneles de igual compuesto pero distinta posición. En la Gráfica 6.30 se observa que los paneles del compuesto de referencia se comportan de forma similar a los paneles del compuesto con $70 \% \mathrm{PR}$, esto es, el panel colocado en posición interior es el que alcanza la mayor temperatura, sobrepasando ligeramente los $600^{\circ} \mathrm{C}$; en cambio, es el panel en posición media el que alcanza menor temperatura, no superando los $390^{\circ} \mathrm{C}$; los paneles situados en posición exterior, al contrario de lo que se podría pensar, alcanzan también temperaturas cercanas a los $600^{\circ} \mathrm{C}$. En cuanto a los compuestos con $50 \%$ PR y $60 \%$ PR, sus paneles tienen comportamientos similares. En este caso, es el panel colocado en la posición media el que alcanza la mayor temperatura de alrededor de $600^{\circ} \mathrm{C}$; el panel colocado en posición interior es el que menos temperatura adquiere, sin llegar a superar los $330^{\circ} \mathrm{C}$ y; finalmente el panel colocado en posición exterior alcanza temperaturas ligeramente superiores al panel interior, que se acercan a los $370^{\circ} \mathrm{C}$.

En general, el panel que presentó un mejor comportamiento al fuego, exceptuando

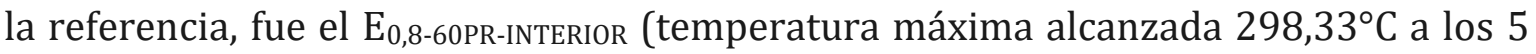

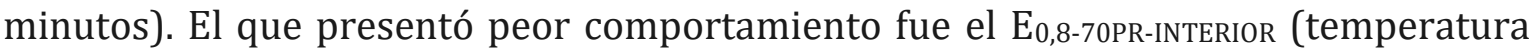
máxima alcanzada $628,33^{\circ} \mathrm{C}$ a los 5 minutos). 


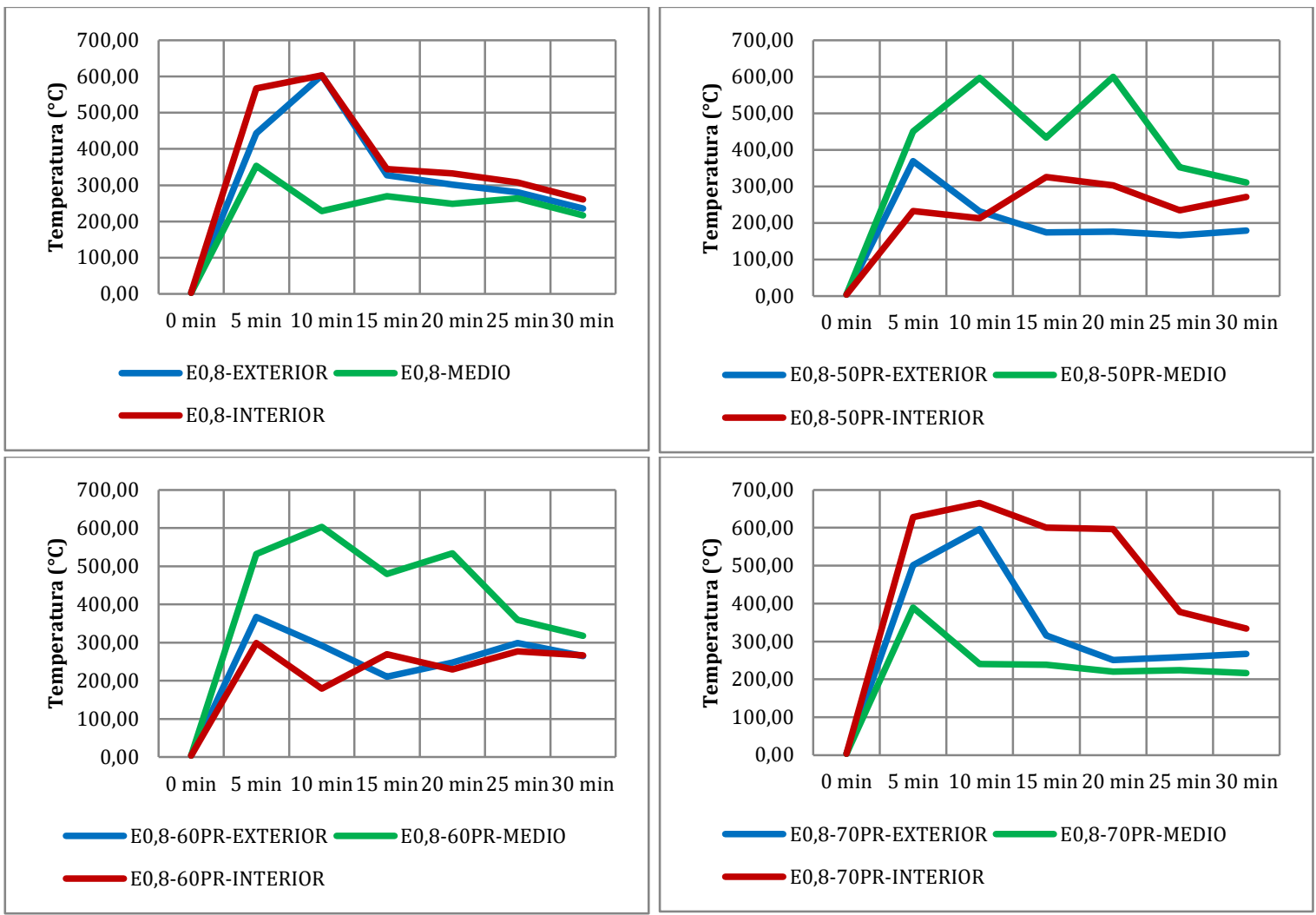

Gráfica 6.30. Temperatura alcanzada por los paneles $\left({ }^{\circ} \mathrm{C}\right)$. Superior izquierda: $E_{0,8}$; superior derecha. $E_{0,8-50 P R}$ inferior izquierda: $E_{0,8-60 P R}$ inferior derecha: $E_{0,8-70 P R}$

Por otro lado se analiza el comportamiento entre los paneles de igual posición pero distinto compuesto. En la Gráfica 6.31 se observan los paneles colocados en el exterior, es decir, los menos expuestos al fuego. El compuesto de referencia y el compuesto 70\%PR presentan el pico máximo de temperatura a los 10 minutos del comienzo del ensayo alcanzando los $600^{\circ} \mathrm{C}$ para, a continuación, comenzar el proceso de enfriamiento bruscamente en los siguientes 5 minutos hasta los $330^{\circ} \mathrm{C}$ aproximadamente $\mathrm{y}$, llegar a $\operatorname{los} 260^{\circ} \mathrm{C}$ a los 30 minutos del comienzo. Los compuestos de 50\%PR y 60\%PR presentan su pico máximo de temperatura antes, a los 5 minutos del comienzo del ensayo, pero no alcanzan los $370^{\circ} \mathrm{C}$ y empiezan su proceso de enfriamiento de una forma más paulatina hasta la finalización del mismo, llegando a los $180^{\circ} \mathrm{C}$ y $265^{\circ} \mathrm{C}$ respectivamente.

El panel situado en la zona exterior que presentó un mejor comportamiento al

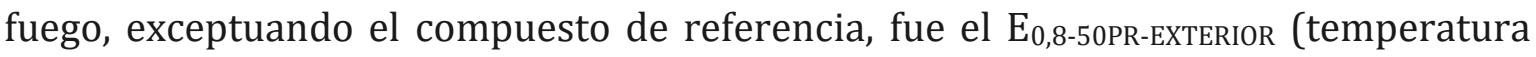
máxima alcanzada $369,00^{\circ} \mathrm{C}$ a los 5 minutos y final de $178,67^{\circ} \mathrm{C}$ ). El que presentó peor

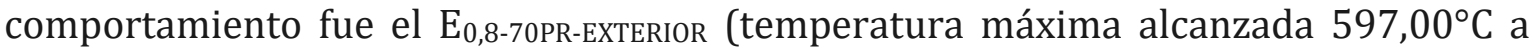
los 10 minutos y final de $267,33^{\circ} \mathrm{C}$ ). 


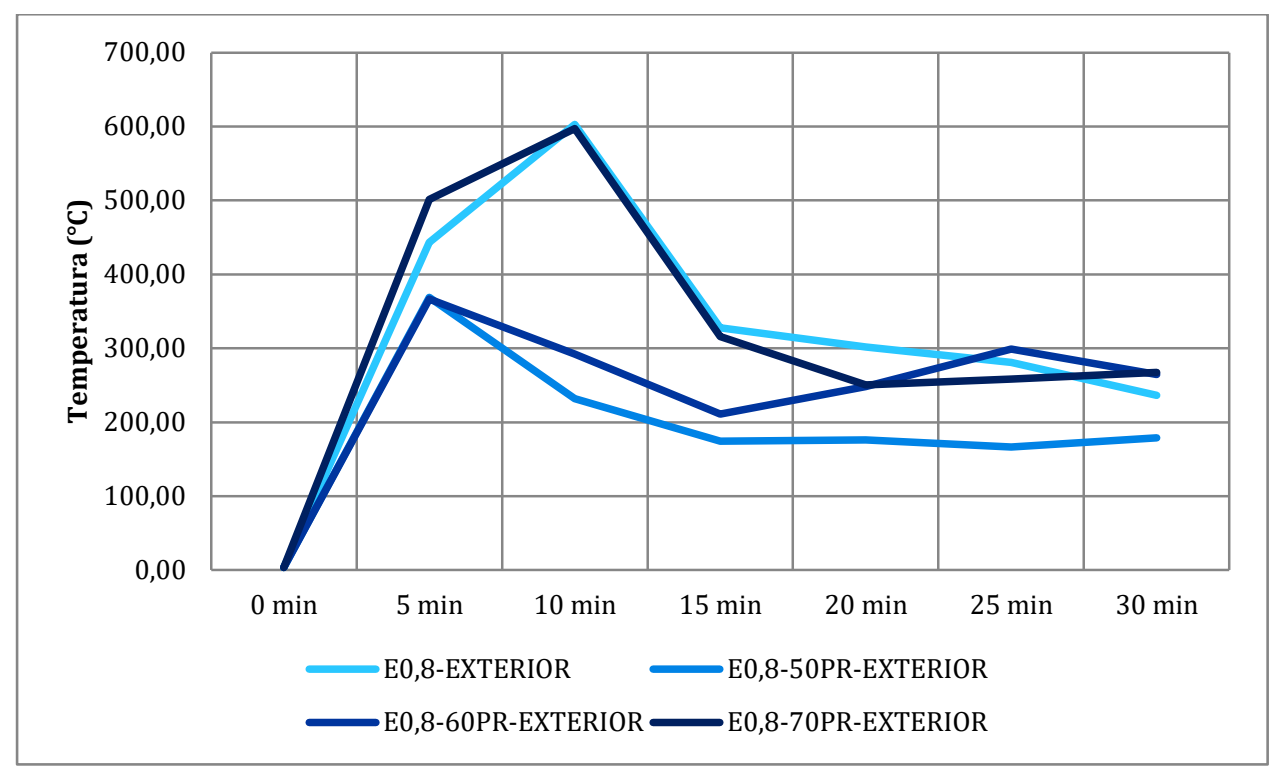

Gráfica 6.31. Temperatura $\left({ }^{\circ} \mathrm{C}\right)$ alcanzada por los paneles en posición exterior de todos los compuestos

Los resultados de los paneles colocados en la posición media se observan en la Gráfica 6.32. Al contrario de lo que ocurre con la posición exterior, son los compuestos de 50\%PR y $60 \%$ PR los que presentan el pico máximo de temperatura a los 10 minutos del comienzo del ensayo alcanzando los $600^{\circ} \mathrm{C}$ para, a continuación comenzar el descenso de su temperatura durante 5 minutos hasta los $460^{\circ} \mathrm{C}$ aproximadamente y, volver a subirla en los siguientes 5 minutos, hasta los $600^{\circ} \mathrm{C}$ en el caso del $50 \% \mathrm{PR}$ y hasta los $535^{\circ} \mathrm{C}$ en el caso del $60 \% \mathrm{PR}$ y, terminar con unos $320^{\circ} \mathrm{C}$ al final del ensayo. Los compuestos de referencia y 70\%PR presentan un único pico máximo de temperatura a los 5 minutos del comienzo del ensayo y no llegan a alcanzar los $390^{\circ} \mathrm{C}$, a continuación comienzan a perder temperatura gradualmente hasta el final del ensayo, llegando a los $217^{\circ} \mathrm{C}$. El panel situado en la zona media que presentó un mejor comportamiento al fuego, exceptuando la referencia, fue el $\mathrm{E}_{0,8}$ 70PR-MEDio (temperatura máxima alcanzada $389,33^{\circ} \mathrm{C}$ a los 5 minutos y final de $216,33^{\circ} \mathrm{C}$ ). El que presentó peor comportamiento fue el $\mathrm{E}_{0,8-60 \mathrm{PR}-\mathrm{MEDIO}}$ (temperatura máxima alcanzada $603,33^{\circ} \mathrm{C}$ a los 10 minutos y final de $318,00^{\circ} \mathrm{C}$ ). 


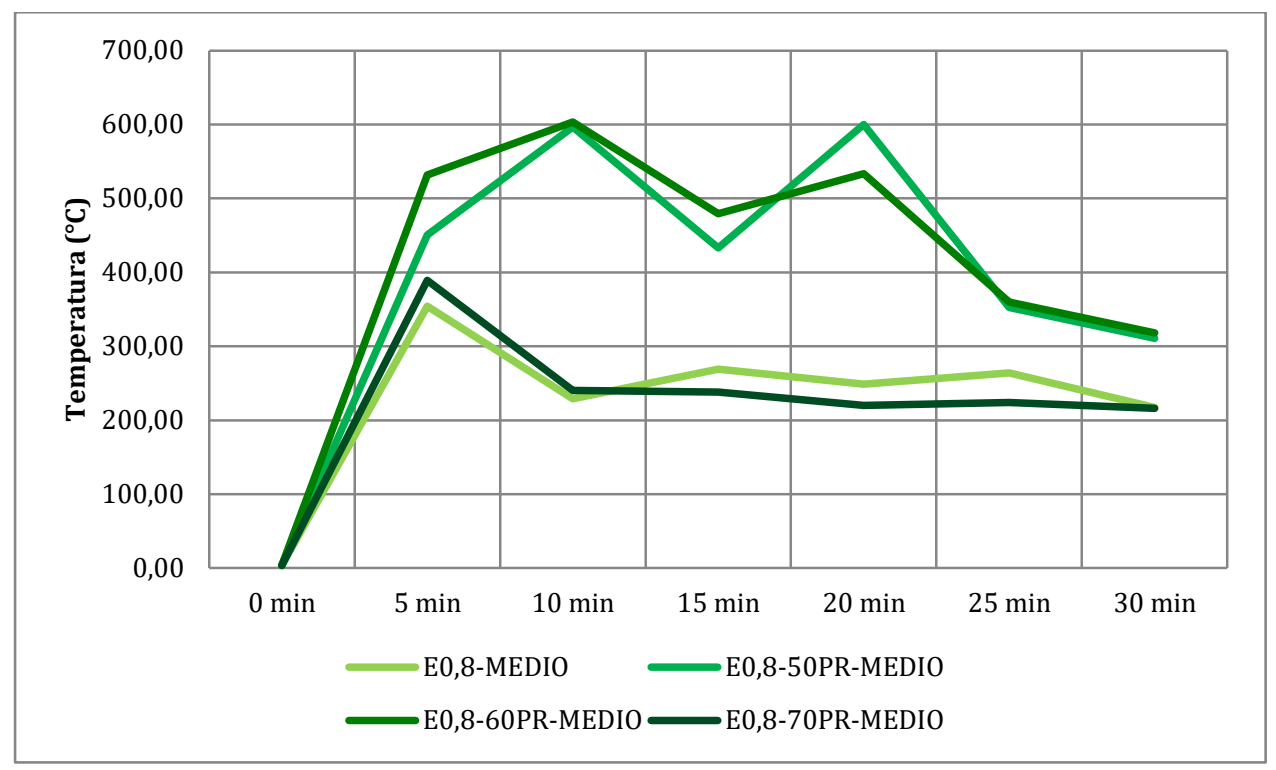

Gráfica 6.32. Temperatura $\left({ }^{\circ} \mathrm{C}\right)$ alcanzada por los paneles en posición media de todos los compuestos

La Gráfica 6.33 muestra los resultados de los paneles colocados en el interior, es decir, los más expuestos al fuego. Como ocurre con los paneles situados en la posición exterior, también en este caso son los compuestos de referencia y de 70\%PR los que presentan el pico máximo de temperatura a los 10 minutos del comienzo del ensayo superando los $600^{\circ} \mathrm{C}$ en ambos casos, $603,33^{\circ} \mathrm{C}$ la referencia y $665,33^{\circ} \mathrm{C}$ el $70 \% \mathrm{PR}$. Mientras que el compuesto con $70 \% \mathrm{PR}$ comienza su proceso de enfriamiento de forma paulatina hasta los 20 minutos y luego lo hace de manera más repentina hasta los $260^{\circ} \mathrm{C}$; el compuesto de referencia tiene un descenso brusco hasta los 15 minutos y a partir de ahí lo hace de manera suave hasta los $335^{\circ} \mathrm{C}$. El compuesto de $50 \% \mathrm{PR}$ presenta su pico máximo de temperatura a los 15 minutos del comienzo del ensayo para, a continuación, comenzar su descenso de temperatura gradualmente hasta llegar a los $270^{\circ} \mathrm{C}$ a la finalización del mismo. Para el compuesto de $60 \% \mathrm{PR}$ el pico máximo de temperatura se establece en $300^{\circ} \mathrm{C}$ a los 5 minutos, reduce su temperatura en los siguientes 5 minutos hasta los $180^{\circ} \mathrm{C}$; a partir de ese momento comienza a incrementar nuevamente la temperatura en los siguientes minutos hasta alcanzar los $265^{\circ}$ al término del ensayo. El panel situado en la zona interior que presentó un mejor comportamiento al fuego, exceptuando el compuesto de referencia, fue el $\mathrm{E}_{0,8-}$ 60PR-INTERIOR (temperatura máxima alcanzada $298,33^{\circ} \mathrm{C}$ a los 5 minutos y final de $266,33^{\circ} \mathrm{C}$ ). El que presentó peor comportamiento fue el $\mathrm{E}_{0,8-70 \mathrm{PR}-\mathrm{INTERIOR}}$ (temperatura máxima alcanzada $628,33^{\circ} \mathrm{C}$ a los 5 minutos y final de $334,33^{\circ} \mathrm{C}$ ). 


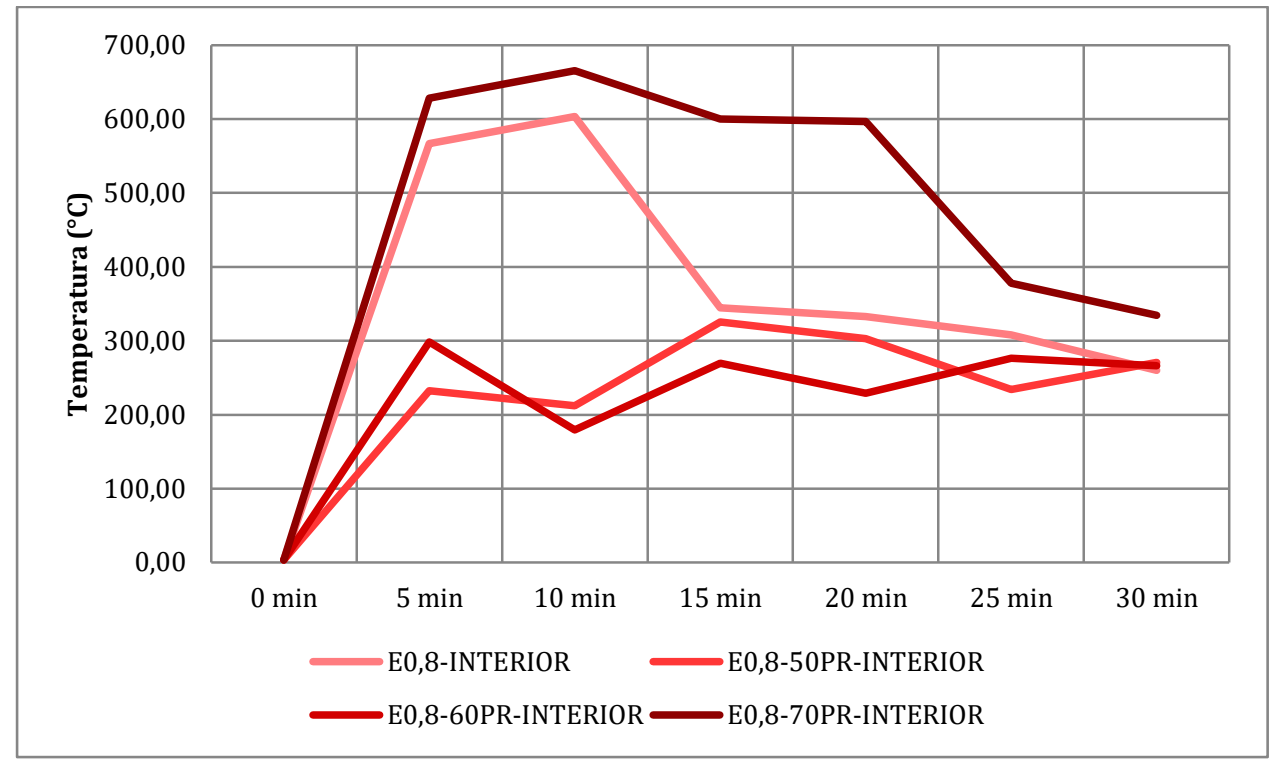

Gráfica 6.33. Temperatura $\left({ }^{\circ} \mathrm{C}\right)$ alcanzada por los paneles en posición interior de todos los compuestos

El comportamiento general de los todos los paneles ensayados en cuanto al aspecto exterior es de carbonización (Foto 6.12); si bien es cierto que el interior de los paneles de referencia se conserva intacto, debido a su propiedad de incombustibilidad, el interior de los paneles con granza presenta oquedades por la desaparición de los polímeros tras su fusión (Foto 6.13) que se produce desde una temperatura aproximada de $200^{\circ} \mathrm{C}$ como puede comprobarse en el análisis termogravimétrico del apartado 6.1.2.1. Los paneles de referencia se vuelven más frágiles, llegando a partirse durante el ensayo; los paneles con PR también parten y, además, se deshacen con facilidad. Cabe mencionar que, como en los estudios de Gutiérrez González y Ramos se observa el efecto retardante de llama que realiza el yeso respecto a los polímeros (Alameda et al., 2016; Ramos \& Mendes, 2014).
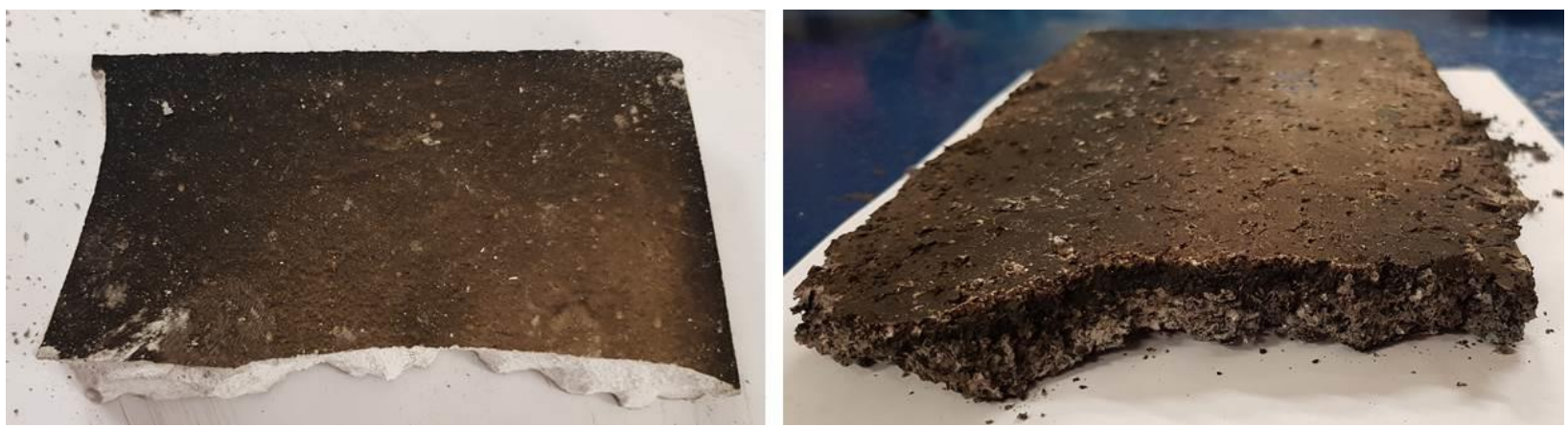

Foto 6.12. Aspecto exterior de los paneles tras la finalización del ensayo a fuego real directo. Izquierda: panel de referencia; derecha: panel con $P R$ 

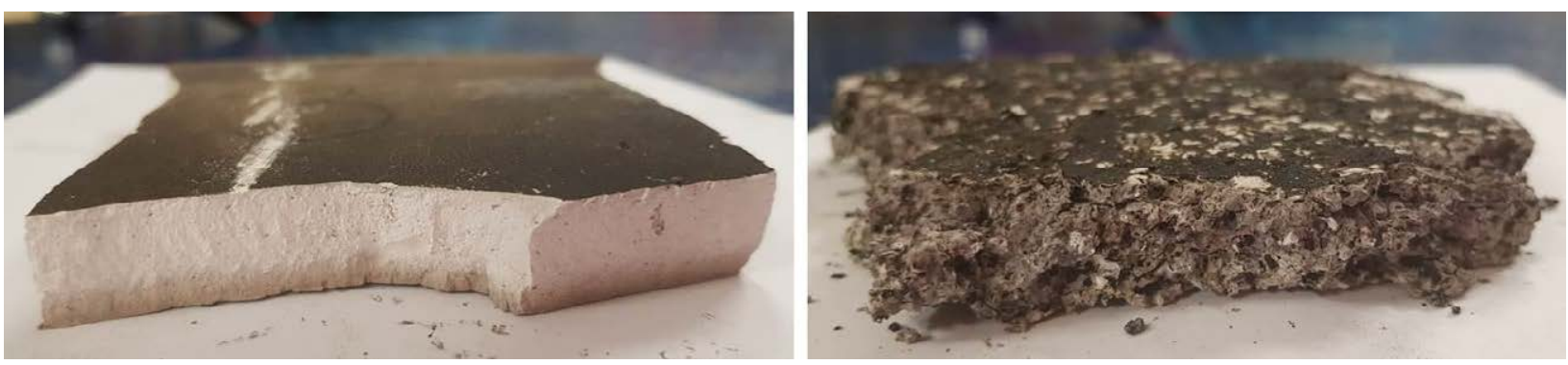

Foto 6.13. Interior de los paneles tras la finalización del ensayo a fuego real directo. Izquierda: panel de referencia sin oquedades; derecha: panel de PR con oquedades

Aunque fuera del alcance de esta Tesis, la realización de ensayos normalizados permitiría caracterizar la respuesta al fuego de los paneles que incorporan PR conforme al sistema de Euroclases de acuerdo al Reglamento de Productos de la Construcción (CPR). El yeso tiene la clasificación A1 como material no combustible (Saint-Gobain, 2019). Dado el carácter orgánico del PR, y tal y como se ha puesto de manifiesto en el ensayo real al fuego, los paneles bajo estudio que incorporan PR previsiblemente serían clasificados como combustibles (clasificación entre B, combustible con limitada contribución, y E, combustible con contribución alta), para los que sería necesario establecer las clasificaciones adicionales según la opacidad de humos y las gotas o partículas inflamables.

\subsection{Análisis y detección de los gases desprendidos en combustión}

Además del riesgo de las excesivas temperaturas que pueden alcanzarse durante un incendio, el humo en sí representa un riesgo importante para cualquier persona por lo que es fundamental analizar los gases que se producen en la combustión de los compuestos con PR.

\subsection{1. Gases desprendidos en la combustión de polímeros}

En este punto es preciso diferenciar dos escenarios distintos. El primer escenario sería el comportamiento frente al fuego de los paneles de yeso que incorporan PR, cuya aplicación en el sector de la construcción constituye el objeto de esta Tesis Doctoral. El segundo escenario sería la valorización energética del residuo de PR, usado como combustible, o simplemente la incineración de los residuos plásticos como método de eliminación de los mismos; este segundo escenario es el destino actual de los residuos de PR recogidos en la planta de Lyrsa Álava.

En el primero de los escenarios, en el que se considera el comportamiento de los paneles de yeso que incorporan PR en un incendio, hay que tener en cuenta que todos 
los humos que se generan en un incendio son tóxicos, siendo el factor más importante la concentración de CO generado. Todos los materiales combustibles, sean naturales o sintéticos, producen CO cuando arden. Como ya se ha comentado, la cantidad y naturaleza de las sustancias liberadas en un incendio depende tanto del material implicado como de las condiciones del incendio.

En el segundo de los escenarios, la combustión del residuo de PR en instalaciones de combustión de residuos, que no constituye el objeto de esta Tesis, es donde cobran importancia, además del monóxido de carbono, el resto de las sustancias descritas en el apartado 1.3.3. Los gases procedentes de la incineración pueden contener partículas (cenizas volantes), compuestos gaseosos ácidos tales como cloruro de hidrógeno ( $\mathrm{HCl}$ ), dióxido de azufre $\left(\mathrm{SO}_{2}\right)$, óxidos de nitrógeno ( $\mathrm{NOx}$ ), compuestos de metales pesados o productos de combustión incompleta (dioxinas, furanos, etc) (Aracil Sáez, 2008). Las corrientes gaseosas procedentes de estas plantas deben ser tratadas antes de su descarga a la atmósfera para cumplir con los límites de emisión establecidos en el Real Decreto 815/2013, de 18 de octubre, por el que se aprueba el Reglamento de emisiones industriales y de desarrollo de la Ley 16/2002, de 1 de julio, de prevención y control integrados de la contaminación.

\subsection{2. Cálculo del $\mathrm{CO}_{2}$ y CO emitidos en la combustión del PR}

Para el cálculo de este apartado se tienen en cuenta los resultados analíticos obtenidos para el PR tras el análisis termogravimétrico en atmósfera de aire (apartado 6.1.2.1) así como los resultados obtenidos en el análisis elemental (apartado 6.1.2.3).

De acuerdo a los resultados del análisis termogravimétrico, el PR pierde un 84\% de masa y su proceso de descomposición se produce en el intervalo entre $200-500^{\circ} \mathrm{C}$. Dadas las temperaturas que se alcanzan en el ensayo de fuego, más de $600^{\circ} \mathrm{C}, \mathrm{y}$ teniendo en cuenta las temperaturas que llegan a darse en un incendio, de $800^{\circ} \mathrm{C} \mathrm{a}$ $1200^{\circ} \mathrm{C}$ (Peinado Moreno, 2003), es muy posible que los procesos de descomposición de la granza hayan finalizado tras producirse cualquiera de ellos. El 16\% restante de PR queda en forma de cenizas, constituidas por compuestos inorgánicos presentes en los polímeros (óxidos de aluminio, silicio o metales alcalinos), metales pesados de baja volatilidad y materia carbonosa residual (Aracil Sáez, 2008). Atendiendo también al análisis elemental del PR, que contiene $\mathrm{Si}$ y $\mathrm{Ca}$, en las cenizas podrían estar presentes óxido de silicio y óxido de calcio.

En la pérdida de masa del 84\% pueden estar incluidos tanto la combustión de la materia carbonosa (orgánica) como la formación de compuestos derivados de los metales volátiles; atendiendo de nuevo a la composición elemental del PR, pueden 
producirse óxidos volátiles de $\mathrm{Pb}$ y Sb; la presencia de cloro en la granza favorecería la formación de otros compuestos volátiles, como por ejemplo cloruro de $\mathrm{Pb}$ o de $\mathrm{Zn}$. Adicionalmente, pueden generarse gases ácidos como $\mathrm{HCl}$ y $\mathrm{SO}_{2}$ debidos a la mencionada presencia de cloro y a la presencia azufre. Pueden originarse, además, muchos otros compuestos tóxicos de acuerdo a la exhaustiva revisión llevada a cabo por Aracil Saez acerca de la combustión de materia orgánica. La formación de estos compuestos depende no solamente del material, sino también de otros factores, como por ejemplo la concentración de oxígeno presente, y las temperaturas alcanzadas. No se ha encontrado en la bibliografía ningún trabajo que estudie la composición de los gases de combustión de los residuos de plásticos de cables, por lo que podría ser una futura línea de investigación, que requiere la realización de ensayos de combustión en condiciones controladas y puesta a punto de métodos y equipos de análisis instrumental complejos, tales como espectrofometría de masas y cromatografía de gases, para la identificación y cuantificación de las sustancias formadas.

No obstante, la materia orgánica es el principal constituyente del PR, con un 77,2\% de acuerdo al análisis elemental, por lo que su descomposición térmica y oxidativa es la principal fuente de las emisiones gaseosas derivadas de la combustión del PR de los paneles ensayados, siendo el CO el compuesto más importante en cuanto a emisiones producidas si a un incendio se refiere. Por su parte, el yeso únicamente pierde agua a bajas temperaturas, cercanas a $100^{\circ} \mathrm{C}(9 \%$ de acuerdo al análisis termogravimétrico), quedando como sulfato de calcio anhidro, de ahí que se considere incombustible. Su presencia como envolvente de las partículas del PR en los paneles, actúa como una barrera física que podría tener como efectos el retraso en la combustión de la granza y la obstaculización de la emisión de los gases de combustión, si se compara con otros materiales poliméricos expuestos al fuego que puedan estar presentes en una estancia sin ningún tipo de protección física. Con el análisis elemental (apartado 6.1.2.3) también se pone de manifiesto la utilización de aditivos retardantes de la llama en la formulación de los polímeros, ya que se detecta la presencia de bromo y antimonio, que aumentan la duración de la etapa de fuego latente anterior al punto de inflamación (Gráfica 5.3).

A partir de la composición de los compuestos, se calcula la cantidad de $\mathrm{CO}_{2}$ y $\mathrm{CO}$ que se genera en la combustión de $1 \mathrm{~kg}$ de $\mathrm{PR}$, teniendo en cuenta la siguiente información:

- De acuerdo al análisis termogravimétrico, se queman 0,84 kg de PR, quedando el resto de masa como cenizas.

- Se considera que en la granza están presentes dos tipos de polímeros, policloruro de vinilo (PVC) y polietileno (PE), ya que son los más abundantes en este tipo de residuo (Suresh et al., 2017). 
- Se calcula la cantidad de PVC en el PR asignando al PVC todo el cloro presente en el $\mathrm{PR}$, un 3,35\% según el análisis elemental. Se considera la siguiente fórmula general para el PVC: $-\left(\mathrm{CH}_{2}-\mathrm{CHCl}\right)_{n}$ - es decir, $\left(\mathrm{C}_{2} \mathrm{H}_{3} \mathrm{Cl}\right)_{n}$. Se considera que el resto de material combustible en el PR estaría formado por PE, cuya fórmula general es: - $\left(\mathrm{CH}_{2}-\mathrm{CH}_{2}\right)_{\mathrm{n}}$ - es decir, $\left(\mathrm{C}_{2} \mathrm{H}_{4}\right)_{\mathrm{n}}$.

- Una vez conocida la cantidad de cada uno de los polímeros, se calcula la cantidad de $\mathrm{CO}_{2}$ que se emitiría en la combustión, considerada completa, del PR.

- Si la combustión fuese incompleta puede generarse monóxido de carbono (CO), pero dado que tanto el dióxido como el monóxido contienen un átomo de carbono, el número de moles de ambos sería el mismo.

\section{Cálculos para el PVC:}

1. Cálculo del peso molecular del monómero de PVC, en base a la fórmula $\left(\mathrm{C}_{2} \mathrm{H}_{3} \mathrm{Cl}\right)_{\mathrm{n}}$, y del porcentaje de masa que supone el Cloro en el PVC (kg de cloro/kg de PVC):

$$
\begin{gathered}
\left(\frac{12 \mathrm{kgC}}{\mathrm{kmol} \mathrm{C}} \cdot 2 \frac{\mathrm{kmol} \mathrm{C}}{\mathrm{kmol} \mathrm{PVC}}\right)+\left(\frac{1 \mathrm{~kg} \mathrm{H}}{\mathrm{kmol} \mathrm{H}} \cdot 3 \frac{\mathrm{kmol} \mathrm{H}}{\mathrm{kmol} \mathrm{PVC}}\right)+\left(\frac{35,5 \mathrm{~kg} \mathrm{Cl}}{\mathrm{kmol} \mathrm{Cl}} \cdot 1 \frac{\mathrm{kmol} \mathrm{Cl}}{\mathrm{kmol} \mathrm{PVC}}\right) \\
=62,5 \frac{\mathrm{kg} \mathrm{PVC}}{\mathrm{kmol} \mathrm{PVC}} \\
\left(\frac{1 \mathrm{kmol} \mathrm{Cl}}{1 \mathrm{kmol} \mathrm{PVC}} \frac{35,5 \mathrm{~kg} \mathrm{Cl}}{\mathrm{kmol} \mathrm{Cl}} \frac{1 \mathrm{kmol} \mathrm{PVC}}{62,5 \mathrm{~kg} \mathrm{PVC}}\right) \cdot 100=56,80 \%
\end{gathered}
$$

2. Cálculo de la cantidad de PVC en $1 \mathrm{~kg}$ de PR que contiene $3.35 \%$ de cloro:

$$
0,0335 \mathrm{kgCl} \cdot\left(\frac{1 \mathrm{kgPVC}}{0,5680 \mathrm{kgCl}}\right)=0,059 \mathrm{~kg} P V C
$$

3. Cálculo de la masa de $\mathrm{CO}_{2}$ o $\mathrm{CO}$ emitido por la combustión del PVC contenido en $1 \mathrm{~kg}$ de PR:

$$
\begin{gathered}
0,059 \mathrm{kgPVC} \cdot\left(\frac{1 \mathrm{kmol} \mathrm{PVC}}{62,5 \mathrm{kgPVC}}\right) \cdot\left(\frac{2 \mathrm{kmol} \mathrm{C}}{1 \mathrm{kmol} \mathrm{PVC}}\right) \cdot\left(\frac{1 \mathrm{kmol} \mathrm{CO}}{1 \mathrm{kmol} \mathrm{C}}\right) \cdot\left(\frac{44 \mathrm{kgCO}}{1 \mathrm{kmol} \mathrm{CO}_{2}}\right) \\
=8,3 \cdot 10^{-2} \mathrm{kgCO} \mathrm{CO}_{2}
\end{gathered}
$$


Si la combustión no es completa, y con la hipótesis de que todo el carbono genera CO, se puede calcular la masa de CO emitido por la combustión del PVC contenido en $1 \mathrm{~kg}$ de PR:

$$
\begin{gathered}
0,059 \mathrm{~kg} \mathrm{PVC} \cdot\left(\frac{1 \mathrm{kmol} \mathrm{PVC}}{62,5 \mathrm{kgPVC}}\right) \cdot\left(\frac{2 \mathrm{kmol} \mathrm{C}}{1 \mathrm{kmol} \mathrm{PVC}}\right) \cdot\left(\frac{1 \mathrm{kmol} \mathrm{CO}}{1 \mathrm{kmol} \mathrm{C}}\right) \cdot\left(\frac{28 \mathrm{~kg} \mathrm{CO}}{1 \mathrm{kmol} \mathrm{CO}}\right) \\
=5,28 \cdot 10^{-2} \mathrm{kgCO}
\end{gathered}
$$

4. Cálculo del porcentaje de PVC en el material combustible de PR:

$$
\left(\frac{0,059 \mathrm{~kg} P V C}{0,84 \mathrm{~kg} \text { material combustible PR }}\right) \cdot 100=7,0 \%
$$

Por lo que, si hay una proporción en masa del 7\% de PVC, el 93\% en masa restante de material combustible sería PE. Si se calcula como porcentajes en masa de la granza resultan 5,9\% y 94,12\% de PVC y PE respectivamente.

\section{Cálculos para el PE:}

1. Cálculo del peso molecular del monómero de PE, en base a la fórmula $\left(\mathrm{C}_{2} \mathrm{H}_{4}\right)_{\mathrm{n}}$ :

$$
\left(\frac{12 \mathrm{~kg} \mathrm{C}}{\mathrm{kmol} \mathrm{C}} \cdot 2 \frac{\mathrm{kmol} \mathrm{C}}{\mathrm{kmol} \mathrm{PE}}\right)+\left(\frac{1 \mathrm{~kg} \mathrm{H}}{\mathrm{kmol} \mathrm{H}} \cdot 4 \frac{\mathrm{kmol} \mathrm{H}}{\mathrm{kmol} \mathrm{PE}}\right)=28 \frac{\mathrm{kg} \mathrm{PE}}{\mathrm{kmol} \mathrm{PE}}
$$

2. Cálculo de la cantidad de PE en el material combustible de 1 kg de PR:

$$
(0,84 \mathrm{~kg} \text { material combustible }-0,059 \mathrm{~kg} P V C)=0,781 \mathrm{~kg} P E
$$

3. Cálculo de la masa de $\mathrm{CO}_{2}$ o $\mathrm{CO}$ emitido por la combustión del PE contenido en $1 \mathrm{~kg}$ de PR:

$$
\begin{gathered}
0,781 \mathrm{kgPE} \cdot\left(\frac{1 \mathrm{kmol} \mathrm{PE}}{28 \mathrm{kgPE}}\right) \cdot\left(\frac{2 \mathrm{kmol} \mathrm{C}}{1 \mathrm{kmol} \mathrm{PE}}\right) \cdot\left(\frac{1 \mathrm{kmol} \mathrm{CO}}{1 \mathrm{kmol} \mathrm{C}}\right) \cdot\left(\frac{44 \mathrm{~kg} \mathrm{CO}}{1 \mathrm{kmol} \mathrm{CO}_{2}}\right) \\
=2,45 \mathrm{kgCO}_{2}
\end{gathered}
$$

Si la combustión no es completa, y con la hipótesis de que todo el carbono genera CO, se puede calcular la masa de CO emitido por la combustión del PE contenido en $1 \mathrm{~kg}$ de PR: 
$0,781 \mathrm{~kg} P E \cdot\left(\frac{1 \mathrm{kmol} \mathrm{PE}}{28 \mathrm{kgPE}}\right) \cdot\left(\frac{2 \mathrm{kmol} \mathrm{C}}{1 \mathrm{kmol} \mathrm{PE}}\right) \cdot\left(\frac{1 \mathrm{kmol} \mathrm{CO}}{1 \mathrm{kmol} \mathrm{C}}\right) \cdot\left(\frac{28 \mathrm{kgCO}}{1 \mathrm{kmol} \mathrm{CO}}\right)=1,56 \mathrm{~kg} \mathrm{CO}$

Según los cálculos realizados, en la combustión completa de 1 kg de granza PR, con las hipótesis de trabajo, se emitirían un total de $2,53 \mathrm{~kg} \mathrm{CO}_{2}\left(8,3 \cdot 10^{-2} \mathrm{~kg} \mathrm{CO}_{2}\right.$ del PVC $+2,45 \mathrm{~kg} \mathrm{CO} 2$ del PE). Si la combustión fuera incompleta, se emitirían un total de $1,61 \mathrm{~kg}$ CO $\left(5,28 \cdot 10^{-2} \mathrm{~kg}\right.$ CO del PVC $+1,56 \mathrm{~kg}$ CO del PE).

\subsection{3. Estimación de $\mathrm{CO}_{2}$ y $\mathrm{CO}$ emitidos en un supuesto tipo}

Una vez obtenido el $\mathrm{CO}_{2}$ y $\mathrm{CO}$ posible por cada kg de PR, es importante poder compararlo con la cantidad que se estima peligrosa para la salud de las personas. Para ello, se realiza el cálculo de estos gases de combustión en una estancia tipo de 4 m x 3 m x 2,6 m en la que sus particiones están hechas de paneles estándar (2000 x $1200 \times 12,5 \mathrm{~mm}^{3}$ ) de los compuestos en estudio. Los resultados se muestran en la Tabla 6.33.

Tabla 6.33. Cantidad de $\mathrm{CO}_{2}$ yCO emitida en la combustión del PR de los compuestos en una estancia propuesta de $12 \mathrm{~m}^{2}$ y $2,6 \mathrm{~m}$ de altura (volumen $31,2 \mathrm{~m}^{3}$ )

\begin{tabular}{|c|c|c|c|c|c|c|c|}
\hline Referencia & Denom. & $\begin{array}{l}\text { Cantidad de } \\
\text { PR por } \\
\text { panel } \\
(\mathrm{Kg} / \mathrm{ud})\end{array}$ & $\begin{array}{c}\text { Cantidad } \\
\text { estimada de } \\
\text { paneles en } \\
\text { estancia tipo } \\
\text { (ud) } \\
\end{array}$ & $\begin{array}{c}\text { Total PR en la } \\
\text { estancia } \\
\text { propuesta (Kg) }\end{array}$ & $\begin{array}{c}\mathrm{CO}_{2} / \mathrm{CO} \text { emitido } \\
\text { (Kg) }\end{array}$ & $\begin{array}{c}\mathrm{CO}_{2} / \mathrm{CO} \text { emitido } \\
\text { por unidad de } \\
\text { volumen }\left(\mathrm{Kg} / \mathrm{m}^{3}\right)\end{array}$ & $\begin{array}{c}\mathrm{CO}_{2} / \mathrm{CO} \text { emitido } \\
\text { (ppm) }\end{array}$ \\
\hline \multirow{4}{*}{ Serie XIX } & $\mathrm{E}_{0,8}$ & 0,00 & 15 & 0,00 & 0,00 & 0,00 & \\
\hline & $\mathrm{E}_{0,8-50 \mathrm{PR}}$ & 10,49 & 15 & 157,35 & $398,10 / 253,33$ & $12,76 / 8,12$ & $12.760 / 8.120$ \\
\hline & $\mathrm{E}_{0,8-60 \mathrm{PR}}$ & 11,72 & 15 & 175,80 & $444,77 / 283,04$ & $14,26 / 9,07$ & $14.260 / 9.070$ \\
\hline & $\mathrm{E}_{0,8-70 \mathrm{PR}}$ & 13,67 & 15 & 205,05 & $518,78 / 330,13$ & $16,63 / 10,58$ & $16.630 / 10.580$ \\
\hline
\end{tabular}

El principal efecto que puede producir el $\mathrm{CO}_{2}$ es la asfixia por desplazamiento del oxígeno, pero esto se produce en concentraciones muy altas, de más de 30.000 ppm (Fundación para la Salud Geoambiental, 2018). En los resultados obtenidos considerando una combustión completa de la estancia tipo propuesta, se puede observar que la concentración de $\mathrm{CO}_{2}$ generado por los compuestos con PR no superaría esta cantidad por lo que no supondrían, a priori, un riesgo en la salud de las personas expuestas a un incendio en una vivienda que optara por incluir estos paneles en su construcción.

En cuanto al CO, considerando una combustión incompleta de la estancia tipo propuesta, simplemente se pone de manifiesto que la materia orgánica, tanto 
sintética como natural, dará lugar a concentraciones elevadas de monóxido de carbono en un incendio. Los valores de CO calculados son extremos, supuesto que no se forma nada de $\mathrm{CO}_{2}$. Habría que tener en cuenta otros factores de los que se hablan en los Manuales de Incendio que estudian los Bomberos en su aprendizaje: en los últimos años, la incorporación masiva de materiales sintéticos en la fabricación de mobiliario y enseres domésticos ha tenido una importante repercusión en el desarrollo de los incendios de interior, ya que presentan un poder calorífico muy superior al de los combustibles tradicionales con curvas de desarrollo más rápidas. A esto habría que añadir el mayor número de elementos de mobiliario presentes en los hogares actuales, una mayor superficie y un mayor grado de aislamiento térmico (Arnalich Castañeda \& Ayuso Blas, 2015). Por tanto, todos estos materiales sintéticos que están en el interior de la estancia pueden emitir CO durante un incendio, posiblemente antes que los paneles de los compuestos en estudio, cuyas emisiones se verían seguramente retardadas por la barrera física del yeso.

\subsection{Propiedades térmicas}

Es importante analizar también el comportamiento térmico de los compuestos puesto que, las normativas, respecto a la demanda energética, son cada vez más restrictivas. A continuación se describen los resultados de los dos métodos empleados para este estudio así como una simulación de dos sistemas constructivos utilizando los paneles y placas propuestos en las aplicaciones.

\subsection{Coeficiente de conductividad térmica según técnica modificada de fuente plana transitoria}

En la Tabla 6.34 se indican los valores de conductividad térmica y efusividad térmica obtenidos para los compuestos de la Serie XIX mediante el equipo C-Therm TCi.

Tabla 6.34. Conductividad y efusividad térmica de los compuestos - Según técnica modificada de fuente plana transitoria

\begin{tabular}{|c|c|c|c|c|c|c|}
\hline Referencia & Denom. & $\begin{array}{c}\text { Densidad } \\
\left(\mathrm{kg} / \mathrm{m}^{3}\right)\end{array}$ & $\begin{array}{c}\text { Conductividad } \\
\text { térmica }-\lambda \\
(\mathrm{W} / \mathrm{mK}) \\
\end{array}$ & $\begin{array}{c}\Delta \text { conductividad } \\
\text { térmica respecto a la } \\
\text { referencia }\end{array}$ & $\begin{array}{c}\text { Efusividad } \\
\text { térmica } \\
\left(\mathbf{W s}^{1 / 2} / \mathbf{m}^{2} \mathrm{~K}\right)\end{array}$ & $\begin{array}{l}\Delta \text { efusividad térmica } \\
\text { respecto a la } \\
\text { referencia }\end{array}$ \\
\hline \multirow{4}{*}{ Serie XIX } & $\mathrm{E}_{0,8}$ & 988,9 & 0,3265 & 0,00 & 683,98 & 0,00 \\
\hline & $\mathrm{E}_{0,8-50 \mathrm{PR}}$ & 1008,5 & 0,3278 & $+0,40 \%$ & 685,52 & $+0,23 \%$ \\
\hline & $\mathrm{E}_{0,8-60 \mathrm{PR}}$ & 1022,1 & 0,3312 & $+1,40 \%$ & 688,88 & $+0,72 \%$ \\
\hline & $\mathrm{E}_{0,8-70 \mathrm{PR}}$ & 1014,6 & 0,3177 & $-2,70 \%$ & 674,56 & $-1,38 \%$ \\
\hline
\end{tabular}


Tanto el coeficiente de conductividad térmica, $\lambda$, como el coeficiente de efusividad térmica, son similares en todos los compuestos con PR y en la referencia (Gráficas 6.34 y 6.35) aunque difiere el primero, en un 25\% aproximadamente, del valor genérico que se le adjudica al yeso de alta dureza $\left(900-1200 \mathrm{~kg} / \mathrm{m}^{3}\right)$ en el Código Técnico de la Edificación $(0,43 \mathrm{~W} / \mathrm{mK})$. La diferencia entre ellos, de aumento o disminución, no sigue una relación creciente o decreciente según se incorpora más granza sino que los datos resultantes son aleatorios. Indicar que estos ensayos se repitieron en varias ocasiones y el resultado fue semejante en todas ellas.

De esta manera se obtiene un coeficiente de conductividad térmica mayor en un $0,40 \%$ y un $1,44 \%$ para los compuestos de $50 \%$ PR y $60 \%$ PR respecto a la mezcla sin granza y, sin embargo, se obtiene un coeficiente de conductividad térmica 2,70\% menor en el compuesto 70\%PR. En el caso de la efusividad, estos valores alcanzan un 0,23\% y un 0,72\% más en las mismas mezclas de 50\%PR y $60 \%$ PR en relación a la referencia y, un 1,38\% menos en la mezcla de 70\%PR.

En general, los coeficientes de conductividad y efusividad térmica dependen de la densidad, pues cuanto mayor es la cantidad de poros más se reducen dichos coeficientes y, del contenido de humedad del compuesto, pues a mayor cantidad de agua mejora la conductividad (Villanueva Domínguez \& García Santos, 2001). En el caso de esta investigación, se ha comprobado en el apartado 6.4.2.1.1 una disminución del volumen de poros en los compuestos con PR pero que, asociado a la menor cantidad de agua en la mezcla, hace que esta propiedad no siempre se cumpla en dichos compuestos. El compuesto de mayor densidad, el $\mathrm{E}_{0,8-60 \mathrm{PR}}$, presenta el coeficiente de conductividad y efusividad térmica mayor; sin embargo, el compuesto de menor densidad, el $\mathrm{E}_{0,8-50 \mathrm{PR}}$, no presenta el coeficiente de conductividad y efusividad térmica menor. La mezcla que presenta menor coeficiente de conductividad y efusividad térmica es la $\mathrm{E}_{0,8-70 \mathrm{PR}}\left(0,3177 \mathrm{~W} / \mathrm{mK}-674,56 \mathrm{Ws}^{1 / 2} / \mathrm{m}^{2} \mathrm{~K}\right)$ y la de mayor coeficiente de conductividad y efusividad térmica la $\mathrm{E}_{0,8-60 \mathrm{PR}}(0,3312$ $\left.\mathrm{W} / \mathrm{mK}-688,88 \mathrm{Ws}^{1 / 2} / \mathrm{m}^{2} \mathrm{~K}\right)$.

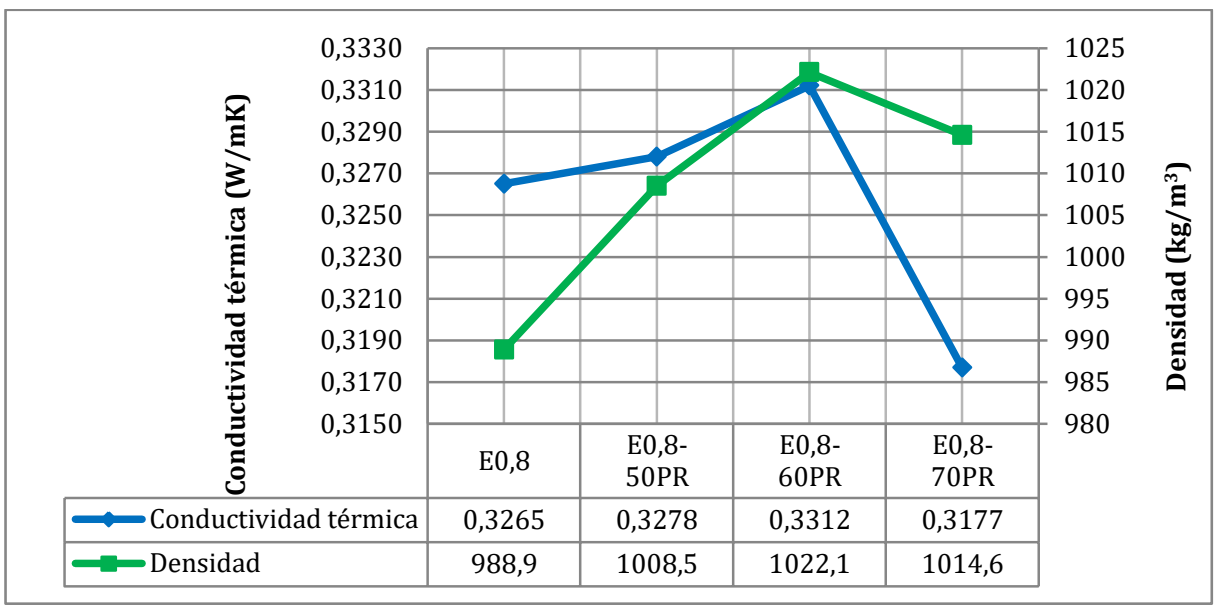

Gráfica 6.34. Conductividad (W/mK) térmica obtenida con técnica modificada de fuente plana transitoria 


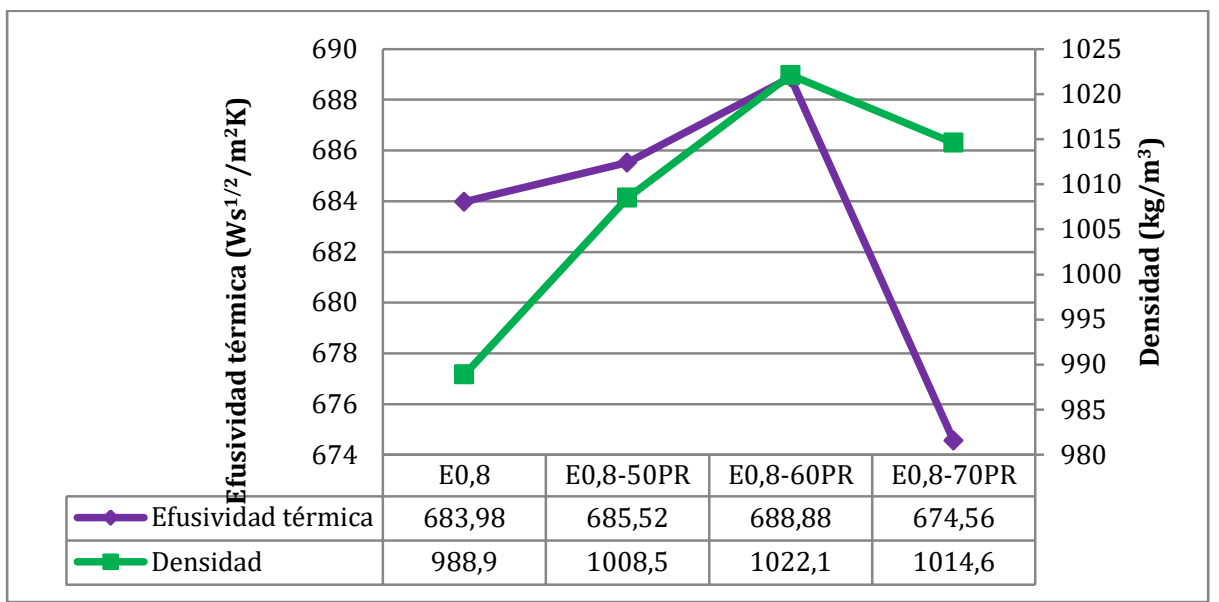

Gráfica 6.35. Efusividad (Ws $\left.{ }^{1 / 2} / m^{2} K\right)$ térmica obtenida con técnica modificada de fuente plana transitoria

\subsection{Coeficiente de conductividad térmica mediante el método del flujo de calor}

Los resultados obtenidos en el Instituto de Ciencias de la Construcción "Eduardo Torroja" tras el ensayo de "Determinación de la resistencia térmica por el método de la placa caliente y el método del medidor de flujo de calor. Productos de alta y media resistencia térmica", realizado en la Serie XX, se muestran en la Tabla 6.35. En esta ocasión se consigue además de la conductividad térmica, el flujo de calor y la resistencia térmica.

Tabla 6.35. Conductividad térmica, flujo de calor y resistencia térmica de los compuestos - UNE-EN 12667

\begin{tabular}{|c|c|c|c|c|c|c|c|c|}
\hline Referenc. & Denom. & $\begin{array}{c}\text { Densidad } \\
\left(\mathrm{kg} / \mathrm{m}^{3}\right)\end{array}$ & $\begin{array}{c}\text { Conductividad } \\
\text { térmica }-\lambda \\
(\mathrm{W} / \mathrm{mK})\end{array}$ & $\begin{array}{c}\Delta \text { conductividad } \\
\text { térmica respecto } \\
\text { a la referencia }\end{array}$ & $\begin{array}{c}\text { Flujo de } \\
\text { calor }\left(\mathrm{W} / \mathrm{m}^{2}\right)\end{array}$ & $\begin{array}{c}\Delta \text { flujo de calor } \\
\text { respecto a la } \\
\text { referencia }\end{array}$ & $\begin{array}{c}\text { Resistencia } \\
\text { térmica } \\
\left(\mathrm{m}^{2} \mathrm{~K} / \mathrm{W}\right) \\
\end{array}$ & $\begin{array}{l}\Delta \text { resistencia } \\
\text { térmica respecto } \\
\text { a la referencia }\end{array}$ \\
\hline \multirow{4}{*}{ Serie XX } & $\mathrm{E}_{0,8}$ & 969,97 & 0,2444 & 0,00 & 151,8 & 0,00 & 0,1326 & 0,00 \\
\hline & $\mathrm{E}_{0,8-50 \mathrm{PR}}$ & 980,30 & 0,2298 & $-5,97 \%$ & 143,8 & $-5,27 \%$ & 0,1395 & $+5,20 \%$ \\
\hline & $\mathrm{E}_{0,8-60 \mathrm{PR}}$ & 994,27 & 0,2264 & $-7,36 \%$ & 137,0 & $-9,75 \%$ & 0,1488 & $+12,22 \%$ \\
\hline & $\mathrm{E}_{0,8-70 \mathrm{PR}}$ & 998,67 & 0,2469 & $+1,02 \%$ & 149,0 & $-1,84 \%$ & 0,1346 & $+1,51 \%$ \\
\hline
\end{tabular}

En este caso, los valores obtenidos con este método para la conductividad térmica, se diferencian del valor genérico $(0,43 \mathrm{~W} / \mathrm{mK})$ adjudicado en Código Técnico de la Edificación para yesos de alta dureza $\left(900-1200 \mathrm{~kg} / \mathrm{m}^{3}\right)$, en aproximadamente un 40 $50 \%$.

En ninguna de las tres propiedades ensayadas (conductividad térmica, flujo de calor y resistencia térmica) se observa una relación lineal creciente o decreciente entre las mezclas con PR y la referencia (Gráficas 6.36-6.37-6.38), como ocurría en el ensayo según técnica modificada de fuente plana transitoria del apartado anterior. Si 
bien es cierto que en los compuestos con 50\%PR y 60\%PR disminuyen los valores de conductividad térmica (un 5,97\% y 7,36\% respectivamente) y flujo de calor (un $5,27 \%$ y 9,75\% respectivamente) y aumenta el valor de resistencia térmica (un 5,20\% y 12,22\% respectivamente), en el compuesto con 70\%PR ocurre todo lo contrario, aumenta un 1,02\% la conductividad térmica, disminuye ligeramente un 1,84\% el flujo y aumenta ligeramente también la resistencia térmica un 1,51\%. Este hecho puede ser debido a la menor cantidad de poros del compuesto, la distribución de la granza o a la diferencia de temperatura y humedad relativa de los días en que se realizó el ensayo, por lo que sería recomendable volver a realizar el ensayo.

De la relación entre la densidad y los coeficientes analizados, no se puede decir tampoco que se cumpla la propiedad comentada en el apartado anterior 6.4.2.1.1. El

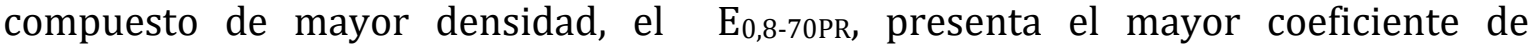
conductividad térmica $(0,2469 \mathrm{~W} / \mathrm{mK})$, el mayor flujo de calor $\left(149,0 \mathrm{~W} / \mathrm{m}^{2}\right)$ y la menor resistencia térmica $\left(0,1346 \mathrm{~m}^{2} \mathrm{~K} / \mathrm{W}\right)$; sin embargo, el compuesto de menor densidad, el $\mathrm{E}_{0,8-50 \mathrm{PR}}$, no presenta el menor coeficiente de conductividad, menor flujo de calor y mayor resistencia térmica, sino que es el compuesto de densidad intermedia, el $\mathrm{E}_{0,8-60 \mathrm{PR}}$, con valores de 0,2264 W/mK, 137,0 W/m² y 0,1488 $\mathrm{m}^{2} \mathrm{~K} / \mathrm{W}$ respectivamente.

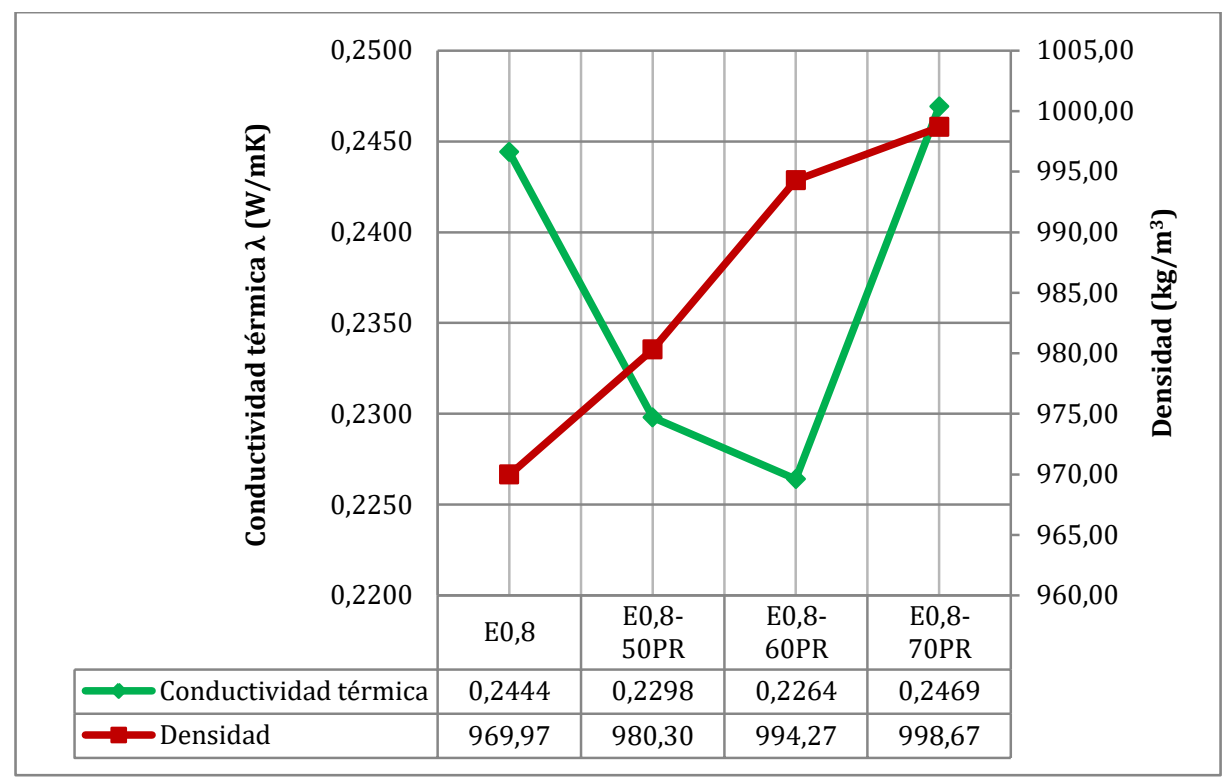

Gráfica 6.36. Conductividad (W/mK) térmica obtenida según UNE-EN 12667 


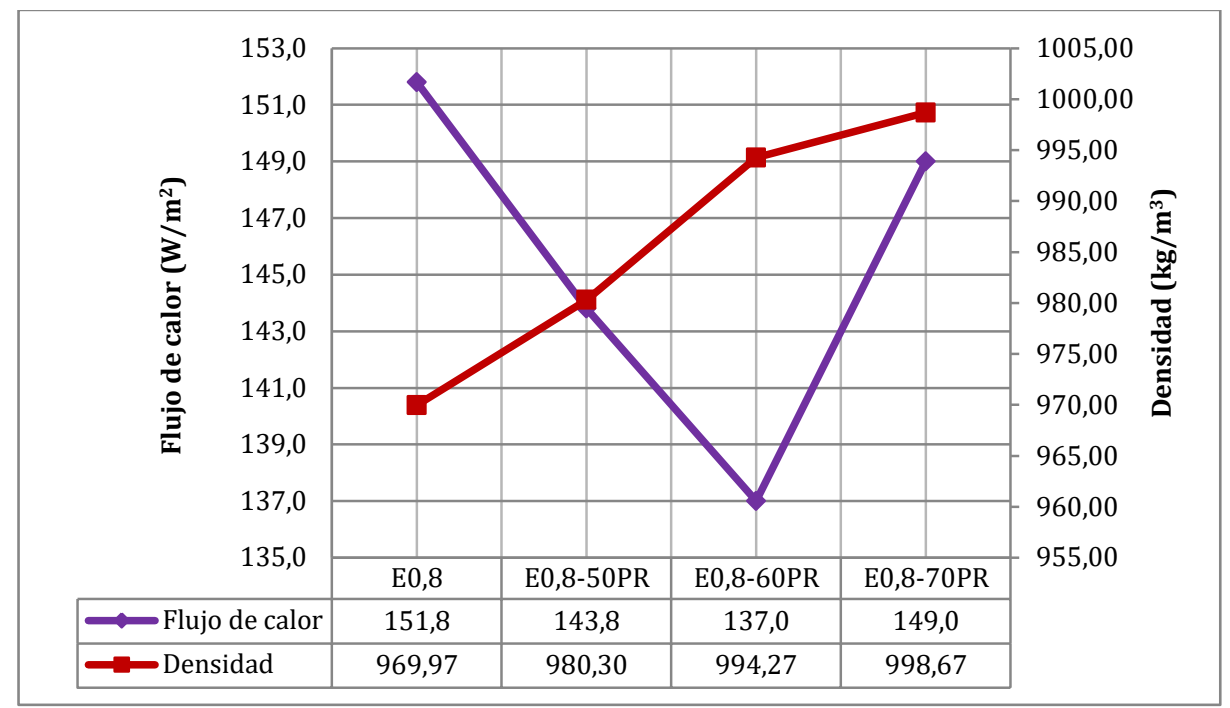

Gráfica 6.37. Flujo de calor $\left(\mathrm{W} / \mathrm{m}^{2}\right)$ obtenido según UNE-EN 12667

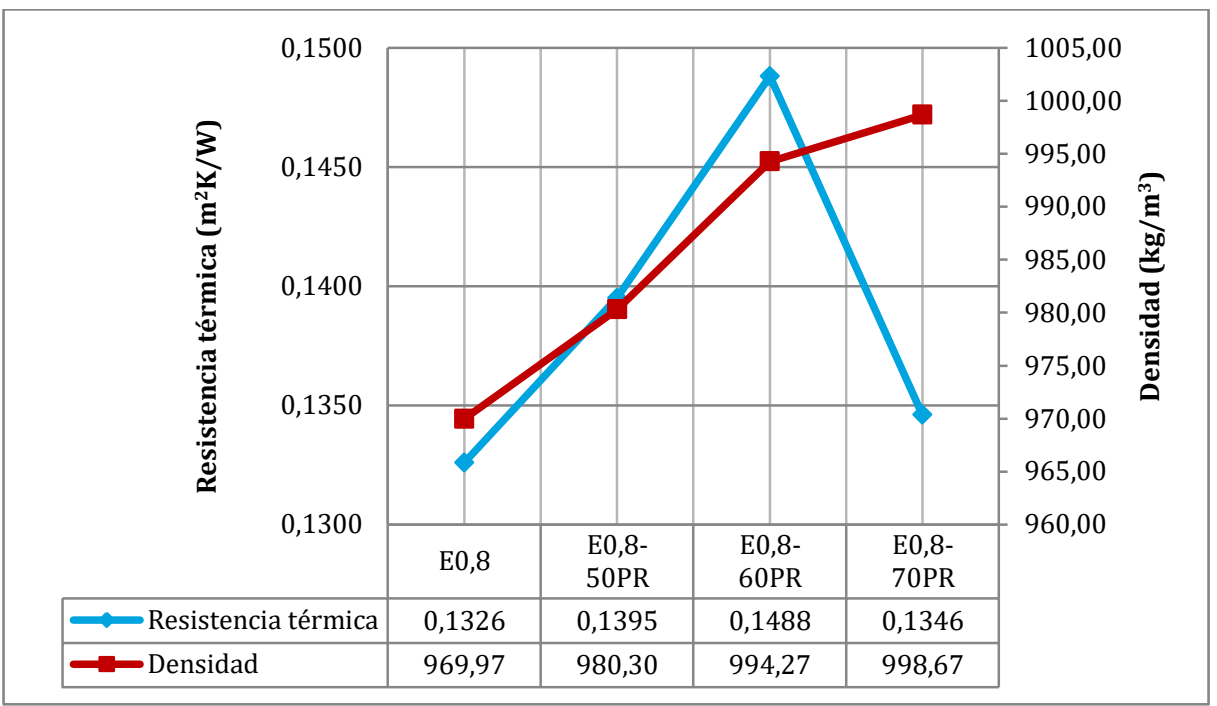

Gráfica 6.38. Resistencia térmica ( $\left.m^{2} K / W\right)$ obtenida según UNE-EN 12667

\subsection{Análisis energético de los aplicaciones propuestas}

En este apartado se analizan los resultados obtenidos mediante el software STAR_CCM+ en cuanto al comportamiento térmico de los modelos planteados en el apartado 5.4.2.3.3.3, en estado estacionario. El compuesto óptimo seleccionado para la realización de la simulación, en base a su coeficiente de transmisión térmica según el ensayo elaborado en el Instituto de Ciencias de la Construcción "Eduardo Torroja", es el $\mathrm{E}_{0,8-60 \mathrm{PR}}(\lambda=0,2264 \mathrm{~W} / \mathrm{mK})$. 


\subsection{1. Envolvente vertical: cerramiento de fachada}

Se parte de la representación $1 \mathrm{~m}^{2}$ de la geometría del cerramiento modelo de referencia 1 especificado en el apartado 5.4.2.3.3.3. A los materiales de los que está compuesto se les asignan los siguientes parámetros: constant density, segregated solid energy, steady, solid, gradients, three dimensional. En cambio, a la cámara de aire por tratarse de una gas, se le asignan estos otros parámetros: segregated fluid temperatura, constant density, laminar, segregated flow, gas, steady, gradients, three dimensional.

A continuación, se introducen los parámetros principales en el modelo, esto es, densidad, coeficiente de conductividad térmica y calor específico y, se realiza un mallado tetraédrico (Figura 6.2) con las siguientes condiciones:

- Temperatura superficial exterior de $-2^{\circ} \mathrm{C}$.

- $\quad$ Flujo de calor de 6,5 W/ $\mathrm{m}^{2}$.

- Resto de caras con comportamiento adiabático.

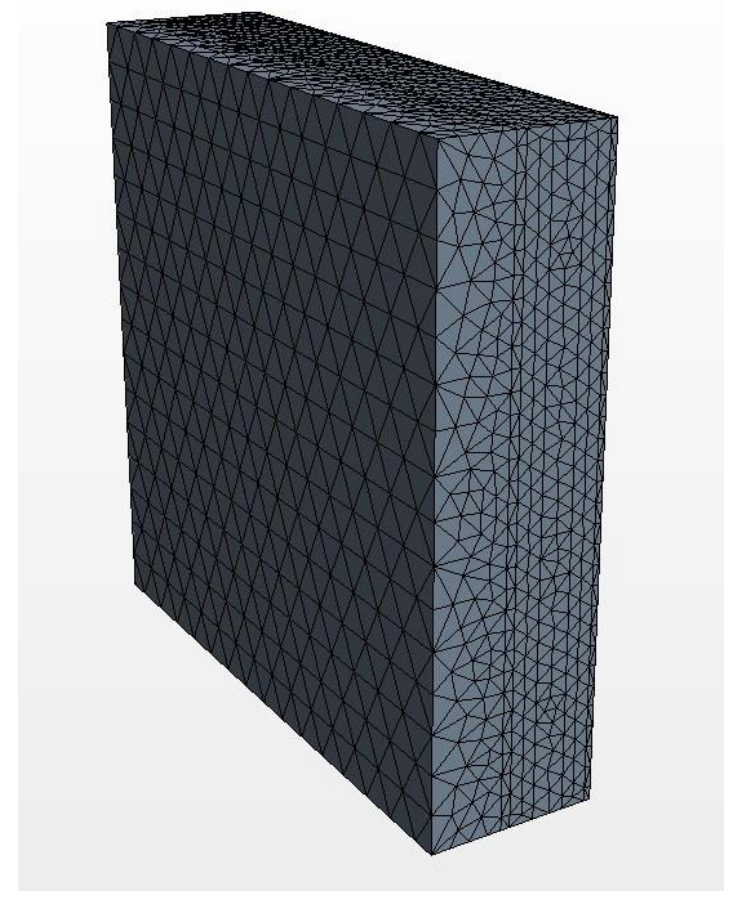

Figura 6.2. Mallado tetraédrico del modelo de referencia 1 - envolvente vertical

Se completa la simulación con el programa y se obtiene la diferencia de temperatura entre cada capa del modelo de referencia 1 si éste estuviera sometido a un flujo constante de calor de 6,5 W/ $\mathrm{m}^{2}$ (Figura 6.3). El resultado indica que, con una temperatura de aproximadamente $-2^{\circ} \mathrm{C}$ en el exterior se tiene una temperatura interior de $21,103^{\circ} \mathrm{C}$. 


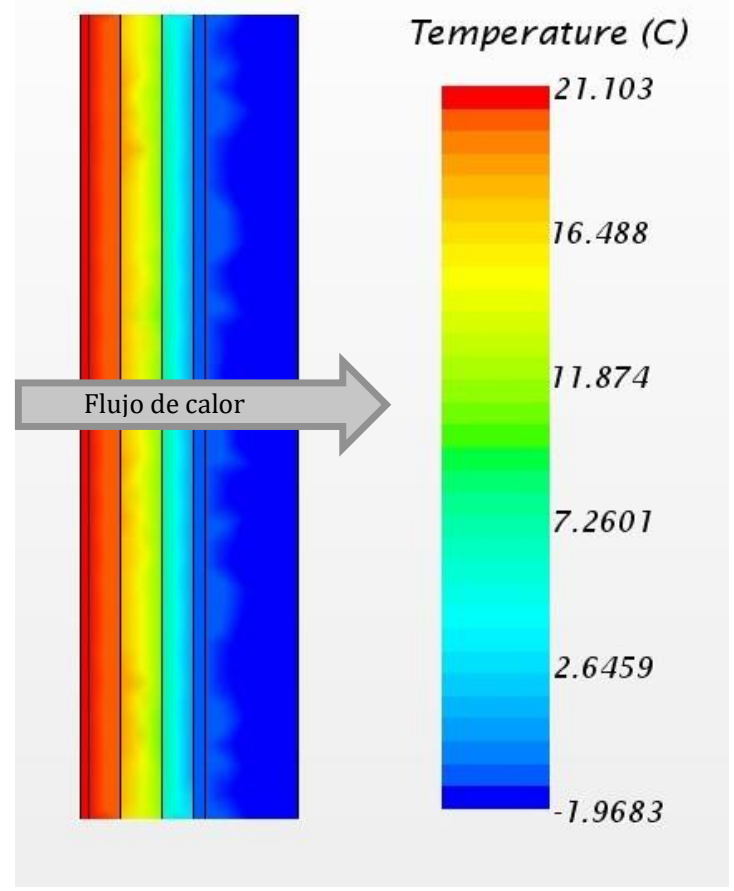

Figura 6.3. Representación de la temperatura obtenida en cada capa del modelo de referencia 1, con un flujo de calor constante de $6,5 \mathrm{~W} / \mathrm{m}^{2}$

En la segunda parte de la simulación, se modifica el escenario sustituyendo, en el modelo de referencia 1, la capa "revestimiento" de enlucido de yeso tradicional por una capa de paneles prefabricados con el compuesto óptimo $\mathrm{E}_{0,8-60 \mathrm{PR}}$. Los datos utilizados para este nuevo escenario se muestran en la Tabla 6.36.

Tabla 6.36. Datos modificados para nuevo escenario del modelo de referencia 1

\begin{tabular}{|c|c|c|c|c|}
\hline Denominación & $\begin{array}{l}\text { Espesor } \\
\text { (cm) }\end{array}$ & $\begin{array}{c}\text { Coeficiente de conductividad } \\
\text { térmica } \lambda(\mathrm{W} / \mathrm{mK})\end{array}$ & $\begin{array}{c}\text { Densidad } \\
\left(\mathrm{kg} / \mathrm{m}^{3}\right)\end{array}$ & $\begin{array}{c}\text { Calor específico } \\
(\mathrm{J} / \mathrm{kgK})\end{array}$ \\
\hline $\begin{array}{l}\text { Fábrica de ladrillo cara } \\
\text { vista }\end{array}$ & 11,5 & 0,85 & 2300 & 1000 \\
\hline $\begin{array}{l}\text { Enfoscado de mortero de } \\
\text { cemento }\end{array}$ & 1,0 & 1,00 & 1600 & 1000 \\
\hline Cámara de aire vertical & 4,0 & $\mathrm{R}=0,177 \mathrm{~m}^{2} \mathrm{~K} / \mathrm{W}$ & --- & --- \\
\hline Aislamiento térmico XPS & 5,0 & 0,034 & 35 & 1000 \\
\hline Ladrillo hueco doble & 7,0 & 0,32 & 770 & 1000 \\
\hline $\begin{array}{l}\text { Revestimiento - paneles } \\
\text { prefabricados compuesto } \\
\text { óptimo } \mathrm{E}_{0,8-6 \mathrm{-}-\mathrm{PR}}\end{array}$ & 1,5 & 0,226 & 994,27 & 1000 \\
\hline
\end{tabular}

Una vez realizados estos cambios en el modelo de referencia 1, se completa la simulación con el programa y se obtiene la diferencia de temperatura entre cada capa del nuevo escenario del modelo de referencia 1 si éste estuviera sometido a un flujo constante de calor de 6,5 W/ $\mathrm{m}^{2}$ (Figura 6.4). El resultado indica que, con una temperatura de aproximadamente $-2^{\circ} \mathrm{C}$ en el exterior se tiene una temperatura interior de $21,101^{\circ} \mathrm{C}$. 


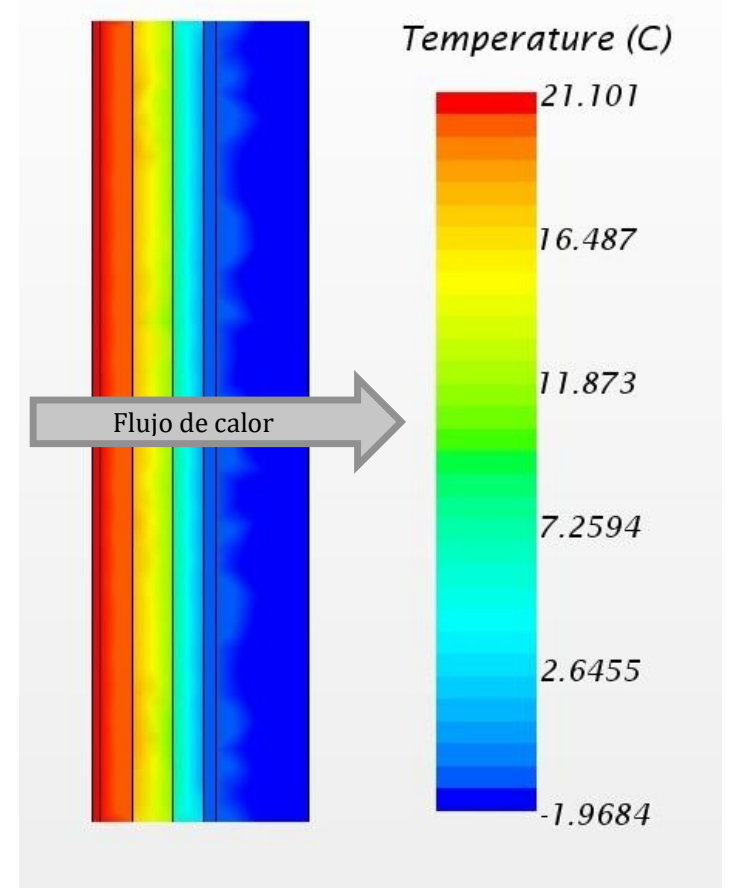

Figura 6.4. Representación de la temperatura obtenida en cada capa del nuevo escenario del modelo de referencia 1, con un flujo de calor constante de $6,5 \mathrm{~W} / \mathrm{m}^{2}$

Si se comparan ambas simulaciones, se comprueba que la diferencia entre los dos supuestos es inapreciable.

\subsection{2. Envolvente horizontal: cerramiento de cubierta plana}

De la misma manera que se ha procedido con el modelo de referencia 1, se procede con el modelo de referencia 2 especificado en el apartado 5.4.2.3.3.3. Se parte de la representación de $1 \mathrm{~m}^{2}$ de la geometría del cerramiento propuesto. A los materiales de los que está compuesto se les asignan los siguientes parámetros: constant density, segregated solid energy, steady, solid, gradients, three dimensional. En cambio, a la cámara de aire por tratarse de una gas, se le asignan estos otros parámetros: segregated fluid temperatura, constant density, laminar, segregated flow, gas, steady, gradients, three dimensional.

A continuación, se introducen los parámetros principales en el modelo, esto es, densidad, coeficiente de conductividad térmica y calor específico y, se realiza un mallado tetraédrico (Figura 6.5) con las siguientes condiciones:

- Temperatura superficial exterior de $-2^{\circ} \mathrm{C}$.

- Flujo de calor de 6,5 W/ $\mathrm{m}^{2}$.

- Resto de caras con comportamiento adiabático. 


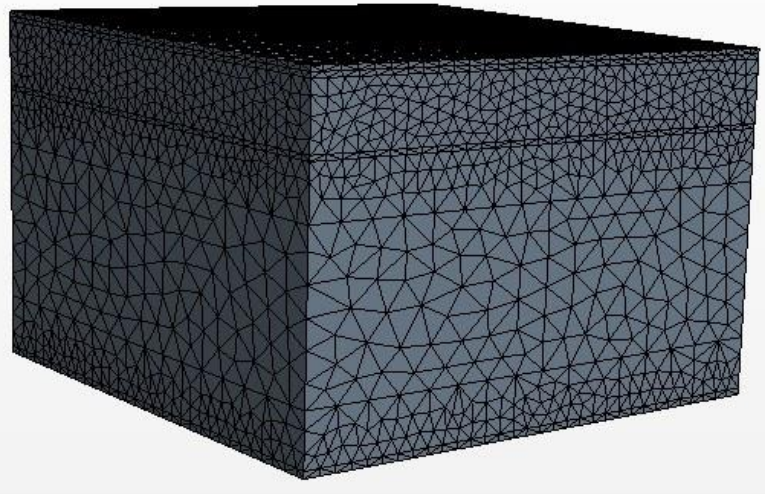

Figura 6.5. Mallado tetraédrico del modelo de referencia 2 - envolvente horizontal

Se completa la simulación con el programa y se obtiene la diferencia de temperatura entre cada capa del modelo de referencia 2 si éste estuviera sometido a un flujo constante de calor de $6,5 \mathrm{~W} / \mathrm{m}^{2}$ (Figura 6.6). El resultado indica que, con una temperatura de aproximadamente $-2^{\circ} \mathrm{C}$ en el exterior se tiene una temperatura interior de $21,653^{\circ} \mathrm{C}$.

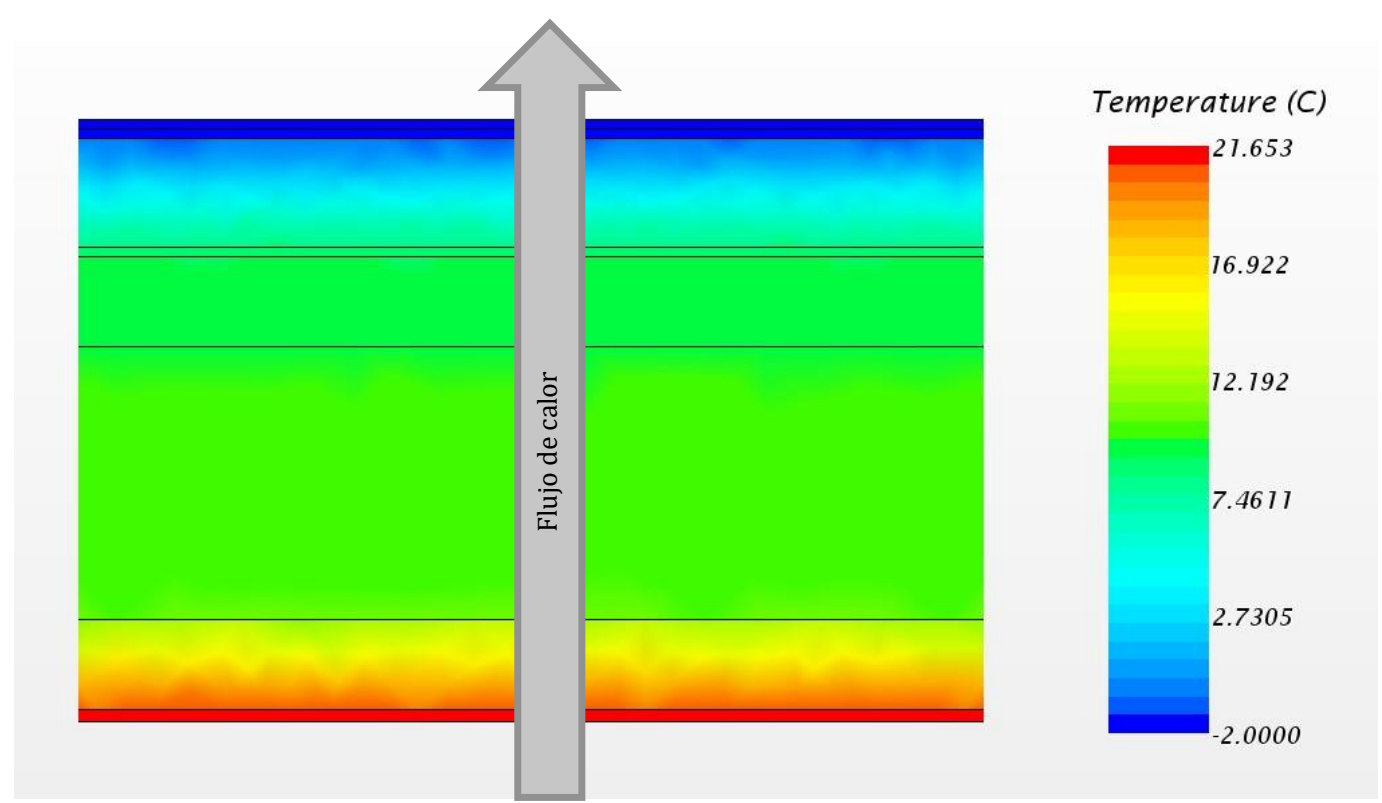

Figura 6.6. Representación de la temperatura obtenida en cada capa del modelo de referencia 2, con un flujo de calor constante de $6,5 \mathrm{~W} / \mathrm{m}^{2}$

En la segunda parte de la simulación del modelo de referencia 2, se modifica el escenario sustituyendo en el modelo la capa "revestimiento" de placa de yeso por una placa del compuesto óptimo $\mathrm{E}_{0,8-60 \mathrm{PR}}$. Los datos utilizados para este nuevo escenario se muestran en la Tabla 6.37. 
Tabla 6.37. Datos modificados para nuevo escenario del modelo de referencia 2

\begin{tabular}{|c|c|c|c|c|}
\hline Denominación & $\begin{array}{l}\text { Espesor } \\
\text { (cm) }\end{array}$ & $\begin{array}{c}\text { Coeficiente de conductividad } \\
\text { térmica } \lambda(\mathrm{W} / \mathrm{mK})\end{array}$ & $\begin{array}{c}\text { Densidad } \\
\left(\mathrm{kg} / \mathrm{m}^{3}\right)\end{array}$ & $\begin{array}{c}\text { Calor específico } \\
\text { (J/kgK) }\end{array}$ \\
\hline $\begin{array}{l}\text { Lámina impermeable } \\
\text { autoprotegida }\end{array}$ & 0,5 & 0,23 & 1100 & 1000 \\
\hline Geotextil & 0,5 & 0,05 & 120 & 1300 \\
\hline Aislamiento térmico XPS & 5,0 & 0,034 & 35 & 1000 \\
\hline Barrera de vapor & 0,5 & 0,23 & 1100 & 1000 \\
\hline $\begin{array}{l}\text { Formación de pendiente } \\
\text { con hormigón ligero }\end{array}$ & 5,0 & 0,41 & 900 & 1000 \\
\hline Forjado tipo $(25+5 \mathrm{~cm})$ & 30,0 & $\mathrm{R}=0,32 \mathrm{~m}^{2} \mathrm{~K} / \mathrm{W}$ & 1110 & 1000 \\
\hline $\begin{array}{l}\text { Cámara de aire } \\
\text { horizontal }\end{array}$ & 10,0 & $\mathrm{R}=0,16 \mathrm{~m}^{2} \mathrm{~K} / \mathrm{W}$ & --- & --- \\
\hline $\begin{array}{l}\text { Revestimiento - placa de } \\
\text { compuesto óptimo }\end{array}$ & 1,2 & 0,226 & 994,27 & 1000 \\
\hline
\end{tabular}

Una vez realizados estos cambios en el modelo de referencia 2, se completa la simulación con el programa y se obtiene la diferencia de temperatura entre cada capa del nuevo escenario del modelo de referencia 2 si éste estuviera sometido a un flujo constante de calor de 6,5 W/m² (Figura 6.7). El resultado indica que, con una temperatura de aproximadamente $-2^{\circ} \mathrm{C}$ en el exterior se tiene una temperatura interior de $21,653^{\circ} \mathrm{C}$ igual que en el modelo inicial de referencia 2 .

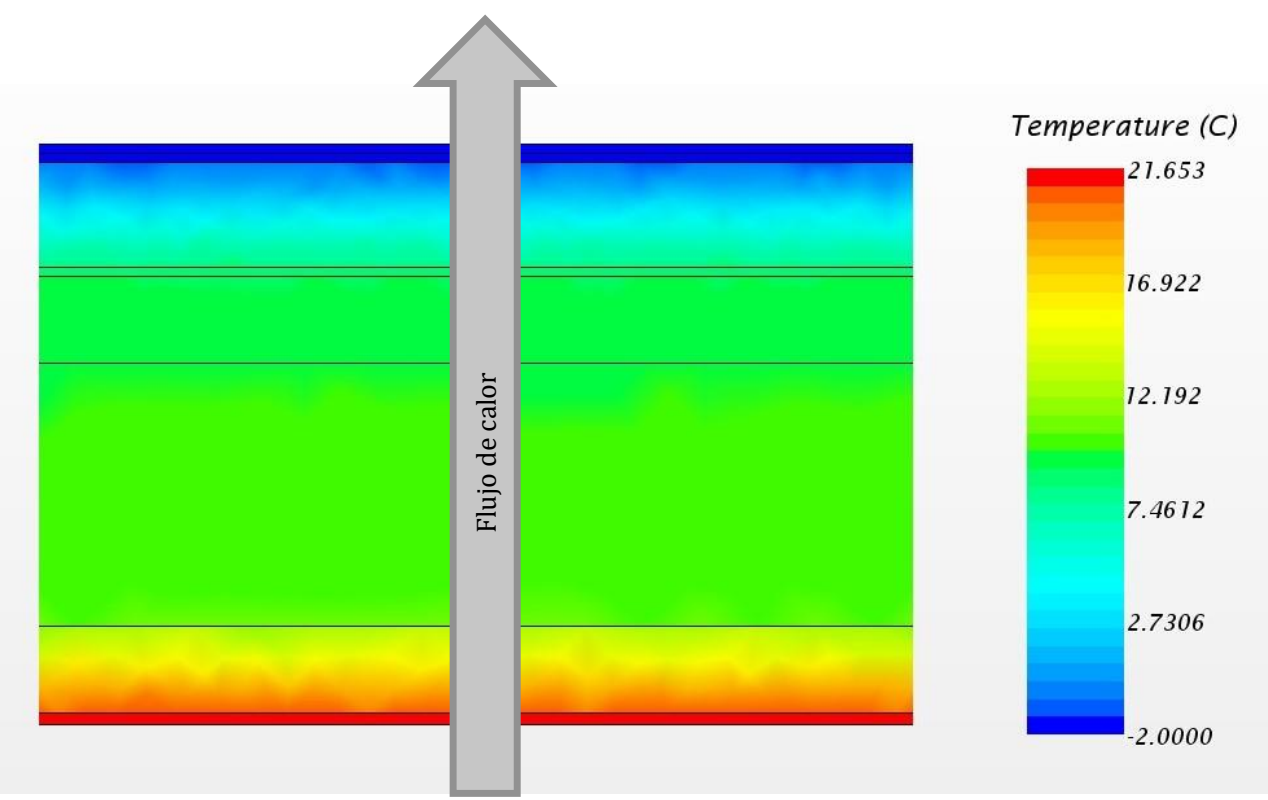

Figura 6.7. Representación de la temperatura obtenida en cada capa del nuevo escenario del modelo de referencia 2, con un flujo de calor constante de $6,5 \mathrm{~W} / \mathrm{m}^{2}$ 
Al igual que ocurre con el modelo de referencia 1, si se comparan ambas simulaciones en el modelo de referencia 2, se comprueba que la diferencia entre los dos supuestos es inapreciable.

En definitiva, el resultado alcanzado es el esperado teniendo en cuenta que el coeficiente de conductividad térmica del material estudiado es muy superior respecto al propio aislamiento de la solución constructiva o a la cámara de aire (Piña Ramírez, 2019; San Antonio González, 2017). Sin embargo, cabe destacar que según los datos obtenidos en el apartado 6.4.2.3.3.2 el panel del compuesto óptimo, por sí solo, supone una mejora térmica respecto al panel sin PR (7\% aprox.), una disminución del flujo de calor (10\% aprox.) y un aumento de la resistencia térmica (12\% aprox.), lo que lo hace más eficiente energéticamente hablando, que el material tradicional, corroborando los estudios de otros investigadores que utilizan residuos de caucho (Abu-Lebdeh, Fini, \& Fadiel, 2014; Lozano-Díez, López-Zaldívar, Herrero del Cura, Mayor-Lobo, \& Hernández-Olivares, 2019).

Es interesante por tanto, analizar el compuesto en paneles o placas de mayor espesor o en paneles sándwich. Finalmente, para obtener una idea más real de la efectividad del panel propuesto, es conveniente realizar un análisis dinámico donde se evalúe la demanda energética, estudiando las distintas condiciones que se producen a lo largo de un año.

\subsection{Propiedades superficiales de los paneles y placas elaborados con los compuestos seleccionados}

Los paneles y placas propuestas se han planteado colocados en trasdosados, división de interiores y falsos techos, por lo que resulta importante conocer el acabado superficial para ver si es necesario o no aplicar un tratamiento de terminación a los compuestos.

\subsection{Confort térmico}

Una de las propiedades a considerar es el confort térmico o sensación percibida cuando se toca la superficie de un material. Utilizando los coeficientes de conductividad térmica y las densidades obtenidas mediante el ensayo realizado a través del método del flujo de calor (Serie XX), se han calculado los coeficientes de penetración térmica de cada uno de los compuestos (Tabla 6.38) de manera que, cuanto menor es éste, más confortable se considera el tacto de su superficie, menos frío y, por tanto, menos condensaciones aparecen en él (Villanueva Domínguez \& García Santos, 2001). 
Tabla 6.38. Confort térmico mediante coeficiente de penetración térmica - MANUAL DEL YESO

\begin{tabular}{|c|c|c|c|c|c|c|}
\hline Referencia & Denom. & $\begin{array}{c}\text { Densidad } \\
\left(\mathrm{kg} / \mathrm{m}^{3}\right)\end{array}$ & $\begin{array}{l}\text { Conductividad } \\
\text { térmica }-\lambda \\
(W / \mathrm{mK})\end{array}$ & $\begin{array}{c}\text { Calor } \\
\text { específico } \\
\text { (J/kgK) }\end{array}$ & $\begin{array}{c}\text { Coeficiente de } \\
\text { penetración } \\
\text { térmica }\left(J / \mathbf{s}^{1 / 2} \mathbf{m}^{2} \mathbf{K}\right)\end{array}$ & $\begin{array}{c}\Delta \text { coeficiente de } \\
\text { penetración térmica } \\
\text { respecto a la } \\
\text { referencia }\end{array}$ \\
\hline \multirow{4}{*}{ Serie XX } & $\mathrm{E}_{0,8}$ & 969,97 & 0,2444 & 1000 & 486,89 & 0,00 \\
\hline & $\mathrm{E}_{0,8-50 \mathrm{PR}}$ & 980,30 & 0,2298 & 1000 & 474,63 & $-2,52 \%$ \\
\hline & $\mathrm{E}_{0,8-60 \mathrm{PR}}$ & 994,27 & 0,2264 & 1000 & 474,45 & $-2,55 \%$ \\
\hline & $\mathrm{E}_{0,8-70 \mathrm{PR}}$ & 998,67 & 0,2469 & 1000 & 496,56 & $+1,99 \%$ \\
\hline
\end{tabular}

El confort superficial de todos los compuestos es muy similar al de la referencia. Las mezclas con 50\%PR y 60\%PR presentan una ligera mejora del 2,50\% aproximadamente, en cambio, la mezcla con 70\%PR empeora sensiblemente un 2\% (Gráfica 6.39). El compuesto de menor coeficiente de penetración térmica y, por tanto, mejor confort superficial fue el $\mathrm{E}_{0,8-60 \mathrm{PR}}\left(474,45 \mathrm{~J} / \mathrm{s}^{1 / 2} \mathrm{~m}^{2} \mathrm{~K}\right)$; el de mayor coeficiente de penetración térmica $\mathrm{y}$, por tanto, peor confort superficial el $\mathrm{E}_{0,8-70 \mathrm{PR}}$ $\left(496,56 \mathrm{~J} / \mathrm{s}^{1 / 2} \mathrm{~m}^{2} \mathrm{~K}\right)$.

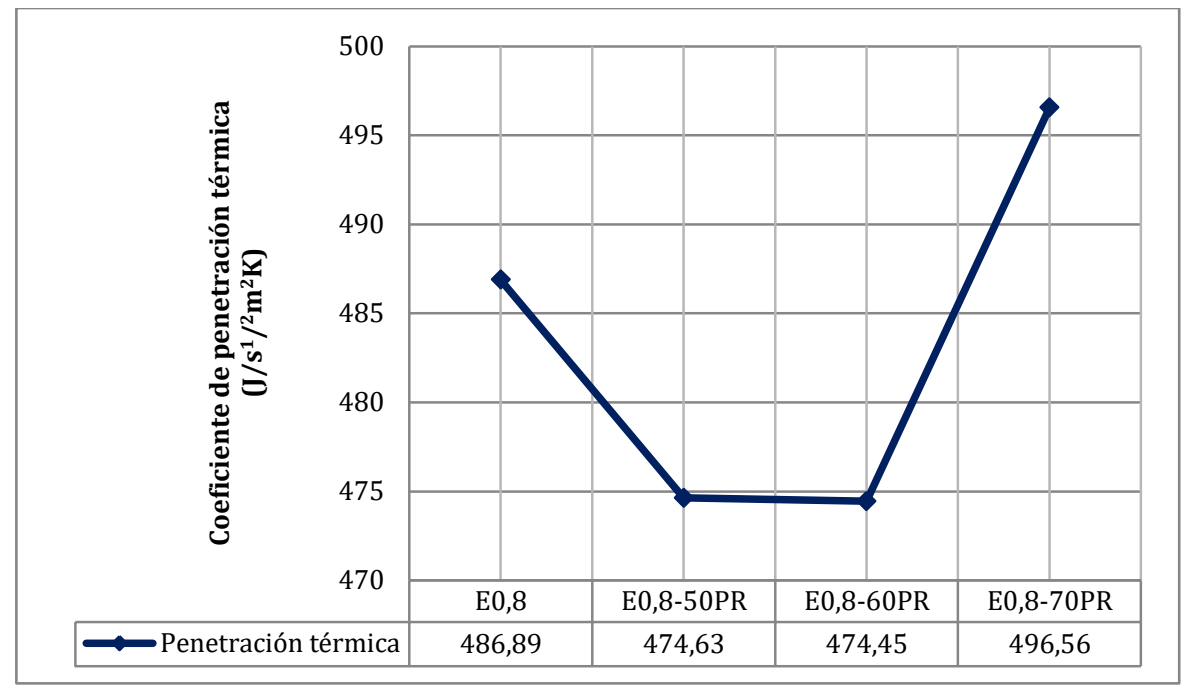

Gráfica 6.39. Coeficiente de penetración térmica $\left(m^{2} K / W\right)$ obtenida según UNE-EN 12667

\subsection{Análisis visual de la superficie}

Generalmente, las aplicaciones propuestas son tratadas con un acabado superficial que puede verse afectado por pequeños movimientos de asentamiento o dilataciones por cambios de temperatura en la edificación. El efecto visual de los acabados superficiales de los compuestos con PR (Serie XXI), son semejantes a los de los compuestos sin PR (Fotos 6.14-6.15-6.16-6.17), destacando una mejora del comportamiento de los compuestos con PR respecto a la aparición de fisuras, debido a su gran elasticidad (apartado 6.3.2.1). También supone una ventaja el hecho de que 
los compuestos con PR sin ningún revestimiento presenten un aspecto rugoso, pues facilita la adherencia de los materiales de revestimientos como pinturas o alicatados.

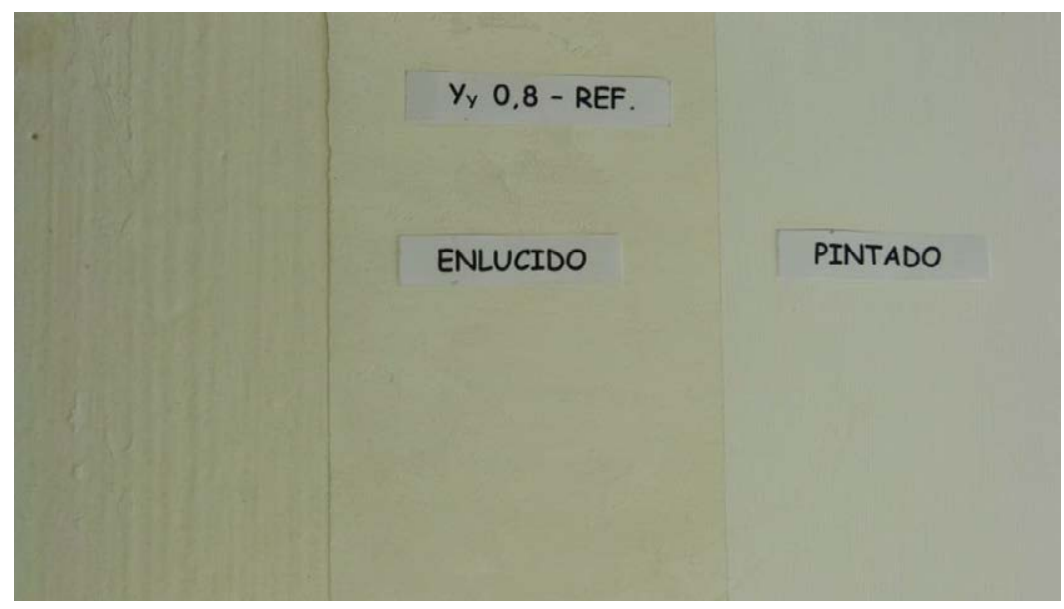

Foto 6.14. Acabados en compuesto de referencia. Izquierda: sin acabado; Centro: enlucido; Derecha: enlucido y pintado

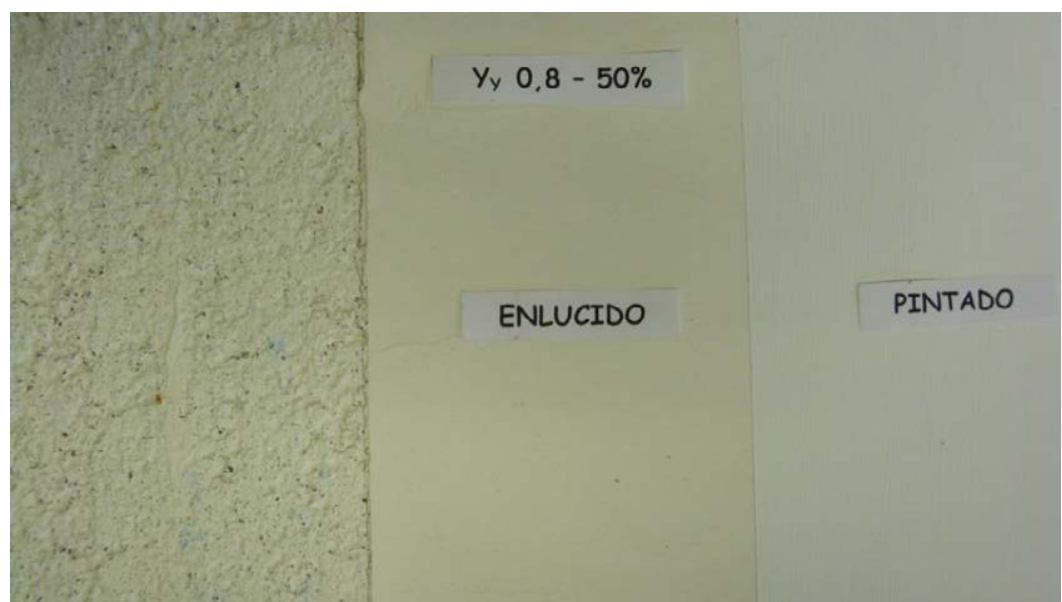

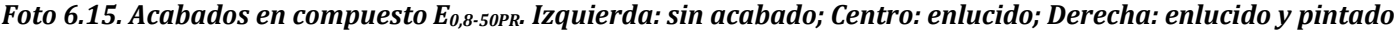

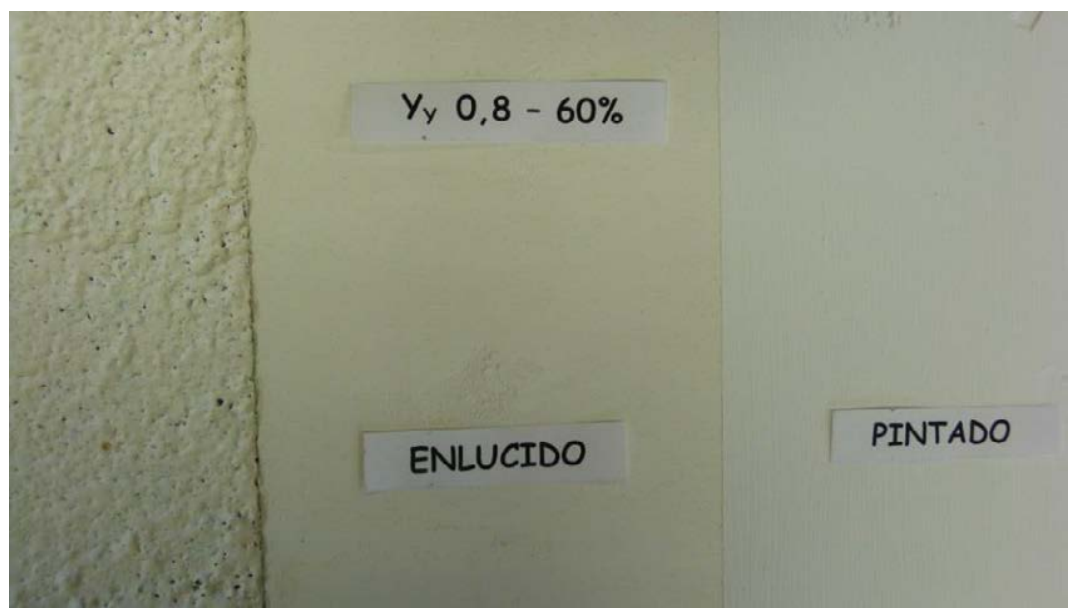

Foto 6.16. Acabados en compuesto E, ${ }_{0,8-60 P .}$ Izquierda: $\sin$ acabado; Centro: enlucido; Derecha: enlucido y pintado 


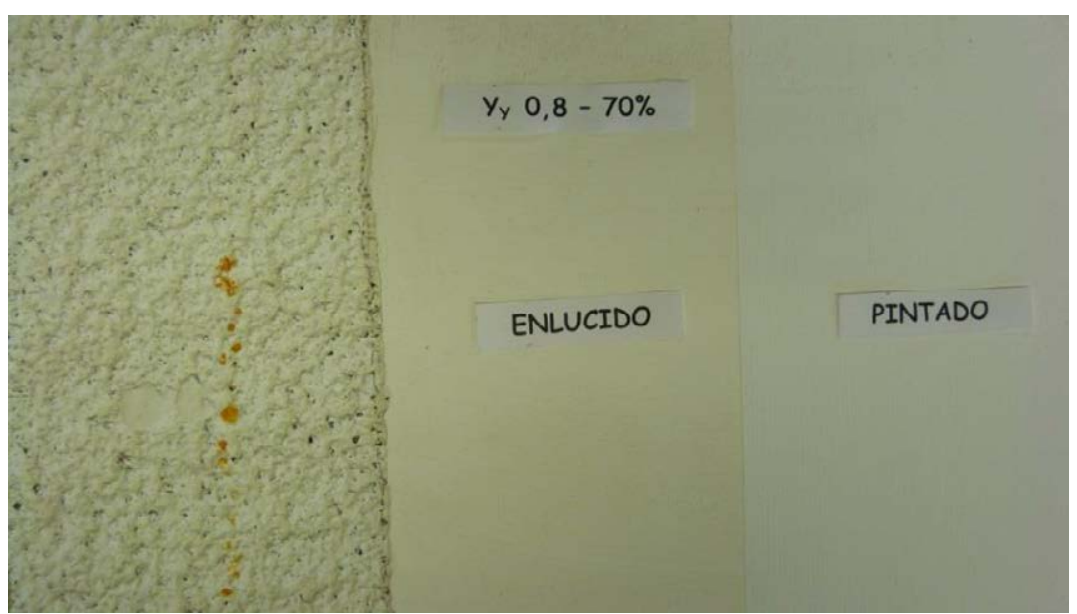

Foto 6.17. Acabados en compuesto E,8-70pR. Izquierda: $\sin$ acabado; Centro: enlucido; Derecha: enlucido y pintado 


\subsection{ANÁLISIS DEL IMPACTO AMBIENTAL - OBJETIVO 5}

En este apartado se presenta el análisis del impacto ambiental en cuanto al uso de recursos naturales y minimización del PR de los compuestos propuestos.

\subsubsection{Análisis del uso de recursos naturales}

El yeso presenta un impacto ambiental negativo en todo su proceso de manufactura, desde el deterioro del suelo durante la extracción en cantera, hasta el uso de recursos naturales no renovables (piedra de aljez), pasando por el transporte y la cocción de las materias primas con los lixiviados generados en los hornos. Por ello, es importante trabajar en la mejora de su sostenibilidad incorporando agregados que reduzcan el consumo de materia prima virgen.

Por otro lado, no cabe la menor duda de la importancia del agua para el desarrollo de la vida y de la necesidad de asegurar su abastecimiento a futuras generaciones, por lo que también se hace imprescindible buscar nuevas formas de ahorro de este recurso natural.

Como se indica en la metodología, se utiliza el estudio realizado por Santa Cruz para el cálculo de la materia prima utilizada para cada compuesto propuesto. En la Tabla 6.39 se muestran los datos y resultados obtenidos, tomando como referencia la fabricación de 1 probeta prismática de $4 \times 4 \times 16 \mathrm{~cm}^{3}$.

Tabla 6.39. Materia prima, densidad, peso al desmolde, peso a los 7 días de 1 probeta prismática de 4 x 4 × $16 \mathrm{~cm}^{3}$

\begin{tabular}{lcccccc}
\hline Denomin. & Escayola (g) & Agua (g) & $\begin{array}{c}\Delta \text { materia prima } \\
\text { respecto a la } \\
\text { referencia }\end{array}$ & $\begin{array}{c}\text { Densidad } \\
\mathbf{( g / \mathbf { c m } ^ { 3 } \text { ) }}\end{array}$ & $\begin{array}{c}\text { Peso húmedo } \\
\mathbf{( g )}\end{array}$ & $\begin{array}{c}\text { Peso seco } \\
\text { (g) }\end{array}$ \\
\hline $\mathrm{E}_{0,8}$ & 237,87 & 190,30 & 0,00 & 988,9 & 389,7 & 253,4 \\
$\mathrm{E}_{0,8-50 \mathrm{PR}}$ & 179,07 & 143,26 & $-24,72 \%$ & 1008,5 & 354,2 & 258,4 \\
$\mathrm{E}_{0,8-60 \mathrm{PR}}$ & 166,67 & 133,33 & $-29,93 \%$ & 1022,1 & 352,6 & 261,7 \\
$\mathrm{E}_{0,8-70 \mathrm{PR}}$ & 166,67 & 133,33 & $-29,93 \%$ & 1014,6 & 346,2 & 260,1 \\
\hline
\end{tabular}

En la Gráfica 6.40 se observa que, a medida que se incorpora PR en las mezclas, se utiliza menos cantidad de yeso y agua, llegándose a reducir su uso aproximadamente un $25 \%$ en las mezclas con un $50 \%$ de PR y aproximadamente un $30 \%$ en las mezclas con $60 \%$ y $70 \%$ de PR. 


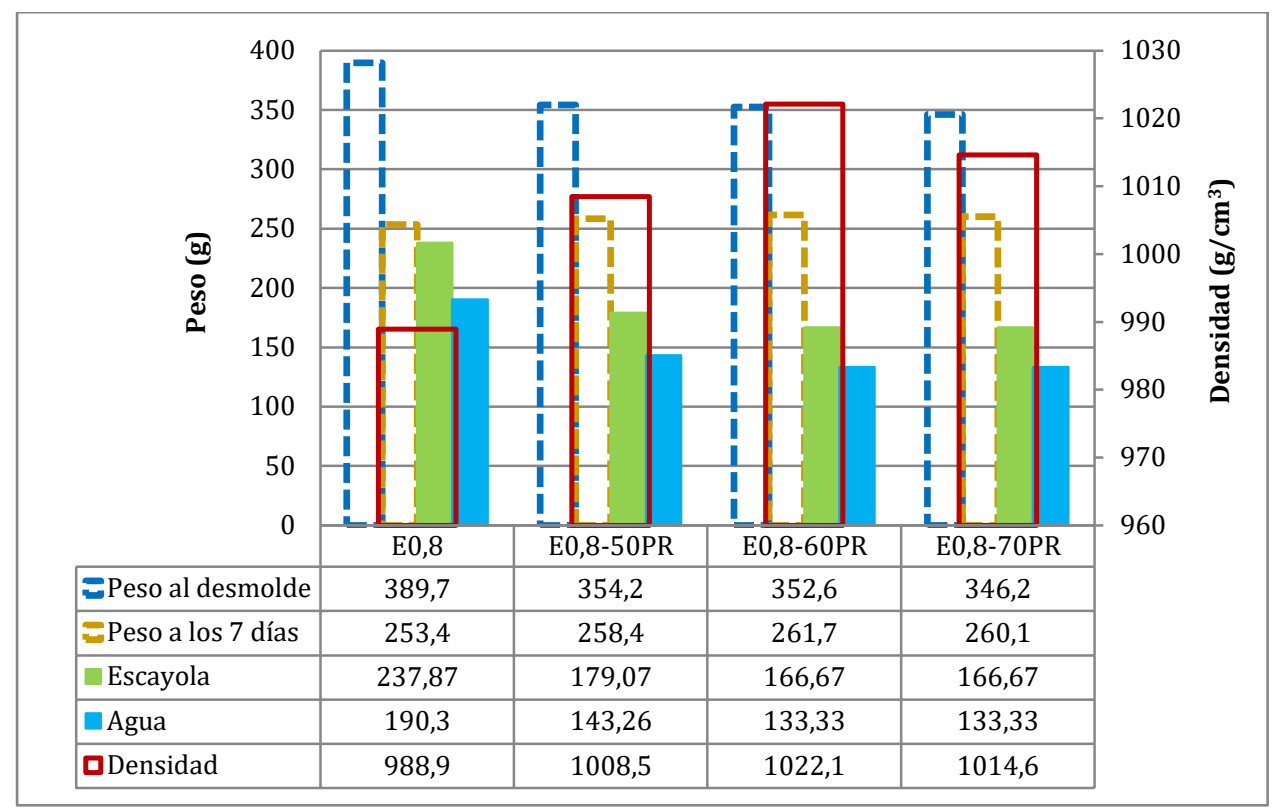

Gráfica 6.40. Comparativa de materia prima (g), densidad $\left(\mathrm{g} / \mathrm{cm}^{3}\right)$, peso al desmolde (g), peso a los 7 días (g) de 1 probeta prismática de $4 \times 4 \times 16 \mathrm{~cm}^{3}$

\subsubsection{Análisis de la minimización del PR}

En esta investigación se incide en la adecuada gestión del PR para llegar a convertirlo en un recurso, a pesar de su heterogeneidad y sin pasar por ningún tratamiento intermedio. Según lo indicado en el apartado 5.5.2 de la metodología y considerando que cada empresa de reciclaje de cables genera unas $50 \mathrm{Tn} / \mathrm{mes}$ de residuo, se obtiene la cantidad de paneles tipo (2000 x $1200 \times 12,5 \mathrm{~mm}^{3}$ ) de cada compuesto que, al mes, se podría fabricar por cada una de estas empresas (Tabla $6.40)$.

Tabla 6.40. Producción media mensual de paneles tipo (2000 x 1200 x 12,5 mm3) con PR, por cada empresa de reciclaje de cables

\begin{tabular}{|c|c|c|c|c|c|}
\hline Denomin. & $\begin{array}{l}\text { Reciclaje } \\
\text { (kg/mes) }\end{array}$ & $\begin{array}{c}\text { Granza } \\
\left(\mathrm{kg} / \mathrm{m}^{3}\right)\end{array}$ & $\begin{array}{l}\text { Cantidad de compuesto } \\
\text { para fabricar }\left(\mathrm{m}^{3} / \mathrm{mes}\right)\end{array}$ & $\begin{array}{l}\text { Panel tipo } \\
\left(\mathrm{m}^{3} / \mathbf{u d}\right)\end{array}$ & $\begin{array}{c}\text { Total paneles tipo para } \\
\text { fabricar (ud/mes) }\end{array}$ \\
\hline $\mathrm{E}_{0,8}$ & 0,00 & 0,00 & 0,00 & 0,00 & 0,00 \\
\hline $\mathrm{E}_{0,8-50 \mathrm{PR}}$ & 50000 & 349,50 & 143,06 & 0,03 & 4768,67 \\
\hline $\mathrm{E}_{0,8-60 \mathrm{PR}}$ & 50000 & 390,60 & 128,01 & 0,03 & 4267,00 \\
\hline $\mathrm{E}_{0,8-70 \mathrm{PR}}$ & 50000 & 455,75 & 109,71 & 0,03 & 3657,00 \\
\hline
\end{tabular}


Según estos datos y considerando la producción media de una empresa de prefabricados de yeso de tamaño medio en 25.000 uds/mes, se observa la viabilidad de fabricación de paneles con los compuestos en estudio, puesto que se genera suficiente PR en las empresas de reciclaje de cables para abastecer a las empresas de prefabricados de yeso. Por tanto, y a la vista de los resultados obtenidos, se podría llegar a minimizar el $100 \%$ de este tipo de residuos. 


\subsection{CONSIDERACIONES PARCIALES DEL CAPÍTULO}

En vista a los resultados obtenidos, en este capítulo se ha podido confirmar que:

Es posible utilizar el residuo plástico de cables tal y como se produce en las empresas de reciclaje de cables.

Los residuos plásticos de cables se mezclan de forma homogénea con el yeso y la escayola hasta adiciones del 70\%; a partir de esta cantidad la mezcla se hace intrabajable pues se acelera el inicio y finalización del fraguado.

La densidad real del residuo plástico de cables es considerablemente menor que la del yeso. La densidad de los compuestos con residuo plástico de cables en estado endurecido es ligeramente mayor respecto a la referencia; sin embargo, la densidad real de los compuestos (excluyendo poros) es ligeramente menor.

Los compuestos de escayola, en general, se comportan mejor que los compuestos de yeso en resistencias mecánicas, densidad, dureza superficial y módulo de Young. Y dentro de los de escayola, los del 60\%PR tienen un comportamiento más constante.

Las aplicaciones óptimas para los compuestos en estudio, sin añadirles ningún tipo de aditivo, sería la fabricación de paneles para trasdosados y divisiones interiores y placas para falsos techos.

La adhesión entre yeso y granza es buena pero presenta discontinuidades en la interfase que minorizan algunas de las propiedades mecánicas, aunque se ajustan a normativa.

Los compuestos con residuos plásticos de cables presentan una significativa mejora frente a la acción del agua, un aceptable comportamiento frente a la acción del fuego debido al recubrimiento de escayola, una mejoría de las propiedades térmicas y un óptimo acabado superficial. 


\subsection{TRABAJOS CITADOS}

Abu-Lebdeh, T., Fini, E., \& Fadiel, A. (2014). Thermal conductivity of rubberized gypsum board. American Journal of Engineering and Applied Sciences, 7(1), 1222. https://doi.org/10.3844/ajeassp.2014.12.22

Ahmed, A., Ugai, K., \& Kamei, T. (2011). Investigation of recycled gypsum in conjunction with waste plastic trays for ground improvement. Construction and Building Materials, 25, 208-217.

https://doi.org/10.1016/j.conbuildmat.2010.06.036

Alameda, L., Calderón, V., Gadea, J., \& Gutiérrez-González, S. (2015). Reciclado de placas de yeso laminado aligeradas con residuos de poliuretano. Anales de Edificación, 1(1), 33-39. https://doi.org/10.20868/ade.2015.3037

Alameda, L., Calderón, V., Junco, C., Rodríguez, Á., Gadea, J., \& Gutiérrez-González, S. (2016). Characterization of gypsum plasterboard with polyurethane foam waste reinforced with polypropylene fibers. Materiales de Construcción, 66(324), e100. https://doi.org/10.3989/mc.2016.06015

Alcón Calla, S., Salcedo Quispe, F., Gallardo Tapia, V., \& Echazú Cortez, J. (2011). Mortero de yeso reforzado con fibra reciclada de botellas PET para su aplicación como junta en mampostería de ladrillo. Revista Investigación y Desarrollo, 6(6). https://doi.org/2078-7731

Aracil Sáez, I. (2008). Formación de contaminantes y estudio cinético en la pirólisis y combustión de plásticos (PE, PVC y PCP) (Tesis Doctoral, Universidad de Alicante (España)). https://doi.org/978-84-691-6015-2

Arnalich Castañeda, A., \& Ayuso Blas, J. L. (2015). Incendios de interior. Ventilación de incendios. Grupo Tragsa (Ed.), Manual de incendios (pp. 84-175). Guadalajara (España)

Arroyo López, P., Villanueva Bringas, M., Gaytán Iniestra, J., \& García Vargas, M. (2014). Simulación de la tasa de reciclaje de productos electrónicos: Un modelo de dinámica de sistemas para la red de logística inversa. Contaduría y Administración, 59(1), 9-41. https://doi.org/0186-1042

del Río Merino, M. (1999). Elaboración y aplicaciones constructivas de paneles prefabricados de escayola aligerada y reforzada con fibras de vidrio $E$ y otros aditivos (Tesis Doctoral, Universidad Politécnica de Madrid (España)). https://doi.org/http://oa.upm.es/612/

Domínguez Lepe, J., \& Guemez Pacheco, D. (2011). Fabricación y evaluación de paneles aplicables a la industria de la construcción a partir del reciclaje de envases multicapa. Ingeniería, 14(3), 191-195. https://doi.org/1665-529-X

Ehrenstein, G. W., Riedel, G., \& Trawiel, P. (2004). Thermal analysis of plastics: theory and practice (Hanser Gardner Publications, Ed.). Munich (Alemania).

Fleck, W., Jones, M., Kuntze, R., \& McAdie, H. J. C. J. o. C. (1960). The differential thermal analysis of natural and synthetic hydrates of calcium sulphate. Canadian 
Journal of Chemistry.Revue Canadienne de Chimie, 38(6), 936-943. https://doi.org/10.1139/v60-131

Flores Medina, N., \& Barbero Barrera, M. del M. (2017). Mechanical and physical enhancement of gypsum composites through a synergic work of polypropylene fiber and recycled isostatic graphite filler. Construction and Building Materials, 131,165-177. https://doi.org/10.1016/j.conbuildmat.2016.11.073

Fundación para la Salud Geoambiental. (2018). Dióxido de carbono $\mathrm{CO}_{2}$. Retrieved from https://www.saludgeoambiental.org/dioxido-carbono-co2

García Santos, A. (1988). Comportamiento mecánico de yeso reforzado con polímeros sintéticos (Tesis Doctoral, Universidad Politécnica de Madrid (España)). https://doi.org/oai:oa.upm.es:10747

Herrero del Cura, S. (2016). Influencia de la dosificación y granulometría del caucho de neumático fuera de uso (NFU) y de las dimensiones físicas en las propiedades térmicas, acústicas y mecánicas de placas de mortero de yeso y caucho (Tesis Doctoral, Universidad Politécnica de Madrid (España)).

https://doi.org/10.20868/UPM.thesis.43070

Jiménez Rivero, A., Guzmán Báez, A. de, García Navarro, J., \& González Cortina, M. (2011). Nuevos materiales de base yeso con incorporación de residuos de caucho: caracterización físico-mecánica. Actas de IX Jornadas Iberoamericanas de Materiales de Construcción, (1), 1-13. Retrieved from http://oa.upm.es/12206/

Khalil, A. A., Tawfik, A., Hegazy, A. A., \& El-Shahat, M. F. (2014). Effect of some waste additives on the physical and mechanical properties of gypsum plaster composites. Construction and Building Materials, 68, 580-586. https://doi.org/10.1016/j.conbuildmat.2014.06.081

Lozano-Díez, R., López-Zaldívar, Ó., Herrero del Cura, S., Mayor-Lobo, P., \& Hernández-Olivares, F. (2019). Influencia de la incorporación de fibras de caucho procedente de neumáticos fuera de uso (NFU) en morteros de yeso. Estudio de las propiedades mecánicas, térmicas y acústicas. Dyna Ingeniería e Industria, 94, 460-464. https://doi.org/10.6036/9020

Mayor Lobo, P., Bustamante Montoro, R., Rangel, C., \& Hernández Olivares, F. (2008). Propiedades térmicas, acústicas y mecánicas de placas de mortero de yesocaucho. In Instituto de Ciencias de la Construcción Eduardo Torroja (Ed.), Actas de II Jornadas de Investigación en Construcción.

https://doi.org/oai:oa.upm.es:4611

Mejía Betancourt, L. A. (2017). Elaboración de compositos a partir de matriz cementicia y adicionamiento de botellas PET y PVA en la ciudad de Villavicencio, Meta. Repositorio Institucional Universidad Cooperativa de Colombia, p. 46

Morillas, A. V., Villavicencio, M. B., Valdemar, R. M. E., Pérez, M. V., \& Neyra, D. V. C. (2017). Desafíos en el aprovechamiento de plásticos en residuos electrónicos. Sociedad Mexicana de Ciencia y Tecnología Aplicada a Residuos Sólidos A.C. (Ed.), Avances en el estudio de residuos de aparatos eléctricos y electrónicos (pp. 31-40). https://doi.org/2395-8170 
Peinado Moreno, A. (2003). Manual S.E.P.E.I de Bomberos (Dipualba, Ed.). Albacete (España)

Piña Ramírez, C. (2019). Comportamiento físico-mecánico y térmico de los morteros de cemento aditivados con fibras minerales procedentes de residuos de construcción y demolición (Tesis Doctoral, Universidad Politécnica de Madrid (España)). https://doi.org/oa.upm.es/54144/

Ramos, F., \& Mendes, L. (2014). Recycled high-density polyethylene/gypsum composites: evaluation of the microscopic, thermal, flammability, and mechanical properties. Green Chemistry Letters and Reviews, 7(2), 199-208. https://doi.org/10.1080/17518253.2014.924591

Rouquerol, F., Rouquerol, J., Sing, K. S. W., Llewellyn, P., \& Maurin, G. (2014). Adsorption by powders and porous solids: principles, methodology and applications (2a; Academic Press, Ed.). Montpellier (France)

Saint-Gobain, P. (2019). El código técnico de la edificación. https://www.placo.es/sites/gypsum.eeap.placo.es/files/manual_pyl_02_el_cte.p df

San Antonio González, A. (2017). Caracterización de compuestos eco-eficientes de yeso aligerado con residuo de poliestireno extruido (XPS) (Tesis Doctoral, Universidad Politécnica de Madrid (España)). https://doi.org/10.20868/UPM.thesis.48007

Santos Jiménez, R. (2018). Reciclaje de residuos de construcción y demolición (RCD) de tipo cerámico para nuevos materiales de construcción sostenibles (Tesis Doctoral, Universidad Politécnica de Madrid (España)). https://doi.org/10.20868/UPM.thesis.53564

Strydom, C. A., \& Potgieter, J. H. (1999). Dehydration behaviour of a natural gypsum and a phosphogypsum during milling. Thermochimica Acta, 332(1), 89-96. https://doi.org/10.1016/S0040-6031(99)00083-0

Suresh, S. S., Mohanty, S., \& Nayak, S. K. (2017). Composition analysis and characterization of waste polyvinyl chloride (PVC) recovered from data cables. Waste Management, 60, 100-111.

https://doi.org/10.1016/j.wasman.2016.08.033

Tapia Batallas, L. E. (2015). Diseño de una planta para la fabricación de paneles de yeso con la adición de piedra pómez y polipropileno como materiales alternativos (Proyecto Fin de Grado, Escuela Politécnica Nacional de Quito (Ecuador)). https://doi.org/http://bibdigital.epn.edu.ec/handle/15000/11108

UNE-EN 13279-2:2014. (2014). Yesos de construcción y conglomerantes a base de yeso para la construcción. Parte 2: Métodos de ensayo

Vidales Barriguete, A., del Río Merino, M., Atanes Sánchez, E., Piña Ramírez, C., \& Viñas Arrebola, C. (2018). Analysis of the feasibility of the use of CDW as a lowenvironmental-impact aggregate in conglomerates. Construction and Building Materials, 178, 83-91. https://doi.org/10.1016/j.conbuildmat.2018.05.011

Villanueva Domínguez, L. de, \& García Santos, A. (2001). Manual del yeso (Asociación Técnica y Empresarial del Yeso. ATEDY, Ed.). Madrid (España) 
Zhu, C., Zhang, J., Peng, J., Cao, W., \& Liu, J. (2018). Physical and mechanical properties of gypsum-based composites reinforced with PVA and PP fibers. Construction and Building Materials, 163, 695-705.

https://doi.org/10.1016/j.conbuildmat.2017.12.168 
CAPITUL0 6:RESULTADOSY DISCUSIÓN 


\section{Conclusiones}

El desarrollo sostenible desde el sector de la construcción implica una disminución del uso de recursos, la minimización de la generación de residuos y la reducción de emisiones de $\mathrm{CO}_{2}$. Por su parte, cada vez son más restrictivas las normativas implicadas en estos procesos y que afectan a cada una de las fases del proceso constructivo.

Para la reducción del impacto ambiental que se produce durante el ciclo de vida de los materiales de construcción es fundamental el desarrollo de nuevos materiales con el que frenar el uso de recursos naturales y la generación de residuos, entre otros. El yeso, durante todo su proceso de fabricación (desde la extracción hasta la puesta en obra) y, los plásticos por su uso masivo, lenta degradabilidad y difícil reciclaje influyen negativamente en la preservación del medio ambiente.

Por ello, el objetivo principal de esta tesis doctoral ha sido el estudio de un nuevo compuesto de yeso y residuos plásticos de cable con el que, aplicando criterios de economía circular, se contribuya en este sentido. A continuación se presentan las conclusiones obtenidas para cada uno de los objetivos específicos establecidos en ella. 


\section{Conclusiones al OBJETIVO 1:}

"Caracterización de la materia prima utilizada: yeso, escayola y residuo plástico procedente del reciclaje de cables".

- Heterogeneidad del residuo plástico de cables, formado por distintos tipos de polímeros, y presencia de elementos y compuestos procedentes de la fabricación del cable (hilo metálico y recubrimiento polimérico).

- La densidad del residuo plástico de cables es aproximadamente la mitad que la densidad de yeso y/o escayola.

- No es necesario hacer un tratamiento previo al residuo después de su recogida de la empresa de reciclaje de cables, pues la granulometría confirma que el tamaño máximo de partícula es de $3 \mathrm{~mm}$.

- Se confirma la incombustibilidad del yeso y escayola y la pérdida de masa del residuo plástico de cables a partir de $200^{\circ} \mathrm{C}$ debido a su naturaleza fundamentalmente orgánica.

\section{Conclusiones al OBJETIVO 2:}

"Análisis de la viabilidad de compuestos de yeso con PR".

- Existen numerosos estudios que analizan la incorporación de residuos y polímeros en matrices de yeso con el fin de mejorar alguna de sus propiedades pero no se han encontrado estudios que incorporen residuos plásticos procedentes del reciclaje de cables.

- Las pastas de los compuestos se hacen intrabajables a partir de la adición de un $70 \%$ de residuo plástico de cables.

- Las consistencias de los compuestos no cumplen normativa y el fraguado se acelera considerablemente, por lo que sería interesante la utilización de un retardador de fraguado o fluidificante natural.

\section{Conclusiones al OBJETIVO 3:}

“Caracterización de los compuestos de yeso con PR".

- Comparados con el compuesto de referencia de yeso que no incorpora residuo plástico de cable, se obtienen compuestos de densidad ligeramente mayor en estado endurecido, con valores de resistencia a flexión y compresión por encima de la normativa, con mayor dureza superficial y menor rigidez. 


\section{Conclusiones al OBJETIVO 4:}

"Propuestas de aplicaciones para los compuestos de yeso con PR".

- Las aplicaciones idóneas para los compuestos son paneles trasdosados y/o particiones interiores así como placas para falsos techos. Los más indicados para estas aplicaciones son los compuestos de matriz de escayola con relación A/Y de 0,8, por su densidad, dureza superficial, resistencias a flexión y compresión, su baja absorción de agua por capilaridad y su menor tiempo de fraguado, destacando entre ellos el de 60\% PR por su regularidad en los resultados de los ensayos. Sin embargo, para revestimientos continuos habría que utilizar un retardador de fraguado o fluidificante natural con el fin de mantener el requisito de sostenibilidad.

- La fabricación de paneles y placas es viable, económicamente hablando, tanto para las empresas de producción de este tipo de productos, como para las empresas de reciclaje de cables.

- La cohesión entre los cristales de escayola y las partículas del residuo plástico de cables en general es buena aunque existen zonas con grietas que explican la disminución de las resistencias mecánicas.

- Los compuestos presentan un magnífico comportamiento frente a la acción del agua como consecuencia de la contribución impermeabilizante del residuo plástico y de la menor cantidad de poros existentes en su composición.

- Por su parte, la incombustibilidad del yeso también contribuye a la mejora del comportamiento de los residuos plásticos frente al fuego, proporcionándoles, durante un tiempo, un mecanismo físico de acción. El recubrimiento constituye una barrera física al paso de calor y/o sustancias volátiles.

- Las propiedades térmicas también se mejoran ligeramente, lo que supone una contribución a una menor demanda energética respecto al material tradicional.

- El acabado de los compuestos presenta un buen confort superficial, una mejora en la aparición de fisuras, debido a la mayor elasticidad, y una mejora en la adherencia al soporte debido a la mayor rugosidad).

\section{Conclusiones al OBJETIVO 5:}

"Estudio del impacto ambiental".

- La incorporación del PR en la matriz de escayola disminuye un 25-30\% la utilización de los recursos naturales: piedra de aljez y agua. 
- Las empresas de reciclaje de cables generan PR suficiente para abastecer a las empresas de fabricación de prefabricados de yeso, pudiéndose conseguir la minimización de este residuo al 100\%.

Por todo esto, se demuestra la viabilidad e interés del material de yeso con residuo plástico de cables para la fabricación de elementos para la construcción, aplicando los criterios de sostenibilidad y economía circular. 


\section{Conclusions}

Sustainable development in the construction sector implies a decrease in the use of resources, the minimisation of waste generation and reduction of $\mathrm{CO}_{2}$ emissions. Moreover, the regulations involved in these processes are increasingly restrictive and affect each phase of the construction process.

In order to reduce the environmental impact that occurs during the life cycle of construction materials, it is essential to develop new materials and prevent the use of natural resources and the generation of waste, among others. Gypsum, throughout its manufacturing process (from extraction to commissioning) and plastics, due to their large-scale use, slow degradability and difficult recycling, have a negative impact on environmental conservation.

Therefore, the main objective of this doctoral thesis was to study a new compound made of gypsum and plastic waste from cables and help find a solution to this problem by applying the principles of the circular economy. Below are the conclusions obtained for each of the specific objectives set out in this thesis. 


\section{Conclusions to OBJECTIVE 1:}

"Characterisation of the raw material used: gypsum, plaster and plastic waste from cable recycling".

- Heterogeneity of plastic cable waste, formed by different types of polymers, and the presence of elements and compounds from cable manufacture (metal wire and polymer coating).

- The density of the plastic waste from cables is approximately half that of gypsum and/or plaster.

- Pre-treatment of the waste after collection from the cable recycling company is not necessary, since it is confirmed that the maximum particle size is $3 \mathrm{~mm}$.

- The non-flammability of the gypsum and plaster was confirmed as well as the loss of mass of the plastic waste from cables above $200{ }^{\circ} \mathrm{C}$ due to its primarily organic nature.

\section{Conclusions to OBJECTIVE 2:}

"Analysis of the viability of gypsum compounds with PR".

- Numerous studies analyse the incorporation of waste and polymers in gypsum matrices to improve some of their properties, but no studies have been found that incorporate plastic waste from cable recycling.

- Compound pastes become unworkable after adding 70\% of plastic waste from cables.

- Compound consistencies do not comply with regulations and setting is accelerated considerably, so it would be interesting to use a setting retarder or natural fluidiser.

\section{Conclusions to OBJECTIVE 3:}

"Characterisation of gypsum compounds with PR".

- Compared to the gypsum reference compound that does not incorporate plastic waste from cables, compounds are obtained with a slightly higher density in their hardened state, with bending and compression resistance values above the norm as well as greater surface hardness and less stiffness. 


\section{Conclusions to OBJECTIVE 4:}

"Proposed applications for plaster compounds with PR".

- The ideal applications for the compounds are cladding panels and/or interior partitions as well as false ceiling boards. Those most suitable for these applications are plaster matrix compounds with an $\mathrm{W} / \mathrm{P}$ ratio of 0.8 , due to their density, surface hardness, bending and compression resistance, low capillary water absorption and shorter setting time, highlighting among them the $60 \%$ PW for its regularity in the test results. However, for continuous coatings, a setting retarder or natural fluidiser should be used in order to maintain sustainability.

- The manufacture of panels and boards is economically viable both for companies producing this type of products and those recycling cables.

- The cohesion between the plaster crystals and the waste particles from the plastic cables in general is good, although there are areas with cracks that explain the decrease in mechanical resistance.

- The compounds are extremely water resistant because of the waterproofing properties of the plastic waste and the smaller number of pores.

- Moreover, the non-flammability of the gypsum also contributes to an increase in the fire resistance of the plastic waste, providing it with a physical mechanism of action for a given period. The coating constitutes a physical barrier to heat and/or volatile substances.

- Thermal properties are also slightly improved, which means heating and air conditioning costs will be lower than average.

- The finishing on the compounds provides a comfortable surface, helps to cover cracks due to its greater elasticity and improves adherence to the base material because of increased roughness.

\section{Conclusions to OBJECTIVE 5:}

"Study of the environmental impact".

- The incorporation of plastic waste from cables in the plaster matrix decreases the use of natural resources by 25-30\%: gypsum and water.

- Cable recycling companies generate enough plastic waste from cables to supply prefabricated gypsum manufacturers, resulting in a $100 \%$ reduction in this waste. 
This shows that gypsum with plastic waste from cables is viable and interesting for the manufacture of construction elements following the principles of sustainability and the circular economy. 


\section{FutuRAS LÍNEAS dE INVESTIGACIÓN}

El trabajo de investigación realizado y las conclusiones obtenidas, abren las siguientes líneas para futuros proyectos de investigación relacionados con esta área:

- Analizar el comportamiento acústico de los compuestos propuestos en esta tesis.

- Analizar los efectos de incorporar un retardador de fraguado natural en los compuestos.

- Realizar paneles con lámina de papel y analizar sus propiedades.

- Realizar un nuevo estudio energético del material mediante un análisis dinámico, a través de otro programa como el DesignBuilder.

- Ampliar los ensayos de comportamiento frente al fuego y gases de combustión.

- Analizar el comportamiento del residuo plástico de cables en otros materiales como el mortero de cemento o el hormigón. 


(NDICIOS DE CALIDAD




\section{INDICIOS DE CALIDAD}

\section{Publicaciones científicas}

Vidales Barriguete, A., Atanes Sánchez, E., del Río Merino, M. \& Piña Ramírez, C. (2019). Analysis of the improved water-resistant properties of plaster compounds with the addition of plastic. Construction and Building Materials, 230, (2020) 116956. (Índice de impacto 4,046; cuartil Q1). https://doi.org/10.1016/j.conbuildmat.2019.116956

Vidales Barriguete, A., del Río Merino, M., Atanes Sánchez, E., Piña Ramírez, C., \& Viñas Arrebola, C. (2018). Analysis of the feasibility of the use of CDW as a lowenvironmental-impact aggregate in conglomerates. Construction and Building Materials, 178, 83-91. (Índice de impacto 4,046; cuartil Q1). https://doi.org/10.1016/j.conbuildmat.2018.05.011

\section{Premios}

Vidales Barriguete, A., Premio mejor ponencia presentada "Tu tesis en 4 minutos" en el I Simposio de Doctorado UPM, "Residuo plástico de cables en una matriz de yeso con criterios de economía circular", Escuela Técnica Superior de Ingenieros de Caminos, Canales y Puertos de la UPM, 27 de Octubre de 2017. 


\section{Congresos y conferencias científicas}

Vidales Barriguete, A., del Río Merino, M., Atanes Sánchez, E., Piña Ramírez, C., \& Galán González, A. "Study of the thermal behavior of plaster compounds additioned with plastic waste of cables", Universidad de Córdoba (España), 8 de Abril de 2019, International Conference on Green Construction - ICGC 2019. Depósito legal y ISBN en proceso.

Vidales Barriguete, A., Piña Ramírez, C., del Río Merino, M. \& Atanes Sánchez, E. "Adding plastic waste to plasters to improve their properties in contact with water", Escuela Técnica Superior de Edificación de la UPM, 6 de Marzo de 2019, IV Congreso Internacional de Innovación Tecnológica en Edificación - CITE 2019. Depósito legal M-6324-2019. ISBN 978-84-16397-88-4.

Vidales Barriguete, A., "Contributing to sustainable construction through plastic waste of cables", Escuela Técnica Superior de Ingenieros Industriales de la UPM, 14 de Marzo de 2018, II Symposium de Doctorado UPM.

Vidales Barriguete, A., del Río Merino, M., Atanes Sánchez, E. \& Piña Ramírez, C. "Influence of the dosage of plastic waste of cables in the thermal and mechanical properties of plaster compounds", Escuela Técnica Superior de Edificación de la UPM, 8 de Marzo de 2018, III Congreso Internacional de Innovación Tecnológica en Edificación - CITE 2018. Depósito legal M-7604-2018. ISBN 978-84-1639771-6.

Vidales Barriguete, A., Atanes Sánchez, E., del Río Merino, M., Piña Ramírez, C. \& Kosior-Kazberuk, M. "Analysis of the contribution of plastic waste of cables in a plaster matrix", Escuela Politécnica Superior de Ingeniería de la Universidad de La Laguna (Tenerife), 14 de Diciembre de 2017, IV International Congress on Construction and Building Research - COINVEDI 2017.

Vidales Barriguete, A., "Residuo plástico de cables en una matriz de yeso con criterios de economía circular", Escuela Técnica Superior de Ingenieros de Caminos, Canales y Puertos de la UPM, 27 de Octubre de 2017, I Simposio de Doctorado UPM. 


\section{BIBLIOGRAFÍA}

Abu-Lebdeh, T., Fini, E., \& Fadiel, A. (2014). Thermal conductivity of rubberized gypsum board. American Journal of Engineering and Applied Sciences, 7(1), 1222. https://doi.org/10.3844/ajeassp.2014.12.22

Aguilar, A. (1997). Reciclado de materiales de construcción. Residuos, 2. https://doi.org/1578-097X

Ahmed, A., Ugai, K., \& Kamei, T. (2011). Investigation of recycled gypsum in conjunction with waste plastic trays for ground improvement. Construction and Building Materials, 25, 208-217. https://doi.org/10.1016/j.conbuildmat.2010.06.036

Alameda, L., Calderón, V., Gadea, J., \& Gutiérrez-González, S. (2015). Reciclado de placas de yeso laminado aligeradas con residuos de poliuretano. Anales de Edificación, 1(1), 33-39. https://doi.org/10.20868/ade.2015.3037

Alameda, L., Calderón, V., Junco, C., Rodríguez, Á., Gadea, J., \& Gutiérrez-González, S. (2016). Characterization of gypsum plasterboard with polyurethane foam waste reinforced with polypropylene fibers. Materiales de Construcción, 66(324), e100. https://doi.org/10.3989/mc.2016.06015

Alavedra, P., Domínguez, J., Gonzalo, E., \& Serra, J. (1997). La construcción sostenible: el estado de la cuestión. Informes de La Construcción, 49(451), 41-47. https://doi.org/10.3989/ic.1997.v49.i451

Alba Rodríguez, M. D., Marrero, M., Leiva Fernández, C., Montes, M. V., \& Vilches, L. (2012). Facade solutions using panels made of power plant byproducts. Informes de La Construcción, 64(526), 179-190. https://doi.org/10.3989/ic.10.042

Alcón Calla, S., Salcedo Quispe, F., Gallardo Tapia, V., \& Echazú Cortez, J. (2011). Mortero de yeso reforzado con fibra reciclada de botellas PET para su aplicación como junta en mampostería de ladrillo. Revista Investigación y Desarrollo, 6(6). https://doi.org/2078-7731

A Almagro Gorbea, A. (1986). El yeso, material mudéjar. Actas del III Simposio Internacional de Mudejarismo. http://hdl.handle.net/10261/21641

Amara, I., Mazioud, A., Boulaoued, I., \& Mhimid, A. (2017). Experimental study on thermal properties of bio-composite (gypsum plaster reinforced with palm tree fibers) for building insulation. International Journal of Heat and Technology, 35(3), 576-584. https://doi.org/10.18280/ijht.350314

Amador Blanco, J. J., Díaz-Guerra Pérez, J., \& Fernández del Olmo, E. (2016). Materiales de construcción. Ligantes, yeso y cal. Madrid (España)

Aracil Sáez, I. (2008). Formación de contaminantes y estudio cinético en la pirólisis y combustión de plásticos (PE, PVC y PCP) (Tesis Doctoral, Universidad de Alicante (España)). https://doi.org/978-84-691-6015-2 
Arenas Cabello, F. J. (2008). Los materiales de construcción y el medio ambiente. Ecosostenible, 41, 30-37. https://doi.org/1699-3942

Argiz, C. (2016). La economía circular en el contexto de las futuras normas de especificaciones de cementos. Cemento Hormigón, 976(8). http://cementohormigon.com/Articulos/Articulos?id=1061

Arnalich Castañeda, A., \& Ayuso Blas, J. L. (2015). Incendios de interior. Ventilación de incendios. Grupo Tragsa (Ed.), Manual de incendios (pp. 84-175). Guadalajara (España)

Arroyo López, P., Villanueva Bringas, M., Gaytán Iniestra, J., \& García Vargas, M. (2014). Simulación de la tasa de reciclaje de productos electrónicos: Un modelo de dinámica de sistemas para la red de logística inversa. Contaduría y Administración, 59(1), 9-41. https://doi.org/0186-1042

ASTM D7984. (2016). Standard test method for measurements of thermal effusivity of fabrics using a modified transient plane source (MTPS) instrument.

Baño Nieva, A., \& Vigil-Escalera del Pozo, A. (2005). Guía de construcción sostenible. https://doi.org/M-51636-2005

Barriga Miño, C. R. (2017). Estudio de la conductividad térmica de residuos sólidos dentro de una matriz de yeso, provenientes del proceso de rebajado del cuero en la empresa Curtiduría Tungurahua S.A. (Proyecto Fin de Grado, Universidad Técnica de Ambato (Ecuador)). http://repositorio.uta.edu.ec/jspui/handle/123456789/25258

Barrios, Á. (2012). Impactos ambientales en construcción sostenible. In Construcción sostenible. https://www.eoi.es/wiki/index.php/Construcción_sostenible

Barrón Ruiz, Á. (2002). Ética, ecología y educación ambiental en el siglo XXI. (Universidad de Salamanca Ed.), La educación y el medio ambiente natural y humano: libro homenaje al profesor Nicolás S. Sosa. 21-38

Belayachi, N., Hoxha, D., \& Ismail, B. (2016). Impact of fiber treatment on the fire reaction and thermal degradation of building insulation straw composite. International Conference on Materials \& Energy, 544-549.

https://doi.org/10.1016/j.egypro.2017.11.251

Bicer, A., \& Kar, F. (2017). Thermal and mechanical properties of gypsum plaster mixed with expanded polystyrene and tragacanth. Thermal Science and Engineering Progress, 1, 59-65. https://doi.org/10.1016/j.tsep.2017.02.008

Binici, H., \& Aksogan, O. (2017). Insulation material production form onion skin and peanut shell fibers, fly ash, pumice, perlite, barite, cement and gypsum. Materials Today Communications, 10, 14-24.

https://doi.org/10.1016/j.mtcomm.2016.09.004 
Borreguero, A. M., Serrano, Á., Garrido, I., Rodríguez, J. F., \& Carmona, M. (2014). Polymeric-SiO ${ }_{2}$-PCMs for improving the thermal properties of gypsum applied in energy efficient buildings. Energy Conversion and Management, 87, 138-144. https://doi.org/10.1016/j.enconman.2014.07.027

Braiek, A., Karkri, M., Adili, A., Ibos, L., \& Ben Nasrallah, S. (2017). Estimation of the thermophysical properties of date palm fibers/gypsum composite for use as insulating materials in building. Energy and Buildings, 140, 268-279. https://doi.org/10.1016/j.enbuild.2017.02.001

Braungart, M., McDonough, W., \& Bollinger, A. (2007). Cradle to cradle design: creating healthy emissions - a strategy for ecoeffective product and system design. Journal of Cleaner Production, 15(13), 1337-1348.

https://doi.org/https://doi.org/10.1016/j.jclepro.2006.08.003

Buezas Sierra, N. (2010). Guía: plásticos y fuego (p. 66). Valencia (España): AIMPLAS Instituto Tecnológico del Plástico

Calderón, V., Rodríguez, Á., Horgnies, M., \& Gadea, J. (2013). Morteros de yeso fabricados con escorias de horno de cuchara. Workshop on Environmental Impact of Buildings Construction. Madrid (España)

Cerrillo, A. (2012, February 19). España modera el uso de recursos naturales. La Vanguardia.

https://www.lavanguardia.com/medio-ambiente/20120219/54256331741/espana-modera-uso-recursos-naturales.html

Cherki, A., Remy, B., Khabbazi, A., Jannot, Y., \& Baillis, D. (2014). Experimental thermal properties characterization of insulating cork-gypsum composite. Construction and Building Materials, 54, 202-209.

https://doi.org/10.1016/j.conbuildmat.2013.12.076

Comisión de las Comunidades Europeas. (2000). Comisión 2000/532/CE, que establece una lista de residuos. L226/3-L226/24. Diario oficial de las Comunidades Europeas

Comisión Europea. (2014). Comisión 2014/955/UE, que establece una lista de residuos. L370/44-L370/86. Diario oficial de la Unión Europea

CTE. (2007). Código Técnico de la Edificación. http://cte-web.iccl.es/sistemas.php

CTN 102-Yeso y productos a base de yeso. (2009). UNE-EN 13279-1:2009 Yesos de construcción y conglomerantes a base de yeso para la construcción. Parte 1: Definiciones y especificaciones. AENOR.

de Moraes Rossetto, J. R., Santos Correia, L., Henrique Geraldo, R., \& Camarini, G. (2016). Gypsum plaster waste recycling: analysis of calcination time. Key Engineering Materials, 668, 312-321.

https://doi.org/10.4028/www.scientific.net/KEM.668.312 
del Río Merino, M. (1999). Elaboración y aplicaciones constructivas de paneles prefabricados de escayola aligerada y reforzada con fibras de vidrio $E$ y otros aditivos (Tesis Doctoral, Universidad Politécnica de Madrid (España)). https://doi.org/http://oa.upm.es/612/

del Río Merino, M. (2005). Nuevas aplicaciones del corcho en el campo de la edificación. III Encuentro Eurocork. http://oa.upm.es/1896/

del Río Merino, M. (2008). Los residuos de construcción-demolición. Retrieved from https://www.edificacion.upm.es/personales/mercedesdelrio/documentos

del Río Merino, M., García Navarro, J., \& Villoria Sáez, P. (2011). Legal aspects which implement good practice measures in the management of construction and demolition waste. Open Construction \& Building Technology Journal, 5, 124-130. https://doi.org/10.2174/1874836801105010124

del Río Merino, M., Santa Cruz Astorqui, J., \& Villoria Sáez, P. (2018). Eco plaster mortars with addition of waste for high hardness coatings. Construction and Building Materials, 158, 649-656.

https://doi.org/10.1016/j.conbuildmat.2017.10.037

Deng, Y.-H., \& Furuno, T. (2001). Properties of gypsum particleboard reinforced with polypropylene fibers. Journal of Wood Science, 47(6), 445-450. https://doi.org/10.1007/BF00767896

Díaz Carretero, I., Landa Cánovas, Á. R., \& Otero-Díaz, L. C. (2002). Microscopía electrónica de transmisión (TEM) y de barrido (SEM). Consejo Superior de Investigaciones Científicas (Ed.), Técnicas de análisis y caracterización de materiales (1'a pp. 455-459). Madrid (España)

Domínguez Lepe, J., \& Guemez Pacheco, D. (2011). Fabricación y evaluación de paneles aplicables a la industria de la construcción a partir del reciclaje de envases multicapa. Ingeniería, 14(3), 191-195. https://doi.org/1665-529-X

Ecoembes. (2019). El reciclaje en datos. https://www.ecoembes.com/es/ciudadanos

Ehrenstein, G. W., Riedel, G., \& Trawiel, P. (2004). Thermal analysis of plastics: theory and practice (Hanser Gardner Publications, Ed.). Munich (Alemania).

Elías Castells, X., Altadill Colominas, R., Andrés Payán, A. M., Bruno, A., Bruno, J., Canales Rojas, Á. M., ... Soliva Torrentó, M. (2009). Reciclaje de residuos industriales (2a). Ediciones Díaz de Santos

Erbs, A., Nagalli, A., de Carvalho, K. Q., Mymrin, V., Passig, F. H., \& Mazer, W. (2018). Properties of recycled gypsum from gypsum plasterboards and commercial gypsum throughout recycling cycles. Journal of Cleaner Production, 183, 13141322. https://doi.org/10.1016/j.jclepro.2018.02.189

Erdem, S., \& Arioglu, N. (2017). An analysis of the properties of recycled pet fibergypsum composites. A/Z ITU Journal of the Faculty of Architecture, 14(1), 91-101. https://doi.org/10.5505/itujfa.2017.70288 
Eurostat. (2019). Toneladas de residuos en Europa y España. https://ec.europa.eu/eurostat/data/statistics-a-z/abc

FACEL. (2018). Estadísticas generales. https://www.facel.es/estadisticas

FERCD y RCD Asociación. (2019). Evolución de los RCD generados en España en los últimos años. http://www.rcdasociacion.es/

Fleck, W., Jones, M., Kuntze, R., \& McAdie, H. J. C. J. o. C. (1960). The differential thermal analysis of natural and synthetic hydrates of calcium sulphate. Canadian Journal of Chemistry.Revue Canadienne de Chimie, 38(6), 936-943. https://doi.org/10.1139/v60-131

Flores Medina, N., \& Barbero Barrera, M. del M. (2017). Mechanical and physical enhancement of gypsum composites through a synergic work of polypropylene fiber and recycled isostatic graphite filler. Construction and Building Materials, 131, 165-177. https://doi.org/10.1016/j.conbuildmat.2016.11.073

Font, R., Aracil, I., Fullana, A., Martín-Gullón, I., \& Conesa, J. A. (2003). Semivolatile compounds in pyrolysis of polyethylene. Journal of Analytical and Applied Pyrolysis, 68, 599-611. https://doi.org/10.1016/S0165-2370(03)00038-X

Fresneda, C. (2014, March 8). La economía circular. El Mundo. https://www.elmundo.es/economia/2014/03/08/5319cae3e2704e3b248b457 a.html

Fresneda, C. (2016, November 26). Las ciudades serán el motor de la economía circular. El Mundo.

https://www.elmundo.es/economia/2016/11/26/582eec07e2704eb87c8b466 a.html

Fundación para la Salud Geoambiental. (2018). Dióxido de carbono $\mathrm{CO}_{2}$. https://www.saludgeoambiental.org/dioxido-carbono-co2

García Santos, A. (1988). Comportamiento mecánico de yeso reforzado con polímeros sintéticos (Tesis Doctoral, Universidad Politécnica de Madrid (España)). https://doi.org/oai:oa.upm.es:10747

García Santos, A. (2004). Caracterización de compuestos de escayola reforzados, en relación con el tipo de refuerzo y la relación A/Y. Informes de La Construcción, 56(493), 19-31. https://doi.org/10.3989/ic.2004.v56.i493.436

Gencel, O., del Coz Diaz, J. J., Sutcu, M., Koksal, F., Rabanal, F. P. A., Martinez-Barrera, G., \& Brostow, W. (2014). Properties of gypsum composites containing vermiculite and polypropylene fibers: Numerical and experimental results. Energy and Buildings, 70, 135-144. https://doi.org/10.1016/j.enbuild.2013.11.047

González Madariaga, F. J. (2008). Mezclas de residuos de poliestireno expandido (EPS) conglomerados con yeso o escayola para su uso en la construcción. Informes de La Construcción, 60(509), 35-43.

https://doi.org/10.3989/ic.2008.v60.i509.589 
González Pericot, N. (2010). Gestión de residuos de embalajes en una obra de edificación (Trabajo Fin de Máster, Universidad Politécnica de Madrid (España)). http://oa.upm.es/10764/2/TESIS_MASTER_NATALIA_GONZALEZ_PERICOT.pdf

Gutiérrez-González, S., Alonso, M. M., Gadea, J., Rodríguez, Á., \& Calderón, V. (2013). Rheological behaviour of gypsum plaster pastes with polyamide powder wastes. Construction and Building Materials, 38, 407-412. https://doi.org/10.1016/j.conbuildmat.2012.08.034

Gutiérrez-González, S., Gadea, J., Rodríguez, Á., Blanco-Varela, M. T., \& Calderón, V. (2012). Compatibility between gypsum and polyamide powder waste to produce lightweight plaster with enhanced thermal properties. Construction and Building Materials, 34, 179-185. https://doi.org/10.1016/j.conbuildmat.2012.02.061

Gutiérrez González, S., Gadea, J., Rodríguez, Á., Junco, C., \& Calderón, V. (2012). Lightweight plaster materials with enhanced thermal properties made with polyurethane foam wastes. Construction and Building Materials, 28(1), 653-658. https://doi.org/10.1016/j.conbuildmat.2011.10.055

Hammond, G., \& Jones, C. (2011). Embodied energy and carbon. http://www.circularecology.com/embodied-energy-and-carbon-footprintdatabase.html\#.XSYwE2Z7nMU

Haselein, C. R., Calegari, L., Alberti, L. F., Minello, A. L., da Silva, P. A., \& Pintos Figueredo, R. G. (2002). Manufacturing gypsum-bonded-particleboard with recycled paper and pine wood particle. Ciência Florestal, 12(1), 81-88. https://doi.org/10.5902/198050981703

Hermida Balboa, C., \& Domínguez Somonte, M. (2014). Economía circular como marco para el ecodiseño: el modelo ECO-3. Informador Técnico, 78(1), 82-90. https://doi.org/10.23850/22565035.71

Hernández Olivares, F., Zuñiga Suárez, A., Medina Alvarado, R., \& Burneo Valdivieso, X. (2015). Reuse of organic waste type in the development of ecoefficient and sustainable composites. Universidad de Sevilla (Ed.), II International congress on sustainable construction and ecoefficient solutions (pp. 297-309). https://doi.org/978-84-61739646

Herrero del Cura, S. (2016). Influencia de la dosificación y granulometría del caucho de neumático fuera de uso (NFU) y de las dimensiones físicas en las propiedades térmicas, acústicas y mecánicas de placas de mortero de yeso y caucho (Tesis Doctoral, Universidad Politécnica de Madrid (España)). https://doi.org/10.20868/UPM.thesis.43070

IDAE. (2018). Consumo de energía final en España por sectores 2000-2016. https://www.idae.es/sites/default/files/estudios_informes_y_estadisticas/infor me_indicadores_ee_2016_accesib.pdf 
Iousef, S., Montazeri, H., Blocken, B., \& Van Wesemael, P. J. V. (2017). On the use of non-conformal grids for economic LES of wind flow and convective heat transfer for a wall-mounted cube. Building and Environment, 119, 44-61. https://doi.org/10.1016/j.buildenv.2017.04.004

ISO 834. (2014). Fire resistance tests. Elements of building construction.

Iucolano, F., Liguori, B., Aprea, P., \& Caputo, D. (2018). Evaluation of bio-degummed hemp fibers as reinforcement in gypsum plaster. Composites Part B: Engineering, 138, 149-156. https://doi.org/10.1016/j.compositesb.2017.11.037

Jefatura del Estado. (2011). Ley 22/2011, de 28 de julio, de residuos y suelos contaminados. 85650-85705. BOE núm. 181

Jiménez Rivero, A., Guzmán Báez, A. de, García Navarro, J., \& González Cortina, M. (2011). Nuevos materiales de base yeso con incorporación de residuos de caucho: caracterización físico-mecánica. Actas de IX Jornadas Iberoamericanas de Materiales de Construcción, (1), 1-13. http://oa.upm.es/12206/

Khalil, A. A., Tawfik, A., Hegazy, A. A., \& El-Shahat, M. F. (2014). Effect of some waste additives on the physical and mechanical properties of gypsum plaster composites. Construction and Building Materials, 68, 580-586. https://doi.org/10.1016/j.conbuildmat.2014.06.081

Lakrafli, H., Tahiri, S., Albizane, A., \& El Otmani, M. E. (2012). Effect of wet blue chrome shaving and buffing dust of leather industry on the thermal conductivity of cement and plaster based materials. Construction and Building Materials, 30, 590-596. https://doi.org/10.1016/j.conbuildmat.2011.12.041

Leiva Aguilera, M. J. (2017). Escayola aditivada con residuos de cáscara de arroz (Tesis Doctoral, Universidad Politécnica de Madrid (España)).

https://doi.org/10.20868/UPM.thesis.54716

Liuzzi, S., Rubino, C., \& Stefanizzi, P. (2017). Use of clay and olive pruning waste for building materials with high hygrothermal performances. 72nd Conference of the Italian Thermal Machines Engineering Association, 234-241. https://doi.org/10.1016/j.egypro.2017.08.145

López de Asiain, J. (2001). Arquitectura, ciudad, medioambiente (Universidad de Sevilla, Ed.). Sevilla (España)

López-Zaldívar, Ó., Lozano-Díez, R., Herrero del Cura, S., Mayor-Lobo, P., \& Hernández-Olivares, F. (2017). Effects of water absorption on the microstructure of plaster with end-of-life tire rubber mortars. Construction and Building Materials, 150, 558-567. https://doi.org/10.1016/j.conbuildmat.2017.06.014

Lozano-Díez, R., López-Zaldívar, Ó., Herrero del Cura, S., Mayor-Lobo, P., \& Hernández-Olivares, F. (2019). Influencia de la incorporación de fibras de caucho procedente de neumáticos fuera de uso (NFU) en morteros de yeso. Estudio de las propiedades mecánicas, térmicas y acústicas. Dyna Ingeniería e Industria, 94, 460-464. https://doi.org/10.6036/9020 
Mamani Delgado, D. (2016). Evaluación comparativa de las propiedades mecánicas entre el yeso y el yeso adicionado con materiales reciclados según la norma UNEEN 13279-2 para uso en la fabricación de placas de yeso (Proyecto Fin de Grado, Universidad Andina del Cusco (Perú)).

https://doi.org/repositorio.uandina.edu.pe/handle/UAC/699

Marrero, M., Martínez Escobar, L., Mercader Moyano, P., \& Leiva Fernández, C. (2013). Minimización del impacto ambiental en la ejecución de fachadas mediante el empleo de materiales reciclados. Informes de La Construcción, 65(529), 89-97. https://doi.org/10.3989/ic.11.034

Mascarós, S. M. (2002). Difracción de rayos X. Consejo Superior de Investigaciones Científicas (Ed.), Técnicas de Análisis y Caracterización de Materiales (1ª). Madrid (España)

Mayor Lobo, P., Bustamante Montoro, R., Rangel, C., \& Hernández Olivares, F. (2008). Propiedades térmicas, acústicas y mecánicas de placas de mortero de yesocaucho. Instituto de Ciencias de la Construcción Eduardo Torroja (Ed.), Actas de II Jornadas de Investigación en Construcción. https://doi.org/oai:oa.upm.es:4611

Mejía Betancourt, L. A. (2017). Elaboración de compositos a partir de matriz cementicia y adicionamiento de botellas PET y PVA en la ciudad de Villavicencio, Meta. Repositorio Institucional Universidad Cooperativa de Colombia, p. 46

Ministerio de Agricultura Alimentación y Medio Ambiente. (2016). Plan Estatal Marco de Gestión de Residuos (PEMAR) 2016-2022

Ministerio de Agricultura y Pesca, Alimentación y Medio. (2017). Orden APM/1007/2017, de 10 de octubre, sobre normas generales de valorización de materiales naturales excavados para su utilización en operaciones de relleno y obras distintas a aquéllas en las que se generaron

Ministerio de Ciencia y Tecnología. (2002). Real Decreto 842/2002, de 2 de agosto, por el que se aprueba el Reglamento electrotécnico para baja tensión.

Ministerio de la Presidencia. (2008). Real Decreto 105/2008, de 1 de febrero, por el que se regula la producción y gestión de los residuos de construcción y demolición.

Ministerio de Medio Ambiente. (2002a). Orden MAM/304/2002, de 8 de febrero, por la que se publican las operaciones de valorización y eliminación de residuos y la lista europea de residuos.

Ministerio de Medio Ambiente. (2002b). Real Decreto 1481/2001, de 27 de diciembre, por el que se regula la eliminación de residuos mediante depósito en vertedero.

Ministerio de Medio Ambiente y Medio Rural y Marino. (2009). Plan Nacional Integrado de Residuos para el período 2008-2015.

Ministerio para la transición ecológica. (2002). Protocolo de Kioto. https://www.miteco.gob.es/es/cambio-climatico 
Miranda Nieto, O. I. (2012). Mejora de la calidad de vivienda económica mediante el uso de polímeros y compuestos inorgánicos tradicionales para mejorar su aislamiento térmico (Universidad Autónoma de Querétaro (México)). https://doi.org/handle/123456789/1847

Miravete, A. (1995). Los nuevos materiales en la construcción (2a; Reverté, Ed.). Zaragoza (España)

Mohandesi, J. A., Sangghaleh, A., Nazari, A., \& Pourjavad, N. (2011). Analytical modeling of strength in randomly oriented PP and PPTA short fiber reinforced gypsum composites. Computational Materials Science, 50(5), 1619-1624. https://doi.org/10.1016/j.commatsci.2010.12.020

Moltó, J., Font, R., Gálvez, A., \& Conesa, J. A. (2009). Pyrolysis and combustion of electronic wastes. Journal of Analytical and Applied Pyrolysis, 84(1), 68-78. https://doi.org/10.1016/j.jaap.2008.10.023

Morales-Conde, M. J., Rodríguez-Liñán, C., \& Pedreno Rojas, M. A. (2016). Physical and mechanical properties of wood-gypsum composites from demolition material in rehabilitation works. Construction and Building Materials, 114, 6-14. https://doi.org/10.1016/j.conbuildmat.2016.03.137

Moraño Rodríguez, A. J. (2016). Hormigón estructural térmico. Economía circular. Cemento Hormigón, 976(8).

http://cemento-hormigon.com/Articulos/Articulos?id=1061

Morillas, A. V., Villavicencio, M. B., Valdemar, R. M. E., Pérez, M. V., \& Neyra, D. V. C. (2017). Desafíos en el aprovechamiento de plásticos en residuos electrónicos. Sociedad Mexicana de Ciencia y Tecnología Aplicada a Residuos Sólidos A.C. (Ed.), Avances en el estudio de residuos de aparatos eléctricos y electrónicos (pp. 31-40). https://doi.org/2395-8170

Morsy, M. S., Shebl, S. S., \& Saif, M. A. E. G. (2008). Development of perlite-gypsumslag-lime sludge-composite system for building application. Building Research Journal, 56(1), 49-58.

Musa, M. N., \& Abdul Aziz, M. F. (2016). Thermal conductivity for mixture of rice husk fiber and gypsum. Applied Mechanics and Materials, 819, 69-73. https://doi.org/10.4028/www.scientific.net/AMM.819.69

Nazerian, M., \& Kamyab, M. (2013). Gypsum-bonded particleboard manufactured from agricultural based material. Forest Science and Practice, 15(4), 325-331. https://doi.org/10.1007/s11632-013-0420-6

National Oceanic and Atmospheric Administration. (2017a). Partes de dióxido de carbono por millón de partículas de aire. https://www.noaa.gov

National Oceanic and Atmospheric Administration. (2017b). PPM en los inicios de la Revolución Industrial. https://www.noaa.gov/news/carbon-dioxide-levels-inatmosphere-hit-record-high-in-may

Novo Villaverde, M. (2006). El desarrollo sostenible: su dimensión ambiental y educativa (Pearson, Ed.). Madrid (España) 
Núñez, M. (2017, September 25). Economía circular, echa a rodar la mayor revolución global en 250 años. $A B C$. https://www.abc.es/economia/abci-economia-circularecha-rodar-mayor-revolucion-global-250-anos-201602151450_noticia.html

Oliveira, C. E. A., Oliveira, M., Oliveira, J. L., \& Damasceno, F. A. (2016). Gypsum-based composites with addition of woody endocarp of Barueiro nut residue and sawdust. ASABE Annual International Meeting. https://doi.org/10.13031/aim.20162461357

Oliver-Ramírez, A. (2009). Integración de materiales de cambio de fase en placas de yeso reforzadas con fibras de polipropileno. Aplicación a sistemas de refrigeración y calefacción pasivos para almacenamiento de calor latente en edificios (Tesis Doctoral, Universidad Politécnica de Madrid (España)). https://doi.org/oa.upm.es/2910

Oliver Ramírez, A., García Santos, A., \& Neila González, F. J. (2011). Caracterización física y mecánica de placas de yeso con materiales de cambio de fase incorporados para almacenamiento de energía térmica mediante calor latente. Materiales de Construcción, 61(303), 465-484. https://doi.org/0465-2746

ONU. (1972). Conferencia de las Naciones Unidas sobre el Medio Humano. https://www.un.org/es/index.html

ONU. (1980). Convenciones de Basilea, Estocolmo y Rotterdam y Protocolo de Montreal. https://www.un.org/es/index.html

ONU. (1987). Protocolo de Montreal. https://www.undp.org

ONU. (1991). Temas mundiales-Medio ambiente. https://www.un.org/es/index.html

ONU. (1992). Cumbre para la Tierra. https://www.un.org/es/index.html

ONU. (1998). Convención de Rotterdam. https://www.un.org/es/index.html

ONU. (1999). Pacto mundial de las Naciones Unidas.

https://www.un.org/es/index.html

ONU. (2000a). Cumbre del Milenio. https://www.un.org/es/index.html

ONU. (2000b). Toneladas de residuos por habitante.

https://www.un.org/es/index.html

ONU. (2002). Cumbre de Johannesburgo. https://www.un.org/es/index.html

Parlamento Europeo. (1975). Directiva 75/442/CEE.

Parlamento Europeo. (2008). Directiva Marco de Residuos 2008/98/CE

Parlamento Europeo. (2018). Directiva (UE) 2018/851

Peinado Moreno, A. (2003). Manual S.E.P.E.I de Bomberos (Dipualba, Ed.). Albacete (España) 
Pinheiro, S. M. M., \& Camarini, G. (2015). Characteristics of gypsum recycling in different cycles. International Journal of Engineering and Technology, 7(3), 215218. https://doi.org/10.7763/IJET.2015.V7.794

Piña Ramírez, C. (2019). Comportamiento físico-mecánico y térmico de los morteros de cemento aditivados con fibras minerales procedentes de residuos de construcción y demolición (Tesis Doctoral, Universidad Politécnica de Madrid (España)). https://doi.org/oa.upm.es/54144/

Planelles, M. (2016, November 4). El acuerdo de París contra el cambio climático entra en vigor en un tiempo récord. El País.

https://elpais.com/internacional/2016/11/03/actualidad/1478183747_14165 2.html

PlasticsEurope. (2017). Los plásticos y la seguridad contra incendios en el sector de la construcción. https://www.plasticseurope.org/es/resources/publications/319los-plasticos-y-la-seguridad-contra-incendios-en-el-sector-de-la-construccion

PlasticsEurope. (2018). An analysis of European plastics production, demand and waste data. https://www.plasticseurope.org/es/resources/publications/1240plasticos-situacion-en-2018

PlasticsEurope. (2019). Tipos de plásticos. https://www.plasticseurope.org

Porras Amores, C., Viñas Arrebola, C., Rodríguez Sánchez, A., \& Villoria Sáez, P. (2014). Assessing the potential use of strategies independent from the architectural design to achieve efficient ventilation: a Spanish case study. Building Services Engineering Research and Technology, 35(5), 529-542.

https://doi.org/10.1177/0143624414524065

Quinchía Figueroa, A. M., Valencia García, M. F., \& Giraldo Orozco, J. M. (2007). Uso de lodos provenientes de la industria papelera en la elaboración de paneles prefabricados para la construcción. Revista EIA, 8, 9-19. https://doi.org/24630950

RAE. (2017). Diccionario de la Lengua Española. http://www.rae.es

Ramos, F., \& Mendes, L. (2014). Recycled high-density polyethylene/gypsum composites: evaluation of the microscopic, thermal, flammability, and mechanical properties. Green Chemistry Letters and Reviews, 7(2), 199-208. https://doi.org/10.1080/17518253.2014.924591

RILEM RC 25-PEM. (1980). Recommended tests to measure the deterioration of stone and to assess the effectiveness of treatment methods. Materials and Structures, 13(75), 175-253

Roberto, Á. (2013). La parkesina y sus hermanos. https://historiasdeempaques.wordpress.com

Rodríguez, A., Gutiérrez-González, S., Horgnies, M., \& Calderón, V. (2013). Design and properties of plaster mortars manufactured with ladle furnace slag. Materials \& Design, 52, 1980-2015. https://doi.org/10.1016/j.matdes.2013.06.041 
Rodríguez Orejón, A., del Río Merino, M., \& Fernández Martínez, F. (2014). Characterization mixtures of thick gypsum with addition of treated waste from laminated plasterboards. Materiales de Construcción, 64(314). https://doi.org/10.3989/mc.2014.03413

Romaniega Piñeiro, S. (2016). Refuerzo de la escayola mediante fibras de lana mineral procedentes del reciclaje de RCD (Tesis Doctoral, Universidad Politécnica de Madrid (España)). https://doi.org/10.20868/UPM.thesis.43030

Romaniega Piñeiro, S., del Río Merino, M., \& Pérez García, C. (2015). New plaster composite with mineral wool fibres from CDW recycling. Advances in Materials Science and Engineering, 9. https://doi.org/10.1155/2015/854192

Rouquerol, F., Rouquerol, J., Sing, K. S. W., Llewellyn, P., \& Maurin, G. (2014). Adsorption by powders and porous solids: principles, methodology and applications (2a; Academic Press, Ed.). Montpellier (France)

Sackett, C. (2017). Augustine Sackett. Retrieved from The Sackett family association website: https://sackettfamily.info

Sahin, S., \& Karaman, S. (2012). The Properties of Expanded Polystyrene - Pumice Gypsum Blocks as a Building Material. Journal of Tekirdag Agricultural Faculty, 9(1), 51-56. https://doi.org/1302-7050

Saint-Gobain, P. (2019). El código técnico de la edificación. https://www.placo.es/sites/gypsum.eeap.placo.es/files/manual_pyl_02_el_cte.p df

San-Antonio-González, A., Del Río-Merino, M., Viñas-Arrebola, C., \& Villoria-Sáez, P. (2015). Lightweight material made with gypsum and extruded polystyrene waste with enhanced thermal behaviour. Construction and Building Materials, 93, 57-63. https://doi.org/10.1016/j.conbuildmat.2015.05.040

San Antonio González, A., del Río Merino, M., Viñas Arrebola, C., \& Villoria Sáez, P. (2016). Lightweight material made with gypsum and EPS waste with enhanced mechanical strength. Journal of Materials in Civil Engineering, 28(2). https://doi.org/10.1061/(ASCE)MT.1943-5533.0001382

San Antonio González, A. (2017). Caracterización de compuestos eco-eficientes de yeso aligerado con residuo de poliestireno extruido (XPS) (Tesis Doctoral, Universidad Politécnica de Madrid (España)). https://doi.org/10.20868/UPM.thesis.48007

Sanjuán-Barbudo, M. Á. (2016). Cemento y hormigón en la economía circular. Cemento Hormigón, 976(10). http://cemento-hormigon.com/Articulos

Santa Cruz Astorqui, J., del Río Merino, M., Villoria Sáez, P., \& Porras Amores, C. (2019). Análisis de la viabilidad de elementos prefabricados para particiones con yeso y EPS procedente del reciclaje. DYNA - Ingeniería e Industria, 94(4), 415420. 
Santos Jiménez, R., del Río Merino, M., \& González Cortina, M. (2013). Análisis de la viabilidad del yeso con adiciones de residuo cerámico para la aplicación en edificación. Jornadas Internacionales de Investigación en Construcción. Vivienda: Pasado, Presente y Futuro. Resúmenes y Actas. https://doi.org/9788472924215

Santos Jiménez, R. (2018). Reciclaje de residuos de construcción y demolición (RCD) de tipo cerámico para nuevos materiales de construcción sostenibles (Tesis Doctoral, Universidad Politécnica de Madrid (España)). https://doi.org/10.20868/UPM.thesis.53564

Santos Marián, D. de, Monercillo Delgado, B., \& García Martínez, A. (2011). Gestión de residuos en las obras de construcción y demolición (2a; S. L. . Tornapunta Ediciones, Ed.). Madrid (España)

Sastre de Andrés, E., \& Ferreira Aparicio, P. (2002). Análisis térmico. Consejo Superior de Investigaciones Científicas (Ed.), Técnicas de Análisis y Caracterización de Materiales (1 $\left.{ }^{\mathrm{a}}\right)$. Madrid (España)

Schwarz, M. J. (2009, March 9). El plástico y sus problemas. El Comercio. https://www.elcomercio.es/gijon/20090309/sociedad

Secretaría de Estado y Medio Ambiente. (2016). Plan Estatal Marco de Gestión de Residuos 2016-2022 p. 192. https://www.miteco.gob.es/es/calidad-y-evaluacionambiental/planes-y-estrategias/pemaraprobado6noviembrecondae_tcm30170428.pdf

Serrano, R., Cobo, A., Prieto, M. I., \& González, M. de las N. (2016). Analysis of fire resistance of concrete with polypropylene or steel fibers. Construction and Building Materials, 122, 302-309.

https://doi.org/10.1016/j.conbuildmat.2016.06.055

Serrano Somolinos, R. (2018). Estudio del comportamiento frente al fuego del hormigón en masa con adición de nanofibras de carbono (CNFS) y su comparación con hormigones sin adición y con otras adiciones (Tesis Doctoral, Universidad Politécnica de Madrid (España)). https://doi.org/10.20868/UPM.thesis.52181

Seymour, R. B. (1995). Introducción a la química de los polímeros (2a; Editorial Reverté S.A, Ed.). Mississippi (EEUU)

Soriano Baeza, M. (2010). Innovación y medio ambiente en materiales de construcción. http://www.coiim.es/rrii/Descargas/jornadasyconferencias/innovacion_medio ambiente

Soriano Baeza, M. (2011). Valorización energética de residuos. http://www.coiim.es/rrii/Descargas/jornadasyconferencias/mediambiente201 $1 /$ msoriano.pdf

Sorrentino, M. (2017). Viability of eco-gypsum composites with construction and demolition waste: physical, environmental and economic analysis for building applications. Trabajo Fin de Máster, Universidad Politécnica de Madrid (España) 
Strydom, C. A., \& Potgieter, J. H. (1999). Dehydration behaviour of a natural gypsum and a phosphogypsum during milling. Thermochimica Acta, 332(1), 89-96. https://doi.org/10.1016/S0040-6031(99)00083-0

Suresh, S. S., Mohanty, S., \& Nayak, S. K. (2017). Composition analysis and characterization of waste polyvinyl chloride (PVC) recovered from data cables. Waste Management, 60, 100-111.

https://doi.org/10.1016/j.wasman.2016.08.033

Tapia Batallas, L. E. (2015). Diseño de una planta para la fabricación de paneles de yeso con la adición de piedra pómez y polipropileno como materiales alternativos (Proyecto Fin de Grado, Escuela Politécnica Nacional de Quito (Ecuador)). https://doi.org/http://bibdigital.epn.edu.ec/handle/15000/11108

Tasán Cruz, D. M. (2011). Caracterización de morteros de yeso reforzados con fibras recuperadas de eslingas textiles de un solo uso (Trabajo Fin de Máster, Universidad Politécnica de Madrid (España)). http://oa.upm.es/10836

Tayibi, H., Pérez, C., López, F. A., \& López Delgado, A. (2005). Evolución de las propiedades mecánicas de un residuo de la metalurgia secundaria del aluminio estabilizado con yeso. Revista de Metalurgia, 41(4).

https://doi.org/10.3989/revmetalm.2005.v41.i4.215

Téllez, J., Rodríguez, A., \& Fajardo, Á. (2006). Contaminación por monóxido de carbono: un problema de salud ambiental. Revista de Salud Pública, 8(1), 108117. https://doi.org/10.1590/S0124-00642006000100010

Tertre Torán, J. I. (2016). Realizaciones con áridos reciclados. Cemento Hormigón, 976(8). http://cemento-hormigon.com/Articulos/Articulos?id=1061

The World Bank Group. (1999). World development indicators. https://data.worldbank.org/indicator

The World Bank Group. (2016). Población mundial. https://data.worldbank.org/indicator

UNE-EN 12667:2002. (2002). Materiales de construcción. Determinación de la resistencia térmica por el método de la placa caliente guardada y el método del medidor de flujo de calor. Productos de alta y media resistencia térmica

UNE-EN 12859. (2012). Paneles de yeso. Definiciones, especificaciones y métodos de ensayo

UNE-EN 12880. (2001). Caracterización de lodos. Determinación de la humedad y del contenido en materia seca

UNE-EN 13279-1:2009. (2009). Yesos de construcción y conglomerantes a base de yeso para la construcción. Parte 1: Definiciones y especificaciones

UNE-EN 13279-2:2014. (2014). Yesos de construcción y conglomerantes a base de yeso para la construcción. Parte 2: Métodos de ensayo 
UNE-EN 520:2005+A1. (2010). Placas de yeso laminado. Definiciones, especificaciones y métodos de ensayo

UNE-EN 933-1. (2012). Ensayos para determinar las propiedades geométricas de los áridos. Parte 1: Determinación de la granulometría de las partículas. Método del tamizado

UNE-EN 933-2. (1996). Ensayo para determinar las propiedades geométricas de los áridos. Parte 2: Determinación de la granulometría de las partículas. Tamices de ensayo, tamaño nominal de las aberturas

UNE-EN ISO 12572:2018. (2018). Prestaciones higrotérmicas de los productos y materiales para edificación. Determinación de las propiedades de transmisión de vapor de agua. Método del vaso

UNE 102042. (2014). Yesos y escayolas de construcción. Otros métodos de ensayo

UNED. (2016). Gestión y tratamiento de los residuos urbanos. https://www2.uned.es/biblioteca/rsu

Urzulin, T. A., Akasaki, J. L., \& Pinto, N. A. (2016). Estudo de compósitos de gesso incorporados com duas diferentes granulometrias de borracha de pneus. Revista Científica ANAP Brasil, 9(16). https://doi.org/10.17271/1984324091620161439

Universidade da Coruña. (2008). Ligantes: Yesos. ftp://ceres.udc.es/ITS_Caminos/1_Ciclo/Materiales_Construccion

Vasconcelos, G., Lourenco, P. B., Camoes, A., Martins, A., \& Cunha, S. (2015). Evaluation of the performance of recycled textile fibres in the mechanical behaviour of a gypsum and cork composite material. Cement and Concrete Composites, 58, 2939. https://doi.org/10.1016/j.cemconcomp.2015.01.001

Vidales Barriguete, A., del Río Merino, M., Atanes Sánchez, E., Piña Ramírez, C., \& Viñas Arrebola, C. (2018). Analysis of the feasibility of the use of CDW as a lowenvironmental-impact aggregate in conglomerates. Construction and Building Materials, 178, 83-91. https://doi.org/10.1016/j.conbuildmat.2018.05.011

Villanueva Domínguez, L. de, \& García Santos, A. (2001). Manual del yeso (Asociación Técnica y Empresarial del Yeso. ATEDY, Ed.). Madrid (España)

Villanueva Domínguez, L. de. (2004). Evolución histórica de la construcción con yeso. Informes de La Construcción, 56(493), 5-12. https://doi.org/0020-0883

Villoria Sáez, P., Santa Cruz Astorqui, J., \& del Río Merino, M. (2016). Conglomerados sostenibles realizados con residuos de construcción generados en obras de rehabilitación energética. Universidad de los Andes (Ed.), Proceedings of the VII Elagec. Bogotá (Colombia)

Williams, P. T. (1994). Pollutants from incineration: an overview. In R. M. Harrison R. E. Hester (Ed.), Waste incineration and the environment (pp. 27-52). https://doi.org/10.1039/9781847552327 
Zhu, C., Zhang, J., Peng, J., Cao, W., \& Liu, J. (2018). Physical and mechanical properties of gypsum-based composites reinforced with PVA and PP fibers. Construction and Building Materials, 163, 695-705.

https://doi.org/10.1016/j.conbuildmat.2017.12.168 


SIGLASY ACRONIMOS




\section{SIGLAS Y ACRÓNIMOS}

\begin{tabular}{|c|c|}
\hline Siglas/acrónimos & Significado \\
\hline AENOR & Asociación Española de Normalización y Certificación \\
\hline $\mathrm{Ca}$ & Calcio \\
\hline $\mathrm{CE}$ & Comunidad Europea \\
\hline CMMAD & Comisión Mundial de Medio Ambiente y Desarrollo \\
\hline $\mathrm{CO}$ & Monóxido de carbono \\
\hline $\mathrm{CO}_{2}$ & Dióxido de carbono \\
\hline CPR & Construction Products Regulations \\
\hline CSD & Comisión sobre el Desarrollo Sostenible \\
\hline CTE & Código Técnico de la Edificación \\
\hline EPR & Etileno-propileno \\
\hline EPS & Poliestireno expandido \\
\hline EVA & Acetato de etil-vinil \\
\hline FEAMA & Federación Española de Asociaciones del Medio Ambiente \\
\hline FRX & Fluorescencia de Rayos X \\
\hline GEF & Fondo para el Medio Ambiente Mundial \\
\hline $\mathrm{HCl}$ & Cloruro de hidrógeno \\
\hline $\mathrm{H}_{2} \mathrm{O}$ & Agua \\
\hline HR & Humedad relativa \\
\hline ICE & Inventory of Carbon \& Energy \\
\hline IGF & Grafito isostático \\
\hline IPCC & Intergovernmental Panel on Climate Change \\
\hline ITC-BT & Instrucción Técnica Complementaria de Baja Tensión \\
\hline IUPAC & International Union of Pure and Applied Chemistry \\
\hline MTPS & Modified Transient Plane Source \\
\hline NOAA & National Oceanic and Atmospheric Administration \\
\hline NOx & Óxidos de nitrógeno \\
\hline ONU & Organización de Naciones Unidas \\
\hline $\mathrm{Pb}$ & Plomo \\
\hline PCDDs & Dioxinas \\
\hline PCDFs & Furanos \\
\hline
\end{tabular}




\begin{tabular}{|c|c|}
\hline PCPW & Envases vacíos o usados de plástico \\
\hline PE-HD & Polietileno de alta densidad \\
\hline PE-LD & Polietileno de baja densidad \\
\hline PE-LLD & Polietileno de muy baja densidad \\
\hline PEMAR & Plan Estatal Marco de Gestión de Residuos \\
\hline PE-MD & Polietileno de media densidad \\
\hline PET & Polietileno tereftalato \\
\hline PMMA & Polimetilmetacrilato \\
\hline PP & Polipropileno \\
\hline ppm & Partes por millón \\
\hline PPTA & Poliparafenileno tereftalamida \\
\hline PR & Residuo plástico de cables \\
\hline PS & Poliestireno \\
\hline PS-E & Poliestireno expandido \\
\hline PTFE & Politetrafluoretileno \\
\hline PUMA & Programa de las Naciones Unidas para el Medio Ambiente \\
\hline PUR & Poliuretano \\
\hline PVA & Polivinil alcohol \\
\hline PVC & Policloruro de vinilo \\
\hline PVC-U & Policloruro de vinilo rígido \\
\hline RAE & Real Academia Española \\
\hline RCD & Residuos de Construcción y Demolición \\
\hline $\mathrm{RD}$ & Real Decreto \\
\hline REBT & Reglamento Electrotécnico de Baja Tensión \\
\hline RILEM & $\begin{array}{l}\text { International Union of Laboratories and Experts in Construction } \\
\text { Materials, Systems and Structures }\end{array}$ \\
\hline$S$ & Azufre \\
\hline $\mathrm{Sb}$ & Antimonio \\
\hline SEM & Scanning Electron Microscope \\
\hline $\mathrm{Si}$ & Silicio \\
\hline $\mathrm{SO}_{2}$ & Dióxido de azufre \\
\hline STAR_CCM+ & $\begin{array}{l}\text { Software de simulación mediante dinámica computacional de } \\
\text { fluidos }\end{array}$ \\
\hline UE & Unión Europea \\
\hline UNE & Una Norma Española \\
\hline UNED & Universidad Nacional de Educación a Distancia \\
\hline
\end{tabular}


UV Ultravioleta

XLPE-PEX Polietileno reticulado

XPS

Poliestireno extruido

$\mathrm{Zn}$

Zinc 


SIGLAS Y ACRONIMOS




\section{LISTADO DE TABLAS, GRÁFICAS, FIGURAS Y FOTOS}




\section{LISTADO DE TABLAS, GRÁFICAS, FIGURAS Y FOTOS}

\section{Listado de tablas}

\begin{tabular}{|c|c|c|c|c|}
\hline & Orden & Contenido & Fuente & Pág. \\
\hline $\begin{array}{l}\overrightarrow{0} \\
\frac{0}{Z} \\
\stackrel{0}{0} \\
\stackrel{0}{0}\end{array}$ & $\begin{array}{l}\text { Tabla } 1.3 \\
\text { Tabla } 1.4 \\
\text { Tabla } 1.5 \\
\text { Tabla } 1.6\end{array}$ & $\begin{array}{l}\text { Resumen del Informe "Inventory of Carbon \& Energy (ICE) } \\
\text { versión } 2.0 \text { ". } \\
\text { Impacto ambiental de algunos materiales de construcción. } \\
\text { Instalaciones de transferencia, tratamiento y vertederos de } \\
\text { RCD en España. } \\
\text { Características de la piedra de yeso o aljez } \\
\text { Productos de yeso según la temperatura de cocción } \\
\text { Yesos y conglomerantes de yeso para la construcción } \\
\text { Especificaciones para los yesos de construcción }\end{array}$ & $\begin{array}{l}\text { ICE versión } \\
2.0 \\
\text { Guía de la } \\
\text { construcción } \\
\text { sostenible } \\
\text { de } 2005 \text { del } \\
\text { ISTAS } \\
\text { PEMAR } \\
2016-2022 \\
\text { Manual del } \\
\text { yeso } \\
\text { Manual del } \\
\text { yeso } \\
\text { UNE-EN } \\
\text { 13279- } \\
\text { 1:2009 } \\
\text { Fuente: } \\
\text { UNE-EN } \\
\text { 13279- } \\
\text { 1:2009 }\end{array}$ & 40 \\
\hline 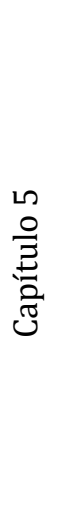 & $\begin{array}{l}\text { Tabla } 5.1 \\
\text { Tabla } 5.2 \\
\text { Tabla } 5.3 \\
\text { Tabla } 5.4 \\
\text { Tabla } 5.5 \\
\text { Tabla } 5.6 \\
\text { Tabla } 5.7 \\
\text { Tabla } 5.8\end{array}$ & $\begin{array}{l}\text { Características técnicas Yeso Iberplast - Placo } \\
\text { Características técnicas Escayola Iberyola - Placo } \\
\text { Composición química del agua utilizada en los ensayos } \\
\text { Matriz general - Diseño de experimentos } \\
\text { Denominación probetas del compuesto. FASE III } \\
\text { Denominación probetas del compuesto. FASE IV } \\
\text { Datos iniciales para modelo de referencia } 1 \\
\text { Datos iniciales para modelo de referencia } 2\end{array}$ & $\begin{array}{l}\text { Placo } \\
\text { Placo } \\
\text { Canal de } \\
\text { Isabel II } \\
\text { Propia } \\
\text { Propia } \\
\text { Propia } \\
\text { Propia } \\
\text { Propia }\end{array}$ & $\begin{array}{l}100 \\
101 \\
102 \\
116 \\
117 \\
127 \\
143 \\
144\end{array}$ \\
\hline 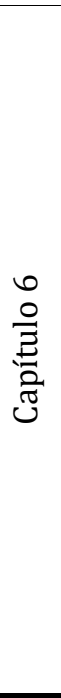 & $\begin{array}{l}\text { Tabla } 6.2 \\
\text { Tabla } 6.3 \\
\text { Tabla } 6.4 \\
\text { Tabla } 6.5\end{array}$ & $\begin{array}{l}\text { Resultados de densidad de empaquetamiento de materia } \\
\text { prima }\left(\mathrm{g} / \mathrm{cm}^{3}\right) \\
\text { Resultados de densidad real mediante picnometría de Helio } \\
\left(\mathrm{g} / \mathrm{cm}^{3}\right) \\
\text { Resultados de contenido de humedad (\%) - UNE EN } 12880 \\
\text { Análisis granulométrico del PR - UNE EN 933-1 } \\
\text { Pérdida de masa de las muestras en el análisis } \\
\text { termogravimétrico (\%) } \\
\text { Análisis elemental de las muestras - concentración (\%) } \\
\text { superior a 0,5\% } \\
\text { Resultados del ensayo de consistencia de las pastas (mm) - } \\
\text { UNE EN 13279-2 } \\
\text { Principio de fraguado de los compuestos (minutos) - UNE }\end{array}$ & $\begin{array}{l}\text { Propia } \\
\text { Propia } \\
\text { Propia } \\
\text { Propia } \\
\text { Propia }\end{array}$ & $\begin{array}{l}152 \\
153 \\
153 \\
154 \\
155 \\
159\end{array}$ \\
\hline
\end{tabular}


Tabla 6.9

Tabla 6.10

Tabla 6.11

Tabla 6.12

Tabla 6.13

Tabla 6.14

Tabla 6.15

Tabla 6.16

Tabla 6.17

Tabla 6.18

Tabla 6.19

Tabla 6.20

Tabla 6.21

Tabla 6.22

Tabla 6.23

Tabla 6.24

Tabla 6.25

Tabla 6.26

Tabla 6.27

Tabla 6.28

Tabla 6.29

Tabla 6.30

Tabla 6.31

Tabla 6.32

Tabla 6.33

Tabla 6.34

Tabla 6.35

Tabla 6.36

\section{EN 13279-2}

Dureza Shore C de los compuestos - UNE EN 102042:2014

Tabla ANOVA para la variable Dureza

Resultados medios de ensayo a flexión y compresión de los compuestos $\left(\mathrm{N} / \mathrm{mm}^{2}\right)$ - UNE EN 13279-2

Tabla ANOVA para la variable R. Flexión

Tabla ANOVA para la variable R. Compresión

Densidad (UNE 102042:2014) y módulo de Young de los compuestos

Tabla ANOVA para la variable Densidad

Análisis de las aplicaciones

Materia prima, transporte y producción para la fabricación de $1 \mathrm{~m}^{3}$ de compuesto

Costes totales para $1 \mathrm{~m} 3$ de compuesto

Propiedades texturales obtenidas a partir de la porosimetría de mercurio de los compuestos seleccionados

Resistencia al choque-impacto (mm) - UNE EN 520

Resistencia a flexión de paneles (kN) - UNE-EN 12859

Adherencia superficial (N/mm2) - UNE EN 13279-2

Pesos húmedos y secos de los compuestos (g) - capacidad de retención de agua (\%)

Ascenso de agua por capilaridad en los compuestos (mm) RILEM RC 25-PEM

Resultado final de transmisión, permeancia, permeabilidad y resistencia al vapor de agua - UNE-EN ISO 12572

Retención de agua después de ensayo de cámara húmeda

Resultados de dureza Shore C antes y después de ensayo de cámara húmeda

Resultados de resistencias a flexión y compresión después de ensayo de cámara húmeda

Retención de agua después de 2 ciclos de agua-estufa

Resultados de dureza Shore $\mathrm{C}$ antes y después de 2 ciclos de agua-estufa

Resultados de resistencias a flexión y compresión después de 2 ciclos de agua-estufa

Temperatura media $\left({ }^{\circ} \mathrm{C}\right)$ de los paneles tomada cada 5 minutos

Cantidad de $\mathrm{CO} 2$ yCO emitida en la combustión del PR de los compuestos en una estancia propuesta de $12 \mathrm{~m} 2$ y 2,6 m de altura (volumen $31,2 \mathrm{~m} 3$ )

Conductividad y efusividad térmica de los compuestos Según técnica modificada de fuente plana transitoria

Conductividad térmica, flujo de calor y resistencia térmica de los compuestos - UNE-EN 12667

Datos modificados para nuevo escenario del modelo de \begin{tabular}{l|l} 
Propia & 164
\end{tabular}

\begin{tabular}{l|l} 
Propia & 166
\end{tabular}

\begin{tabular}{l|l} 
Propia & 167
\end{tabular}

\begin{tabular}{l|l} 
Propia & 169
\end{tabular}

\begin{tabular}{l|l} 
Propia & 170
\end{tabular}

\begin{tabular}{l|l} 
Propia & 172
\end{tabular}

\begin{tabular}{l|l} 
Propia & 174
\end{tabular}

\begin{tabular}{l|l} 
Propia & 175
\end{tabular}

\begin{tabular}{l|l} 
Propia & 176
\end{tabular}

Propia 176

\begin{tabular}{l|l} 
Propia & 177
\end{tabular}

Propia 182

Propia 183

\begin{tabular}{l|l} 
Propia & 186
\end{tabular}

\begin{tabular}{l|l} 
Propia & 188
\end{tabular}

\begin{tabular}{l|l} 
Propia & 189
\end{tabular}

\begin{tabular}{l|l} 
Propia & 191
\end{tabular}

\begin{tabular}{l|l} 
Propia & 192
\end{tabular}

\begin{tabular}{l|l} 
Propia & 192
\end{tabular}

$\begin{array}{ll}\text { Propia } & 192\end{array}$

\begin{tabular}{l|l} 
Propia & 193
\end{tabular}

\begin{tabular}{l|l} 
Propia & 193
\end{tabular}

Propia

193

Propia

198

Propia

209

Propia

Propia

Propia 


\begin{tabular}{|c|c|c|c|}
\hline & referencia 1 & & \\
\hline Tabla 6.37 & $\begin{array}{l}\text { Datos modificados para nuevo escenario del modelo de } \\
\text { referencia } 2\end{array}$ & Propia & 219 \\
\hline Tabla 6.38 & $\begin{array}{l}\text { Confort térmico mediante coeficiente de penetración } \\
\text { térmica - MANUAL DEL YESO }\end{array}$ & Propia & 221 \\
\hline Tabla 6.39 & $\begin{array}{l}\text { Materia prima, densidad, peso al desmolde, peso a los } 7 \text { días } \\
\text { de } 1 \text { probeta prismática de } 4 \times 4 \times 16 \mathrm{~cm}^{3}\end{array}$ & Propia & 224 \\
\hline Tabla 6.40 & $\begin{array}{l}\text { Producción media mensual de paneles tipo ( } 2000 \text { x } 1200 \text { x } \\
12,5 \mathrm{~mm} 3 \text { ) con PR, por cada empresa de reciclaje de cables }\end{array}$ & Propia & 225 \\
\hline
\end{tabular}




\section{Listado de gráficas}

\begin{tabular}{|c|c|c|c|c|}
\hline & Orden & Contenido & Fuente & Pág. \\
\hline & Gráfica 1.1 & $\begin{array}{l}\text { Consumo de Energía Final en España por Sectores 2000- } \\
2016\end{array}$ & $\begin{array}{l}\text { IDAE, Julio } \\
2018\end{array}$ & 12 \\
\hline & Gráfica 1.2 & Gráfica 1.2. Izquierda: Composición de los RCD & $\begin{array}{l}\text { Fundación } \\
\text { laboral, } \\
2011\end{array}$ & 17 \\
\hline & Gráfica 1.3 & $\begin{array}{l}\text { Gráfica 1.3. Derecha: RCD no peligrosos y peligrosos } \\
\text { generados en España entre } 2010 \text { y } 2016\end{array}$ & $\begin{array}{l}\text { Eurostat, } \\
2019\end{array}$ & 17 \\
\hline & Gráfica 1.4 & $\begin{array}{l}\text { Residuos generados por actividades económicas y hogares } \\
\text { en la UE-28 y España- Año } 2016\end{array}$ & $\begin{array}{l}\text { Eurostat, } \\
2019\end{array}$ & 17 \\
\hline 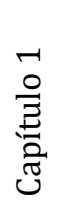 & Gráfica 1.5 & $\begin{array}{l}\text { Evolución de los RCD generados en España en los últimos } \\
\text { años }\end{array}$ & $\begin{array}{l}\text { Fuente: } \\
\text { FERCD y } \\
\text { RCD } \\
\text { Asociación, } \\
2019\end{array}$ & 18 \\
\hline & Gráfica 1.6 & $\begin{array}{l}\text { Tratamiento de los residuos en Europa, España, Italia y } \\
\text { Bélgica - año } 2017\end{array}$ & $\begin{array}{l}\text { Eurostat, } \\
2019\end{array}$ & 21 \\
\hline & Gráfica 1.7 & Consumo de plástico en Europa - año 2017 & $\begin{array}{l}\text { Plastics } \\
\text { Europe, } \\
2019\end{array}$ & 28 \\
\hline & Gráfica 1.8 & $\begin{array}{l}\text { Variedad de plásticos según distintas necesidades europeas } \\
\text { - año } 2017\end{array}$ & $\begin{array}{l}\text { Plastics } \\
\text { Europe, } \\
2019\end{array}$ & 28 \\
\hline & Gráfica 1.9 & $\begin{array}{l}\text { Destino de la granza de plástico obtenida en el reciclaje de } \\
\text { cables }\end{array}$ & Lyrsa Álava & 38 \\
\hline & Gráfica 6.1 & Curva granulométrica del PR & Propia & 154 \\
\hline & Gráfica 6.2 & Resultado del análisis termogravimétrico del yeso & Propia & 156 \\
\hline & Gráfica 6.3 & Resultado del análisis termogravimétrico de la escayola & Propia & 156 \\
\hline & Gráfica 6.4 & Resultado del análisis termogravimétrico del $\mathrm{PR}_{1}$ & Propia & 157 \\
\hline & Gráfica 6.5 & Resultado del análisis termogravimétrico del $\mathrm{PR}_{2}$ & Propia & 158 \\
\hline & Gráfica 6.6 & Resultado del análisis termogravimétrico del $\mathrm{PR}_{3}$ & Propia & 158 \\
\hline & Gráfica 6.7 & Difractograma de Rayos X en yeso y escayola & Propia & 159 \\
\hline $\begin{array}{l}0 \\
0\end{array}$ & Gráfica 6.8 & Principio de fraguado de los compuestos & Propia & 163 \\
\hline 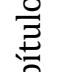 & Gráfica 6.9 & Dureza Shore C de los compuestos & Propia & 165 \\
\hline $\overrightarrow{\widetilde{J}}$ & Gráfica 6.10 & Diagnóstico del factor dureza & Propia & 166 \\
\hline & Gráfica 6.11 & Resistencia a flexión de los compuestos & Propia & 168 \\
\hline & Gráfica 6.12 & Resistencia a compresión de los compuestos & Propia & 169 \\
\hline & Gráfica 6.13 & Diagnóstico del factor R. flexión & Propia & 170 \\
\hline & Gráfica 6.14 & Diagnóstico del factor R. compresión & Propia & 171 \\
\hline & Gráfica 6.15 & Densidad de los compuestos en estado endurecido & Propia & 172 \\
\hline & Gráfica 6.16 & Módulo de Young estático & Propia & 173 \\
\hline & Gráfica 6.17 & Módulo de Young dinámico & Propia & 173 \\
\hline
\end{tabular}




\section{Gráfica 6.18 \\ Gráfica 6.19 \\ Gráfica 6.20 \\ Gráfica 6.21 \\ Gráfica 6.22}

Gráfica 6.23

Gráfica 6.24

Gráfica 6.25

Gráfica 6.26

Gráfica 6.27

Gráfica 6.28

Gráfica 6.29

Gráfica 6.30

Gráfica 6.31

Gráfica 6.32

Gráfica 6.33

Gráfica 6.34

Gráfica 6.35

Gráfica 6.36

Gráfica 6.37

Gráfica 6.38

Gráfica 6.39
Diagnóstico del factor densidad

Distribución de tamaño de poro acumulada

Distribución de tamaño de poro diferencial

Valores medios de fuerza-deformación de los compuestos seleccionados

Gráfica fuerza-deformación del compuesto de referencia E0,8

Gráficas fuerza-deformación de los compuestos con PR. Superior: E0,8-50PR; Centro: E0,8-60PR; Inferior: E0,870PR

Pesos de los compuestos antes y después del ensayo de absorción de agua por capilaridad y ascenso medio del agua por capilaridad

Permeabilidad al vapor de agua cada semana durante 8 semanas

Pesos antes y después del ensayo de absorción total de agua según UNE -EN 520

Dureza Shore C para compuestos no sometidos a ensayos con agua (Serie III) y sometidos a ensayos con agua en cámara húmeda (Serie XV) y ciclos agua-estufa (Serie XVI)

Resistencia a flexión para compuestos no sometidos a ensayos con agua (Serie III) y sometidos a ensayos con agua en cámara húmeda (Serie XV) y ciclos agua-estufa (Serie XVI)

Resistencia a compresión para compuestos no sometidos a ensayos con agua (Serie III), y sometidos a ensayos con agua en cámara húmeda (Serie XV) y ciclos agua-estufa (Serie XVI)

Temperatura alcanzada por los paneles $\left({ }^{\circ} \mathrm{C}\right)$. Superior izquierda: E0,8; superior derecha. E0,8-50PR; inferior izquierda: E0,8-60PR; inferior derecha: E0,8-70PR

Temperatura $\left({ }^{\circ} \mathrm{C}\right)$ alcanzada por los paneles en posición exterior de todos los compuestos

Temperatura $\left({ }^{\circ} \mathrm{C}\right)$ alcanzada por los paneles en posición media de todos los compuestos

Temperatura $\left({ }^{\circ} \mathrm{C}\right)$ alcanzada por los paneles en posición interior de todos los compuestos

Conductividad $(\mathrm{W} / \mathrm{mK})$ térmica obtenida con técnica

modificada de fuente plana transitoria

Efusividad (Ws $1 / 2 / \mathrm{m}^{2} \mathrm{~K}$ ) térmica obtenida con técnica modificada de fuente plana transitoria

Conductividad $(\mathrm{W} / \mathrm{mK})$ térmica obtenida según UNE-EN 12667

Flujo de calor $\left(\mathrm{W} / \mathrm{m}^{2}\right)$ obtenido según UNE-EN 12667

Resistencia térmica $\left(\mathrm{m}^{2} \mathrm{~K} / \mathrm{W}\right)$ obtenida según UNE-EN 12667

Coeficiente de penetración térmica $\left(\mathrm{m}^{2} \mathrm{~K} / \mathrm{W}\right)$ obtenida según UNE-EN 12667

\begin{tabular}{|l|l} 
Propia & 174 \\
Propia & 178 \\
Propia & 178 \\
Propia & 184 \\
Propia & 184 \\
Propia & 184 \\
Propia & 189 \\
Propia & 214 \\
Propia & 190 \\
Propia & 214 \\
Propia & 194 \\
Propia & 212 \\
Propia & 195 \\
Propia & 203 \\
& \\
Propia & 196
\end{tabular}




\begin{tabular}{l|l|l|l|} 
Gráfica 6.40 & $\begin{array}{l}\text { Comparativa de materia prima }(\mathrm{g}), \text { densidad }\left(\mathrm{g} / \mathrm{cm}^{3}\right), \text { peso } \\
\text { al desmolde }(\mathrm{g}), \text { peso a los } 7 \text { días }(\mathrm{g}) \text { de } 1 \text { probeta } \\
\text { prismática de } 4 \times 4 \times 16 \mathrm{~cm}^{3}\end{array}$ & Propia & 225 \\
\hline
\end{tabular}




\section{Listado de figuras}

\begin{tabular}{|c|c|c|c|c|}
\hline & Orden & Contenido & Fuente & Pág. \\
\hline & $\begin{array}{l}\text { Figura } 1.1 \\
\text { Figura } 1.2 \\
\text { Figura } 1.3 \\
\text { Figura } 1.4 \\
\text { Figura } 1.5 \\
\text { Figura } 1.6 \\
\text { Figura } 1.7\end{array}$ & $\begin{array}{l}\text { Programa } 21 \\
\text { Ciclo de las fases de la actividad de construcción. } \\
\text { Esquema de economía circular } \\
\text { Jerarquía en la gestión de residuos } \\
\text { Clasificación de los plásticos } \\
\text { Producción de plástico en millones de toneladas al año } \\
\text { Cables }\end{array}$ & $\begin{array}{l}\text { Naciones } \\
\text { Unidas, } \\
2019 \\
\text { Holcim } \\
\text { España } \\
\text { PEMAR } \\
\text { 2016-2022 } \\
\text { PEMAR } \\
2015 \\
\text { Plastics } \\
\text { Europe, } \\
2018 \\
\text { Plastics } \\
\text { Europe, } \\
\text { 2019 } \\
\text { Topcable.es }\end{array}$ & $\begin{array}{l}27 \\
31\end{array}$ \\
\hline 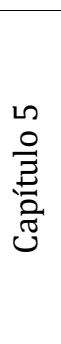 & $\begin{array}{l}\text { Figura } 5.1 \\
\text { Figura } 5.2 \\
\text { Figura } 5.3 \\
\text { Figura } 5.4 \\
\text { Figura } 5.5\end{array}$ & $\begin{array}{l}\text { Yeso Iberplast - Placo } \\
\text { Escayola Iberyola - Placo } \\
\text { Fases de un fuego natural y fases de un fuego estandarizado } \\
\text { Modelo de referencia } 1 \text { - envolvente vertical } \\
\text { Modelo de referencia } 2 \text { - envolvente horizontal }\end{array}$ & $\begin{array}{l}\text { Placo } \\
\text { Placo } \\
\text { (Serrano et } \\
\text { al., 2016) } \\
\text { Propia } \\
\text { Propia }\end{array}$ & $\begin{array}{l}100 \\
101 \\
138 \\
142 \\
143\end{array}$ \\
\hline 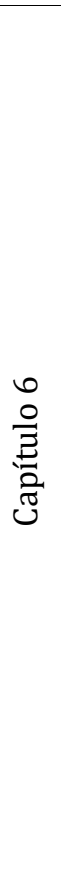 & $\begin{array}{l}\text { Figura } 6.4 \\
\text { Figura } 6.5\end{array}$ & $\begin{array}{l}\text { Esquema de la colocación de las probetas en la parrilla de } \\
\text { ensayo } \\
\text { Mallado tetraédrico del modelo de referencia } 1 \text { - envolvente } \\
\text { vertical } \\
\text { Representación de la temperatura obtenida en cada capa del } \\
\text { modelo de referencia } 1 \text {, con un flujo de calor constante de } \\
6,5 \mathrm{~W} / \mathrm{m}^{2} \\
\text { Representación de la temperatura obtenida en cada capa del } \\
\text { nuevo escenario del modelo de referencia } 1 \text {, con un flujo de } \\
\text { calor constante de } 6,5 \mathrm{~W} / \mathrm{m}^{2} \\
\text { Mallado tetraédrico del modelo de referencia } 2 \text { - envolvente } \\
\text { horizontal } \\
\text { Representación de la temperatura obtenida en cada capa del } \\
\text { modelo de referencia } 2 \text {, con un flujo de calor constante de } \\
6,5 \mathrm{~W} / \mathrm{m} 2 \\
\text { Representación de la temperatura obtenida en cada capa del } \\
\text { nuevo escenario del modelo de referencia } 2 \text {, con un flujo de } \\
\text { calor constante de } 6,5 \mathrm{~W} / \mathrm{m} 2\end{array}$ & $\begin{array}{l}\text { Propia } \\
\text { Propia }\end{array}$ & $\begin{array}{l}198 \\
215\end{array}$ \\
\hline
\end{tabular}




\section{Listado de fotos}

\begin{tabular}{|c|c|c|c|c|}
\hline & Orden & Contenido & Fuente & Pág. \\
\hline$\frac{\vec{o}}{\stackrel{0}{Z}}$ & $\begin{array}{l}\text { Foto } 1.1 \\
\text { Foto } 1.2 \\
\text { Foto } 1.3 \\
\text { Foto } 1.4 \\
\text { Foto } 1.5 \\
\text { Foto } 1.6 \\
\text { Foto } 1.7 \\
\text { Foto } 1.8 \\
\text { Foto } 1.9 \\
\text { Foto } 1.10 \\
\text { Foto } 1.11 \\
\text { Foto } 1.12 \\
\text { Foto } 1.13 \\
\text { Foto } 1.14 \\
\text { Foto } 1.15 \\
\text { Foto } 1.16\end{array}$ & $\begin{array}{l}\text { Recogida de cables } \\
\text { Clasificación manual por tipo de conductor } \\
\text { Primera trituración } \\
\text { Primera trituración } \\
\text { Primera trituración } \\
\text { Segunda trituración } \\
\text { Segunda trituración } \\
\text { Segunda trituración } \\
\text { Segunda trituración } \\
\text { Tamizado } \\
\text { Tamizado } \\
\text { Tamizado } \\
\text { Soplado por aire comprimido } \\
\text { Cobre preparado para ser fundido de } \\
\text { Depósito del plástico recuperado (granza) } \\
\text { Contenedor de la granza de plástico obtenida }\end{array}$ & $\begin{array}{c}\text { Lyrsa Álava } \\
\text { Lyrsa Álava } \\
\text { Lyrsa Álava } \\
\text { Lyrsa Álava } \\
\text { Lyrsa Álava } \\
\text { Lyrsa Álava } \\
\text { Lyrsa Álava } \\
\text { Lyrsa Álava } \\
\text { Lyrsa Álava } \\
\text { Lyrsa Álava } \\
\text { Lyrsa Álava } \\
\text { Lyrsa Álava } \\
\text { Lyrsa Álava } \\
\text { Lyrsa Álava } \\
\text { Lyrsa Álava } \\
\text { Lyrsa Álava }\end{array}$ & $\begin{array}{l}33 \\
34 \\
34 \\
34 \\
34 \\
35 \\
35 \\
35 \\
35 \\
35 \\
35 \\
35 \\
36 \\
36 \\
37 \\
37\end{array}$ \\
\hline 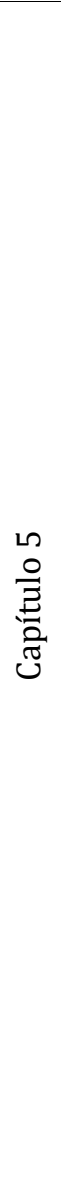 & $\begin{array}{l}\text { Foto } 5.6 \\
\text { Foto } 5.7 \\
\text { Foto } 5.8 \\
\text { Foto } 5.9 \\
\text { Foto } 5.10 \\
\text { Foto } 5.11 \\
\text { Foto } 5.12\end{array}$ & $\begin{array}{l}\text { Residuo plástico de cables - Granza procedente de LYRSA } \\
\text { Álava } \\
\text { Determinación de densidad bulk de PR (izquierda) y yeso } \\
\text { (derecha) } \\
\text { Equipo de determinación de la densidad real mediante } \\
\text { picnómetro de Helio } \\
\text { Determinación del contenido de humedad de la materia } \\
\text { prima } \\
\text { Superior: columna de tamizado. Inferior: PR retenido en } \\
\text { cada tamiz } \\
\text { Izquierda: equipo de análisis térmico gravimétrico. Derecha: } \\
\text { brazos de la termobalanza (interno de referencia, externo de } \\
\text { muestra) con cápsulas de platino } \\
\text { Izquierda: equipo de Difracción de Rayos X. Derecha: } \\
\text { cápsulas de yeso y escayola preparadas para ensayo } \\
\text { Izquierda: equipo espectrofotómetro. Derecha: } \\
\text { portamuestras con PR preparada para ensayo } \\
\text { Confección de probetas (molde } 4 x 4 x 16 \text { cm3) } \\
\text { Izquierda: probetas en condiciones de laboratorio. Derecha: } \\
\text { probetas en desecador } \\
\text { Probetas de referencia } \\
\text { Izquierda: materia prima del compuesto (agua, yeso, PR). } \\
\text { Derecha: probetas del compuesto }\end{array}$ & $\begin{array}{l}\text { Propia } \\
\text { Propia } \\
\text { Propia } \\
\text { Propia } \\
\text { Propia } \\
\text { Propia } \\
\text { Propia }\end{array}$ & $\begin{array}{l}108 \\
109 \\
109 \\
111 \\
111 \\
112 \\
113\end{array}$ \\
\hline
\end{tabular}


Foto 5.13

Foto 5.14

Foto 5.15

Foto 5.16

Foto 5.17

Foto 5.18

Foto 5.19

Foto 5.20

Foto 5.21

Foto 5.22

Foto 5.23

Foto 5.24

Foto 5.25

Foto 5.26

Foto 5.27

Foto 5.28

Foto 5.29

Foto 5.30

Foto 5.31

Foto 5.32

Fases del fuego - Parque de Bomberos Collado Villalba (Madrid). Izquierda: ignición; derecha: fuego latente;

Foto 5.33

Compuestos (sección de probetas endurecidas). De izquierda a derecha: $50 \% \mathrm{PR}-60 \% \mathrm{PR}-70 \% \mathrm{PR}$

Determinación de la consistencia de la pasta

Dispositivo de Vicat para la determinación del tiempo de fraguado

Determinación de la Dureza Shore C mediante durómetro

Determinación de la resistencia a flexión mediante equipo Autotest de Ibertest

Determinación de la resistencia a compresión mediante equipo Autotest de Ibertest

Probetas prismáticas

Equipo Ultrasonic tester para la determinación del Módulo de Young dinámico

Equipo Autotest de Ibertest para la determinación del Módulo de Young estático

Izquierda: Equipo Autopore para la determinación del volumen de poros de los compuestos. Derecha: muestras preparadas para analizar

Izquierda: equipo SEM-Quanta para la realización de ensayo de microscopía electrónica de barrido (SEM). Derecha:

muestras preparadas para su análisis

Izquierda: bola de acero. Derecha: huella de la bola por impacto

Izquierda: equipo MPX-22. Centro: panel en proceso de ensayo. Derecha: carga aplicada en el centro del panel

Izquierda: superficie del soporte con cortes de $5 \mathrm{~mm}$ de profundidad. Centro: discos de metal pegados con adhesivo epoxi al conglomerante aplicado sobre el soporte. Derecha: equipo Dynatest aplicando carga.

Determinación de la absorción de agua por capilaridad Izquierda superior: recipiente con solución saturada acuosa (nitrato potásico disuelto en agua). Izquierda inferior: moldes circulares sellados. Derecha: anotación semanal del peso de las probetas

\section{Probetas en cámara húmeda}

Izquierda probetas sumergidas $1 \mathrm{er}$ ciclo agua-estufa. Derecha: probetas sumergidas $2^{\circ}$ ciclo agua-estufa

Panel sumergido completamente en agua

Fases del fuego - Parque de Bomberos Collado Villalba (Madrid). Izquierda: calentamiento; derecha: enfriamiento

\begin{tabular}{l|c} 
Propia & 113 \\
Propia & 114 \\
Propia & 115 \\
Propia & 119 \\
Propia & 120 \\
Propia & 121 \\
Propia & 121 \\
Propia & 122 \\
Propia & 123 \\
Propia & 129 \\
Pomber \\
Collado
\end{tabular}

Villalba

(Madrid)
20

121

122 


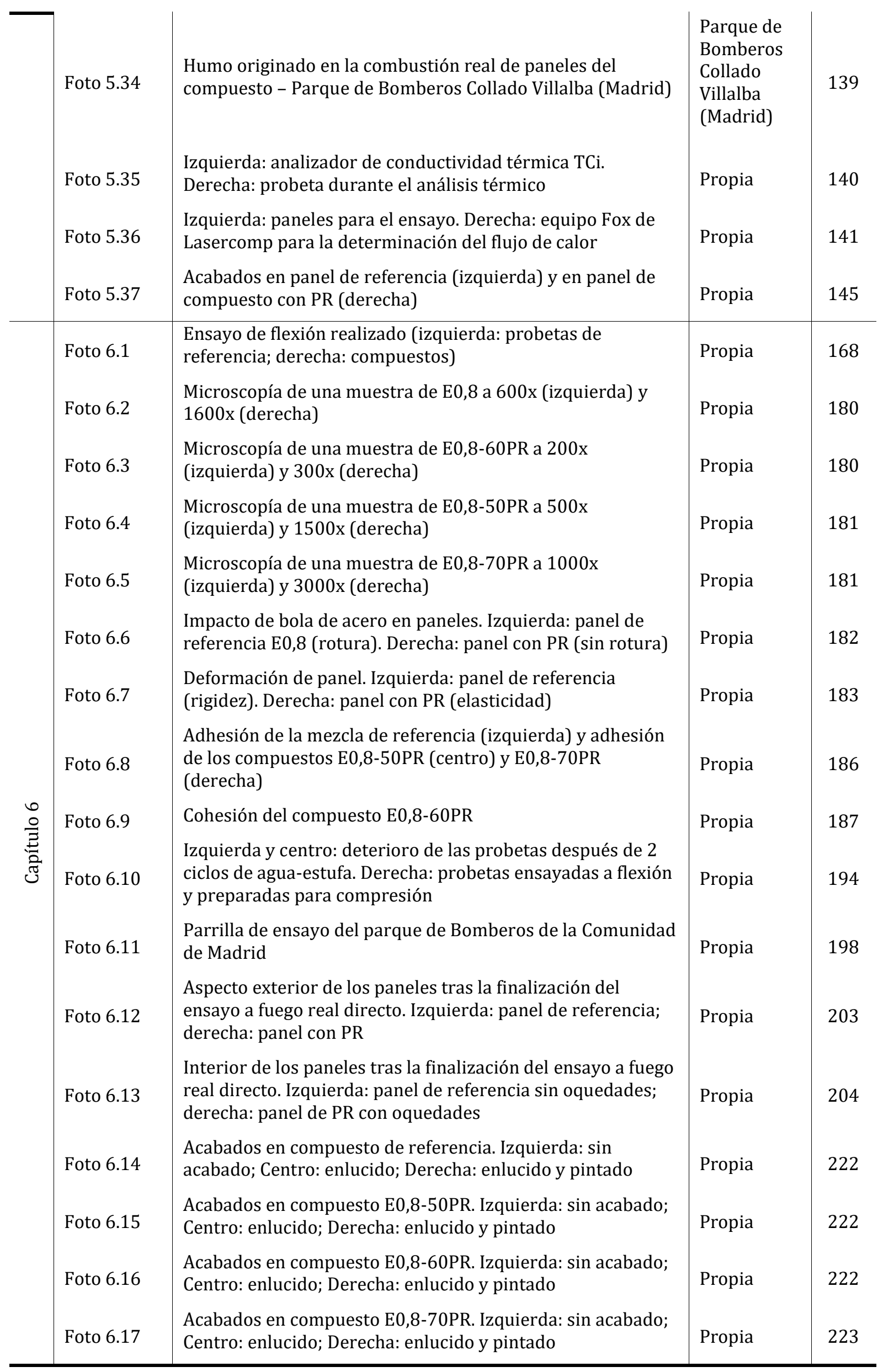

